Hans Vorländer (Hg.)

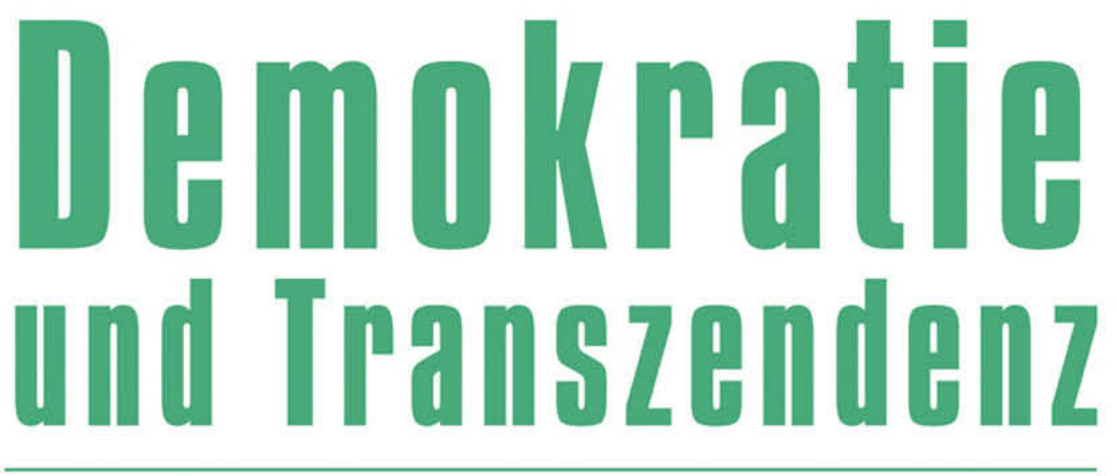

Die Begründung politischer Ordnungen

[transcript] Edition Politik 
Hans Vorländer (Hg.)

Demokratie und Transzendenz

Edition Politik | Band I2 

Hans Vorländer (Hg.)

\section{Demokratie und Transzendenz}

Die Begründung politischer Ordnungen

[transcript $]$ 
Gefördert mit Mitteln der Deutschen Forschungsgemeinschaft im Rahmen des Sonderforschungsbereiches 804 »Transzendenz und Gemeinsinn« an der Technischen Universität Dresden.

\section{(6) $(1) \Theta$}

Dieses Werk ist lizenziert unter der Creative Commons Attribution-NonCommercial-NoDerivs 4.0 Lizenz (BY-NC-ND). Diese Lizenz erlaubt die private Nutzung, gestattet aber keine Bearbeitung und keine kommerzielle Nutzung. Weitere Informationen finden Sie unter https://creativecommons.org/licenses/by-nc-nd/4.o/deed.de/.

Um Genehmigungen für Adaptionen, Übersetzungen, Derivate oder Wiederverwendung zu kommerziellen Zwecken einzuholen, wenden Sie sich bitte an rights@transcript-verlag.de

\section{(C) 2013 transcript Verlag, Bielefeld}

Die Verwertung der Texte und Bilder ist ohne Zustimmung des Verlages urheberrechtswidrig und strafbar. Das gilt auch für Vervielfältigungen, Übersetzungen, Mikroverfilmungen und für die Verarbeitung mit elektronischen Systemen.

\section{Bibliografische Information der Deutschen Nationalbibliothek}

Die Deutsche Nationalbibliothek verzeichnet diese Publikation in der Deutschen Nationalbibliografie; detaillierte bibliografische Daten sind im Internet über http://dnb.d-nb.de abrufbar.

Umschlagkonzept: Kordula Röckenhaus, Bielefeld

Lektorat \& Satz: Jan Röder und Steven Schäller

Druck: Majuskel Medienproduktion GmbH, Wetzlar

Print-ISBN 978-3-8376-2278-2

PDF-ISBN 978-3-8394-2278-6

Gedruckt auf alterungsbeständigem Papier mit chlorfrei gebleichtem Zellstoff.

Besuchen Sie uns im Internet: http://www.transcript-verlag.de

Bitte fordern Sie unser Gesamtverzeichnis und andere Broschüren an unter: info@transcript-verlag.de 


\section{Inhalt}

\section{Vorwort | 9}

Demokratie und Transzendenz

Politische Ordnungen zwischen Autonomiebehauptung und Unverfügbarkeitspraktiken

Hans Vorländer | 11

\section{Konzeptionelle und systematische Perspektiven}

\section{Das religiös-kulturelle Dispositiv der modernen Politik}

Jürgen Gebhardt | 41

\section{Macht und Autorität}

Das Problem der (Un)Verfügbarkeit

Pier Paolo Portinaro | 81

\section{Abschied von der normativen Transzendenz}

Rortys Moderne

Enno Rudolph | 105

\section{Basiskonsens und Willensnation}

Die Kontingenz des Unverfügbaren und das Modell der Schweiz

Georg Kohler | 121

\section{Brauchen Demokratien eine Zivilreligion?}

Über die prekären Grundlagen republikanischer Ordnung

Überlegungen im Anschluss an Jean-Jacques Rousseau

Hans Vorländer | 143 


\section{BEGRÜNDUNGSDISKURSE DES 16.-21. JAHRHUNDERTS}

Zwischen Selbstermächtigung und Endlichkeitsbewusstsein Das Politische und seine Grenzen im florentinischen

Republikanismus

Daniel Schulz | 165

\section{Zwischen sakraler Legitimation und}

politischer Säkularisierung

Die Monarchie in England und Frankreich im späten

17. Jahrhundert im Vergleich

Ronald G. Asch | 199

Politische Tugenden bei Hobbes

Alessandro Pinzani | 217

\section{Zur Kritik liberaler Ordnungsentwürfe}

Bernard de Mandeville, Adam Smith, Karl Marx

und Alexis de Tocqueville

Julia Schulze Wessel | 247

\section{Naturerzählungen und republikanische Geltungsbedingungen} bei Rousseau

Daniel Schulz | 277

Die Tugend, der Markt, das Fest und der Krieg Über die problematische Wiederkehr vormoderner Gemeinsinnserwartungen in der Postmoderne

Herfried Münkler | 297 


\section{DEMOKRATISCHE ORDNUNGEN IN GRÜNDUNGS-,}

KRISEN- UND UMBRUCHSZEITEN

Das Sakrale im Zeitalter seiner politischen Reproduktion

Die Französische Revolution zwischen Verfassungsfest

und Missionierungskrieg

Daniel Schulz | 335

Verfassung, Vertrag und Monarchie

Der Prozess der Verfassunggebung in Württemberg (1815-1819)

Jan Röder | 361

Der Volksstaat als Selbstverständlichkeit

Friedrich Naumann und die Begründung der Weimarer Republik

Jan Röder | 391

\section{Rechtsgeltung}

Dekonstruktion und Konstruktion in den Umbrüchen nach 1933 und 1945

Steven Schäller | 415

Die Willensnation Schweiz im Spannungsfeld konkurrierender Transzendenzbezüge

Angelo Maiolino | 449

Ordnungsbegründung als politisch-kultureller Deutungskampf Der Verfassungsdiskurs im demokratischen Polen nach 1989

Maik Herold | 473

Von der Gründung zur Begründung?

Über die Rolle der Imagination im globalen Konstitutionalismus

Oliviero Angeli | 509

Autorenverzeichnis | 527 



\section{Vorwort}

Demokratische Ordnungen sind fragil und voraussetzungsreich. Worauf beruhen ihre Gründung und ihr Bestand? Welche Ressourcen werden für ihre Konstituierung und Stabilisierung in Anspruch genommen? Die in diesem Band versammelten Beiträge geben eine neue Antwort auf diese alte Frage, sie entfalten in historischen Einzelfalluntersuchungen und systematischen Studien das demokratische Paradox von Autonomiebehauptung und Unverfügbarkeitspraxis. Demokratien begründen sich durch einen umfassenden Anspruch auf die Gestaltung der politischen Ordnung und doch leben sie von Voraussetzungen und Ressourcen, über die sie nicht oder nur bedingt verfügen können und wollen. Das wird in Begründungsdiskursen und in Gründungs-, Krisen- und Umbruchzeiten von Demokratien besonders deutlich.

Die Beiträge gehen zu einem großen Teil aus Arbeiten des Teilprojektes „Demokratische Ordnung zwischen Transzendenz und Gemeinsinn“ des im Juli 2009 eingerichteten Dresdner Sonderforschungsbereiches 804 „Transzendenz und Gemeinsinn“ und einer im März 2012 durchgeführten Tagung „Die Transzendenz politischer Gründungsmomente“ hervor. Sie werden ergänzt um Studien aus zwei weiteren Teilprojekten, einem schweizerischen und einem italienischen, und von Autoren, die dem SFB durch Tagungen, Vorträge und steten Austausch vielfältig verbunden sind. Für die Zusage der Publikation ist ihnen an dieser Stelle zu danken. Ohne einen Druckkostenzuschuss der Deutschen Forschungsgemeinschaft wäre die Veröffentlichung nicht möglich geworden. Schließlich ist Steven Schäller und Jan Röder für ihre große Hilfe bei der redaktionellen Fertigstellung des Bandes Dank zu sagen.

Dresden, im Dezember 2012

Hans Vorländer 



\section{Demokratie und Transzendenz}

Politische Ordnungen zwischen Autonomiebehauptung und Unverfügbarkeitspraktiken

HANS VORLÄNDER

\section{Die UnVerfügbarkeit der Menschenwürde}

„Die Demokratie ist nun einmal das System, in dem jeder und alles abwählbar ist (außer die Menschenwürde). "'l So brachte ein Kommentator in der Frankfurter Allgemeinen Zeitung auf den Begriff, was als Common Sense der Demokratieauffassung im Allgemeinen und der bundesdeutschen politischen Ordnung im Besonderen bezeichnet werden kann. Alles ist änderbar, alles ist dem Spiel der politischen Willens- und Entscheidungsbildung ausgesetzt, nichts ist der historischen Kontingenz entzogen. Nur die Würde des Menschen ist unantastbar. Sie ist nicht verfügbar, mithin der Disposition des demokratischen Gesetzgebers, auch der Exekutive und Judikative entzogen. Aber nicht nur das. Auch der öffentliche Diskurs scheint dort an seine Grenzen zu stoßen, wo er die Menschenwürde disponibel zu machen versucht.

$\mathrm{Zu}$ Beginn des Jahres 2008 ging es um die Besetzung einer frei werdenden Richterstelle am Bundesverfassungsgericht und auch um die Nachfolge im Amt des Präsidenten. Alles lief auf Horst Dreier zu, einen hoch angesehenen Rechtsphilosophen, Staats- und Verfassungsrechtler, Herausgeber eines der renommiertesten Kommentare zum Grundgesetz. Alles schien unproblematisch zu sein, bis völlig überraschend Heribert

1 Patrick Bahners: Nagelprobe, in: Frankfurter Allgemeine Zeitung, 28.9.2010, S. 29. - Für wertvolle Hinweise danke ich Daniel Schulz und Steven Schäller. 
Prantl in der Süddeutschen Zeitung einen Artikel verfasste mit der Aufsehen erregenden Überschrift „Die Würde des Menschen wird antastbar“. ${ }^{2}$ Es dauerte nicht lange, da legte die Frankfurter Allgemeine Zeitung nach und schrieb „Richterkandidat Dreier rechtfertigt die Folter“. ${ }^{3}$

Was war passiert? Horst Dreier hatte in einer Kommentierung des Artikels 1 Abs. 1 des Grundgesetzes angesichts der Bedrohungslagen von Terrorismus und Kindesentführung von Fällen gesprochen, in denen die Würde des einen Rechtsträgers unter Berufung auf die Würde eines anderen angetastet werde. Hier könnten sich, so formulierte er vorsichtig, ,staatliche Organe im Einzelfall mit zwei prinzipiell gleichwertigen [...] Rechtspflichten konfrontiert sehen“ und „nach Ausschöpfung aller anderen Mittel nur noch die Würde des Opfers oder die des Täters" verletzen. In diesen Konstellationen dürfe „der Rechtsgedanke der rechtfertigenden Pflichtenkollision nicht von vornherein auszuschließen sein ““4. Darauf hatte Prantl Bezug genommen. Im übrigen hatte ein anderer Redakteur der Frankfurter Allgemeinen Zeitung einige Tage zuvor einen weitgehend unbemerkt gebliebenen Artikel veröffentlicht, in dem er zunächst den Kandidaten Horst Dreier lobte - „zweifellos eine Spitzenwahl für einen Spitzenjob!“-, dann aber im Rekurs auf seinen Grundgesetzkommentar formulierte: „Wenn aber, wie von Dreier vorgeschlagen, auch das Folterverbot oder das Lebensrecht Ungeborener künftig vom Menschenwürdesatz entkoppelt werden sollten, dann stellt sich die Frage nach der Entwertung der Menschenwürde auf unerwartete Weise neu. “5 Die Artikel in Frankfurter Allgemeiner Zeitung und Süddeutscher Zeitung führten dazu, dass Horst Dreier nicht länger Kandidat blieb. Am 25. April 2008 wurde der Staatsrechtler und Rektor der Universität Freiburg, Andreas Voßkuhle, anstelle Dreiers zum Richter des Bundesverfassungsgerichtes gewählt. Michael Stolleis sprach von einem „konzertierten Rufmord“. 6

2 Heribert Prantl: Die Würde des Menschen wird antastbar, in: Süddeutsche Zeitung, 23.1.2008, S. 5.

3 Patrick Bahners: Diffamiert? Richterkandidat Dreier rechtfertigt Folter, in: Frankfurter Allgemeine Zeitung, 11.2.2008, S. 31.

4 Horst Dreier: Artikel 1 I: Menschenwürde, in: ders. (Hrsg.): GrundgesetzKommentar, Bd. 1, 2. Aufl., Tübingen 2004, S. 139-231, hier: S. 211.

5 Christian Geyer: Die neue Staatsraison. Wachablösung: Lehmann geht, Dreier kommt, in: Frankfurter Allgemeine Zeitung, 17.1.2008, S. 31.

6 Michael Stolleis: Konzertierter Rufmord. Die Kampagne gegen Horst Dreier, in: Merkur 62 (2008) 711, S. 717-720. 
Nun geht es hier nicht darum, diesen Vorgang im Einzelnen zu würdigen, auch nicht darüber zu spekulieren, was die wahren Gründe für die konzertierte Aktion gewesen sein mochten. Dieses Beispiel eröffnet indes die Möglichkeit, die systematischen Perspektiven einer durch die beiden Zentralbegriffe Transzendenz und Demokratie bezeichneten Problemstellung $\mathrm{zu}$ entfalten. Zunächst wird das Beispiel noch in einer Hinsicht fortgeführt, sodann argumentiert, dass politische Ordnungen begründungsbedürftig sind und dabei Transzendierungen und Transzendenzauslegungen eine besondere, nämlich sinnkonstitutive Bedeutung einnehmen. Anschließend wird dieser Ansatz theoretisch kontextuiert, indem er gegen die Kontrastfolie des politisch-theologischen Komplexes profiliert wird. Auf diese Weise lässt sich der Transzendenzbegriff aus seiner religiösen Umklammerung lösen. Systematische und historische Überlegungen, die den Blick auf die in diesem Band vereinigten theoretischen und exemplarischen Studien lenken, beschließen die Einführung.

\section{DISKURS ÜBER DIE UNVERFÜGBARKEIT}

Ganz offensichtlich handelt es sich bei der Causa Dreier um einen Diskurs über die Unverfügbarkeit. Die Menschenwürde ist unantastbar, sie zu schützen und zu achten, ist die Staatsräson der Bundesrepublik Deutschland. Sie ist nicht antastbar, sie ist auch nicht abwägbar, was bedeutet, dass sie jeder Abwägung mit anderen Werten und Rechten von Verfassungsrang entzogen ist. ${ }^{7}$ Jede Antastung ist eine Verletzung. Bei Artikel 1 des deut-

7 Ein weiterer Beleg für die Behauptung absoluter, verfassungsrechtlich gebotener Unverfügbarkeit der Menschenwürde stellt ein bereits 2003, ebenfalls in der Frankfurter Allgemeinen Zeitung, erschienener Artikel von Ernst-Wolfgang Böckenförde dar, der, nicht zuletzt mit Blick auf den Schutz des ungeborenen Lebens, eine Neukommentierung des Artikels 1 in dem Leitkommentar von Maunz/Dürig/Herzog einer Fundamentalkritik unterzogen hatte. Hier lautete die Überschrift: „Die Würde des Menschen war unantastbar“. Nun habe die Kommentierung (durch Matthias Herdegen) die „Würde des Menschen der Abwägung ausgeliefert wie jede andere Rechtsposition auch“. Böckenförde inkriminierte, dass es beim pränatalen Würdeschutz zu einer ,gleitenden Skala variierender Disponibilität" kommen werde, wohingegen auf der Menschenwürde als einer „Unabdingbarkeit“, die jede Disposition verbiete, zu bestehen sei. Ernst-Wolfgang Böckenförde: Die Würde des Menschen war unantastbar. Abschied von den Verfassungsvätern: Die Neukommentierung von Art. 1 des 
schen Grundgesetzes handelt es sich um eine Grundnorm, die als Folge des nationalsozialistischen Unrechtsstaates für die Verfassungsordnung der Bundesrepublik Deutschland eine sinnstiftende Bedeutung erlangt hat und mithin als eine ihrer zentralen Leitideen bezeichnet werden kann. Wer die Menschenwürde, ihre Unantastbarkeit und Unabwägbarkeit, zur Disposition stellt, und sei es nur in zwei Zeilen akademisch-wissenschaftlichen Räsonnements, der verletzt anscheinend ein Tabu. Tabus errichten Grenzen des Handelns und markieren Einschränkungen, deren Verletzung den Ausschluss aus der Gemeinschaft nach sich zieht. Tabus entbehren einer rationalen Begründung. Das ist in dem Eingangsfall anders, weshalb hier auch die Erklärungskraft des Tabubegriffs endet.

Der Unterschied liegt darin, dass es sich bei der grundgesetzlichen Menschenwürde um eine Form der Unverfügbarstellung handelt, die auf einen bewussten und begründeten Akt zurückzuführen ist. Es war der Parlamentarische Rat, die verfassunggebende Versammlung von 1948 und 1949, die den so klaren wie apodiktischen und in ihrer Einfachheit beeindruckenden Satz des ersten Artikels des Grundgesetzes formulierte. Die Normativierung des Menschenwürdeschutzes war das Ergebnis eines reflexiven Prozesses, in dem sowohl über die Folgerungen aus der nationalsozialistischen Vergangenheit wie die unterschiedlichen Herleitungen einer solchen Grundnorm debattiert wurde: Das Naturrecht, das Sittengesetz, die religiöse Tradition, die griechische Stoa, die Lektionen der Geschichte begründeten je für sich die Unverfügbarstellung, aber sie rekurrierten wiederum auf unterschiedliche metaphysische, religiöse, humanistische und geschichtsphilosophische Auffassungen, die in ihren jeweiligen Geltungsansprüchen keineswegs kompatibel waren. So konnte sich der Menschenwürdeschutz nur als eine, wie Theodor Heuss formulierte, „nicht interpretierte These ${ }^{\text {“8 }}$ normieren lassen. Carlo Schmid hatte schon vorher darauf hingewiesen, dass die Würde des Menschen von Verschiedenen verschieden definiert wurde und dass dennoch die Menschenwürde erst der Verfas-

Grundgesetzes markiert einen Epochenbruch, in: Frankfurter Allgemeine Zeitung, 3.9.2003, S. 33 und S. 35.

8 Theodor Heuss, in: Der Parlamentarische Rat, Bd. 5, Tlbd. I: Ausschuß für Grundsatzfragen, bearbeitet von Eberhard Pikart, Boppard am Rhein 1993, S. 67. 
sung und der neuen Ordnung Legitimität zu geben in der Lage war. ${ }^{9}$ Und so wie die Verfassung selbst als höherrangiges Recht dem einfachen Gesetzesrecht vorgeordnet ist, so ist der Menschenwürdeschutz des Grundgesetzes selbst noch einmal eine höherrangige, der Verfassung insgesamt Legitimität verleihende Norm. Es handelt sich also um eine durch den Parlamentarischen Rat vorgenommene doppelte Unverfügbarstellung. In der Perspektive der Akteure von 1948 und 1949 werden Verfassung und Menschenwürde dem normalen politischen Prozess entzogen, quasi entrückt, und doch sollen sie auf die soziale und politische Ordnung zurückwirken und ihr Sinn und Geltung geben. Zugleich wird in diesem konkreten historischen Prozess der Unverfügbarstellung eine Gemeinsinnsbehauptung erzeugt, die den gemeinsamen Horizont des Handels und Verhaltens auch für die Zukunft zum Ausdruck bringen soll, sich nämlich als Gemeinschaft über die Achtung und den Schutz der menschlichen Würde zu definieren.

Nun sind solche Diskurse, die Indisponibilitäten zu generieren versuchen, in freien und offenen, demokratischen Gesellschaften indes nie unstreitig, weshalb auch ihr Gelingen, die Verstetigung in Form eines institutionellen Ordnungsarrangements, keineswegs gesichert ist. Basis- oder Grundkonsense $^{10}$ gründen zwar auf der Annahme ihrer fraglosen Anerkennung, doch sind es allenfalls Geltungen pro tempore, die durch konforme Anschlusspraktiken und bisweilen auch durch sanktionsbewehrte Mechanismen, ähnlich denen, die das Grundgesetz im Sinne seines Konzeptes „wehrhafter Demokratie“ vorsieht, befestigt werden können. Allein schon die Deutungsoffenheit solcher, die jeweilige Gegenwart der politischen Ordnungen überschreitenden Vorstellungen - wie der Menschenwürde lässt jedoch unterschiedliche, sich durchaus widersprechen könnende Interpretationen $\mathrm{zu}$, die je für sich eigene Geltungsbehauptungen in Anspruch

9 „Eine Verfassung wird aber von dem Volk, das sie ,in Verfassung bringt“, immer dann als legitim angesehen, wenn sie der Ausdruck dessen ist, was sie aus dem Lebensgefühl der Menschen in einer bestimmten Epoche an Folgerungen für den Aufbau des Staates und die Art seiner Funktion ergibt.“ (Carlo Schmid [Karl Schmid]: Die Legitimität der Verfassung, in: Deutsche RechtsZeitschrift 1 (1946), S. 2-4, hier: S. 2)

10 Zum Basiskonsens vgl. den Beitrag von Georg Kohler: Basiskonsens und Willensnation. Die Kontingenz des Unverfügbaren und das Modell der Schweiz, in diesem Band. Vgl. auch schon Hans Vorländer: Verfassung und Konsens. Der Streit in der Grundlagen- und Grundgesetz-Diskussion der Bundesrepublik Deutschland, Berlin 1981. 
nehmen. Das kann letztlich zu einer bestärkenden Geltung des Status der Unverfügbarkeit führen, weil sich die unterschiedlichen Auslegungen im Rekurs auf die gemeinsame Grundvorstellung treffen und nur über die angemessene Interpretation streiten. Das kann aber auch zu einer Bestreitung des Indisponiblen selbst und seiner Wiederverfügbarmachung führen.

Diskurse über Unverfügbares beruhen indes nicht alleine auf reflexiven Formen bewusster Unverfügbarstellung wie bei der normativen Vorrangstellung des grundgesetzlichen Menschenwürdeschutzes. Tugend- und Moraldiskurse rekurrieren auf Vorstellungen, Ideen und Werte, die der jeweiligen politischen Ordnung vorausliegen, also nicht direkt verfügbar sind, gleichwohl aber für sie geltend gemacht werden. Historisch beobachtbar sind auch Praktiken der Sakralisierung und Zivilreligiosität, der kultischen Verehrung und rituellen Beschwörung politischer Ordnungsvorstellungen, mittels derer sozio-moralische Verhaltensdispositionen und gemeinsinnige Handlungsmotivationen erzeugt und auf Dauer gestellt werden sollen. Hier geben sich vielfältige, teils verdeckte, teils offene Verweisungszusammenhänge zu erkennen, die die jeweilige Ordnung transzendieren. Das wird beispielsweise schon im neuzeitlichen Begründungsdiskurs moderner Ordnungen dort deutlich, wo im Paradigma kontraktualistischer oder utilitaristischer Rationalitäten die vermeintlich großen, auf Gott und Religion verweisenden Transzendenzen verschwinden, aber durch Gemeinsinnsbehauptungen, den sensus communis, den ,Bürgersinn“ oder die ,Bürgerreligion' ersetzt werden. Die Tugendideologie Robespierres, eine Rousseau'sche Zivilreligion in praxi, die Feier des ,Höchsten Wesens', später die die Idee der République noch übersteigende Grande Nation-Mythisierung, die amerikanischen Freiheits- und Glücksversprechen, die bis in den Faschismus und die kommunistische Partei wirkende Risorgimento-Ideologie Italiens, die Reichsmythen und die Reichsgründungsemphase in Deutschland etc. - sie alle verweisen auf transzendierende Vorstellungen, die in ihrer Wirkungsmächtigkeit alte Ordnungen zu sprengen in der Lage sind beziehungsweise neue Ordnungen etablieren und verstetigen wollen. Wie aber wirken diese Transzendenzen, wie lassen sich ihre unterschiedlichen Modi von der invocatio dei in Präambeln von demokratischen Verfassungen über den Rekurs auf Ursprungs- und Gründungsgeschichten bis eben zur Unverfügbarkeit der Würde des Menschen in den Prozessen politischer Ordnungsbegründung verstehen und welchen Bindungs- und Verpflichtungscharakter erzeugen sie? 
Auch auf eines der zentralen Steuerungsmedien moderner demokratischer Gesellschaften scheint nicht zuzutreffen, was Rudolf Wiethölter in einer einprägsamen Formel als die Signatur des modernen Rechts und des Rechtspositivismus bezeichnete, dass nämlich „Recht als Recht durch Recht" ${ }^{\text {11 }}$ gelte. Dem Recht an- beziehungsweise vorgelagert, dem Geltungsanspruch nach könnte auch gesagt werden: nachgelagert, sind Annahmen, Vorstellungen, Diskurse und Praktiken, die dieses positiv gesetzte Recht selbst überschreiten und doch auf es, seine Umsetzung und Befolgung, seine Legitimation und Akzeptanz, zurückwirken. Recht, so scheint es, legitimiert sich nicht alleine aus dem korrekten Verfahren seiner Genese, sondern ist in komplexer Weise an Vorstellungen von Gerechtigkeit zurückgebunden. ${ }^{12}$ Und schließlich lebt auch das andere moderne Medium gesellschaftlicher Koordination, das Marktprinzip, nicht alleine von der Rationalität von Angebot und Nachfrage, sondern auch von der Annahme eines sich von allein einstellenden Gleichgewichts und eines Allen dienenden Nutzens.

Der Blick auf diese Zusammenhänge gibt Anlass zu der These, dass moderne, demokratische Ordnungen mit dem Paradox leben, dass sie in der eigenen Wahrnehmung zwar auf Autonomie und Selbstgesetzgebung beruhen, zu ihrer Begründung und Stabilisierung indes auf Voraussetzungen, Vorstellungen und Ressourcen zurückgreifen, über die sie nicht oder nur bedingt verfügen. Nun ist eine solche These nicht neu, sie ist in etwas anderem Gewande als sogenanntes Böckenförde-Paradox hinreichend bekannt und diskutiert worden. ${ }^{13}$ Aber anders als Böckenförde glaubte, die

11 Rudolf Wiethölter: Julius Hermann von Kirchmann (1802-1884). Der Philosoph als wahrer Rechtslehrer, in: Thomas Blanke (Hrsg.): Streitbare Juristen. Eine andere Tradition. Jürgen Seifert, Mitherausgeber der Kritischen Justiz, zum 60. Geburtstag, Baden-Baden 1988, S. 44-58, hier: S. 46.

12 Niklas Luhmann (Das Recht der Gesellschaft, Frankfurt a.M. 1995, S. 214ff.) spricht in diesem Zusammenhang von der „Kontingenzformel Gerechtigkeit“. Paolo Prodi (Eine Geschichte der Gerechtigkeit. Vom Recht Gottes zum modernen Rechtsstaat, München 2003) zeigt, wie auch das Recht in der Moderne noch von nachwirkenden religiösen Traditionsbeständen, vor allem von Praktiken der Sakralisierung lebt. Vgl. zu diesen Zusammenhängen auch Friedrich Wilhelm Graf: Moses Vermächtnis. Über göttliche und menschliche Gesetze, München 2006; Marie Theres Fögen: Das Lied vom Gesetz, München (Carl Friedrich von Siemens Stiftung) o.J. (2006).

13 Vgl. Ernst-Wolfgang Böckenförde: Die Entstehung des Staates als Vorgang der Säkularisation, in: ders.: Recht, Staat, Freiheit. Studien zur Rechtsphilosophie, Staatstheorie und Verfassungsgeschichte, 2. Aufl., Frankfurt a.M. 1992, S. 92- 
Problembeschreibung als eine solche der religiös-christlichen Fundamente moderner säkular-freiheitlicher Ordnungen ansetzen $\mathrm{zu}$ sollen, wird hier mit einem Transzendenzbegriff argumentiert, der nicht allein auf Vorstellungen des Religiösen rekurriert, sondern die diskursiven und in Praktiken symbolisch zum Ausdruck kommenden Vorgänge sozialer und politischer Überschreitungen und der in ihnen enthaltenen Vorstellungen in ihrer sinnkonstitutiven Funktion sowie in ihren stabilisierenden wie destabilisierenden Wirkungen in den Blick nimmt. Dabei ist es keineswegs ausgeschlossen, dass sich Transzendierungen, vor allem solche der säkularen Sakralisierung, auch in den ,elementaren Formen“ vollziehen, die Durkheim mit dem „,religiösen Leben“"14 identifizierte, aber sie sind nicht mit den Substraten und Inhalten religiöser Glaubenssysteme gleichzusetzen, auch dann nicht, wenn sie, wie in Kirche und Sekte, Gemeinschaften konstituieren.

\section{TRANSZENDENZ UND POLITISCHE ORDNUNG}

In gesellschaftlichen Diskursen und Praktiken werden Geltungsbehauptungen erzeugt, mittels derer politische Ordnungen begründet, das heißt in ihrer Existenz gerechtfertigt und damit auch stabilisiert, aber auch bestritten und damit gefährdet werden können. Politische Ordnungen, demokratische in ganz besonderer Weise, sind mithin keine feststehenden, überzeitlichen, den Kontingenzen der Zeitläufte enthobenen Ordnungen. ${ }^{15}$ Sie sind labil, dem historischen Wandel ausgesetzt, ihre Dauer versteht sich nicht von selbst. Sie bedürfen insofern der Selbstsymbolisierung, als die ihnen zugrundeliegenden Handlungs- und Kommunikationsstrukturen erst durch spezifische Formen, Zeichen und Verkörperungen, also Repräsentationen ihrer Leitideen, ein Verständnis ihrer selbst zu entwickeln in der Lage sind

114, hier: S. 112: „Der freiheitliche, säkularisierte Staat lebt von Voraussetzungen, die er selbst nicht garantieren kann.“

14 Vgl. Émile Durkheim: Die elementaren Formen des religiösen Lebens, Frankfurt a.M. 1981 (Hervorhebung HV).

15 Für dieses und das nächste Kapitel greife ich auszugsweise, teils mit wörtlichen Übernahmen, teils verändert, auf meine sehr viel ausführlichere Darstellung: Transzendenz und die Konstitution von Ordnungen. Eine Einführung in systematischer Absicht, in: Hans Vorländer (Hrsg.): Transzendenz und die Konstitution von Ordnungen, Berlin/New York 2013 (i.E.) zurück; vgl. auch zum diesbezüglichen Forschungsprogramm ders. (Hrsg.): Transzendenz und Gemeinsinn. Themen und Perspektiven des Dresdner Sonderforschungsbereichs 804, Dresden 2011. 
und damit aus latenten Strukturen institutionelle Ordnungen erwachsen, die fortwährende Geltung von Verhaltensnormen und lebenspraktischen Regulationen beanspruchen. ${ }^{16}$

So, wie in Prozessen der ,sinnhaften Überschreitung des Gegebenen“ sich für den auf Symbolisierung angewiesenen Menschen die umgebende Welt erschließt, soziale Erfahrung ${ }^{17}$ und überpersönliche Geltung des eigenen Lebens ${ }^{18}$ möglich wird, so konstituieren sich auch politische Ordnungen durch spezifische Mechanismen der Überschreitung von Situationen und Lebenslagen: Überschreitungen können sich in verschiedenen Formen und unterschiedlichen, sprachlichen, performativen, rituellen, narrativen, bild- und zeichenhaften, ikonischen Medien vollziehen und dabei soziale Wirklichkeiten und sinnhafte Bezüge zur Welt herstellen, welche für die Konstitution von Ordnungen wesentlich sind. Transzendierungen können sich auf Personen und Institutionen, Orte und Länder, Städte und Nationen, Räume und Zeiten, Gottheiten, Bilder und Dinge beziehen. Sie können auf den unterschiedlichen Modi von Heiligung, Auratisierung, Charismatisierung, Fetischisierung, Tabuisierung beruhen und sich in

16 Vgl. zu diesem Verständnis institutioneller Ordnung die aus dem Dresdner SFB 537 „Institutionalität und Geschichtlichkeit“ hervorgegangenen Arbeiten zur Symbolizität (Gert Melville (Hrsg.): Institutionalität und Symbolisierung: Verstetigung kultureller Ordnungsmuster in Vergangenheit und Gegenwart, Köln/Weimar/Wien 2001), zur Narrativität (ders./Hans Vorländer (Hrsg.): Geltungsgeschichten. Über die Stabilisierung und Legitimisierung institutioneller Ordnungen, Köln/Weimar/Wien 2002) und zur Macht institutioneller Ordnungen (Gert Melville (Hrsg.): Das Sichtbare und das Unsichtbare der Macht. Institutionelle Prozesse in Antike, Mittelalter und Neuzeit, Köln/Weimar/Wien 2005). Zuletzt: Karl-Siegbert Rehberg: Institutionelle Analyse und historische Komparatistik. Zusammenfassung der theoretischen und methodischen Grundlagen und Hauptergebnisse des Sonderforschungsbereiches 537 ,Institutionalität und Geschichtlichkeit‘, in: Gert Melville/Karl-Siegbert Rehberg (Hrsg.): Dimensionen institutioneller Macht. Fallstudien von der Antike bis zur Gegenwart, Köln/Weimar/Wien 2012, S. 417-443.

17 Vgl. Alfred Schütz/Thomas Luckmann: Strukturen der Lebenswelt, Konstanz 2003, S. 634ff.

18 Vgl. Ernst Cassirer: Philosophie der symbolischen Formen, Bd. 3, Darmstadt 1994, S. 447ff.; zur überpersönlichen, transzendenten Geltung des Symbolischen vgl. auch John Michael Krois: Problematik, Eigenart und Aktualität der Cassirerschen Philosophie der symbolischen Formen, in: Hans-Jürg Braun/Helmut Holzhey (Hrsg.): Über Ernst Cassirers Philosophie der symbolischen Formen, Frankfurt a.M. 1988, S. 15-44, hier: S. $28 f$. 
unterschiedlichen Formen, in Verkörperungen, Narrationen, Legenden, Mythen oder Festinszenierungen zum Ausdruck bringen.

In die unterschiedlichen Transzendierungsprozesse sind spezifische Transzendenzvorstellungen eingelagert, die in der Perspektive handelnder Akteure über alltägliche Situationen und Lebenslagen hinausweisen, die gleichwohl aber auf sie zurückwirken und ihnen Sinn und Geltung verleihen. In diskursiven und praktischen Prozessen werden unterschiedliche Vorstellungen sichtbar, auf die hin transzendiert wird und die in systematischer Perspektive als ein Repertoire von miteinander konkurrierenden Vorstellungen bezeichnet werden können: Gott, Tradition, Vernunft, Fortschritt, Natur, Geschichte, Nation, Staat, Volk etc. sind historisch je unterschiedlich $\mathrm{zu}$ identifizierende und interferierende Vorstellungen von etwas Transzendentem, um deren Aneignung und Verwerfung, Behauptung und Bestreitung, Interpretation und Auslegung es in Prozessen der Transzendierung geht. Geteilte Transzendenzvorstellungen erzeugen Transzendenzressourcen, man kann an ihnen geltungserhöhend partizipieren, in Begründungsdiskursen auf sie rekurrieren: Der Bürger beruft sich auf die Demokratie, der Richter urteilt im Namen des Volkes und der Gerechtigkeit, der Politiker rechtfertigt sich mit Bezug auf die Durchsetzung der Würde des Menschen, der Reformer bezieht sich auf den Fortschritt, der Revolutionär auf die historischen Gesetzmäßigkeiten, der Konservative auf die Tradition, der Liberale auf die Freiheit. Transzendenzvorstellungen können gerade in pluralistisch verfassten demokratischen Gemeinwesen in Konkurrenz und Spannung zueinander stehen, eine Ordnung sprengen, sie können - bis zu einem Zustand der complexio oppositorum - amalgamiert werden und eine Ordnung auf Dauer stellen. In Transzendierungsvorgängen finden auch jene Umbesetzungen, Verlagerungen und Übernahmen statt, welche zwischen religiösem, kulturellem und politischem System zu Irritationen führen können und die in den Diskurslagen von Politischer Religion, Politischer Theologie oder auch Zivilreligion - zumeist polemisch - diskutiert werden. ${ }^{19}$ Das Gleiche gilt für die ikonischen Darstel-

19 Henning Ottmann bedient sich in diesem Zusammenhang (Politische Theologie als Begriffsgeschichte, in: Volker Gerhardt (Hrsg.): Der Begriff der Politik. Bedingungen und Gründe politischen Handelns, Stuttgart 1990, S. 169-188, hier: S. 175) des schönen Begriffs der „vagabondage“, der auf die - prima facie evident erscheinenden - Umbesetzungen von Begriffen und damit auf die vermeintlichen Analoga von beispielsweise Allmacht Gottes und Absolutismus 
lungen und Imaginationen von Gott, König, Volk, Nation, innerweltlichen Demiurgen etc., die, im „Getriebe der Verkörperungsmechanismen““20, auf genuin religiöse Zeichen- und Symbolsysteme, Semantiken und Rhetoriken verweisen und damit sowohl sozialen und politischen Ordnungen einen heiligen, Raum und Zeit transzendierenden Ort, Ursprung und Telos geben als auch eine Geltungserhöhung Einzelner, sozialer Gruppen und Formationen bewirken.

Mit dem Begriff der Transzendenz werden gemeinhin religiöse Phänomene verbunden, ${ }^{21}$ weshalb auch der gleichzeitige Bezug auf die Konstitutionsfrage politischer Ordnung jene Theorien aufruft, in denen das „religiös-kulturelle Dispositiv““22 der modernen Politik verhandelt wird. So steht die Reflexion des Verhältnisses von Religion und Politik nach wie vor unter dem Bann jener Politischen Theologie Carl Schmitts, die dieser zuerst für den zweiten Band der Erinnerungsgabe für Max Weber - zumindest in den ersten drei Kapiteln - geschrieben hatte und die, ursprünglich von der „verstehenden Soziologie“ Webers ausgehend, Strukturähnlichkeiten von Begriffen der Staatsrechtslehre und der Theologie zur These brachte, dass „,[a]lle prägnanten Begriffe der modernen Staatslehre [...] säkularisierte theologische Begriffe ${ }^{\text {، } 23}$ seien. Wo Max Weber die hermeneutischen Sinnhorizonte des Handelns in seiner Religionssoziologie von den religiösen Prägungen her analysiert, behauptet Schmitt die konfessionelle, vor allem katholische Herkunft genealogisch als unhintergehbare Sinnressource und bestreitet damit, trotz und gegen die Säkularisierung, die Eigenlegitimation der Moderne. Wo Blumenberg dann in der Kontroverse mit Schmitt die Eigenlegitimität der Moderne verteidigt, aber der modernen Gesellschaft auch die Last der Generierung eigener Legitimitätsgründe auferlegt, sieht Schmitt die moderne Gesellschaft in der Legitimitätsschuld der religiös

des Herrschers und Souveränität des Staates, von Trinitätslehre und Gewaltenteilungslehre, von Unfehlbarkeit des Willens Gottes und Unfehlbarkeit der volonté générale, von religiösem Gesetz und menschlichem Gesetz, von religiösem Heil und weltlichem Heil usw. aufmerksam macht (vgl. ebd., S. 180ff.).

20 Claude Lefort: Fortdauer des Theologisch-Politischen?, Wien 1999, S. 93.

21 Bei Niklas Luhmann heißt es, „daß eine Kommunikation immer dann religiös ist, wenn sie Immanentes unter dem Gesichtspunkt der Transzendenz betrachtet.“(Die Religion der Gesellschaft, Frankfurt a.M. 2002, S. 77)

22 Vgl. Jürgen Gebhardt: Das religiös-kulturelle Dispositiv der modernen Politik, in diesem Band.

23 Carl Schmitt: Politische Theologie: Vier Kapitel zur Lehre von der Souveränität [1922], 7. Aufl., Berlin 1996, S. 43. 
geordneten Vormoderne. ${ }^{24}$ Schmitt wie auch Blumenberg tragen zum hier entfalteten Problemzusammenhang wenig Erhellendes bei, weil sie selbst in einer enggeführten Legitimitätsfrage gefangen bleiben, die sich um die Selbstbeschreibung der westlichen Moderne entzündet hat und ganz entscheidend von der Behauptung beziehungsweise der Bestreitung eines Epochenbruchs lebt. Wo Schmitt Politische Theologie in polemischer Absicht betreibt, bestreitet Blumenberg in Verteidigung der Moderne die Existenz eines politisch-theologischen Komplexes. ${ }^{25}$ Der Ansatz, die Begründung von politischen Ordnungen auf die in ihnen enthaltenen Transzendierungsvorgänge historisch zu untersuchen, untertunnelt hingegen die Epochenthese und unterwirft sich darüber hinaus auch keinen starken, normativ imprägnierten Thesen über die Rechtfertigung von Ordnungen der Vormoderne und Moderne.

Den Epochenbruch überspielen Claude Lefort und Marcel Gauchet mit ihren Arbeiten über das „Theologisch-Politische“ bzw. „Die Entzauberung der Welt ${ }^{\star 2}{ }^{26}$ Beide Autoren setzen grundsätzlicher an und sehen in der Religion eine spezifische Form der Alterität, die unverfügbar bleibt und zugleich den reflexiven Selbstbezug der Gesellschaft garantiert: Mit der räumlichen Spaltung der Welt in ein Diesseits und Jenseits wird paradoxerweise auch die soziale Welt als solche erfahrbar. Zugleich aber arbeitet sich die soziale und politische Welt an den substantiellen Einheitsvorstellungen des einen Gottes ab und kann sich, auch in der modernen Demokratie, dem Theologisch-Politischen nicht entziehen, indem es das System von Repräsentationen der Einheit auf den sozialen und politischen Bereich überträgt. Bei König, Staat, Nation, Volk, Menschheit handelt es sich um ,transzendente Personifizierungen und Subjektivierungen kollektiver Einheiten, die den Schlüssel zur politischen Entwicklung der Moderne enthalten ${ }^{\text {‘27 }}$. In seiner Geschichte der Metamorphosen des Transzendenten

24 Vgl. Carl Schmitt/Hans Blumenberg: Briefwechsel 1971-1978, hrsg. und mit einem Nachwort versehen von Alexander Schmitz, Frankfurt a.M. 2007.

25 Vgl. Hans Blumenberg: Die Legitimität der Neuzeit, erneuerte Ausgabe, Frankfurt a.M. 1996; Jan Assmann (Herrschaft und Heil. Politische Theologie in Altägypten, Israel und Europa, Frankfurt a.M. 2002, S. 20) glaubt, dass Schmitt Politische Theologie sowohl in einem betreibenden als auch in einem beschreibenden Sinne meine.

26 Vgl. Lefort, Fortdauer des Politisch-Theologischen?, 1999; Marcel Gauchet: Le désenchantement du monde. Une histoire politique de la religion, Paris 1985.

27 Gauchet, Le désenchantement, 1985, S. 179. 
glaubt Gauchet sodann einen historischen Prozess der Entleerung von Transzendenzvorstellungen (von Gott über König bis zum Volk in der Demokratie) zu erkennen, der in der für moderne, plural-heterogene Gesellschaften charakteristischen Leerstelle des Transzendenten endet. Dass der Totalitarismus diese Leerstelle durch Sakralisierungen des Volkes oder des Proletariates und Verkörperungssymboliken der Einheit wieder zu besetzen suchte, verdeutlicht einmal die Fortdauer des politisch-theologischen Problems und zum anderen die Labilität moderner Demokratien. Dieses historisch entfaltete Argument legt zwei grundlegende Problemstellungen, auch Erkenntnisgewinne, offen: Zum einen verweist der Begriff der Transzendenz über die spezifische Transzendenzauslegung der Religion hinaus auf das Grundproblem der Begründung von sozialen und politischen Ordnungen und die Legitimierung von Macht durch Figuren und Modi, Diskurse und Praktiken, die die jeweilige Ordnung überschreiten, für ihre Sinnorientierung und Geltung aber konstitutiv sind. Zum anderen hat sich trotz der Entleerung des Transzendenten auch in (post)modernen Gesellschaften und Demokratien das Problem der sinnkonstitutiven Transzendenzbezüge keineswegs überlebt. Es lässt sich indes nicht in den Kategorien religiöser beziehungsweise nicht- oder anti-religiöser Frontstellungen zureichend erfassen - was wiederum nicht heißt, dass moderne demokratische Ordnungen nicht doch noch von überhängenden Transzendenzvorstellungen des Religiösen zehren, aber gewiss nicht von ihnen alleine (wenn politische Ordnungen das denn jemals getan haben).

\section{UNVERFÜGBARKEIT UND LIMINALITÄT}

Bei Transzendenzkonstruktionen handelt es sich um die Produktion oder Bewältigung von ,Unverfügbarkeiten‘. Als ,unverfügbar‘ werden solche Sachverhalte angesehen, die in der Perspektive von Akteuren der unmittelbaren, alltäglichen Lebenswelt entzogen sind und deshalb quasi entrückt erscheinen, die gleichwohl aber auf sie zurückwirken und ihr Sinn und Geltung verleihen: Rechtstheoretiker unterscheiden zwischen Recht und Unrecht, indem sie auf das Naturrecht verweisen, dabei über diese, sich aus der ,Natur' ergeben sollenden Grundnormen nicht verfügen können. Verfassungsordnungen stellen ihre Bürger unter den besonderen, unveräußerlichen Schutz der Menschenwürde und entziehen staatlichem Zuwiderhandeln Legitimation und Wirksamkeit. Demokratien bemühen die Ge- 
schichte, um aus deren vermeintlichen ,Lektionen' dem eigenen Handeln Grenzen aufzuerlegen oder aber besondere Handlungspflichten abzuleiten. Solche ,Unverfügbarkeiten', wie sie hier beispielhaft illustriert werden, sind keine überhistorischen oder metasozialen Phänomene. Sie werden, auch wenn sie hinter dem Rücken der Akteure wirken, konstruiert, sie beruhen auf Prozessen der Unverfügbarstellung, die diskursiver wie praktischer Veränderung unterliegen. Wo die staatliche Gefahrenabwehr alle Mittel zu erfordern scheint, wird auch die Menschenwürde wieder disponibel gemacht, wie in zeitgenössischen Diskursen um Terrorismusbekämpfung oder Rettungsfolter deutlich wird. Mithin entspricht der Unverfügbarmachung spiegelbildlich die Verfügbarmachung des vordem unverfügbar Gestellten. Transzendierungsvorgänge sind insofern Prozesse der Liminalität, sie konstruieren (immer verschiebbare) Grenzen, die bestimmen, was verfügbar sein soll und was nicht.

Mit dem Begriff der Unverfügbarkeit wird ein Akzent gesetzt, der sich somit vom traditionellen Verständnis der Transzendenz als Unbedingtes, Unvordenkliches und Unvorstellbares unterscheidet. ${ }^{28}$ Damit soll indes nicht bestritten werden, dass es in der Natur des Menschen liegende und insofern seiner Verfügung entzogene Problemlagen gibt wie: Natalität und Mortalität, Geburt und Tod, schwere Krankheiten, Verlusterfahrungen, materielle Unerreichbarkeiten oder auch die ,Launen' der Natur oder die des Wetters. Der Mensch sieht sich ihnen ausgesetzt, und oft entziehen sie sich seiner Erklärung. Diese Unverfügbarkeiten markieren in der Perzeption der ihnen Unterworfenen oder der Handelnden absolute Grenzen. Als ,harte', materiale Unverfügbarkeiten können auch soziale, politische und ökonomische ,Verhältnisse" und Machtstrukturen bezeichnet werden, denen gegenüber Menschen sich ebenfalls als „ohnmächtig“ ausgesetzt fühlen wie einer Naturkatastrophe. Selbst wenn man sie verändern wollte

28 Vgl. begriffsgeschichtlich: Jens Halfwassen/Markus Enders: Art. „Transzendenz, Transzendieren“, in: Joachim Ritter/Karlfried Gründer (Hrsg.): Historisches Wörterbuch der Philosophie, Bd. 10, Darmstadt 1998, Sp. 1442-1455; außerdem: Ludger Honnefelder/Werner Schüßler (Hrsg.): Transzendenz. Zu einem Grundwort der klassischen Metaphysik, Paderborn u.a. 1992; Eberhard Simons: Art. „Transzendenz“, in: Michael Baumgartner/Hermann Krings/Christoph Wild (Hrsg.): Handbuch der philosophischen Grundbegriffe, Bd. 6, München 1974, S. 1541-1556; Alan M. Olson/Leroy S. Rouner (Hrsg.): Transcendence and the Sacred, Notre Dame 1981. 
oder könnte, so stellt sich, nicht zuletzt angesichts der Komplexität der modernen Welt, die Erfahrung ein, dass ,,ich fast nichts ändern kann“29.

Solche anthropologischen Unverfügbarkeiten können aus der Sicht der ihnen ausgesetzten Individuen, Gruppen und Gemeinschaften nicht überstiegen, indes sehr wohl symbolisch und sozial ,bewältigt‘ werden. Riten, Kulte, Mythen und Legenden machen das Unvordenkliche und Unsagbare, das Faszinierende und Erschreckende durch performative und narrative Akte erzählbar und in diesem Sinne partiell auch verfügbar. Religionen stellen eines der umfassendsten symbolischen Systeme zur Bewältigung von Unverfügbarkeit dar. Auch können diese unverfügbaren Transzendenzen einer ästhetischen Bearbeitung (in Kunst und Architektur), einer philosophischen Betrachtung und wissenschaftlichen Erklärung zugeführt werden, also in den Modi ihrer kulturellen Bearbeitung reflexiv werden und damit sinnvolle und angemessene Formen des Verhaltens zu und des Umgangs mit dem Unverfügbaren erzeugen. ${ }^{30}$

Demgegenüber laufen Begriffe radikaler oder absoluter Unverfügbarkeit, wenn sie metaphysisch, essentialistisch, naturalistisch, biologistisch oder materialistisch gesetzt werden, Gefahr, die entscheidende Pointe eines kulturell gefassten Begriffs von Unverfügbarkeit zu verfehlen. In einer konstruktivistischen Wendung, die vergleichender und historischer Forschung zugleich eine empirische Perspektive eröffnet, wird nach der „Kultur unseres Verhaltens mit dem Unverfügbaren“31 ${ }^{\text {(31 }}$ gefragt. Diskurse und Praktiken werden daraufhin analysiert, wie in ihnen der Umgang mit dem für unverfügbar Gehaltenen bestimmt wird.

29 Niklas Luhmann: Komplexität und Demokratie, in: ders.: Politische Planung, Opladen 1971, S. 35-45, hier: S. 44.

30 Vgl. Thomas Rentsch: Transzendenz - Konstitution und Reflexion. Systematische Überlegungen, in: Hans Vorländer (Hrsg.): Transzendenz und die Konstitution von Ordnungen, Berlin 2013 (i.E.); vgl. auch Thomas Rentsch: Transzendenz und Negativität. Religionsphilosophische und ästhetische Studien, Berlin 2011.

31 Friedrich Kambartel: Bemerkungen zu Verständnis und Wahrheit religiöser Praxis und Rede, in: ders.: Philosophie der humanen Welt, Frankfurt a.M. 1989, S. 100-102, hier: S. 101. In diesem Zusammenhang ließe sich auch Religion deskriptiv-analytisch als ein spezifischer Modus der Reflexion über die Grenzziehungen von Verfüg- und Unverfügbarem verstehen (Kambartels Definition wird auch zitiert von Hermann Lübbe: Religion nach der Aufklärung, Neuausgabe, München 2004, S. 149). 
Dabei sind die Grenzziehungen von Verfügbarem und Unverfügbarem kontingent und Ausdruck je spezifischer historischer und kultureller Prägungen und Bestimmungen. Sie bestimmen sich zum einen von dem her, was sozial überhaupt als möglich, disponibel und machbar angesehen wird. In antiken Kulturen setzten ananke und tyche unüberschreitbare Grenzen, in der christlichen Tradition bestimmten der Wille Gottes und die providentia menschliches Handeln, in der Renaissance ließ fortuna nicht alles zu, wenngleich der geschickte Stratege, mit virtù ausgestattet, sich des Schicksals in einer geeigneten occasione bemächtigen konnte, um fortuna für sich und die Gemeinschaft nutzbar zu machen. Erst die Moderne hat ein umfassendes Kontingenzbewusstsein entwickelt, welches auf der Grundlage wissenschaftlicher Erkenntnis und rationaler Aufklärung die Räume der Möglichkeiten und Gestaltung weit, manche würden sagen: ins Unbegrenzt-Unendliche hinein geöffnet haben. ${ }^{32}$ Im Prinzip wird damit alles verfügbar, wenngleich sich empirisch zeigt, dass dies bei der Konstituierung von politischen Ordnungen auch in der Moderne keineswegs der Fall ist, ja in nahezu paradoxaler Weise Unverfügbarstellungen erfolgen, weil scheinbar alles verfügbar geworden ist. ${ }^{33}$ Das beginnt bei Theorien und

32 Vgl. zur tyche Gregor Vogt-Spira: Dramaturgie des Zufalls. Tyche und Handeln in der Komödie Menanders, München 1992; fortuna: Niccolò Machiavelli: Il Principe/Der Fürst, ital.-dt., übersetzt und hrsg. von Philipp Rippel, Stuttgart 1986; Kontingenz: Gerhart von Graevenitz/Odo Marquard (Hrsg.): Kontingenz. Poetik und Hermeneutik, Bd. 17, München 1998; Peter Vogt: Kontingenz und Zufall. Eine Ideen- und Begriffsgeschichte, Berlin 2011; Michael Th. Greven: Die politische Gesellschaft. Kontingenz und Dezision als Probleme des Regierens und der Demokratie, 2., aktualisierte Aufl., Wiesbaden 2009.

33 Hier handelt es sich dann um das, was Hermann Lübbe in einem anderen Zusammenhang über die Religion gesagt hat, dass sie „Kontingenzbewältigungspraxis“ sei (Hermann Lübbe: Kontingenzerfahrung und Kontingenzbewältigung, in: Graevenitz/Marquard, Kontingenz, 1998, S. 35-47, hier: S. 40). Eine solche Praxis setzt indes auch ein Kontingenzbewusstsein voraus, was für die Zeiten dominierender religiöser Weltdeutungen schwerlich behauptet werden kann. Unter den Bedingungen eines ausgeprägten Kontingenzbewusstseins kann indes mit Jürgen Gebhardt die „Kontingenzbewältigungspraxis“ auch in nichtreligiösen Kategorien, aber mit Blick auf die Konstitution sozialer und politischer Ordnungen wie folgt reformuliert werden: Im kommunikativen Charakter einer symbolischen Selbstverständigung sind individuelle Kontingenzbewältigung und kollektive Sinndeutung aufeinander bezogen. Diese Ordnungs- und Sinngehalte, die sich in den verschiedenen kulturellen Modi sinnhafter Symbolstrukturen zum Ausdruck bringen, sind als Kontingenzbewältigungspraxis zu verstehen: „Die Mitglieder der Gesellschaft erleben im Medium der symbolischen Formen gesellschaftlicher Sinndeutung diese Gesellschaft als kontin- 
revolutionären Begründungen moderner demokratischer Ordnungen, die Recht und Vergesellschaftung aus den Prinzipien der Autonomie entfalten und dennoch die Dauerhaftigkeit dieser Ordnung durch Mechanismen der Heiligung unantastbarer Prinzipien oder durch zivilreligiöse Kulte garantieren wollen. ${ }^{34}$ In diesem Sinne sind Verfassungen ihrerseits Arrangements der Selbstbindung qua Unverfügbarstellung der grundlegenden Prinzipien einer Ordnung. Das kann man auch für die Bildung von - demokratischen Nationalstaaten zeigen, deren unsicherer, oft über Kriege, Gewalt und Zwangshomogenisierung hergestellter Zusammenhalt durch sakralisierende Bild-, Architektur- und Denkmalprogramme oder gemeinsinnstimulierende Diskurse gestärkt werden soll. ${ }^{35}$ Kultische Praktiken und mythische Narrationen können auch der Stabilisierung partizipativer und demokratisierender Formen des politischen Lebens dienen. Verbunden mit der Vergött-

genzresistent und als Teil ihres menschlichen Wesens. Erst die Mittlerfunktion ihrer gesellschaftlichen Symbolwelten bindet die Vielfalt individueller Psychen in das Ganze des Soziallebens ein, transformiert individuelle Ordnungserfahrungen in eine kollektive Erfahrungswelt und bedingt den Aufbau institutioneller Komplexe des politischen und ökonomischen Systems." (Jürgen Gebhardt: ,Politik' und ,Religion': Eine historisch-theoretische Problemskizze. Peter Opitz zum 60. Geburtstag gewidmet, in: Manfred Walther (Hrsg.): Religion und Politik, Baden-Baden 2004, S. 51-71, hier: S. 68)

34 So bei Jean-Jacques Rousseau: Vom Gesellschaftsvertrag oder Grundsätze des Staatsrechts, in Zusammenarbeit mit Eva Pietzcker neu übersetzt und hrsg. von Hans Brockard, Stuttgart 1977.

35 Vgl. etwa Mary A. Perkins: Word and Nation, 1770-1850. Religious and Metaphysical Language in European National Consciousness, Aldershot 1999; Martin Geyer/Hartmut Lehmann (Hrsg.): Religion und Nation. Nation und Religion. Beiträge zu einer unbewältigten Geschichte, Göttingen 2004; Heinz-Gerhard Haupt/Dieter Langewiesche (Hrsg.): Nation und Religion in Europa, Frankfurt a.M. 2004; Dieter Langewiesche: Unschuldige Mythen: Gründungsmythen und Nationsbildung in Europa im 19. und 20. Jahrhundert, in: Kerstin von Lingen (Hrsg.): Kriegserfahrung und nationale Identität in Europa nach 1945. Erinnerung, Säuberungsprozesse und nationales Gedächtnis, Paderborn 2009, S. 2741; Martin Schulze Wessel (Hrsg.): Nationalisierung der Religion und Sakralisierung der Nation im östlichen Europa, Stuttgart 2006; Bernhard Giesen: Die Intellektuellen und die Nation: Eine deutsche Achsenzeit, Frankfurt a.M. 1993; ders.: Die Intellektuellen und die Nation 2: Kollektive Identität, Frankfurt a.M. 1999; Alberto M. Banti: La nazione del Risorgimento. Parentela, santità e onore alle origini dell'Italia unita, Torino 2000; Alberto M. Banti/Roberto Bizzocchi: Immagini della nazione nell'Italia del Risorgimento, Roma 2002 sowie Marzia Ponso: Die Sakralisierung der Nation in der Ikonographie des Risorgimento, in: Stephan Dreischer u.a. (Hrsg.): Jenseits der Geltung. Konkurrierende Transzendenzbehauptungen von der Antike bis zur Gegenwart, Berlin 2013, S. 345-369. 
lichung politischer Gemeinschaft werden sie allerdings in den Dienst totalitärer Ordnungen gestellt - vom Tugendterror Robespierres in der französischen Revolution bis zu den Aufzügen und Inszenierungen faschistischer und nationalsozialistischer Regime. ${ }^{36}$ In Sakralisierungen des Sozialen, etwa im Vergleich der Gesellschaft mit dem ,Heiligen“ oder in der Insistenz auf dem Vorrang des moralisch Guten gegenüber dem Recht als Medium interessengeleiteter Nutzenkalküle, kommen transzendierende Aufladungen einer um politische Integration und sozialen Zusammenhalt besorgten Weltdeutung zum Ausdruck. ${ }^{37}$ Und es endet dies keineswegs bei der Sakralität der Person im Begründungsdiskurs von Menschenrechten. ${ }^{38}$

Grenzziehungen von Verfügbarem und Unverfügbarem differieren auch gemäß der historisch distinkten Wirk- und Deutungsmacht sowie der sozialen Akzeptanz jeweiliger Transzendenzvorstellungen. Ein die Lebenswelt deutungsmächtig bestimmendes religiöses System zieht ganz andere Grenzen von Verfügbarkeiten und Unverfügbarkeiten, mithin auch für politische Handlungsmöglichkeiten, als eine Ordnung, die sich als säkular und wissenschaftlich aufgeklärt beschreibt. Fortschrittsgläubigkeit auf der einen und Fortschrittsskepsis auf der anderen Seite (aus welchen Quellen sie auch immer gespeist sein mögen) machen verständlich, warum in der einen demokratischen Ordnung Schwangerschaftsabbrüche, Stammzellforschung oder pränatale Diagnostik erlaubt, in einem anderen politischen Kontext aber verboten oder stark reglementiert sind. ${ }^{39}$ In den diesbezüglichen Dis-

36 Vgl. Eric Voegelin: Die politischen Religionen, Wien 1938.

37 Zum Heiligen vgl. Rudolf Otto: Das Heilige: Über das Irrationale in der Idee des Göttlichen und sein Verhältnis zum Rationalen, Nachdruck, München 2004; Mircea Eliade: Das Heilige und das Profane. Vom Wesen des Religiösen, Frankfurt a.M. 1998; als Überblick auch Hans Joas: Die Soziologie und das Heilige, in: ders.: Braucht der Mensch Religion? Über Erfahrungen der Selbsttranszendenz, Freiburg i.B. 2006, S. 64-77; zur Diskussion des Heiligen in der französischen Debatte der dreißiger Jahre vgl. Stephan Moebius: Die Zauberlehrlinge. Soziologiegeschichte des Collège de sociologie (1937-1939), Konstanz 2006. Zum Vorrang des Guten vor dem Rechten vgl. Alasdair MacIntyre: Der Verlust der Tugend. Zur moralischen Krise der Gegenwart, erweiterte Neuaufl., Frankfurt a.M./New York 2006; Martha C. Nussbaum: Gerechtigkeit oder das gute Leben, Frankfurt a.M. 1999; Charles Taylor: Wieviel Gemeinschaft braucht die Demokratie?, Frankfurt a.M. 2005.

38 Vgl. Hans Joas: Die Sakralität der Person. Eine neue Genealogie der Menschenrechte, Frankfurt a.M. 2011.

39 Vgl. nur Klaus Tanner: Ethische Probleme der Stammzellforschung, in: BerlinBrandenburgische Akademie der Wissenschaften (Hrsg.): Berichte und Abhand- 
kursen wirken beispielsweise Rekurse auf die göttliche Schöpfung und die Unverfügbarkeit des menschlichen Lebens wie Stoppschilder und Handlungsbegrenzungen, wohingegen der Bezug auf die biotechnologisch möglich erscheinende Lebensoptimierung eine Vorfahrtsregelung und Handlungsermächtigung zu beanspruchen sucht.

Kultur- und geschichtsspezifische Unrechtserfahrungen lassen so zum Beispiel nachvollziehen, warum für Selbstverständigungsprozesse einer Demokratie wie die der Bundesrepublik Deutschland der Schutz der Menschenwürde einen zentralen Rang eingenommen hat. Die Menschenwürde, in Artikel 1 der Verfassung als höchste Schutz- und Achtungsnorm aller staatlichen Gewalten ausgewiesen, wird als letzter Geltungsgrund - mit Kelsen formuliert: als Grundnorm ${ }^{40}$ - einer politischen Ordnung unverfügbar gestellt, sie wird der Dispositionsmacht von politischen Akteuren entzogen. Die demokratische Ordnung wird an eine Leitidee gebunden, diese stiftet Sinn und Geltung und zeigt zugleich die Grenzen dessen auf, was möglich und was nicht möglich ist. Damit wirkt sie zugleich als diskursive Sperre in Begründungsdiskursen. Sie in Frage oder zur Disposition zu stellen, erscheint kaum möglich. Ein solches Berührungs-, hier: Thematisierungsverbot errichtet eine Grenze des politischen Handelns, die zugleich einen Bereich des Heiligen und Unantastbaren markiert. Das ist mit Verboten verbunden, deren Verletzung den Ausschluss aus der Gemeinschaft und des für legitim gehaltenen Diskurses nach sich ziehen kann. ${ }^{41}$

Das Beispiel macht damit deutlich, dass Unverfügbarstellungen zwar historisch kontingent, aber keineswegs indifferent sind gegenüber Strukturen und Kontexten, die durch sie miterzeugt wurden. Erst die spezifische Aufarbeitung deutscher Geschichte, insbesondere der Vernichtungspolitik des Nationalsozialismus und des Scheiterns der Weimarer Republik, hat es erlaubt, im Rahmen der konstituierenden Verfassungsdiskurse der Bundes-

lungen, Bd. 12: Akademievorlesungen. Gentechnologie in Deutschland, Berlin 2006, S. 77-97.

40 Hans Kelsen: Reine Rechtslehre. Einleitung in die rechtswissenschaftliche Problematik, Leipzig 1934.

41 Vgl. Durkheim, Die elementaren Formen, 1981, S. 60ff. und S. 598ff.; Roger Caillois: Der Mensch und das Heilige, München/Wien 1988; Mary Douglas: Ritual, Tabu und Körpersymbolik. Sozialanthropologische Überlegungen zur Industriegesellschaft und Stammeskultur, Frankfurt a.M. 2004; Bernhard Giesen: Zwischenlagen. Das Außerordentliche als Grund der sozialen Wirklichkeit, Weilerswist 2010, bes. S. $187 \mathrm{ff}$. 
republik die Menschenwürde als unverfügbar zu behaupten und ihr einen normativen Rang zuzuweisen, der sie der Verfügungsmacht staatlicher Gewalten entzieht. Es bedarf also auch besonderer situativer und kontextueller Passungen, um Unverfügbarstellungen erfolgreich für eine demokratische Ordnung so wirksam werden zu lassen, dass sie auf Dauer ihre Geltung bewahren können.

\section{Die Paradoxie von Autonomiebehauptung UND UNVERFÜGBARKEITSPRAXIS}

Der demokratische Verfassungsstaat gilt als die säkulare Antwort auf die Frage nach der Legitimation und Gestaltung politischer Ordnung. Kontraktualistische Begründungszusammenhänge haben starke metaphysische Annahmen von sich gewiesen. Insofern kann auch die Verabschiedung normativer Transzendenzen als ein befreiender Akt politischer Selbstbestimmung gedeutet werden. ${ }^{42}$ Demokratie erhebt selbst einen Unverfügbarkeitsanspruch, rückt hier in die leer gewordene Stelle religiös, christlich oder dynastisch-genealogischer Transzendenzvorstellungen ein. Die Idee der Selbstbestimmung des Volkes ist in modernen, auf der Idee der Selbstregierung beruhenden Geltungsdiskursen politischer Ordnungen nicht übersteigbar, was nicht heißt, dass sie nicht durch andere Transzendenzrekurse (auf die Schöpfung, die Geschichte, die Tradition, die Entscheidungsnotwendigkeiten, die Alternativlosigkeit in Krisenzeiten) bestritten oder hintergangen werden könnte. Aber die Demokratie versteht sich zunächst einmal als Ermächtigung zum kollektiven Handeln mit unbeschränkter Gestaltungskompetenz, die politische Ordnung ist dem Willen des Volkes damit in toto verfügbar geworden. ${ }^{43}$ Und doch werden auch in der Demokratie grundlegende Prinzipien und Werte als unverfügbar behauptet und dem demokratischen Gestaltungsraum wieder zu entziehen versucht: der Schutz der Menschenrechte, der Vorrang der Verfassung, die unteilbare Republik, die Schöpfung, die Tradition, die Natur und so weiter. Einerseits kann es

42 Vgl. hierzu den Beitrag von Enno Rudolph: Abschied von der normativen Transzendenz. Rortys Moderne, in diesem Band.

43 So als „Willensnation“, ein Konzept, das ohne Transzendenzen (wenn nicht die Willensnation selber eine ist) auszukommen scheint. Vgl. dazu den Beitrag von Georg Kohler: Basiskonsens und Willensnation. Die Kontingenz des Unverfügbaren und das Modell der Schweiz, in diesem Band. 
sich dabei um konsentierte Unverfügbarkeitspraktiken handeln, die Ergebnis einer bewussten und diskursiv vollzogenen normativen Setzung sind und Selbstbindungseffekte erzeugen. Der Konstitutionalismus kann als ein solcher Modus demokratischer Ordnungsstabilisierung verstanden werden. ${ }^{44}$ Andererseits sind es diskursive, machtgestützte Geltungsstrategien, die den politischen Prozess zu lenken oder zu besetzen suchen und dabei Transzendenzkonstruktionen erkennen lassen, mittels derer der potentiell offene demokratische Gestaltungsraum verengt oder geschlossen werden soll. $^{45}$

In systematischer Hinsicht wird dieser paradoxe Zusammenhang von demokratischer Autonomie und Unverfügbarkeit bereits in den Diskursen um die Gründung und Aufrechterhaltung antiker demokratischer und republikanischer Ordnungen, wenngleich in anderer Terminologie, geführt, dann im 18. Jahrhundert, also in einer formativen Phase moderner Demokratie, zugespitzt. So stellte Jean-Jaques Rousseau in seinen Überlegungen zur Etablierung einer Republik die Frage, wie diese gegründet und erhalten werden kann. Dabei reichten anscheinend kontraktualistische, auf Selbstautorisierung und Selbstgesetzgebung beruhende Begründungen für die Einrichtung des état civil nicht aus, um diesen auch für die Zukunft abzusichern. Rousseaus Lösung des Problems besteht in drei Formen der Sakralisierung des Gründungsvorgangs: zum einen in der Transzendierung

44 In der gegenwärtigen politischen Theorie werden diese Figuren demokratischer Selbstbindung, nicht zuletzt an historischen Exempla der Verfassunggebung, als Paradoxa des demokratischen Konstitutionalismus verhandelt. Im Grunde geht es hier um die Vereinbarkeit von konstitutionell, im Medium des Rechts und der Legeshierarchien abgesicherten Unverfügbarstellungen bei gleichzeitiger potenziell unbeschränkter Verfügbarmachung der politischen Ordnung im demokratischen Prozess. Vgl. etwa Stephen Holmes: Precommitment and the Paradox of Democracy, in: Jon Elster/Rune Slagstad (Hrsg.): Constitutionalism and Democracy, Cambridge, Mass. 1988, S. 195-240; Martin Loughlin/Neil Walker (Hrsg.): The Paradox of Constitutionalism. Constituent Power and Constitutional Form, Oxford 2007. Mit Bezug auf die Problematik von Transzendenz und Unverfügbarkeit vgl. auch Karsten Fischer: Die Zukunft einer Provokation. Religion im liberalen Staat, Berlin 2009, der (S. 48ff.) davon spricht, dass das frühneuzeitliche absolutistische „Souveränitätsparadox“ (dass auf Religion zur Generierung von Sozio-Moralität zurückgegriffen werde, um die Macht zu binden, welche zur Einhegung von Religion gerade souverän gestellt wurde) vom „Paradox demokratischer Volkssouveränität“ abgelöst worden sei, welches wiederum im „konstitutionalistischen Unverfügbarkeitsparadox“ kulminiere.

45 Vgl. hierzu den Beitrag von Angelo Maiolino: Die Willensnation Schweiz im Spannungsfeld konkurrierender Transzendenzbezüge, in diesem Band. 
des Gesellschaftsvertrags zum quasi-göttlichen Schöpfungswerk des grand législateur, zum zweiten in der Kreierung einer religion civile, eines bürgerschaftlichen Glaubensbekenntnisses, welches, zusammen mit der dritten Form, der Etablierung einer republikanischen Festkultur, die als unverfügbar angesehenen Geltungsvoraussetzungen republikanischer Ordnung in rituellen, kultischen und performativen Akten abrufbar und damit präsent und symbolisch verfügbar machen sollte. ${ }^{46}$ Auf diese Weise erhoffte sich Rousseau, dass der von einem „großen Gesetzgeber“ vollzogene Einsetzungsakt des Staates celeste et indestructible gestellt werden konnte. Die Zivilreligion sollte ein über die Befolgung der Gesetze hinausgehendes $\mathrm{Ma}$ an Soziabilität, die sentiments de sociabilité, sichern, ohne welche die republikanische Ordnung auf Dauer nicht werde bestehen können. Und in den Festen sollte die Gemeinschaft immer wieder vollzogen, erneuert und bekräftigt werden. ${ }^{47}$

In den Begründungsdiskursen moderner, demokratischer und republikanischer Ordnungen finden sich auch zahlreiche andere Transzendenzkonstruktionen, in denen die Paradoxie von Autonomiebehauptung und Unverfügbarkeiten aufscheint. Das gilt zum einen für das Recht, das Medium gesellschaftlicher Steuerung, in dem die individuellen Rechtspositionen mit der auf das allgemeine Wohl zielenden Gesetzgebung vereinbar sein sollen. Zugleich zeigen Metaphern wie die hochsymbolisch aufgeladene Figur des „politischen Körpers“ (Locke) - als das den vertragstheoretischen Individualismus transzendierende Gemeinsame des bürgerlichen Gemeinwesens oder der in der überlieferten Legitimitätsrhetorik verbleibende und zugleich durch seinen adjektivischen Zusatz eben diese Tradition revolutionierende „sterbliche Gott“" von Hobbes, dass sich in den Begründungskontexten zahlreiche verdeckte, im Recht aufgehobene Transzendenzen aufspüren lassen, in denen implicite auf Zielvorstellungen und Geltungsgründe der politischen Ordnung jenseits des Rechts verwiesen wird. Auch enthält die bekannte, auf die Begründung unveräußerlicher Menschenrechte bezogene

46 Vgl. die Beiträge von Hans Vorländer: Brauchen Demokratien eine Zivilreligion? Über die prekären Grundlagen republikanischer Ordnung. Überlegungen im Anschluss an Jean-Jacques Rousseau; und Daniel Schulz: Naturerzählungen und republikanische Geltungsbedingungen bei Rousseau, beide in diesem Band.

47 Zur ordnungstranszendierenden und ordnungsstabilisierenden Bedeutung von orgiastischen Festen vgl. den Beitrag von Herfried Münkler: Die Tugend, der Markt, das Fest und der Krieg. Über die problematische Wiederkehr vormoderner Gemeinsinnserwartungen in der Postmoderne, in diesem Band. 
Formel der amerikanischen Unabhängigkeitserklärung (,We hold these truths to be self-evident") die Spannung von Selbstautorisierung und Verweis auf die nicht verfügbaren Geltungsressourcen, die sich der autonomen Setzung entziehen. Solche Paradoxien zeigen sich ebenfalls, wenn die politische Begründung der rechtlichen Ordnung zwar auch einem „Volk von Teufeln“ möglich sein muss (Kant), die Verstetigung einer demokratischen Ordnung indes nur einem „Volk von Göttern“ zugetraut wird (Rousseau).

Ein weiteres Moment paradoxaler Ordnungsbegründung zeigt sich dort, wo es um die liberal oder republikanisch zu deutenden Voraussetzungen gesellschaftlichen Zusammenhalts geht. ${ }^{48}$ Während in der Vor- und Frühmoderne in den sozio-moralischen, personalen Tugend- und Gemeinsinnsdispositionen der Bürger das entscheidende, Integration, Einheit und Stabilität verbürgende Integral des Gemeinwesens gesehen wird, so etwa im italienischen Städterepublikanismus, ${ }^{49}$ sind es ab dem späten 17. Jahrhundert Leidenschaften und Interessen des homo oeconomicus, die es zur Aufgabe machen, aus private vices public benefits werden zu lassen. ${ }^{50}$ Die diskursive Umstellung auf die Behauptung eines Gemeinwohleffektes gerade durch die Verfolgung des individuellen Eigennutzes ist aber ohne die Konstruktion von Vorstellungen der Transzendierung eigensinniger Dispositionen des Bürgers zum gemeinen Wohl der ganzen Gesellschaft nicht denkbar, auch nicht plausibel zu machen. So setzten Theorien des

48 Herfried Münkler: Politische Tugend. Bedarf die Demokratie einer soziomoralischen Grundlegung?, in: ders.: Die Chancen der Freiheit. Grundprobleme der Demokratie, München 1992, S. 25-46; Hans Vorländer: Institution und Tugend. Zur Dialektik des Liberalismus, in: Joachim Fischer/Hans Joas (Hrsg.): Kunst, Macht, Institution. Studien zur philosophischen Anthropologie, soziologischen Theorie und Kultursoziologie der Moderne. Festschrift für KarlSiegbert Rehberg, Frankfurt a.M./New York 2003, S. 316-330.

49 Vgl. Daniel Schulz: Zwischen Selbstermächtigung und Endlichkeitsbewusstsein. Das Politische und seine Grenzen im florentinischen Republikanismus, in diesem Band. Aber auch bei Hobbes zeigen sich diese Gemeinsinnsdispositionen noch. Vgl. dazu Alessandro Pinzani: Politische Tugenden bei Hobbes, in diesem Band.

50 So die klassische Formulierung bei Bernard de Mandeville: The Fable of the Bees or Private vices, publick benefits. With a commentary critical, historical and explanatory by Frederick B. Kaye, Indianapolis, In. 1924. Für eine deutsche Ausgabe vgl. Bernard de Mandeville: Die Bienenfabel oder private Laster, öffentliche Vorteile [1705-1714], eingeleitet von Walter Euchner, 2. Aufl., München 1980. 
Marktes auf Modelle eines sich ,systemisch“ herausbildenden, gleichsam hinter dem Rücken der eigennützig agierenden Individuen sich autonom vollziehenden Gemeinnutzes. Diese Annahmen einer in den Mechanismen von Angebot und Nachfrage verborgenen Rationalität operieren mit Transzendenzfiguren, wie sie beispielhaft bei Adam Smith in seinem Verweis auf die das Marktgeschehen ordnende ,unsichtbare Hand“ anklingen. Marx und Tocqueville haben dann später die immanente Selbstbeschreibung liberaldemokratischer Marktgesellschaften mit ihren verdeckten Geltungsvoraussetzungen konfrontiert. ${ }^{51}$ Im Übrigen lassen die zeitgenössischen Diskurse um die Fehlallokationen, Spekulationen und Dysfunktionalitäten der (Finanz-)Märkte eine erstaunliche Renaissance eines Tugenddiskurses erkennen, der jene Erwartungen gemeinsinnigen Handelns zu restituieren sucht, die in ihrem Ursprung auf vormoderne Quellen rekurrieren. ${ }^{52}$

Die Herausbildung demokratischer Verfassungsstaaten hat zwar den legitimatorischen Zusammenhang von - monarchischer - Herrschaft und religiösen Transzendenzrekursen aufgehoben, damit aber keineswegs das Problem der Transzendenzen beseitigt. Das zeigt sich auch in historischer Perspektive. Wo in England nach der Glorious Revolution das alte Bündnis zwischen Bischöfen und einem sakralen Monarchen von Gottesgnaden zerbrach, blieb in Frankreich der Monarch auch nach 1715, nach dem Tode Ludwig XIV., zumindest dem Anspruch nach rex et sacerdos. ${ }^{53}$ Im Zuge der Französischen Revolution kam dann zwar das Sakralkönigtum zu einem Ende, aber es wurde durch die republikanischen Transzendenzformen, erst eines Kultes der Menschenrechte, dann der Bürgertugenden, schließlich des Höchsten Wesens abgelöst. Die mit diesen Transzendierungen einhergehenden Semantiken bargen in sich eine Dynamik, deren Entfesselung nicht nur die Stabilität der jungen Republik gefährden, sondern auch eine neue, zuvor unbekannte revolutionäre Kriegsbegeisterung und ein republi-

51 Vgl. Julia Schulze Wessel: Zur Kritik liberaler Ordnungsentwürfe. Bernard de Mandeville, Adam Smith, Karl Marx und Alexis de Tocqueville, in diesem Band.

52 Vgl. Münkler, Die Tugend, der Markt, das Fest und der Krieg, in diesem Band.

53 Ronald G. Asch: Zwischen sakraler Legitimation und politischer Säkularisierung. Die Monarchie in England und Frankreich im späten 17. Jahrhundert im Vergleich, in diesem Band. 
kanisches Missionsbewusstsein entfachen sollte. ${ }^{54}$ Diese von Frankreich ausgehenden revolutionären Umwälzungen wurden im deutschen Kontext der konstitutionellen Bewegung des 19. Jahrhunderts vor allem durch transzendente Bezugnahme auf die angestammte Tradition stillgestellt. ${ }^{55}$ Der für revolutionäre Gründungssituationen beobachtbare Zusammenhang der Verfügbarmachung demokratischer Gestaltungsansprüche einerseits und der symbolischen Transzendierung des Gründungsmomentes und der verfassunggebenden Gewalt andererseits durch performative, ikonische oder narrative Praktiken lässt sich auch im Prozess von Entstehung und Scheitern der Weimarer Republik beobachten. Friedrich Naumanns Versuch „,volksverständlicher Grundrechte“, der in Form eines Grundrechte-Katechismus die kultisch-rituelle Befestigung demokratischer Überzeugungen und rechtlicher Normen intendierte, ${ }^{56}$ misslang ebenso wie die Unternehmung des Reichskunstwarts, Edwin Redslob, der Weimarer Republik durch die Beseitigung aller Bilder, ,deren Verbleib als Widerspruch gegen die verfassungsmäßige Staatsform“ anzusehen sei, eine eigene demokratische Symbolik zu verschaffen. ${ }^{57}$ Die Stabilisierungsbemühungen der Verfassung scheiterten angesichts konkurrierender, totalitärer Transzendenzdiskurse, die auch die Ausbildung eines gemeinsamen, die Republik transzendierenden demokratischen Sinnhorizontes verhinderten. Die totalitären Regime des zwanzigsten Jahrhunderts entkleideten den rechtlich-konstitutionellen Kern politischer Ordnung seiner unverfügbaren Dimension und machten ihn damit der Disponibilität eines politischen Dezisionismus zugänglich. Zur Legitimierung dieses Prozesses nahmen sie dabei wiederum andere Transzendenzfiguren in Anspruch, wie ,Volk', ,Gemeinschaftserlebnis', ,Blut' oder die ,historische Gesetzmäßigkeit‘ ${ }^{58}$

54 Vgl. Daniel Schulz: Das Sakrale im Zeitalter seiner politischen Reproduktion. Die Französische Revolution zwischen Verfassungsfest und Missionierungskrieg, in diesem Band.

55 Vgl. Jan Röder: Verfassung, Vertrag und Monarchie. Der Prozess der Verfassunggebung in Württemberg (1815-1819), in diesem Band.

56 Vgl. Jan Röder: Der Volksstaat als Selbstverständlichkeit. Friedrich Naumann und die Begründung der Weimarer Republik, in diesem Band

57 Vgl. hierzu Hans Vorländer: Demokratie und Ästhetik. Zur Rehabilitierung eines problematischen Zusammenhangs, in: ders. (Hrsg.): Zur Ästhetik der Demokratie. Formen der politischen Selbstdarstellung, Stuttgart 2003, S. 11-28.

58 Vgl. Steven Schäller: Rechtsgeltung. Dekonstruktion und Konstruktion in den Umbrüchen nach 1933 und 1945, in diesem Band. 
In posttotalitären Begründungsphasen demokratischer Ordnung werden auch deren Bindungs- und Verpflichtungsformen neu artikuliert. ${ }^{59}$ Es entstehen neue Verfassungen, die als gemeinsinnige Stiftungen verstanden oder, wie im Fall des Grundgesetzes, angeeignet werden konnten. Insbesondere die Präambeln, denen ausdrücklich die Aufgabe zugeschrieben wird, die Quellen des Rechts explizit zu machen, bringen dabei Legitimitätsressourcen symbolisch zum Ausdruck, die den Moment der Ordnungsstiftung transzendieren. Dabei finden sich Verfassungen mit explizitem Verweis auf „Gott“ neben Verfassungen, die starke gemeinwohlorientierte Verpflichtungsformeln in den Mittelpunkt stellen, ebenso wie Verfassungen, die neben Gott andere Quellen universeller Werte kennen und damit die Möglichkeit pluraler Transzendenzstiftung explizit hervorheben. Diese Unverfügbarstellung wird mit Semantiken des Heiligen befestigt, um so der demokratischen Ordnung Stabilität zu sichern. ${ }^{60}$ Gleichzeitig geben neuere Diskurse um die Formen eines globalen Konstitutionalismus Tendenzen zu erkennen, die den Stiftungsakt des nationalstaatlich verfassten demokratischen Verfassunggebers enttranszendieren und ihn im Zuge emergenter transnationaler konstitutioneller Praktiken wieder verfügbar werden lassen. $^{61}$

Das begriffliche Spannungsfeld von Demokratie und Transzendenz mündet demnach in die Paradoxie von Autonomiebehauptung und Unverfügbarkeitspraktiken. Die Bewältigungsversuche dieser Paradoxieerfahrung sind es, aus denen der demokratische Verfassungsstaat in seinen unterschiedlichen historischen Gestalten und institutionellen Formen hervorgegangen ist - ohne die Spannung der Paradoxie zu einer Seite hin aufzulösen, wird hier eine prekäre Balance auf Dauer gestellt, in dem der Konflikt institutionell gerahmt und von einem begrifflich-konzeptuellen

59 Vgl. Maik Herold: Ordnungsbegründung als politisch-kultureller Deutungskampf. Der Verfassungsdiskurs im demokratischen Polen nach 1989, in diesem Band.

60 Kritisch zu den empirisch vorfindbaren Formen der Verfassungssakralisierung (vgl. zu den USA etwa: Hans Vorländer: Verfassungsverehrung in Amerika. Zum konstitutionellen Symbolismus in den USA, in: Amerikastudien 34 (1989), S. 69-82) mit Blick auf Deutschland jetzt Horst Dreier: Gilt das Grundgesetz ewig? Fünf Kapitel zum modernen Verfassungsstaat, München (Carl Friedrich von Siemens Stiftung) o.J. (2008).

61 Vgl. Oliviero Angeli: Von der Gründung zur Begründung? Über die Rolle der Imagination im globalen Konstitutionalismus, in diesem Band. 
Problem in eine praktisch-historische Problembewältigung übersetzt wird. ${ }^{62}$ Die hier versammelten Beiträge bilden daher die Varianzen dieser Spannungsbalance, aber auch deren Fragilität $a b$ und zeigen, dass aus dem historischen Variantenreichtum der demokratischen Transzendenzparadoxie, der kontextabhängigen Genese, den Verlaufsformen und dem Scheitern, eine Vorstellung davon entspringt, dass die behaupteten Unverfügbarkeiten je Ausdruck einer vorläufigen, dem Wandel nicht entziehbaren und damit genuin politischen Konstellation bleiben.

62 So könnte, das zeigt Pier Paolo Portinaro (Macht und Autorität. Das Problem der (Un)Verfügbarkeit, in diesem Band), eine historische Darstellung politischer Machtprozesse auch geschrieben werden als eine Geschichte von Kämpfen um die (Un)Verfügbarkeiten, der Behauptung und der Grenzen von Machtdurchsetzung und Souveränitätsansprüchen oder der Geltung und Bestreitung von Rechten und Dispositionsräumen. 



\section{KONZEPTIONELLE UND SYStematische PeRsPektiven}





\section{Das religiös-kulturelle Dispositiv der modernen Politik}

\section{Die Problemstellung: Religion und Politik ${ }^{1}$}

In den politisch-sozialen Wissenschaften spielten bis in die jüngste Zeit Forschungen zu religiös-politischen Ordnungsproblemen eine weitgehend marginale Rolle, beschränkten sie sich doch auf kirchensoziologische Fragestellungen oder spezielle Politikfeldanalysen.

Die Einrichtung eines akademischer Exzellenz verpflichteten Forschungsprogramms ,Religion und Politik' und eines Sonderforschungsbereichs ,Transzendenz und Gemeinsinn' dokumentiert offensichtlich auch eine gleichsam hochschulöffentliche und insbesondere fachwissenschaftliche Anerkennung der wissenschaftlichen Relevanz des Gegenstandes und signalisiert einen tendenziellen Paradigmenwechsel in der einschlägigen Forschungslandschaft. ${ }^{2}$

1 Vgl. hierzu auch: Jürgen Gebhardt: Religion und Politik, in: Dieter Nohlen/ Rainer-Olaf Schultze (Hrsg.): Lexikon der Politikwissenschaft, Bd. 2, München 2005, S. 854-860; ders.: Religion und Politik. Eine historisch-politische Problemskizze, in: Manfred Walther (Hrsg.): Religion und Politik. Zur Theorie und Praxis des theologisch-politischen Komplexes, Baden-Baden 2004, S. 51-71; ders.: Das politisch-kulturelle Dispositiv des Verfassungsstaates. Zur Kritik des Böckenförde-Theorems, in: Werner J. Patzelt/Martin Sebaldt/Uwe Krahnenpol (Hrsg.): Res publica semper reformanda. Wissenschaft und politische Bildung im Dienste des Gemeinwohls. Festschrift für Heinrich Oberreuter zum 65. Geburtstag, Wiesbaden 2007, S. 114-122.

2 Vgl. Hans Vorländer (Hrsg.): Transzendenz und Gemeinsinn. Themen und Perspektiven des Dresdner Sonderforschungsbereiches 804, Dresden 2011; Michael Minkenberg/Ulrich Willems (Hrsg.): Politik und Religion, Wiesbaden 2002; Claus-Ekkehard Bärsch/Peter Berghoff/ Reinhard Sonnenschmidt (Hrsg.): Wer 
Religion und deren sozio-politische Erscheinungsformen blieben bisher weitgehend den Wissenschaftsdiskursen von Spezialisten in Religionssoziologie, Religionswissenschaft oder Theologie überlassen. In den historisch-politischen Wissenschaften spielten jene Autoren, die frühzeitig zur politischen Religiosität der modernen totalitären Ideologien forschten, eine eher marginale Rolle, schienen sie doch durch die modernisierungstheoretisch unterfütterte herrschende Lehre von der irreversiblen Säkularisierung der modernen Welt widerlegt. Für eine politische Wissenschaft, die sich auf der Höhe der Zeit zu bewegen glaubte, konnte dies nur bedeuten, ,that secularization had removed religion from the realm of political affairs ${ }^{\text {“3 }}$. Die wechselseitige Durchdringung von Politik und Religion, wie immer dies im einzelnen sich darstellte, wurde als Definitionsmerkmal der kulturell-politischen Verfassung der vormodernen traditionalen Gesellschaftsformationen historisch relativiert. In einer modernisierten Gesellschaftsformation treten nunmehr Politik und Religion in ein Verhältnis interagierender jedoch voneinander separierter gesellschaftlicher Lebenssphären, wobei die erstere zusehends an sozialer Formkraft verliert. Diese theoretisch anspruchslose und methodisch einfach zu handhabende Bestimmung von Politik und Religion als die Wechselbeziehung jeweils eigenlogischer sozialer Teilsysteme wird in der Regel als Beziehung von säkularem Staat und christlicher Kirche bzw. Religionsgemeinschaft beschrieben und untersucht. Die im zeitgenössischen westlichen Diskurs vorherrschende Konzeptionalisierung ist jedoch ihrerseits selbst ein historischkulturell bedingtes Produkt des europäischen Zivilisationsprozesses, insofern das Spannungsverhältnis von staatlichem Herrschaftsapparat und kirchlich verfasster Religionsgemeinschaft konstitutiv war für die neuzeitliche Staatswerdung nach der Desintegration der bipolaren Ordnung von Sacerdotium und Imperium in der lateinischen res publica Christiana. Entscheidend für die herrschenden Diskurse der positiven Sozialwissenschaften war Max Webers Axiom, dass in der durch den okzidentalen Rationalismus geschaffenen modernen Kulturwelt die „religiösen Wurzeln“ des Menschentums abgestorben sind. Hieraus resultiert ein von jeder

Religion verkennt, erkennt Politik nicht. Perspektiven der Religionspolitologie, Würzburg 2005. Bärsch optiert für die Einführung einer speziellen Religionspolitologie analog der Religionssoziologie, ein m.E. theoretisch und methodologisch problematischer Vorschlag.

3 George Moyser: Preface, in: ders. (Hrsg.): Politics and Religion in the Modern World, London 1991, S. IX. 
,religiösen Weltdeutung' gereinigter Politikbegriff: „Die gesamte Politik aber orientiert sich an der sachlichen Staatsraison, der Pragmatik und dem absoluten - religiös angesehen fast unvermeidlich völlig sinnlos erscheinenden - Selbstzweck der Erhaltung der äußeren und inneren Gewaltenverteilung. " 4

Dieser weberianischen Vorgabe verdankt sich eine geschichtsspekulativ aufgeladene Theorie der politischen Entwicklung, welche die Evolution des modernen politischen Systems durch das Zusammenspiel von struktureller Differenzierung und kultureller Säkularisierung erklärt. Das am westlichen, vorzüglich anglo-amerikanischen Modell entwickelte Paradigma moderner politischer Kultur, geht aus von der Annahme eines Säkularisierungsprozesses, in dem die Menschen ,become increasingly rational, analytical, and empirical in their political action" während, traditionale", das heißt ,nicht-rationale" und ,a-empirische“ Orientierungen und Haltungen ihre sinnstiftende Funktion verlieren. ${ }^{5}$ Denn ,,[o]ne of the hallmarks of ,modernity $^{\text {' }}$ is the substitution of rational calculation for traditional criteria in the making of decisions "66. Apodiktisch formuliert: Die wissenschaftliche Begrifflichkeit läuft letztlich auf einen aller Ordnungsgehalte entleerten Politikbegriff hinaus, dem - wie noch im Verlauf dieser Untersuchung zu zeigen ist - ein entwirklichter, auf das subjektiv Imaginäre bezogener Religionsbegriff entspricht, wobei nur die jeweilige gesellschaftliche Funktionslogik als Objekt wissenschaftlicher Analysen interessiert. Folgerichtig wurden auch die Untersuchungen des Religiösen als sozio-politisches Phänomen von Durkheim, Weber bis zu Luhmann und Luckmann vorwiegend von Soziologen betrieben. Das dominierende Denkmodell der Soziologie als der Wissenschaft der modernen Gesellschaft definiert tendenziell das Religiöse und das Politische als gesellschaftliche Epiphänomene, und übersetzt das Religiöse in a-religiöse soziale Kategorien. Hier ist allerdings ein caveat angebracht: Im internationalen Wissenschaftsdiskurs artikulierte sich schon früh eine Kritik des sozialwissenschaftlichen Paradigmas und der aporetische Charakter des Modernisierungstheorems und

4 Max Weber: Wirtschaft und Gesellschaft, hrsg. von Johannes Winckelmann, Köln 1964, S. 464.

5 Gabriel A. Almond/ G. Bingham Powell: Comparative Politics. System, Process, and Policy, Boston 1966, S. 24.

6 Sidney Verba: Conclusion: Comparative Political Culture, in: Lucian W. Pye/Sidney Verba (Hrsg.): Political Culture and Political Development, Princeton 1965, S. 512-560, hier: S. 546. 
des hiervon abgeleiteten Säkularisierungsbegriffs wurde von Autoren wie Bell, Martin, Bellah oder Tenbruck mit Nachdruck betont. ${ }^{7}$

Es war die politische Realität selbst, welche das vorherrschende Selbstverständnis der westlichen Eliten unterminierte und die konventionelle Konzeptionalisierung von ,Politik“ und ,Religion“ als kategorial unzureichend erwiesen hat und einen Paradigmenwechsel von grundsätzlicher Bedeutung induzierte. Denn mit Blick auf die historisch-politische Erfahrungswelt stellt sich die Frage nach der theoretischen Verortung der gesellschaftlichen Konfiguration von Religion und Politik im Ordnungsgefüge der menschlichen Welt insgesamt. Daraus folgt, dass der wissenschaftliche Diskurs die Persistenz des theologisch-politischen oder präziser religiös-politischen Komplexes ${ }^{8}$ gerade auch in seiner globalen Erscheinungsform wissenschaftlich zur Kenntnis nimmt und dessen zentrale Bedeutung für die modernen Gesellschaften zum Gegenstand der systematisch-theoretisch angeleiteten empirischen Analyse macht. Diese Intention bestimmt den konzeptionellen Ansatz, der - vorbehaltlich der weiteren Überlegungen - dem Begriff des religiös-kulturellen Dispositivs zur Kennzeichnung der für die Erscheinungsform des religiös-politischen Komplexes charakteristischen Modalität des Politischen zu Grunde liegt. Dieser französisch geprägte Begriff des Dispositivs meint in meinem Verständnis das Folgende: Es umschreibt ein politisch-kulturelles, symbolisch vermitteltes Ensemble von Ideen, Normen, Attitüden und Sentiments, und es ist insofern „religiös“ konnotiert, als es den der sinnstiftenden Symbolwelt einer politischen Deutungs- und Sozialkultur inhärenten Legitimitätsglauben auf ein meta-physisch letztbegründendes Absolutes verweist. Das solchermaßen definierte Dispositiv artikuliert somit, symbolisch kodiert, die für das Selbstverständnis und das Institutionengefüge einer politisch organisierten Gesellschaft konstitutive formgebende Ordnungsidee. Folge-

7 Vgl. Daniel Bell: The Return of the Sacred? The Argument on the Future of Religion, in: British Journal of Sociology 28 (1977) 4, S. 419-450; David Martin: A General Theory of Secularization, Oxford 1978; Robert N. Bellah: Civil Religion in America, in: Daedalus 96 (1967), S. 1-21; Friedrich Tenbruck H.: Die unbewältigten Sozialwissenschaften, oder: Die Abschaffung des Menschen, Graz 1984.

8 Vgl. Claude Lefort: Permanence du theologico-politique?, in: ders.: Essais sur le politique, Paris 1986, S. 251-300. Die Begriffsbildung, theologisch-politisch“ schränkt durch den Bezug auf die ganz spezifische westliche Symbolfigur der ,Theologie' den Objektbereich des Religiös-Politischen in unzulässiger Weise ein, siehe hierzu die Diskussion der ,politischen Theologie". 
richtig begründet das politische Selbstverständnis einer machtpragmatisch konsolidierten gesellschaftlichen Formation in der Regel ihre geschichtliche Existenz durch den Bezug auf eine ihre Existenz legitimierende höhere transzendente, Wahrheit‘. Das religiös-kulturelle Dispositiv ist, so meine These, integrales Moment des Politischen als Modalität menschlicher Vergesellschaftung in allen postaxial differenzierten politischen Ordnungsformen und, so meine Schlussfolgerung, auch konstitutiv für die moderne Politik, wenn wir deren spezifische Gestalt des politisch-religiösen Komplexes näher betrachten. Eisenstadt nennt dies die „charismatic dimension of social interaction“. Sie ist, so Eisenstadt, grundlegend für die Konstruktion einer kulturellen und sozialen Ordnung und geht in deren Institutionalisierung ein. ${ }^{9}$

Der hier einleitend skizzierte konzeptionelle Ansatz ist Jan Assmanns Aufforderung zu einem Paradigmenwechsel in der systematischen Betrachtung des religiös-politischen Komplexes verpflichtet:

„Die Sprengung des abendländischen Horizontes legt den Blick frei auf ein noch weitgehend unerforschtes Terrain: auf die Ethnologie, Anthropologie, Archäologie und Religionsgeschichte der politischen Ordnung und ihre Beziehung zu Vorstellungen jenseitiger Ordnung, auf die Beziehung von Herrschaft und Heil in den verschiedenen Kulturen der Erde. In meinen Augen handelt es sich um eine der aktuellsten, wichtigsten und offensten Fragen der Kulturwissenschaften überhaupt. “10

\section{PARADIGMENWECHSEL I: DER SÄKULARISIERUNGSDISKURS}

In seiner kritischen Studie zur politischen Religiosität des Nationalsozialismus forderte Eric Voegelin schon 1938 eine Reintegration des Religiösen in die Theorie der Politik mit der folgenden Begründung:

„Das Leben des Menschen in politischer Gemeinschaft kann nicht als profaner Bezirk abgegrenzt werden, in dem wir es nur mit Fragen der Rechts - und Machtorganisation zu tun haben. Die Gemeinschaft ist auch ein Bereich der religiösen Ordnung, und die Erkenntnis eines politischen Zustands ist in einem entscheidenden

9 Shmuel N. Eisenstadt: Power, Trust and Meaning. Essays on Sociological Theory and Analysis, Chicago 1995, S. 312-317.

10 Jan Assmann: Heil und Herrschaft. Politische Theologie in Altägypten, Israel und Europa, München 2000, S. 29. 
Punkt unvollständig, wenn sie nicht die religiösen Kräfte der Gemeinschaft und die Symbole, in denen sie Ausdruck finden, mitumfaßt, oder sie zwar umfaßt, aber nicht als solche erkennt, sondern in a-religiöse Kategorien übersetzt. “11

Die normale Wissenschaft der einschlägigen Disziplinen weigerte sich mit wenigen Ausnahmen, dem Vorschlag Voegelins zu folgen. Erst heute unter dem Eindruck tiefgreifender Wandlungen in der politisch-kulturellen Tektonik der Welt kündigt sich in den internationalen politischen, intellektuellen und wissenschaftlichen Diskursen ein tendenzieller Paradigmenwechsel an, der im folgenden näher zu betrachten ist. Dieser läuft auf eine Rekonzeptionalisierung der Rolle des religiös-politischen Komplexes in der Moderne hinaus, die nicht zuletzt eine grundsätzliche Revision des Säkularismustheorems im Gefolge hat und das Verhältnis von Religion und Politik unter den Bedingungen seiner globalen Relevanz thematisiert.

Wie angemerkt, galt in der politikwissenschaftlich dominanten Theorie der geschichtlichen Evolution politischer Systeme die ,kulturelle Säkularisierung' als zentrales Definitionsmerkmal der politischen Modernisierung. Es bestimmte als erkenntnisleitendes Axiom explizit oder zumindest implizit die von Almond, Verba, Pye und anderen Autoren in den 1950er Jahren neu begründete vergleichende Politikwissenschaft und deren international akzeptiertes Forschungsprogramm. Mit Blick auf diese Vorgeschichte kann der Paradigmenwechsel in der Politischen Wissenschaft exemplarisch verdeutlicht werden. Almond selbst muss sich eine „secular myopia“ eingestehen. „Secularists may have internalized the privatization of belief, but religion continues to perform complex, multiple roles and functions in societies from the United States and Europe, across the Middle East, Africa, and South America, to Indonesia"12, so erkennen Almond und seine Ko-Autoren Appleby und Sivan und vollziehen in Strong Religion eine intellektuelle Kehrtwendung:

„The denial of the causal significance of religion rests, at least in part, on an inertial persistence of the culture of ,progress ${ }^{\text { }}$ - a survival of Enlightenment expectations of

11 Erich Voegelin: Die politischen Religionen, Stockholm 1939, S. 63f.; vgl. Jürgen Gebhardt: Wie vorpolitisch ist ,Religion'? - Anmerkungen zu Eric Voegelins Studie, Die politischen Religionen', in: Herfried Münkler (Hrsg.): Bürgerreligion und Bürgertugend. Debatten über die vorpolitischen Grundlagen politischer Ordnung, Baden-Baden 1996, S. 81-102.

12 Gabriel A. Almond/R. Scott Appleby/Emmanuel Sivan: Strong Religion. The Rise of Fundamentalism Around the World, Chicago 2003, S. 4f. 
continued cultural secularization, growth of scientific knowledge, technical and institutional creativity, and enhanced welfare, with religion seen only as fading tradition." ${ }^{\text {13 }}$

Die zutreffende Einsicht: ,this version of an idea of progress no longer reflects reality" zeugt von einer beachtlichen theoretischen Hilflosigkeit, denn schließlich delegitimiert sie die modernisierungstheoretische Grundlage der politikwissenschaftlichen Theorie der politischen Entwicklung. ${ }^{14}$ Die ,Realität', die zum Paradigmenwechsel zwingt, war ,the rise of fundamentalism around the world" (so der Untertitel des Buches). Es war in der Tat das im Sinn der herrschenden Lehre völlig unerwartete Phänomen der islamisch-politischen Revolutionsbewegung, die 1979 im Iran begann und nachhaltig die politische Landschaft prägen sollte und den Blick für parallele Erscheinungsformen religiös motivierter Radikalismen in den USA, Israel und Indien öffnete und seit den 1980er Jahren in Gestalt des Fundamentalismusdiskurses generalisiert wurde. So argumentiert Strong Religion „that while Islam has produced a particular virulent and potentially global form of radical fundamentalism, other major religious traditions have also given birth to movements that can be fruitfully compared with the Islamist movements. “15

Thematisierte auch der Fundamentalismus-Diskurs in Wissenschaft und Politik nunmehr die Erscheinungsvarianten des ,globalen Fundamentalismus', so waren die Analysen doch insoweit noch modernisierungstheoretisch eingefärbt, als diese einen generischen Fundamentalismusbegriff konstruierten, der die Formenvielfalt antimoderner und antisäkularer, religiös motivierter militanter Bewegungen auf einen idealtypischen Generalnenner zu bringen versuchte, wobei die sogenannten ,Abrahamitischen Religionen“ im Zentrum standen. Unter der Voraussetzung dieser begrifflichen Vorgabe zögert der Politologe, ,ideologisch' motivierte militante revolutionäre Bewegungen - also „secular movements“ - dem Fundamentalismus zuzuordnen, denn ,they are pseudo-religious rather than authentically religious. They may call upon their followers to make the ultimate sacrifice, but,

13 Ebd.

14 Ebd., S. 5.

15 Ebd., S. 6f. 
unlike the monotheistic religions [...] they do not reassure their followers that God or an eternal reward awaits them."“16

Infolge dieser konzeptionellen Festlegung qualifizieren sich auch analoge Phänomene in Hinduismus oder Buddhismus nicht als fundamentalistisch, soweit diese nicht als ,westliche', das heißt ,theistische' Derivationen bestimmt werden können. Der hier exemplarisch vorgeführte politikwissenschaftliche Fundamentalismusdiskurs verstrickt sich in seine eigenen Aporien: Er restringiert den Fundamentalismus auf die Revolte der ,traditionellen theistischen Religion' gegen die säkulare Moderne einerseits und negiert andererseits den „secular fundamentalism“ der totalitären Bewegungen, da hier die theistisch inspirierte Antimodernität fehlt. Eine solche Engführung des analytischen Ansatzes betont auf ihre Weise das bewegungspolitisch wirksame religiöse Moment, hat sich aber im intellektuellen und politischen Diskurs nur bedingt durchgesetzt.

Hier reüssierte ein diffuses und expansives Verständnis von Fundamentalismus, das im Sinne eines Kampfbegriffes jede gesellschaftliche Gruppierung oder Bewegung, die einen vorgeblich modernitätskritischen normativen Absolutheits- und Wahrheitsanspruch geltend machte, unter Fundamentalismusverdacht stellte. Solchermaßen inflationär erweitert auf religiösen, politischen, moralischen und sogar staatlichen Fundamentalismus, endete der Fundamentalismusdiskurs in einer intellektuellen Sackgasse. ${ }^{17}$ Ungeachtet dessen hatten die unübersehbaren religiös-politischen Auf- und Umbrüche das herrschende akademische Weltbild soweit erschüttert, dass die gesellschaftlichen Konfigurationen von Politik und Religion in ihrer ihnen eigentümlichen modernen Gestalt in das Zentrum der Aufmerksamkeit rückten. Denn die Untersuchungen des globalen Fundamentalismus zwangen erstens zu einem neuen Blick auf die historischen, kulturellen und politischen Implikationen der Modernisierungstheorien und

16 Ebd., S. 15. Grundlegend: Martin E. Marty/R. Scott Appleby (Hrsg.): Fundamentalism and Society. Reclaiming the Sciences, the Family, and Education, Chicago 1993; dies. (Hrsg.): Accounting for Fundamentalisms. The Dynamic Character of Movements, Chicago 1994; Heiner Bielefeldt/Wilhelm Heitmeyer (Hrsg.): Politisierte Religion. Ursachen und Erscheinungsformen des modernen Fundamentalismus, Frankfurt a.M. 1998; Victor Trimondi/Victoria Trimondi: Krieg der Religionen, München 2006.

17 Thomas Meyer: Fundamentalismus. Aufstand gegen die Moderne, Reinbek bei Hamburg 1989; Stephan H. Pfürtner: Fundamentalismus, Freiburg 1992; Christian J. Jäggi/David Krieger: Fundamentalismus, Zürich 1991. 
insbesondere deren säkularistischen Voraussetzungen. ${ }^{18}$ Zweitens erwies es sich als unvermeidlich, die formative Rolle von Religion in modernen und modernisierenden Gesellschaften zu reevaluieren.

Diese thematischen Reorientierungen verwandelten den Fundamentalismus-Diskurs implicite und explicite in einen Religionsdiskurs, der das Phänomen der Religion in seinem gesellschaftlichen Kontext diskutiert und als integrales Moment der politischen Modernität in globaler Perspektive analysiert. Exemplarisch für diesen, in einer nahezu unübersehbaren wissenschaftlichen und politischen Literatur dokumentierten Paradigmenwechsel ist das Bekenntnis Martin Riesebrodts angesichts des weltweiten Aufstiegs ,konservativer und fundamentalistischer Bewegungen“:

„Die dramatische weltweite Rückkehr der Religionen und ihrer Bedeutung als öffentlicher Macht hat die meisten von uns überrascht, ob wir nun Sozialwissenschaftler sind oder nicht. Wir glaubten alle mehr oder weniger zu wissen, dass ein solches Wiedererstarken der Religion nicht möglich sei [...]. Nur wenige waren auf eine weltweite Revitalisierung von Religion als einer Macht gefasst, die erfolgreich religiöse Subjekte formt und öffentlichen Einfluss gewinnt. “19

Riesebrodt kommt zu dem Schluss, ,dass weder die Leugnung areligiöser Strukturmerkmale der westlichen Moderne noch ein blinder Glaube an einen unaufhaltsamen Trend zur Säkularisierung überzeugende Antworten auf die Herausforderung der weltweiten Rückkehr der Religionen darstellen“ ${ }^{20}$. Er schlägt zu Recht vor, ,unsere sozialwissenschaftlichen Grundannahmen hinsichtlich der Religion kritisch zu prüfen“, um eine religionstheoretisch begründete Erklärung für die Rolle der Religion in der modernen Welt zu finden. ${ }^{21}$ Rückkehr des Religiösen, Renaissance der Reli-

18 Mathias Hildebrandt/Manfred Brocker/Hartmut Behr (Hrsg.): Säkularisierung und Resakralisierung in westlichen Gesellschaften. Ideengeschichtliche und theoretische Perspektiven, Wiesbaden 2001; Hartmut Lehmann: Säkularisierung. Der europäische Sonderweg in Sachen Religion, Göttingen 2004; Craig Calhoun/Mark Juergensmeier/Jonathan van Antwerpen (Hrsg.): Rethinking Secularism, Oxford 2011; Martin Treml/Daniel Weidner (Hrsg.): Nachleben der Religionen. Kulturwissenschaftliche Untersuchungen zur Dialektik der Säkularisierung, München 2007.

19 Martin Riesebrodt: Die Rückkehr der Religionen. Fundamentalismus und der „Kampf der Kulturen“, München 2000, S. 9.

20 Ebd., S. 10.

21 Ebd., S. 11f. Vgl. auch: Hans-Joachim Höhn: Postsäkular. Gesellschaft im Umbruch - Religion im Wandel, Paderborn 2007. 
gion oder Wiederkehr der Götter - wie auch immer das Problem definiert wird, es ist unmittelbar verknüpft mit der für das westliche Selbstverständnis zentralen Frage nach dem Bedeutungsgehalt des ,Säkularen“: „Rethinking Secularism“ steht auf der intellektuellen Tagesordnung. Die Autoren eines gleichnamigen Bandes machen darauf aufmerksam, dass das ,Säkulare ' und das ,Religiöse' im modernen Verständnis in Form und Inhalt wechselseitig konstitutiv sind und in globaler Perspektive die Grenzziehung zwischen dem ,Religiösen' und dem ,Säkularen' ein weltweites konfliktträchtiges Phänomen geworden ist, insofern es unmittelbar verknüpft ist mit der Präsenz von „multiple and competing, secularisms ““22. Dieser Ansatz einer strukturgeschichtlichen Revision des Säkularisierungstheorems geht auf José Casanova zurück. Er beschreibt die „reemergence“ des Religiösen in Gestalt einer neuartigen Form von „,modern public religion“ als säkularisierungsinduzierte „deprivatization“ der Religion: die sozial- und lebensweltliche privatisierte Religiosität antwortet auf die Herausforderungen der säkularisierten Welt mit der Rückkehr in die öffentliche Arena. Casanova kommt somit zur Schlussfolgerung ,to view the public interventions of religion analyzed here as immanent critiques of particular forms of institutionalization of modernity from a modern normative perspective.، ${ }^{23}$

Casanova und eine Reihe weiterer Autoren - Norris und Inglehart, Jelen und Wilcox, Juergensmeier, Beyer - versuchen den unerwarteten politischen Aufbruch des Religiösen in der politisch-sozialen Welt im Kontext der modernisierungstheoretisch begründeten Säkularisierung zu erklären. ${ }^{24}$ Klingt dies auf den ersten Blick plausibel, so sind doch die Aporien dieser Ansätze offenkundig: Erstens arbeiten sie mit dem westlichen konventionellen christentumsaffinen Religionsbegriff. Zweitens generalisieren sie das westliche Verständnis des ,Säkularen “ unzulässigerweise, indem sie beide Begriffe auf nicht-westliche Gesellschaften übertragen. Schon Joachim Matthes hat zu der Projektion solcher Theorien von Religion und Säkularisierung auf außerchristliche Kulturwelten kritisch angemerkt, dass

22 Craig Calhoun/Mark Juergensmeier/Jonathan van Antwerpen: Introduction, in: dies. (Hrsg.): Rethinking Secularism, Oxford 2011, S. 3-30, hier: S. 21f.

23 José Casanova: Public Religion in the Modern World, Chicago 1994, S. 230.

24 Pippa Norris/Ronald Inglehart: Sacred and Secular. Religion and Politics Worldwide, Cambridge 2004; Ted Gerard Jelen/Clyde Wilcox (Hrsg.): Religion and Politics in Comparative Perspective. The One, The Few, and The Many, Cambridge 2002; Mark Juergensmeier (Hrsg.): Religion in Global Civil Society, Oxford 2005; Peter Beyer: Religion in Global Society, London 2007. 
man dann, ,die islamische und jüdische ausgenommen, überraschenderweise von den meisten von ihnen als schon immer säkularisiert sprechen (müsste) - was mit dem evolutionistischen, epochalen Sinn des Konzepts von ,Säkularisierung' ins Gehege käme. ‘25

Drittens, last but not least, ist der Objektbereich der Untersuchung auf jene spezifischen religiös-politischen Phänomene beschränkt, denen seit den 80er Jahren des 20. Jahrhunderts weltpolitische Relevanz zugemessen wird - unter der nach wie vor axiomatisch formulierten Annahme der , harten' Version des Säkularisierungstheorems, dass die neuzeitliche Geschichte bis zu diesem Zeitpunkt durch die Marginalisierung, traditionaler' Religiosität in der Politik gekennzeichnet war. Damit war analog zum Fundamentalismus-Diskurs jede grundsätzliche Reflexion auf die Bedingung der Möglichkeit spezifisch neuzeitlicher religiös-politischer Ausdrucksformen gesellschaftlicher Sinnstiftung unter dem Horizont der Moderne ausgeschlossen.

Mit Blick auf den neuen Religionsdiskurs ist es nicht falsch, mit George Weigel festzustellen: ,the unsecularization of the world is one of the dominant social facts in the late twentieth century. "26 Ähnlich spricht Peter Berger von der ,desecularization of the world“: „The world today is anything but the secularized world that has been predicted by so many analysts of modernity.“ „The world today [...] is as furiously religious as it ever was, and in some places more than ever. “27

Die Beobachtung einer ,resurgent religion“ erlaubt es somit nur bedingt, von einer Desäkularisierung des Westens oder gar der Welt insgesamt zu sprechen, denn die dynamischen Umbrüche der westlichchristlichen Zivilisation, die der Modernisierungsbegriff analytisch zu

25 Joachim Matthes: Was ist anders an anderen Religionen? Anmerkungen zur zentristischen Organisation des religionssoziologischen Denkens, in: Jörg Bergmann/Alois Hahn/Thomas Luckmann (Hrsg.): Religion und Kultur, Opladen 1993, S. 16-30, hier: S. 24; vgl. ders.: Religion als Thema komparativer Sozialforschung, in: Soziale Welt 1 (1983), S. 3-21, hier: S. 4. Die bahnbrechenden Analysen von Matthes wurden zu Unrecht in der einschlägigen Forschung ignoriert. Vgl. hierzu: Rudolf G. Wagner: Säkularisierung: Konfuzianismus und Buddhismus, in: Hans Joas/Klaus Wiegandt (Hrsg.): Säkularisierung und die Weltreligionen, Frankfurt a.M. 2007, S. 224-252.

26 George Weigel: Religion and Peace. An Argument Complexified, in: Washington Quarterly 14 (1991) 2, S. 27-41, hier: S. 27.

27 Peter L. Berger: The Desecularization of the World. A Global Overview, in: ders. (Hrsg.): The Desecularization of the World. Resurgent Religion and World Politics, Grand Rapids 1999, S. 1-18, hier: S. 2 und S. 9. 
entschlüsseln versucht, haben ja unleugbar gerade auch das geistig-kulturelle und sozial-politische Substrat der christlich verfassten Gesellschaftsordnung umgewälzt. Insofern trifft die ,schwache' Säkularisierungsthese zu, der zufolge in Europa - weniger in den Amerikas - die öffentliche Stellung und der soziokulturelle Einfluss der privilegierten Großkirchen schleichend erodiert und die überkommenen gesellschaftlich verbindlichen Frömmigkeitsformen zugunsten individualisierter Privatreligiositäten zurücktreten, ohne dass die traditionale kirchlich verfasste Religion verschwindet. Diesem Sachverhalt trägt Martys alternatives „double paradigm“ einer „all-pervasive religiousness and persistent secularity“ Rechnung. ${ }^{28}$ So mussten alle traditionellen Religionskulturen, in den Worten von Graf, ,auf die modernitätsspezifischen Transformationen und Brüche reagieren“229, doch der „religiöse Glaube“ verlor nicht an „kulturprägender Kraft“. Daher lässt sich

„eine Geschichte der Modernisierung auch als Religionsgeschichte schreiben. Gerade wegen der permanenten Traditionsabbrüche und krisenhaften Veränderungsdynamik verlieren religiöse Weltdeutungen in der Moderne nicht an orientierender Kraft, sondern gewinnen umgekehrt eine neue und in vielem sehr viel existentiellere. Religiöser Glaube wird in der Moderne nicht insgesamt weniger. Er nimmt in einem bestimmten Sinne vielmehr zu. ${ }^{\text {(30 }}$

Graf erkennt an, dass hieraus die semantischen Differenzierungen des Religionsbegriffs resultieren:

„Um die vielfältigen Phänomene ,neuen Glaubens` und ,vagierender Religiosität` zu erfassen [spricht man] von ,politischen Religionen', ,Säkularreligionen', ,Sozialreligionen', ,Ersatzreligionen', ,quasireligiösen Weltanschauungen', ,Diesseitsreligionen', ,Parareligionen', ,Jugendreligionen` und ,Intellektuellen-Religiösität‘، ،31

Graf hält zwar die begriffsgeschichtliche Erforschung ,dieser diversen neuen Komposita des Religionsbegriffs“" für ein Desiderat, hält aber die Vorstellung ,einer Ablösung des alten christlichen durch neue säkulare, innerweltliche Glaubenssysteme“ für nur bedingt zutreffend, denn diese

28 Martin E. Marty: Religion and Republic. The American Circumstance, Boston 1989, S. 22.

29 Friedrich Wilhelm Graf: Die Wiederkehr der Götter. Religion in der modernen Kultur, München 2004, S. 40.

30 Ebd., S. 97.

31 Ebd., S. 97. 
blieben ,sehr stark geprägt durch die Anknüpfung an christliche Symbolbestände ${ }^{\text {“32 }}$. Die Beobachtung ist richtig, die Folgerung aber falsch. Richtig ist, dass der im Verlauf der Soziogenese der modernen westlichen Zivilisation - und nur um diese geht es in diesem Zusammenhang - entscheidende, im Christentum wirksame heterodoxe Komplex von Ideen, Haltungen und Sentiments im Kontext der christlichen Symbolwelt gesellschaftlich wirksam wird. Doch die heterodoxen Deutungsbestände fungieren als Ferment gesamtgesellschaftlicher Metamorphosen von Ordnungsgehalt und sozialer Form der tradierten christlich determinierten Symbolwelten im Westen und den durch sie erschlossenen Weltregionen, wobei es sich bei solchen Glaubenssystemen - anders als von Graf vermutet - um neue genuin religiös-politische Phänomene sui generis handelt. Lehmann teilt in gewissem Sinn die Skepsis von Graf in dieser Hinsicht, wenn auch seine Äußerungen zur neuzeitlichen „Transformation des Religiösen“ durch eine gewisse Ambivalenz gekennzeichnet sind. „Innerweltliche Zukunftshoffnungen, die sich auf Bereiche wie Aufklärung, Volk, Nation oder auch Reich beziehen, auch innerweltlich zu realisierende Visionen, wären demnach als pseudo-religiöse Einstellungen zu klassifizieren, nicht aber als genuin religiöse Glaubensvorstellungen. “33

Doch dann relativiert er diese These auf eigenwillige Weise: „Freilich sind auch auf diesem Gebiet Grenzfälle nicht zu übersehen. Dazu gehören die ,politischen Religionen', deren Zukunftsversprechen in dem schillernden, äußerst ambivalenten Feld von tatsächlicher Immanenz und angeblicher Transzendenz angesiedelt sind. “34

\section{PARADIgMENWECHSEl II: DER RELIGIONSDISKURS}

Die hier skizzierten Ansätze eines Paradigmenwechsels in den sozialen und politischen Disziplinen stecken in Bezug auf den Religionsbegriff durchaus noch in den Anfängen. Insbesondere die Untersuchung des religiös-politischen Komplexes steht noch weitgehend im Bann des christentumsspezifischen Dualismus von machtpragmatischer Herrschaftsordnung und

32 Ebd.

33 Lehmann, Säkularisierung, 2004, S. 63.

34 Ebd. 
institutionalisierter Religionsgemeinschaft. Die Religionsforschung, so die kritische Argumentation des Soziologen,

,ist bis in ihre grundlegenden Konzeptionalisierungen hinein geprägt von der Überlieferungsgeschichte und Erfahrungswirklichkeit des Christentums; sie übernimmt deren Besonderheiten in ihren kategorialen und problemdefinierenden Apparat ebenso wie in ihren Bestand an Forschungsverfahren, wobei mit dieser Übernahme jene Besonderheiten konzeptuell generalisiert werden. ${ }^{\text {(35 }}$

Entscheidend für diesen christentumsgeschichtlichen Hintergrund des modernen Religionsbegriffs ist die okzidentale Kulturgeschichte seit der Reformation, denn in dieser wurzeln die zentralen Bedeutungskonstituentien des Konzepts ,Religion“, einmal dessen generalisierender Charakter, „,der die fragmentarisierten Christentümer überwölbt und das ,Nicht-Christliche einschließt - soziologisch gesprochen ,nostrifiziert““ -, zum anderen, dessen Differenzfunktion, die gesellschaftliche Dichotomien konstruiert: „Religion und Magie, Religion und Wissenschaft, Religion und Staat, und eben auch die Differenz von ,Religion und Gesellschaft ${ }^{\text {“ } 36}$. So kann Tenbruck feststellen: „Die Religionsgeschichte Europas ist einzigartig durch ihren Besitz des Begriffs ,Religion`، ‘37

Die Geschichte dieses Religionsbegriffs wurde von Ernst Feil in seinem vierbändigen Werk ,Religio' meisterhaft dokumentiert ${ }^{38}$ und es würde zu weit führen, seine Ergebnisse hier ausführlich zu rekapitulieren. Feils Befund bestätigt en detail die These, dass der moderne Religionsbegriff in seiner vielfältigen Gestalt selbst ein Produkt der neuzeitlichen Geistesgeschichte ist, der retrospektiv historisch und global generalisiert wurde. Wichtig ist aber daran zu erinnern, dass keine der nichtwestlichen

35 Matthes, Religion als Thema komparativer Sozialforschung, 1983, S. 3.

36 Matthes, Was ist anders an anderen Religionen, 1993, S. 20.

37 Friedrich H. Tenbruck: Die Religion im Maelstrom der Reflexion, in: Jörg Bergmann/Alois Hahn/Thomas Luckmann (Hrsg.): Religion und Kultur, Opladen 1993, S. 31-67, hier: S. 55.

38 Ernst Feil: Religio I. Die Geschichte eines neuzeitlichen Grundbegriffs vom Frühchristentum bis zur Reformation, Göttingen 1986; ders.: Religio II. Die Geschichte eines neuzeitlichen Grundbegriffs zwischen Reformation und Rationalismus (1540-1620), Göttingen 1997; ders.: Religio III. Die Geschichte eines neuzeitlichen Grundbegriffs im 17. und 18. Jahrhundert, Göttingen 2001; ders.: Religio IV. Die Geschichte eines neuzeitlichen Grundbegriffs im 18. und 19. Jahrhundert, Göttingen, 2007; vgl. auch: Michel Desplan: La Religion en Occident, Montreal 1979. 
Zivilisationen (das Judentum eingeschlossen) mit Ausnahme des Islam einen irgendwie gearteten generischen Begriff ,Religion“ gebildet haben. Ein der westlichen Semantik akkulturierter Sprachgebrauch beruht entweder auf Neologismen oder adaptiert tradierte Begriffe, in denen stets der historische Bedeutungsgehalt mitschwingt. Die hellenische Antike kannte einen solchen Begriff nicht, sondern drückte die vielgestaltige Welt von Kult und Götterlehre als integrales Formelement der politischen Gemeinschaftsbildung durch jeweils spezifische Sprachsymbole aus. Das kosmopolitische hellenistische Denken differenzierte kritisch zwischen der Götterlehre (Theologie) der Philosophen, der Dichter und der Stadtkulte, ohne dass hieraus ein übergreifender Religionsbegriff entwickelt wurde. Das gilt auch für die Rezeption dieser ,theologia tripertita ${ }^{39}$ bei dem Römer Varro und ebenso für den durch die Vermittlung der christlichen Kirchenväter insbesondere Augustin - für die westliche Begriffsgeschichte folgenreiche semantische Neuprägung, religio‘. Sie bezieht sich auf das für das öffentliche Leben kultische Element der res publica. ,Religio“ umschreibt die für die individuelle und kollektive Existenz der Römer unabdingbare Haltung, welche die Weisungen der Götter gewissenhaft beachtet und den entsprechenden Kultvorschriften sorgfältig nachkommt. Ist der Begriff hier durchaus auf eigentümliche Weise zivilpolitisch konnotiert und symbolisches Moment eines kompakten politisch-religiösen Komplexes im Sinne meiner Argumentation, so reduziert die christliche Deutung ihn auf den kultbezogenen Wahrheitsanspruch der vera religio. ${ }^{40}$ Bis zur Reformation und Renaissance hinein spielte der Begriff der ,religio“ eine untergeordnete Rolle, war sein eingeschränkter und letzthin marginaler Bedeutungsgehalt auf die durch Cicero und die Kirchenväter vorgegebenen Inhalte beschränkt: ,Religio“ ist im Kult praktizierte pietas; sie zeigt sich in der Gottesverehrung und Gottesfurcht und den hierauf bezogenen Praktiken und Handlungen des Gottesdienstes sowie in ethischer Hinsicht in der hierfür geforderten Tugend, Gerechtigkeit gegen über den Göttern oder Gott zu üben. Das christlich-kirchliche Selbstverständnis entfaltete seine

39 Vgl. Godo Liberg: Die ,theologia tripertita' in Forschung und Bezeugung, in: Hildegard Temporin (Hrsg.): Der Aufstieg und Niedergang der römischen Welt, Bd. I/4, Berlin 1973, S. 63-115.

40 Matthias Riedl: Vera Religio - ein Schlüsselbegriff im politischen Denken des spätantiken Christentums, in: Mathias Hildebrandt/Manfred Brocker (Hrsg.): Der Begriff der Religion. Interdisziplinäre Perspektiven, Wiesbaden 2008, S. 33-57. 
eigene komplexe Semantik der kirchlich institutionalisierten fides Christiana. Erst die postreformatorische Fragmentierung des Christentums und die konkomitanten Staat-Kirchen-Konflikte in und nach den Religionskriegen generierten einen Begriff der Religion, der die Identifikationsmerkmale einer Pluralität von sozial, dogmatisch und institutionell separierten Vergemeinschaftungen der konfessionell definierten Christentümer bestimmte. Parallel dazu rekurrierte der Renaissance-Humanismus auf den ursprünglichen Begriff der ,religio' als eine transkonfessionelle Grundbestimmung des Menschen und - politisch - als Garant von Gemeinschaftstugend und Gesetzestreue der Bürger. Dieser politische Monotheismus des Humanismus war eng verbunden mit dem bürgerzentrierten Politikbegriff der städtischen Kultur. Es liegt nahe, hier von einem politisch-religiös bewussten Rückgriff auf eine Tradition des politisch-religiösen Ordnungskomplexes zu sprechen; er prägte den politischen Humanismus von Machiavelli und Bodin bis Montesquieu und Locke und den anglophonen Konstitutionalismus. ${ }^{41}$ Im Prinzip setzt er auf die Eliminierung der Kirchen als Definitionsfaktor der geistig-politischen Ordnung des emergenten Konfessionsstaates. Dieser republikanisch akzentuierte Religionsbegriff wurde im modernen Religionsdiskurs marginalisiert im Gegensatz zur Dominanz des postreformatorischen Religionsbegriffes, der das moderne Paradigma von Religion und Politik kennzeichnen sollte und - wie oben ausgeführt - Ausgangspunkt eines entpolitisierten generischen Religionsbegriffs im 19. und 20. Jahrhundert wurde. Dieser löste sich von den spezifischen christlichen Inhalten und wurde unter dem Einfluss der gewaltigen Erweiterung des historisch-kulturellen Erfahrungshorizontes in der sich komplementär konstituierenden disziplinär organisierenden ,Religionsforschung ' generalisiert. Solchermaßen reflektiert dieser Religionsbegriff die gesellschaftlichen Umbrüche der anhebenden Moderne.

„Wenn man einen Kontext sucht, in dem das historische Konzept Religion entstand und in dem es seine Plausibilität hatte, dann ist es das Phänomen der Modernisierung. ${ }^{\text {‘42 }}$

41 Jürgen Gebhardt: Religion und Christentum in der humanistischen Politik der frühen Neuzeit, in: Peter Haungs u.a. (Hrsg.): Civitas. Widmungen für Bernhard Vogel zum 60. Geburtstag, Paderborn 1992, S. 211-222.

42 Hans G. Kippenberg: Die Entdeckung der Religionsgeschichte. Religionswissenschaft und Moderne, München 1997, S. 265. 
„Der Terminus ,Religion“ dient neuzeitlich als Oberbegriff, und zwar zunächst in dem Sinn, dass er alle Vorstellungen, Einstellungen und Handlungen gegenüber jener Wirklichkeit bezeichnet, die Menschen als Mächte oder Macht, als Geister oder auch Dämonen, als Götter oder Gott, als das Heilige oder Absolute oder schließlich auch nur als Transzendenz annehmen und benennen. “43

In der systematischen Gestalt eines generischen Abstraktums ,Religion“ ist dieser Komplex durch den Bezug auf eine übernatürliche, überempirische, magisch-mythische, sakrale oder jenseitige Wirklichkeit gekennzeichnet, deren kontrafaktische Natur sie in Widerspruch zur kulturell säkularisierten entzauberten modernen Welt und Politik setzt. Einer negativen Formaldefinition von Colpe entsprechend ist dann ,Religion [...] die Qualifikation einer lebenswichtigen Überzeugung, deren Begründung, Gehalt und Intention mit den innerhalb unserer Anschauungsformen von Raum und Zeit gültigen Vorstellungen und mit dem Denken in den dazugehörigen Kategorien weder bewiesen noch widerlegt werden kann. ${ }^{44}$

Auf den christentumshistorischen Hintergrund wurde bereits ausführlich verwiesen. Zum Verständnis von Form und Inhalt des generischen Religionsbegriffs im Kontext des Säkularisierungsglauben muss jedoch zusätzlich auf den geistes- und symbolgeschichtlichen Zusammenhang Bezug genommen werden, der sich in der eigentümlich dichotomischen Struktur des neuzeitlichen Religionsbegriffs niedergeschlagen hat. Dies lässt sich auf den prägenden Einfluss der hochmittelalterlichen Theologie zurückführen. Die Hochscholastik entwickelt in ihrer rationalen Wirklichkeitsauslegung eine Semantik, die auf der elaborierten Dichotomie von ,Wissen und Glauben', ,Vernunft und Offenbarung', ,sakral und profan', ,natürlich und übernatürlich` beruht und auf die fundamentale christentümliche Dichotomie von ,Diesseits` und ,Jenseits‘ bezogen ist. Diese Dichotomien verdanken sich einer theologischen Systematisierung, die versuchte, die natürliche Autorität und den Wahrheitsanspruch der antiken Philosophen mit der göttlich verbürgten übernatürlichen Offenbarungswahrheit

43 Feil, Religio I, 1986, S. 29.

44 Carsten Colpe: Mythische und religiöse Aussage außerhalb und innerhalb des Christentums, in: Hans-Joachim Birkner/Dietrich Rössler (Hrsg.): Beiträge zur Theorie des neuzeitlichen Christentums, Berlin 1968, S. 16-36, hier: S. 19. Vgl. auch: Christoph Elsas (Hrsg.): Religion. Ein Jahrhundert theologischer, philosophischer, soziologischer und psychologischer Interpretationsansätze, München 1979; Ulrich Barth: Religion in der Moderne, Tübingen 2003. 
der Heiligen Schrift in Einklang zu bringen. Je stärker der Druck innerweltlicher Erkenntnisformen wird und die institutionellen Repräsentanten, Theologie und Kirche an öffentlicher Bedeutung verlieren, desto intensiver schreitet die Delegitimierung der Welt des Übernatürlichen voran, um in dem oben beschriebenen Religionsbegriff zu enden. Dessen dichotomischer Charakter bleibt erhalten, doch die Welt des Übernatürlichen, der religiösen Vorstellungen und Praktiken, ist gleichsam ontisch grundlos geworden gegenüber dem Realitätsanspruch der metrisch strukturierten weltimmanenten phänomenalen Welt in der Folge des Aufstiegs der mathematisch-physikalischen Wissenschaften in der Neuzeit.

In Betrachtung des säkularisierungskritischen Fundamentalismusdiskurses zeigt sich, dass dieser sich sachlogisch auf das Problem des Religionsbegriffs einlassen muss. Aber wie selbst die innovativen Arbeiten Riesebrodts exemplarisch belegen, wirkt der Einfluss traditioneller Denkmodelle fort, wenn es gilt „Religion [...] im Angesicht ihrer dramatischen Rückkehr theoretisch zu überdenken “45. Riesebrodt schlägt einen akteursbezogenen Religionsbegriff vor. „Religion [ist] ein Komplex religiöser Praktiken, die auf der Prämisse der Existenz in der Regel unsichtbarer persönlicher oder unpersönlicher übermenschlicher Mächte beruhen [...], die sich direkter menschlicher Kontrolle entziehen. ${ }^{“ 46}$

Durch die Relativierung personalistischer oder monotheistischer Gottesvorstellung und den Rückgriff auf die Denkfigur einer „Imagination übermenschlicher Kräfte" möchte Riesebrodt seinen Religionsbegriff durch den „Bezug auf eine ihnen zugrundeliegende allgemeine Sinnstruktur vergleichbar machen “47. Tatsächlich gerät dieser Versuch einer Revision des Religionsbegriffs letzten Endes doch in Gefahr, nur eine Variation des forschungsdominanten Allgemeinkonzepts von ,Religion` zu formulieren, das eine Rekonzeptionalisierung der überkommenen theologisch fundierten Dichotomie von Wissen und Glauben vermeidet.

Riesebrodt und andere Forscher wie Graf lösen sich auch in anderer Hinsicht nicht von der christentumsspezifischen Verengung des Religionsbegriffs, die Joachim Matthes gerade unter komparatistischen Gesichtspunkten kritisiert: ,[D]ie Konnotation von ,Religion“ als etwas in sich Ge-

45 Martin Riesebrodt: Cultus und Heilsversprechen - eine Theorie der Religionen, München 2007, S. 12.

46 Ebd., S. 113.

47 Ebd., S. 217. 
schlossenem, in sich folgerichtig Angelegtem und folglich auch in anderen Erscheinungsformen von ,Religion“ Abgegrenzten.“ Dies sei

,dem westlichen Agnostiker, dem alltagsweltlichen wie dem wissenschaftlichen nur allzu geläufig, und es ist ihm, betreibt er Sozialforschung, auch nur allzu willkommen, ermöglicht ihm dieses Verständnis doch eine verhältnismäßig klare ,definitorische“ Abgrenzung seines Gegenstandes. Doch den weitaus meisten nichtchristlichen ,Religionen“ ist diese ,Apartheit‘ des ,Religiösen` fremd.“48

Gerade mit Blick auf Riesebrodts Betrachtung der ostasiatischen ,Religionen' wird die Ambivalenz des neueren Religionsdiskurses offenkundig: Er konstatiert, dass ostasiatische Religionen sich am besten als Systeme von religiösen Praktiken beschreiben lassen, die sich aus unterschiedlichen „religiös-theologisch definierten Traditionen“ speisen und deren Elemente sich nicht in „doktrinärer Reinheit“" voneinander trennen lassen. ${ }^{49} \mathrm{Als}$ Erscheinungsformen des Religiösen liegt auch ihnen jene Sinnstruktur zugrunde, die nach Riesebrodt das Definitionsmerkmal der ,Religion“ ist und somit die nach Matthes problematische Nostrifizierung der Erscheinungsformen der ostasiatischen Symbolwelten erlaubt. Die Ambivalenz dieser Analysen wird noch deutlicher, wenn Riesebrodt das interzivilisatorisch präsente Phänomen der ,,prophetischen Verheißungen“ untersucht.

„Unter dem Begriff der prophetischen Propaganda subsumiere ich hier Ideologien messianischer, millenarischer, apokalyptischer und fundamentalistischer Bewegungen, die eine religiöse Heilsbotschaft verkünden, in der zur Umkehr oder radikaler Veränderung aufgerufen wird. Dabei geht es in der Regel um das Schicksal politischer und religiöser Gemeinschaften." ${ }^{50}$

Zurecht wird die religiöse Konnotierung apokalyptisch-messianischer Ideologien in ihrem Charakter als Ausdruck gesellschaftlicher Religiosität beschrieben, wobei die Materialanalysen dann doch wiederum sich nur auf traditionsgeleiteten Messianismen abrahamitischen Ursprungs in West und Ost beschränken, die doch wirkungsgeschichtlich unmittelbar mit dem Aufstieg heilsgeschichtlicher Ideologien verknüpft sind. Deswegen bleibt die Frage, inwieweit dies mit Riesebrodts ursprünglicher Definition von ,Religion' vereinbar ist und der Gesamtkomplex religiös-politischer Formen

48 Matthes, Was ist anders in anderen Religionen, 1993, S. 23.

49 Riesebrodt, Cultus und Heilsversprechen, 2007, S. 145.

50 Ebd., S. $228 f$. 
symbolischer Selbstlegitimierung gesellschaftlicher Existenz nur sehr bedingt zum eigentlichen Gegenstand eines modernen Religionsdiskurses wird.

Wie schwer es ist, sich von dem generischen Verständnis von Religion zu lösen, zeigt die vermittelnde Position, die Robert N. Bellah in seinem 2011 publizierten monumentalen Werk Religion in Human Evolution einnimmt. Er möchte einerseits aus eher pragmatischen Gründen weiterhin von Religion sprechen, deutet sie jedoch dem Anthropologen Geertz und dessen Gewährsmann Schütz folgend als offenes Symbolsystem.

„Religion is a system of symbols, that when enacted by human beings, establishes powerful, pervasive, and long lasting moods and motivations that make sense in terms of a general order of existence. It is interesting to note what Geertz left out. There is no mention of ,belief in supernatural beings' or , belief in gods (God) which many current definitions take for granted as essential. It is not that Geertz or I think such beliefs are absent in religion, though in some cases they may be, just that they are not the defining aspect." ${ }^{\text {51 }}$

Geertz symboltheoretischer Ansatz rekurriert auf eine von Alfred Schütz formulierte sozialphänomenologische Interpretation gesellschaftlicher Symbolformen, auf welche die eingangs gegebene Exposition des erkenntnisleitenden Begriffs des religiös-kulturellen Dispositivs Bezug genommen hat. Schütz geht von den fundamentalen Problemen der philosophischen Anthropologie aus, „namely, the place of man in a cosmos that transcends his existence, but within which he has to find his bearings. Signs and symbols [...] are among the means by which man tries to come to terms with his manifold experiences of transcendence. ${ }^{\text {(52 }}$

Der heuristische Rekurs auf einen modernen empirisch ausgewiesenen Transzendenzbegriff erlaubt eine Problematisierung latenter Dichotomien religiös-politischer Symbolformen, denn im Zusammenspiel von Herrschaft und Heil spiegelt sich in der Tat ein dialektisches Verhältnis von mundaner Welterfahrung und einer diese transzendierenden geistigen Ordnungserfahrung in Gestalt einer universalen Vision einer höheren moralischen oder

51 Robert N. Bellah: Religion in Human Evolution. From the Paleolithic to the Axial Age, Cambridge 2011, S. XIV; vgl. Clifford Geertz: The Interpretation of Culture, New York 1973, S. 90.

52 Alfred Schütz: Collected Papers I. The Problem of Social Reality, The Hague 1962, S. 293. 
meta-physischen Wirklichkeit wider, die beide jeweils im gesellschaftlichpolitischen Selbstverständnis Ausdruck finden. Dies erlaubt es, einen empirisch ausgewiesenen analytischen Zugriff auf den religiös-politischen Komplex jenseits der christentumsspezifischen theologischen Vorgabe zu formulieren, auf den sich die hier vorgetragene Konzeption des religiöskulturellen Dispositivs berufen kann, insbesondere wenn es um dessen moderne Formgestalt geht. Einem solchen konzeptionellen Ansatz widerspricht auch sachlogisch der semantische Rückgriff auf Carl Schmitts Begriff der politischen Theologie, der gleichermaßen ,für das Ineinander von Religion und Politik, für die Theologisierung der Politik und Politisierung der Religion verwandt" wird. ${ }^{53}$ Ohne im Detail auf die Umstände von Schmitts eigenwilliger Verknüpfung von Jurisprudenz und Theologie einzugehen, bleibt festzuhalten, dass diese Begriffsbildung auf einer normativen, das heißt offenbarungstheologisch begründeten und gegenwartskritisch akzentuierten Position beruht. In generalisierter Form einer ,institutionellen politischen Theologie“ (Böckenförde) umschreibt diese den „Inbegriff der Aussagen eines Gottesglaubens (einer inhaltlich näher bestimmten göttlichen Offenbarung) über den Status, der Legitimation, Aufgabe und evtl. Struktur der politischen Ordnung, einschließlich des Verhältnisses der politischen Ordnung zur Religion. “54

Folgerichtig ist nach Heinrich Meier für das Selbstverständnis der politischen Theologie „die göttliche Offenbarung die höchste Autorität und die letzte Grundlage“ ${ }^{65}$. Jan Assmann konzediert, dass „Theologie überhaupt als ein Prärogativ des Christentums angesehen wird“56, politische Theologie daher ,als ein Spezifikum der abendländischen Geschichte und damit des Christentums“" gelte. Doch, so argumentiert er, es habe sich ein „,religionswissenschaftlicher Begriff der Theologie herausgebildet, der auch auf andere Religionen anwendbar" sei. So versteht er den Begriff der Politischen Theologie ,,als lehrhaft entfaltete Rede über die Beziehung von Herrschaft und Heil“", der, deskriptiv gewendet, die Frage nach den religiös-

53 Siegfried Wiedenhofer: Politische Theologie, Stuttgart 1976, S. 11.

54 Ernst-Wolfgang Böckenförde: Politische Theorie und politische Theologie, in: Jacob Taubes (Hrsg.): Der Fürst dieser Welt. Carl Schmitt und die Folgen, München 1984, S. 16-25, hier: S. 19. Vgl. auch: Paul Kahn: Political Theology. Four New Chapters on the Concept of Sovereignty, New York 2011.

55 Hans Meier: Was ist Politische Theologie?, in: Jan Assmann (Hrsg.): Politische Theologie zwischen Ägypten und Israel, München 1992, S. 7-19, hier: S. 17.

56 Hier wie im Folgenden: Assmann, Herrschaft und Heil, 2000, S. 16. 
politischen Konfigurationen dieser Beziehung zu „einer allgemeinen religionswissenschaftlichen und anthropologischen“ bzw. ,religionspolitologischen Fragestellung“ ausweitet. Assmanns „Theologie der Herrschaft in religionsgeschichtlicher Perspektive" gilt ihm jedoch wiederum als ein Spezifikum der Religion (in der geschichtlichen Unterscheidung von präund postaxialen Religionen), was letztlich in der Natur des Theologiebegriffs liegt. Entsprechend kommentiert Hent de Vries, Mitherhausgeber einer Aufsatzsammlung über Political Theologies, Assmann wie folgt:

"we had to wait for an elaboration of the ,comparative' concept of the ,religious " indeed, for the concept of ,world religions ${ }^{\text {- }}$ before the fundamentally Christian designation political theology could be significantly broadened, extended, and retroactively projected into the historically and culturally different contexts of ancient Egypt, Mesopotamia, India, China, and the pre-Columbian empires of America. ${ }^{\text {“57 }}$

De Vries nimmt die Frage nach einem ,explicit concept of the theologicopolitical“" auf und antwortet mit dem Versuch einer vorläufigen Generalisierung

"which distinguished ,political theology", on the one hand, as the scientia of the elusive and absolute that, governs and often unconsciously drives and inspires, or destabilizes and terrorizes, the public domain (the ,theologico-political ${ }^{\circ}$ ), and on the other hand, especially in its plural dimension, as the name and description of the many diverse forms in which this ,empty" notion or open dimension can become dogmatically fixated, socially reified, and aesthetically fetished. ${ }^{658}$

Hier wie auch in der Mehrzahl der durchweg interessanten wenn auch in sich heterogenen Aufsätze des Bandes vermisst man eine systematische theoretisch und methodisch ausgewiesene Begriffsbestimmung der politischen Theologie. Die symbolischen Ordnungskomplexe des religiös-kulturellen Dispositivs mögen traditionelle Theologumena aufweisen, doch in Inhalt und Form bewegen sie sich jenseits des spezifisch westlichen Horizontes, der durch die Semantik der politischen Theologie definiert ist. Wo es nicht um den einfachen Fall einer offenbarungstheologisch begründeten Politik geht, handelt es sich in der Regel um Analysen des Zusammenspiels

57 Hent de Vries: Introduction, in: ders./Lawrence E. Sullivan (Hrsg.): Political Theologies. Public Religions in a Post-Secular World, New York 2006, S. 1-88, hier: S. 29.

58 Ebd., S. 46. 
von Politik und Religion, d.h. ,public religion', die wiederum kurzschlüssig mit ,Theologie' identifiziert wird. Ein generalisiertes Konzept der politischen Theologie endet notwendig bei den Aporien des Religionsbegriffs selbst, soweit es nicht ausdrücklich christlich-theistisch gedeutet wird. ${ }^{59}$

\section{ParadigmenWeChSEl III: TRANSZENDENZ UND ERFAHRUNG}

In einem symboltheoretisch ausgewiesenen analytischen Zugriff kommt dem Transzendenzbegriff eine entscheidende Bedeutung zu. Eine historisch-empirisch durchgearbeitete begriffsgeschichtliche Untersuchung hierzu liegt meines Wissens bisher nicht vor.

Folgt man den lexikographischen Ausführungen Jens Halfwassens und Markus Enders, ${ }^{60}$ dann ist es höchst problematisch, ,Transzendenz' als „Grundwort der klassischen Metaphysik“ zu begreifen. ${ }^{61}$ Der seinem Ursprung nach verbale Ausdruck eines spirituellen Überstiegs (transcendere) über das Sein und alles Seiende hinaus zu einem Absoluten in der platonisch-christlichen Tradition verdichtet sich in der mittelalterlichen Theologie nicht zu einem eigenen Begriff der Transzendenz analog der dichotomischen Strukturierung der theologischen Seinsinterpretation. Transzendenz und Immanenz als geistig-religiöse Schlüsselbegriffe in den Diskursen des 19. Jahrhunderts sind ihrer Entstehung nach semantische Folgen des modernen Religionsbegriffs nicht zuletzt von Kants Religionsphilosophie,

59 Vgl. hierzu: Peter Scott/William T. Cavanaugh: Introduction, in: dies. (Hrsg.): The Blackwell Companion to Political Theology, Oxford 2004, S. 1-5, hier: S. 1; Michael Kirwan: Political Theology. An Introduction, Darton 2009, S. 13f.; Rowan Williams: Introduction, in: Creston Davis/John Milbank/Slavoj Žižek (Hrsg.): Theology and the Political. The New Debate, Durham 2005, S. 1-3, hier: S. 3.

60 Vgl. Jens Halfwassen/Markus Enders: Art. „Transzendenz, Transzendieren“, in: Joachim Ritter/Karlfried Gründer (Hrsg.): Historisches Wörterbuch der Philosophie, Bd. 10, Darmstadt 1998, Sp. 1442-1455.

61 Ludger Honnefelder/Werner Schüßler (Hrsg.): Transzendenz. Zu einem Grundwort der klassischen Metaphysik, Paderborn 1992; Alan M. Olson/Leroy S. Rouner (Hrsg.): Transcendence and the Sacred, Notre Dame 1981; Eberhard Simons: Art. „Transzendenz“, in: Michael Baumgartner/Hermann Krings/Christoph Wild (Hrsg.): Handbuch der philosophischen Grundbegriffe, Bd. 6, München 1974, S. 1541-1556. Die theologische, philosophische und religionswissenschaftliche Literatur geht durchwegs von der Annahme eines traditionell vorgegebenen Transzendenzbegriffs aus. 
welche eine theoretische Vernunfterkenntnis auf den Bereich der phänomenalen Welt beschränkt und die intellegible Welt der Noumena als erfahrungstranszendent ausweist. Die Vernunftbegriffe bzw. Ideen, die als Begriffe des Unbedingten die Grenzen der immanenten Verstandeserkenntnis bzw. der Erfahrung überschreiten, nennt er , transzendent ${ }^{\star}$. Somit sind die für die moralische Welt unabdingbaren transzendenten, d.h. übersinnlichen Vernunftideen (Gott, Unsterblichkeit, Freiheit), einerseits nur regulative Erkenntnisprinzipien und Postulate der praktischen Vernunft, andererseits aber ist sittliches Handeln des Menschen als Vernunftwesen nur unter der Voraussetzung der Geltung dieser transzendenten Ideen möglich. Diese unzulässig knappen Bemerkungen tragen keineswegs der Komplexität des Kant'schen Denkens ${ }^{62}$ Rechnung und ebenso wenig kann hier die in sich verwickelte Rezeptionsgeschichte der neuzeitlichen Rede von der ,Transzendenz' in den philosophischen und theologischen Diskursen nach Kant rekonstruiert werden. ${ }^{63}$

Zwei Aspekte sind jedoch in diesem Zusammenhang bedeutsam. Erstens, der generische Religionsbegriff bezieht sich unter gewissen Umständen auf das Transzendente, um der theologischen Tradition entsprechend das Übersinnliche der religiösen Glaubenswelt als seinem Wesen nach erfahrungstranszendent zu bestimmen, wie das Beispiel Colpes belegt.

Zweitens, ungeachtet dessen, evoziert der gesellschaftliche Machtverlust kirchlicher Dogmenverwaltung eine vielgestaltige nationalkulturell gefärbte intellektuelle Bewegung, welche die spirituell-religiöse Erfahrungswelt theoretisch und methodologisch reflektiert und das Spannungsverhältnis von Immanenz und Transzendenz als substantiellen Ausdruck der intellegiblen Verfassung menschlichen Seins und seiner Ordnung verstehen möchte. „Der Gegensatz von Transzendenz und Immanenz bezeichnet nicht die Grenzlinie der Erkenntnis “64, diese These Diltheys ist für eine in sich heterogene Formierung einer erfahrungswissenschaftlichen Hermeneutik der geistigen Welt erkenntnisleitendes Prinzip. Die innere Erfahrung, geistig-religiöse Erfahrung und ihre Gestaltungswirkung in den kulturellen und sozialen Lebenszusammenhängen wird zum Ausgangspunkt der

62 Vgl. zusammenfassend: Aloysius Winter: Transzendenz bei Kant, in: Ludger Honnefelder/Werner Schüßler (Hrsg.): Transzendenz. Zu einem Grundwort der klassischen Metaphysik, Paderborn 1992, S. 193-221.

63 Vgl. Enders, Transzendenz, 1993, Sp. 1447-1455.

64 Wilhelm Dilthey: Weltanschauungslehre, in: ders.: Gesammelte Schriften, Bd. 8, Leipzig 1931, S. 178. 
Deutung der menschlichen Verhältnisse und deren Erfahrungs-, Bewusstseins- und Symbolwelten. In der philosophisch-anthropologischen Wissenschaft tritt an die Stelle der „Metaphysik eines Geisterreiches“ „das MetaPhysische unseres Lebens als persönliche Erfahrung d.h. als moralisch-religiöse Wahrheit". „[D]ie metaphysische Wissenschaft ist ein historisch begrenztes Phänomen, das metaphysische Bewusstsein der Person ist ewig. “65 Was mit der deutschen Geisteswissenschaft beginnt, in der deutsch-amerikanischen Synthese des amerikanischen Pragmatismus und der Religionspsychologie James thematisiert wird, amalgamiert sich wissenschaftsgeschichtlich in theoretischen Analysen, die das Religiöse über die Sozialform der Religion hinaus als Konstitutionsprinzip menschlicher Selbstauslegung verstehen möchten. Das Leben, heißt es bei Simmel, ist „als ein solches zu begreifen, welches die Grenze gegen sein Jenseits stetig übergreift, und in diesem Übergreifen sein eigenes Wesen hat". Dies begründet die Grundtatsache, ,dass dem Leben die Transzendenz immanent ist" ${ }^{\text {} 66}$. In einer vorhergehenden Abhandlung näherte er sich dem eigentümlichen Quellgrund des Transzendenzerlebnisses, dem

„Grundgefühl einer Erschütterung schlechthin, [...] ein Ergriffensein, als spräche durch ihren Gegenstand eine Seele zu uns, - welches alles nur als religiös zu bezeichnen ist. Dies ist nicht Religion; aber es ist derjenige Vorgang, der Religion wird, indem er sich ins Transzendente fortsetzt. ${ }^{\text {“67 }}$

Die Grundlage für die wechselseitige Durchdringung von ,religiöser Kategorie" und sozialen Beziehungen sieht Simmel

„durch die merkwürdige Analogie geschaffen, die zwischen dem Verhalten des Individuums zur Gottheit und dem zur sozialen Allgemeinheit besteht. Vor allem ist

65 Wilhelm Dilthey: Einleitung in die Geisteswissenschaften. Versuch einer Grundlegung für das Studium der Gesellschaft und der Geschichte, in: ders.: Gesammelte Schriften, Bd. 1, 2. Aufl., Leipzig/Berlin 1923, S. 384 und S. 386. Dilthey setzt sich semantisch von der Engführung des Kant'schen Erfahrungsbegriffs ab, indem er die innere oder geistige Erfahrung als ,Erlebnis' oder ,Erleben' näher bestimmt. In den anderen westlichen Kultursprachen dominiert nach wie vor ein semantisch offener Erfahrungsbegriff, ein Grund, weswegen James gegen die deutsche Professorenphilosophie polemisiert.

66 Georg Simmel: Lebensanschauung, München 1918, S. 14f.

67 Georg Simmel: Die Religion, in: ders.: Gesamtausgabe, Bd. 10, Frankfurt a.M. 1995, S. 41-118, hier: S. 50f.; vgl. den zeitnahen Ansatz Rudolf Ottos (Das Heilige [1917], München 1979), der das Heilige als eine Kategorie rein a priori aus den Erfahrungsmomenten des Numinosen gewinnt. 
das Gefühl der Abhängigkeit entscheidend. Das Individuum fühlt sich an ein Allgemeines, Höheres gebunden, aus dem es fließt und in das es fließt, dem es sich hingibt, aber von dem es auch Hebung und Erlösung erwartet, von dem es verschieden und doch auch mit ihm identisch ist. “68

Was Simmel analogisch fasst, entspricht cum grano salis der Quintessenz von James' radikal empirischem Begriff der religiösen Erfahrung als Moment des Glaubens ,that beyond each man and in a fashion continuous with him there exists a larger power which is friendly to him and his ideals. All that the facts require is that the power should be both other and larger than our conscious selves. “69

Diese notwendig kursorischen Bemerkungen beschränken sich auf einige signifikante Stationen in der Entwicklung eines offenen, empirisch fundierten Transzendenzbegriffs, der sich unter dem Horizont des Religionsdiskurses in Gestalt einer allgemeinen Kategorie der individuellen und gesellschaftlichen Selbstdeutung generalisiert, das heißt Transzendenzerlebnisse als Wesensbestand des Menschen anerkennt und deren Formenvielfalt auf ihre Rückwirkung im kulturell-symbolischen Leben der Gesellschaft hin analysiert.

\section{ParadigmenWechsel IV: TRANSZENDENZ, SymBOL UND GESELLSChAFT}

Rückblickend dokumentiert das Werk Alfred Schütz' eine theoretische Weichenstellung für die konzeptionelle Reorientierung. Ausgehend von

68 Simmel, Die Religion, 1995, S. 59f.. Die Natur der personalen ,religiösen Erfahrung' der Transzendenz ist seither Gegenstand einer breiten disziplinübergreifenden Diskussion. Sie dokumentiert einerseits den empirischen Charakter der Erscheinungsformen des, Religiösen“ und arbeitet das einschlägige Symbolmaterial hermeneutisch auf, hält aber andererseits in der materiellen und theoretischen Definition ihres Gegenstandes am Religionsbegriff fest. Dies gilt auch für die neueren und höchst scharfsinnigen einschlägigen Studien zu den postaxialen Religionen von John Hicks: An Interpretation of Religion, London 1989 (bes. S. 246-249) und Wolfgang Leidhold: Gottes Gegenwart. Zur Logik der religiösen Erfahrung, Darmstadt 2008 (bes. S. 28-35). Vgl. auch: Wilfred Cantwell Smith: The Meaning and End of Religion, New York 1964, der den historisch belasteten Religionsbegriff ablehnt und das personale Moment der Transzendenzerfahrung terminologisch als Ausdruck der "human religiousness“ verstanden wissen will (ebd., S. 175f.).

69 William James: Varieties of Religious Experience, London 1902, S. 499. 
William James' Theorie der multiplen Realitäten formuliert er seine eigene Theorie der symbolischen Appräsentation (ein Terminus Husserls) jener transzendenten finiten Sinnbereiche jenseits der kompakten Urrealität (,paramount reality“) der alltäglichen Lebenswelt, welche im Transzendenzerlebnis (,experience of trancendence“) allein erschlossen werden. Symbolische Appräsentation einer höheren Ordnung einerseits und das aktuelle Hier und Jetzt der Alltagswelt andererseits durchdringen sich wechselseitig in der Erfahrung der gemeinsamen sozio-kulturellen Welt, wobei erstere in der Gestaltung der pragmatischen Handlungssphäre wirksam werden. Im Transzendenzerlebnis konstituiert sich eine Mehrzahl von Sinnbereichen (Religion, Wissenschaft, Dichtung, Mythos), doch der hier entscheidende Punkt ist, dass Schütz die Sozialwelt, d.h. die Gesellschaft selbst, als symbolische Appräsentation in der Transzendenzerfahrung konstituiert in Gestalt eines „,cosmion illuminated from within“, wie Schütz unter Bezug auf Eric Voegelins Analysen es nennt. In ihrem Selbstverständnis erlebt sich die politische Gesellschaft als der ,representative of something beyond itself, of a transcending reality ${ }^{670}$. Somit deckt sich das Muster der Transzendenzerfahrung, das konstitutiv für die Sinnprovinz oder Welt des Politischen ist, mit der symbolischen Appräsentation von Gesellschaft. In diesem Sinn reformulieren die Schütz-Schüler Luckman und Berger das Problem der sozialen Realität: „Symbolic universes [...] integrate different provinces of meaning and encompass the institutional order in a symbolic totality." ${ }^{71}$ „The symbolic universe shelters the individual from ultimate terror by bestowing ultimate legitimation upon the protective structures of the institutional order.“72

Das Zusammenspiel von Transzendenzerfahrung und gesellschaftlicher Symbolisierung bestimmt Form und Struktur des religiös-politischen Komplexes, in dem das religiös-politische Dispositiv analytisch zu verorten ist, wie an den weiterführenden Überlegungen Luckmanns und Voegelins zu zeigen sein wird.

Luckmann verfeinert und verdeutlicht den symboltheoretischen Ansatz in seinen neueren Arbeiten. Er nennt die symbolische Konstruktion gesellschaftlicher Realität insgesamt einen grundsätzlichen religiösen Vorgang.

70 Ebd., S. 355; vgl. Eric Voegelin: The New Science of Politics, Chicago 1952, S. 54.

71 Peter L. Berger/Thomas Luckmann: The Social Construction of Reality, Garden City 1966, S. 95.

72 Ebd., S. 101. 
So spricht er von der „gesamten Sinnstruktur einer Gesellschaft, deren historische Kultur, die den Einzelnen in einer ihn transzendierenden geschichtlich-gesellschaftlichen Welt verortet ${ }^{673}$. Auf das spezifisch religiöse Moment des religiös-politischen Komplexes zielt die These vom „religiösen Kern einer gesamtgesellschaftlichen Sinnkonfiguration, der aus der Konstruktion einer , anderen“ Wirklichkeit besteht“. Sie „baut auf zwei Schichten kommunikativer Vorgänge auf, in denen subjektive Erfahrungen von Transzendenz erstens intersubjektiv rekonstruiert und zweitens gesellschaftlich bearbeitet werden“. Die politischen Implikationen solcher ,gesellschaftlicher Systematisierungen intersubjektiver Rekonstruktionen subjektiver Transzendenzerfahrungen“" werden deutlich im Spannungsverhältnis zwischen der alltäglichen und der, anderen' Wirklichkeit innerhalb der gesellschaftlichen Ordnung, die machtpragmatisch ein Deutungsmonopol beansprucht und somit dazu tendiert, ,die Normen, die das allägliche Handeln der Gesellschaftsmitglieder leiten und der Aufrechterhaltung der gesellschaftlichen Ordnung dienen, an die Bedeutungen und Werte einer übergeordneten, die gesellschaftliche Ordnung legitimierenden ,anderen ${ }^{6}$ Wirklichkeit anzubinden." ${ }^{\text {77 }}$

Luckmanns paradigmatische Analyse der „religiösen Grundfunktion“ erstreckt sich in gleicher Weise - wenn auch eher beiläufig - auf den westlichen Fall moderner symbolischer Konstruktion gesellschaftlicher Sinngebung, denn - wie er ausführt - die traditionell religiösen Orientierungen, welche von der institutionalisierten Religion der Kirchen (den Sachwaltern der großen ,Transzendenzen') repräsentiert wurden,

„,sind im modernen Bewusstsein von solchen überschattet, die sich ausschließlich auf diesseitige Transzendenzen verschiedenen Niveaus beziehen: die Nation, das Volk, die gesellschaftlichen Klassen bzw. deren Überwindung, die Individuen, das alter ego (,Gemeinschaft $\left.{ }^{\dagger}\right)$ und das sakralisierte, weitgehend selbstgenügsame Ich. “75

„Religion in the modern world“, schreibt Luckmann an anderer Stelle, ,represents an extraordinary amalgam of old and new social forms of

73 Hier wie im Folgenden: Thomas Luckmann: Privatisierung und Individualisierung. Zur Sozialform der Religion in spätindustriellen Gesellschaften, in: Karl Gabriel (Hrsg.): Religiöse Individualisierung oder Säkularisierung. Biographie und Gruppe als Bezugspunkte moderner Religiosität, Opladen 1996, S. 17-28, hier: S. 22.

74 Ebd., S. 23.

75 Ebd., S. 27. 
religion; the incorporation of religious functions by political movements; civil religions of modern states; fervent socialisms and nationalisms in modernizing states and similar self-declared secular entities." ${ }^{\text {“76 }}$

Luckmanns Explikation eines enttheologisierten Religionsbegriffs bestimmt letztlich die konkrete und in ihrer Unmittelbarkeit primär ,a-politische" personale Religiosität oder Spiritualität als den Kristallisationskern der für die symbolische Generierung von symbolischen Sinnkonfigurationen und Ordnungsinterpretationen konstitutiven Transzendenzerfahrungen.

Eine solche der philosophischen Anthropologie verpflichtete Interpretation lieferte bereits Voegelin in seiner frühen Untersuchung der religiös-spirituellen Grundmotive, aus denen sich die Symbolformen der Sakralisierung von Seinswirklichkeiten speist. Ihr existentieller Grund sind „die Erregungen, die dem Zustand der Kreatürlichkeit entspringen“, sie

„können stimmungsmäßig verschieden gefärbt sein durch Angst, Hoffnung, Verzweiflung, Seligkeit, anschauende Ruhe, suchende Unruhe, Empörung, Auflehnung, Erhebung etc. Der Reichtum an Schattierungen [...] entfaltet sich auf einer einzigen Dimension des religiösen Erlebnisses, an den Erregungen der Kreatürlichkeit. Er wird vervielfacht durch die Mannigfaltigkeit der Arten des Seins, in denen die Erregung sich erfüllt und erlöst. In allen Richtungen, in denen die menschliche Existenz zur Welt hin offen ist, kann das umgebende Jenseits gesucht und gefunden werden: im Leib und im Geist, im Menschen und in der Gemeinschaft, in der Natur, in Gott. Die große Anzahl der grundsätzlichen Möglichkeiten und die unendliche der geschichtlich-konkreten, die sich hier auftut, verbindet sich mit den Versuchen der Selbstdeutung, mit allen Missverständnissen und Kampfverzerrungen zu einer unendlichen Fülle an Erlebnissen, ihren Rationalisierungen und Systembildungen. “77

Aus dieser Grundstruktur des religiösen Erlebnisses erklärt sich, dass „wo immer ein Wirkliches im religiösen Erlebnis sich als ein Heiliges zu erkennen gibt, [...] es zum allerwirklichsten, zum Realissimum“ wird. „Diese Grundwandlung vom Natürlichen zum Göttlichen hat zur Folge eine sakrale und wertmäßige Rekristallisation der Wirklichkeit um das als göttlich Erkannte." Deren symbolische Artikulation verfestigt sich zu Systemen und

76 Thomas Luckmann: The New and the Old in Religion, in: Pierre Bourdieu/ James Samuel Coleman (Hrsg.): Social Theory for a Changing Society, Boulder 1991, S. 167-182, hier: S. 170.

77 Hier wie im Folgenden: Voegelin, Die politischen Religionen, 1939, S. 16-18. 
diese „füllen sich mit dem Geist der religiösen Erregung und werden fanatisch als die richtige Ordnung des Seins verteidigt“.

Damit kommt die Religiosität oder - allgemeiner - Spiritualität konkreter Personen als der primäre Quellgrund ursprünglicher sinnstiftender Ordnungserfahrungen in den Blick, die als der Ausgangspunkt von gesellschaftlich wirksamen Ordnungssymboliken identifiziert werden können. Voegelin bezog diese Analyse zuvörderst auf die moderne Transzendenzproblematik, wollte sie aber verstanden wissen im Sinne eines historisch und interzivilisatorischen Konstruktionsprinzips des politisch-religiösen Komplexes.

Universalgeschichtlich gesehen verdankt der politisch-religiöse Komplex seine Entstehung und Permanenz in Inhalt und Form den ,großen Transzendenzen', die sich, wie bereits angemerkt, symbolisch in den geistigen Umbrüchen der Achsenzeit artikulieren und in der Unterscheidung zwischen mundaner und transzendenter Lebenssphäre jene fundamentalen Ordnungskonfigurationen bedingen, welche die mundanen Wirklichkeiten von Mensch und Gesellschaft analog zu den transzendenten Visionen politisch-kulturell durchformen. Die Symboliken der ,großen Transzendenzen' des Konfuzianismus, Buddhismus, Hinduismus, Judaismus, Christentum und Islam etablierten sich nicht zuletzt durch ihre jeweilige Allianz mit der politischen Macht und gewannen dadurch jene soziokulturelle Stabilität, der sie ihre dynamische Gestaltungskraft im historischen Prozess schulden. Unter dem Horizont der gesellschaftlichen Präsenz der ,großen Transzendenzen“ öffnete sich das geschichtliche Feld für eine Vielzahl von derivativen Transzendenzaufbrüchen und, dem folgend, von transzendent begründeten Ordnungskomplexen sowie ein Spielraum für wechselnde Sakralisierungen der in der menschlichen Erfahrungswelt präsenten Seinstatsachen. Hierauf beruhen die sakralen und werthaltigen Rekristallisationen der Wirklichkeiten um das als transzendent Erkannte, die sich aus geschichtlich vorgegebenen Symbolbeständen bedienen und diese situationsbedingt auslegen. Die achsenzeitlichen Symboliken erheben jeweils universale Geltungsansprüche auf ihre Wahrheit, die in den post-axialen politisch-religiösen Komplexen handlungsleitend wirksam werden.

Gleichsam paradigmatisch wirkte fortan der historische Prototyp einer mythospekulativen Extrapolation der geschichtlichen Emergenz der großen Ordnungssymboliken auf ihren Transzendenz verbürgenden Ursprung hin 
in Gestalt großer Stifterfiguren von repräsentativer Menschlichkeit: Konfuzius, Buddha, Moses, Solon. Der historiogenetische Rückbezug auf die mythischen Gründer-Legislatoren als authentische Schöpfer vermittelt der, mit ihrer Personalität verknüpften, Entstehung von kanonisierten Leittexten und Textkompilationen ihre spezifische ordnungsstiftende Autorität. Sie ist den Texten eingeschrieben, deren Normativität wiederum auf dem verpflichtenden, Wahrheitsanspruch ' beruht, welcher im Leben und Werk der Stifter der Ordnung zum Ausdruck kommt.

Das Prinzip einer historiogenetischen Rekonstruktion des Ordnungsursprungs wurde zum prägenden Element im architektonischen Gefüge autoritativer Symbolformen normativer Ordnungsbegründung und unverzichtbare Bedingung für die herrschaftslegitimierende Funktion des religiös-kulturellen Dispositivs. Die Reihe archetypischen Stifterfiguren setzt sich bis in die Gegenwart fort: Die Römer setzten ihre Ordnung in Bezug zu Romulus und schließlich Äneas, die christlichen und islamischen Ordnungen werden durch Christus und Mohammed legitimiert, die postaxialen Sakralmonarchien kennen unterschiedliche mytho-spekulativ autorisierte Begründer ihrer jeweiligen Herrschaft. Exemplarisch für die Moderne ist der weltgeschichtlich definierte Geltungsanspruch der revolutionären Neugründung eines novus ordo seclorum der amerikanischen Republik, der in der politischen Existenz der Gründungsväter unmittelbaren Ausdruck fand. Der symbolische Geltungsanspruch der kommunistischen Imperien legitimierte sich durch die Verknüpfung der revolutionären Gründung des Reiches durch Lenin mit der normativen Autorität der kanonischen Texte von Marx und Engels.

Symbolstrategisch involviert dies die Explikation eines geschichtlichen Anfangspunktes, der sich in einem Gründungsmythos niederschlägt und das religiös-kulturelle Dispositiv im kollektiven Gedächtnis der Gesellschaft fundiert. „Im kollektiven Gedächtnis [wird] faktische Geschichte in erinnerte und damit in Mythos transformiert. “78 "Mythos ist eine fundierende Geschichte, eine Geschichte, die erzählt wird, um eine Gegenwart vom Ursprung her zu erhellen.“

Das entscheidende hierbei ist jedoch, dass die geschichtliche Kontingenz eines jeden gesellschaftlichen Anfangs sich tendenziell als unverfügbar in einem sakral konnotierten essentiellen Sinn erweist. „Durch die

78 Hier wie im Folgenden: Jan Assmann: Das kulturelle Gedächtnis. Schrift, Erinnerung und politische Identität in frühen Hochkulturen, München 1992, S. 52. 
Erinnerung wird Geschichte zum Mythos. Dadurch wird sie nicht unwirklich, sondern im Gegenteil erst Wirklichkeit im Sinn einer fortdauernden normativen und formativen Kraft", aus der das religiöspolitische Dispositiv seine ordnungspolitische Gestaltungsmacht bezieht.

Im Politischen resultiert hieraus ein permanenter Spannungszustand von Konflikt und Konsens im machtgestützten Ringen um die symbolische Deutungshoheit und die stets prekäre Legitimität der Herrschaft nach innen und nach außen, die Gefahr läuft, in kritischen Momenten der Erosion des symbolischen Dispositivs auch machtpragmatisch zu scheitern.

Herrschaftslegitimierende autoritative Symbolformen der normativen Ordnungsbegründung bedürfen der gesellschaftlichen Fundierung und dies führt zur speziellen gesellschaftlichen Binnenproblematik politischer Symbolisierungen. Deren Verankerung in den Denk- und Verhaltensmustern der politischen Kultur ist bedingt durch die normativen Vorgaben der in der politischen Deutungskultur verbindlich artikulierten Normen. Unter diesem Gesichtspunkt sind die politischen Deutungskulturen einer Gesellschaft mehr oder weniger ausdifferenzierte Handlungssphären, in denen sich die für eine politische Kultur konstitutive symbolische Repräsentation des Ganzen artikuliert und sich die kollektive Identitätsbildung vollzieht. Als Handlungssphäre manifestiert sich die Deutungskultur in Gestalt von institutionalisierten Trägergruppen und den von diesen verantworteten Medien und Organisationsformen von Speicherung, Überlieferung und Zirkulation kulturellen Sinns, wobei sich zwischen institutionell abgesicherten Inhabern eines Deutungsmonopols und einer oligopolistisch verfassten politischen Deutungskultur unterscheiden lässt.

Der in den bisherigen Ausführungen vorgestellte moderne heuristisch ausgewiesene Transzendenz- und Symbolbegriff zielt auf eine Rekonzeptionalisierung des religiös-politischen Komplexes. Damit ist jene kategoriale Unterscheidung zwischen religiösen und säkularen Symbolordnungen vermieden, welche Epochen übergreifende und interkulturell konzipierte vergleichende Strukturanalysen sozio-politischer Ordnungszusammenhänge erschweren. ${ }^{79}$

79 Vgl. hierzu: Mathias Hildebrandt/Manfred Brocker: Der Begriff der Religion: interdisziplinäre Perspektiven, in: dies. (Hrsg.): Der Begriff der Religion. Interdisziplinäre Perspektiven, Wiesbaden 2008, S. 9-29, hier: S. $24 f$. 


\section{Paradigmenwechsel V: SAKRALISIERUNG IN DER MOdernen PolitiK}

Der fundamentale geschichtliche Umbruch des menschlichen Selbst- und Ordnungsverständnisses rekonfiguriert die traditionell eingeschliffenen symbolischen Appräsentationen von gesellschaftlicher Ordnung und die sie fundierenden Transzendenzauslegungen in den christlich geprägten Kulturen des Westens und diesen folgend in der globalen Ökumene.

Es emergieren moderne politisch-religiöse Komplexe sui generis, die einmal spezifische Momente des historischen symbolischen Kosmos aktivieren, zum andern aber den sinnstiftenden transzendenten Ordnungsgrund in resakralisierten Wirklichkeiten finden, welche im religiöskulturellen Dispositiv funktional wirksam werden.

Modern sind die spezifischen Konstruktionsprinzipien der Ordnungssymboliken, in der Sache selbst aber, das gilt es zu betonen, gab es historisch gesehen stets eine durchaus flexible Formensprache des Transzendenten und einer entsprechenden politisch-kulturellen Sakralisierung von Herrschern, Dynastien, Institutionen, Gemeinschaften oder Orten. Der Theologe Graf spricht davon, dass ,viele moderne Theophanien [...] religionshistorisch uralten Modellen von Apotheose" folgen und diagnostiziert kritisch ,[d]ie Expansion des divinalsemantischen Universums“ und eine wachsende „Theodiversität“, die sich insbesondere auch in der Sakralisierung gesellschaftlicher und politischer Sachverhalte dokumentieren. ${ }^{80}$

Wie bereits dargelegt, ist die Transformation traditioneller Religiosität und deren institutioneller Ordnungen ein zentrales Moment in der Entstehung der modernen politischen Religiosität. Auf diesen Sachverhalt hatte schon Reinhard Wittram in seiner Untersuchung des Wechselspiels von Säkularisierung und Sakralisierung der Nation hingewiesen. Er sprach von einem ,riesenhaften Einschmelzungsprozess, in dem das alte christliche Weltbild Stück für Stück verweltlicht, in eine neue Idealität umgewandelt wurde ${ }^{\text {(81 }}$. In seiner Einleitung zu einer Sammlung älterer Studien verdeutlicht er, dass das Problem der Sakralisierung von Politik, Gesellschaft und

80 Friedrich Wilhelm Graf: Missbrauchte Götter. Zum Menschenbilderstreit in der Moderne, München 2009, S. 45 und S. 54.

81 Reinhard Wittram: Nationalismus und Säkularisierung. Beiträge zur Geschichte und Problematik des Nationalgeistes, Lüneburg 1949, S. 10f. 
Geschichte seinerzeit schon präzise begriffen wurde: An die Stelle Kirche als Repräsentant des Sakralen treten

„konkurrierende Größen wie Volk, Nation, Vaterland, Menschheit oder Persönlichkeit [...]. Das Heilige verlagert sich im Beginn der Neuzeit auf eine dieser Größen und besetzt damit im psychischen Haushalt der Zeitgenossen frühere Sacra [...]. Auch hier werden die im Phänomen der Säkularisation liegende Ambivalenz von Verweltlichung des Religiösen und Sakralisierung des Weltlichen sichtbar. ${ }^{\text {(82 }}$

Im Stiftungsakt der französischen Soziologie verdichten sich diese Elemente zur wissenschaftlich legitimierten Idee der , sakralen Gesellschaft', die in Durkheims Reinterpretation der Religion als Ausdruck der Selbsttranszendenz des Individuums in der divinisierten nationalen Gesellschaft als Garant einer ewigen Moral kumulierte. ${ }^{83}$ Durkheims religionspolitische Doktrin zieht die Konsequenz aus den kultischen Experimenten der Französischen Revolution und transformiert diese in das politisch-kulturelle Dispositiv einer durch den Begriff des Laizismus definierten Symbolordnung der französischen Republik. Deren Ziel ist die Erziehung zu einem republikanischen Patriotismus, ,d.h. zur Heiligung Frankreichs und seiner Gesellschaft als eines die Individuen transzendierenden Wesens", denn „die moralische Einheit des republikanischen Frankreich offenbart sich auch in der Einheit seiner Geschichte und ihrer Bewegung auf das Heute hin ${ }^{\text {c84 }}$.

Insofern dies den spezifischen Fall der Sakralisierung der politischsozialen Sphäre bedeutet, erscheinen gesellschaftliche Kollektive nunmehr als Subjekt eines heilsgeschichtlichen Prozesses, der die christliche Geschichtsdeutung im Sinne einer innerweltlichen Vervollkommnung von Mensch und Gesellschaft in einem zukünftigen Zivilisationsparadies verzeitigt. ${ }^{85}$ Exemplarisch sei Friedrich Engels' heilsgeschichtliches Programm

82 Heinz-Horst Schrey: Einleitung, in: ders. (Hrsg.): Säkularisierung, Darmstadt 1981, S. 1-48, hier: S. 6 und S. 9; vgl. Jürgen Gebhardt: Nationale Identität und nationale Ideologie, in: Zeitschrift für Politik 32 (1985) 3, S. 237-250.

83 Émile Durkheim: Formes élémentaires de la vie religieuse, Paris 1912.

84 Horst Firsching: Die Sakralisierung der Gesellschaft. Emile Durkheims Soziologie der ,Moral' und der ,Religion' in der ideenpolitischen Auseinandersetzung der Dritten Republik, in: Volkhard Krech/Hartmann Tyrell (Hrsg.): Religionssoziologie um 1900, Würzburg 1995, S. 159-193, hier: S. 138.

85 Jürgen Gebhardt: Messianische Politik und ideologische Massenbewegung, in: Joachim H. Knoll/Julius Hans Schoeps/Wolfgang Schirmacher (Hrsg.): Von kommenden Zeiten. Geschichtsprophetien im 19. und 20. Jahrhundert, Stuttgart 
angeführt: „Beide, Christentum und Arbeitersozialismus, predigen eine bevorstehende Erlösung aus Knechtschaft und Elend; das Christenthum setzt diese Erlösung in ein jenseitiges Leben nach dem Tod in den Himmel, der Sozialismus in diese Welt, in eine Umgestaltung der Gesellschaft. “ ${ }^{\star 86}$

Tendenziell arbeitet auch die sakralisierte Politik mit einem transzendent definierten Erlösungsglauben in einer jenseitigen geschichtlichen Zukunft. Die semantisch-symbolische Fernwirkung dieser Eschatologien zeigt sich in der heute allgegenwärtigen Idee Hegels, dass „der Geist der Welt“ sein allerhöchstes Recht, ,in der Weltgeschichte als Weltgericht ausübt ${ }^{\text {“87 }}$. Nicht mehr Gott fällt am Ende der Zeiten den Richterspruch über Recht und Unrecht, sondern die Weltgeschichte, auf die sich nunmehr jede politische Instanz in ihrem absoluten Urteil berufen darf. Ein anderes Beispiel liefert der Unsterblichkeitsglauben in der resakralisierten Gemeinschaft, der besagt, ,dass wie wir das Schaffen großer Männer und ganzer Völker fortwirken sehen von Geschlecht zu Geschlecht [...] in der großen Kette der Geschichte, dass darum keine unserer Taten verloren geht ${ }^{\text {“88 }}$.

Eric Voegelin prägte in seinen Politischen Religionen für diese Modalität des Religiös-Politischen den heute geläufigen Begriff der ,politischen Religion', in dem er den konventionellen Religionsbegriff differenzierte und ,überweltliche Religionen` von ,innerweltlichen Religionen“ unterschied, die das Göttliche in Teilinhalten der Welt finden. Artikuliert sich die innerweltliche Religiosität in Gestalt der Vergöttlichung des sozialen Kollektivs, wie in den paradigmatischen Fall der Totalitarismen (Nationalsozialismus und Kommunismus) des 20. Jahrhunderts, dann handele es sich um eine politische Religion. Voegelin selbst hat diese Begriffsbildung später sehr kritisch gesehen, da er nicht seine Analyse, wohl aber den Begriff der Religion selbst aus Gründen, die bereits diskutiert wurden, für theoretisch wenig tragfähig hielt. ${ }^{89}$ Solche kritischen Zweifel sind wohl

1984, S. 40-59; ders.: Political Eschatology and Soteriological Nationalism, in: Athanasios Moulakis (Hrsg.): The Promise of History. Essays in Political Philosophy, Berlin 1986, S. 51-68.

86 Friedrich Engels: Zur Geschichte des Urchristentums, in: Die Neue Zeit 13 (1894/95) 1, S. 4-13, hier: S. 4.

87 Georg Wilhelm Friedrich Hegel: Grundlinien der Philosophie des Rechts, hrsg. von Johannes Hoffmeister, Hamburg 1955, S. 288.

88 Heinrich von Treitschke: Freiheit, Einheit, Völkergemeinschaft. Eine Auswahl aus Reden und Schriften, München/Wien/Zürich 1953, S. 56.

89 Voegelin, Politische Religionen, 1939; Jürgen Gebhardt: Was heißt totalitär?, in: Totalitarismus und Demokratie 1 (2004) 2, S. 167-182; Jean-Pierre Sironneau: 
auch für Gentiles Begriff der Sakralisierung der Politik zu bedenken, wenn er von der „religion of politics“ oder „secular religion“ spricht und diese auf alle modernen religiös-politischen Strukturverhältnisse bezieht, die nicht durch die traditionelle Religion und ihre jeweils spezifische Beziehungen zur politischen Sphäre bestimmt sind. ${ }^{90}$ Bedenken sind weniger gegen Gentiles Begriff der „political religion“ angebracht als gegen die Verallgemeinerung seiner These von der Sakralisierung der Politik. Gentile bezieht das Prinzip der Sakralisierung der Politik sowohl auf die politische Religion totalitärer Regime und auf die Zivilreligion in demokratischen Regimen, denn ,the possibility that civil and political religions have

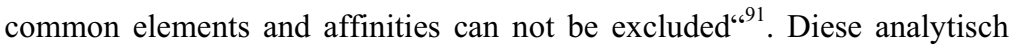
und empirisch nicht ausgewiesene These ist wenig überzeugend, denn das jeweilige herrschaftslegitimierende religiös-kulturelle Dispositiv differiert in essentieller und nicht in gradueller Hinsicht.

Gentiles Versuch einer Typisierung des modernen religiös-politischen Komplexes ist unbefriedigend, zeigt aber die Notwendigkeit einer solchen Typisierung der Vielgestaltigkeit symbolisch-politischer Ordnungsformen in der westlichen Zivilisationswelt, auf die sich die folgenden zusammenfassenden und unzulässig knappen Bemerkungen konzentrieren, die den globalen Kontext äquivalenter Erscheinungsformen des religiös-politischen Komplexes in der nichtwestlichen Welt vernachlässigen.

Erstens, die Respiritualisierung und Divinisierung innerweltlicher Kollektive (Nation, Rasse, klasse, Menschheit) mit der sinnstiftenden Rückbindung an das Absolutum eines innerweltlichen zukünftigen innerweltlichen Heilszustandes ist in der Tat ein der Moderne eigentümliches religiös-politisches Phänomen des Westens mit globalen Implikationen. In seiner starken Form kennzeichnet es die totalitäre Politik, in seiner schwachen Form die integralen Nationalismen, wozu auch die positivistisch fundierte Laïcité Frankreichs in der III. Republik gerechnet werden kann ${ }^{92}$

Sécularisation et religions politiques, Paris 1982; Jacob Leib Talmon: Political Messianism, New York 1980; ders.: The Myth of the Nation and the Vision of Revolution, New York 1981. Einen Überblick über den Stand der Diskussion liefert Hans Maier (Hrsg.): Totalitarismus und politische Religionen, 3 Bde., Paderborn 1994-2003; vgl. auch: Barry Cooper: New Political Religions, Or an Analysis of Modern Terrorism, Columbia 2004.

90 Emilio Gentile: Politics as Religion, Princeton 2006, S. XIV.

91 Ebd., S. 140.

92 Bernhard Plé: Säkularismus als Religion?, in: Mathias Hildebrandt/Manfred Brocker/Hartmut Behr (Hrsg.): Säkularisierung und Resakralisierung in west- 
ebenso wie der positivistisch inspirierte Kemalismus in der türkischen Republik.

Zweitens, modern ist auch die durch die konstitutionellen Revolutionen generierte Ordnungssymbolik einer variantenreichen transkonfessionellen meta-physischen Verortung des Legitimitätsglaubens in Gestalt einer religiös-politisch fundierten normativen Verfassungsordnung, die ihre symbolisch-politische Begründung aus der Idee einer übergeordneten transzendenten lex aeterna gewinnt. Die USA repräsentieren gleichsam den Prototypus dieses Ordnungsparadigmas für die zahlreichen derivativen Realisierungen dieses Modells in der atlantischen politischen Kultur einschließlich der konstitutionellen ordnungspolitischen Neuanfänge in den post-kommunistischen Regimen. ${ }^{93}$ Historisch ist hier der Bezug auf einen bürgerzentrierten Politikbegriff stärker ausgebildet als in den etatistisch geprägten Gesellschaften Europas. Es handelt sich konzeptionell um eine ,politische Metaphysik der Bürgerschaft' (Lüthy), ein Sachverhalt, der seit Bellah ${ }^{94}$ mit Rückgriff auf Rousseau als Zivilreligion oder Bürgerreligion beschrieben wird. Ihr sind

„exklusiv diejenigen Symbole, symbolischen Handlungen, rituellen und freien Bekundungen, Normen und freien Gewohnheiten zugeordnet, durch die innerhalb des politischen Systems öffentlich ein Sinnbezug zu prinzipiellen nicht disponiblen Voraussetzungen seiner eigenen Existenz hergestellt wird, und durch die darüber hinaus der Grund bekannt und anerkannt wird, der uns normativ festlegen lässt, was prinzipiell menschlicher Dispositionsfreiheit entzogen werden soll.“95

lichen Gesellschaften. Ideengeschichtliche und theoretische Perspektiven, Wiesbaden 2001, S. 97-116; Claude Nicolet: L'idée républicaine en France, Paris 1982.

93 Vgl. hierzu: Jürgen Gebhardt: Americanism. Revolutionary Order and Societal Self-Interpretation in the American Republic, Baton Rouge 1993.

94 Bellah, Civil Religion in America, 1967.

95 Hermann Lübbe: Staat und Zivilreligion. Ein Aspekt politischer Legitimität, in: Norbert Achterberg/Werner Krawietz (Hrsg.): Legitimation des modernen Staates, Wiesbaden 1981, S. 40-64, hier: S. 56; Heinz Kleger/Alois Müller (Hrsg.): Religion des Bürgers. Zivilreligion in den USA und Europa, Münster 2004; Jürgen Gebhardt: Politische Kultur und Zivilreligion, in: Dirk BergSchlosser/Jakob Schissler (Hrsg.): Politische Kultur in Deutschland, Opladen 1987, S. 49-60. Ich sehe von der Frage ab, ob im Anschluss an Bellah ,Zivilreligion" als generalisierter Begriff strukturanalytisch auf alle geschichtlichen politisch-kulturellen Ordnungssymboliken anwendbar ist. Diese Frage muss andernorts diskutiert werden. Vgl. hierzu: Ronald Weed/John von Heyking 
Drittens, eine moderne Form des frühneuzeitlichen Konfessionsstaates bestimmt insbesondere noch das 19. und 20. Jahrhundert dort, wo der Ordnungsgrund unmittelbar bezogen ist auf spezifische überkommene Symbolbestände der institutionalisierten Religiosität, wobei es sich in der Regel um rekonfigurierte politisch-religiöse Arrangements handelt, indem hier gleichfalls integral nationalistische Symboliken einfließen. Dies gilt für europäische Fälle wie Spanien oder Irland und das moderne Israel. Bemerkenswert in diesem Zusammenhang ist der Fall des postkommunistischen Russland: Er dokumentiert eine politisch-religiöse Involution in Gestalt der tendenziellen Rückkehr zur vorrevolutionären Allianz von Kirche und Regime. Das von seiner Entstehung allein machtpragmatisch konstruierte und daher symbolpolitisch instabile plebiszitär-autoritäre Herrschaftssystem versichert sich eines herrschaftslegitimierenden religiöspolitischen Dispositivs im Rückgriff auf das orthodoxe Christentum. Diese symbol-politische Wende erlaubt der politischen Deutungskultur die unmittelbare Rückbindung an die imperiale Tradition des Zarenreiches, das sich als Erbin des Imperiums von Byzanz verstand und Moskau zum ,dritten Rom' ausgerufen hatte.

Viertens aber und unter globalen Gesichtspunkten von entscheidender Bedeutung ist der emergente moderne Typus des religiös-politischen Komplexes in den ost- und südostasiatischen Gesellschaften. Hier bilden sich zivilisationsspezifische Formen des religiös-kulturellen Dispositivs heraus, die geschichtliche Symboltraditionen mit indigenisierten Ordnungskonzeptionen aus dem modernen Ideenbestand verschmelzen, wie sich paradigmatisch am japanischen Fall zeigen lässt ebenso wie an dem Ringen um eine religiös-kulturell begründete politische Form in der islamischen Welt. Dies bleibt einer weitergehenden Untersuchung vorbehalten, die hier nicht geleistet werden kann.

\section{SCHLUSSBEMERKUNG}

Ausgangspunkt der Überlegungen war der eingangs knapp umrissene Begriff des religiös-kulturellen Dispositivs, dem diese abschließenden Bemerkungen gelten sollen.

(Hrsg.): Civil Religion in Political Thought. Its Perennial Questions and Enduring Relevance in North America, Washington 2010. 
Erstens liegt der Argumentation die Hypothese zu Grunde, dass alle geschichtlichen Konfigurationen von symbolischer Selbstdeutung und gesellschaftlichen Ordnungsformen in langfristig stabilen politisch organisierten Gesellschaften für ihren Legitimitätsglauben auf das politisch-kulturelle, religiös konnotierte Dispositiv angewiesen sind.

Zweitens drückt sich in diesem Dispositiv das wie immer geartete für die individuelle und kommunitäre Existenz des Menschen konstitutive Spannungsverhältnis von seinsgebundener Bedingtheit und Transzendenzoffenheit für Erfahrungen eines letzten Unbedingten aus, in der - theoretisch formuliert - der vielfältig symbolisierte noumenale Grund einer universalen Humanität des Menschseins aufscheint, ungeachtet der Tatsache, dass die im reflexiven Begriff der Humanität manifeste Dimension des Geistes und der Freiheit sich nur bedingt in den Symbolordnungen reproduziert, nicht zuletzt aufgrund der ihnen inhärenten Tendenz zur sakralen Kontraktion des sozio-symbolischen Kosmos nach innen und nach außen.

Die Erfahrungskonstellationen von Immanenz und Transzendenz, auf die hier Bezug genommen wird, zielt drittens auf die umfassende empirische Realität einer Existentialerfahrung, die sich in der Spannung von Zeit und Ewigkeit, Tod und Leben, Mangel und Fülle, Unheil und Heil und Unordnung und Ordnung artikuliert und sich in den symbolischen Selbstdeutungen der Menschheit und deren politischen Ordnungsformen auf eine historisch vielfältige Weise widerspiegelt.

Viertens, wie immer im einzelnen sich in der Modernität die gesellschaftliche Symbolisierung des politisch-religiösen Strukturverhältnis darstellt, ist es einerseits wie alles Geschichtliche den kontingenten Bedingungen der condicio humana unterworfen, andererseits aber authentische Manifestation der geistigen Existenz des Menschen in der jeweils besonderen historischen Gestalt, welche die Modalität des Politischen und das diese konstituierende religiös-kulturelle Dispositiv auch annimmt. 



\title{
Macht und Autorität
}

\section{Das Problem der (Un)Verfügbarkeit}

\author{
PiER PAOLO PORTINARO
}

\section{MACHT UND AUTORITÄT}

Die Literatur zu Macht, Herrschaft, Gewalt und Autorität ist im Laufe des 20. Jahrhunderts stetig gewachsen - man kann aber wirklich nicht sagen, dass der Konsens über den inhaltlichen Gehalt dieser Begriffe größer geworden sei. Im Gegenteil: Eine beachtliche Polarisierung der Phänomenbeschreibungen und Deutungsprogramme hat stattgefunden. Der Aufwand an Differenzierungen in der neuesten Literatur fällt auf. Aber es wird immer noch danach gefragt, was wir darunter verstehen. Viele bedeutende Autoren - Max Weber, Elias Canetti, Hannah Arendt, Bertrand de Jouvenel, Michel Foucault, Pierre Bourdieu, Heinrich Popitz - haben sich mit diesem Fragenkomplex auseinandergesetzt. Die Begriffe bleiben dennoch in ihrem semantischen Fundament enigmatisch. ${ }^{1}$ Die Abgrenzung von

1 Byung-Chul Han: Was ist Macht?, Stuttgart 2005, S. 7: „Hinsichtlich des Machtbegriffs herrscht immer noch ein theoretisches Chaos. Der Selbstverständlichkeit des Phänomens steht eine totale Unklarheit des Begriffs gegenüber. Für den einen bedeutet sie Unterdrückung. Für den anderen ist sie ein konstruktives Element der Kommunikation. Die juristische, die politische und die soziologische Vorstellung von der Macht stehen einander unversöhnt gegenüber. Die Macht wird bald mit der Freiheit, bald mit dem Zwang in Verbindung gebracht. Für die einen beruht die Macht auf dem gemeinsamen Handeln. Für die anderen steht sie mit dem Kampf in Beziehung. Die einen grenzen die Macht von der Gewalt scharf ab. Für die anderen ist die Gewalt nichts anderes als eine intensivierte Form der Macht. Die Macht wird bald mit dem Recht, bald mit der Willkür assoziiert." Und: David Strecker: Logik der Macht. Zum Ort der Kritik zwischen Theorie und Praxis, Weilerswist 2012, S. 
Macht, Herrschaft, Gewalt und Autorität scheint immer noch kontrovers zu sein.

Die Begriffsgeschichte bringt auch in diesem Fall, wie so oft bei den semantischen Grundsteinen des politischen Multiversums, wenig Licht ins Dunkel, selbst wenn wir darauf verzichten, das ganze Umfeld zu untersuchen, um eine Strategie der Komplexitätsreduzierung $\mathrm{zu}$ verfolgen (zumindest wird das Problem der Gewalt hier im Hintergrund bleiben). Kratos und Arke, Potestas und Auctoritas, Imperium und Dominium gehören zum Reservoir der Begriffe, die sich über die Jahrhunderte hinweg als beständig ausgewiesen und dennoch chamäleonartig verwandelt haben. Über das Rätsel der Macht gibt vielleicht am eindrucksvollsten Lukrez in De rerum natura Auskunft, als er die Macht (imperium) als ein Ding beschreibt, das in sich leer ist und sich nicht ergreifen lässt: „imperium quod inane est, nec datur umquam. “2

Allgemein versteht man unter Macht das Vermögen, eine Wirkung zu erzielen. Das Verstehen der Macht in Kategorien der Kausalität geht auf die Ursprünge des politischen Denkens zurück. Dieser Begriff der Macht lässt sich auf den aristotelischen Begriff der dynamis zurückführen, der das Vermögen eines Seienden zur Veränderung eines anderen Seienden bezeichnet. ${ }^{3}$ Aber in Kontinuität zu dieser ehrwürdigen Tradition definiert sich Macht auch in der Soziologie als ,Wirkungsvermögen in sozialen Beziehungen“4 . „Macht‘ in einem anthropologischen Sinn meint etwas, was der Mensch vermag: das Vermögen, sich gegen fremde Kräfte durchzusetzen. ${ }^{\text {"5 }}$ Bekanntlich definiert Max Weber Macht als ,,jede Chance, innerhalb einer sozialen Beziehung den eigenen Willen auch gegen Wider-

15, mit Schmitt'schem Akzent: „Macht ist ein umkämpfter Begriff, weil er ein Kampfbegriff ist, der in unseren Sprachspielen eine politisch-polemische Funktion ausübt."

2 Lukrez: De rerum natura, III, 998-1002. Zur Bedeutung dieser Stelle bei Lukrez vgl. Luciano Canfora: La natura del potere, Roma-Bari 2009, S. 12.

3 Vgl. Han, Was ist Macht?, 2005, S. $11 \mathrm{ff}$. Ein Beispiel eines solchen Konzepts findet sich bei Hans Albert: Macht und Gesetz. Grundprobleme der Politik und der Ökonomik, Tübingen 2012.

4 Es ist „die Kanonisierung des Machtbegriffs als des Vermögens, seinen Willen in sozialen Konfliktbeziehungen zu verwirklichen, die den Ausgangspunkt sozialwissenschaftlicher Machtanalysen bildet", so Strecker, Logik der Macht, 2012, S. 23 (Hervorhebung PPP).

5 Heinrich Popitz: Phänomene der Macht, Tübingen 1992, S. 22. 
streben durchzusetzen, gleichviel worauf diese Chance beruht" ${ }^{\text {“6 }}$. Laut dieser Definition ist also Macht prinzipiell Durchsetzungsmacht. Durchsetzungsmacht ist dennoch zunächst Handlungsmacht: Die „Macht über“ (als Herrschaft über Andere, potestas oder imperium, aber auch als Herrschaft über Dinge, dominium) setzt immer die „Macht zu“ (als Vermögen zum Handeln, potentia) voraus. ${ }^{7}$ Das Ursache-Wirkung-Schema schließt übrigens die Intentionalität nicht aus. Nur wer Intentionen hat, kann über Macht verfügen.

Die Weber'sche ist nicht die einzig mögliche Definition der Macht. Man unterscheidet oft, nach einer treffenden Formulierung von Gerhard Göhler, transitive und intransitive Macht. Transitive Macht ist - ganz weberianisch - Durchsetzungsmacht, eine „Macht, die den eigenen Willen auf andere überträgt und auf diese Weise Einfluss nimmt“. Also auch: „Verfügungsgewalt“‘8. Das deutsche Wort „Gewalt“ geht auf den indogermanischen Wortstamm val und auf das Verb giwaltan/waldan zurück, das primär „Verfügungsfähigkeit über etwas besitzen“ heißt. ${ }^{9}$ Die Verfügungsgewalt hat immer eine subjektive und eine objektive Seite: Subjektiv in dem Sinne, dass der Machtinhaber über bestimmte Qualitäten (in der Antike oder im Mittelalter über die quasi-magische Kraft des Königsheils,

6 Max Weber: Wirtschaft und Gesellschaft. Grundriß der Sozialökonomik, Tübingen 1972, S. 28. Hauptsächlich auf der Form der Durchsetzungsmacht basiert für Weber jede Autoritätsbeziehung. Autorität heißt für ihn „ein unabhängig von allen Interessen bestehendes Recht auf Gehorsam gegenüber den tatsächlich Beherrschten“" (ebd., S. 542).

7 Diese Unterscheidung ist schon bei Hobbes deutlich formuliert in der Entgegenstellung von Macht und Autorität. Vgl. Thomas Hobbes: Leviathan oder Stoff, Form und Gewalt eines kirchlichen und bürgerlichen Staates, hrsg. von Iring Fetscher, Frankfurt a.M. 1984, S. 123 (Hervorhebung im Original): „Und wie man das Recht auf Besitz Herrschaft (Dominion) nennt, so nennt man das Recht auf irgendeine Handlung Autorität (Authority). "Vgl. Gerhard Göhler: Macht, in: ders./ Matthias Iser/Ina Kerner (Hrsg.): Politische Theorie. 22 umkämpfte Begriffe zur Einführung, Wiesbaden 2004, S. 257-258 sowie Strecker, Logik der Macht, 2012, S. $17 \mathrm{ff}$.

8 Albrecht Koschorke: Macht und Fiktion, in: Thomas Frank u.a. (Hrsg.): Des Kaisers neue Kleider. Über das Imaginäre politischer Herrschaft. Texte, Bilder, Lektüren, Frankfurt a.M. 2002, S. 73-84, hier: S. 73: „Nichts, denkt man, ist realer als Macht. Wer sie ausübt, besitzt faktische Verfügungsgewalt über andere. Wer sie erleidet, hat noch weniger Grund, ihre Wirklichkeit zu bezweifeln."

9 Jacob Grimm/Wilhelm Grimm: Deutsches Wörterbuch, Bd. 6, München 1984, Sp. 4910. 
in der Moderne über technisches Wissen und mediale Führungskompetenz) verfügt, objektiv in dem Sinne, dass er über äußere Ressourcen (Männer, Land, Waffen, Geld) verfügt. Intransitive Macht dagegen ist eine Macht, die im Zusammenhandeln der Akteure besteht und ,in sich selbst, in der Gesellschaft erzeugt und aufrechterhalten wird “10.

Dem intransitiven Machtbegriff ist die Qualifikation der Verfügungsgewalt eher fremd. Intransitive Machttheorien sind bekanntlich aus der Kritik der ökonomischen und der juridischen Machtanalyse (komplementär aber auch antipodisch bei Hannah Arendt und Michel Foucault) hervorgegangen. ${ }^{11}$ Wenn wir mit Hobbes Autorität als ,das Recht auf irgendeine Handlung" definieren, dann lässt sich auch Hannah Arendts Definition der Macht davon herleiten: denn Macht entsteht aus einer Pluralität von Autoren, die in erster Instanz als Menschenrechtsträger handeln. Macht ist für sie die Fähigkeit zum kollektiven Handeln, zum acting in concert. Aber als Medium des Sozialen, als Konstitutionsraum von interpersonalen Verhältnissen ist Macht auch für Foucault ein allgemeines Konstitutionsprinzip. ${ }^{12}$ Für ihn ist Macht der Oberbegriff für sozio-politische Kräfte-

10 Göhler, Macht, 2004, S. 258. Diese Definition basiert eben auf Formulierungen der klassischen Machttheorie, die am besten in der Theorie Hobbes und in der meist zitierten Definition Max Webers auf den Begriff gebracht wird. Vgl. José Antonio Marina: Die Passion der Macht. Theorie und Praxis der Herrschaft, Basel 2011.

11 Vgl. Michel Foucault: In Verteidigung der Gesellschaft. Vorlesungen am Collège de France (1975-76), Frankfurt a.M. 2001, S. 31. Dort wird die These vertreten, ,dass die Macht nicht gegeben wird, dass sie weder getauscht noch zurückgewonnen werden kann, sondern dass sie ausgeübt wird und nur im Vollzug existiert“. Ebenso: Hannah Arendt: Macht und Gewalt, München 1970, S. 45: ,Macht entspricht der menschlichen Fähigkeit, nicht nur zu handeln oder etwas $\mathrm{zu}$ tun, sondern sich mit anderen zusammenzuschließen und im Einvernehmen mit ihnen zu handeln. Über Macht verfügt niemals ein Einzelner; sie ist im Besitz einer Gruppe und bleibt nur solange existent, als die Gruppe zusammenhält.“ Antipodisch sind diese Konzeptionen insoweit, da Foucault Macht „,in Kategorien wie Kampf, Konflikt oder Krieg“" analysiert und Arendt eher in Kategorien des Einvernehmens und der Verständigung. An diesen Arendt'schen Machtbegriff knüpft bekanntlich Habermas an. Vgl. Jürgen Habermas: Hannah Arendts Begriff der Macht [1976], in: ders.: Philosophischpolitische Profile, Frankfurt a.M. 1987, S. 228-248.

12 Martin Saar: Macht und Kritik, in: Rainer Forst u.a. (Hrsg.): Sozialphilosophie und Kritik, Frankfurt a.M. 2009, S. 567-587: „Die philosophische Frage nach der Macht ist in erster Linie eine Frage nach der Effektivität und in zweiter Linie eine Frage nach der Legitimität von Wirkungskräften.“ (ebd., S. 571) „Steht auf der einen Seite ein Verständnis von Macht als Herrschaft, steht auf 
verhältnisse, „der Name, den man einer komplexen strategischen Situation in einer Gesellschaft gibt"13.

An diesem intransitiven Machtbegriff orientiert sich bekanntlich die gegenwärtige Politikauffassung immer mehr: Nicht nur, dass der transitive Machtbegriff viel zu eng in einer repressiven Konzeption der Macht verwickelt bleibt; der intransitive erweist sich als ein tauglicheres Instrument, um den verschiedenen Abstufungen der Kontrollmacht und die Phänomene der Subjektivierung der Herrschaft und der Vernetzung der Machtverhältnisse zu begegnen. Er ermöglicht auch, das Verhältnis von Macht und Autorität nicht nur als prinzipiellen Gegensatz, sondern auch als relative Differenz zu konzeptualisieren. Und Herrschaft, Macht und Autorität in dieser Verknüpfung sind immer noch Protagonisten in der heutigen Diskussion über das Politische. ${ }^{14}$

In seiner Analyse der anthropologischen Grundformen der Macht unterscheidet der Soziologe Heinrich Popitz vier Typen, die auf ,vitale Abhängigkeiten und konstitutive Handlungsfähigkeiten des Menschen“ zurückzuführen sind: die Aktionsmacht, die in der physischen, körperlichen, aggressiven Kraft, in der Fähigkeit zu verletzen innewohnt; die instrumentelle Macht, deren Voraussetzung die „für die Betroffenen glaubhafte Verfügung über Strafen und Belohnungen“ ist, und deren Ausdrucksform die des Drohens und Versprechens ist; die autoritative Macht, die „einwilligende Folgebereitschaft erzeugt“, indem sie die Einstellungen, die Perspektiven und die Kriterien der Betroffenen steuert; die datensetzende Macht, die Macht der Technik, die ermöglicht, über Menschen durch die Vermittlung von Artefakten zu herrschen. ${ }^{15}$ Diese Unterscheidungen des

der anderen ein Konzept von Macht als Konstitution; geht es im einen Fall um Durchsetzung und Unterwerfung von Willen, geht es im anderen um die Entfesselung und Kanalisierung von vielfältigen Kräften.“ (ebd., S. 575)

13 Michel Foucault: Der Wille zum Wissen. Sexualität und Wahrheit, Frankfurt a.M. 1976, S. 114.

14 Vgl. Christoph Lau: Subjektivierung von Macht - Diffusion von Herrschaft. Zum Formwandel von Herrschaft in der Zweiten Moderne, in: Wolfgang Bonß/Christoph Lau (Hrsg.): Macht und Herrschaft in der reflexiven Moderne, Weilerswist 2011, S. 48-66.

15 Popitz, Phänomene der Macht, 1992, S. 32-33: „Die Wurzeln sozialer Macht liegen in der Entsprechung vitaler Abhängigkeiten und konstitutiver Handlungsfähigkeiten des Menschen. Vitale Abhängigkeiten: seine Verletzbarkeit, seine Sorge um die Zukunft, seine Maßstabs- und Anerkennungsbedürftigkeit, seine Angewiesenheit auf Artefakte. Konstitutive Handlungsfähigkeiten: die Fähigkeit 
Machtbegriffs helfen uns auf dem Weg zu einer Präzisierung der Fragestellung.

Aller Macht liegt die Bewegung zur innerweltlichen Transzendierung in verstärkter Form zugrunde, die Fähigkeit zum Weltverändern ist für sie konstitutiv. Diese Transzendierung macht vor keiner Lebenserscheinung und vor keiner körperlichen Integrität halt. Als Aktionsmacht kennt die Macht also keine Unverfügbarkeit: „Verletzungskraft, verletzende Aktionsmacht hat der Mensch gegenüber allen Organismen, auch gegenüber anderen Menschen. ${ }^{\prime 16} \mathrm{Am}$ anderen Pol erweist sich jedoch die autoritative Macht als Hüterin der Unverfügbarkeit der angeborenen Menschenwürde, der körperlichen Integrität, der ökonomischen Subsistenz, der gesellschaftlichen Teilhabe, letztendlich der Grundrechte. Beide Seiten gehören zum Machtkomplex und zu seiner Lebensdynamik.

Autorität hat immer mit dem Vermögen zu tun, die Zustimmung anderer zu gewinnen. Sie baut auf dem Prinzip der Zwangsökonomisierung auf. „Der Rat, der auctoritas hat, ist kein Befehl, aber wirkt so, als ob er ein Befehl wäre. “17 Wo Autorität vorhanden ist, reduziert sich konsequenterweise die Wahrscheinlichkeit der Gewaltanwendung in innenstaatlichen Beziehungen auf ein Minimum. Anders als die Macht entzieht sich Autorität grundsätzlich der Verrechtlichung. „Im Gegensatz zu der durch Recht oder Amt verliehenen oder mit Gewalt behaupteten potestas ist die auctoritas ein Phänomen, das sich zunächst jeder rechtlichen oder institutionellen Sicherung entzieht. ${ }^{\text {“18 }}$ Der auctor ist ursprünglich der Gründer oder der Schöpfer einer neuen Gemeinschaft, der Förderer einer Tradition und der Mehrer einer Identität. ${ }^{19}$ Jemandes auctor sein heißt im antiken

zur verletzenden Aktion, die Fähigkeit, Angst und Hoffnungen zu erzeugen, die Fähigkeit, Maßstäbe zu setzen, die Fähigkeit zum technischen Handeln.“

16 Ebd., S. 24 (Hervorhebung im Original).

17 Theodor Eschenburg: Über Autorität, Frankfurt a.M. 1965, S. 10 (Hervorhebung PPP). Vgl. Christoph Lundgreen: Regelkonflikte in der römischen Republik. Geltung und Gewichtung von Normen in politischen Entscheidungsprozessen, Stuttgart 2011.

18 Eschenburg, Über Autorität, 1965, S. 29 (Hervorhebung PPP). Auch Giorgio Agamben (Ausnahmezustand, Frankfurt a.M. 2004, S. 91, Hervorhebung PPP) meint: auctoritas ist weniger die freiwillige Ausübung eines Rechts als vielmehr „das Sich-Verwirklichen einer unpersönlichen Macht in eben der Person der auctor".

19 Bertrand de Jouvenel: Über Souveränität. Auf der Suche nach dem Gemeinwohl, Neuwied/Berlin 1963, S. 48: „Der auctor ist der Vater in Freiheit began- 
Rom auch „,beraten“. Auctoritas wird vom römischen Recht mit der Fähigkeit gleichgesetzt, mit maßgeblichem Rat zur Ordnungsgestaltung der Gesellschaft aktiv beizutragen. ${ }^{20}$ Autoritätsbindungen sind Alltagsphänomene. Eine besondere Bedeutung kommt aber für unsere Betrachtung der politischen Autorität zu. ,Politische Autorität ist Amtsautorität, aber mit ihr verbunden ist die Vorstellung der Autoritätsverpflichtung, des amtsgemäßen, des amtswürdigen Verhaltens im Dienst und im privaten Leben." ${ }^{21}$ Mit der Einführung des Amtsbegriffs beginnt die Konstruktion der Unverfügbarkeit im Bereich des Politischen. Das Amt ist etwas, über das

gener Handlungen, deren Ursprung bei ihm liegt, deren Vollbringer aber andere sind."

20 Die auctoritas maiorum war in Rom ,der moralisch-politische Maßstab schlechthin“. So Hannah Arendt: Was ist Autorität?, in: dies.: Zwischen Vergangenheit und Zukunft. Übungen im politischen Denken I, München 1994, S. 159-200, hier: S. 190. Auctoritas war die Herrschaftsweise des Senats, potestas die der Magistratur, der Senato hatte keine Vollzugsgewalt, nur consilium.

21 Eschenburg, Über Autorität, 1965, S. 108. „Das Amt hat die persönliche Autorität des Amtsträgers nötig, um mehr zu sein als ,Bürokratie', das Amt als honor verleiht aber auch Ansehen und wird so in gleicher Weise wie virtus, ingenium usw. zu einem Grund der auctoritas." (ebd., S. 32, Hervorhebung PPP) Zum Amtsbegriff vgl. noch Wilhelm Hennis: Amtsgedanke und Demokratiebegriff, in: ders.: Politikwissenschaft und politisches Denken. Politikwissenschaftliche Abhandlungen II, Tübingen 2000, S. 127-147, hier: S. 132: „Wo das Amt im Mittelpunkt des politischen Denkens steht, ist die entscheidende legitimierende Basis der Amtsinnehabung, das Band, das den Amtsinhaber mit demjenigen, der ihn in das Amt berufen hat, verbindet, nicht eine identitäre Willensrelation, sondern das Vertrauen." Das Amt ist der institutionelle Ort der Verkörperung des sozialen Ganzen durch eine Person: vgl. Koschorke, Macht und Fiktion, 2002, S. 79 (Hervorhebung im Original): „Als Bindeglied zwischen Körper und Körperschaft erfüllt das Amt nicht bloß eine neutrale Funktion, sondern bietet den Schauplatz einer Verwandlung von geradezu magischer Qualität. Je höher das Amt, desto größer ist diese magische Wirkung, die das gewöhnliche Erscheinungsbild des Amtsinhabers in einem übernatürlichen Glanz aufstrahlen lässt. Im Amt durchdringt sich die Welt der empirischen Körper mit der Sphäre der sozialen Transzendenz, die ihrem Wesen nach unsichtbar ist. Das Amt kleidet den Körper des Herrschers, so wie dieser seinerseits das Amt bekleidet. Das Amt macht seinen Inhaber zum Vertreter der Körperschaft. Es schafft eine institutionelle und symbolische Verbindung zwischen der natürlichen Person und der persona ficta des Kollektivs." Ausgangspunkt der neueren Literatur zum Thema sind die scharfsinnigen Analysen von Kantorowicz über die Trennung der Krone vom König als Inhaber des Königsamts: vgl. Ernst H. Kantorowicz: Die zwei Körper des Königs. Eine Studie zur politischen Theologie des Mittelalters, Stuttgart 1992, S. 377. 
der Amtsinhaber nicht verfügen kann. Gleichzeitig gilt auch, dass der Amtsinhaber jemand ist, über den andere, mit Macht dotierte Akteure, nicht beliebig verfügen können.

Auch zur Klärung des Begriffs Autorität hat die Soziologie mehrfach beigetragen, indem sie klassische Entgegenstellungen wie die von potestas und auctoritas, oder von persönlicher und amtlicher Autorität immer wieder relativiert und neu definiert hat. Für eine soziologische Betrachtung sind solche klare Grenzstellungen nicht leicht nachvollziehbar. Nach Simmel sprechen wir von Autorität, wenn eine Person ein Vertrauen erwirbt, „das den Charakter einer objektiven Instanz trägt ${ }^{\text {‘22 }}$. Man unterscheidet oft zwischen persönlicher und institutioneller Autorität; aber selbst die persönliche Autorität (wenn man von den Beziehungen in den Primärgruppen absieht) ist immer auf die Ausübung eines Amtes bezogen: „die Persönlichkeit hat eine prärogative und axiomatische Zuverlässigkeit für ihre Entscheidungen gewonnen, die über den immer variablen, relativen, der Kritik unterworfenen Wert einer subjektiven Persönlichkeit mindestens um einen Teilstrich hinausragt. “23 Macht ist an erster Stelle Verfügungsmacht. Autorität geht über diese Qualifikation deutlich hinaus. Bertrand de Jouvenel stellte in seiner klassischen Analyse des Phänomens fest: ,wenn alle Menschen immer nur disponieren, gäbe es keine Gesellschaft. Die Gesellschaft besteht nur darum, weil der Mensch auch die Fähigkeit besitzt, zu proponieren und durch seine Vorschläge die Verfügungen der anderen zu beeinflussen. “24

Autorität galt im alten Rom als Ergebnis eines kumulativen Anerkennungsprozess (augēre heißt allgemein vermehren, zunehmen, wachsen lassen - diese Bedeutung schließt die Akkumulation der Erkenntnisse, des Wissens aber auch der Anerkennung und der Zustimmung ein). Und das gilt immer noch. Wer Autorität hat, verfügt über einen Mehrwert an

22 Georg Simmel: Soziologie. Untersuchungen über die Formen der Vergesellschaftung, hrsg. von Otthein Rammstedt, Frankfurt a.M. 1992, S. 162. Vgl. auch: Eschenburg, Über Autorität, 1965, S. 31: „die auctoritas erhält ihre Wirkungskraft nicht wie die potestas von einer höheren Instanz verliehen, sondern hat ihren Grund in sich selbst: in Anlagen und Fähigkeiten, die andere Menschen zu ihrer Anerkennung als auctoritas führen.“

23 Simmel, Soziologie, 1992, S. 162.

24 Jouvenel, Über Souveränität, 1963, S. 49-50. Zur Unterscheidung zwischen gefestigter und aufsteigender Autorität vgl. ders.: Reine Theorie der Politik, Neuwied/Berlin 1967, S. 129-135. 
Anerkennung. Und die Sanktionsfähigkeit einer Autorität, also z.B. auch für uns, im demokratischen Zeitalter, eines Verfassungsgerichts, liegt in der Verweigerung der sozialen Anerkennung. Wer die Alternative zwischen erhofften Anerkennungen und befürchteten Anerkennungsentzügen ,einsetzen kann und bewusst einsetzt, um Verhalten und Einstellung anderer zu

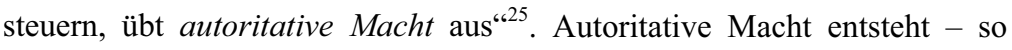
argumentiert nochmals Popitz - aus der Anerkennungsbedürftigkeit und aus der Anerkennungsfixiertheit sozialer Akteure. Gleichwohl entsteht sie aus ihrer Orientierungslosigkeit: sie ist immer auch Deutungsmacht, deren Voraussetzung die Tatsache ist, dass menschliche Taten, Intentionen und Motivationen strukturell immer „vielversional“ sind. Ihre Entscheidungen beruhen infolgedessen auf Interpretationen.

Und nochmals: Kennzeichnen der Autorität nach Hannah Arendt

,ist die fraglose Anerkennung seitens derer, denen Gehorsam abverlangt wird; sie bedarf weder des Zwanges noch der Überredung [...] Autorität bedarf zu ihrer Erhaltung und Sicherung des Respekts entweder vor der Person oder dem Amt. Ihr gefährlichster Gegner ist nicht Feindschaft sondern Verachtung, und was sie am sichersten unterminiert, ist das Lachen. “26

Eine besondere Aura gewinnt die Autorität dadurch, dass sie immer aus der Anerkennung einer Sphäre der unverfügbaren Rechte von Gruppen oder Individuen (manchmal auch nur bestimmter Individuen) hervorgeht und damit auch ihre eigene Unverfügbarkeit begründet. Mit diesen Ausführungen zum Verhältnis von Macht und Autorität ist das begriffliche Umfeld allgemein umrissen.

25 Popitz, Phänomene der Macht, 1992, S. 29 (Hervorhebung im Original). Vgl. Jan-Philipp Reemtsma: Vertrauen und Gewalt. Versuch über eine besondere Konstellation der Moderne, Hamburg 2009, S. 101-184.

26 Arendt, Macht und Gewalt, 1970, S. 46-47. Dazu die Ausführungen - auch in diesem Fall nur mit Vorsicht zu genießen - von Agamben, Ausnahmezustand, 2004, S. 88ff. Gegen den juristischen Begriff potestas wird hier auctoritas biopolitisch interpretiert (ebd., S. 98). 


\section{Die KONSTRUKTION UNEINGESCHRÄNKTER VERFÜGUNGSMACHT}

Die Verfügungsmacht der Herrschenden ist den Gesetzen der Natur und der Geschichte unterstellt. Die Erfahrung ihrer Beschränktheit stellt eine Konstante des menschlichen Erlebens dar. Anthropologisch betrachtet, liegt eine Grenze der Macht in der Verwundbarkeit des Körpers: die physischen Kapazitäten auch des Machtmenschen bleiben deshalb immer beschränkt. Aber auch ananke und tyche, Notwendigkeit und Kontingenz, setzen untranszendierbare Grenzen des handelnden Subjekts. Unverfügbarkeit über historische Verläufe - dies ist ein klassisches Thema des politischen Realismus. Von dieser Herausforderung ausgehend arbeitet die frühneuzeitliche Staatstheorie mit ihrem Hauptbegriff ,Souveränität“ dennoch an der Konstruktion einer uneingeschränkten Verfügungsmacht. In ihrem Drang nach unbegrenzter Verfügbarkeit der Welt glaubt die Moderne auf diesem Weg einen festen Boden zu gewinnen, der sich indes als unverfügbar darstellen soll.

Unbestreitbar ist der Souveränitätsbegriff der Kern der Machttheorie des modernen Staates. ${ }^{27}$ Maiestas est summa in cives ac subditos legibusque soluta potestas, so definiert Bodin die höchste Gewalt. Unter diesem Begriff versteht die klassische Lehre ,die tatsächliche Fähigkeit einer Herrschaftseinheit, auf ihrem Gebiet regelmäßig jeden ihre Existenz bedrohenden Willensakt selbstständig zu brechen“ ${ }^{\text {28 }}$. Diese Fähigkeit impliziert die (wie auch immer begründete) Berechtigung, sich die äußere Welt verfügbar zu machen. Was die Macht eines Souveräns auszeichnet, ist zunächst seine Verfügung über das Leben und die Ressourcen der Untertanen. Zur materiellen Verfassung der souveränen Macht gehören Land und Leute. Im Patrimonialismus werden Untertanen hauptsächlich als Habe des Machtinhabers betrachtet.

Die Geschichte der Staatsmacht ist oft als Geschichte der Steigerung und Maximierung ihres Durchsetzungspotentials dargestellt worden: Dabei

27 Vgl. Foucault, In Verteidigung der Gesellschaft, 2001, S. 40: „Die Theorie des Rechts hat seit dem Mittelalter im wesentlichen die Funktion, über die Legitimität der Macht zu bestimmen: das Haupt- und Zentralproblem, um das herum sich die gesamte Theorie des Rechts organisiert, ist das Problem der Souveränität.“

28 Hermann Heller: Staat [1931], in: ders.: Gesammelte Schriften, Bd. 3: Staatslehre als politische Wissenschaft, Tübingen 1992, S. 3-23, hier: S. 21. 
geht es hauptsächlich um das Verfügbar-Machen der sozialen Welt. Vertikale Hierarchisierung und Intensivierung der Herrschaftsdynamik gehören $\mathrm{zu}$ ihren unverzichtbaren Attributen. Die Errichtung eines wirksamen Finanzmonopols und die Rationalisierung des Steuereintreibens führen in der Neuzeit zu einer Intensivierung der Verfügungsgewalt über Eigentum und Marktgüter (und aus diesem intensivierten Druck lässt sich natürlich das steigende Sicherheitsbedürfnis und die Frage nach Eigentumsschutz erklären). Mit der Verstaatlichung des Krieges und der daraus folgenden Vermehrung der militärischen Kräfte verstärkt sich auch die Verfügungsmacht des Staates über die Bevölkerung. ${ }^{29}$

Entscheidend für die Stabilität der Herrschaft ist aber auch die Akkumulation von symbolischem Kapital. Die Dreieinigkeit von Autorität, Tradition und Religion, die für die altrömische Gesellschaft und Politik prägend war, hört in der Neuzeit auf, ein krisenfestes Paradigma darzustellen. ${ }^{30}$ Es mag daher sein, dass im Zeitalter der zentralistischen Staaten die absoluten Monarchen - das hat z.B. Theodor Eschenburg unterstrichen eher Souveränität als Autorität für sich in Anspruch nahmen. „Die Worte Souveränität und Autorität decken einander nicht; es gibt nur eine Souveränität im Staat, jedoch vor allem nach damaliger Vorstellung, abgestufte politische Autoritäten. “31 Dennoch wird immer, wie in früheren Epochen, nicht nur auf die technischen, sondern auch auf die symbolischen Dispositive der Machtakkumulation Rücksicht genommen. Die Sakralisierung der Macht dient immer noch zur Abwehr des stets drohenden Machtverfalls. ${ }^{32}$

29 Bertrand de Jouvenel: Über die Staatsgewalt. Die Naturgeschichte ihres Wachstums, Freiburg i.B. 1972. Zur Frage nach der Herrschaftsintensität des Absolutismus nun Johann Baptist Müller: Herrschaftsintensität und politische Ordnung, Berlin 1986, S. 16ff.

30 Hannah Arendt: Über die Revolution, München 1974, S. 259 (Hervorhebung im Original): „Dass Autorität, Tradition und Religion - Begriffe, die alle so alt sind wie Römertum überhaupt - der Sache, wenn auch nicht dem Inhalt nach zusammenfallen können, weil sie alle drei aus der gleichen Quelle hervorgehen, der Gründung der Stadt, das war und blieb von Anfang bis Ende der Rückhalt römischer Geschichte [...] Auf Grund der auctoritas waren Dauer und Wandel miteinander verbunden."

31 Eschenburg, Über Autorität, 1965, S. 116.

32 Friedrich Balke: Figuren der Souveränität, Paderborn 2009, S. 300ff. Er thematisiert (in Anlehnung an Kantorowicz) die Mutation der Lehre von den zwei Körpern des Königs im Übergang zu den neuzeitlichen Souveränitäts- 
Souveränität ist, laut der bekannten Definition Carl Schmitts, die Entscheidung über den Ausnahmezustand. ${ }^{33}$ Der Souverän, der im Ausnahmefall entscheidet, hat eine absolute Macht, die jede positive Rechtsnorm suspendieren kann: indem er über ihre Geltung entscheidet, verfügt er über die Rechtsordnung. Oder, um die gelungene, juristisch präzise, synthetische Formulierung von Martin Kriele zu verwenden: „Der Souverän besitzt die ungeteilte, unbedingte, unbeschränkte Macht, Recht zu schaffen, zu ändern und $z u$ durchbrechen. “34 Souveränität wird also zum Inbegriff der Durchsetzungsmacht. Befürworter und Kritiker des Begriffs begegnen sich in der Hervorhebung dieser Merkmale. Auch der heutige en vogue befindliche biopolitische Ansatz kann trotz aller Umwertungen auf den Begriff nicht verzichten. „Der Ausnahmezustand als Rechtsinstitut im Verfügungsbereich der Regierungskunst (Michel Foucault) bezeichnet die höchstmöglich konzentrierte Form von Souveränität. ${ }^{\text {(35 }}$

Die souveräne Macht verfügt über die soziale Welt. Als solche ist aber auch sie unverfügbar. Die Unverfügbarkeit der persona publica des Herrschaftsinhabers, der lebendes Gesetz und lebende Gerechtigkeit ist, gehört eigentlich zu den Dogmen politisch-apologetischer Literatur aller Zeiten. In der Neuzeit erfährt dieser Zug freilich eine beachtliche Transformation, bleibt aber eine unverzichtbare Komponente der Staatstheorie. Alle Rationalisierungsbestrebungen des monozentrischen großflächigen Fürstenstaates dienen eigentlich dazu, diese Unverfügbarkeit zu untermauern. Die frühneuzeitliche Entpolitisierung - die „Verwandlung des Bürgers in den

theorien, die den politischen Körper vollständig denaturalisieren und dem kontingenten Prozess der Institutionalisierung überantworten.

33 Carl Schmitt: Politische Theologie. Vier Kapitel zur Lehre von der Souveränität [1922], Berlin 1979, S. 11.

34 Martin Kriele: Einführung in die Staatslehre. Die geistesgeschichtlichen Legitimitätsgrundlagen des demokratischen Verfassungsstaats, Reinbek bei Hamburg 1975, S. 59 (Hervorhebung im Original). Und ausführlicher: „1. Der Souverän kann unbeschränkt über das Recht verfügen. [...] 2. Der Souverän kann das Recht durchbrechen. [...] 3. Der Souverän kann jede Kompetenz jederzeit an sich ziehen. Er hat damit die Gewalt ungeteilt in seiner Hand. [...] 4. Die Souveränität des Souveräns gilt unbedingt, unwiderruflich und zeitlich unbeschränkt. [...] 5. Die Souveränität des Souveräns gilt inhaltlich unbeschränkt.“ (ebd., S. 57-58)

35 Matthias Lemke: Das Alter Ego der Souveränität. Zur Begründung von Normsuspendierungen im Ausnahmezustand, in: Samuel Salzborn/Rüdiger Voigt (Hrsg.): Souveränität. Theoretische und ideengeschichtliche Reflexionen, Stuttgart 2010, S. 83-102, hier: S. 83 (Hervorhebung im Original). 
Untertan“636 - ist ein deutliches Zeichen dieser institutionellen und symbolischen Konstruktion. Der Gesetzesbefehl des Monarchen „kann nicht bezweifelt, verhandelt, revidiert werden, sondern schafft im Akt seiner Bekundung eine für die Untertanen unumstößliche und letztgültige Realität ${ }^{\star 37}$. Keine andere Konstruktion der politischen Theorie als die Sozialvertragslehre von Thomas Hobbes macht es deutlich, wie selbst die Konstituierung der politischen Macht durch gegenseitige Verpflichtung unwiderruflich sei. Dieser Theorie zufolge ist die souveräne Macht, auf die sich die Rechtsordnung gründet, ihrerseits den Gesetzen nicht unterworfen.

Unverfügbar ist aber nun an erster Stelle nicht so sehr die Person des Herrschenden, sondern eher das überpersönliche Geflecht der Institutionen und das Produkt seiner Entscheidungsprozesse. Nicht jede Machtausübung ist institutionell geformt. Zu dem Souveränitätsdenken der Moderne gehört dagegen die utopische Vorstellung einer totalen institutionellen mise en form der Macht. Schon bei Hobbes war die Macht des Souveräns nichts anderes als eine Macht der Unterwerfung unter eine souveräne - und auch schon von ihm rechtlich verstandene - Ordnung. In der Theorie der Souveränität findet diese Erkenntnis in reifer Form ihren Ausdruck, dass Herrschaft ,institutionalisierte Macht“ ist. Im Prozess der Institutionalisierung lassen sich drei Tendenzen zusammenfügen: die Entpersonalisierung der Machtverhältnisse, ihre Formalisierung (immer stärkere Orientierung an Regeln, Verfahrensweisen, Ritualen) und die Integrierung in eine übergreifende Ordnung („Positionalisierung der Macht“"). ${ }^{38}$

Die Unverfügbarkeit der alten Ordnungen und Verfassungen seitens der kontingenten Herrschaftsinhaber ist andererseits ein klassisches Thema der

36 Herfried Münkler: Im Namen des Staates. Die Begründung der Staatsraison in der Frühen Neuzeit, Frankfurt a.M. 1987, S. 148ff. „In diesem Sinne ist die Theorie der Staatsraison das öffentliche Zeichen für die politische Entmachtung der Bürger, für die Verlagerung der Politik aus der Sphäre ihrer subjektiven Entscheidungen in die vorgeblich objektiver Belange des Staates.“ (ebd., S. 150)

37 Albrecht Koschorke u.a.: Der fiktive Staat. Konstruktionen des politischen Körpers in der Geschichte Europas, Frankfurt a.M. 2007, S. 113. Die Kopplung von juristischer Unverfügbarkeit und physischer Verfügbarkeitsmacht wird hier thematisiert: „Vom Souverän der politischen Theorie des Absolutismus zum Tyrannen ist es nur ein kleiner Schritt. Jederzeit kann eine rechtlich ungebundene Herrschaft in Unrecht umschlagen; jederzeit kann die Person des Herrschers, in der die Machtfülle des Staates sich manifestiert und einen individuellen Körper erhält, in ihrer physischen Natur entfesselt werden." (S. 115)

38 Popitz, Phänomene der Macht, 1992, S. 233ff. 
herrschaftskritischen politischen Theorien. In seiner Schrift Franco-Gallia (1573), die als Counterpart zu Jean Bodins Meisterwerk, Les six livres de la République (1576) gelten kann, wird ein Klassiker der Widerstandsrechtslehre wie Franz Hotman nicht müde, in seiner Darstellung der Rechten und der Pflichten der Könige und der Bürger darzulegen, wie „den Königen Frankreichs von ihren Bürgern keine unermessliche und unbegrenzte Macht übertragen worden ist“ und wie sie der grundlegenden Verpflichtung unterzogen waren, ,die Macht der allgemeinen Versammlung unverletzlich und unantastbar zu bewahren “39.

Diese unbeschränkte Macht bleibt unberührt mit dem Übergang von der monarchischen absolutistischen Souveränität, mit ihrem Dogma vom göttlichen Recht der Könige, zu der demokratischen Souveränität der Nation, mit ihrem entsprechenden Dogma vom göttlichen Recht der Völker. ${ }^{40}$ In einigen Formulierungen der klassischen Demokratietheorie sieht es tatsächlich so aus, als sei Volkssouveränität nichts anderes als umgewendete Fürstensouveränität, die im extremen Fall in einen Absolutismus oder Despotismus des Volkes münden kann. Die Staats- und Verfassungstheorie der Französischen Revolution bringt das in einer Vielfalt von Formulierungen eindrucksvoll zum Ausdruck. So schreibt - um ein einziges Beispiel aus dem gemäßigten Lager zu bemühen - der Abbé Sieyès in seiner bekannten Schrift Qu'est-ce-que le Tiers Etat? (1789): „Die Nation ist immer Herrin, ihre Grundverfassung umzugestalten. ${ }^{* 41}$

Wenn in Hinblick auf die klassische Demokratielehre der Aufklärung ein ,überpositiv-rechtliche Privileg der gesellschaftlichen Basis“ postuliert wird, dann geschieht es heute noch im Sinne einer als unverfügbar geltenden Volkssouveränität. Vor kurzem ist abermals hervorgehoben wor-

39 Franz Hotman: Franco-Gallia, in: Jürgen Dennert (Hrsg.): Beza, Brutus, Hotman. Calvinistische Monarchomachen, Köln/Opladen 1968, S. 203-327, hier: S. 303-304.

40 Zur Souveränität der Nation als „Axiom“, also als „kein bewiesenes und beweisbares soziales Phänomen"vgl. noch die klassische Behandlung von Boris Mirkin-Getzewitsch: Die Souveränität der Nation [1936], in: Hans Kurz (Hrsg.): Volkssouveränität und Staatssouveränität, Darmstadt 1979, S. 179-194, hier: S. $190 \mathrm{ff}$.

41 Emmanuel Joseph Sieyes: Was ist der Dritte Stand?, hrsg. von Otto Dann, Essen 1988, S. 87. Immer noch lesenswert dazu: Karl Loewenstein: Volk und Parlament nach der Staatstheorie der französischen Nationalversammlung von 1789. Studien zur Dogmengeschichte der unmittelbaren Volksgesetzgebung [1922], Aalen 1990. 
den, dass ,,in dem engen Zusammenhang zwischen Volkssouveränität und Vollpositivierung des Rechts ein neues Prinzip der Unverfügbarkeit etabliert“" worden ist. ${ }^{42}$ Die Verfassung von 1791 proklamiert: „Die Souveränität ist eine, unteilbar, unveräußerlich und unverjährbar. Sie gehört der Nation." Das wird insbesondere deutlich bei der Lehre des pouvoir constituant. Die verfassunggebende Gewalt ist nicht verfassungsmäßig gebunden und im eigentlichen Sinne souverän. Durch eine Als-ob-Konstruktion (der pouvoir constituant als direkter aber fiktiver Ausdruck der volonté générale) wird Unverfügbarkeit statuiert. Diese Konstruktion hat die Funktion, den Moment der gewaltsamen Usurpation der Staatsgewalt durch den Mächtigen zu verdecken.

Alle diese theoretischen Postulate werden natürlich von den historischen Wirklichkeitswissenschaften regelmäßig relativiert. Die Geschichtsschreibung belehrt uns über die vielfältigen Hindernisse, gegen die diese unbeschränkten Machtansprüche in der Praxis mit beschränkten Erfolgsaussichten zu kämpfen haben. Die Geschichte der neuzeitlichen Staatlichkeit ist von ihrem Anfang von einer komplexen Dialektik von Machtsteigerung, Machterosion und Machtverdrängung durchgedrungen. Die Formalisierung und Positionalisierung der Macht erzeugt ständig Bremsen und Gegengewichte. Und bereits im Zeitalter des (einmal sogenannten) Absolutismus sind wir konfrontiert mit einer spezifischen Paradoxie der Macht. „Es gibt eine Allgegenwart von Mächtigkeitspotentialen bei gleichzeitigem Unsichtbarmachen konkreter Machtbeziehungen. “43

Politische Dynamik reduziert sich auch nicht auf den Antagonismus von Machthabern und Machtunterworfenen. Dazwischen stellt sich immer ein komplexes Gefüge von Machtbeziehungen, die aus der Praxis eines (oder mehrerer) Verwaltungsstabes (oder -stäbe) hervorgehen. Die Dienst-

42 Ingeborg Maus: Über Volkssouveränität. Elemente einer Demokratietheorie, Frankfurt a.M. 2011, S. 125. Bezeichnenderweise zitiert Maus in diesem Kontext ausgerechnet den Abbé Sieyès, wo er die These vertritt, dass „die Verfassung [...] sich nur auf die Regierung bezieht“, während es „lächerlich wäre anzunehmen, die Nation selbst sei durch die Formen oder durch die Verfassung gebunden, denen sie ihre Beauftragten unterstellt hat" (ebd., S. 133134).

43 Karl-Siegbert Rehberg: Institutionen als symbolische Ordnungen. Leitfragen und Grundkategorien zur Theorie und Analyse institutioneller Mechanismen, in: Gerhard Göhler (Hrsg.): Die Eigenart der Institutionen. Zum Profil politischer Institutionentheorie, Baden-Baden 1994, S. 47-84, hier: S. 70. 
leistungen der Verwaltungsstäbe erzeugen zwar den Überschuss an Eigenbedeutung, der den Souverän zu überragender Größe erhebt, beinhalten aber auch eine Kontrollfunktion, die seine Macht einschränkt. Dieses dritte Element (zwischen Machthabern und Machtunterworfenen) verfügt nämlich - historisch in den verschiedensten Formen - über besondere Zugänge zu den Machthabern. ${ }^{44}$ Als Selektionsinstanz der Informationen, die zum Machthaber eindringen, und durch ihre beratende Funktion, eignet sich dieser Stand eine Kontrollmacht an. Besonders in Hinblick auf diese Konstellation, nämlich auf die vielfältigen Abhängigkeiten, die die Machthaber mit der Ausübung ihres Amtes unweigerlich eingehen, ergeben sich folglich beachtliche Einschränkungen der Verfügungsmacht der Herrschenden.

\section{DiE EINSCHRÄNKUNG DER MACHT DURCH UNVERFÜGBARKEIT}

Der moderne Staat ist oft als „Doppelstaat“ beschrieben worden: er ist gleichzeitig, ausgerechnet durch die Verbindung von Macht und Normativität in der Figur der Souveränität, Machtstaat und Rechtsstaat im selben Glied. ${ }^{45}$ Er ist als Machtstaat durch faktische Überlegenheit in existentiellen Konflikten gekennzeichnet. In diesem Gewand agiert er als unverfügbare Gewalt, die über das Ensemble der sozialen Beziehungen verfügt. Der moderne Staat ist aber auch Rechtsstaat. ${ }^{46}$ Als solcher hört er auf, die

44 Das Thema ist bekanntlich aufgezeichnet in Carl Schmitt: Gespräch über die Macht und den Zugang zum Machthaber, Pfullingen 1954. Dazu Ethel Matala de Mazza: Zugänge zum Machthaber. Über Spiegel und andere Medien, in: Rudolf Behrens/Jörn Steigerwald (Hrsg.): Die Macht und das Imaginäre. Eine kulturelle Verwandtschaft in der Literatur zwischen Früher Neuzeit und Moderne, Würzburg 2005, S. 71-87. ,An der Stelle vermeintlicher Stärke legt er eine strukturelle Ohnmacht im Machtzentrum bloß, eine in sich verschobene Relation zwischen Machthabern und heimlichen Machtkontrolleuren, die der Froschperspektive des regierten Volks ebenso verborgen bleibt wie den gebietenden Souveränen selbst.“ (ebd., S. 71-72)

45 Luigi Ferrajoli: La sovranità nel mondo moderno. Nascita e crisi dello Stato nazionale, Milano 1995. Vgl. Walter Pauly/Gunter Heiss: Kritische Skizze zu Staat, Verfassung und Souveränität, in: Salzborn/Voigt (Hrsg.), Souveränität, 2010, S. 149-177.

46 Carl J. Friedrich: Der Verfassungsstaat der Neuzeit, Berlin 1953; Katarina Sobota: Das Prinzip Rechtsstaat. Verfassungs- und verwaltungsrechtliche Aspekte, Tübingen 1997. 
Souveränität als unverfügbar zu betrachten. An der Stelle der Souveränität treten die immer verfügbaren und förmlich verfassten Kompetenzen. Das Pendel der Unverfügbarkeit schlägt nun in eine andere Richtung um.

Die Einschränkung der Macht erfolgt in der Neuzeit bekanntlich dank verfassungstechnischer Arrangements, an erster Stelle dank der Gewaltenteilung. Die Idee der Gewaltenteilung, die unverzichtbar ist für Rationalität und Berechenbarkeit der Herrschaft, bildet die Grundlage für die moderne Verfassung. Indem sie die Ausübung politischer Herrschaft unabhängig von den Launen einzelner Amtsinhaber macht, dient die Gewaltenteilung dazu, eine Sphäre der Unverfügbarkeit institutionell zu gewährleisten. Verfügungsmacht in hohem Maße besitzt demzufolge nur noch die vollziehende Gewalt - sie selbst muss aber vor der Sphäre der unantastbaren Grundrechte halt machen. Im Rechtsstaat übt die Exekutive Autorität kraft Legalität aus, also „,kraft des Glaubens an die Geltung legaler Satzung und der durch rational geschaffene Regeln begründeten sachlichen ,Kompetenz ““47. Die Macht der Richter ist andererseits nur mittelbar Durchsetzungsmacht, sie ist vor allem - und immer stärker in demokratischen Verfassungsstaaten - Deutungsmacht. In dieser Funktion kommt der Charakter der intransitiven Macht gerade bei der Judikative besonders zum Ausdruck. Auch die gesetzgebende Gewalt findet in den Normen der Verfassung die festdefinierten Grenzen ihrer Verfügungsmacht. ${ }^{48}$

Die Einschränkung der Macht erfolgt zweitens durch Menschenrechte ausgehend vom Ur-Grundrecht des rule of law, dem Schutz vor willkürlicher Verhaftung (Habeas corpus), der einen Raum der Unverfügbarkeit schafft. Gegen die staatszentrierte Sicht eines Thomas Hobbes und deren im Anschluss an Carl Schmitt vorgenommenen Modifikationen erlangen im Verfassungsdenken unserer Zeit die individuellen Grundrechte autonome und konstituierende Bedeutung. Die Geschichte ihrer Institutionalisierung und ihrer Ausweitung ist die eines Prozesses ständiger verfassungs-

47 Weber, Wirtschaft und Gesellschaft, 1972, S. 830.

48 Über die Gewaltenteilung als „Bedingung der Möglichkeit von Volkssouveränität“ vgl. Maus, Über Volkssouveränität, 2011, S. 128: Für die klassische Demokratietheorie „hatte die gewaltenteilige Monopolisierung aller Rechtssetzung beim ,Volk' und aller Gewaltressourcen bei den rechtsanwendenden Instanzen den präzisen Sinn, die Staatsapparate durch Gesetzesbindung den Direktiven der gesellschaftlichen Basis zu unterwerfen“. Zum Konzept der ,Deutungsmacht“ vgl. Hans Vorländer (Hrsg.): Die Deutungsmacht der Verfassungsgerichtsbarkeit, Wiesbaden 2006. 
rechtlicher Zurückweisungen von Souveränitätsansprüchen. Verfügbarkeit der Macht und Unverfügbarkeit der Menschenrechte stehen im demokratischen Verfassungsstaat in einem klärungsbedürftigen Verhältnis. ${ }^{49}$ Unbestreitbar ist jedenfalls, dass man nun von der Doktrin einer der Verfassung vorgeordneten Souveränität Abschied nimmt.

Im Zentrum der Theorie der Grundrechte steht die Behauptung, dass Menschen in ihrer Würde ,unantastbar“ sind, was als Folge eines normativen Verständnisses der Person als Grundlage fundamentaler moralischer Ansprüche zu erklären ist. Damit wird eine Sphäre der Unverfügbarkeit konstruiert, die ihrerseits auf eine bestimmte Auffassung von Macht- und Autoritätsverhältnissen (als Anerkennungsbeziehungen) verweist. Einerseits ist die Macht im Rechtsstaat immer autorisierte Macht und das Recht das Ergebnis der Akte autorisierter Amtsträger. Selbst wenn mit organisiertem Zwang durchgesetzt, unterliegt es immer einem Anspruch auf Legitimität auf Seiten der sich wechselseitig anerkennenden Adressaten. Der demokratische Mythos der verfassunggebenden Gewalt gilt andererseits als überwunden. ${ }^{50}$ Selbst die Verfassungen werden als unverfügbar proklamiert. ${ }^{51}$ Selbst wo die Art und Weise der Verfassungsänderung großzügig reglementiert wird, bleibt der Gedanke zentral, über das Gesamte einer Verfassung könne der Verfassungsgesetzgeber nicht verfügen. Das Recht zur Verfassungsänderung ist selbst nur ,eine verfassungsrechtliche Kompetenz, die an bestimmte Verfahrensvoraussetzungen und qualifizierte Mehrheiten gebunden ist ${ }^{\star 52}$.

49 Als letzte Figur der modernen Dialektik einer übergreifenden Verfügungsmacht kann die These der systemische „Kolonisierung der Lebenswelt“ (Habermas) mindestens erwähnt werden.

50 Pauly/Heiss, Kritische Skizze, 2010, S. 156-157: „Im politischen Diskurs wirke er integrativ, juristisch hingegen würde das verfassungsgebende Volk mehr und mehr Grenzbegriff, wenn nicht gar schlicht obsolet.“ An seine Stelle tritt eine entmythologisierte Legitimation der politischen Einheit ein: „Damit wandelt sich das Denken politischer Einheit von der Vorstellung eines unmittelbar vorgegebenen Substrats hin zu einem Projekt, das durch ausstehende Entscheidungen und Handlungen in einem ordnungsgemäßen Verfahren noch realisiert werden muss.“

51 Vgl. Hans Vorländer: Die Suprematie der Verfassung. Über das Spannungsverhältnis von Demokratie und Konstitutionalismus, in: Wolfgang Leidhold (Hrsg.): Politik und Politeia. Formen und Probleme politischer Ordnungen. Festgabe für Jürgen Gebhardt zum 65. Geburtstag, Würzburg 2000, S. 373-383.

52 Kriele, Einführung in die Staatslehre, 1975, S. 113. 
Die Unverfügbarkeit der Souveränität kann in der heutigen politischen Welt auch nicht mehr als Leitprinzip der internationalen Beziehungen gelten. Im internationalen Recht hat sich mit dem Grundsatz ,responsibility to protect" eine Orientierung durchgesetzt, die zur Umwertung des Interventionsverbots in die innere Angelegenheiten geführt hat. Die supranationale Ebene des Verfassungsrechts scheint ebenso dekonstruktiv auf Ansprüche der Souveränität zu reagieren. Die Europäische Union ist daher ein gutes Beispiel. „Die Kompetenzen werden ihr von den Mitgliedstaaten vertraglich nach dem Grundsatz der begrenzten Einzelermächtigung eingeräumt und können ihr auf demselben Weg wieder entzogen werden. Die Kompetenz-Kompetenz darf nicht auf die Union übergehen. “53

Diese in der Staatslehre weit verbreitete Darstellung der Zähmung der Verfügungsmacht in der Moderne ist natürlich nicht unangefochten geblieben. Man denke nur an Foucaults Abschied von der ,juristischen Gesellschaft": sein Versuch einer Analyse der Macht, „die sich nicht auf einen juristischen, rein negativen Machtbegriff beschränkt, sondern den Gedanken einer Technologie der Macht entwickelt ${ }^{654}$, stellt die klassische Lehre in Frage. Die Gesellschaft wird hier als ein Netz von Unterwerfungen, das Individuum als „Machteffekt“ verstanden: konsequenterweise erfolgt die Vorverlagerung von Machtverhältnissen in die subinstitutionelle Sphäre lokaler Auseinandersetzungen. Am Ende dieser Entwicklung der Disziplinarmacht steht ,die Vereinnahmung des Lebens durch die Macht [...] eine Machtergreifung über den Menschen als Lebewesen“55. Übernimmt man diese Sichtweise, dann ergibt sich als Konsequenz, dass mit der Biomacht eine neue Art Verfügbarkeit entstanden ist, die nicht minder als jene der Pastoral- und der Disziplinargesellschaft in die verklärte Sphäre der Subjektivität eindringt.

Zur Illustration dieser gegenläufigen Lektüre der politischen Moderne kann noch Agambens Darstellung der Dialektik der Menschenrechte an-

53 Dieter Grimm: Das Grundgesetz als Riegel vor einer Verstaatlichung der Europäischen Union. Zum Lissabon-Urteil des Bundesverfassungsgerichts, in: Der Staat 48 (2009) 4, S. 475-495, hier: S. 482.

54 Michel Foucault: Die Maschen der Macht, in: ders.: Schriften in vier Bänden. Dits et Ecrits, Band IV: 1980-1988, Frankfurt a.M. 2005, S. 224-244, hier: S. 225. „Ich glaube, seit der Entstehung der von mir sogenannten Biomacht oder anatomischen Politik leben wir in einer Gesellschaft, die dabei ist, nicht länger eine juristische Gesellschaft zu sein.“ (ebd., S. 241)

55 Foucault, In Verteidigung der Gesellschaft, 2001, S. 282. 
geführt werden. Für ihn bedeutet die Verwandlung des Untertanen in Bürger dank der Anerkennung der Menschenrechte nichts anderes als die Tatsache, dass die Geburt - „das natürliche nackte Leben als solches“ - „zum unmittelbaren Träger der Souveränität wird“56; und die Souveränität nichts anderes als eine Art Sakralisierung der Macht ist, die die Existenz einer unverfügbaren Sphäre der Menschenrechte negiert und die Legitimität des allgemeinen Tötens proklamiert. ${ }^{57}$ Damit ist jeder Zusammenhang zwischen Macht und unverfügbarem Recht gesprengt. Die Entzauberung des Rechts führt bei solchen kritischen Analysen zur Infragestellung jeder modernen Manifestation der Unverfügbarkeit.

\section{UNVERFÜGBARKEIT DES DEMOKRATISCHEN PRINZIPS?}

Der Zeitgeist der Spätmoderne ist der Macht, aber im Grunde auch der Autorität, nicht wohlgesonnen. Seit Jahrzehnten steht die Macht im Kreuzfeuer der Kritik. Sie wird als unterdrückend und zerstörerisch wahrgenommen und im Namen einer unverfügbaren Sphäre der individuellen Freiheiten und der Grundrechte abgelehnt. Die Debatte um die Inflation der Macht (Luhmann) ist im Grunde eine Debatte über die Untauglichkeit der Durchsetzungsmacht in einer komplexen Gesellschaft - Untauglichkeit auch in Hinblick auf ihre Ineffektivität beim problem solving wie auch in der Gewährleistung der Grundrechte. Parallel dazu hat sich eine Diagnose des Verfalls oder gar des Verschwindens der Autorität entwickelt. Unter den bedeutendsten Beiträgen der nachkriegszeitlichen Literatur zur Frage der Autorität (und des Autoritätsuntergangs) gehören der schon erwähnte Aufsatz Was ist Autorität? und der folgende große Essay On Revolution von Hannah Arendt. Demzufolge leben wir im Zeitalter der Autoritätsentzauberung. Dagegen kann man immer noch mit Popitz einwenden:

56 Giorgio Agamben: Homo sacer. Die souveräne Macht und das nackte Leben, Frankfurt a.M. 2002, S. 137. „Die Erklärung der Menschenrechte stellt die originäre Figur der Einschreibung des natürlichen Lebens in die juridisch-politische Ordnung des Nationalstaates dar." (ebd., S. 136)

57 Ebd., S. 93: „Souverän ist die Sphäre, in der man töten kann, ohne einen Mord zu begehen und ohne ein Opfer zu zelebrieren, und heilig, das heißt tötbar, aber nicht opferbar, ist das Leben, das in diese Sphäre eingeschlossen ist.“ 
„Autoritätswirkungen sind gegenwärtig; keine Modernität, keine Rationalisierung hat sie beseitigt. “58

Es gibt noch einen dritten kritischen Ansatz, der sich seit geraumer Zeit wachsender Zustimmung erfreut. Es handelt sich um die Diagnose, nach der wir in Zeiten des Verfassungseklektizismus leben, infolge dessen ,die Idee, dass nur demokratisch gesetztes Recht legitim sei, verabschiedet und die Initiative der Rechtsentwicklung an die Gerichte zurückgegeben“659 wird. Hier lässt sich der Gravitationspunkt der Debatte ausmachen, die um die Frage der Legitimität richterlicher Politikkontrolle kreist. Immer öfter ist diesbezüglich von Politisierung der Gerichte oder von „Entgrenzung der richterlichen Macht“ die Rede. ${ }^{60}$ Es ist manchmal gesagt worden, dass die historische Leistung des demokratischen Verfassungsstaates darin bestand, „die Depersonalisierung durch Politisierung der Staatsregierung zu ermöglichen “61. Manche befürchten nun eine usurpierte Politisierung durch die rechtsprechende Gewalt.

Die Geschichte des modernen Staates ist an erster Stelle Geschichte einer souveränen Instanz, die schrittweise die Souveränität aus sich selbst ausschließt. Nach der Inthronisierung des Begriffs bei Bodin und Hobbes, nach den vielfältigen Versuchen ihrer Zähmung im Zeitalter des liberalen Konstitutionalismus endet sie bei Hans Kelsen mit einer regelrechten Enteignung der Souveränität. Die Geschichte des modernen Staates ist zweitens die Geschichte eines Verfassungsstaates, der nach seiner Etablierung die verfassunggebende Gewalt enteignet. Der pouvoir constituant ist der Schwanengesang der unbeschränkten Souveränität, ein letzter Akt voluntaristischer Selbstbehauptung, der zu ihrer Einschläferung führt. ${ }^{62}$

58 Popitz, Phänomene der Macht, 1992, S. 104.

59 Maus, Über Volkssouveränität, 2011, S. 27.

60 Sehr differenziert und ausführlich zu dieser Frage: Matthias Jestaedt u.a.: Das entgrenzte Gericht. Eine kritische Bilanz nach sechzig Jahren Bundesverfassungsgericht, Frankfurt a.M. 2011.

61 Hubertus Niedermaier: Reflexive Modernisierung von Herrschaft? Überlegungen zur Soziologie des Epochenbruchs, in: Wolfgang Bonß/Christoph Lau (Hrsg.): Macht und Herrschaft in der reflexiven Moderne, Weilerswist 2011, S. 122-146, hier: S. 129.

62 Kriele, Einführung in die Staatslehre, 1975, S. 226: „Der demokratische Souverän gibt, indem er vom ,pouvoir constituant" Gebrauch macht, seine Souveränität auf. Er ist nicht mehr unmittelbar handlungsfähig. Er ist als politischer Faktor nur latent vorhanden: Er tritt erst wieder in Funktion, wenn 
Die Geschichte des modernen Verfassungsstaates ist dann drittens die Geschichte eines Gesetzgebungsstaates, der schrittweise die gesetzgebende Gewalt enteignet, indem der politische Prozess immer stärker durch Verfassungsgerichte und andere rechtsprechende Instanzen in gerichtlichen Verfahren kontrolliert und eingegrenzt wird. ${ }^{63}$

Aus der Schutzfunktion der Grundrechte erwächst eine neue Legitimation für die autoritative Macht der Richter, insbesondere der Verfassungsrichter. Die Entsakralisierung der Staatsmacht muss durch Autorität kompensiert werden. Die richterliche Macht erweist sich als der letzte wirksame Katalysator der Autorität. Die richterliche Macht im allgemeinen ist nicht unmittelbar Verfügungsmacht, sie verweist für die Vollstreckung ihrer Urteile auf die institutionalisierte Zwangsmacht der Polizei und der Organe, die eine Sanktion ausführen sollen. Sie ist vor allem autoritative Macht. Zur physischen Durchsetzung einzelner Entscheidungen gegen Widerstände bedürfen die Gerichte der Vollstreckung durch die Exekutive. Aber auch als autoritative Macht verfügen sie schon über Durchsetzungsmacht: Ihre Sanktionsfähigkeit besteht in der Verweigerung der sozialen Anerkennung. Das wird umso deutlicher, wenn wir auf die Praxis der Verfassungsgerichtsbarkeit Bezug nehmen. Im politischen Bereich üben die Verfassungsgerichte ihre Sanktionsfähigkeit als Legitimitätsverteiler aus. Mit ihrer Interpretationsbefugnis sind sie auch im normativen Bereich „datensetzende Macht“ (im Sinne Popitz') oder maßstabsetzende Macht, die Exempel statuiert. ${ }^{64}$

Eine der Schlüsselfragen, mit denen sich die politische Theorie der Gegenwart konfrontiert sieht, betrifft das Verhältnis zwischen gesetzgebender und rechtsprechender Gewalt. Der Streit um die Rolle der judicial power in den demokratischen Verfassungsstaaten ist vor allem in den letzten zwei Jahrzehnten entbrannt. Die Anklage lautet: Durch eine Anhäufung von Entscheidungs- und Deutungskompetenzen eignen sich die Gerichte (und vor allem die Verfassungsgerichte) eine Macht an, die sie in

der Verfassungsstaat zusammenbricht. Man kann auch sagen: Die demokratische Souveränität ruht, solange der Verfassungsstaat besteht.“

63 Ausführlicher dazu Pier Paolo Portinaro: Il labirinto delle istituzioni nella storia europea, Bologna 2007, S. 196ff.

64 Vorländer, Deutungsmacht, 2006; André Brodocz: Die Macht der Judikative, Wiesbaden 2009. Vgl. Anna Pintore: I diritti della democrazia, Roma-Bari 2003, S. $98 \mathrm{ff}$. 
Stand setzt, letztendlich über die demokratische Willensbildung zu verfügen. Die Anpassung der Verfassung an die Dynamik gesellschaftlicher Entwicklung wird von Gerichten in Anspruch genommen. „Hatte die Demokratietheorie des 18. Jahrhunderts noch darauf bestanden, dass dies Aufgabe der permanenten verfassunggebenden Gewalt des Volkes sei, so ist dieser wesentliche Aspekt von Volkssouveränität heute durch die Verfassungsgerichtsbarkeit usurpiert. “65

Verfassungsgerichte gewinnen ihre Autorität nicht nur aus der Bewahrungsfunktion der Grundrechte, sondern auch als Hüter der Unverfügbarkeit des demokratischen Prinzips. Als Institutionen gegen die Selbstgefährdungen der Demokratie errichtet, und immer wieder als ,gewalthabende Gerechtigkeitsexpertokratien" ${ }^{\text {66 }}$ denunziert, entwickeln sich solche Gerichte in der letzten Zeit als Verteidiger der Prärogativen der demokratischen Repräsentation und Gesetzgebung zu Hütern des demokratischen Verfassungsprinzips. Wo die Parteien immer öfter als „Volksfeinde" erlebt werden und als Usurpatoren und Verfälscher der demokratischen Macht vor der öffentlichen Meinung entkleidet dastehen, steigen die Verfassungsgerichte in ihrer Rolle als Bewahrer dieser Macht in der Anerkennung des Volkes. Darüber hinaus markieren sie immer deutlicher die Grenzen, die die Regierungsorgane bei Kompetenzausweitungen der supranationalen Institutionen nicht überschreiten dürfen. Das kann man am besten am Beispiel des Bundesverfassungsgerichts und seiner EuropaJurisprudenz zeigen. Seine diesbezüglichen Urteile sind bei der Betonung der „souveränen Verfassungsstaatlichkeit“ der Bundesrepublik von dem Bewusstsein des demokratiegefährdenden Risikos getragen, welches aus der Tatsache resultiert, dass das, ,was auf die supranationale Ebene abwandert, auf der nationalen nicht mehr zur Verfügung “67 steht. Anders gesagt: das demokratische Prinzip steht prinzipiell einer fortschreitenden Übertragung von Hoheitsrechten auf die EU im Wege.

In Folge der Komplexität und Asymmetrie der Verfassungslagen kann man es sich keineswegs einfach machen und daraus den Schluss ziehen, dass eine Trendwende bevorsteht, die zu einer Revitalisierung der demo-

65 Maus, Über Volkssouveränität, 2011, S. 27-28.

66 Ebd., S. 117 und S. 119. Vgl. Jürgen Habermas: Faktizität und Geltung. Beiträge zur Diskustheorie des Rechts und des demokratischen Rechtsstaats, Frankfurt a.M. 1994, S. 324ff.

67 Grimm, Das Grundgesetz als Riegel, 2009, S. 160. 
kratisch gewählten Organe dank verfassungsgerichtlicher Unterstützung führen wird. Inwieweit diese erneute Inanspruchnahme der Souveränität des Volkes in der fragmentierten Welt der Globalisierung die Funktion einer Stabilisierung der Macht noch annehmen kann, lässt sich nicht sagen. Anders als Rechtsordnungen, die auf Tradition oder zurückliegender Gründung beruhten, galt das Prinzip der Volkssouveränität immer als zukunftsorientiert. Es bleibt abzuwarten, in welche Richtung sich der makroregional vernetzte demokratische Verfassungsstaat entwickeln wird. 


\title{
Abschied von der normativen Transzendenz
}

\author{
Rortys Moderne
}

\section{ENNO RUDOLPH}

Richard Rortys Verhältnis zur Moderne ist ambivalent. ${ }^{1}$ Einerseits steht er für eine primär politisch begründete Ablehnung dessen, was von einem Großteil der repräsentativen Kritiker der Moderne als das Menschenbild dieser Epoche bezeichnet wird, andererseits identifiziert er sich wiederholt mit den Idealen der europäischen Aufklärung. Gelegentlich weitet sich seine Kritik unmittelbar auf das Gesamtgebiet der Philosophie aus. Philosophie steht dann sowohl für eine bestimmte Tradition, als auch für einen einflussreichen Typ der universellen Kommunikation: es ist der Typ des Argumentierens und der diskursiven Vermittlung von Doktrinen, die einem metaphysischen Essentialismus verhaftet bleibt. Dagegen spielt Rorty ein originäres Verständnis narrativer Kommunikation aus, das sich gerade auch auf dem Feld der politischen Auseinandersetzung zwischen unterschiedlichen Kulturen bewähren soll. Dabei zeigt sich, dass Rorty, auch um seine Position gegen konkurrierende Zeitströmungen behaupten zu können, in wesentlichen Punkten der Moderne verpflichtet bleibt.

1 Dieser Beitrag stellt die erheblich überarbeitete, korrigierte und wesentlich erweiterte Fassung ausgewählter Abschnitte eines Textes dar, der unter dem Titel: Soziale Asymmetrie - der Preis pluralistischer Demokratie? Rortys Antwort auf Rawls, in: Babara Henry/Alberto Pirni (Hrsg.): Der asymmetrische Westen, Bielefeld 2012, erschienen ist. 


\section{Die Politik der Poesie im Dienste Des Weltanschaulichen PluRalismus}

In seinem Essay Der Vorrang der Demokratie vor der Philosophie ${ }^{2}$ vertritt Rorty einen normativen Vorrang des weltanschaulichen Pluralismus vor dem Anspruch der klassischen westlichen Philosophie, das politische Handeln auf die Grundlage einer eigens dazu entwickelten anthropologischen Theorie zu stellen - eine, die eine bestimmte politische Option, etwa die Verteidigung der Menschenrechte, aus Wesensmerkmalen der Gattung Mensch ableitet. Ein solches Vorgehen steht unter dem Verdacht eines imperialen „Essentialismus“, und der Essay dokumentiert die markantesten Absagen Rortys an diese Tradition. Die Plausibilität der Meinung, der zufolge die Demokratie als optimale Regierungsform einer humanen Gesellschaftsordnung zu bewerten sei, lässt sich nicht aus anthropologischen Axiomen herleiten, wie dasjenige einer gattungsspezifischen Vernünftigkeit, die als integrative Universalie gilt, und die das Menschenbild in den westlichen Regionen spätestens seit der Aufklärung geprägt und normiert hat.

Der anmaßende anthropologische Idealismus europäischer Herkunft wurde Rorty zufolge durch zwei eminente wissenschaftsgeschichtliche Ereignisse definitiv dementiert: zum einen durch die Wirkungsmacht des darwinistischen Naturalismus in den Naturwissenschaften und über sie hinaus, und zum anderen - komplementär dazu - durch den Siegeszug des Historismus in den Geisteswissenschaften. Rortys wiederholt abgeliefertes Bekenntnis zur maßgeblichen Bedeutung von Darwinismus und Historismus als points of no return in der Wissenschaftsentwicklung der westlichen Kulturgeschichte, ${ }^{3}$ kommt einer uneingestandenen Hommage an Friedrich Nietzsche gleich: Rortys Apologie des weltanschaulichen Pluralismus nämlich lässt sich lesen wie eine Aneignung von Nietzsches unter anderem in der Fröhlichen Wissenschaft vorgetragener sarkastischer Kritik am „Genius

2 Richard Rorty: Der Vorrang der Demokratie vor der Philosophie, in: ders.: Solidarität oder Objektivität? Drei philosophische Essays, übersetzt von Joachim Schulte, Stuttgart 1988, S. 82-125, hier: S. 82ff.

3 Richard Rorty: Menschenrechte, Vernunft und Empfindsamkeit, in: ders.: Wahrheit und Fortschritt, übersetzt von Joachim Schulte, Frankfurt a.M. 2000, S. 241-268, hier: S. 251 und passim. 
der Gattung“"4 ${ }^{4}$ Nietzsche überführt hier den Hang der Moderne eines performativen Widerspruchs: einerseits sei ihr ein fundamentales Bekenntnis zum humanen Individualismus eigen, das sie niemals aufgegeben habe, andererseits reduziere sie die wesentlichen Eigenschaften des animal rationale auf gattungsspezifische Merkmale wie Bewusstsein und Sprache.

Wie Nietzsche bewertet Rorty den Historismus (Nietzsche: das „historische Philosophiren “5) als unhintergehbare Zäsur, von der an es nicht zulässig sei, die Erfahrung historischer Kontingenz durch Hypothesen eines ahistorischen, unveränderlich bleibenden Wesens des Menschen zu dementieren. Zudem folgt Rorty Nietzsche de facto in der stillschweigenden Anerkennung der ,zweiten Kränkung der Menschheit', der zufolge der Mensch aus unverdrängbarer Einsicht in den kontingenten Verlauf der Evolution, dem er uneingeschränkt unterworfen ist, seinen bis dato eingebildeten privilegierten Status einbüßt. Er gilt von nun an als ein hinreichend im Rahmen des naturalistischen Paradigmas erklärbares Phänomen, ein „Mängelwesen“ (Herder) mit biologischen Eigenschaften, die der „Mängelkompensation“ (Gehlen) dienlich sind. Entsprechend bewerten beide, Nietzsche wie Rorty, den Historismus als das geisteswissenschaftliche Spiegelbild des Evolutionsparadigmas: Historismus als Gegenentwurf zur Geschichtsphilosophie, als Manifest der Einsicht in die Kontingenz alles Historischen und der Abkehr von teleologischen Ideologisierungen.

Unter diesen Voraussetzungen versteht sich Rortys - unter Berufung auf John Rawls vorgetragene - Apologie des weltanschaulichen Pluralismus als Einsatz für ein bestimmtes soziales Lebensmilieu. Für dessen Bestand finden sich bei Rorty konkrete Postulate - besser: politische ,Kardinaltugenden “-, die sich als Bedingungen einer langfristigen Konsolidierung dieses Bestandes verstehen lassen.

An erster Stelle steht die Tugend der „Toleranz“ - hier stellt sich Rorty ausdrücklich in eine Reihe mit John Stuart Mill, Thomas Jefferson und John Dewey: Toleranz verstanden als rational begründete Haltung der

4 Friedrich Nietzsche: Die Fröhliche Wissenschaft, in: ders.: Sämtliche Werke. Kritische Studienausgabe in 15 Bänden, Bd. 3, hrsg. von Giorgio Colli und Mazzino Montinari, München 1980, S. 343-651, hier: S. 593.

5 Friedrich Nietzsche: Menschliches, Allzumenschliches. Ein Buch für freie Geister. Erster Band, in: ders.: Sämtliche Werke. Kritische Studienausgabe in 15 Bänden, Bd. 2, hrsg. von Giorgio Colli und Mazzino Montinari, München 1980, S. 9-366, hier: S. 25. 
kontrollierten wechselseitigen Anerkennung, die dem Ziel der Aufrechterhaltung einer diskreten Indifferenz als Basis sozialer Koexistenz dient. Wer wäre nicht an die Idylle des Naturzustands bei Jean-Jacques Rousseau erinnert: „Indifférence“ gilt ihm als naturgegebener Habitus und als Bedingung stabiler Friedlichkeit. Hinzu kommt an zweiter Stelle, ebenfalls in ebenso auffälliger wie uneingestandener Parallelität zu Rousseau, die Tugend der „Empfindsamkeit“. Ihr entspricht bei Rousseau „pitié“ als Eigenschaft einer natürlichen Disposition zum Mitleid.

Diese Tugenden sind in unterschiedlicher Weise erlernbar: Die ,Schule der Toleranz' besteht in der Auswirkung des sich trotz Terror und Fanatismus unaufhaltsam global durchsetzenden weltanschaulichen Pluralismus selbst: Der Pluralismus ist stärker als die Intoleranz, und das ist es, was John Rawls mit der These vom „Faktum des Pluralismus“ sagen will. Pluralismus nötigt zur Toleranz. Beide sind einander bedingende Resultate der globalen sozialen Evolution. Es ist in unserem Interesse, die anderen, die schon da sind, zu dulden, anstatt sie zu diskriminieren oder zu vertreiben. Sie zu eliminieren ist sinnlos - sie werden ersetzt. Rorty hält sich demnach konsequent an sein Bekenntnis zur dominanten Bedeutung des Evolutionsparadigmas als Prämisse der Interpretation der Gesellschaftsgeschichte: Toleranz als emergierender sozialer Habitus.

Anders steht es mit der "Schule der Empfindsamkeit“. Sie ist neu zu gründen und nicht sozialevolutionär determiniert. Ihr Curriculum ist die Poesie - genauer die literarische Gattung des Romans, die es seit langem zwar in grenzüberschreitender Wahrnehmbarkeit gibt, deren Einsatz als Medium zur interkulturellen Verständigung allerdings erst noch bevorsteht: Narration statt Argumentation, literarische Bilder statt Belehrung, Poesie statt Rhetorik. Der Roman ist dabei insbesondere gefragt in seiner kompetenten Funktion als narrative Verdichtung von Menschenschicksalen, Konflikten und Konfliktbewältigungen, denen allesamt gemeinsam ist, die Vielfältigkeit des Menschlichen nicht auf den Singular Mensch zu reduzieren. Der Roman, ob von Charles Dickens oder Milan Kundera, handelt von Menschen, nicht vom Menschen: er belehrt nicht, er erzählt; er fordert nicht, er zeigt; er missioniert nicht, er fasziniert ästhetisch; er richtet sich nicht an die Menschheit, er richtet sich an die Menschlichkeit: Rorty 
zufolge habe Kundera recht mit der Feststellung, „der Roman sei die für die Demokratie geltende Gattung“66.

Das Ziel dieser beiden ,pragmatisch“ genannten, d.h. aus legitimem Selbsterhaltungsinteresse erwachsenen, Tugenden' liegt in einer nachhaltigen Sensibilisierung für das Leid anderer, - ein Ziel, das mit dem Mittel der offensiven Verteidigung abstrakter, weil mit universalistischem Anspruch vorgetragener Grundsätze, wie sie etwa den geläufigen Definitionen der Menschenrechte zugrunde liegen, auch bona fide nicht zu erreichen ist: Sie sind Manifestationen einer essentialistischen und keiner historistischdarwinistisch gefilterten Anthropologie. Angehörige verschiedener Kulturen bedürfen in Fällen von Normenkonflikten vielmehr einer besonderen Fertigkeit - derjenigen, sich Geschichten zu erzählen, verbalisierte Erfahrungen zur Diskussion zu stellen, um sich wechselseitig für ihre jeweiligen Empfindsamkeiten zu sensibilisieren.

Natürlich stellt sich die Frage, was die beiden markierten kulturhistorischen Zäsuren - Darwinismus und Historismus (Nietzsches Vermittlungsrolle immer vorausgesetzt) - mit den zwei Tugenden einer pluralistischen Demokratie zu tun haben, und in welchem Sinne sie als plausible Konsequenzen aus dem von Rorty, ausdrücklich bei John Rawls entliehenen Befund des „Faktums des Pluralismus“, zu bewerten sind, die Herstellung sozialer Gerechtigkeit zu befördern.

\section{Rortys Rawls - oder Pluralismus ALS TERTIUM ZWISCHEN LIBERALISMUS UND PRAgMATISMUS}

Rorty unterscheidet in einem kleinen Traktat über Solidarität und Objektivität $^{7}$ grundsätzlich zwei Archetypen kollektiver ,Sinngebungsstrategien': Die eine realisiert sich durch Solidarität mit einer sei es bereits vorhandenen Gesellschaft - etwa Hegels bürgerliche Gesellschaft, verstanden als historische Ausgangslage nach dem Erfolg der Französischen Revolution -, sei es erst noch zu etablierenden Gesellschaft - etwa Kants

6 Richard Rorty: Heidegger, Kundera und Dickens, in: ders.: Eine Kultur ohne Zentrum. Vier philosophische Essays und ein Vorwort, übersetzt von Joachim Schulte, Stuttgart 2008, S. 72-103, hier: S. 76.

7 Richard Rorty: Solidarität oder Objektivität? in: ders.: Solidarität oder Objektivität?, 1988, S. 11-37. 
Ideal einer Gesellschaft der Weltbürger. Die andere hingegen entsteht durch kollektive Orientierung an einer als verbindlich anerkannten, z.B. durch religiöse Autorität legitimierten Wahrheit, die nicht nur für Partikulargesellschaften (Hegel), sondern für alle Menschen zu aller Zeit (Kant) Geltung beansprucht.

Für diesen zweiten, an einem mit universalem Anspruch vertretenen Wahrheitsbegriff orientierten Typ reserviert Rorty dem klassisch erkenntnistheoretischen Terminus der „Objektivität" eine spezifische Bedeutung. Dies geschieht in offenkundig, dekonstruktiver' Absicht, indem der Terminus als Bezeichnung für die Idealform eines Wissens gedeutet wird, das allein mit einer exakten Methode Erkenntnis generierender „Selbstüberschreitung" des individuellen zum transzendentalen Subjekt erzielt wird, ein Reflexionsakt, an dem alle Menschen unabhängig von ihrer geographischen oder ethnischen Position partizipieren können sollen, um so zu einem universal verbindlichen Wissensbestand zu gelangen: Transzendentalität als Fall von sozial integrierender, Transzendenz', wie sie wohl schon dem „pragmatistischen Credo“ von Peirce zugrunde gelegen habe dürfte. ${ }^{8}$ Evident ist, dass Rorty damit den modernen, auf Descartes und Kant zurückgehenden Erkenntnisobjektivismus als Modell einer säkularen Strategie universaler Sinngebung und demzufolge Wissenschaft in ähnlich epigonaler Abhängigkeit von Nietzsche wie Foucault - als einen Typ von szientistisch maskierter Ideologie bewertet. Das Ziel dieser Objektivität stiftenden Strategie liegt auf der Hand - es sollen Solidaritäten erzeugt werden, wie sie bei Kant durch eine dazu komplementär eingerichtete Ethik eigens postuliert werden, und wie sie bei dem bekennenden Kantianer Charles S. Peirce bereits durch den sensus communis einer scientific community generiert werden.

Es handelt sich Rorty zufolge bei einer solchen intersubjektiven Verpflichtung auf Objektivität um einen Fall von modernem, um nicht zu sagen: säkularisiertem Transzendenzbezug. Denn die vormals über die Religion, nunmehr über die Wissenschaft als Leitmedium miteinander kommunizierenden Bürger beurteilen sich selbst als solche, die ihre jeweilige Partikularperspektive überwinden, und die sich auf diese Weise

8 Vgl. dazu Charles S. Peirce: Über die Klarheit unserer Gedanken/How to make our ideas clear. Eingeleitet, übersetzt und kommentiert von Klaus Oehler, Frankfurt a.M. 1985, S. 64. 
als Repräsentanten einer Universalvernunft verstehen. Sie stehen in „unmittelbarer Beziehung [...] zu einer nichtmenschlichen Realität“99. Dieser zweite, wissenschaftsstrategische Typ von Sinngebung, der ohne Gott bzw. ohne eine ausschließlich symbolisch vermittelte außerweltliche Transzendenz auskommt, hat zweifellos das moderne Wissenschaftsideal mit nachhaltigem Erfolg bis heute geprägt.

Die an epistemischer Objektivität interessierten ,Wahrheitsfreunde“ sind vom Typ des idealisierten Sokrates: Sie zweifeln an der Tauglichkeit bloß partikularen Wissens und verzweifeln an der exklusiven Selbstgenügsamkeit partikularer Gesellschaften - deshalb die Flucht in den Universalismus. Dies wäre - im wohl verstandenen Sinne Rortys - der „Sokratismus“ der Moderne zu nennen, wie Nietzsche ihn taufte und wiederholt karikierte. Eine erhebliche Anzahl der praktizierenden Anhänger dieses Solidaritätskonzepts sind zudem überzeugte „Realisten“, d.h. sie glauben, wie ausdrücklich Peirce - der eigentliche Erfinder des Pragmatismus -, an die Übereinstimmung der Wahrheit, die wir entdecken und objektivieren können, mit einer unabhängig von unserer Wahrnehmung existierenden Realität, ${ }^{10}$ und auch deshalb sind sie eo ipso Universalisten: d.h. Wahrheit gilt für sie überall in gleicher Verbindlichkeit und nicht nur in einer Region der Erde oder innerhalb einer Ethnie dieser Welt. Deshalb konstruieren die Realisten eine Erkenntnistheorie, die Rorty - in auffälliger Analogie zu Kant - konsequent unter dem Titel „Metaphysik“ subsumiert, und die geeignet sein soll, die normative Geltung von Wahrheit dadurch intersubjektiv zu sichern, dass sie ihren Ursprung ihrer kollektiven Erkennbarkeit in die intellektuelle Natur des menschlichen Subjekts verlegen.

Davon zu unterscheiden sind die post-Peirce'schen Pragmatisten - von James über Dewey bis zu Rorty selbst. Sie verzichten auf einen emphatischen Wahrheitsanspruch und ersetzen ihn durch pragmatische Konvention: „Nach ihrer Auffassung ist Wahrheit das, woran zu glauben für uns gut ist, um mit William James zu reden. “11 Und wenig später: „Soweit Pragmatisten überhaupt einen Unterschied machen zwischen Wissen und Meinung, handelt es sich bloß um die Unterscheidung zwischen Themen,

9 Rorty, Solidarität, 1988, S. 11.

10 Vgl. Peirce, Über die Klarheit, 1985, S. 81.

11 Rorty, Solidarität, 1988, S. 14. 
bei denen man verhältnismäßig leicht zu einer Übereinstimmung gelangen kann, und Themen, bei denen Einhelligkeit schwer zu erreichen ist." “12

Es geht also um den Grad der Anwendbarkeit des Wörtchens „Wir“ als Index eines erreichten Konsenses, der je erneut zur Disposition steht: geteilte Meinungen, gerade auch diejenige, der zufolge es sinnvoll ist, unbegrenzt viele Meinungen nebeneinander gelten zu lassen - solidarisieren, ohne das für die betreffende Meinung der Anspruch objektiver Verbindlichkeit erhoben werden würde. Sie dienen der pragmatischen Lebensbewältigung durch und in Gemeinschaft - bis auf Widerruf.

„Pragmatismus“ - verstanden als das Prinzip des solidarischen Umgangs mit sozialer Diversität bzw. weltanschaulicher Divergenz - und weltanschaulicher Pluralismus - verstanden als die normative Gestalt der irreduziblen Pluralität individueller und kollektiver Lebensformen auf diesem Globus - komplementieren einander. Und diese Synthese spiegelt sich tatsächlich in Rortys Berufung auf die paradigmatische Bedeutung von Historismus und Darwinismus: „Eine Untersuchung des Wesens der Erkenntnis kann nach pragmatischer Auffassung nur eine sozio-historische Darstellung der Verfahren sein, mit deren Hilfe verschiedene Leute versucht haben, Einigkeit über die zu vertretenen Überzeugungen zu erzielen. “13

Eine solche Einigkeit wird sich nach Überzeugung der Pragmatisten stets eher in zumeist ethnisch integrierten Partikulargruppen herstellen, und dies genügt dem Pragmatisten: der Pragmatist ist ein strategischer, kein ideologischer Ethnozentrist, und deshalb freilich auch kein Kommunitarist:

„Sich ethnozentristisch verhalten heißt: das Menschengeschlecht einteilen in diejenigen, vor denen man seine Überzeugungen rechtfertigen muss, und die übrigen. Die erste Gruppe - der ethnos - umfasst diejenigen, mit deren Meinungen man genügend übereinstimmt, um ein fruchtbares Gespräch möglich zu machen.““14

Dies ist der Punkt, an dem die konstruktive Bezugnahme Rortys auf Rawls an ihre Grenzen gerät. Rorty ist sich dessen bewusst, dass „,kantianische Liberale wie Rawls" eher als Gegner der ethnozentrisch orientierten, des Relativismus verdächtigen und vor allem der wahrheitsenthaltsamen Pragmatisten einzustufen sind. Der „einsame Provinzialismus“ dieser Hal-

12 Ebd., S. 15.

13 Ebd., S. 17.

14 Ebd., S. 27f. 
tung, wie die kantianischen Liberalen ihn in analoger Form bei den kommunitaristischen Apologeten des kulturellen und politischen Partikularismus kritisieren, ist ihnen unheimlich. Andererseits vertritt der Liberale Rawls'scher Prägung Rorty zufolge die Auffassung, dass epistemischer Realismus, wie er zuvor als eine Methode der Solidaritätsstiftung beschrieben wurde, nur eine mögliche Variante methodischer Objektivierung ist, aber keine notwendige. Es ist diese Flexibilität, die es Rorty ermöglicht, sich, trotz seiner Selbstzurechnung zum „Ethnozentrismus“, als bekennender Rawlsianer zu profilieren. Genauer: Rorty stilisiert die Verteidigung des weltanschaulichen Pluralismus, wie Rawls sie vornimmt - der die allgemeine Duldung einer undeterminierten Vielfalt von Optionen des Guten als gerecht bezeichnet - zum Profil des ,ethnozentristischen Pragmatismus" und vermittelt ihm damit normative Bedeutung. Mit anderen Worten: Ethnozentrismus und Pluralismus bewertet Rorty als zwei Elemente einer einheitlichen Position. Und durch diese Wendung vollzieht Rorty nicht nur eine subtile Aneignung Rawls'scher Intentionen, die einer ,freundlichen Übernahme‘ gleichkommt - er stiftet vielmehr eine originäre politische Synthese aus Pragmatismus und Liberalismus. Rorty weiß: Die Liberalisten haben unseren Demokratien unverzichtbare Freiheitsgrade verschafft: „Selbst wenn der typische Charakter der Menschen in liberalen Demokratien tatsächlich fade, berechnend, kleinlich und unheroisch sein sollte“ - hier markiert Rorty mit auffälliger Ironie das Feindbild der Kommunitaristen -, ,kann die Vorherrschaft solcher Personen dennoch ein angemessener Preis sein für die politische Freiheit ${ }^{\text {“15 }}$ : Pluralismus der Ethnien als dritter Weg zwischen Individualismus und Universalismus. Dieses Projekt eines Pluralismus der Ethnien und der mit ihm gegebene Pluralismus der Weltanschauungen hat nur Chancen auf eine dauerhafte Stabilität, wenn die Medien der interethnischen Kommunikation von der Art narrativer Stoffe und nicht von der Art doktrinärer Apologien sind.

15 Rorty, Der Vorrang der Demokratie, 1982, S. 103. 


\section{Vom VermeintLichen TROSt DER MEtAPHYSIK: DER BEFREIENDE ABSCHIED VON DER NORMATIVEN TRANSZENDENZ}

Was erklärt den Erfolg des universalistischen Realismus von Platon bis Peirce, bzw. den der abgewandelten nominalistischen Version Kants? Was an ihm ist immer noch nützlich, ja unverzichtbar, was hingegen ist überholt in der Zeit eines sei es inzwischen Faktum gewordenen, sei es normativ vorgegebenen sozialen und weltanschaulichen Pluralismus? Die universalistischen Realisten und ihre vermeintlich nominalistischen Nachfolger sind erkenntnistheoretische und wahrheitskonstruktive Metaphysiker, die ihrer Position eine anthropologische Legitimation verschaffen. Diese Metaphysik führte deshalb zum Erfolg, weil sie ein anthropologisches Bedürfnis auf hohem Niveau befriedigte - und noch befriedigt: Sie stiftet Trost.

„Die Vorstellung von der menschlichen Natur als einer inneren Struktur, durch die alle Angehörigen der Art zur Annäherung an denselben Konvergenzpunkt und zur Anerkennung der Ruhmwürdigkeit der gleichen Theorien, Tugenden und Kunstwerke gebracht werden, gibt uns die Gewissheit, dass die Künste und Wissenschaften der Griechen auch im Falle eines Sieges der Perser früher oder später an anderer Stelle zum Vorschein gekommen wären. Sie gibt uns die Gewissheit, dass die Errungenschaften der westlichen Demokratien von unseren späten Nachfahren wiederholt werden, selbst wenn die Orwell'schen Bürokraten des Terrors tausend Jahre lang regieren. Sie gibt uns die Gewissheit, dass sich der Mensch durchsetzen wird $[\ldots]$. “16

Und: Der Mensch habe ein „Recht“ darauf, er zählt darauf.

Die Überzeugung von einer objektiven Gegebenheit der Welt - einer Welt, die verständlich ist für eine die menschliche Gattung auszeichnende Vernunft - korrigiert nicht nur den Subjektivismus partikularer Perspektiven, sondern: Wahrheit, sofern sie der Kontingenz entzogen ist, tröstet, und darin liegt ihr religionsäquivalenter Wert und ihre religionsanaloge Wirkung. Auch hier erweist sich Rorty als authentischer Nietzscheaner. Keine Gesellschaft ohne Trostbedürfnis, ergo: keine Gesellschaft ohne Appetit auf Wahrheit. Was die Religion auf diesem Markt nicht mehr verbürgen kann, bietet das objektivierbare Wissen. Das Geheimnis des epocha-

16 Rorty, Solidarität, 1988, S. 29. 
len Erfolgs der Säkularisierung scheint gelüftet - anders allerdings als bei Hans Blumenberg, der behauptet, dass die Säkularisierung erfolgreich war, weil der Mensch sich hinreichend dafür gerüstet hatte, ohne Trost leben zu können. Der Transzendenzbedarf der Realisten hingegen befriedigt sich über eine anthropologische Begründung der Rechte des Menschen auf universal verbindliche Verankerung ihrer Gattungsprivilegien.

Davon setzt sich der Pragmatist programmatisch ab - mit dem Gestus des Abschieds von einer Epoche, der Moderne. Er beansprucht für sich, ohne einen solchen, immer noch metaphysischen, Trost leben zu können, und stattdessen mit einem sozialen Trost auszukommen, der den metaphysischen ersetzt: „Er will es erreichen, dass die Solidarität als unser einziger Trost gilt, und man solle einsehen, dass sie keiner metaphysischen Stützung bedarf." ${ }^{17}$ Das wirkt ebenso souverän wie moderat, ebenso nüchtern wie selbstbewusst, zugleich aber verweist Rorty auf den Anspruch der Pragmatisten, eine attraktivere Form von Solidarität zu ermöglichen, nicht diejenige in Gestalt der verbindenden Übereinstimmung in der gegebenen Objektivität der Wahrheit - ich nenne sie die ,abstrakte“ oder (nach wie vor) „vertikale“ Transzendenz -, sondern diejenige in Gestalt praktikabler Solidarität, wie sie in überschaubaren und bereits traditionell integrierten Ethnien herstellbar sind, - ich nenne sie „konkrete“ oder „horizontale“ Transzendenz.

Bliebe es bei diesem Ergebnis - Rorty ersetzt den Trost der Metaphysik durch den der Solidarität -, entstünde allerdings der Verdacht, dass Rorty etwa im Anschluss an den ersten der beiden eingangs unterschiedenen Sinngebungsstrategien - zum Advokaten einer pragmatistischen Version des Kommunitarismus geworden ist - wofür nicht zuletzt sein Plädoyer für einen spezifischen Ethnozentrismus sprechen würde. Aber als Gegengift gegen eine drohende babylonische Gefangenschaft im Lager des kommunitaristischen Antiliberalismus wirkt seine spezifische Aneignung des pluralistischen Credo von John Rawls, und zwar, wie abschließend zu zeigen ist, über die schon erwähnte Synthese von Ethnozentrismus und Pluralismus hinaus in zwei Schritten:

a) Rorty vollzieht die Abgrenzung gegen die Kommunitaristen im gleichen Zuge wie gegen solche Autoren, die die liberale Demokratie nur auf dem Fundament einer essentialistischen Anthropologie als legitimiert

17 Ebd. 
erachten. Hier stellt der provokante Ironiker sowohl die frühen Frankfurter als auch Heidegger mit den Kommunitaristen polemisch in eine Reihe: Charles Taylor, Martin Heidegger und die Autoren der „Dialektik der Aufklärung" stünden gleichermaßen für die These, dass keine Gesellschaft überleben könne, die die Idee einer „ahistorischen moralischen Wahrheit“ beiseite räume:

„Horkheimer und Adorno etwa vermuten, in einer entzauberten Welt könne es keine moralische Gemeinschaft geben, weil es nicht klar sei, wie es sich verhindern ließe, dass ,das blindlings pragmatisierte Denken seinen aufhebenden Charakter (verliert), und darum auch die Beziehung auf Wahrheit‘.،18

Rorty, selbst engagierter Kritiker der Moderne, möchte nicht verwechselt werden. Er lokalisiert den im Gewande einer Modernekritik pathetisch vorgetragenen Wahrheitsessentialismus, wie er die Frankfurter, Heidegger und Taylor miteinander verbinde, zwar gemeinsam im Schlepptau der Moderne; um sich aber zugleich definitiv von ihnen abzugrenzen, verteidigt Rorty gegen sie entschieden einen spezifischen, unverzichtbaren Profit der Moderne: die „Entzauberung“. Rortys Urteil über sein Verhältnis zum Kommunitarismus lässt an Klarheit nicht zu wünschen übrig:

„Anstatt $[\ldots]$ anzudeuten, die philosophische Reflexion oder eine Rückkehr zur Religion könne uns instand setzen, die Welt erneut zu verzaubern, sollten sich die Kommunitarier meines Erachtens an die Frage halten, ob die Entzauberung uns per Saldo mehr Schaden als Nutzen gebracht oder mehr Gefahren herbeigeführt als verhütet hat. “'19

Die durch die Entzauberung gewonnenen Freiheiten seien das Experiment der Moderne jedenfalls wert gewesen, selbst wenn es scheitert.

b) Für diese im Namen einer wohlverstandenen Moderne vorgetragene Abgrenzung gegen eine illegitime Modernekritik rüstet sich Rortys nachmetaphysischer Pragmatismus zusätzlich mit einer eigenwilligen Interpretation der Thesen zum Pluralismus aus der Feder von John Rawls: Dies, indem er ihn ausdrücklich außerhalb des normativen Vernunftuniversalismus im Sinne Kants positioniert. Zwar hat Rawls in Theory of Justice, wie Rorty wissen sollte, affirmativ erklärt, sein fiktiver „Urzustand“, - in

18 Rorty, Der Vorrang der Demokratie, 1982, S. 86.

19 Ebd., S. 109. 
dem sich die Menschen hinter einem „Schleier der Unwissenheit“ auf einen von ihnen als gerecht akzeptierten Status in einer künftigen Gesellschaft verständigen -, lasse sich auffassen ,,als eine erfahrungsmäßige Deutung von Kants Begriff der Autonomie und des Kategorischen Imperativs im Rahmen einer empirischen Theorie ${ }^{620}$. Jedoch hier entsteht kein Widerspruch. Denn nur vordergründig betrachtet liest sich diese Bezugnahme auf Kant wie ein uneingeschränktes Bekenntnis zum Kantianismus. Genau besehen bleibt Rortys Versuch einer, freundlichen Übernahme' der Position von John Rawls gerade auf der Grundlage solcher Festlegungen plausibel, da die Transformation des transzendental verankerten sittlichen Imperativs in eine bloß ,empirisch“ begründete Theorie, wie Rawls sie tatsächlich für sich reklamiert - d.h. eine Theorie, die auf Fakten, wie den Pluralismus, und auf mehr oder weniger gesicherte Befunde, wie den natürlichen „Gerechtigkeitssinn“ baut -, von Kant keinesfalls akzeptiert worden wäre: Sie ist mit dem Ansatz einer gerade nicht empirisch, sondern transzendental fundierten Rechtsethik unvereinbar.

Rorty sieht sich mit Rawls einig in dem Fazit, dass ,die Philosophie als Suche nach der Wahrheit in Bezug auf eine unabhängige metaphysische und sittliche Ordnung keine anwendbare gemeinsame Basis abgeben [kann] für ein politisches Gerechtigkeitskonzept in einer demokratischen Gesellschaft.“21 Rawls ist Rorty zufolge ein konsequenter Empiriker, der dem methodischen Zugang genüge, ,eingefleischte Überzeugungen zu sammeln, wie etwa den Glauben an religiöse Toleranz und die Ablehnung der Sklaverei, um dann zu versuchen, die in diesen Überzeugungen enthaltenen intuitiven Grundgedanken und Prinzipien in ein kohärentes Gerechtigkeitskonzept einzugliedern. “22

Mit dieser „durch und durch historisch und antiuniversalistischen“ Einstellung könne sich Rawls erfolgreich ,gegen Kant behaupten“ und ,das Bemühen der Aufklärung, sich von der Überlieferung und der Geschichte loszusagen und sich auf, Vernunft“ oder ,Natur' zu berufen“, als „Selbstbetrug“" entlarven. ${ }^{23}$

20 John Rawls: Eine Theorie der Gerechtigkeit, Frankfurt a.M. 1979, S. 289 (Hervorhebung ER)

21 Rorty, Der Vorrang der Demokratie, 1982, S. 91.

22 Ebd.

23 Ebd. 
Im Anschluss an diese nicht ohne sanfte hermeneutische Gewalt vorgenommene Einvernahme hat Rorty Rawls dort, wo er ihn haben will: emanzipiert von Kant und eo ipso unbetroffen vom Universalismus des zweiten Solidaritätsmodells - dem der „horizontalen Transzendenz“ -, versöhnt er ihn mit dem Prinzip des Historismus. Er entzieht ihn damit nicht nur ,solidarisch“ dem Visier der wiederholt unversöhnlich vorgetragenen Kantkritik der Kommunitaristen, sondern mehr noch - er schließt einen Pakt und konstruiert in demonstrativer Einvernehmlichkeit eine originäre Synthese aus Pragmatismus und Liberalismus: Ein exemplarisches Specimen dekonstruktivistischer Methodik. ${ }^{24}$

Rawls - ein pragmatistischer (und nicht metaphysischer) Liberaler, Rorty ein liberaler (und nicht kommunitaristischer) Pragmatist: die Koalition ist geschmiedet. Der dritte Weg - nicht derjenige aus Frankfurt, sondern derjenige eines Bündnisses zwischen Princeton und Harvard - ist gefunden. Er führt zu einem konstruktiv modernekritischen Liberalismus, der nicht in derselben Weise, wie die erwähnten ,drei Männer im Boot ${ }^{\star}$ (Horkheimer, Heidegger, Taylor) mit der Moderne in toto bricht. Dieser dritte Weg ist weder kommunitaristisch - die Verpflichtung „frei situierter“ Individuen auf eine Polismoral lehnt er kompromisslos ab -, noch ist er im klassischen Sinn liberalistisch - sein eindeutiges Bekenntnis zum Gerechtigkeitsidealismus eines John Rawls richtet sich eo ipso gegen jede Form von Sozialdarwinismus. Liberalität als dritter Weg besagt, darauf zu insistieren, dass es - unter Berufung auf Mill und Jefferson - so viele Freiheiten gibt wie Menschen, denen Freiheit zugebilligt wird.

Rorty übersieht: Mit Kant wäre diese pluralistische Auslegung seines Freiheitsbegriffs durchaus vereinbar - ergibt sie sich doch zwingend aus der Anwendungslogik des moralischen Imperativs, der zufolge jedes

24 Für das, was sich Rawls vorgenommen habe, sei es dementsprechend unnötig, das menschliche Ich als eine Entität mit Zentrum, Wesen, Vernunft oder göttlichem Funken zu denken. „Es steht uns frei, das Ich als etwas ohne Zentrum, als reine historische Zufälligkeit anzusehen. Den Vorrang des Rechten vor dem Guten so zu verteidigen, wie Kant - nämlich durch Berufung auf eine Theorie des Ich, die es für mehr erklärt als ein ,empirisches Ich', für mehr als ein ,radikal situiertes Subjekt', hat Rawls weder nötig, noch will er so vorgehen.“ (Rorty, Der Vorrang der Demokratie, 1982, S. 99) „Rawls könne sich zufrieden geben mit einer Konzeption, die das Ich des Menschen als mittelpunktloses Netz historisch bedingter Überzeugungen und Wünsche auffaßt.“(ebd. S. 104f.) 
individuelle Subjekt in autonomer Entscheidung von der Freiheit Gebrauch macht, die zu erhalten der Imperativ gebietet, ohne dem Einzelnen den Inhalt seiner Entscheidungen vorzuschreiben. Diese pluralistische Konsequenz aus Kants Freiheitskonzeption entgeht Rorty: Er unterschätzt den Grad seiner eigenen versöhnlichen Modernität. $\mathrm{Zu}$ sehr ist er fixiert auf seine Kritik an Kants vermeintlich rationalem Essentialismus.

\section{FAZIT}

Rortys Synthese aus Liberalismus (der Toleranz) und Pragmatismus (der Unverbindlichkeit) - wie auch die analog vorgeschlagene aus Pluralismus (der unbegrenzten weltanschaulichen Diversität) und Ethnozentrismus (der jeweiligen , wir ${ }^{6}$ ) - unterläuft nicht nur das Trostangebot des sokratischkantischen Transzendenztyps, sondern ebenso den des Solidaritätsdogmas im Sinne der normativen Gemeinschaftlichkeit, wie sie unverdrossen monoton und nicht ohne Penetranz von den Missionaren des Kommunitarismus eingeklagt wird. Die pragmatistische Unabhängigkeit von den Geltungsansprüchen der Wahrheitsmodelle vormoderner oder moderner Metaphysik und den ihnen korrespondierenden Trostangeboten konvergiert mit der Verteidigung des, Menschenrechts auf Ungebundenheit des menschlichen Selbst' nach dem Vorbild David Humes und John Deweys: das „ungebundene Selbst“ als Gegenentwurf zur traditionellen Anthropologie des animal rationale. Die Gemeinschaft dieser Individuen ist weder nur Gesellschaft von ,atomistischer Struktur“ (so die geläufige Kritik der Kommunitaristen an der Dekadenz des modernen Liberalismus), noch republikanisch im traditionellen Sinne. Sie ist ein Zweckbündnis von Menschen, die sich in der ersten Person Plural auf sich beziehen, weil und solange sie dieselben Überzeugungen teilen - z.B. die, dass das Leid der Menschen auf dieser Welt verringert werden soll, vor allem aber die, dass eine Gesellschaft erst dann das Prädikat ,well ordered“ verdient, wenn sie eine unbegrenzte Anzahl unterschiedlicher und einander entgegen gesetzter Überzeugungen koexistieren lassen kann, ohne zu zerbrechen und ohne sich über einen normativen Transzendenzbezug zu integrieren. 



\title{
Basiskonsens und Willensnation
}

\author{
Die Kontingenz des Unverfügbaren
}

und das Modell der Schweiz

\section{GEORG KOHLER}

„Der freiheitliche, säkularisierte Staat lebt von Voraussetzungen, die er selbst nicht garantieren kann. “1 Ernst-Wolfgang Böckenfördes viel zitierter Satz bildet im Folgenden unter zwei Hinsichten den Ausgangspunkt der Reflexion: Erstens beim Versuch, diese Voraussetzungen abstrakt unter Titeln wie ,hypothetische Grundnorm‘, ,Legitimitätsglaube‘, ,Basiskonsens‘ sowie ,Gemeinsinn` und ,Transzendenz‘ zu analysieren. Zweitens bei der Auseinandersetzung mit dem konkreten Modell direktdemokratischer Institutionen, das im Fall der Schweiz verwirklicht worden ist.

Das von Böckenförde namhaft gemachte Problem wird in der, Willensnation' Schweiz nämlich weniger durch zivilreligiöse Transzendenzkonstruktionen gelöst als durch die besondere, in der politischen Kultur des Landes verankerten Kombination anspruchsvoller, verfassungsmäßig gesicherter, plebiszitärer Mitbestimmungsverfahren mit prozedural vermittelten Diskurserfahrungen. Die Schweiz lässt sich als ,transzendenzaverses“ Integrationsmodell interpretieren: Gerade im politischen Streit erneuert sich die Zusammengehörigkeit der Bürger und Bürgerinnen. Darum stützt das Beispiel die These, dass eine funktionierende deliberative Demokratie mit

1 Ernst-Wolfgang Böckenförde: Die Entstehung des Staates als Vorgang der Säkularisation, in: ders.: Recht, Staat, Freiheit. Studien zur Rechtsphilosophie, Staatstheorie und Verfassungsgeschichte, 2. Aufl., Frankfurt a.M. 1992, S. 92114, hier: S. 112. 
vergleichsweise geringem Aufwand an Transzendenzstellung ihrer basalen Legitimationsbedingungen auskommen kann: Je besser die allgemeine politische Diskursfähigkeit ausgeprägt ist, desto geringer das zivilreligiöse Transzendenzbedürfnis und desto besser bestätigen sich common sense und Gemeinsinn aus dem Vollzug ihrer eigenen Praxis.

\section{Die Perspektive der Rechtstheorie}

Der Begriff ist berühmt und sein Erfinder ebenso: die - hypothetische „Grundnorm“ Hans Kelsens, die dieser als unbedingte Grundlage seiner Theorie der Rechtsordnung und ihrer Verbindlichkeit definiert:

„Unter der Voraussetzung, dass sie gilt, gilt auch die Rechtsordnung, die auf ihr beruht. Sie verleiht dem Akt des ersten Gesetzgebers und sohin allen anderen Arten der auf ihm beruhenden Rechtsordnung den Sinn des Sollens, jenen spezifischen Sinn [der den Rechtssatz als solchen charakterisiert, GK]. In der Grundnorm wurzelt letztlich die notwendige Bedeutung aller die Rechtsordnung konstituierenden Tatbestände. Nur unter Voraussetzung der Grundnorm kann das empirische Material, das sich der rechtlichen Deutung darbietet als Recht [...] gedeutet werden.“²

Allerdings (und diese Feststellung verknüpft das Problem der Kelsen'schen Grundnorm mit dem Problem des Basiskonsenses und der Frage nach dem, was als apriorisches Moment in die Konstitution legitimer politischer Herrschaft immer schon eingegangen sein muss): Die Grundnorm kann im Rahmen einer ,reinen“, von empirisch-soziologischen Umständen explizit abstrahierenden Theorie, nur als Hypothese gedacht werden:

„Sie ist nur der Ausdruck der notwendigen Voraussetzung jeder positivistischen Erfassung des Rechtsmaterials. Sie gilt, da sie nicht im Rechtsverfahren erzeugt wird, nicht als positive Rechtsnorm, ist nicht gesetzt, sondern - als Bedingung aller Rechtssetzung - vorausgesetzt. ${ }^{\text {*3 }}$

Die Grundnorm ist normlogisch betrachtet Hypothese, Voraussetzung, aber sie ist keine faktische Setzung. Diese Besonderheit - und damit die Dif-

2 Hans Kelsen: Reine Rechtslehre, Aalen 1985 (Neudruck der 1. Auf., Leipzig und Wien 1934), S. 66.

3 Ebd. (Hervorhebung GK). 
ferenz zum empirisch analysierbaren Basiskonsens - will ich noch einmal herausarbeiten:

Ein tatsächlich geltendes Grundgesetz, eine gegebene, in Kraft befindliche Verfassung, begründet alle normativen Sätze, die als präskriptive Bestimmungen auf sie und auf es zurückgeführt werden können und müssen: die einfache Gesetzgebung, die Rechtsprechung, die Erlasse der Verwaltung bis zum einzelnen Vollstreckungsakt. „Die Rechtsordnung ist [...] eine Stufenordnung verschiedener Schichten von Rechtsnormen. “4 Geht man Stufe um Stufe hinab, gelangt man aber - über die Verfassung hinaus - zuletzt zur erwähnten Grundnorm, welche lautet: Die vorliegende Verfassung gilt, genauer: Diese Verfassung und die aus ihr resultierende Rechtsordnung im Ganzen verfügen über die Eigenschaft, ihre Beachtung rechtmäßig erzwingen zu können. (,Rechtsgeltung“ im strengen Sinn bedeutet ja nichts anderes, als das Recht zu haben, die Geltung mit Zwangsmitteln durchzusetzen.)

Normen, Sollenssätze, sind stets allein durch vorgeordnete Sollenssätze zu begründen. Sollenssätze sind aus Sätzen, die Tatsachen feststellen, nicht abzuleiten; so das Verdikt gegen den ,naturalistischen Fehlschluss'. Für jemanden, der, wie Kelsen, nicht auf einen natur- oder vernunftrechtlichen Basiskanon zurückgreifen will, bleibt deshalb und dann als allerletztes Ankerprinzip, an dem alles übrige Sollen festgemacht ist, einzig die Doppelgestalt der (einerseits) umfassenden Ermächtigung, die (andererseits) ausschließlich als logische Voraussetzung - als Hypothese qua Unterstellung - gedacht werden kann.

Würde der Theoretiker der ,reinen Rechtslehre“ mehr tun wollen, als die Grundnorm qua Hypothese zu postulieren, müsste er das ihm gehörende Arbeitsfeld überschreiten und von der präzisen Analyse des Normzusammenhanges als solchem ins Gebiet der Rechtssoziologie, allgemeiner gesagt: in den Bereich der politischen Theorie der Legitimität und Legitimation hinüberwechseln.

Genau diesen Schritt möchte ich jetzt vollziehen, wenn und indem ich den Begriff des Basiskonsenses erläutere. Ich möchte nämlich den Basiskonsens als dasjenige verstehen, was der hypothetischen Grundnorm nicht primär die logische, aber die faktische Geltung und Verbindlichkeit verschafft. Das Hypothetische der Grundnorm Kelsens verwandelt sich bei der

4 Ebd., S. 74. 
Betrachtung des Basiskonsenses dann zum einen in dessen reale Kontingenz und Fragilität und zum anderen in dessen faktische Notwendigkeit und unabdingbare Wirklichkeit.

\section{Die Perspektive der politischen Philosophie}

Die politische Philosophie beschäftigt sich seit jeher mit dem Problem von sozialer Ordnung im Sinn funktionierender Herrschaft oder - normativ anspruchsvoller - im Sinn von kollektiver Selbstbestimmung: Wie ist es möglich, dass eine Vielzahl von Menschen eine Einheit bilden, in der - und durch die - die Kräfte der vielen Einzelnen so gebündelt sind, dass das Leben aller gesichert und womöglich verbessert wird, ohne die Folge, dass dadurch entweder ein chaotischer Konflikt zwischen den Angehörigen des Verbandes entsteht oder - konträr dazu - die Lähmung all der diversen Begabungen und Energien bewirkt wird, die für den Erfolg des Ganzen unentbehrlich sind und die allein in der Vielfältigkeit individueller Akteure und ihrer unterschiedlichen Perspektiven und Vermögen vital sein können?

So lässt sich die (einigermaßen komplizierte) Leitfrage der politischen Philosophie von der Antike bis zu Rousseau und Kant und, darüber hinaus, bis zu den Exponenten der radikal-liberalen Demokratie und der republikanisch-egalitaristischen Gemeinschaft zusammenfassen. Wenn das zutrifft, dann ist klar, das sich daran das Thema anschließt, erstens, wie man zur buchstäblich entscheidenden Handlungsfähigkeit der jeweiligen politischen Einheit gelangt, und zweitens (und komplementär dazu), wie die Folgebereitschaft der jeweiligen Mitglieder des Kollektivs, ihre Loyalität zu den Dezisionen und deren Effekten, zustande kommen bzw. erzeugt und gesichert werden kann.

Das Problem der Handlungs- und Entscheidungsfähigkeit eines politischen Verbandes ist nicht leicht zu lösen. Das zeigt sich, sofern man an die Elementargegensätze denkt, die sich schnell herausbilden müssen. Es sind Spaltungen, die die Zuverlässigkeit von Loyalitätserwartungen spätestens dann bedrohen, wenn die Resultate von Dezisionen sichtbar werden. Denn für das Kollektiv verbindliche Entscheidungen schaffen beinahe unvermeidlich den Gegensatz von Gewinnern und Verlierern. Außerdem verführen gemeinschaftsbestimmende Dezisionen oft - mindestens in den Fällen externer Ansprüche oder Anfechtungen an eine gegebene politische Einheit - zur Verschärfung der Identitätsgrenzen des jeweiligen Kollektivs. 
Das im eigentlichen Sinn politische Handlungsvermögen und dessen regelmäßige Folgen konfrontieren uns also in zweierlei Hinsicht mit möglichen Spaltungen zwischen ,Ich und Wir' bzw. ,Ihr und Wir': in der internen Dimension unter dem Gesichtspunkt der Spaltung zwischen den Nutznießern und den Belasteten von politischen Entscheidungen; in der externen Dimension unter dem Gesichtspunkt vertiefter Integrationszumutungen an die einzelnen Mitglieder. Wer zum gemeinsamen ,Wir ${ }^{\star}$ gehören will, der soll sich abweichender Ideen, Haltungen oder Forderungen enthalten, und zwar im Namen eines mehr oder weniger weitreichend verstandenen Gemeinsinns.

Die (interne) Spannung zwischen ,Ich und Wir', die das normale Produkt wirksamer politischer Dezisionsfähigkeit ist, ist auf Dauer nur durch jene besondere Einstellung bei den betroffenen Angehörigen des Verbandes, d.h. bei den Bürgern und Bürgerinnen aufzuheben, die man mit Max Weber „Legitimitätsglauben“5 nennen darf. Der Legitimitätsglaube gilt dem leitenden politischen Handeln und dem, was daraus entsteht. Sein Inhalt ist die Annahme, dass die Handlungen, die als Handlungen des Kollektivs auftreten, richtigerweise für alle verbindlich gelten bzw. dass die Organe des Kollektivs und die Initianten seiner Aktionen zurecht und in anerkannter und anerkennenswürdiger Weise tätig geworden sind.

Jedes politische System hängt mithin in je eigener und besonderer Art vom allgemeinen Glauben an die basale Legitimität, d.h. an die Anerkennungswürdigkeit und Verbindlichkeit seiner Dezisionen, so ab, dass zwar nicht jede Entscheidung im Einzelnen als die beste und richtige zu verstehen, dass diese aber trotz allem zu akzeptieren ist; und zwar weil sie in ,richtiger Manier' zustande gekommen und von der richtigen Instanz und Befugnisinhaberin getroffen worden ist.

\section{ZUM KONZEPT DER ,BASALEN LEGITIMITÄT“}

Politische Legitimität ist ein Begriff, der nur aus der Teilnehmerperspektive der in einer politischen Einheit zum ,Wir‘ einer gemeinsamen Handlungsgemeinschaft und -betroffenheit zusammengeschlossenen Personen zureichend erläutert werden kann. Legitimität ist zuerst und zuletzt Legi-

5 Vgl. Max Weber: Grundriß der Sozialökonomik. Dritte Abteilung: Wirtschaft und Gesellschaft, Tübingen 1922, S. 16 und S. 122. 
timitätsglaube: eine subjektive Einstellung, die diejenigen, die sie besitzen, zur Anerkennung und zum freiwilligen Gehorsam gegenüber den Akten und Anordnungen der sie betreffenden Herrschaftsmacht motiviert. Der ,Glaube' mag sich auf rationale Einsicht, auf schlichte Gewohnheit oder auch auf (quasi)religiöse Annahmen bezüglich der Richtigkeit (= des Gerechtfertigt-Seins) der anordnenden Autorität stützen; wichtig ist jedenfalls, dass angesichts unvermeidlicher Dezisionen der dafür verantwortlichen Ordnungsmacht die Folgebereitschaft nicht entzogen wird. Und zwar auch nicht von denen, die man in ihren Wünschen enttäuscht hat. Dieser Legitimitätsglaube erzeugt das, was ,basale Legitimität heißen kann; deren (bzw. der durch sie charakterisierten Macht) zentrales Merkmal ist die Fähigkeit, Entscheidungen eine ursprüngliche, allgemeine Anerkennung ermöglichende Gültigkeit - Legitimität eben - zu verleihen.

Um es mit den Mitteln antithetischer Verkürzung zu sagen: Die Wirkungen der mit basaler Legitimität ausgestatten Instanz sind gut bzw. legitim, weil sie von der richtigen, grundsätzlich anerkannten Legitimationsinstanz ausgehen, während diese Handlungsmacht selbst nicht etwa darum gut ist, weil sie die ,richtigen“ (z.B. die den Wünschen der Betroffenen gemäßen) Entscheide fällt. Die Autorität der basalen Legitimität ist das Kriterium für die Anerkennungswürdigkeit einer bestimmten Entscheidung, während die sonstige Qualität dieser Entscheidung gerade nicht als Kriterium für die Geltung der verantwortlichen Autorität dient.

Über basale Legitimität verfügt also jene Autorität, die nicht primär am Erfolg ihres Entscheidungshandelns gemessen wird. Die Effizienz ihrer jeweiligen Akte bleibt gerade außer Betracht, wenn es um das Eigentümliche der basalen Legitimität geht. Deren vernünftiger Sinn liegt darin, den Glauben an die Legitimität der Autorität aus dem Konflikt um die stets umstrittene (oder mindestens bestreitbare) Qualität der einzelnen Entscheidungen herauszuhalten.

\section{DER BASISKONSENS IST DISKURSEMPFINDLICH}

Das Vorhandensein basaler Legitimität, d.h. des Glaubens an die Notwendigkeit und Qualität der zentralen, die Handlungsfähigkeit der politischen Einheit ermöglichenden Institutionen, ist für jede Form von Staatlichkeit wesentlich, und das gilt natürlich auch für die Demokratie. An den zeitgenössischen Schwierigkeiten insbesondere der repräsentativen Demokratie 
zeigt sich freilich ebenso, dass und wie basale Legitimität erodieren kann. Hans Vorländer markiert Ursachen solcher Erosion. Zum Beispiel die Intransparenz und Komplexität der Entscheidungsbildung im Rahmen der repräsentativen Demokratie von heute:

„Die gewaltenteilige und föderale Organisation des Systems, seine Einbindung in supranationale Organisationen und internationale Governance-Strukturen, führt zu einer komplexen und zeitintensiven Struktur von Willens- und Entscheidungsbildung, die kaum den demokratischen Grundsätzen der Transparenz und der klaren Zurechenbarkeit von Verantwortlichkeiten genügt. Zahlreiche veto players, Institutionen, Akteure und Interessengruppen, sind in der Lage, den Prozess der Aushandlung von Lösungen undurchschaubar zu machen, und ihn zu blockieren. Verhandlungssysteme dieser Art mögen, wenn sie zu Lösungen kommen, für die jeweils Beteiligten befriedigende, auch effektive Ergebnisse einbringen. Aber sie benachteiligen - und zwar in struktureller Weise - solche Gruppen und Individuen, die nicht die Macht oder die Organisationsfähigkeit ihrer Interessen besitzen und deshalb kein Gehör finden. Insofern werden hier Teilhabechancen verwehrt, die aber zum Kern demokratischer Ordnungsvorstellungen gezählt werden müssen. “6

Die Mängelliste der zeitgenössischen Demokratie, die deren basale Legitimität in Frage stellt oder zumindest schwächt, wäre nicht schwer zu verlängern. ${ }^{7}$ Es genügt jedoch dies eine Beispiel, um zu belegen, dass der die Handlungsfähigkeit eines politischen Systems tragende Konsens unvermeidlich mit Ansprüchen - und zwar mit vernünftig diskutierbaren Ansprüchen, d.h. mit rationaler Kritik unterworfenen Geltungsvoraussetzungen - ausgestattet ist. Die Nichtabweisbarkeit dieser Ansprüche verdeutlicht, weshalb der Legitimitätsglaube (und ergo die funktionale Kraft des Basiskonsenses) kein blinder Glaube ist und daher auch nicht außerhalb argumentativer Begründbarkeit gestellt werden darf. Reformuliert bedeutet dies, dass basale Legitimität die Handlungsfähigkeit einer politischen Einheit ermöglicht, und dabei nichts anderes darstellt als einen durch argumen-

6 Hans Vorländer: Spiel ohne Bürger, in: Frankfurter Allgemeine Zeitung, 12.7.2012, S. 8 (Hervorhebung im Original).

7 Vgl. etwa: Jürgen Krönig: Mängelliste Demokratie, in: Merkur. Deutsche Zeitschrift für europäisches Denken 667 (November 2004), S. 1042-1047; Urs Marti: Demokratie. Das uneingelöste Versprechen, Zürich 2006; Pierre Rosanvallon: La démocratie inachevée: histoire de la souveraineté du peuple en France, Paris 2000; Colin Crouch: Postdemokratie, Frankfurt a.M. 2008. 
tative Gründe immer wieder irritierbaren Konsens über die Verfasstheit der politischen Einheit und ihre notwendigen Entscheidungsprozeduren.

Zum Basiskonsens etwa der repräsentativen Demokratie gehört die anspruchsvolle Annahme, dass die verantwortlichen Repräsentanten und staatlichen Institutionen die Aufgabe haben, die Mitwirkung prinzipiell aller Bürger und Bürgerinnen zu vermitteln. Sie dienen also weder allein als Selektionsfilter gut organisierter Interessen, noch agieren sie als von den Befürchtungen, Wünschen und Situationseinschätzungen breiter Bevölkerungsschichten abgekoppelte Regierungselite. Und eben darum ist dann, wenn diese Voraussetzungen fraglich geworden sind, der Basiskonsens nicht einfach faktisch, sondern aus guten und rational rekonstruierbaren Gründen gefährdet.

Legitimitätsglaube und Basiskonsens sind essentiell ,diskursempfindlich`. ,Diskurs‘ meint den Austausch von Gründen und Gegengründen bezüglich problematischer Geltungsansprüche. Wie vermischt reale Diskurse auch immer mit manipulativen Operationen sein mögen, im Kern sind sie stets mehr als das Instrument rhetorischer Überwältigungen. Zwar bleiben sie immer beeinflussbar durch dominante Meinungsmacher und durch deren mediale Verstärker. Aber trotz aller rein kausalistisch-verhaltenspsychologisch erklärbaren Steuerung der Menschen durch Propaganda und Reklame sind der Legitimationsglaube und der in ihn eingelassene Basiskonsens konstitutiv auf Argumente, Argumentationen und auf den Austausch von Kritik und Gegenkritik bezogen. Legitimitätsglaube und Basiskonsens sind a priori eingespannt in ein Netz von expliziten und impliziten Überlegungen, die, je nach Bedarf und Lage zum Thema öffentlicher, auch massenmedial wirksamer Reflexion werden können.

Daran zeigt sich schließlich eine weitere Differenz zwischen der Grundnorm von Kelsen und dem Basiskonsens, in dem die Faktizität gesellschaftlich wirksamer Mentalitäten und Bewusstseinslagen eingelagert ist. Aus der Sicht von Kelsens methodischer Intention - einer streng rechtspositivistisch limitierten Erläuterung des „Stufenbaus des Rechts“ - ist es konsequent und evident, zunächst auf eine letzte, für das eigentliche System des Rechts transzendente Norm zurückzugreifen, und diese Norm dann bloß noch formal zu bestimmen, inhaltlich aber leer zu lassen. Das hat den Sinn, den besonderen Geltungsanspruch des Rechts nicht mit der Wirklichkeit empirisch messbarer normativer Erwartungen und sozialer Überzeugungen zu vermischen. 
Zwischen ,Grundnorm“ und ,Basiskonsens' existiert daher kein unüberbrückbarer Gegensatz, sondern die Verschiedenheit zweier Fragestellungen und wissenschaftlicher Themenfelder: Während Kelsen den internen Verweisungszusammenhang des gesellschaftlich ausdifferenzierten Rechtssystems studiert und ausdrücklich nicht behandeln will, wie und warum es als Teil der sozialanthropologischen Selbstgestaltung zu funktionieren vermag, behandeln Konzepte wie ,Legitimitätsglaube‘ und ,Basiskonsens‘ exakt die Leerstelle, die der Grenzbegriff der ,hypothetischen Grundnorm' aus gutem Grund markiert, aber nicht weiter ausführt.

\section{Die Kontingenz des UnVerfügbaren}

Nachdem das Verhältnis zwischen den Kategorien der hypothetischen Grundnorm, des Legitimitätsglaubens und des Basiskonsenses einigermaßen geklärt ist, ist noch die inhaltliche Triftigkeit des Ausdrucks ,Basiskonsens` auszuweisen: Erstens basiert jede nicht durch direkte Gewaltandrohung stabilisierte Ordnung auf der großmehrheitlich im Bewusstsein der Verbandsangehörigen verankerten Annahme, dass das Handeln ihrer Ordnung - in letzter Instanz betrachtet - richtigerweise (oder schwächer formuliert: nicht zu Unrecht) so geschieht, wie es geschieht. Diese Überzeugung ist zweitens ein Basiskonsens, da sie offensichtlich die Loyalitätsgrundlage innerhalb der Gruppe der Verbandsmitglieder bildet. Drittens ist diese Grundlage als Konsens zu bezeichnen, weil sie auf der gemeinsamen Übereinstimmung der Bürger und Bürgerinnen hinsichtlich einer zwar schwachen, aber inhaltlich diskutierbaren Richtigkeitsannahme beruht.

Der über Richtigkeitsannahmen wirksame Basiskonsens stellt ein permanentes Problem für die Ordnung dar, die sich auf ihn stützt. Das wird offensichtlich, wenn man bedenkt, dass Richtigkeitsannahmen niemals zwingend begründbar und allemal fallibel sind: Unter der Voraussetzung, dass der menschlichen Sozialnatur ein Vermögen vernünftiger Reflexion eignet, kann die basale Annahme stets thematisiert und in ihrer Kontingenz - d.h. in ihrer Abhängigkeit von wechselnden historischen Bedingungen durchsichtig gemacht werden. Richtigkeitsannahmen können also nie apodiktisch gesichert werden. Sie sind spätestens dann offen für ihre kritische Relativierung, wenn die geschichtlichen Voraussetzungen ihrer Plausibilität verschwinden, bzw. konkurrierende neue, das kollektive Bewusstsein verändernde Faktoren auftauchen. 
In der neuzeitlichen politischen Philosophie wird die Bedingung der Richtigkeitsunterstellung im Hinblick auf die staatlich-politische Grundordnung kontraktualistisch eingelöst: Die Idee eines alle Bürger und Bürgerinnen umfassenden Gesellschafts- und Herrschaftsvertrages liefert die Legitimitätskriterien der notwendigen Zustimmung zur institutionellen Struktur der jeweiligen politischen Einheit, des - mit Locke zu sprechen jeweiligen body politick. Dieser Vorstellung eines von allen mit allen zum Nutzen aller geschlossenen Vertrags entspricht mehr oder weniger die Figur des Basiskonsenses. Dennoch ist die Theorie des Basiskonsenses nicht mit der Theorie des Gesellschaftsvertrages identisch. Die erstere ist die Reflexionsform der letzteren; sie ist metanormativ, insofern sie die allgemeine Tatsache zu erklären versucht, weshalb es überhaupt zur neuzeitlichen Gesellschaftsvertragstheorie kommen konnte. Zugleich insistiert sie im speziellen auf dem Faktum, dass die historisch jeweils verlangten bzw. realisierten Gestalten des Basiskonsenses/Gesellschaftsvertrags auf geschichtlich kontingente Gegebenheiten zurückweisen.

Wenn die den jeweiligen Basiskonsens ermöglichenden Übereinstimmungen im Kollektivbewusstsein abhängig von historischen Umständen, also kontingent sind, dann sind sie (und ist mithin jeder Basiskonsens als solcher) stets durchzogen und latent beunruhigt von einer unlösbaren Paradoxie: Qua Basiskonsens müssen diese geteilten Überzeugungen als unverfügbar vorgegeben erscheinen, qua richtigkeitsempfindlichen, diskursiv irritierbaren Annahmen sind sie im Gegenteil an Plausibilitätsbedingungen gebunden, die mehr oder weniger rasch wechseln können und die alles andere als apodiktisch sicher sind. Allen Basiskonsenskonkretisierungsformen eignet immer schon und notwendigerweise der Zwiespalt zwischen ihrem Anspruch, die basale politische Begründungsfunktion zu erfüllen, und der Tatsache ihrer je nur historisch-relativen Geltung und Plausibilität. Diese Paradoxie will die Formel von der Kontingenz des Unverfügbaren auf den Begriff bringen. Mit ihrer Hilfe ist der Zugang zum systematischen Zusammenhang zwischen Gemeinsinn und Transzendenz (6) und darauf aufbauend, die Darstellung dieses Verhältnisses am besonderen Beispiel der „schweizerischen Willensnation“ (7) zu entwickeln. 


\section{Gemeinsinn und Transzendenz}

Die Kategorie des Gemeinsinns ist zweifellos umfangreicher und mehrdeutiger als das oben präzisierte Konzept des Basiskonsenses. Wenn ich im Folgenden den Zusammenhang zwischen Basiskonsens und Gemeinsinn beleuchte, dann ist unter Gemeinsinn im speziellen die Bereitschaft der Menschen zu verstehen, dem Basiskonsens und seinen Richtigkeitsprätentionen nicht bloß zu trauen, sondern ihn erstens zugunsten der funktionierenden Ordnung zu verteidigen und ihn zweitens in Tätigkeiten zu übersetzen, die dem (basiskonsensfundierten) Gemeinwesen insgesamt zuträglich sind. Kurz: Gemeinsinn meint nicht bloß die subjektive Bereitschaft der Einzelnen oder der Gemeinschaft, zugunsten kooperativer Leistungen auf persönliche Vorteile zu verzichten. Gemeinsinn braucht, um wirksam werden zu können, intersubjektiv geteilte, inhaltliche Vorstellungen und Überzeugungen von dem, was das gemeinsame Eigene ist und sein soll. Zum Gemeinsinn als dem Unverfügbaren, das die Legitimität einer gegebenen politischen Ordnung fundiert und sichert, gehört sowohl ein inhaltlichpropositionales wie ein praktisch-voluntatives Element; und jedes dieser Momente kann im Lauf der Zeit seine Verbindlichkeit verlieren.

Um den Begriffsgebrauch zu schärfen, ist es nützlich, hier sehr genau zwischen zwei Perspektiven auf das Verhältnis von Gemeinsinn und Transzendenz zu unterscheiden: So ist der Gemeinsinn erstens als unverfügbare Basis einer gegebenen Ordnung für diese selbst ein ,Jenseitiges“, Transzendentes. Da er aber in dieser Funktion des legitimitätsbegründenden Apriori wegen seiner eigenen Kontingenz und Historizität allemal als gefährdet erscheint, gehört zu ihm zweitens der Umstand, selber in dieser Transzendenz gesichert werden zu müssen. Dies geschieht entweder durch Operationen der Tabuisierung seiner eigenen, diskursiv kritisierbaren Geltungsbedingungen oder durch deren dogmatische Rückversicherung mittels (angeblich) ,letzter Wahrheiten' aus der Sphäre der Metaphysik oder der Religion, die dann ,Naturrecht' heißen können oder ,göttlicher Wille‘.

Die im Kontext der Schweiz entscheidende Strategie der Sicherung des kontingenten Basiskonsenses erfolgt durch die Behauptung vorgeblich unhintergehbarer Orientierungsmuster. Der Gebrauch von Narration und Metaphern rekurriert auf die gegebenen Selbstdeutungen einer Gemeinschaft und die dazugehörigen, in Ritualen erinnerten Ursprungsmythen. Diese transzendenzsichernden Erzählungen kommen natürlich auch im Fall 
der schweizerischen Eidgenossenschaft vor. Sie werden aber auf eine besondere Weise gewendet: Die spezifische Form der schweizerischen Transzendenzsicherung ist nicht am Vorhandensein bzw. Fehlen politischer Mythen abzulesen, sondern an der Art, wie mit der Diskursempfindlichkeit des im Gemeinsinn gegebenen Basiskonsens umgegangen wird. So zeigt sich, dass die leitenden basiskonsensualen Annahmen im Vollzug der politischen Entscheidfindung expliziert, umgebildet und erneuert werden können. Die Arbeit der Konsenssicherung und damit gleichzeitig auch die Arbeit an den transzendenzsichernden Erzählungen wird dem Volk selbst durch die Verfassung ohne Weiteres zugemutet.

Gleichwohl konfrontiert die Kontingenz des Unverfügbaren jede politische Ordnung mit ihrer Endlichkeit. Dass damit schwerwiegende Probleme und Fragen verbunden sind, ist nicht nur Rechtsphilosophen und Verfassungstheoretikern klar, und es ist nicht allein der ,freiheitliche, säkularisierte Staat“ (Böckenförde), der mit den Folgen der Kontingenz des Unverfügbaren und der funktionalen Transzendenz von Gemeinsinn und Legitimitätsglaube konfrontiert ist. Im Grunde ist, wie gesagt, jede gesellschaftliche Struktur auf eine Basis angewiesen, von der man wissen kann, dass sie so notwendig wie erosionsanfällig ist. Alle soziale Ordnung ruht auf prinzipiell brüchigem Fundament. Deswegen enthält sie stets Konstruktionen, die zum einen die möglichen Bruchstellen des tragenden Konsens unsichtbar machen sollen, und die zum anderen den Glauben an dessen Unbestreitbarkeit in Gewissheit verwandeln möchten.

Das im Einzelnen zu zeigen und zu entfalten, ist ein Hauptthema der verschiedensten Gestalten von Gesellschaftstheorie - von der Ethnologie, die uns lehrt, wie archaische Gruppen gemeinsamkeitsstiftende Annahmen stabilisieren, über die Mentalitätshistorie (die verständlich macht, wie selbst befremdlichste Glaubensinhalte in Geltung zu bleiben vermögen, sofern sie dem Gemeinsinn zu nützen scheinen) bis zu den diversen Formen soziologisch-geschichtswissenschaftlicher Kultur- und Politikforschung. Der Einsatz von glaubensstärkenden Ritualen, bestätigenden Narrativen, von verklärenden Sakralisierungen und scheinbar kritikimmunen Traditionen, aber auch die Praktiken gezielter Indoktrinierungsstrategie, strafstarker Tabuisierung und zensurbewehrter Ideologiepolitik sind allesamt Mittel der ,Transzendenzstellung' von notwendigen und zugleich prekären kontingenten historischen Aprioris, die sich - bei aller Differenz - auf ein und 
dasselbe Problem zurückführen lassen: Wie das, was unverzichtbar, aber verderblich ist, so lange und so gut wie möglich erhalten werden kann. ${ }^{8}$

\section{7 „WILLENSNATION“}

Eine Weise, auf das Problem der Kontingenz des Unverfügbaren zu reagieren, sind die Antworten der sogenannten ,Zivilreligion“. Sie sind eine viel genutzte Möglichkeit, funktional notwendige Transzendenzstellungen zu erzielen. Zivilreligionen bilden einen Schutz gegen die Diskursempfindlichkeit kritisierbarer Basiskonsense und zerbrechlicher Legitimitätsüberzeugungen. ${ }^{9}$ So unterschiedlich die zivilreligiösen Methoden auch sind, was

8 Aus dem fast unübersehbaren Feld von Forschungsthemen, das sich damit eröffnet, möchte ich bloß an ein einziges erinnern: an das (selbst wiederum hochdifferenzierte) Thema der Zivilreligion(en). Vgl. dazu insbesondere: Heinz Kleger/Alois Müller (Hrsg.): Religion des Bürgers. Zivilreligion in Amerika und Europa, Münster 2004.

9 Unter dem Begriff der Zivilreligion sind verschiedene und jedenfalls drei symptomatische Weisen der Transzendenzstellung basiskonsensualer Gemeinsinnsvorstellung zu versammeln: Die Transzendenzstellung im Modus der religion civile à la Rousseau; die Transzendenzstellung im Modus der Grundwerte- und Grundrechtefixierung; die Transzendenzstellung im Modus restreligiöser common-sense-Orientierung. Der erste Fall bezieht sich auf die noch im 18. Jahrhundert als tendenziell (staats)gefährlich interpretierten Überzeugungen des Christentums. Rousseau überlegt, wie sie sich für die politische Gemeinschaft nutzbar machen lassen. Zugleich will er die religiöse Ritualpraxis für die Sakralisierung der säkularen Wir-Gemeinschaft und ihres Sinnes gewinnen. Vgl. dazu Iring Fetscher: Rousseaus politische Philosophie. Zur Geschichte des demokratischen Freiheitsbegriffs, Neuwied 1975, hier v.a. § 14 „Die Bedeutung der Religion für die Erhaltung einer politischen Gemeinschaft“". Im zweiten Fall geht es um die - unerlässliche, aber prinzipiell diffuse - Wertebasis einer komplexen, also in autonomen Teilsystemen sich selbst reproduzierenden gesellschaftlichen Einheit: dementsprechend deutet Niklas Luhmanns „Systemtheorie" die im verfassungsmäßigen Grundgesetz kodifizierten Wertideen als nur allgemein formulierbare Regulative, die einerseits die Unterstellung eines umgreifenden normativen Konsens zulassen, andererseits darauf angewiesen sind, in den jeweiligen Teilsystemen je funktional spezifiziert zu werden. Vgl. dazu: Niklas Luhmann: Grundwerte als Zivilreligion. Zur wissenschaftlichen Karriere eines Themas, Opladen 1981, wieder abgedruckt in: Kleger/Müller, Religion des Bürgers, 2004, S. 175-194. Im dritten Fall, für den u.a. die Theorie Hermann Lübbes steht, bedeutet „Zivilreligion“ im besonderen, historisch definierten Kontext liberaldemokratischer Staatlichkeit das, was aus der bestimmten, christlich-religiösen Tradition als Minimalkonsens übernommen werden kann, um die staatliche Gemeinschaft als solche zu stabilisieren - aber auch das, was sie als pluralistisch-liberale Einheit vor repressiv-dogmatischen Beschrän- 
sie eint, ist das Bestreben, die öffentliche Auseinandersetzung über den Sinn und die Geltung der basalen Einstellungen und Werte zu minimalisieren. Da diese Voraussetzungen aber kaum von politisch wichtigen Entscheidungen abzulösen sind, daher sofort in konkrete und speziellere Debatten einbezogen werden können, ist jede zivilreligiöse Transzendenzsicherung tendenziell diskussionsavers: Nicht die Verbreitung von Deliberationsanlässen ist ihr Zweck, sondern der Diskursstopp. Und ebenso gehört zu ihr die Wirkung, eine klare Trennung zwischen politischem Entscheidungssystem und zivilgesellschaftlicher Meinungsbildung zu begünstigen.

Auf eine demokratietheoretische Formel gebracht, bedeutet dies, dass die zivilreligiöse Praxis der Transzendenzstellung vor allem in der repräsentativen, sehr viel weniger aber in der direkten Demokratie mit ihrer unmittelbar folgenreichen Öffentlichkeit gebraucht wird.

Weil für die direkte Demokratie der gesellschaftliche Prozess permanenter politisch-partizipativer Meinungs- und Beschlussbildung zentral ist, kann diese erstens viele ihrer basalen Legitimationsbedingungen ohnehin nicht der öffentlichen Thematisierung entziehen, und zweitens muss sie das gar nicht tun: Deswegen nämlich, weil der direktdemokratische Prozeduralismus sich gerade durch die explizite Präsenz der strittigen Fragen kollektiver Ordnungsgestaltung erneuert. Die basale politische Kultur hält er am Leben, indem er Bürger und Bürgerinnen stets von neuem ins übergreifende Interesse am Gelingen der gemeinsamen Institutionen integriert. Entsprechend gering - bzw.: hochkonzentriert ${ }^{10}$ - ist der Bedarf an zivilreligiöser Transzendenzstellung. Was zivilreligiös gedeckt werden muss, ist allein die grundlegende Gestalt der politischen Willens- und Entscheidbildung selbst. In der Schweiz (dem deutlichsten Exempel direktdemokra-

kungen der individuellen Freiheit ihrer Bürger zu warnen vermag. Vgl. dazu: Hermann Lübbe: Staat und Zivilreligion. Ein Aspekt politischer Legitimität, in: Kleger/Müller, Religion des Bürgers, 2004, S. 195-220.

10 An dieser Stelle würde eigentlich ein größerer Exkurs fällig, der die Differenz zwischen Rousseaus Vorstellung von Volkssouveränität und dem Konzept der direkten Demokratie herausarbeitet. Entgegen einer ersten Vermutung sind das nämlich zwei verschiedene Gestalten. Die direkte Demokratie gehört ebenso in den Bereich der Staats- wie der Regierungsform, die Rousseau bekanntlich strikt unterscheidet, um zu betonen, dass Demokratie als Regierungsform nicht geeignet ist. Es ist darum nicht überraschend, dass Rousseau eine spezielle religion civile entwirft, während die direkte Demokratie diesbezüglich weniger Bedürfnisse hat. Mit einer Ausnahme: Sie selbst als Verfahren, das zugleich zur kollektiven Identität der (Willens)Nation gehört. 
tischer Organisationform) trägt diese Gestalt den besonderen Namen der ,Willensnation“.

Der Ausdruck ,Willensnation', der seit langer Zeit die ultrakurze Form der Antwort auf die Frage liefert, inwiefern die Schweiz überhaupt eine ,Nation' sei, lässt sich begriffshistorisch auf eine Formulierung des französischen Philosophen Ernest Renan zurückführen:

„La Suisse, si bien faite, puisqu'elle a été faite par l'assentiment de ses différentes parties, compte trois ou quatre langues. Il ya dans l'homme quelque chose de supérier à la langue: c'est la volonté. La volonté de la Suisse d'être unie, malgré la variété des ces idiomes, est un fait bien plus important qu'une similitude souvent obtenue par des vexations." “11

Nicht irgendeiner quasi-naturalen, ethnischen oder sprachlich-kulturellen Homogenität verdanke die Schweiz ihre nationalstaatliche politische Form, meint Renan, sondern dem ausdrücklichen, freien und bewussten, also rational bestimmten Wollen ihrer Bürger. Natürlich konnte diese Behauptung schon zu Renans Zeiten als Übertreibung kritisiert werden: Allzu stark verdrängt sie die historisch-strukturellen Kräfte und unpersönlichen Traditionsmächte, die auch im Fall der Schweiz die explizite Bundesstaatsgründung getragen und mitverursacht haben. Dennoch trifft sie den entscheidenden Punkt, und zwar sowohl in ereignisgeschichtlich-erklärender wie in theoretisch-systematischer Hinsicht.

Die moderne Gründung der Schweiz im Jahre 1848 war zwar das Produkt einer intentionalen Konstruktion; zunächst von Eliten und dann der gesamten Bevölkerung. Die Schweiz konnte aber als solche Konstruktion erfolgreich nur werden und bleiben, weil sie der Einsicht in die Logik der Sache folgte, nämlich dem Lösungsprimat des politischen Problems: Wie unter den Bedingungen der Moderne tragfähige politische Einheiten möglich sind, also rechtlich institutionalisierte Gebilde, die zwischen ihren, in vielfacher Hinsicht sehr ungleichen Mitgliedern jenes Maß an gegenseitiger Loyalität zu erzeugen und zu bewahren vermögen, ohne welches eine Ordnung nicht bestehen kann.

Renan betont, dass das ,Wir' der - nicht anders als demokratisch verfasst zu denkenden - Willensnation nichts ist, das als primär naturhaft oder historisch konstituiert zu verstehen wäre. Als Demos (also nicht als Ethnos

11 Ernest Renan: Discours et Conférences, Paris 1887, S. $298 \mathrm{f}$. 
oder Natio) ist es die gewiss auch geschichtlich bedingte und ermöglichte, letztlich aber durch den bloßen Willen zur gemeinsamen Selbstbestimmung getragene Zusammengehörigkeit derjenigen Menschen, die sich aus ihrer besonderen, rechtlich strukturierten Möglichkeit kollektiver Entscheidungsmacht als zusammengehörig begreifen und bestätigen. Nicht zufällig lassen sich daher das, Wir' der demokratischen Willensnation und dessen direktdemokratische Verfahren der Willens- und Entscheidungsbildung nicht sinnvoll voneinander separieren: Das eine verwirklicht sich im jeweils anderen. Das gelingende, Wir' ist der zentrale Wert, der das Verfahren selbst begründet und der in ihm zugleich seinen inhaltlichen Sinn erzeugt.

Wo daher, wie in der stark direktdemokratisch verfassten Schweiz, auf allen Ebenen politischen Handelns (von den Gemeinden über die Gliedstaaten bis zum Bund) ${ }^{12}$ die entscheidungsmächtige Partizipation der Bürger und Bürgerinnen ermöglicht, erwartet und in beträchtlichem Ausmaß auch realisiert wird, ${ }^{13}$ sind auf dem Feld der politischen Kultur zwei Konsequenzen hoch wahrscheinlich und im Fall der Schweiz empirisch gut ausweisbar: Erstens die breite Lagerung der Macht, samt der verlässlichen Bürgerbereitschaft, sich institutionell zu engagieren (in der Schweiz „Milizsystem“" genannt) und zweitens die Minimalisierung von Repräsentationsbedürfnissen bzw. Symbolisierungsformen der politischen Macht und der staatlich-republikanischen Einheit. Das lässt sich für beide auf die Eigenlogik direktdemokratischer Verhandlungsprozesse zurückführen.

Wenn beispielsweise die wichtigen Entscheide des Parlaments (zum Teil sogar diejenigen der Exekutive) durch aktuelle Volksmehrheiten gedeckt sein müssen, dann verlangt das von Parlament und Regierung, mögliche Oppositionsgruppen und involvierte Interessenverbände von vornherein in den Gestaltungsvorgang einzubeziehen. „Um ein Gesetzgebungs-

12 Vgl. dazu den Abschnitt „Volkssouveränität als Legitimationsgrundlage des Staates" im Gemeinschaftswerk der in der Schweiz lehrenden Professoren des öffentlichen Rechts, welches 2001 anlässlich der Totalrevision der schweizerischen Bundesverfassung veröffentlicht worden ist: Daniel Thürer/Jean-François Aubert/Jörg Paul Müller (Hrsg.): Verfassungsrecht der Schweiz, Zürich 2001, S. 301-425.

13 Zwar beträgt die Stimmbeteiligung in der Regel nur etwa $40 \%$ der Stimmberechtigten. Angesichts der Tatsache, dass die Bürger und Bürgerinnen pro Jahr mehrere Male (je zu einer Vielzahl von Entscheidungen) zur Urne gerufen werden, darf von Politikverdrossenheit aber nicht die Rede sein. Es ist ja auch nicht der Fall, dass stets die gleichen 40\% zur Abstimmung gehen. 
vorhaben abzusichern, muss der Gesetzgeber das Vorhaben gegenüber den

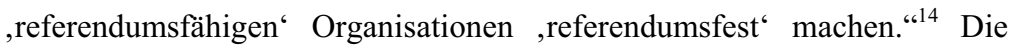
schweizerische Verhandlungsdemokratie beruht nicht zuletzt darum auf einer breiten und permanenten Regierungskoalition mit beinahe achtzig Prozent der Parteiwählerstimmen. Die notwendige Oppositionsfunktion übernimmt dagegen immer wieder und in wechselnden Zusammensetzungen von links bis rechts das Volk, d.h. die in den diversen Abstimmungen sich artikulierende jeweilige Bürgerminderheit. Eine Minderheit, die im nächsten Plebiszit mindestens teilweise wieder zur Mehrheit gehören kann. Dass solche Strukturen nur dann brauchbar sind, wenn sie tragfähige Kompromisse erzeugen und dadurch nachhaltige Integrationsleistungen erbringen, liegt auf der Hand und lässt sich empirisch überprüfen. ${ }^{15}$

Die direkte Demokratie ist als Institution daher stets vor die Alternative gestellt, entweder zuverlässig zu funktionieren und vor allem für gute Resultate zu sorgen oder ziemlich rasch zu scheitern. Im Fall der Schweiz ist das Letztere bis heute mit Erfolg verhindert worden. Zurückführen lässt sich dies erstens auf die eben angedeuteten Elemente ihrer politischen Kultur einer frühzeitigen Einbindung kontroverser Kräfte. Zweitens sorgen eine typisch schweizerische Kompromisssuche bzw. -bereitschaft für dauerhaft funktionierende Institutionen der direkten Demokratie. Und schließlich kommt drittens die prinzipielle Offenheit für die Interessen mehr oder weniger aller Minderheiten des Landes einer breiten Akzeptanz der Institutionen und ihrer Entscheidungen entgegen.

Gelingt aber diese Integration des Diversen in die Einheit der gemeinsamen Föderation, dann verwandeln sich gerade die gefährlich zerbrechlichen Realisierungsbedingungen der direkten Demokratie in Stärken: Das, was unter weniger günstigen Umständen zur fatalen Blockademacht werden könnte, die Vetodrohung des Referendumsrechts, befördert durch seinen permanenten Zwang zur Zusammenarbeit sowohl die Kenntnisnahme des jeweils Anderen in dessen Alterität als auch die geduldige Entwicklung breit abgestützter Entscheidungen. Anders gesagt: Die Schweiz liefert das Beispiel für die Vermutung, dass möglicher und nicht selten manifester Streit über das Gemeinwohl und das politisch Richtige die für die demo-

14 Manfred G. Schmidt: Demokratietheorien, Opladen 2006, S. 367.

15 Vgl. Leonhard Neidhart: Plebiszit und pluralitäre Demokratie, Bern 1970. 
kratische Selbstbestimmung konstitutive Gemeinsinnigkeit nicht schädigen muss, sondern im Gegenteil zum Kitt des Demos werden kann. ${ }^{16}$

Hinsichtlich des Verhältnisses zwischen dem Bedürfnis nach sogenannter ,Transzendenzstellung des Basiskonsens einerseits und der Diskursempfindlichkeit und diskursiven Kritisierbarkeit der fundierenden Gewissheiten anderseits zeigt sich an der schweizerischen Direktdemokratie, dass - je besser die allgemeine politische Diskursfähigkeit ausgeprägt ist - die Notwendigkeit einer Überhöhung und diskursiven Entzogenheit des Basiskonsenses abnimmt. So

„kennt die Schweiz keine emphatische, sondern eine rationale und pragmatische Kultur. Zwar hängen überall Fahnen, die mit ihrem Kreuz im internationalen Fahnenkonzert überdies besonders gut sichtbar sind und vergleichsweise stark auffallen [...]. Die erfolgreiche Entwicklung des Landes, die Abwesenheit schwerer Krisenerfahrungen und kollektiver Nöte hat auch die Mittel der ideologischen Notlösungen, der kompensatorischen Tröstungen und propagandistischen Täuschungen sowie der Ablenkungen weniger notwendig gemacht.“17

Diese Feststellung Neidharts gilt einerseits der Erscheinungsweise der politischen Kultur der Schweiz, andererseits der Erklärung ihrer besonderen Phänomenalität. Deren „rationale“ und ,pragmatische“, wenig aufgeregte, „selbstverständliche“ Form verdanke sich den langen Perioden relativ ungebrochener Selbsterhaltung und friedlicher Selbstbestimmung. Dabei legt Neidhart das Gewicht seiner Argumentation mehr auf die Erfahrung der Dauer, während ich vor allem das aktive Moment der direktdemokratisch ermöglichten und geforderten Gestaltungstätigkeit in und an der Autonomie betone: Eben weil man den eigenen Zusammenhalt immer wieder durch die Notwendigkeit gemeinsamer Willens- und Entscheidungsbildung regeneriert, ist man gefeit vor der Schwächung des fundamentalen, aber prinzipiell fragilen Basiskonsens durch das Verblassen der ihn verklärenden Mythen. Weil man die res publica in der politischen Selbstgestaltung immer wieder bestätigen, ja allererst verwirklichen muss, braucht sie weniger rituell-sakrale Erinnerungsarbeit. Der politisch-soziale Zusammenhalt erneuert sich durch die unauffällige Anpassung seiner Verfu-

16 Vgl. Georg Kohler: Common sense und die Hirschmann-These, in: ders.: Bürgertugend und Willensnation, Zürich 2010, S. 59-62.

17 Leonhard Neidhart: Die politische Schweiz. Fundamente und Institutionen, Zürich 2002, S. 214f. (Hervorhebung GK). 
gungen an die fälligen Problemlösungen, so dass allzu starre Transzendenzkonstruktionen geradezu kontraproduktiv wirken würden. Vollkommen einig bin ich jedoch mit Neidhart in der Beschreibung der eigentümlich nicht-emphatischen Selbstinszenierung der politischen Gemeinschaft.

\section{Die Willensnation In DER tRANSNATIONALEN KONSTELlation OdER: DER NERVÖse PUNKT}

Für die meisten Schweizer selbstverständlich und für jeden Nicht-Schweizer einigermaßen schwer begreiflich ist die unmittelbare Verknüpfung des identitätsbildenden Nationalgefühls mit den Elementen der direktdemokratischen Verfassung. Die Strukturen der eidgenössischen Form, Volkssouveränität rechtlich zu realisieren, ${ }^{18}$ sind affektiv hoch besetzte Werte. Die Identifikation mit ihnen gehört zum emotionalen Fundament, zum Kern des Wir-Gefühls und so zum legitimitätsstiftenden Basiskonsens, der das Staatsvolk zur Einheit der mehrsprachigen, alltagskulturell stark diversifizierten politischen Nation integriert.

Die prinzipielle Bereitschaft zur explizit politischen, in der Verfassung institutionell geregelten und auf Dauer gestellten Deliberation und Verständigung bildet also auch den gemeinschaftspsychologischen Grund der nationalen Einheit. Das dies der Fall ist, macht das durchaus Eigenartige der schweizerischen Verbindung von Gemeinsinn (= Wir-Gefühl) und Transzendenz (= der als unverfügbar vorgestellte, inhaltliche Basiskonsens) aus. Alles aber, was diesen Zusammenhang und dessen Möglichkeitsbedingungen in Frage stellt (oder in Frage zu stellen scheint), wird dann als fundamentale Bedrohung des kollektiven Selbst und auch der je individuellen Identität wahrgenommen - mindestens bei denen, die das SchweizerSein als einen wesentlichen Aspekt ihrer Persönlichkeit betrachten.

Das also ist der nervöse Punkt der Willensnation: die Verknüpfung von außenpolitischer Autonomie und direktdemokratischer Selbstgestaltung. Seit etwa zwanzig Jahren ist das Land immer wieder mit Kräften und

18 Auch hier wären längere Exkurse nötig. Die Schweiz besitzt nämlich nicht nur eine plebiszitäre Demokratie, sondern auch ein stark föderal gegliedertes politisches System, das auf dem Prinzip der Subsidiarität aufbaut. Entsprechend wichtig sind die Selbstbestimmungsrechte der Kantone, aber auch diejenigen der Gemeinden. 
Vorgängen beschäftigt, die genau auf diesen Punkt zielen. ${ }^{19}$ Insofern ist es nicht verwunderlich, wenn es heute auch Argumente gibt, die spezifisch schweizerische Verbindung zwischen Gemeinsinn und Transzendenz anders zu beleuchten, als ich das hier getan habe. ${ }^{20}$

Die trans- und postnationale Konstellation, d.h. die bekannten zivilisationstypischen Vernetzungsprozesse der Handlungsbedingungen und Risikofolgen, die einzel- oder gar kleinstaatlich nicht mehr zu bearbeiten sind, nötigen immer häufiger zu institutionellen Arrangements und Politikformen, die die Angehörigen der direktdemokratischen, auf ihre Eigenständigkeit bedachten Willensnation beunruhigen, ja erschrecken müssen. Denn die Willensnation setzte, um ihr gewachsenes Selbstverständnis zu bewahren, stets nicht bloß ein speziell hohes Maß an Engagement und Partizipationsbereitschaft ihrer Bürger und Bürgerinnen voraus, sondern immer auch deren glaubwürdige Überzeugung, dass im ,eigenen Haus' das ,Volk' das letzte Wort hat und allemal behält. Solche Erwartungen werden freilich unplausibel, wenn die staatlichen Institutionen und ihre tragenden Ideen, wie beispielsweise die unantastbare Eigenständigkeit und die unverrückbare Souveränität des Volkes, entmächtigt und haltlos werden.

Dass sich deshalb neben der auch in parlamentarischen Demokratien zu registrierenden Politikmüdigkeit und -verdrossenheit der Bevölkerung seit einiger Zeit eine spezifisch schweizerische Reaktionsform, nämlich ein zum Teil folkloristischer, zum Teil grotesk anmutender Superpatriotismus entwickelt hat, ist nicht überraschend. Man darf ihn als „Helvetofundamentalismus" erläutern und als Wirkung der neuen Situation deuten, in welche die Willensnation mit dem Ende des Kalten Krieges gerückt worden ist. ${ }^{21}$

Im fundamentalistischen Kontext sind nun allerdings Narrative, Sakralisierungen historischer Orte und Traditionen, mythisierende Selbstdeutungen und Ritualisierungen des Gebrauchs von schweizerischen Leitbegriffen wie Neutralität oder Volkssouveränität zu beobachten, die schlecht

19 Im Gegensatz zu Neidhart (Die politische Schweiz, 2002) bin ich der Meinung, dass man heute der Schweiz eine eigentliche Identitätskrise diagnostizieren muss. Vgl. dazu Kohler, Common sense, 2010.

20 Vgl. Angelo Maiolino: Die Willensnation Schweiz im Spannungsfeld konkurrierender Transzendenzbezüge, in diesem Band.

$21 \mathrm{Zu}$ diesem Begriff vgl.: Georg Kohler: Die eigensinnige Willensnation und $\mathrm{Eu}-$ ropas Verfassungslücke. Warum die Schweiz nicht so klein ist, in: ders./Martin Meyer (Hrsg.): Die Schweiz - für Europa? Über Kultur und Politik, München 1998, S. 11-28, insbesondere S. 20f. 
zum pragmatischen Stil der politischen Kultur passen, wie ihn Neidhart charakterisiert. Es sind dies Transzendenzbehauptungen, die damit der Deliberation gerade entzogen werden sollen und so - als der Deliberation entzogene - fatale Folgen für die besondere Diskursivität der Schweizer Prozeduren haben können. Diese Operationen lassen sich im weitesten Sinne als zivilreligiöse Sublimierungen qualifizieren, sowie - aus ideologiekritischer Perspektive - als Symptome von Lernverweigerung und nationalkonservativem Eigensinn. Denn sie gehen diskussionslos davon aus, dass die direktdemokratische Willensnation im Rahmen der postnationalen Konstellation entweder sich abschotten oder aber untergehen muss. Wer für den dritten Weg plädiert, ist - aus dieser Sicht - naiver Dummkopf oder ein Verräter. Doch durch die Hinweise auf diesen aktuellen Streit wird hier von mir bloß das nächste Kapitel in der Selbstreflexion des Landes bezeichnet: die Auseinandersetzung der Willensnation mit den Zwängen der Gegenwart und den Bedingungen von Demokratie in Zeiten der Globalisierung. 



\section{Brauchen Demokratien eine Zivilreligion?}

Über die prekären Grundlagen republikanischer Ordnung Überlegungen im Anschluss an Jean-Jacques Rousseau ${ }^{1}$

HANS VORLÄNDER

\section{Das Rousseau'sche Problem}

Im Grunde, so befand Jean-Jacques Rousseau, brauchte man „Götter, um den Menschen Gesetze zu geben“" ${ }^{\text {2 }}$. Das war gewiss metaphorisch gemeint, aber es bezeichnete ein grundlegendes Problem. Wie nämlich war die Aporie zu lösen, nach der die Gründung eines politischen Gemeinwesens das voraussetzte, was es erst schaffen sollte, nämlich ein corps moral et collectif:

„Damit ein werdendes Volk die gesunden Grundsätze der Politik schätzen und den grundlegenden Ordnungen der Staatsräson folgen kann, wäre es nötig, daß die Wirkung zur Ursache werde, daß der Gemeinsinn, der das Werk der Einrichtung sein soll, der Errichtung selbst vorausgehe und daß die Menschen schon vor den Gesetzen wären, was sie durch sie werden sollen. “3

1 Dieser Beitrag erscheint gleichzeitig in: Jahrbuch der Schweizerischen Philosophischen Gesellschaft/Annuaire de Société suisse de philosophie: Die Idee der Demokratie - L'idée de démocratie, Red.: Anton Hügli/Curzio Chiesa, Basel 2012, S. 119-138.

2 „Il faudroit des Dieux pour donner des lois aux hommes.“ (Jean-Jacques Rousseau: Du contrat social, in: CEuvres Complètes. Tome III, Paris 1964, S. 381)

3 Jean-Jacques Rousseau: Vom Gesellschaftsvertrag, neu übersetzt und hrsg. von Hans Brockard, Stuttgart 1977, S. 46. Im Original: ,[I]1 faudroit que l'effet put devenir la cause, que l'esprit social qui doit être l'ouvrage de l'institution présidât à l'institution même, et que les homes fussent avant les loix ce qu'ils doivent devenir par elles.“ (ders., Euvres, 1964, S. 383) 
Mit Zwang konnte das Gemeinwesen nicht zustande kommen, das widersprach der moralischen Zielsetzung; mit machtgestützter Souveränität auch nicht, denn diese entstand erst durch den Gründungsakt. So bleibt Rousseau nur eine „Autorität anderer Ordnung“, die die „Väter der Nationen zu jeder Zeit zwang, ihre Zuflucht zum Himmel als Mittler zu nehmen“4 ${ }^{\text {. Der Re- }}$ kurs auf die göttliche und himmlische Transzendenz war nicht nur ironisch gemeint, Rousseau verfolgte mit diesem Verweis die Absicht, seine Figur des Législateur mit einer besonderen Aura auszustatten, die es dem Gesetzgeber erlaubte, mit ,großer Seele“ die Verfassung zu stiften und die Völker zu überzeugen, sie anzunehmen - und zwar genau so, wie es Moses, Lykurg, Numa und Mohammed getan hatten.

Das Rousseau'sche Problem ist damit aber nicht erledigt. Es setzt sich fort: Wie kann das einmal gegründete politische Gemeinwesen erhalten werden? Rousseau gibt eine Reihe von Bedingungen an, wobei die begrenzte räumliche Ausdehnung eine nicht geringe Rolle spielt. Eine kleine Republik vermag zu gewährleisten, was Rousseau das Allerwichtigste ist, nämlich das „,soziale Band“, den Zusammenhalt der Gemeinschaft, zu erhalten. Der Bestand scheint ihm, wie er aus der Geschichte glaubt ableiten zu können, indes letztlich nur durch die Religion möglich zu sein: „Sitôt que les h[ommes] vivent en société il leur faut une Religion qui les y maintienne. Jamais peuple n'a subsisté ni ne subsistera sans Religion et si on ne lui en donnoit point, de lui-même il s'en feroit une ou seroit bientôt détruit." 5

Und dennoch gibt sich Rousseau gegenüber der tradierten, christlichen Religion äußerst reserviert. Sie scheint ihm nicht das zu gewährleisten, was er von ihr erwartet, nämlich den Zusammenhalt des corps collectif zu garantieren. Deshalb schlägt er etwas vor, das Religion ist und doch keine

4 Rousseau, Gesellschaftsvertrag, 1977, S. 46. Rousseau kannte seinen Machiavelli, er übernimmt nicht nur den Gedanken, sondern auch fast wörtlich von Machiavelli, der in den Discorsi schreibt: „In der Tat gab es nie einen außerordentlichen Gesetzgeber bei einem Volke, der sich nicht auf Gott berufen hätte, weil seine Gesetze sonst gar nicht angenommen worden wären. Denn ein kluger Mann erkennt vieles Gute, aber die Gründe dafür sind nicht so augenscheinlich, daß man andere davon überzeugen könnte. Darum nehmen weise Männer ihre Zuflucht zu Gott, so Lykurg, so Solon und viele andre, die den gleichen Zweck verfolgen." (Niccolò Machiavelli: Discorsi. Staat und Politik, übersetzt von Friedrich von Oppeln-Bronikowski, Frankfurt a.M./ Leipzig 2000, S. 54)

5 Rousseau, Euvres, 1964, S. 336. 
Religion sein will, eine religion civile, ,une profession de foi purement civile“66.

Rousseaus Begriff der Zivilreligion geriet zunächst in Vergessenheit und tauchte erst wieder in der zweiten Hälfte des 20. Jahrhunderts auf. Der amerikanische Soziologe Robert Bellah knüpfte an Rousseau an, als er in seinem Aufsatz von 1967 Civil Religion in America auf den - in der Sache keineswegs neuen und überraschenden - Befund aufmerksam machte, dass die öffentliche Rhetorik in den Vereinigten Staaten von Amerika die kontinuierliche Wiederkehr eines bestimmten Motivkomplexes erkennen lässt, der in seiner Substanz von biblischen, jüdisch-christlichen Archetypen geprägt ist. ${ }^{7}$ Vorstellungen, Bilder und Metaphern wie Exodus, Chosen People, Promised Land, New Jerusalem, Sacrificial Death und Rebirth geben, wie Bellah argumentierte, dem „Reich der Politik“ eine religiöse Dimension. Dabei sei diese American Civil Religion jedoch weder in den Inhalten noch in der Funktion identisch mit christlichen Glaubensvorstellungen und auch keineswegs an distinkte christliche Konfessionen und Denominationen gebunden. Das Entscheidende sei, dass sich diese Zivilreligion transzendenter Motive und Bilder bediene, um die nationale Existenz in den Begriffen einer religiösen Symbolwelt zu interpretieren. Damit handele es sich, trotz ihrer jüdisch-christlichen Verwurzelung, um eine genuin neue und amerikanische Zivilreligion, die auch ihre eigenen Propheten und Märtyrer, ihre heiligen Ereignisse und Stätten sowie feierliche Rituale und Symbole kenne. Entscheidend war für Bellah die Funktion dieser Zivilreligion, die nämlich, wie Novak später formulierte, als „cohesive force and center of meaning and uniting our many peoples ${ }^{\text {“8 }}$ wirken sollte. Mit dieser Bestimmung konnte Bellah in der amerikanischen Zivilreligion ein Moment des Zusammenhaltes der amerikanischen Gesellschaft sehen - genau so, wie es Rousseau vorgesehen hatte. Bellahs Aufsatz wurde sehr kontrovers rezipiert, ging doch bei ihm wissenschaftliche Analyse und politische Intention eine normativ-präskiptive Verbindung ein. Nicht immer klar getrennt wurde zwischen der analytischen Bestimmung

6 Ebd., S. 468. Rousseau hatte seine Passagen zur Zivilreligion zunächst auf die Rückseite seines Manuskriptes der ersten Fassung des Contrat social geschrieben, und zwar dort, wo er über den Législateur handelt.

7 Robert N. Bellah: Civil Religion in America, in: Daedalus 96 (1967) 1, S. 1-21. Ich folge hier früheren Darstellungen von mir, vgl. Fn. 16.

8 Michael Novak: Choosing our King. Powerful Symbols in Presidential Politics, New York 1974, S. 127 (Hervorhebung im Original). 
einer funktionalen Rolle religiöser Werte und Orientierungen für das soziale und politische System auf der einen Seite und dem von der Sorge um den Zusammenhalt der amerikanischen Gesellschaft getragenen Appell, die religiösen Bestände für die Fortschreibung der amerikanischen Zivilreligion lebendig zu halten und auf dieser Grundlage den Zusammenhalt der amerikanischen Nation zu gewährleisten.

Der Begriff der Zivilreligion ist bis heute, trotz, vielleicht auch wegen der zahlreichen Studien und gelegentlichen Renaissancen, problematisch geblieben. ${ }^{9}$ Das liegt nicht zuletzt daran, dass es sich im Grunde um eine Schimäre handelt, die scheinbar Unvereinbares miteinander verkoppelt, den zivil-profanen und den religiös-sakralen Bereich, und doch in der Amalgamierung weder pure Religion noch reine Zivilität ist, sondern ein Drittes, etwas Eigenes, vor allem Selbständiges, bezeichnen will. Der Begriff suggeriert zweierlei, und dies auf kontradiktorische Weise: zum einen die Verschiedenheit der Zivilreligion von der Religion, zum anderen die Verwiesenheit von Zivilität auf Religion. Anders, und paradox formuliert: Religion, die nicht Religion sein darf, erscheint als Konstituens von Zivilität, als Bedingung, ohne die eine zivile politische Ordnung nicht zu haben, geschweige denn auf Dauer zu stellen ist. Nach dem Selbstverständnis der politischen Moderne aber sind Religion und Staat, das Sakrale und das Profane, deutlich voneinander getrennt, ${ }^{10}$ beziehungsweise,

9 Vgl. etwa Thomas Hase: Zivilreligion. Religionswissenschaftliche Überlegungen zu einem theoretischen Konzept am Beispiel der USA, Würzburg 2001; Martin Honecker: Eschatologie und Zivilreligion. Marginalien zu zwei strittigen Theologumena, in: Evangelische Theologie 50 (1990), S. 40-55; Mathias Hildebrandt: Politische Kultur und Zivilreligion, Würzburg 1996; Heinz Kleger/Alois Müller (Hrsg.): Religion des Bürgers. Zivilreligion in Amerika und Europa, Münster 2004; Hermann Lübbe: Religion nach der Aufklärung, Graz 1986; Niklas Luhmann: Grundwerte als Zivilreligion, in: Kleger/Müller, Religion des Bürgers, 2004, S. 175-194; Herfried Münkler: Die Idee der Tugend. Ein politischer Leitbegriff im vorrevolutionären Europa, in: Archiv für Kulturgeschichte 73 (1991), S. 379-403; Rolf Schieder: Civil Religion. Die religiöse Dimension der politischen Kultur, Gütersloh 1987; Wolfgang Vögele: Zivilreligion in der Bundesrepublik Deutschland, Gütersloh 1994. Jürgen Habermas (Rortys patriotischer Traktat. Aber vor Analogien wird gewarnt, in: Süddeutsche Zeitung, 27.02.1999, S. 13) lehnt den Begriff der Zivilreligion ab.

10 Heilig auf der einen Seite, profan auf der anderen Seite - so die bekannte Leitunterscheidung bei Émile Durkheim, der das Heilige auf ,,abgesonderte und verbotene Dinge, Überzeugungen und Praktiken“ bezieht, die „in einer und derselben moralischen Gemeinschaft, die man Kirche nennt, alle vereinen, die 
normativ gesehen, zu trennen. Befund wie Konzept von Zivilreligion müssen deshalb irritieren.

Ein Weiteres tritt hinzu. In normativer Hinsicht ist und bleibt das Konzept der Zivilreligion vor allem deshalb umstritten, weil es einen Verweisungszusammenhang zu „Religion“, also vermeintlich vormodernen, „voraufgeklärten“ Kulturbeständen, herstellt, weil es mithin in der einen oder anderen Weise mit Religion, zumindest aber mit Religiosität ,rechnet', und sich somit zur Frage der Religion affirmativ oder kritisch-ablehnend verhält. Das Konzept der Zivilreligion ist mithin in einer polemischen Konfliktstellung von (moderner) Politik und (vormoderner) Religion gefangen. Darüber hinaus: Mit dem Konzept der Zivilreligion wird die grundsätzliche Legitimitätsfrage der Neuzeit und ihres Verhältnisses zu einer als christlich-mittelalterlich identifizierten Vormoderne aufgerufen. ${ }^{11}$ In beiden Konstellationen geht es um die Begründung moderner politischer Ordnungen, und zwar in ihren zwei Dimensionen: Der Gründung des Neuen, der demokratisch-republikanischen Ordnung als Ergebnis revolutionärer Wendungen (und der Widerstände alter Ordnungen) und der guten Gründe, die die neue Ordnung rechtfertigen oder sie bestreiten.

\subsection{Das Problem des Anfangs politischer Ordnung}

Mit dem Begriff der Zivilreligion werden zwei zentrale Probleme politischer Ordnung in einer spezifischen Weise adressiert: das der Gründung und das des Zusammenhaltes republikanischer Ordnungen. Für Hannah Arendt ist es eine „uralte Denkgewohnheit des Abendlandes“: Jeder „Ur-

ihr angehören." (Émile Durkheim: Die elementaren Formen des religiösen Lebens, Frankfurt a.M./Leipzig 2007, S. 76)

11 In diesem Sinne hat Carl Schmitt - zuerst in Auseinandersetzung mit Erik Peterson, zuletzt mit Hans Blumenberg - dafür plädiert, ,[a]lle prägnanten Begriffe der modernen Staatslehre“ als ,säkularisierte theologische Begriffe“ zu verstehen (Carl Schmitt: Politische Theologie. Vier Kapitel zur Lehre von der Souveränität, Berlin 1996, S. 43); Hans Blumenberg/Carl Schmitt: Briefwechsel, Frankfurt a.M. 2007. Vgl. zur kritischen Diskussion um den von Schmitt geprägten Begriff der „Politischen Theologie“: Hans Maier: Politische Religionen, München 2007, S. 15ff.; Jan Assmann: Herrschaft und Heil. Politische Theologie in Altägypten, Israel und Europa, Frankfurt a.M. 2002, 15ff.; Henning Ottmann: Politische Theologie als Begriffsgeschichte. Oder: Wie man die politischen Begriffe der Neuzeit politisch-theologisch erklären kann, in: Volker Gerhardt (Hrsg.): Der Begriff der Politik. Bedingungen und Gründe politischen Handelns, Stuttgart 1990, S. 169-188. 
anfang braucht ein Absolutes, aus dem er ,rational ' erklärt werden kann.“12 Zumeist ist es die Figur des Schöpfers, eines höchsten Wesens, eines Urgesetzgebers, auf den der Anfang zurückgeführt wird. Auch sind es Ursprungslegenden oder „Anfangsspekulationen“, die den neuen Anfang ins Recht setzen und ihm eine fortdauernde Legitimität sichern sollen. Es ist

„die biblische Geschichte von dem Auszug der Kinder Israel aus Ägypten und Vergils Erzählung von den Wanderungen Äneas', nachdem er aus dem brennenden Troja entkommen war. In beiden Legenden handelt es sich um Befreiung, um Befreiung aus der Knechtschaft und dem Entrinnen aus sicherem Untergang, und im Mittelpunkt beider Geschichten steht die Prophezeiung künftiger Freiheit, das Versprechen eines gelobten Landes oder die Gründung einer neuen Stadt." “13

Die großen Führer solcher Legenden tauchen in einem ,legendären Zeitraum zwischen Ende und Anfang, zwischen einem Nicht-mehr und dem Noch-nicht“" auf. Dieser Umbruch, der Hiatus, die Spekulation um die Zeit zwischen Knechtschaft und Freiheit, zwischen Untergang und Wiedererstehung, sind als Versuche zu lesen, ,die große, unlösbare Frage nach dem Beginn der Welt oder des Seins überhaupt" zu lösen. ${ }^{14}$

Gründungsmythen, Ursprungslegenden, heldenhafte Führer, große Gesetzgeber sind nicht allein Figuren und Metaphern, die die großen, religiösen Erzählungen über den Ursprung der Welt strukturieren und die im Medium der Sagen und Legenden antike Gemeinwesen zu begründen suchten. Moses, Solon und Lykurg sind die Gründer, von denen sich die Legitimation des Gegründeten nachhaltig ableitete. Und Vergils Äneas landet schließlich in Latium, um hier das antike Troja wiedererstehen zu lassen. ${ }^{15}$ Aber auch die Moderne kennt ihre Ursprungsgeschichten, ihre Gründungslegenden und Gründungsgestalten. So verbinden die Vereinigten Staaten von Amerika ihre revolutionäre Loslösung vom englischen Mutterland zuallererst mit jenen charismatischen Gründungsvätern, mit John

12 Hannah Arendt: Über die Revolution, München 1974, S. 265. Ich folge hier meiner Darstellung: Hans Vorländer (Hrsg.): Gründung und Geltung. Die Konstitution der Ordnung und die Legitimation der Konstitution, in: Gert Melville/ Hans Vorländer: Geltungsgeschichten. Über die Stabilisierung und Legitimierung institutioneller Ordnungen, Köln/Weimar/Wien 2002, S. 243-263, hier: S. $244 \mathrm{ff}$.

13 Arendt, Revolution, 1974, S. $263 \mathrm{f}$.

14 Ebd., S. 264.

15 Ebd. 
Adams, Thomas Jefferson, George Washington, aber auch mit jenen Founding Fathers von 1787, die die noch heute geltende amerikanische Verfassung schufen. Alexander Hamilton, John Jay und James Madison stehen am Anfang einer bisweilen kultisch zu nennenden Verehrung der amerikanischen Verfassung, die mit dem Dokument der amerikanischen Unabhängigkeitserklärung zu den ,heiligen Schriften“ der amerikanischen Gründung und des amerikanischen Selbstverständnisses gezählt wird. ${ }^{16}$ Auch die Rede vom New Jerusalem und der Topos von God's Chosen People gehört zu den Bestandteilen einer großen amerikanischen Erzählung von Einwanderern und Gründern, die das Land ihrer Unterdrückung Europa - verließen und ein neues, das ,gelobte“ Land besiedelten, politisch verfassten und ökonomisch prosperieren ließen. Exodus und Zukunftsverheißung, das Promise of American Life, die Declaration of Independence und die Verfassung von 1787 mit der Bill of Rights von 1791 haben sich zu einer Narration verwoben, die den Moment der Gründung tradieren und die Gegenwart mit der Vergangenheit - in einer großen Geltungsgeschichte - verbinden.

Hier wie dort, in der Moderne wie in der Antike, scheint die Aporie des Neubeginns ganz ähnlich, um nicht zu sagen: analog, aufgelöst zu werden. Der Anfang, die Neugründung, muss selbst, um in seiner Legitimität nicht angezweifelt $\mathrm{zu}$ werden, in ein Absolutes hinein verlegt werden, das jenseits des konstituierten politischen Raumes situiert wird. Dieses Abso-

16 Hannah Arendt weist in Über die Revolution immer wieder auf die amerikanische Gründungsgeschichte hin. Vgl. darüber hinaus zu diesen Zusammenhängen: Sacvan Bercovich: Konsens und Anarchie. Die Funktion der Rhetorik für die amerikanische Identität, in: Frank Unger (Hrsg.): Amerikanische Mythen. Zur inneren Verfassung der Vereinigten Staaten, Frankfurt a.M./New York 1988, S. 16-43; Klaus-Michael Kodalle (Hrsg.): Gott und Politik in USA. Über den Einfluß des Religiösen. Eine Bestandsaufnahme, Frankfurt a.M. 1988; Jürgen Gebhardt: Die Krise des Amerikanismus. Revolutionäre Ordnung und gesellschaftliches Selbstverständnis in der amerikanischen Republik, Stuttgart 1976; Hans Vorländer: Hegemonialer Liberalismus. Politisches Denken und Politische Kultur in den USA 1776-1920, Frankfurt a.M./New York 1997, S. 2770; ders.: Der Kampf um die Deutungsmacht. Nationale Identität und Multikulturalismus in den USA, in: ders./Dietrich Herrmann (Hrsg.): Nationale Identität und Staatsbürgerschaft in den USA. Der Kampf um Einwanderung, Bürgerrecht und Bildung in einer multikulturellen Gesellschaft, Opladen 2001, S. 15-54; Ulrike Fischer/Hans Vorländer: Zivilreligion und politisches Selbstverständnis. Religiöse Metaphorik in den Antrittsreden der Präsidenten Ford, Carter, Reagan und Bush, in: Paul Goetsch/Gerd Hurm (Hrsg.): Die Rhetorik amerikanischer Präsidenten seit F.D. Roosevelt, Tübingen 1993, S. 217-232. 
lute wird lebendig gehalten, es muss unsterblich sein, weil sonst die Dauerhaftigkeit und Stabilität der begründeten Ordnung nicht erhalten werden kann. Und zugleich bedarf es ,einer transzendenten und absoluten Autorität", weil nirgends sonst das Recht und die Gerechtigkeit lokalisiert werden können, ,an denen sich doch die jeweiligen Gesetze orientieren müssen, wollen sie nicht einfach der Willkür und den jeweiligen, ewig wechselnden Bedürfnissen der Menschen anheimfallen “'17. Der Neuanfang als Bruch mit der Kontinuität des Gewesenen bedarf eines transzendenten Ankerpunktes, um den Neubeginn selbst zu legitimieren und die durch den Neubeginn konstituierte Ordnung dauerhaft in Geltung halten zu können.

\subsection{Das Problem der Erhaltung politischer Ordnung}

Republikanische wie demokratische Ordnungen sind labil, ihre politische Stabilität ist latent gefährdet. Das ist das große Thema der Geschichte des politischen Denkens und der politischen Theorien. Auf die Frage nach den Voraussetzungen und Bedingungen stabiler republikanischer Ordnung haben politische Philosophen und Theoretiker immer wieder eine Reihe von Antworten zu geben versucht, die sich cum grano salis auf eine soziomoralische und eine institutionelle Antwortvariante zurückführen lassen. ${ }^{18}$ Die erste argumentiert: Eine gute und gerechte politische Ordnung, will sie dauerhaft bestehen, muss von der Tugend ihrer politischen Führer und ihrer Bürger getragen sein. Tugend bedeutet zum einen, dass sich die Regierung, will sie denn eine gute Regierung sein, wie Ambrogio Lorenzettis Fresko in der Allegorie des guten Regiments in Sienas Palazzo Pubblico zum Ausdruck brachte, an Tugenden wie Frieden, Tapferkeit, Klugheit aber auch an Großmut, Mäßigung und vor allem Gerechtigkeit orientieren. Tugend bedeutet zum anderen auch den Verweis auf soziale und moralische Bestände, seien es gemeinsame Traditionen, Wertvorstellungen oder Religionen, die als Lebensführungsmächte das Verhalten der Bürger prägen und somit zu den Voraussetzungen einer guten und stabilen politischen Ordnung zählen können. Die Tugend des Bürgers und des verant-

17 Arendt, Revolution, 1974, S. 239.

18 Vgl. Hans Vorländer: Institution und Tugend. Zur Dialektik des Liberalismus, in: Joachim Fischer/Hans Joas (Hrsg.): Kunst, Macht, Institution. Studien zur philosophischen Anthropologie, soziologischen Theorie und Kultursoziologie der Moderne. Festschrift für Karl-Siegbert Rehberg, Frankfurt a.M./New York 2003, S. 316-330. 
wortlichen, repräsentativ handelnden Politikers, sich in der Gemeinschaft ein- und dem Gemeinwohl unterzuordnen, wird als eine Bestandsvoraussetzung für das politische Gemeinwesen gesehen, für die Polis, die Republik und die Demokratie gleichermaßen. ${ }^{19}$

Nun ist aber auch in der politischen Theorien- und Ideengeschichte das Bewusstsein vorhanden, dass es sich bei der Tugend um ein flüchtiges Element, um eine höchst prekäre Grundlage politischer Ordnung handelt. Der Tugend scheint zum einen eine Dialektik innezuwohnen, die in ihrem Erfolg, der Stabilität eines Gemeinwesens, bereits den Beginn der Dekadenz, des Verfalls des Gemeinwesens enthält. ${ }^{20}$ In seiner Geschichte der Stadt Florenz schreibt Machiavelli:

„Es ist von der Natur den menschlichen Dingen nicht gestattet, stille zu stehen. Wie sie daher ihre höchste Vollkommenheit erreicht haben und nicht mehr weiter steigen können, müssen sie sinken. [...] Denn die Tapferkeit gebiert Ruhe, die Ruhe Müßiggang, der Müßiggang Unordnung, die Unordnung Verfall.“21

Ähnliche Überlegungen hat Adam Ferguson in seinem Essay on the History of Civil Society angestellt:

„Reichtum, Vergrößerung und Macht der Nationen sind im allgemeinen Wirkungen der Tugend. Der Verlust dieser Vorteile ist aber oft die Folge des Lasters. [...] Die Tugenden der Menschen haben ihren stärksten Glanz während der Zeit ihrer Kämpfe, keineswegs aber nach Erreichung ihrer Ziele gehabt. Diese Ziele selbst werden

19 Ohne die Tugend ihrer Bürger, so hatte Montesquieu im Esprit des Lois geschrieben, kann eine Demokratie nicht bestehen (Charles-Louis de Secondat Montesquieu: Vom Geist der Gesetze, Bd. 1, übersetzt und hrsg. von Ernst Forsthoff, Tübingen 1992, S. 62ff.). Und auch für Machiavelli war die Tugend der Bürger das Lebenselixier der Republik. In den Discorsi (I, 16) erklärte dieser, dass ein Volk, bei dem die Tugend fehle und völlige Sittenverderbnis eingerissen sei, keinen Augenblick in Freiheit leben könne (Machiavelli, Discorsi, 2000, S. 58 ff.). James Harrington, Algernon Sidney, Shaftesbury, Francis Hutcheson, Adam Ferguson, Jean-Jacques Rousseau, die Revolutionäre in Nordamerika, Thomas Jefferson - sie alle führten die Vorstellung fort, dass die Tugend des Bürgers die Voraussetzung eines freiheitlichen Gemeinwesens ist und die Tugend des Bürgers darin zu bestehen habe, dass dieser seine eigenen Interessen dem öffentlichen Wohl unterordnet.

20 Münkler, Idee der Tugend, 1991.

21 Niccolò Machiavelli: Politische Schriften, hrsg. von Herfried Münkler, Frankfurt a.M. 1990, S. 318. 
aufgrund von Tüchtigkeit erreicht, sie bilden dann aber häufig die Ursache von Korruption und Laster.“22

Zum anderen beobachten die Diskurse in der beginnenden Neuzeit, dass die „Emanzipation des Interesses“, die rationale Verfolgung eigener Vorstellungen, Werte und Leidenschaften zu ganz anderen, nämlich institutionellen und kontraktuell-rechtlichen Begründungsmustern von Staatlichkeit zwingt. Ein Thomas Hobbes konstruiert more geometrico einen Begriff ungeteilter Souveränität des Staates. Dieser ist mittels seines Machtmonopols in der Lage, die egoistischen Individuen zum Gehorsam zu zwingen, ihnen aber zugleich durch seinen Schutz den Raum friedlicher Interessenverfolgung und Handlungskoordinierung bereitzustellen, den die Individuen zur Verfolgung ihrer eigenen Interessen benötigen. Legitime staatliche Macht in ungeteilter Form ist die eine Antwort auf das Problem der Emanzipation des Interesses. Die amerikanischen Federalists, die Begründer und Verteidiger der Verfassung von 1787, geben eine andere Antwort, indem sie auf John Locke und seine Konzeption gebrochener Souveränität zurückgreifen, aber auch Montesquieu nicht vergessen, der die Mäßigung politischer Herrschaft durch ein Konzept wechselseitiger Machtkontrolle sicherzustellen glaubte. ${ }^{23}$ Die Ordnung des liberalen Konstitutionalismus wird durch ein Konkurrenz- und Kontrollmodell politischer Macht ergänzt. Die institutionellen Folgerungen horizontaler und vertikaler Gewaltenverschränkung (checks and balances) sind bekannt. Das Entscheidende ist, dass in der Moderne die Stabilität der politischen Ordnung weniger mit der Tugend als mit Institutionen und Gesetzen, also mit autoritativen und sanktionsbewehrten Regeln mit Rechtscharakter identifiziert wird.

Und doch bleibt ein Rest, der nicht in der rechtlich-institutionellen Grundstruktur der politischen Ordnung aufgeht und der nicht nur die Vertragstheoretiker beunruhigt. Wie sonst könnte Rousseau solche massiven Zweifel an der Tragfähigkeit seines Vertragsmodells haben, dass er auf die Religion glaubt zurückgreifen zu müssen, um seinem politischen Gemeinwesen Stabilität zu geben - ganz abgesehen davon, dass vor ihm Spinoza, Machiavelli und andere immer wieder auf die sozialen Funktionen

22 Adam Ferguson: Versuch über die Geschichte der bürgerlichen Gesellschaft, hrsg. und eingeleitet von Zwi Batscha und Hans Medick, Frankfurt a.M. 1988, S. 372.

23 Bei Montesquieu (De l'Esprit des Lois, Paris 1970, S. 167 - Livre XI, Ch. IV) heißt es: „le pouvoir arrête le pouvoir.“ 
von Religion zur Stabilisierung politischer Ordnungen insistiert haben. Die Frage lässt sich zuspitzen und auch als ein Grundproblem politischer Vergemeinschaftung beschreiben. Der moderne Staat, der sich, bei Hobbes ganz deutlich, als eine säkulare Antwort auf die Frage nach der Gestaltung und Begründung politischer Ordnung versteht, lebt mit dem Paradox, dass er in seiner Begründung auf Autonomie und Selbstgesetzgebung beruht, und doch, um sein rechtlich-institutionelles Ordnungsarrangement auf Dauer stellen zu können, auf genau jene Voraussetzungen und Ressourcen zurückgreifen muss, auf die er nicht mehr glaubt zurückgreifen zu sollen. ${ }^{24}$

\section{Rousseaus lösung der Probleme: Die Heiligung der Republik}

Zivilreligionen können mithin als Antworten auf das Problem der Begründung und Stabilisierung politischer Ordnungen verstanden werden. ${ }^{25}$ Hier ist an Rousseaus zentrale Frage anzuschließen, wie eine republikanische Ordnung gegründet und erhalten werden kann. Anscheinend reichen kontraktualistische, auf Autonomie und Selbstgesetzgebung beruhende Begründungsformen für die Einrichtung des moi commun und die Ausbildung von sentiments de sociabilité nicht aus. Rousseaus Antworten bestehen zum einen in der heiligend-divinisierenden Selbsttranszendierung des Contrat social, seiner und des Gesetzgebers Unverfügbarstellung qua Sakralisierung, und zum anderen in der - bei Rousseau sanktionsbewehrten Kreierung einer religion civile, eines republikanischen, rein bürgerlichen Glaubensbekenntnisses. Der Einsetzungsakt des Staates wird damit „,celeste et indestructible“26. Die Zivilreligion sichert das, über die Befolgung der Gesetze hinaus gehende Maß an Soziabilität, ohne welches der Staat auf Dauer nicht bestehen kann.

24 Etwas anders die bekannte Formulierung bei Ernst-Wolfgang Böckenförde: Die Entstehung des Staates als Vorgang der Säkularisation, in: ders.: Recht, Staat, Freiheit. Studien zur Rechtsphilosophie, Staatstheorie und Verfassungsgeschichte, Frankfurt a.M. 1992, S. 92-114, hier: S. 112.

25 In diesem Sinne sind Zivilreligionen auch als politisch-soziale Selbstthematisierung des Politisch-Theologischen Komplexes zu verstehen. Vgl. hierzu: Claude Lefort: Fortdauer des Politisch-Theologischen?, Wien 1999; Marcel Gauchet: Le désenchantement du monde. Une histoire politique de la religion, Paris 2009.

26 Rousseau, Euvres, 1964, S. 318. 
Rousseaus doppeltes Argument ist von der Intention sicher weit weniger ,totalitär', als es - nicht zuletzt in der doppelten Erfahrung des Revolutionsterrors und der Totalitarismen des 20. Jahrhunderts - gedeutet worden ist. $^{27}$ Gewiss lässt es sich in einer zugespitzten Lesart zu einem repressiven Instrument verschärfter Loyalitäts- und Bekenntnispflichten, auch solcher eines totalitären oder diktatorischen Staates, schmieden. ${ }^{28}$ Es lässt sich aber auch, wesentlich entspannter, als Versuch lesen, einen Kernbestand an Wissen und Überzeugungen über den Ursprung und die tragenden Prinzipien der politisch-gemeinschaftlichen Verfasstheit zu sichern und durch ihn einen wechselseitigen Verpflichtungs- und Bindungszusammenhang zu erzeugen, der das erforderliche Minimum an Loyalität und Solidarität unter den Bürgern ermöglicht - eine „Gesinnung des Miteinander, ohne die es unmöglich ist, ein guter Bürger und ein treuer Untertan zu sein““29. Die Dogmen der Zivilreligion, von denen er meint, sie müssten ,einfach, gering an Zahl und klar ausgedrückt" sein, unterstützen diese wohlwollende Lesart des Rousseau'schen Konzeptes, denn sie beinhalten ein Verbot der Intoleranz, das Prinzip der Gerechtigkeitsliebe und den Glauben an das zukünftige Leben. ${ }^{30}$ Letzteres wie auch das ebenfalls zur Zivilreligion zu zählende Dogma der ,Existenz der allmächtigen, allwissenden, wohltätigen, vorhersehenden und sorgenden Gottheit" können als kanonische Bestände des christlichen Glaubens gelesen werden, sie sind aber auch außerhalb des christlichen Bezugsrahmens verstehbar: Rousseau meint den deistischen Gott. Und der Glaube an die Zukunft ermöglicht verantwortungsvolles

27 So vor allem Jacob L. Talmon: The Rise of Totalitarian Democracy, Boston, Mass. 1952.

28 Rousseau lädt natürlich auch in den Passagen zur Zivilreligion dazu ein, wenn er davon spricht, dass es allein der Souverän ist, der befugt ist, die Dogmen zu formulieren und die ,Ungläubigen', die die Gesetze und die Gerechtigkeit „ernstlich“ nicht lieben und ,sein Leben im Notfall der Pflicht zu opfern“, zu verbannen (Rousseau, Gesellschaftsvertrag, 1977, S. 151). Noch drastischer hatte Rousseau in der ersten Version des Contrat social argumentiert. Zum einen sollte das bürgerliche Glaubensbekenntnis explizit beschworen werden (Euvres, 1964, S. 340), zum anderen war der öffentliche Verrat am heiligen Gesellschaftsvertrag und den heiligen Gesetzen mit nichts weniger als der Todesstrafe zu ahnden (ebd., S. 341).

29 Hier wie im Folgenden: Rousseau, Gesellschaftsvertrag, 1977, S. 151.

30 Was - nicht nur in den Augen Rousseaus - Voraussetzung für das gemeinnützige Engagement des Bürgers ist, der auf den Nachruhm seines Opfers für das Gemeinwesen setzt; eine zutiefst römisch-republikanische, auch griechischpolisdemokratische Erwartung, die sich dann vor allem im Städterepublikanismus - nicht nur - Oberitaliens wiederfindet. 
Handeln des Bürgers, und zwar auch dann, wenn nicht die Vorstellung des Jüngsten Gerichtes damit verbunden wird. Denn der Nachruhm als Motiv bürgerschaftlichen Handelns benötigt ebenfalls die Gewissheit zukünftigen Lebens, zumindest die Erwartung, dass eine Generation nachfolgt.

Gleichwohl zeigt sich gerade in diesen Bestimmungen, dass Rousseaus Konzept durchaus noch auf den Beständen religiöser Vorstellungen und Praktiken und einer Indienstnahme der christlichen Tradition aufruht, auch wenn er seine Zivilreligion deutlich sowohl vom spirituellen Christentum als auch der katholischen Priesterreligion, einer Form der religion des Lamas, abgrenzt. Wo erstere ihm mit ihrem Universalanspruch trop sociable erscheint und in der Betonung allumfassender Brüderlichkeit keine spezifischen Bindungen erzeugt, entwickelt letztere Pflichtenkonkurrenzen zwischen dem religiösen und dem politischen Reich und spaltet so die Gesellschaft in ein système théologique und ein système politique. ${ }^{31}$ Hingegen geht es Rousseau darum, die christliche Orientierung auf den Anderen für den Zusammenhalt des politischen Gemeinwesens nutzbar zu machen, zugleich aber die christlichen Dogmen in ihren Absolutheitsansprüchen unschädlich zu halten. Rousseau findet damit zu einer instrumentellen Religionsauffassung, welche den Wahrheits- und Bekenntnisanspruch des christlichen Glaubens ablehnt, seinen Nutzen aber in Form und Funktion für die Zivilreligion vereinnahmt: „Je vois [..] deux manières d'examiner et comparer les religions diverses: l'une selon le vrai et le faux [...] l'autre selon leurs effets temporels et moraux sur la terre,

31 Rousseau grenzt seine Konzeption der Zivilreligion auch von den Polisreligionen $\mathrm{ab}$, in denen er - wohl historisch unrichtig - eine vollständige Identität von Religion und Staat, also eine theokratische Herrschaft, erblickt. Auch die religion du citoyen ist nicht die gesuchte religion civile, weil sie partikulare Glaubens- und Bekenntnispflichten fordert. Die Zivilreligion ist also eine Mischform zwischen der religion de l'homme des ursprünglichen Christentums und einer religion du citoyen. Gegenüber ersterer reklamiert die religion civile erhöhte Ansprüche an Loyalität und Engagement, gegenüber letzterer ist das bürgerliche Glaubensbekenntnis offener, weniger militant, vor allem toleranter gegenüber anderen partikularen Gemeinschaften. $\mathrm{Zu}$ diesen Unterscheidungen vgl. die Arbeit von Sonja Asal: Der politische Tod Gottes. Von Rousseaus Konzept der Zivilreligion zur Entstehung der Politischen Theologie, Dresden 2007, S. 97ff.; Iring Fetscher: Rousseaus politische Philosophie. Zur Geschichte des demokratischen Freiheitsbegriffes, Frankfurt a.M. 1975, S. 184ff. sowie Michaela Rehm: Bürgerliches Glaubensbekenntnis. Moral und Religion in Rousseaus politischer Philosophie, München 2006. 
selon le bien ou le mal qu'elles peuvent faire à la société et au genre humain $[\ldots]$...32

Damit folgt Rousseau nicht den rigiden, kämpferischen Negations- und Abwehrstrategien christlich-religiöser Ordnungsansprüche, wie sie etwa Hobbes mit der polemischen Einführung seines „sterblichen Gottes“, dem auf kontraktueller Grundlage entstandenen Leviathan, intendiert hatte. Rousseau schlägt sich eher auf die Seite der Versuche, ein strategisches Kalkül der Instrumentalisierung von tradierter Religion bei gleichzeitiger Neutralisierung ihrer universalen Geltungsansprüche zu entwerfen. Schon mit Machiavelli beginnt die Suche nach den spezifischen funktionalen Leistungen von Religion und Religiosität für den Erhalt einer - prekär gewordenen - republikanischen Ordnung. Dabei können, wie die nordamerikanischen Diskurse um Besiedlung, Gründung oder Krise der USA zeigen, Formen des friendly takeover $^{33}$ von Inhalten und Formen religiöser (in diesem Fall vor allem puritanischer) Bestände zu zivilreligiösen Amalgamierungen einer public, political, national oder civic religion ${ }^{34}$ führen.

\subsection{Gesellschaftliche Selbsttranszendierung}

Indes bleibt die Frage offen, ob eine religion civile auch ohne diese religiösen Bestände oder Überhänge konstruiert werden und die erhofften integrativen und stabilisierenden Wirkungen entfalten kann. Im neuzeitlichen Diskurs über die Begründungs- und Rationalitätsannahmen moderner politischer Ordnungen verschwinden zwar die ,großen“ religiösen Transzendenzen, sie kehren aber in kleineren Formen, Figuren und Metaphern wieder: der „sterbliche Gott“ einerseits als Beschreibung des artifiziellen, auf Vereinbarung beruhenden Leviathan, „Jesus is the Christ“ andererseits als den bürgerlichen Gehorsam verbürgendes Dispositiv bei Hobbes, und bei Rousseau der Gott der Gründungssituation und die religion civile der Befestigung bürgerschaftlicher Selbstregierung. Anscheinend sind nur diese religiösen Ressourcen in der Lage, jenen zusätzlichen Bindungs- und

32 Brief von J.J. Rousseau an M. de Beaumont, zitiert nach: Fetscher, Rousseaus politische Philosophie, 1975, S. 336.

33 Die schöne Formulierung verdanke ich Enno Rudolph, der sie bei einem Kolloquium über Zivilreligion am Inter University Center in Dubrovnik im September 2011 gebrauchte.

34 So entsprechende Begriffsprägungen bei Benjamin Franklin, Thomas Jefferson, Abraham Lincoln u.a. 
wechselseitigen Verpflichtungszusammenhang zu erzeugen, der dem auf Recht und Autonomie gegründeten Gemeinwesen letztlich Geltung und Stabilität verleiht.

Ein Blick auf die Geschichte und Gegenwart moderner, demokratischer und republikanischer Ordnungen lässt indes auch Überzeugungen, Glaubenssysteme und Rituale erkennen, die nicht unbedingt auf die Inhalte, vielmehr auf die Form religiöser Überzeugungen und Praktiken rekurrieren: von den Revolutionskulten in Frankreich mit der Verehrung des Etre suprême, den feierlichen Prozessionen von Abgeordneten bei Parlamentseröffnungen, den Ritualen der Bürger in den Landsgemeinden, den Zeremonien des Eides, der US-amerikanischen Pledge of Allegiance, den Gedenk- und Jubiläumspraktiken, der Erinnerung von Anfang und Geschichte der politischen Ordnungen in nationalen, einzelstaatlichen oder kantonalen Feiertagen, den Semantiken öffentlicher Rede, usw. Gründungsmythen wie der Rütlischwur und Ursprungslegenden - man denke nur an die zahlreichen ,konstruierten' Stadt- und Herrschaftsgenealogien - vermögen der biblischen Heilsgeschichte vergleichbare Narrative auszubilden, in denen Herkunft und Zukunft der politischen Ordnung in den Erzählstrukturen eines schöpferischen Anfangs, einer Periode von Anfechtung und Bewährung und der Hoffnung auf ,bessere Zeiten“ aufgespannt werden. Historische Figuren rücken in die Position von Propheten und Märtyrern ein, Dokumenten wird die Bedeutung heiliger Schriften zugeschrieben. Die National Mall in Washington D.C. vereint in ihrer an antike, griechische und römische Formensprache gemahnenden Repräsentationsarchitektur die Schöpfer, Erneuerer und Helden, auch die im Einsatz für das Land gefallenen Opfer des novus ordo seclorum, wie es auch auf der Dollarnote zu lesen ist. Und die Rhetorik amerikanischer Präsidenten lässt das Bild hohepriesterlicher Kulthandlungen entstehen, deren korrekter Vollzug an die „Orthopraxie“ antiker Gesellschaften erinnert. ${ }^{35}$ Nicht zuletzt werden die Gründungsdokumente, Unabhängigkeitserklärung und Verfassung, in einem Schrein in den National Archives aufbewahrt.

In diesen Darstellungs- und Inszenierungspraktiken kommt gewiss das puritanisch-religiöse Erbe zum Tragen, aber zugleich haben sich diese Repräsentationsformen nationaler Geschichte daraus abgelöst und eine eigene Symbolizität entwickelt, die nicht alleine im Rekurs auf die in ihren

35 John Scheid: La religion des Romains, Paris 1998, S. 20. 
Anfängen genuin protestantische Tradition ,lesbar ${ }^{6}$ ist. ${ }^{36}$ Gerade hier, im amerikanischen Kontext, wird deutlich, dass Zivilreligionen als ein Set von Überzeugungen, Symbolen und Ritualen verstanden werden können, welche eine konstitutive, auch integrative Bedeutung für die gesellschaftliche Konstruktion politischer Wirklichkeit besitzen. Zivilreligionen stellen politisch-kulturelle Systeme von gesellschaftlichen Selbstinterpretationen dar, deren Spezifik in der Anknüpfung oder Übernahme von Formen oder Gehalten religiöser Glaubenssubstrate oder -praktiken besteht, sie aber zugleich, im Prozess der Übertragung in den politischen Bereich, transformieren. Der entscheidende Mechanismus zivilreligiöser Aufladung und Überhöhung säkularer Ereignisse, Figuren und Zusammenhänge muss in den Diskursen, Formen und Praktiken ihrer Sakralisierung, in den ,Heiligungen', gesehen werden, mittels derer politische Gesellschaften einen ihnen - in Raum und Zeit - vorausliegenden oder sie - in Zeit und Raum - übersteigenden Sinn- und Handlungshorizont gewinnen. Mithin sind Zivilreligionen Formen der Selbsttranszendierung von Gesellschaften mit Sinn stiftender Funktion. Als „Kontingenzbewältigungspraxis“،37 wird

36 Der Einwand etwa, dass es sich bei den genannten Phänomenen um religiöse Relikte, also Überhangphänomene, längst vergangener, gescheiterter oder ridikülisierter Repräsentationspraktiken vor- oder frühdemokratischer Ordnungen handelt, verfängt mithin nicht, sie sind auch nicht, wie Hermann Lübbe (Religion nach der Aufklärung, 1986, S. 309) mit Blick auf Rousseau glaubte festhalten zu sollen, „voraufgeklärt“ zu nennen. Zwar könnte argumentiert werden, dass immer dort, wo biblisch-religiöse Topoi in der öffentlichen Rhetorik auftauchen oder eine invocatio dei in die Verfassung geschrieben wird, Traditionsreste einer religiösen Bewusstseins- und Motivationsdisposition am Werke sind, aber bei ihnen würde es sich dann doch eher um zivilreligiöse und nicht um religiöse Praktiken handeln. Mit ihnen wird die politische Ordnung gerade als etwas anderes denn als religiöse Ordnung bezeichnet. Die politische Ordnung stellt sich unter den Schutz eines nicht spezifisch religiös bestimmten Gottes, macht damit aber zugleich auch ihre Distanz zum Gottesreich wie auch ihre eigene irdische Vergänglichkeit deutlich - und sucht doch Halt im Moment selbstüberschreitender Transzendenz. Ähnlich operieren Mechanismen der Unverfügbarstellung zentraler Leitideen in Verfassungen. Der absolute Schutz der Menschenwürde (Artikel 1 des deutschen Grundgesetzes), die Klausel der Unabänderbarkeit von Regelungen (Artikel 79 Absatz 3 des Grundgesetzes, sogenannte „Ewigkeitsklausel“) entzieht Fundamentalnormen der politischen Disposition, beschränkt die Autonomie der demokratischen Gewalten und bezeichnet damit die - in Verfassunggebungsprozessen - selbsterzeugten Transzendenzen, die der politischen und sozialen Ordnung Sinn, Halt und Orientierung geben sollen.

37 Lübbe, Religion nach der Aufklärung, 1986, S. 149. 
in ihnen das gesamte Repertoire performativer, narrativer und ikonischer Medien wirksam, mittels derer zivilreligiöse Glaubensbestände sozial konstruiert und politisch (re)produziert werden. Dabei ist die religion civile in ihrer Substanz nicht von den Beständen oder Traditionsresten religiöser Bewusstseins- oder Motivationsdispositionen abhängig, vielleicht ruht sie noch auf der „kulturell tradierten Empfänglichkeit religiöser Deutungen“38 auf. Entscheidend ist vielmehr, dass sie sich einer - ebenfalls, aber nicht allein der religiösen Praxis zugrundeliegenden - „Grammatik des Glaubens “39 verschreibt, nach deren Regeln Sakralität erzeugt, Heiliges der alltäglichen Verfügbarkeit entzogen und in Ritualen, Erzählungen und Darstellungen symbolisch wieder präsent gemacht wird. Nicht von ungefähr preist Rousseau deshalb die politische Festkultur, in der sich die republikanische Bürgerschaft in der Erfahrung ihrer Gemeinschaftlichkeit immer wieder erneuert und bestärkt. ${ }^{40}$

Im Grunde wiederholt sich in diesen Formen der Heiligung auch in modernen, republikanischen und demokratischen Ordnungen das, was Hannah Arendt nach der ,bindenden Macht des Gegründeten selbst“41 fragen ließ und, im Rekurs auf Rom, mit einer spezifischen Form der Religion beantwortete. ${ }^{42}$ Im Zentrum römischer Politik stand, so Arendt, vom Beginn der Republik bis fast zum Ende der Kaiserzeit, ,die Überzeugung von der Heiligkeit der Gründung“. Damit sollte das, was einmal gegründet war, bindend bleiben für alle künftigen Generationen: „Politik treiben hieß immer zuerst die Gründung der Stadt Rom wahren und vermehren. ${ }^{\text {"43 }}$ Mit Rom verbindet sich damit zweierlei. Zum einen ist Rom der paradigmatische Fall des historischen Neubeginns. Der römische Gründungsbegriff impliziert, dass jede Gründung eine Rekonstitution, die

38 Wolfgang Kersting: Jean-Jacques Rousseaus ,Gesellschaftsvertrag', Darmstadt 2002, S. 197.

39 Ebd., S. 194.

40 Rousseau, Euvres, 1964, S. 955ff. Dort gibt Rousseau - mit Blick auf Polen teils genaue Regieanweisungen. Vgl. hierzu den Beitrag von Daniel Schulz: Naturerzählungen und republikanische Geltungsbedingungen bei Rousseau, in diesem Band.

41 Hannah Arendt: Was ist Autorität?, in: dies.: Zwischen Vergangenheit und Zukunft. Übungen im politischen Denken I, hrsg. von Ursula Ludz, München 1994, S. 159-200, hier: S. 188.

42 Diesen Absatz entnehme ich meiner Darstellung Vorländer, Gründung und Geltung, 2002, S. 249.

43 Arendt, Autorität, 1994, S. 187. 
„Erneuerung und Restauration eines Uralten ist“". Mit Vergil kann von Rom als einem „Zweiten Troja“ gesprochen werden. Damit verbindet sich die „uralte Vorstellung des Wiedererstehens des Alten in der Neugründung “44. Zum anderen bleibt die Politik in dem einmal begründeten Rom immer wieder auf den Akt der Gründung selbst zurückbezogen. Dies ist dann auch der eigentliche Sinn von Religion, des „re-ligare“, des Zurückgebundenund Verpflichtetseins des politischen Handelns auf den Anfang, auf den Akt der Gründung. Religiös zu sein bedeutet damit, an die Vergangenheit gebunden zu sein. Cicero kann sagen: „In nichts nähert sich menschliche Vollkommenheit so sehr den Wegen der Götter (,numen') als in der Gründung neuer und der Bewahrung bereits begründeter Gemeinwesen.“ Religion ist damit „die bindende Macht des Gegründeten selbst ${ }^{\star 45}$.

\subsection{Zivilreligion als Bürgerreligion}

Anders formuliert: In Zivilreligionen wird das Bewusstsein des Außeralltäglichen der Gründung wie auch der Wegmarken der eigenen Geschichte aufbewahrt, das Vergangene präsent gehalten und das Jenseits des eigenen Erfahrungshorizontes wieder verfügbar gemacht. Das Außerordentliche befestigt die politische Ordnung, ${ }^{46}$ stellt sie indes auch immer wieder in Frage, weshalb Zivilreligionen auch der Veränderung, der Adaptierung an gewandelte Zeitläufte unterliegen. Moderne Demokratien machen von zivilreligiösen Mechanismen in vielfältiger, teils unreflektierter, teils bewusster Form, Gebrauch. In Ritualen und Zeremonien, deren Ablauf festgelegten Inszenierungsmustern folgen, wird die eigene Geschichte als einer besonderen erinnert und durch stete Repetition zu bestärken gesucht. Neben die zivilreligiösen Praxen treten gesellschaftliche Diskurse um die richtige oder angemessene Geschichts- und Erinnerungspolitik, um die Werte und Prinzipien einer politischen Vergemeinschaftung, die für besonders ,heilig ${ }^{6}$ gehalten werden, wie die Unverfügbarkeit der Menschenwürde in der Verfassungsordnung der Bundesrepublik Deutschland, der individuellen Freiheit als Leitidee in den USA, dem Bankgeheimnis in der Schweiz, der Solidarität in westlichen Wohlfahrtsstaaten. Des Weiteren sind Zivil-

44 Arendt, Revolution, 1974, S. 267.

45 Arendt, Autorität, 1994, S. 187f.

46 In soziologischer Perspektive hierzu jetzt Bernhard Giesen: Zwischenlagen. Das Außerordentliche als Grund der sozialen Wirklichkeit, Weilerswist 2010. 
religionen auch immer Bürgerreligionen, religions civiques, also Glaubensbestände, die von Bürgern formuliert und habitualisiert worden und an das politische Gemeinwesen gerichtet sind. Das vivere libero e civile des italienischen Stadtrepublikanismus war immer Ausdruck des Stolzes und des Patriotismus der Bürgerschaft - heutzutage in den Landsgemeinden der Schweiz immer noch anzutreffen.

Diese Illustrationen machen auch deutlich, dass Zivilreligionen mit der Pluralität moderner republikanischer Ordnungen vereinbar sind. Denn sie unterscheiden sich von Staatsreligionen und Politischen Religionen. Während erstere in der Ununterscheidbarkeit von Religion und Staat und einem wechselseitigen Legitimationsverhältnis von Staat und (organisierter) Religion besteht, erklärt sich eine Politische Religion durch die vollkommene Durchdringung der politisch-gesellschaftlichen Lebenswelt mit einer hegemonialen, totale Herrschaftslegitimation beanspruchenden Weltanschauung. ${ }^{47}$ Zivilreligionen bleiben in dieser begrifflichen Unterscheidung ein ambivalentes ,Dazwischen', zwischen zivilem und religiösem Bereich, dessen relative, den politisch-gesellschaftlichen Diskursen ausgelieferte, Unbestimmtheit die Differenz markiert. Zivilreligionen bleiben polyvalent, unterschiedlich interpretierbar, offener. Staatsreligionen und Politische Religionen sind monovalent, sie erheben Eindeutigkeitsansprüche, heben die Differenz von Diesseits und Jenseits in einem teleologisch-chiliastischen Geschichtskonzept der eigenen Ordnung auf. ${ }^{48}$

$\mathrm{Zu}$ Beginn des einundzwanzigsten Jahrhunderts kann gefragt werden, ob es einer Zivilreligion im Sinne Rousseaus überhaupt bedarf, sind doch die Bedingungen gesellschaftlichen Zusammenhaltes andere als sie es vor 250 Jahren gewesen sind, als der vor dreihundert Jahren geborene Genfer seinen Contrat social veröffentlichte. Vor allem ist auf dem Erfahrungshintergrund der Totalitarismen des 20. Jahrhunderts, aber auch der Nationalismen im ausgehenden 19. Jahrhundert eine prinzipielle Skepsis gegen-

47 In diesem Sinne wird der Begriff der Politischen Religion auch von Maier (Politische Religionen, 2007) verwendet. Generell zum Begriff: Eric Voegelin: Die politischen Religionen, München 1993 und Jürgen Gebhardt: Wie vorpolitisch ist ,Religion“? Anmerkungen zu Eric Voegelins Studie „Die politischen Religionen“, in: Herfried Münkler (Hrsg.): Bürgerreligion und Bürgertugend. Debatten über die vorpolitischen Grundlagen politischer Ordnung, Baden-Baden 1996, S. 81-102.

48 Nichts anderes meinte die Rede vom „Tausendjährigen Reich“. Grundlegend: Karl Löwith: Weltgeschichte und Heilsgeschehen. Die theologischen Voraussetzungen der Geschichtsphilosophie, Stuttgart 1953. 
über staatlich formulierten oder gar abverlangten Glaubensbekenntnissen und Ritualen, die sich religiöser Formen bedienen, angebracht. Zugleich aber scheint es auch in zeitgenössischen demokratischen Gesellschaften einen Bedarf zu geben, auf symbolische Formen der gesellschaftlichen Selbstvergewisserung und der politischen Präsenzmachung von Normen und Voraussetzungen guter politischer Ordnung zurückzugreifen oder diese, wo sie in historischen Traditionsabbrüchen verloren gegangen sind, wiederzubeleben. Dabei können alte wie neue Diskurse oder Praktiken nicht immer überzeugen, sie bleiben auch umstritten. Politische „Katechismen", die Glaubenssätze verbindlich machen wollen, laufen von vornherein ins Leere. Das „Faktum gesellschaftlichen Pluralismus“ (Rawls), nicht zuletzt die durch Ausdifferenzierungsprozesse und Migrationsbewegungen bewirkte kulturelle, religiöse und ethnische Heterogenisierung wie auch die polyarchische Diskursstruktur moderner Gesellschaften machen autoritative zivilreligiöse Setzungen, die Rousseau'schen „Dogmen“, ab origine unmöglich. Sie können und dürfen in freien Gesellschaften auch keineswegs oktroyiert und mit Bekenntnispflichten versehen werden.

Bürger, die an die Heiligkeit der Ordnung glauben sollen, müssen zuerst davon überzeugt sein, dass die Ordnung eine gute und gerechte Ordnung ist. Solche Überzeugungen können aus bürgerschaftlicher Praxis, aus der Beteiligung an demokratischen Prozessen, an Wahlakten und Landsgemeinden, gewonnen, quasi gereift sein, und sodann durch Feste oder Rituale, Jubiläen oder Gedenkmomente bestärkt werden. Verfassungen, in denen die Gründung und die Grundlagen der Ordnung aufbewahrt sind, mögen zwar, aus guten und historischen Gründen, tragende Leitideen für unantastbar erklären, doch ihren Status der ,geheiligten` Unverfügbarkeit erhalten diese erst dann, wenn die Gründe ihrer Sakralisierung diskursiv präsent und in symbolischen Praktiken vergegenwärtigt und erinnert und von den Bürgern ,geglaubt', das heißt für richtig gehalten, werden. Am Anfang mögen die „Götter“ stehen, wie Rousseau meinte, am Ende aber kommt es in demokratischen und republikanischen Ordnungen immer auf den Bürger an. 


\section{BEGRÜNDUNGSDISKURSE \\ DES 16.- 21. JAHRHUNDERTS}





\title{
Zwischen Selbstermächtigung und Endlichkeitsbewusstsein
}

\author{
Das Politische und seine Grenzen im florentinischen
} Republikanismus

\section{DANIEL SCHULZ}

Die politische Theorie der Gegenwart hat nicht erst seit den totalitären Erfahrungen der Moderne ein Bewusstsein dafür entwickelt, dass politische Ordnungen ihre Regeln zwar autonom erzeugen, deren Befolgung aber kaum durch direkte Machtmittel dauerhaft beeinflussen können, wenn nicht zugleich radikale Konsequenzen heraufbeschworen werden sollen. Das zwangsbewehrte staatliche Gewaltmonopol vermag allenfalls einzelne oder kurzfristige Devianzen und Regelverstöße zu bewältigen, einem flächendeckenden Legitimitätsentzug steht es jedoch weitgehend machtlos gegenüber. Auch wenn man den abschreckenden Effekt der Sanktionierbarkeit mit einbezieht und ihr einen Anteil am ausbleibenden dauerhaften Gesetzes- oder Verfassungsbruch zuschreiben mag, so geht doch die Geltung einer politischen Ordnung und ihrer Leitideen in einem solchen mechanischen, auf Macht und Gegenmacht reduzierten Kräfteparallelogramm nicht auf. Ob man von den sozio-moralischen Voraussetzungen, von einer entgegenkommenden politischen Kultur oder von einer aufgeklärten Zivilgesellschaft spricht $^{1}$ - all diese Formulierungen verweisen offen oder latent

1 Herfried Münkler: Politische Tugend. Bedarf die Demokratie einer sozio-moralischen Grundlegung?, in: ders. (Hrsg.): Die Chancen der Freiheit, München 1992, S. 25-46; Jürgen Habermas: Faktizität und Geltung, 4. Aufl., Frankfurt 
auf bestimmte Geltungsressourcen, die der autonomen Regelungs- und Entscheidungskompetenz politischer Ordnung weitgehend entzogen zu sein scheinen, mit ihr aber gleichwohl in einem engen Bedingungsverhältnis stehen. Damit muss keineswegs eine spezifisch herausgehobene Rolle religiöser Glaubenspraktiken verbunden werden, wie dies in der Folge des so prominent diskutierten ,Böckenförde-Paradoxons` vielfach unterstellt wurde. In der klassischen politischen Theorie wurde dieser Zusammenhang - weitgehend ohne religiöse Konnotation - unter dem Leitbegriff der Tugend verhandelt. Im Unterschied zu rein ethisch-normativ ausgerichteten Perspektiven ging es dabei nie um die Frage nach dem Guten allein, sondern immer auch um das gegenseitige Bedingungsverhältnis von Tugend als einer spezifisch bürgerlichen Bindungs- und Verpflichtungsdisposition zum einen und deren institutionellen Ermöglichungs- und Entfaltungskontexten zum anderen. Dieses Problem der Unverfügbarkeit soziomoralischer Geltungsressourcen und ihrer institutionellen Verfügbarmachung reicht nun zwar zurück bis in die antike Polis und die römische Republik, wurde aber zum ersten Mal offen im politiktheoretischen Diskurs des italienischen Städterepublikanismus thematisiert.

Das neuzeitliche republikanische Paradigma machte die vormals göttliche und nun erstmals in ihrer Weltlichkeit erfahrene Ordnung durch menschliches Handeln verfügbar, bewahrt sich jedoch ein ausgeprägtes Bewusstsein für die der Verfügung entzogenen Voraussetzungen politischer Ordnung. Diese Geltungsvoraussetzungen können durch politisches Handeln oder institutionelle Vorkehrungen nur bedingt zugänglich gemacht werden. Die Semantik des Republikanismus hat in ihren zentralen Begrifflichkeiten wie fortuna, occasione, virtù, necessità dieses Bewusstsein artikuliert. Die hier ebenfalls erstmals zu beobachtende Form der Funktionalisierung religiöser Transzendenzressourcen zur Stabilisierung der politischen Ordnung ist eine direkte Folge des genannten Problems. Mit der Emanzipation des Politischen aus der religiös legitimierten Schöpfungsordnung werden die bislang dominierenden Geltungscodes zum Instrument funktionaler Verfügungs- und symbolischer Deutungsmacht. Im Zusammenhang des italienischen Städterepublikanismus und seiner Deutungsdiskurse können daher eine Reihe von Formen des Umgangs mit trans-

a.M. 1994, S. 627; Ulrich Rödel/Günter Frankenberg/Helmut Dubiel: Die demokratische Frage, Frankfurt a.M. 1989. 
zendenten Geltungsressourcen beobachtet werden, die über die Funktionalisierung religiöser Gehalte hinausgehen und die zugleich der Stiftung bürgerlichen Gemeinsinns dienen. Die Spannbreite dieser Formen reicht dabei von der philologischen Aufdeckung antiker Quellen, ihrer Einspeisung in den bürgerlichen Kommunikationszusammenhang als humanistisches Bildungsgut, der aktiven dichterischen Fortbildung der gemeinsamen Volkssprache bis hin zur radikalen Mobilisierung einer Semantik heiliger Offenbarung republikanischer Verfassungsideen. In diese Reihe gehört auch das Medium der republikanischen Eigengeschichte, aber auch die politiktheoretischen Reflexionsschriften im engeren Sinne, die zumeist in ihrem näheren historischen Kontext die Funktion einer Selbstverständigung des bürgerlichen Gemeinwesens über seine Ziele und Ordnungsvorstellungen einnahmen.

Ziel dieses Beitrages ist es daher, in den zentralen Begriffen des republikanischen Diskurses diese Verschränkung transzendenter und gemeinsinniger Verweise herauszuarbeiten. Die Analyse konzentriert sich auf folgende Autoren und Felder: 1) Zum einen liegt im Antikendiskurs des Renaissancehumanismus eine Wiederaneignung des Vergessenen, des zeitlich Entzogenen in der Form des Gesprächs mit den römischen Klassikern. In den Schriften von Dante und Petrarca stehen diese Verfügbarkeitsversuche in engem Zusammenhang mit der Verschiebung der sakralen Hierarchie zwischen Kirche und Reich und sind Ausdruck eines wachsenden weltlichen Selbstbewusstseins. Ihren Höhepunkt findet dieser Konflikt bei Marsilius von Padua und einer quasi-republikanischen Selbstermächtigung in Form einer Magistratsverfassung, die zwar in eine umfassende religiöse Transzendenz eingebettet bleibt, aber nicht mehr unmittelbar zur Erzeugung von politischem Gemeinsinn auf sie angewiesen ist und sogar Ansätze zu einer politischen Instrumentalisierung der Religion enthält. 2) In der Selbstbeschreibung der Florentiner Magistrate bei Coluccio Salutati, Leonardo Bruni, und Matteo Palmieri und ihren politischen Schriften wird die Erzeugung der sozio-moralischen Voraussetzungen der guten Verfassung durch Erziehung und durch praktische Teilhabe als Bürger thematisiert. Tugend kann demnach diskursiv und praktisch verfügbar gestellt werden. Zudem entwickeln diese Autoren eine konstitutionelle Eigengeschichte, in der die symbolischen Leitideen des Gemeinwesens präsent gehalten werden. 3) Nachdem sich die republikanische Verfassung mehr und mehr in eine Fassade der Alleinherrschaft 
der Medici verwandelt, tritt an die Stelle des Tugenddiskurses eine philosophische Diskussion der Menschenwürde: Giannozzo Manetti und Pico della Mirandola entwickeln eine universal überhöhte Transzendenz menschlicher Selbstbehauptung, in der gleichwohl zunehmend das Ideal der vita contemplativa an die Stelle der direkten politischen Teilhabe rückt. 4) Mit Savonarola wird die republikanische Ordnung heilsgeschichtlich aufgeladen und als weltliche Ordnung Gottes im Gestus prophetischer Offenbarung propagiert. Durch die ekstatische Transzendenzbehauptung gerät jedoch die Leitidee der durch Mischung gemäßigten Verfassung in den Hintergrund. 5) Erst mit Machiavelli und Guicciardini wird dieses Ideal nach dem Scheitern der Republik wieder belebt, bleibt aber angesichts der aufkommenden, sich mit der Einherrschaft verbindenden Doktrin der Staatsräson retrospektive Reflexion bleiben. Die politische Theorie des Republikanismus geht damit in die Beobachtung der unverfügbaren geschichtlichen Machtkreisläufe über, in denen das Spiel der Herrschaftsinteressen naturähnlichen Gesetzmäßigkeiten zu unterliegen scheint.

\section{Die Konstitution DES BÜRGERLICHEN GEMEINWESENS}

Die ideengeschichtliche Debatte um den italienischen Bürgerhumanismus war immer auch eine Diskussion um seine zeitliche Verortung. Der klassischen Studie von Burckhardt ist so vorgeworfen worden, trotz aller Verdienste zu unkritisch mit dem Epochenbegriff der Renaissance operiert zu haben. ${ }^{2}$ Auch die Studie von Hans Baron, die an Burckhardt anschließend das 15. Jahrhundert als Epoche vom Aufstieg und Verfall humanistischen Bürgerbewusstseins zeichnet, hatte den Ursprung in die Krisenjahre um 1400 gelegt und basiert auf einem konstitutiven Bruch zwischen Mittelalter und Renaissance. ${ }^{3}$ Dagegen haben neuere Studien auf die tiefen Wurzeln verwiesen, die den Diskurs des politischen Humanismus mit der

2 Vgl. das Nachwort von Horst Günther, in: Jacob Burckhardt: Die Kultur der Renaissance in Italien, Frankfurt a.M. 1997, S. 1003-1030, bes. S. $1009 f$.

3 Hans Baron: The Crisis of the Early Italian Renaissance. Civic Humanism and Republican Liberty in an Age of Classicism and Tyranny, Princeton 1966; von einem Bruch geht auch aus John G.A. Pocock: The Machiavellian Moment. Florentine Political Thought and the Atlantic Republican Tradition, Princeton 1975. 
spätmittelalterlichen Umbruchphase des 14. Jahrhunderts verbindet. Quentin Skinner hat in seinem maßgeblichen Werk zu den Grundlagen des modernen politischen Denkens die Bedeutung des Frühhumanismus hervorgehoben. ${ }^{4}$ Dieser auf den ars dictaminis und den Lehren der klassischen Rhetorik verpflichteten Gelehrten konnten in ihrer Epoche zwar kaum Breitenwirkung aufweisen und waren zudem eher akademisch denn politisch ausgerichtet. Aber sie legten die Grundlagen für die späteren Ideen, die in den Städterepubliken eine neue Form des bürgerlichen Autonomiestrebens freisetzten.

Den unmittelbaren intellektuellen Bezugsrahmen des Bürgerhumanismus bildete der Frühhumanismus Dantes und Petrarcas. Auch hier sind es weniger ihre genuin politischen Schriften, als der humanistische Bildungskanon und die Wiederanknüpfung an die antiken Quellen philosophischer, historischer und politischer Reflexion, welche der Etablierung des republikanischen Geltungsspruches dienlich waren. In der zeitgenössischen Machtkonkurrenz von Papst und Kaisertum wurde aber auch die Frage nach der sakralen Legitimation von Herrschaft diskutiert. Wenngleich hier noch keine direkte Rechtfertigung der republikanischen Verfassung zu finden ist und die monarchische Staatsform kaum in Frage gestellt wird, so trugen diese frühhumanistischen Schriften doch wesentlich zur Distanzierung des kirchlichen Machtanspruches bei. Bei Marsilius von Padua werden zudem zentrale Elemente einer bürgerlichen Verfassungsordnung antizipiert. Zunächst aber dominiert noch der Topos der Einheitsverkörperung, des corpus mysticum, der sich in der Figur des Monarchen am natürlichsten repräsentiert. Bereits Thomas von Aquin hat in Über die Herrschaft der Fürsten (um 1265) diese Rechtfertigung der Herrschaft eines Einzigen maßgeblich und einflussreich demonstriert, obgleich er doch schon durch seine Aristoteles-Rezeption über den klassisch-antiken Horizont des Verfassungsdenkens verfügte. Dantes Monarchia (ca. 1316) übernimmt von Thomas zentrale Rechtfertigungsmuster, nutzt diese aber zur Rechtfertigung der kaiserlichen Position gegenüber den päpstlichen Machtansprüchen, die im 14. Jahrhundert mit dem gewachsenen Selbstbewusstsein

4 Quentin Skinner: The Foundations of Modern Political Thought, Vol. 1: The Renaissance, Cambridge 1997; als besten Überblick über die Debatte siehe James Hankins: Introduction, in: ders. (Hrsg.): Renaissance Civic Humanism. Reappraisals and Reflections, Cambridge 2000, S. 1-13. 
weltlicher Macht zunehmend in die Defensive geraten. ${ }^{5}$ Auch wenn eine genuin republikanische Selbstermächtigung noch außerhalb des Dante'schen Möglichkeitsbewusstseins liegt, so wird doch der Herrschaftsanspruch des Papstes radikal in Frage gestellt. Die Autorität des Kaisers leitet er direkt von Gott her - womit sowohl die Kirche als auch der Papst als Legitimitätsgaranten weltlicher Herrschaft ausfallen. Es ist nun diese durch den Ausfall einer weltlichen Stellvertretung des göttlichen Heilsplans entstandene Geltungslücke, die den Raum für die Autonomie weltlicher Politik öffnet. ${ }^{6}$ Dies beginnt bereits mit dem Ziel der weltlichen Verfassung: Höchstes und allen politischen Ordnungen gemeinsames Ziel ist der Frieden. ${ }^{7}$ Zwar wird die Monarchie als beste Regierungsform ausgezeichnet, weil sie in der Einheit des monarchischen Körpers der göttlichen Einheit am nächsten kommt. ${ }^{8}$ Aber neben dieser sakral aufgeladenen Einheit muss das Gemeinwesen auch eine Reihe anderer Zielvorstellungen verkörpern, um als legitim gelten zu können: So muss die politische Ordnung Gerechtigkeit verwirklichen und das größte $\mathrm{Ma} \beta$ an Freiheit gewähren. ${ }^{9}$ Auch dies garantiert die Monarchie von allen Staatsformen am besten, aber gleichwohl liegt das normative Ziel der Verfassung darin,

„dass die Menschen um ihrer selbst willen existieren. Der Bürger nämlich ist nicht um des Konsuln willen da und das Volk nicht um des Königs willen, sondern umgekehrt sind die Konsuln um der Bürger und der König um des Volkes willen da, so wie die Staatsverfassungen nicht im Hinblick auf die Gesetze, sondern diese für jene entworfen werden. “10

Der weltliche Herrschaftsanspruch des Papstes, der sich 1302 in der Bulle Unam sanctam von Bonifaz VIII. besonders deutlich manifestiert hatte, wird damit seiner religiös-transzendenten Legitimation entkleidet und als

5 Thomas von Aquin: Über die Herrschaft der Fürsten, übersetzt von Friederich Schreyvogel, Stuttgart 1971; Dante Alighieri: Monarchia. Einleitung, Übersetzung und Kommentar von Ruedi Imbach und Christoph Flüeler, Stuttgart 1989.

6 Vgl. dazu Marcel Gauchet: Le désenchantement du monde. Une histoire politique de la religion, Paris 1985.

7 Dante, Monarchia 1989, S. 73.

8 Ebd., S. 79.

9 Ebd., S. 95.

10 Ebd., S. $97 \mathrm{ff}$. 
politische Selbstermächtigung enthüllt. ${ }^{11}$ Papst und Kaiser sind keine übernatürlichen Wesen, sondern lediglich Menschen, die jeweils beide von Gott abhängen. Ein Herrschaftsanspruch gegeneinander kann nicht begründet werden. Dante zeigt die unterschiedlichen Legitimitätsgrundlagen des kirchlichen und des staatlichen Machtanspruches, über den die jeweilige Person des Kaiser oder des Papstes selbst nicht verfügen kann: „Die grundlegende Autorität ist dem Herrscher nur zum Gebrauch verliehen, denn kein Herrscher kann sich selbst Autorität verleihen; er kann sie empfangen oder sie ablegen, aber er kann keinen anderen Herrscher einsetzen, da die Einsetzung des Herrschers nicht vom Herrscher selbst abhängt. “12 Die kirchliche Macht besitzt so ihr Fundament in Christus, „das Fundament des Imperiums dagegen ist das menschliche Recht ${ }^{\text {"13 }}$. Dieses Fundament weltlicher Ordnung bleibt auch für die monarchische Gewalt unverletzlich und damit unverfügbar.

Da das Reich Christi aber nicht von dieser Welt ist, wird die Autorität des Imperiums damit unabhängig von der Kirche begründet. Dennoch haben beide eine feste Aufgabe für das Heil des Menschen: Während weltliche Herrschaft Geltung nur über den sterblichen und vergänglichen Aspekt des Menschen beansprucht, erstreckt sich dagegen der Anspruch der Kirche auf den unvergänglichen und ewigen Teil des menschlichen Seins, die Seele. ${ }^{14}$ Dante folgert aus dieser Zweiteilung des Menschen in den vergänglichen Körper und die unvergängliche Seele zwei fundamentale Ziele, die es in jeweils zwei unterschiedlichen Domänen zu verwirklichen gilt. Die Glückseligkeit des Lebens ist das Ziel der weltlichen Herrschaft, die Glückseligkeit des ewigen Lebens dagegen fällt in die Zuständigkeit der Kirche: „Deshalb bedurfte der Mensch einer zweifachen Leitung gemäß des zweifachen Zieles, nämlich des Papstes, der die menschliche Gattung nach dem Offenbarten zum ewigen Leben führt, und des Kaisers, der nach der

11 Der Text der Bulle findet sich ebd., S. 347-355. Zur historischen Kontextualisierung der Auseinandersetzung vgl. Jürgen Miethke/Arnold Bühler: Kaiser und Papst im Konflikt. Zum Verhältnis von Staat und Kirche im späten Mittelalter, Düsseldorf 1988; als ideengeschichtlichen Überblick auch Jürgen Miethke: Politiktheorie im Mittelalter. Von Thomas von Aquin bis Wilhelm von Ockham, Tübingen 2008.

12 Dante, Monarchia, 1989, S. $295 \mathrm{ff}$.

13 Ebd., S. 221.

14 Ebd., S. 241. 
philosophischen Unterweisung die menschliche Gattung zum zeitlichen Glück leitet." "15

Einen bedeutenden Schritt weiter in der Emanzipation politischer Ordnung von der ecclesialen Transzendenzzuschreibung geht Marsilius von Padua. Mit seinem Defensor pacis (1324) radikalisiert er mit starkem Bezug auf die Aristotelische Verfassungslehre die Konsequenzen des bei Dante formulierten politischen Eigenrechts des Kaisers gegen den Papst. ${ }^{16}$ Damit kann er als Ausgangspunkt eines bürgerlich-politischen Ermächtigungsdiskurses gelesen werden: Nicht die religiöse Transzendenz des Papsttums ermächtigt zur weltlichen Verfassung und zur Wahl des Kaisers, sondern in der Bürgerschaft selbst liegt der ursprüngliche Grund einer guten und legitimen Konstitution: „Jede Staatsform besteht entweder mit dem Willen der Untertanen oder gegen ihren Willen. Die erste ist die Gattung der gutgemäßigten Verfassungen, die zweite die der entarteten. “17 Die Wahl des Monarchen durch die Bürger ist das zentrale Legitimitätskritierium. ${ }^{18}$ Die auf Wahl beruhende Staatsform ist besser als die nicht auf Wahl beruhende. Außerdem wird hier der Topos der Gesetzesbindung von Herrschaft explizit hervorgehoben: Erst so kann der Staat auf Dauer gestellt werden und damit auch der Frieden gesichert sein. ${ }^{19}$ Aber auch die Gesetzgebung erfährt eine säkulare Wendung: Nicht mehr die geoffenbarte Verfassung nach dem Vorbild der Mosaischen Gesetze stellt den normativen Maßstab der legislativen Gewalt, sondern der Wille der Mehrheit wird zum Kriterium der Gemeinwohlbindung:

„Ein Gesetz, gleichsam nur seinem Inhalt nach genommen [...] als Wissen vom Gerechten und Nützlichen im bürgerlichen Leben, zu finden, das kann jedem einzelnem Bürger gelingen, mag auch das Forschen danach zweckmäßiger sein und besser zum Ziele kommen aus den Beobachtungen derer, die sich Zeit nehmen können.، ${ }^{، 20}$

15 Ebd., S. 245.

16 Den Begriff der civitas als aristotelisches Verfassungsmodell betont Dolf Sternberger: Die Stadt und das Reich in der Verfassungslehre des Marsilius von Padua, in: ders.: Die Stadt als Urbild, Frankfurt a.M. 1985, S. 76-142.

17 Marsilius von Padua: Der Verteidiger des Friedens (Defensor Pacis), bearbeitet und eingeleitet von Horst Kusch, Berlin 1958, S. 85 (Teil I, Kapitel IX).

18 Ebd., S. 87.

19 Ebd., S. 117 (I, XI).

20 Ebd., S. 119 (I, XII). 
Gesetzgeber ist „das Volk oder die Gesamtheit der Bürger oder deren Mehrheit durch ihre Abstimmung oder Willensäußerung, die in der Vollversammlung der Bürger in einer Debatte zum Ausdruck gekommen ist ${ }^{\star 21}$. Der Mehrheitswille kann damit bei Marsilius eine Gerechtigkeitsvermutung in Anspruch nehmen: „Weil nämlich das Gesetz alle Bürger im richtigen [d.h.: nicht im gleichen! DS] Verhältnis einstufen muss und niemand sich wissentlich schadet oder Ungerechtes will, darum wollen alle oder wenigstens die meisten ein Gesetz, das dem gemeinsamen Nutzen der Bürger entspricht. “22

Marsilius hat damit das Reich als Stadt aufgefasst und ihm die Verfassungslehre der Polis eingeschrieben. Das verbindende Element ist die Teilhabe des Bürgers, die allerdings nicht als gleiche Teilhabe wie in der antiken Polis verstanden wird. Vielmehr bleibt die civitas bei Marsilius noch nach Ständen und Rängen gegliedert und ermöglicht so nur eine höchst ungleiche Teilhabe der Bürger. ${ }^{23}$ Die Ungleichheit der Körperschaften und Stände bildet gleichsam eine noch unverfügbare organische Voraussetzung politischer Ordnung, die zusammen mit dem Selbstregierungsanspruch das politische Gemeinwesen konstituiert.

Der direkte Angriff auf die kirchlichen Legitimationstheorien und die Reklamation eines Eigenrechts weltlicher Ordnung hat jedoch den Weg freigemacht für ein Selbstverständnis, in dem das politische Gemeinwesen als ein Ziel in sich selbst begriffen werden kann. Ein solches politisches Weltlichkeitsbewusstsein konnte damit an die antiken Autoren anknüpfen, die mit ihrer Reflexion republikanischer Ordnungsvorstellungen die idealen Deutungsmuster bereitstellen konnten, um weltliche Freiheit auf der Tugend der bürgerlichen Gemeinschaft aufzubauen und zugleich jegliche Form der Fremdherrschaft als tyrannisch abzuweisen. Auf einer weiteren Ebene werden bereits bei Dante, dann aber vor allem auch bei Petrarca die Grundlagen für eine politische Vergemeinschaftung durch Sprache und Kommunikation gelegt - aber nicht als transzendentes Apriori, sondern als politische Verfügung über die entzogenen Geltungsgrundlagen der politischen Ordnung. Schon mit einer Schrift Über die Redegewandtheit in der Volkssprache (um 1304/1305) beabsichtigte Dante, den Gemeinsinn des

21 Ebd.

22 Ebd., S. 129 (I, XII).

23 Sternberger, Die Stadt, 1984, S. 93. 
Gemeinwesens durch eine gemeinsame Sprache zu stiften. ${ }^{24}$ Auch wenn er sich dabei auf ganz Italien bezog, so bildete doch seine Aufwertung der Volkssprache, der mit der Göttlichen Komödie ein literarisches Monument gesetzt wurde, zusammen mit der neuen bürgerlichen Ethik der vita activa und der neuen realistischen Geschichtsschreibung eine der zentralen Grundlagen für den städtischen Bürgerhumanismus ab 1400, der gerade in seiner Heimatstadt Florenz besonders stark ausgebildet wurde. ${ }^{25}$

Ein eindrückliches Beispiel für diese sprachliche Vergemeinschaftungsidee liefert auch Petrarca, wenngleich in etwas anders gelagerter Weise. Seine vertraulichen Briefe, eines der größten literarischen Zeugnisse des frühen Humanismus, knüpfen das Band des Gesprächs in Form des Gelehrtenbriefs als soziale Integrationsform, aber auch in Gestalt direkter politischer Intervention. ${ }^{26}$ Damit bildet sich neben der politiktheoretischen Hauptlinie des republikanischen Diskurses die Idee einer kommunikativen Vergemeinschaftung heraus, die sich fundamental von den durch Herrschaft gekennzeichneten mittelalterlichen Integrationsvorstellungen unterscheidet. Nachdem die Menschheit sich mit dem Ausbruch aus dem zirkulären Geschichtsbild in ein lineares, zunächst christlich-heilsgeschichtliches, dann protomodernes Geschichtsbild der sich nicht wiederholenden, in jedem Augenblick immer neuen Zeit bewegt, so wurde nach der heilsgeschichtlichen Abschwächung im Spätmittelalter schnell als Kehrseite dieses Zeitverständnisses die stetig wachsende Entfernung von den antiken Ursprüngen thematisiert. Diese Unverfügbarkeit der immer weiter fortschreitenden Entfernung von den Ursprüngen konnte jedoch durch ein Wiederanknüpfen an die verlorenen Traditionen im gelehrten Gespräch begegnet werden. Im Medium der Schrift, der tradierten Texte des Altertums, sind die humanistischen Gründerfiguren in Gestalt des literarischen Exemplum präsent und können so aus der absoluten Entzogenheit gerettet werden. ${ }^{27}$ Diese Rettung der entzogenen Antike in die Geschichtlichkeit,

24 Dante Alighieri: De vulgari eloquentia I. Über die Beredsamkeit in der Volkssprache. Philosophische Werke Bd. 3, hrsg. von Ruedi Imbach, Hamburg 2007.

25 Baron, Crisis, 1966, S. 452.

26 Vgl. dazu die exemplarische Analyse der Briefe an Cola die Renzo und Francesco il Vecchio da Carrara bei Alexander Thumfart/Arno Waschkuhn: Staatstheorien des italienischen Bürgerhumanismus. Politische Theorie von Francesco Petrarca bis Donato Giannotti, Baden-Baden 2005, S. 82ff.

27 Vgl. ebd., S. 99: Tugenden sind demnach nicht mehr apriorisch fundiert, sondern werden ,nur noch historisch begründbar, kontingent, vorläufig und 
die zugleich eine zeitliche Unverfügbarkeit des Vergangenen und seine mögliche Verfügbarmachung durch die historisch-literarische Vergegenwärtigung impliziert, geht daher mit dem Versuch einher, durch den exemplarischen Rekurs auf die ins Geschichtliche transzendierten Vorbilder tugendhaftes Verhalten $\mathrm{zu}$ evozieren und somit Gemeinsinn $\mathrm{zu}$ stiften. Durch die Kunst der antiken Rhetorik streben die Autoren des Renaissancehumanismus danach, ein „Band des Gesprächs“628 zu knüpfen, dass nach dem Vorbild der Polis und der antiken Philosophenschulen eine Kommunikationsgemeinschaft bildet, die vorausweist auf die Gelehrtenrepublik. Dieses Band verknüpft sowohl die Zeitgenossen untereinander als auch die Gegenwart mit den Klassikern und kann so als eine Form des transzendent codierten Gemeinsinns verstanden werden. Die literarische Form des Briefes dient eben dazu, vertrauliche Nähe trotz Entfernung zu schaffen. Ist es sonst die räumliche Ferne, die im Brief zugunsten einer vertraulichen Kommunikation unter Abwesenden überwunden wird, so tritt bei Petrarcas Briefen zudem die Vergangenheit als entfernte Zeit hinzu, die im persönlichen Brief nivelliert wird. Durch die Schrift gelingt es, eine überzeitliche Kommunikationsgemeinschaft herzustellen, in der die Heutigen in direkten Kontakt zu den Klassikern treten können.

Der humanistische Antikendiskurs kann so auch als Wiederaneignung der entzogenen Geschichte verstanden werden. Die Antike als unverfügbares, aber vorbildliches Gemeinwesen wird durch philologische Entdeckungen wieder zurückgeholt in die gegenwärtigen Auseinandersetzungen und Konflikte und entfaltet dort die Kraft eines normativen Maßstabs. Sowohl die Form als auch die Themen spiegeln diese Zielsetzung: Formal wird ein Gespräch mit den Alten wieder aufgenommen, im Medium des fiktiven Briefwechsels sollen die antiken Autoren wieder zur Sprache kommen. Das tempus fugit wird bei Petrarca als die ,unermessliche Flüchtigkeit der Zeit" bezeichnet. ${ }^{29}$ In einem linearen Geschichtsbild, welches das antike zirkuläre kosmologische Weltzeitmodell ablöst, sind die Ursprünge des humanistischen Diskurses von einem permanenten Verlust

situationsabhängig gezeigt und vorgeführt". Dafür sind sie auf die Form des geschichtlichen Exemplum angewiesen.

28 Francesco Petrarca: Epistolae familiares XXIV. Vertrauliche Briefe, übersetzt, kommentiert und mit einem Nachwort von Florian Neumann, Mainz 1999, S. 39.

29 Ebd., S. 9. 
bedroht. Dagegen wird die Notwendigkeit einer wiederaneignenden Verfügbarmachung gestellt. In diesem spezifisch modernen Zeitbild, das sich bei Petrarca artikuliert, sind die Verlust-, Vergehens- und Todesängste, die Unbeständigkeit und der Wandel konstitutiv enthalten. So beklagt er die „Unbeständigkeit der Dinge“, die auch vor dem Autor selbst - „täglich sterbe ich“30 - nicht halt macht. Den einzigen Ausweg aus dieser historischen Konstellation der Vergänglichkeit bietet das tugendhafte Handeln. Nur in der Tugend liegt demnach die Möglichkeit, den geschichtlich unausweichlichen Verlust zu überwinden:

„Wir sterben fortwährend [...] alle sterben wir, immer sterben wir, niemals leben wir, während wir hier sind, wenn wir nicht etwas Tugendhaftes tun und dadurch uns den Weg zum wahren Leben bahnen, wo dagegen niemand stirbt, wo alle und für immer leben, wo das, was einmal Gefallen gefunden hat, immer gefällt, zum wahren Leben, dessen unsagbare und unerschöpfliche Süße und dessen Art der Geist nicht begreifen kann, ein Leben, in dem kein Wandel zu spüren noch ein Ende zu fürchten ist. “31

Die Tugend transzendiert die weltliche Vergänglichkeit zum Ewigen hin, ohne doch damit die zeitliche Dimension ganz zu verlassen - denn abgezielt wird auf das geschichtliche Bewusstsein der Nachwelt. Die Tugend versucht, über den künftigen Ruf zu verfügen und ihn vorzuformen, sie zielt jedoch nicht auf das Jenseits einer räumlichen Transzendenz.

Einer der zentralen Gewährsmänner ist Cicero, dessen ,goldene Eloquenz und den himmlischen Geist" Petrarca bewundert, einen Gott der Beredsamkeit, einen himmlischen Menschen im Reden. ${ }^{32}$ Gleichwohl missfällt ihm die agonale, die konfliktorientierte Seite von Ciceros vita activa und er scheut sich nicht, dieses Missfallen im direkten Brief an den verehrten Autor auszusprechen:

„Francesco grüßt seinen Cicero. [...] oh Du hitziger und elender Alter, was hast Du mit so vielen Streitigkeiten und ganz und gar unnützen Feindschaften ausrichten wollen? [...] Welcher falsche Glanz von Ruhm hat Dich als alten Mann in die Kriege der Jungen hineingezogen und durch alle wechselhaften Fälle in einen Tod gerissen, der eines Philosophen unwürdig ist? ‘33 $^{33}$

30 Ebd., S. 21.

31 Ebd., S. 33.

32 Ebd., S. 41 und S. 45.

33 Ebd., S. 53. 
Petrarcas Rezeption des römisch-antiken Republikanismus ist daher stark durch seine christliche Prägung beeinflusst, die ihn ebenso wie Dante von der späteren, explizit politischen Entwicklung des Bürgerhumanismus unterscheidet. Das Manko der antiken Autoren bleibt daher, dass sie den christlichen Gott noch nicht gekannt haben - eine Kritik, die sich später bei Savonarola wiederholen sollte. ${ }^{34}$ Gleichwohl dominiert zuweilen der pessimistische Ton der Vergeblichkeit: Die Fortuna herrscht, die Tugend ist verloren. Die Zeit ist nur an Geld und Vergnügungen interessiert, Eintracht und Gemeinwohl haben keine Bedeutung mehr. ${ }^{35}$ Die „Trägheit unseres Zeitalters ${ }^{\text {“ } 36}$ hat die antike Leidenschaftlichkeit besiegt. Erst im Florentiner Bürgerhumanismus sollte die handlungsaktivierende Dimension der antiken Semantik und damit ihre politische Macht ganz entfaltet werden.

\section{BÜRgERLICHER HUMANISMUS UND REPUBLIKANISCHE SELBSTVEREHRUNG}

Die Hochphase des Bürgerhumanismus in Florenz ist mit den Namen von Coluccio Salutati, Leonardo Bruni und, in geringerem Maße auch mit Matteo Palmieri verbunden. In ihnen und in ihren Reflexionsschriften von politisch Handelnden in der späten Blütezeit der Florentiner Republik vor der Herrschaft der Medici verkörpert sich das humanistische Ideal einer Vertrautheit mit dem antiken Wissen und der aktiven Sorge um das Gemeinwohl der Stadt. Salutati, seit 1375 bis zu seinem Tod 1406 Kanzler von Florenz, half bei der Rettung der Stadt gegen die Eroberung durch die Mailänder Visconti - einer Krise, die für Hans Baron die Entwicklung des spezifischen Freiheits- und Tugendbewusstseins in Florenz entscheidend beeinflusst hatte. Die künstliche bürgerschaftliche Bindung tritt selbstbewusst neben die religiöse und natürliche Gemeinschaft, und auch der wahre Adel beruht auf Tugend, nicht auf Abstammung. ${ }^{37}$

In Salutatis Traktat vom Tyrannen findet sich eine in dieser expliziten Form neuartige Kritik an der monarchischen Alleinherrschaft, in der die

34 Girolamo Savonarola: O Florenz! O Rom! O Italien! Predigten, Schriften, Briefe, übersetzt und mit einem Nachwort von Jacques Laager, München 2002, S. 103.

35 Petrarca, Epistolae familiars, S. 95 und S. 119.

36 Ebd., S. 117.

37 Coluccio Salutati: De nobilitate legum et medicine [1399], nach: Berthold L. Ullman: The Humanism of Coluccio Salutati, Padua 1963, S. 32 und S. 73. 
Gesetzesbindung eine zentrale Rolle einnimmt. ${ }^{38}$ In der Frage des Tyrannenmordes bleibt die Schrift hingegen zurückhaltend. Einerseits wird die Legitimität des Tyrannenmordes bejaht - ebenso, wie Bürger ihr Eigentum verteidigen dürfen, so haben sie das Recht, ihren Staat gegen einen illegitimen Eroberer zu verteidigen -, andererseits im Falle von Cäsars Ermordung die Legitimität verneint, obwohl er Salutatis Definition zufolge als Tyrann eingestuft werden müsste. ${ }^{39}$ Salutati zeigt hier ähnlich wie später Machiavelli große Sympathien für praktische Klugheitserwägungen: Cäsars Verdienst lag in der Herstellung von Ordnung und Stabilität. Er war demnach kein Tyrann: Seine Herrschaft kam zwar unrechtmäßig zustande, hatte aber gleichwohl positive Effekte für die Befriedung des Gemeinwesens. ${ }^{40}$ Dante hatte also Recht, in seiner Göttlichen Komödie die Cäsarmörder Brutus und Cassius in der untersten Hölle schmoren zu lassen. ${ }^{41}$

Salutatis Schüler war Leonardo Bruni. Leonardo Bruni (Aretino) (13691444), war seit 1427 in der Nachfolge Salutatis Staatssekretär der Republik Florenz. Als Übersetzer von Platon und Aristoteles übertrug er die Nichomachische Ethik und die Politik. In dieser Doppelrolle als Magistrate und als Intellektuelle sind Salutati und Bruni die Hauptexponenten des von Hans Baron in den zwanziger Jahren zuerst so genannten Bürgerhumanismus, der sich vom weitgehend unpolitischen Humanismus eines Petrarcas durch offensives politisches Engagement und Patriotismus absetzte. Dennoch trug Bruni mit seiner Lebensgeschichte Dantes und Petrarcas zu deren Verehrung in Florenz wesentlich bei. ${ }^{42}$ Zudem half er auch mit seiner Geschichte des florentinischen Volkes bei der Steigerung des republikanischen Ruhmes und der städtischen Identität seiner Heimatstadt. ${ }^{43}$ In einem kurzen Traktat über die Staatsverfassung der Florentiner bietet Bruni aufschlussreiche Einblicke in die Selbstbeschreibung des Gemeinwesens, die sich klassisch aristotelisch an dem Vorbild der gemischten Verfassung

38 Coluccio Salutati: De tyranno, in: Ephraim Emerton (Hrsg.): Humanism and Tyranny. Studies in the Italien Trecento, Cambridge 1925, S. 70-119, hier: S. 78; Thumfart/Waschkuhn, Staatstheorien, S. 101ff.

39 Ullman, Humanism, 1963, S. 33.

40 Salutati, De tyranno, 1925, S. $93 \mathrm{ff}$.

41 Ebd., S. 110.

42 Leonardo Bruni: Le vite di Dante e del Petrarca, Florenz 1672.

43 Leonardo Bruni: History of the Florentine People, hrsg. von James Hankins, 3 Bde., Cambridge 2001-2007. 
orientiert. $^{44}$ So sei die Verfassung der Florentiner ,weder ganz aristokratisch noch demokratisch, sondern eine aus beiden Gemischte “45. Der Staat neige sich daher

„,zu dem Mittelstande, vorzüglich aber zu den Adeligen und Reichen, doch nicht übermäßig mächtigen. Eine Volksversammlung findet sehr selten statt in diesem Staate, weil für Alles schon im Voraus gesorgt ist, und die Magistrate und Rathsversammlungen, in Betreff der gewöhnlich vorkommenden Geschäfte, Vollmacht haben, so dass sie niemals der Volksversammlung bedürfen, wenn nicht eine zufällig große Veränderung das ganze Staatsgebäude in Verwirrung bringt; dann wird das ganze Volk zusammengerufen und ist die oberste Behörde; aber, wie gesagt, es geschieht selten. “46

Bruni liefert eine detaillierte Beschreibung der institutionellen Verfassungsstruktur mit den neun obersten Magistratsherren, dem Volksrat und dem adeligen Rat sowie deren Wahlverfahren.

„Da die Staatsverfassung, wie wir sagten, gemischter Form ist, so kann man mit Grund sagen, dass Einiges mehr zur Demokratie, einiges mehr zur Aristokratie sich hinneige. Zum demokratischen Elemente gehört die kurze Dauer der Ämter; denn die längste Amtszeit eines der Neun, dauert nur zwei Monate, der Beisitzer aber theils drei, theils vier. Dies ist wahrhaft demokratisch, und neigt sich vorzüglich zur Gleichheit. Auch ist dies volksthümlich, dass wir durch Wort und That im hohen Grade die Freiheit ehren und bewachen, als Endzweck und Ziel der ganzen Staatsverfassung. Dann auch durchs Loos die Beamten zu erwählen und nicht wegen irgendeines Vorzugs, ist volksthümlich. Wiederum neigt sich vieles der Aristokratie. $\mathrm{Da} ß$ zuerst über Alles eine Vorberathung statt finde, und dass Nichts zum Volke komme, worüber nicht erst abgestimmt, und dass es dem Volke nicht erlaubt sei, daran etwas zu verändern, sondern dass es im Ganzen die Sache entweder billigen oder verwerfen müsse, - dies scheint mir sehr aristokratisch. ${ }^{، 47}$

Zur Zeit der Volksbewaffnung war das Volk stärker, inzwischen aber übernehmen Söldner den Kriegsdienst und haben die Macht zu den Adligen und

44 Leonardo Bruni: Über die Staatsverfassung der Florentiner. Von Leonhardus Aretinus, hrsg. von Carl Friedrich Neumann, Frankfurt a.M. 1822; zur Textgeschichte vgl. die Einleitung des Herausgebers, S. Vf., jedoch ohne genaue Datierung.

45 Bruni, Staatsverfassung, 1822, S. 69.

46 Ebd., S. 71.

47 Ebd., S. 89ff. 
Reichen verschoben: „Indem sich das Volk allmählig so auflöste, bildete sich die Verfassung wie sie jetzt ist. ““48

Seine Lobpreisung der Stadt Florenz kann als republikanische Transzendenzerzählung gelesen werden: Schönheit und Größe entziehen sich jeglichen Begriffen - aber wie der Theologe über Gott spricht, kann auch der Historiker über Florenz handeln: „The splendor of this city is so wonderful, that no one can come even to a near description of it. But serious and trustworthy men dare to speak even of the greatness of God, inspite of the fact, that His glory and greatness is even beyond the speech of the most eloquent. ${ }^{\text {“99 }}$ Neben den Tugenden und Talenten seiner Bürger und den Vorzügen seiner Institutionen ist die römische Abstammung für Bruni besonders betonenswert. Florenz hat sich durch eigene Tugend als würdiger Nachfolger Roms erwiesen. Nicht durch Macht, sondern durch Gerechtigkeit und Humanität hat sie Autorität und Ruhm erworben. Durch ihre eigene Tugend und ihre Kriege hat sich Florenz daher letztlich noch mehr ausgezeichnet als durch ihre Abstammung. ${ }^{50}$

Neben Salutati und Bruni ist für die republikanische Selbstbegründung dieser Zeit auch Matteo Palmieri (1406-1475) von Bedeutung. Der Botschafter von Florenz bei Alfonso von Neapel verfasste 1429 Della vita civile, das zwischen 1435 und 1440 zirkulierte, aber erst 1529 gedruckt wurde. Palmieri hat diese wichtige Schrift des Bürgerhumanismus in Anlehnung an Ciceros De officiis und vor dem Hintergrund seiner eigenen Erfahrungen als Staatsdiener abgefasst. Die Abhandlung diskutiert neben der physischen und intellektuellen Entwicklung von Kindern vor allem das moralische Leben des guten Bürgers und die Spannung zwischen dem Nützlichen und dem Ehrlichen. ${ }^{51}$ Es kann als exemplarisch für das republikanische Transformationsparadigma gelten, demzufolge die gute Verfassung in der Lage ist, den interessegeleiteten Menschen in einen gemeinwohlorientierten Bürger zu wandeln. Damit wird auch hier der bürgerliche Gemeinsinn als etwas institutionell verfügbares, politisch erst Herzustellendes verstanden, das durch gute Gesetze befördert werden kann.

48 Ebd., S. 93.

49 Leonardo Bruni: In Praise of Florence. The Panegyric of the City of Florence and an Introduction to Leonardo Bruni's Civil Humanism, introduced and translated by Alfred Scheepers, Amsterdam 2005, S. 77.

50 Ebd., S. $99 f$.

51 Matteo Palmieri: Libro della vita civile [1529], Florenz 1981. 


\section{Philosophischer humanismus der MENSCHENWÜRDE}

Mit der Krise der Republik ab der Mitte des 15. Jahrhunderts und der zunehmenden Dominanz der Medici-Herrschaft geht ein abnehmendes Interesse an den Fragen der Bürgertugend und der politischen Teilhabe einher. In diesem Zusammenhang entwickelt sich ein anderer Transzendenzdiskurs, der weniger die republikanische Tugend des aktiven Lebens preist, sondern angesichts des zunehmenden Wandels der Republik zu einer Fassade quasi-monarchischer Alleinherrschaft das philosophische Ideal der vita contemplativa wiederentdeckt. In den Schriften von Gianozzo Manetti und Pico della Mirandola wird zwar ebenfalls die Freiheit und Selbstbestimmtheit des Menschen herausgestellt, aber auch der Schutz und die Entzogenheit der menschlichen Würde werden hier thematisiert. Nachdem also der republikanische Humanismus vorwiegend auf Tugend und Ruhm rekurriert hatte, folgt hier eine neuartige Form der protoliberalen Unverfügbarkeitsbehauptungen gegenüber einer zunehmend unter instrumentellen Rationalitätskriterien agierenden weltlichen Macht. Die Hinwendung zu Platon bei Pico oder dem führenden Neuplatoniker dieser Zeit Marsilius Ficinus geht einher mit der Abkehr von Cicero. ${ }^{52}$ Das Thema der politischen Ordnung und ihrer transzendenten Geltungsbedingungen ist noch präsent, gerät aber in den Hintergrund.

Manettis Abhandlung Über die Würde und Erhabenheit des Menschen (1452) geht aus von der Offenheit und damit der politischen Verfügbarstellung menschlicher Ordnung. ${ }^{53}$ Als Sohn eines Florentiner Kaufmanns aus adliger Familie studierte er Philosophie und Theologie. Er war Anhänger des Aristoteles und zugleich ein gewissenhafter Repräsentant des Florentiner Bürgerhumanismus. Tätig in verschiedenen politischen Gremien der Republik sowie als Stadtkommandant in den von der Republik abhängigen Kommunen übernahm er zahlreiche diplomatische Missionen und ging nach Neapel ins Exil, nachdem er ,infolge seiner kompromisslosen republi-

52 Vgl. zu dieser Wende Skinner, Foundations, 1997, S. 114f.; zu Marsilius Ficino und den schon bei Bruni wichtigen Platon-Bezügen vgl. James Hankins: Platon in the Renaissance, 2 Bde., Leiden u.a. 1990.

53 Gianozzo Manetti: Über die Würde und Erhabenheit des Menschen, übersetzt von Hartmut Leppin, hrsg. und eingeleitet von August Buck, Hamburg 1990. 
kanischen Gesinnung" mit Cosimo de'Medici in Konflikt geriet. ${ }^{54}$ Anders als später bei Pico war sein Ziel keine geschlossene Philosophie, sondern eine humanistische „Lebenslehre“. ${ }^{55}$ Damit hatte die vita activa hier im Gegensatz zu Pico noch den höheren Stellenwert. Zwischen beiden kann so ein Bruch beobachtet werden, der den politischen vom philosophischen Humanismus trennt. Erst der politiktheoretische Republikanismus eines Machiavelli und Guicciardini hebt das Politische wieder über die kontemplative Lebensweise, wenngleich durch die neuartige realistische Betrachtungsweise der humanistisch-moralische Tugendbegriff eine Bedeutungsverschiebung erfährt.

Nach ausgiebiger Beschreibung des menschlichen Körpers und seiner Vollkommenheit - unter Rückgriff auf die neuen medizinischen und physiologischen Erkenntnisse der Renaissance - geht Manetti über zu den kulturellen und sozialen Schöpfungen der Welt, die nicht das Werk Gottes, sondern des Menschen selbst sind. ${ }^{56}$ Neben allen Erfindungen ist es auch die „Kunst des Sprechens“, die zu den spezifisch menschlichen Werken und Formen seiner eigenen Vervollkommnung zählt. ${ }^{57}$ Am bedeutendsten jedoch ist für diese spezifisch menschliche Fähigkeit der Weltschöpfung die „Tätigkeit des Ordnens“, das Einteilen und Steuern. ${ }^{58}$ Die göttliche Schöpfung - die Erde, die Tiere etc. - ist gerade deshalb so vollkommen, „weil sie so verschiedene und so unterhaltsame Arten teils belebter, teils aber unbelebter Dinge eben für den Menschen bereitstellen und ihm verfügbar machen wollte“59. Daraus folgt schließlich, „dass der Mensch äußerst reich und mächtig ist, da er alles, was geschaffen ist, nach seinem Willen benutzen und kraft seiner Gewalt beherrschen und leiten kann ${ }^{660}$. Dieser

54 August Buck: Einleitung, in: Manetti, Über die Würde, 1990, S. XV.

55 Ebd., S. XXIII.

56 „Was sollen wir aber über den feinen und scharfsinnigen Verstand dieses so schönen und wohlgestalteten Menschen sagen? Denn er ist wirklich so groß und reich, dass nach der Erschaffung jener ursprünglichen, neuen, rohen Welt offenbar alles weitere von uns aufgrund des einzigartigen, überragenden Scharfsinns des menschlichen Verstandes hinzuerfunden und zur Vollendung und Vollkommenheit geführt worden ist. [...] Unser sind die Bilder, unser die Skulpturen, unser sind die Künste, unser die Wissenschaften, unser ist [...] die Weisheit.“ (Manetti, Über die Würde, 1990, S. 77)

57 Ebd.

58 Ebd., S. 78.

59 Ebd., S. 81.

60 Ebd., S. 83. 
Verfügbarkeitsglaube angesichts der aus der Welt zurückgezogenen Transzendenz des Schöpfergottes ist jedoch nicht ungebrochen: Der Mensch muss sich diese Aneignung des Unverfügbaren stets im Kampf gegen die ihm von der Schöpfung zugedachte Lust und Trägheit abringen. Dieses Vermögen bezeichnet die Tugend, die gegen den ,inneren Feind“, die Lust kämpft. $^{61}$

Die spezifische Würde des Menschen jedoch liegt gerade nicht in der totalen Verfügbarkeit der Welt. Vielmehr verbirgt sie sich in den ebenfalls von der göttlichen Schöpfung gezogenen Grenzen der Handlungsvollmacht: der Unverfügbarkeit des eigenen Körpers und der Würde der anderen Menschen. Zwar hat Gott den Menschen zur Verfügung über die Natur berechtigt - die menschliche Natur jedoch beinhaltet einen göttlich geschaffenen Selbstschutz, der den Menschen vor sich selber und den radikalsten Konsequenzen seiner ihm eigenen Machtfülle bewahrt:

„Daher gab der allmächtige Gott ihm, den er in eine so große und so erhabene Würde eingesetzt hatte, die natürliche Anlage, dass er sich selbst liebt, um sich am Leben zu halten, im übrigen aber erlegte er ihm durch die ganz festen und ausdrücklichen Gebote des geschriebene Gesetzes die Verpflichtung auf, dass er all seine Nächsten, das heißt alle Menschen, liebe, ehre und achte. “62

Der Mensch, so zitiert Manetti zustimmend Laktanz, ist daher mit Gott über die „Gemeinschaftlichkeit des göttlichen Rechts“ verbunden, „denn es widerspricht dem göttlichen Gebot, dass ein Verehrer Gottes von einem anderen Verehrer Gottes verletzt wird“. ${ }^{63}$ Transzendenz und Gemeinsinn verschränken sich hier exemplarisch, um die Verfügbarstellung menschlicher Ordnung zugleich in ihrer Kontingenz zu verdecken. Die Pointe von Manettis Position liegt also gerade darin, am Ende seines gegen den göttlichen Herrschaftsanspruch gerichteten Textes die Notwendigkeit von Schranken und Grenzen zu betonen, die gerade aus der menschlichen Würde des Handeln- und Denkenkönnens entspringen. Pico della Mirandola dagegen flankiert seine Betrachtungen Über die Würde des Menschen (1486) und die Idee der menschlichen Selbstermächtigung nicht durch eine

61 Ebd.

62 Ebd., S. 92.

63 Ebd., S. 93f. 
korrespondierende Selbstbegrenzung. ${ }^{64}$ Die menschliche Würde findet ihren Ausdruck in einem unverhohlenen philosophischen Herrschaftsanspruch: Über die Selbsterkenntnis des Menschen im Medium der Moralphilosophie und der vernünftigen Einsicht in seine von Gott gegebene Natur wird der Mensch selbst gottähnlich zum höchsten Wesen der Schöpfung. In dieser Möglichkeit zum Höchsten liegt seine besondere Würde, die ihn gegenüber allen anderen Geschöpfen auszeichnet: „Nichts Wunderbareres als den Menschen" gebe es in der Schöpfung, so Pico, und rühmt die Vorzüglichkeit der menschlichen Natur; er ist das „am meisten gesegnete und daher ein jeder Bewunderung würdiges Lebewesen “65. Gegen die christlich-augustinische Erbsündetheorie gerichtet, welche die mittelalterlichen Sozialtheorien geprägt hatte und eine dementsprechend skeptische Ordnungsvorstellung menschlicher Freiheit begründete, stellt Pico den Menschen in den Mittelpunkt der göttlichen Schöpfung und stattet ihn mit einer geradezu existenziellen unbegrenzten Freiheit aus, die ihn fähig zum Guten ebenso wie zum Schlechten macht: Gott schuf den Menschen als ein „Geschöpf von unbestimmter Gestalt“ und

„sprach ihn so an: ,Wir haben dir keinen festen Wohnsitz gegeben, Adam, kein eigenes Aussehen noch irgendeine besondere Gabe, damit du den Wohnsitz, das Aussehen und die Gabe, die du selbst dir ausersiehst, entsprechend deinem Wunsch und Entschluss habest und besitzest. Die Natur der übrigen Geschöpfe ist fest bestimmt und wird innerhalb von uns vorgeschriebener Gesetze begrenzt. Du sollst dir deine ohne jede Einschränkung und Enge, nach deinem Ermessen, dem ich dich anvertraut habe, selber bestimmen. Ich habe dich in die Mitte der Welt gestellt, damit du dich von dort aus bequemer umsehen kannst, was es auf der Welt gibt. Weder haben wir dich himmlisch noch irdisch, weder sterblich noch unsterblich geschaffen, damit du wie dein eigener, in Ehre frei entscheidender, schöpferischer Bildhauer dich selbst zu der Gestalt ausformst, die du bevorzugst. Du kannst zum Niedrigeren, zum Tierischen entarten; du kannst aber auch zum Höheren, zum Göttlichen wiedergeboren werden, wenn deine Seele es beschließt‘، ،66

64 Pico della Mirandola: Über die Würde des Menschen, übersetzt von Norbert Baumgarten, hrsg. und eingeleitet von August Buck, Hamburg 1990.

65 Ebd., S. 3.

66 Ebd., S. $6 f$. 
Der Mensch ähnelt daher einem „Chamäleon“, welches ist, was es sein will. ${ }^{67}$ Er hat von Gott „die freie Wahl“ erhalten, der das Höchste erreichen kann, wenn er es den nur will. ${ }^{68}$ Die Menschen sollen

„durch die Morallehre den Drang der Leidenschaften zügeln, durch die Dialektik die Finsternis des Verstandes vertreiben und so gewissermaßen den Schmutz der Unwissenheit und der Laster herauswaschen, unsere Seele reinigen, damit weder die Leidenschaften blindlings wüten noch der unkluge Verstand je zu rasen beginnt. Dann wollen wir unsere wohlgeordnete und geläuterte Seele vom Licht der Naturphilosophie durchfluten lassen, um sie schließlich durch die Erkenntnis der göttlichen Dinge zu vervollkommnen. “69

Die Offenheit der menschlichen Grundsituation wird daher bei Pico durch seinen christlich-esoterischen Platonismus wieder geschlossen, wenn er der Philosophie die Rolle der objektiven Erkenntnis zuschreibt, die den Menschen durch Wissen zu Erlösung von der Offenheit und Unbestimmtheit führt. Denn die existenzielle Grundsituation des Menschen führt zu Konflikten, im Inneren wie im Äußeren: „In der Tat, Väter, ist die Zwietracht in uns vielfältig; schwere innere Kämpfe, schlimmer als Bürgerkriege, führen wir mit uns selbst. ${ }^{\text {“70 }}$ Es ist zunächst die Moralphilosophie, welche die Leidenschaften dieser Kämpfe befriedet. Darauf kann die Dialektik aufbauen und „die Verwirrungen unseres Verstandes beenden““71. Das Heil der Einheit liegt in dem Objektivitätsversprechen der aufkommenden Naturwissenschaften, die damit noch untrennbar von ihrer ethischen Aufgabe sind: „Die Naturphilosophie wird die Meinungsstreitigkeiten und -verschiedenheiten aufheben, die die unruhige Seele hierhin und dorthin ziehen, zerren und zerreißen. “72 Diese mündet in eine theologisch fundierte Gemeinschaftlichkeit, die den zunächst offen und widersprüchlich angelegten Menschen zu einer höheren Einheit führt: „heiligen Frieden, unlösliches Band, einträchtige Freundschaft, durch die alle Seelen in dem einen Geist, der über allem Geist ist, nicht so sehr nur harmonieren, sondern auf unaussprechliche Weise ganz und gar eins werden.“73

67 Ebd., S. 9 und S. 11.

68 Ebd., S. 11.

69 Ebd., S. 15.

70 Ebd., S. 19.

71 Ebd.

72 Ebd.

73 Ebd., S. 21. 
Das politische Einheitsversprechen des Republikanismus wird bei Pico damit nochmals transzendiert in einem philosophisch begründeten spirituellen Einheitsbegriff, der auch normativ von einer höheren Dignität zu sein behauptet als das innerweltliche Engagement des Bürgers für das städtische Gemeinwohl.

\section{Die SPRACHE DER REPUBLIKANISCHEN OFFENBARUNG: SAVONAROLA}

Im ausgehenden 15. Jahrhundert stehen in Florenz sowohl die Semantik des bürgerschaftlichen Gemeinsinns als auch die theologische Sprache des Heiligen im Kampf um die Deutung politischer Ordnung bereit. In der Gestalt des Dominikaner-Mönchs und Predigers Savonarola konvergieren beider Sprachen zu einer explosiven Mischung, die in den ersten Jahren nach der Wiederherstellung der Republik und der Vertreibung der MediciHerrscher einen bedeutsamen Einfluss auf die Verfassungsdiskussion ausüben sollte. Auch wenn Savonarolas Position in ihren Begründungsmustern keineswegs ein hohes Maß an Originalität aufweist und in weiten Teilen stark an das Denken Thomas von Aquins angelehnt ist, ${ }^{74}$ so liegt doch das Besondere hier in der Form: Die Begründung der Bürgerschaft durch Prophetie in der Gestalt Savonarolas ${ }^{75}$ ist paradigmatisch für die Produktionsversuche von bürgerlichem Gemeinsinn durch den Rekurs auf religiöse Transzendenz und die Heiligkeit politischer Ordnung. Savonarolas Transzendenzbehauptungen sind zwar religiös, jedoch in ihrer handlungsmotivierenden Intention nicht weltabgewandt. Savonarola artikuliert in seinen Predigten und Schriften in der Tat eine ,politische Theologie“, da die politische Ordnung unmittelbar in der göttlichen Ordnung verankert wird. ${ }^{76}$ Gottes Gesetz ist der Maßstab für die Gesetze des Menschen. Mit Savonarola aber wird die von den Humanisten gepriesene Macht der Sprache zu einem Instrument der paradoxalen Agitation, der Stiftung von innerweltlichem Gemeinsinn durch die Beschwörung des außerweltlichen Heilsplans. Savonarola steht für den Versuch, eine neue Verfassung durch

74 Vgl. Skinner, Foundations, Bd. 1, 1997, S. 147.

75 Vgl. Pocock, Machiavellian Moment, 1975, S. 115; Donald Weinstein: Savonarola and Florence. Prophecy and Patriotism in the Renaissance, Princeton 1970.

76 Vgl. Matthias Mayer: Die Politische Theologie Savonarolas, Tübingen 2001. 
das Medium der prophetischen Predigt zu schaffen. Die Republik ist der Ort der verfügbar gemachten Eschatologie. Seine Bastion ist die Kanzel, seine Macht liegt in der erfolgreichen Synthese christlicher Heilssemantik und republikanisch-humanistischer Tugendvorstellungen. Im Mittelpunkt der bilderreichen Allegorien und Metaphern steht die Identität von Florenz mit Israel in der ägyptischen Sklaverei, unterworfen der pharaonischen Tyrannei. $^{77}$ Zudem ist die Verfassung des Gemeinwesens korrumpiert durch die Leidenschaften und die Genusssucht: Anstelle des Gemeinwohls herrscht der Eigennutz. ${ }^{78}$ In Savonarolas Augen ist Florenz seit langem dem Verfall der Sitten und der Tugend unterworfen. Florenz ist „ein durchlöchertes Gefäß“, das die „Gnade des Öls des Heiligen Geistes nicht zurückhalten“ kann: „O Florenz, ich sage dir, du ruhst nicht mehr in dir, sondern bist außer dir.“79 Die Balance der guten Verfassung ist dahin, durch die schlechten Leidenschaften droht Bürgerkrieg und Ordnungszerfall. Mitschuld trägt die humanistische Verbildung durch die Lehren der Philosophen und der zunehmende Einfluss von Astrologen und Aberglauben, die den christlichen Geist bedrohen und die einfache christliche Tugendlehre überdecken:

„Ihr, ihr habt viele Bücher zu Hause, die ihr nicht besitzen solltet, weil sich in ihnen viele unanständige Dinge geschrieben finden. Verbrenne solche Bücher, denn sie gehören nicht zu Christen! [...] Die Philosophen suchten die Dinge, über die sie Überlegungen anstellen wollten, allein mittels natürlichem Licht zu ergründen. Zum wahren Christen hingegen gehört es, danach zu streben, sich mit dem übernatürlichen Licht und der Gnade Gottes zu erfüllen. [...] Du nennst Seneca, Aristoteles und Philon - meinetwegen, sie sind gut, aber sie tragen zur christlichen Religion, die vom übernatürlichen Licht lebt, nichts bei. Ich sage dir: Es gibt auf der Welt viele Bücher deren Tilgung und Ausrottung für unseren Glauben und für die christliche Religion einen großen Nutzen brächten. “80

Savonarolas Abwehr konkurrierender Transzendenzvorstellungen zum Erhalt der reinen Lehre stehen im Dienst des Versuchs, eine neue

77 Savonarola, O Florenz!, 2002, S. 20ff; zur politischen Sprengkraft des Exodusmotivs vgl. Michael Walzer: Exodus und Revolution, Frankfurt a.M. 1995.

78 Savonarola, O Florenz!, 2002, S. 121.

79 Ebd., S. 95.

80 Ebd., S. 103; zur Astrologie S. 113; dazu auch Anthony J. Parel: The Machiavellian Cosmos, New Haven/London 1992. 
Verfassungsordnung durch einen monistischen und exklusiven Offenbarungsanspruch zu begründen. Die Betonung der Spiritualität und des Geistes nimmt in religiöser Gestalt die klassischen Themen des Republikanismus auf und fusioniert sie zu einer Sprache der politischen Weltheiligkeit. Nicht lediglich neuer Institutionen bedarf es, sondern ganz im Sinne der republikanischen Verfassungstheorie sind die Sitten und Gewohnheiten, die Bindung von Herz und Geist von entscheidender Bedeutung. Als transzendenter Maßstab zur politischen Verfügbarstellung der Sitten und Gewohnheit, der Verfassung und der menschlichen Gesetze dient Savonarola das Gesetz Gottes:

„O Florenz, [...] wenn du wirklich neu sein und zu einer Veränderung kommen willst, so musst du neue Sitten und eine neue Art zu leben annehmen. Willst du bestehenbleiben und regieren können, musst du einen neuen Gesang anstimmen und dich auf die Suche machen, eine neue Regierungsform zu finden. [...] Gib dir ein Gesetz, damit in Zukunft niemand mehr sich zum Haupt deines Staatswesens erheben kann, sonst bis du auf Sand gegründet! [...] Und wollt ihr gute Gesetze schaffen, so bringt euch selbst in Übereinstimmung mit dem Gesetz Gottes, denn alle guten Gesetze hängen vom ewigen Gesetz ab. [...] So musst du denn, Florenz, von Gott erleuchtet sein.“ ${ }^{81}$

Savonarolas Predigten können daher als eine paradoxe Form der Verfassungsoffenbarung verstanden werden, mit der die Grundlagen der politischen Ordnung als transzendent erfahren werden und zugleich im Akt der Erneuerung politisch verfügbar gestellt werden sollen. Das Gegenmittel gegen die Macht der Gewohnheit ist bei Savonarola die Macht der geoffenbarten Wahrheit:

„Wieviel Kraft die Gewohnheit hat, Geliebteste in Jesus Christus, sieht und erkennt man sehr gut, denn oft überwindet und besiegt diese die Wahrheit. Wenn man deshalb eine neue Gewohnheit an Stelle der alten Gepflogenheiten einführen will, kann dies nicht in einem Zuge geschehen, vielmehr ist es nötig, ganz sachte vorzugehen. Indessen, wenn wir mit unserem Predigen die Absicht haben, eine neue Gewohnheit einzuführen und die (Notwendigkeit einer) Erneuerung aufzuzeigen, die durch eine entgegengesetzte Gewohnheit zu erfolgen hat, werden wir nur behutsam und nach und nach vorzugehen haben. Wenn du, Florenz, deine alte Gepflogenheit aufgeben

81 Savonarola, O Florenz!, 2002, S. $116 f$. 
und dich erneuern willst, musst du die Art und Weise deiner Erneuerung und deiner neuen Regierung überdenken. “ 82

Die unverfügbaren Gewohnheiten lassen sich für Savonarola nur durch Rückgriff auf die göttliche Wahrheit verfügbar machen - erstaunlich aber ist, in welcher Form Savonarola diese konstitutionelle Offenbarung verbindlich machen will: Die göttliche Transzendenz wird so in eine verfassunggebende institutionelle Prozedur überführt, deren formale Struktur zwar einerseits ergebnisoffen ist, zum anderen aber genau jene göttliche Ordnung herbeiführen soll, die Savonarola für die Republik Florenz angemessen hält. Savonarola schlägt daher eine konkrete Prozedur der konstitutionellen Beratung vor, mit der die Bürgerschaft selber über die Verfassung abstimmen kann und gleichzeitig der Frieden des Gemeinwesens gewahrt bleibt: Zunächst ,soll man allerorts während drei Tagen hintereinander Gebete verrichten, damit Gott das Herz eines jeden dazu bewege, diesen Frieden bereitwillig zu schließen“. Daraufhin sollen sich „nun die Bürger versammeln, und zwar jeder bei seinem Banner, und miteinander untersuchen, welche Verfassungsform die beste scheine, um sie für eure Regierung zu wählen. Und jedes Banner wähle die Form, der seine Bürger nah Beratung zugestimmt haben. "83 Darauf mögen die Bannerträger unter diesen Formen

„vier auswählen, die ihnen die besten und die dauerhaftesten zu sein scheinen, und diese vor die ehrwürdige Signora bringen. Und wenn dann hier im Ratssaal, die Messe des Heiligen Geistes gefeiert worden ist, mögen sie von diesen vier vorgeschlagenen eine auswählen, und ihr sollt ganz gewiß sein, dass die Regierungsform, die auf diese Weise gewählt wurde, von Gott ist. “84

Savonarola selbst befürwortet die Regierungsform der Venezianer ohne Dogen, die Regierung einer Mehrheit anstelle der Herrschaft eines Einzelnen, denn diese ist ,sehr gut, und ihr möget euch nicht schämen, von anderen zu lernen, denn die Regierungsform, die jene haben, wurde ihnen von Gott gegeben, und nachdem sie diese angenommen haben, gab es nie Zwietracht unter den Bürgern. “ 85

82 Ebd., S. 124.

83 Ebd., S. 152.

84 Ebd.

85 Ebd. 
Savonarolas Selbstinszenierung als gottgesandter Verfassunggeber geht daher einher mit einem autoritären Verkündigungsgestus, der aufgrund seiner monistischen Züge und seinem universalen, geheiligten Wahrheitsanspruch zudem nicht vor radikalen Maßnahmen zurückschreckt: Nicht nur die Fegefeuer der Eitelkeiten mit ihrer Vernichtung von Büchern, Bildern und Luxusgegenständen ist bekannt. Savonarola empfiehlt auch die Verbrennung „einiger Sodomiten“ zum Wohlgefallen Gottes. ${ }^{86}$ Zudem wird Florenz als ein Kind geschildert, dessen Glieder fest eingebunden werden müssen, um sie zu stärken. ${ }^{87}$ Savonarolas Position zeigt deutlich die ambivalente Brückenstellung zwischen der republikanischen Wertschätzung gelebter Sittlichkeit und der christlichen Naturrechtslehre mit ihrem damit verknüpften universalen Wahrheitsanspruch, die durch ihre Verbindung den Ordnungsanspruch radikalisieren. Gleichwohl nimmt er neben der heilsgeschichtlich aufgeladenen Geste der quasi-apokalyptischen Neugründung auch die Gewohnheit in Anspruch, um die republikanische Regierungsform für Florenz jedem Zweifel zu entziehen. Die auf den Bürgern beruhende Regierung entspricht der Natur des florentinischen Volkes, denn das florentinische Volk ist unter allen Völkern Italiens am besten für diese Regierung geeignet: „Die Natur dieses Volkes lässt es also nicht zu, die Herrschaft eines Fürsten zu ertragen, selbst wenn dieser gut und vollkommen wäre. ${ }^{\text {(68 }}{ }^{8}$ Die Gewohnheit wird zu einer „zweiten Natur“, und so

„verwandelt sich die Gewohnheit zur Natur, und es ist sehr schwierig und sozusagen unmöglich, die Menschen und vor allem ganze Völker von ihren Gewohnheiten zu trennen [...]. Nun hat aber das florentinische Volk seit alter Zeit eine Regierungsform gewählt, die auf den Bürgern fußt. Es hat sich so sehr daran gewöhnt, dass [...] eine solche Regierung [...] auch im Geist der Bürger fest eingeprägt ist. [...] Und mochten die Florentiner auch schon viele Jahre von Tyrannen regiert worden sein, so haben trotzdem jene Bürger, die sich während dieser Zeit das Prinzipat angemaßt hatten, [..] ihm nicht seine natürliche Gewohnheit [geraubt]. ${ }^{489}$

Damit überschneiden sich bei Savonarola entgegen seiner expliziten Absicht mehrere Begründungsstrategien, mit denen die republikanische Verfassung unverfügbar gestellt werden soll: Gott und die offenbarte Wahr-

86 Ebd., S. 215.

87 Ebd., S. 206.

88 Ebd., S. 551.

89 Ebd., S. 551f. 
heit, die Natur, die Gewohnheit. Gemeinsam haben diese Begründungsmuster, dass sie die Verfassung gleichsam als ein Gefäß für den bürgerlichen Gemeinsinn und die Tugend entwerfen. Die asketische Ordnung der Republik lebt damit von einem doppelten Heilsversprechen: Der weltliche Glücksanspruch wird durch die tugendhafte Hingabe an das Gemeinwohl und die Entsagung an Luxus, Korruption und Eigennutz eingelöst. Erst die göttliche Transzendenz aber verleiht der weltlichen Ordnung bei Savonarola jene Heiligkeit, die ihren Mitgliedern trotz aller Vergänglichkeit des von Menschen Gemachten einen heilsgewissen Vorschuss auf die religiöse Erlösungshoffnung des Jüngsten Gerichts gewährt.

\section{VON DER SAKRALISIERTEN REPUBLIK ZUR UNVERFÜGBARKEIT DES REALEN}

Diese emphatische Begründung der Republik wich mit der Rückkehr der Medici nach 1512 einer distanzierteren Betrachtungsweise, die im Rückblick auf den Aufstieg und den Niedergang der republikanischen Ordnung die Bedingungen für ihre Stabilität analytisch auszuloten suchte. Machiavelli unterscheidet sich hier nicht allein von Savonarola, sondern weicht in zwei wichtigen Punkten vom republikanischen Humanismus des 15. Jahrhunderts ab: erstens in seiner Skepsis gegenüber der venezianischen Verfassung und seinem Lob des römischen Konfliktmodells, sowie zweitens in seiner Diskussion der Spannung zwischen Tugend und christlichem Glauben. ${ }^{90}$ Dennoch steht er mit den Discorsi im selben Problemkontext der Florentiner Autoren: Wie kann die Republik trotz ihrer prekären Geltungsvoraussetzungen auf Dauer gestellt werden? Welches sind die Bedingungen, unter denen die Ordnung des Gemeinwesens politisch verfügbar gemacht werden kann? Welche Verweise auf Unverfügbares sollen die neu konstituierte Ordnung stabilisieren und gegen die Anfechtungen der Fortuna, der Kontingenz schützen? Machiavelli differenziert dabei gerade das Verhältnis von politischer und religiöser Ordnung: Republikanische Verfassungen beruhen auf einer politischen Konkurrenzbehauptung zur religiös konnotierten Transzendenz der Fortuna. Die menschliche Selbstermächtigung kann unter bestimmten Umständen die Oberhand über die Macht der Schicksalsgöttin erringen, indem sie der religiösen Transzendenz

90 Skinner, Foundations, Bd. 1, 1997, S. 181f. 
eine spezifisch republikanische Transzendenz gegenüberstellt, die auf den Begriffen der Tugend und der guten Verfassung beruht. ${ }^{91}$ Die individuelle Bürgerfreiheit, die zugleich immer durch die Freiheit des politischen Gemeinwesens bedingt und konstituiert wird, bedarf somit keiner Verankerung in einem universalen Heilsgeschehen. Gleichwohl ist auch sie nicht ohne Wurzeln und Rückbindung gedacht: Diese religio der Republik aber wird bei Machiavelli als Bindung und Verpflichtung durch die soziomoralischen Dispositionen der Bürgerschaft entworfen - der Tugend, die durch verschiedene Mechanismen der Verstetigung institutionell stabilisiert werden soll. ${ }^{92}$ Um die Republik auf Dauer zu stellen, bedarf es zudem einer Wiederholung des zeitlich entzogenen Ursprungs, einer narrativen und visuellen Präsenz der geschichtlichen Ordnung. ${ }^{93}$ Neben dem Bezug auf die römische Republik ist der Venedig-Mythos einer jahrhundertealten republikanischen Bürgerverfassung das beste Bespiel für diese geschichtliche Transzendierung. Machiavelli hat dieses Modell jedoch verworfen. In den Discorsi erhält Rom den Vorzug: Venedig hat das Defizit, keine guten militärischen Einrichtungen zu besitzen, daher kann es auch keine virtù generieren und bleibt in politischen Krisen auf die fortuna angewiesen. ${ }^{94}$ Anders Rom: Durch das gemäßigte Streben nach Eroberung, vor allem aber durch den inneren Konflikt zwischen Volk und Adel generiert das Gemeinwesen ausreichend Tugend, um sich gegenüber der Unbill der Fortuna zu behaupten. ${ }^{95}$

91 Vgl. Niccolò Machiavelli: Der Fürst, mit einem Nachwort von Horst Günther, Frankfurt a.M. 1990 (Kap. XXV: Welche Macht das Glück in menschlichen Dingen hat und wie man ihm widerstehen kann).

92 Dazu gehört bei Machiavelli immer auch die Wehrhaftigkeit. Genau daran, so der direkte Vorwurf, sei auch die nur auf das prophetische Wort allein gegründete Macht Savonarolas gescheitert (ebd., S. 38f. (Kap. VI)).

93 Niccolò Machiavelli: Discorsi, hrsg. von Horst Günther, Frankfurt a.M. 2000 (3. Buch, 1. Kap.: „Soll ein Staat oder eine Religion lange bestehen, so muß man sie häufig zu ihrem Ursprung zurückführen.") Machiavelli selbst hat dazu durch seine Stadtgeschichte beigetragen (Niccolò Machiavelli: Geschichte von Florenz, übersetzt von Alfred von Reumont, hrsg. von Ludwig Goldscheider, Wien 1934).

94 Machiavelli, Discorsi, bes. S. $391 \mathrm{ff}$. (3. Buch, 31. Kap.).

95 Ebd. (1. Buch, 1.-4. Kap). Machiavellis Abwertung Venedigs und seine Aufwertung Roms läuft quer zur Orientierungsfunktion, die Venedig auch in institutioneller Hinsicht für die Florentinische Republik besessen hat. Vgl. nur zur Übernahme des Großen Rates: Felix Gilbert: The Venetian Constitution in Florentine Political Thought, in: Nicolai Rubinstein (Hrsg.): Florentine Studies, 
Zentral aber sind die guten Institutionen: Eine gute Verfassung stellt das Bollwerk gegen die Anarchie der geschichtlichen Dynamik, gegen die Kontingenz dar und vermag es, den tugendhaften Gemeinsinn zu erhalten und zu fördern. ${ }^{96}$ Der Kern solcher guten Institutionen liegt für Machiavelli in ihrer Konfliktfähigkeit, sei es nach innen wie nach außen. Da jedoch die nach außen getragenen Konflikte in eine ungebremste Expansionsdynamik münden können, durch welche die republikanischen Institutionen langfristig bedroht werden, ist dem römischen Verfassungsmodell und seiner politisch ausgetragenen inneren Konflikte der Vorzug zu geben. Zudem ruht hier die Verfassung nicht wie in Venedig auf einer schmalen, quasiaristokratischen Gruppe der Bevölkerung, sondern integriert breite Schichten in das Gemeinwesen.

So deutlich wie kaum ein anderer Autor dieser Zeit weist Machiavelli zudem der Religion im engeren Sinne eine rein funktionale Rolle für den Erhalt des politischen Gemeinwesens zu und verbindet diese Überlegung mit einer unverhohlenen Kritik des christlichen Glaubens. ${ }^{97}$ Auch hier geht es um die Abwehr eines konkurrierenden Transzendenzanspruches, im Vergleich zu Savonarola erfolgt diese Abwehr allerdings mit umgekehrten Vorzeichen. Während dieser alle nicht-christlichen Formen der Heiligung als bedrohlichen Götzendienst verworfen hat, so bezeichnet Machiavelli die christliche Religion aufgrund ihres jenseitigen Heilsversprechens als untauglich für die Stabilisierung der weltlichen Ordnung. ${ }^{98}$ Auch wenn er seine Kritik vor allem am politischen Machtanspruch der Kirche festmacht,

London 1968, S. 463-500 sowie Skinner, Foundations, Bd. 1, 1997, S. 138ff.; vgl. zur gegenläufigen Wertschätzung der Vorbilder Rom und Venedig bei Machiavelli und bei Guicciardini außerdem die zentralen Kapitel bei Pocock, Machiavellian Moment, 1975, S. 183ff.

96 Vgl. nur Machiavelli, Discorsi, 2000 (1. Buch, 18. und 58. Kap.).

97 Ebd. (1. Buch, 11.-14. Kap.).

98 Ebd. (2. Buch, 2. Kap): Die christliche Religion lässt „uns die weltliche Ehre geringer schätzen. Die Heiden hingegen schätzten sie sehr hoch und hielten sie für ihr höchstes Gut, und darum waren sie kühner in ihren Taten. [...] Die alte Religion sprach überdies nur Männer voll weltlichen Ruhm heilig, wie Feldherren und Staatenlenkern. Unsre Religion hat mehr die demütigen und beschaulichen Menschen als die tätigen selig gesprochen. Sie hat das höchste Gut in Demut, Entsagung und Verachtung des Irdischen gesetzt; jene setzten es in hohen Mut, Leibesstärke und alles, was den Menschen kraftvoll macht.“ (ebd., S. 184) Im Vorwort zu den Discorsi verweist er zudem auf die „Schwäche, zu welcher die gegenwärtige Religion die Welt erzogen hat"; den direkten Angriff auf die römische Kirche führt er im 12. Kapitel des ersten Buches. 
so zielt er doch indirekt auch auf ihre Relativierung des Politischen - Ehre, Tugend, Opfer für das Gemeinwohl -, weshalb die christliche Religion einen hochgradig destabilisierenden Charakter aufweist, der politisch-weltliche Bindungen und Loyalitätsverhältnisse im Namen zukünftigen Heils abschwächt.

Schon bei Marsilius von Padua gab es ähnliche Überlegungen, die sich auf die stützende Rolle der Religion für die politische Ordnung beziehen. Das Problem der Entzogenheit der sozio-moralischen Grundlagen für den weltlichen Gesetzgeber hat ihn trotz seiner Kirchenkritik zu einer funktionalen Aufwertung des Priesterstandes bewegt: „[D]ie Moralität des menschlichen Handelns im persönlichen und staatlichen Leben“ kann durch die Beachtung religiöser, göttlicher Gesetze gestärkt werden. Die heidnischen Religionen haben somit durch ihr Versprechen des jenseitigen Heils zum Erhalt des weltlichen Friedens beigetragen. ${ }^{99}$ Eine solche Stabilisierungsfunktion der Religion sei gerade durch viele alte Philosophen - Marsilius nennt Pythagoras und Hesiod - empfohlen worden:

„Denn mögen auch einige der Philosophen, Erfinder solcher Gesetze oder philosophischen Lehren, die Auferstehung der Menschen und jenes sogenannte ewige Leben nicht als Lehre aufgestellt oder daran geglaubt haben, so haben sie doch den Leuten vorgespielt und eingeredet, ein Jenseits gäbe es und in ihm Freuden und Leiden je nach den Werken der Menschen in diesem sterblichen Leben; damit wollten sie den Menschen Ehrerbietung und Furcht vor Gott einflößen und das Verlangen, die Laster zu fliehen und die Tugend zu pflegen. Es gibt nämlich gewisse Handlungen, die der Gesetzgeber durch menschliches Gesetz nicht regeln kann, denn niemand vermag ihr Vorhandensein oder Nichtvorhandensein zu beweisen; Gott jedoch können sie unmöglich verborgen sein, und Gott haben sie vorgespielt als den, der solche Gesetze gegeben hat und sie zu befolgen gebietet unter Androhung einer ewigen Strafe für Übeltäter oder Verheißung einer Belohnung für die Guten. [...] Deswegen hörten in den Gemeinschaften viele Streitigkeiten und Gewalttaten auf. Daher ließen sich auch Friede und Ruhe der Staaten und das befriedigende Leben der Menschen für den Stand der gegenwärtigen Welt leichter wahren, was jene Weisen durch die Einführung solcher Religionssysteme oder -lehren als ihr Endziel erstrebten." ${ }^{100}$

99 Marsilius von Padua, Verteidiger des Friedens, 1958, S. 53ff. (Teil I, Kap. V).

100 Ebd., S. 56ff. 
Allerdings fehlte den heidnischen Religionen der wahre Glaube an Gott. Aber auch die christlichen Priester dienen indirekt der politischen Ordnung: Ihr Zweck ist „die Erziehung des Menschen“; dazu gehören

,alle vom menschlichen Geist gefundenen sittlichen Normen, die theoretischen wie die praktischen, die das menschliche Handeln lenken, das rein innerliche wie das übergreifende, [...], Normen, durch die der Mensch seelisch in gute Verfassung gebracht wird für die gegenwärtige Welt wie die künftige.“101

Machiavellis Funktionalisierung der Religion für die Zwecke des Verfassunggebers dagegen sieht einen deutlichen Unterschied zwischen dem antiken und dem christlichen Heilsglauben. Die antiken Religionen sind gerade deshalb echte Bürgerreligionen gewesen, weil sie keine geteilten Loyalitätsverhältnisse geschaffen haben, sondern aufgrund ihres fehlenden Jenseitsbezuges den Bürger in seinen Pflichten gegenüber der weltlichen Gemeinschaft bestärkten. Neben dieser funktionalen Indienstnahme religiöser Bindungsressourcen für den Zusammenhalt des republikanischen Gemeinwesens wäre es aber dennoch verkürzt, wollte man Machiavelli einen von jeglichen Determinismen und Kausalitäten entbundenen Freiheitsbegriff unterstellen. Wie die Studie von Parel gezeigt hat, lassen sich in seinem Denken zahlreiche Einflüsse eines astrologischen Kausalitätsdenkens nachweisen, das eine enge Verknüpfung zwischen einer mathematisch entschlüsselbaren Himmelsmechanik und den umori, den menschlichen Temperamenten oder Neigungen postuliert. ${ }^{102}$ Auch wenn Machiavellis Emphase des republikanischen Freiheitsideals in den Discorsi eine andere Sprache spricht und die konstitutionelle Verfügbarkeit über die Voraussetzungen eines freien Gemeinwesens in den Vordergrund rückt, so lassen doch seine Analysen im Fürsten auch ganz andere Implikationen zu, die in der Politik weniger eine Verfügung über die Möglichkeit von Freiheit sehen lassen, als vielmehr eine freigelegte Macht- und Interessenmechanik, die zwar vorübergehend der virtuosen Verfügbarkeit herausragender, ans Heroische grenzender Einzelgestalten unterworfen werden mag, die aber im Normalzustand politischer Ordnung einen schicksalhaften und damit der politischen Verfügung entzogenen Charakter anzunehmen drohen. Eben diese Konsequenzen zog Francesco Guicciardini aus dem Scheitern der

101 Ebd., S. 67 (Teil I, Kap, VI).

102 Parels, Machiavellian Cosmos, 1992. 
Florentiner Republik, wenn er die politische Geschichtsschreibung von der republikanischen Selbstsakralisierung auf den Modus des Partikular- und Eigeninteresses großer Männer als Triebfeder geschichtlicher Ereignisse (particolare) umstellte. ${ }^{103}$ Nicht mehr die Tugend, sondern das Interesse bildet die konstitutive Transzendenz politischer Ordnung. Die republikanische Eigengeschichte, vormals noch Quelle der konstitutionellen Selbstermächtigung, erstarrt zum mechanischen Räderwerk der konkurrierenden Einzelinteressen und nimmt die Form einer schicksalhaft erfahrenen, die menschliche Handlungs- und Entscheidungsfreiheit negierenden Macht an. ${ }^{104}$ Sie ist nicht mehr die vorbildhafte Erzählung von der bürgerlichen Freiheit, von der Macht der Tugend und ihrer Bedrohung durch Tyrannei und Korruption, sondern ein Reflex der Einsicht des Historikers in die historische Notwendigkeit auf der Grundlage der unveränderlichen politischen Handlungsgesetze. Das Gemeinwohl wird zur fiktiven Größe ohne politische Wirkungsmacht, zur ideologischen Option bei der Durchsetzung von Eigeninteressen. Die Verfassung versagt in ihrem Bemühen, durch institutionelle Ordnung die Gemeinwohlorientierung der politischen Akteure in den Bereich der Verfügbarkeit zu holen und die interessegeleiteten Menschen zu gemeinwohlfähigen Bürgern zu transformieren. Angesichts dieser Verengung politischer Verfügbarkeits-

103 Francesco Guicciardini: The History of Italy, hrsg. von Sidney Alexander, Princeton 1969; allerdings darf daraus nicht der vereinfachende Schluss gezogen werden, das politische Verfügungsdenken sei allein bei Machiavelli und die geschichtliche Notwendigkeit allein bei Guicciardini zu verorten. Vielmehr handelt es sich zu Beginn des 16. Jahrhunderts um ein Spannungsfeld, das bei Guicciardini treffend in seinem Dialog über die Florentiner Regierung zum Ausdruck kommt (Francesco Guicciardini: Dialogue on the Government of Florence, hrsg. von Alison Brown, Cambridge 1994) und das in seiner Komplexität angemessen beschrieben wird bei Felix Gilbert: Machiavelli and Guicciardini. Politics and History in Sixteenth Century Florence, New York/London 1965. Zur Ablösung der republikanischen Ordnungsvorstellungen durch die Idee der Staatsräson klassisch Friedrich Meinecke: Die Idee der Staatsräson in der neueren Geschichte, Werke Bd. 1, 3. Aufl., München/Wien 1963; außerdem Herfried Münkler: Im Namen des Staates. Die Begründung der Staatsraison in der Frühen Neuzeit, Frankfurt a.M. 1987; Maurizio Viroli: From Politics to Reason of State. The Acquisition and Transformation of the Language of Politics (1250-1600), Cambridge 1992.

104 Gilbert, Machiavelli and Guicciardini, 1965, S. 288: „The master over the events of history is Fortuna. The strongest, most permanent impression which the History of Italy imparts - and was meant to impart - is that of helplessness and impotence of man in the face of fate." 
räume zu eigensinnigen und entzogenen historischen Ablaufmustern bleibt bei Guicciardini nunmehr die Einsicht in den Erhalt menschlicher Würde, die den Eigenwert des Menschen angesichts der inhumanen geschichtlichen Zyklen von Aufstieg und Verfall behauptet. ${ }^{105}$ In dem Maße, wie sich die republikanische Geltungsbehauptung von der politischen Freiheit verliert, gewinnt die Würde des Menschen daher als Gegenmacht zu einer als entzogen und unverfügbar wahrgenommenen Welt politischer Herrschaft selbst eine transzendente Qualität und wird - wie schon bei Manetti und Pico - zu einem jenseits der politischen Ordnung, bzw. ihr immer schon vorausliegenden Geltungsanspruch erhoben.

105 Ebd., S. 290: „In the last analysis the writing of history serves to maintain the dignity of man.“ 



\title{
Zwischen sakraler Legitimation und politischer Säkularisierung
}

\author{
Die Monarchie in England und Frankreich im späten
}

17. Jahrhundert im Vergleich

RONALD G. ASCH

\section{EinLeitung}

In einer klassischen Auseinandersetzung mit dem Phänomen der Säkularisierung der Politik hat der französische Soziologe Gauchet in den 1980er Jahren mit Blick auf das späte 17. und das 18. Jahrhundert festgestellt: „La prose des bureaux se substitue à la poésie du Prince“"1 die Prosa der Bürokratie habe die Poesie der Monarchie ersetzt. Im Zuge des Staatsbildungsprozesses der frühen Neuzeit habe die symbolische Dimension von Machtausübung zunehmend ihre integrative Kraft und ihre politische Bedeutung zugunsten des Einsatzes materieller Ressourcen und streng zweckrationaler Herrschaftsinstrumente verloren, damit jedoch sei auch die Monarchie entzaubert worden, deren Legitimität gerade auf der Überzeugungskraft einer älteren vielfach religiösen Symbolsprache beruht habe. ${ }^{2}$ Das mag eine nicht

1 Marcel Gauchet: Le désenchantement du monde. Une histoire politique de la religion, Paris 1985, S. 385.

2 „Le pouvoir perd apparement son rôle symbolique, comme si ses fonctions signifiantes et ses prérogatives réelles allaient en raison inverse les unes des autres.“ (Ebd., S. 384) - Ich beschränke meine Anmerkungen im Folgenden auf das absolute Minimum und verweise im Übrigen auf mein in der Vorbereitung für den Druck befindliches Buch, Sacral Kingship between Dis-enchantment and Re-enchantment. The French and English Monarchies, 1587-1688, London ca. 2014. 
unproblematische Vereinfachung sein, weil hier vorausgesetzt wird, dass ,moderne' Staaten mehr oder weniger ohne legitimitätsstiftende Symbole, jedenfalls ohne echte ,Präsenzsymbole', auskommen, oder diese jedenfalls nur noch eine gewissermaßen dekorative Funktion haben, ${ }^{3}$ gibt aber in der Tendenz sicher eine auch heute noch weitverbreitete Einschätzung der Forschung wieder. Eine Versachlichung der Staatskonzeption, eine Loslösung des Staatsbegriffes von der Person des Herrschers, ging einher, so scheint es, mit einer Reduktion der sakralen Elemente von Herrschaft, einer tiefgreifenden Entzauberung des Königtums, ja möglicherweise mit einem Verlust der transzendenten Dimension von politischer Legitimation überhaupt. ${ }^{4}$ England respektive Großbritannien bieten für die These, dass ein solcher tiefgreifender Wandel wirklich stattgefunden habe, die Jahre zwischen 1678 und 1714, also zwischen dem Ausbruch der Exclusion Crisis und der Thronfolge des Hauses Hannover, sicherlich am ehesten einen Beleg. An die Stelle einer Erbmonarchie von Gottes Gnaden trat eine durch das Parlament neu konstituierte Monarchie und an die Stelle eines Königs, der dem Anspruch noch rex et sacerdos, weltlicher Herrscher und Inhaber einer priesterähnlichen Autorität war, trat ein Monarch, der die traditionelle Fähigkeit zu Wunderheilungen ebenso verloren hatte wie die Eigenschaft, als persona mixta cum sacerdote gelten zu können. So zumindest scheint es.

Umso größer ist in dieser Perspektive der Kontrast zu Frankreich, wo sich die Monarchie zwischen 1685 und 1715 durch die Vertreibung der Hugenotten auf der einen Seite und den Kampf gegen heterodoxe Tenden-

3 Zur politischen Bedeutung von Symbolen vgl. Karl-Siegbert Rehberg: Weltrepräsentanz und Verkörperung. Institutionelle Analyse und Symboltheorien ein Einführung in systematischer Absicht, in: Gert Melville (Hrsg.): Institutionalität und Symbolisierung. Verstetigungen kultureller Ordnungsmuster in Vergangenheit und Gegenwart, Köln 2001, S. 3-49; ders.: Präsenzmagie und Zeichenhaftigkeit. Institutionelle Formen der Symbolisierung, in: Gerd Althoff (Hrsg.): Zeichen - Rituale - Werte, Münster 2004, S. 19-26.

4 Paul Kléber Monod: The Power of Kings: Monarchy and Religion in Europe, 1589-1715, New Haven, Conn. 1999, bes. S. 273-328, siehe auch aus anderer Perspektive: Quentin Skinner: From the State of Princes to the Person of the State, in: ders.: Visions of Politics, vol. 2, Renaissance Virtues, Cambridge 2002, S. 368-413. Zum Verfall einer spezifischen Form symbolischer Kommunikation als Legitimation von Herrschaft siehe auch Barbara Stollberg-Rilinger: Des Kaisers alte Kleider. Verfassungsgeschichte und Symbolsprache des Alten Reiches, München 2008. 
zen im Katholizismus - besonders gegen den Jansenismus - auf der anderen Seite fester denn je an den tridentinischen Katholizismus, aber letztlich auch an das Papsttum band und die religiöse Legitimation von Herrschaft noch einmal an Bedeutung gewann. Ob diese emphatische ReKonfessionalisierung der Monarchie (wenn man das Edikt von Nantes und die Toleranzpolitik der folgenden Jahrzehnte, aber auch eine höfische Kultur, die sich zur Legitimation des Monarchen eher auf die Sprache der Mythologie als auf die der Theologie verließ, als eine Distanzierung gegenüber einem allzu militanten und eindeutigen Konfessionalismus verstehen will) in den späteren Regierungsjahren Ludwigs XIV. die sakrale Dimension von Herrschaft freilich wirklich nachhaltig gestärkt hat, ist umstritten. Dagegen steht die Auffassung, dass das Königtum auch hier schon im Laufe der 1680er Jahre zunehmend seiner sakralen Aura beraubt wurde, so dass die religiöse Legitimation monarchischer Herrschaft schon vor der Revolution zur bloßen Fassade geworden sei. ${ }^{5}$ In jedem Fall erscheinen in Frankreich die 1680er Jahre als wichtige Phase einer schrittweisen Neudefinition der religiösen und sakralen Dimension der Monarchie - unabhängig davon, ob man diese Neudefinition nun als erfolgreich betrachtet oder nicht - also als ein Gründungsmoment im strengen Sinne des Worte. Umgekehrt scheiterte in England in eben diesen Jahren ein traditionelles Modell der Verbindung von Transzendenz und Politik, wie in der Glorious Revolution von 1688, die den katholischen König Jakob II. zu Fall brachte, deutlich wurde. ${ }^{6} \mathrm{Ob}$ dies freilich wirklich gleichbedeutend war mit einer durchgehenden Säkularisierung der politischen Ordnung, kann durchaus als fraglich erscheinen. Dieses Problem soll im Folgenden mit einem vergleichenden Blick auf die gleichzeitige Entwicklung in Frankreich näher untersucht werden.

5 Gérard Sabatier: Versailles ou la figure du roi, Paris 1999, S. 547-566; Peter Burke: The Fabrication of Louis XIV, New Haven, Conn. 1992, S. 125-135. Zur sakralen Dimension der französischen Königtums siehe jetzt auch Alexandre Maral: Le Roi et Dieu, Paris 2012.

6 Dazu jüngst Steve C.A. Pincus: 1688: The First Modern Revolution, New Haven, Conn. 2009. Vgl. aber: Scott Sowerby: Pantomime History, in: Parliamentary History 30 (2011) 2, S. 236-258. 


\section{Der Monarch als Kirchenoberhaupt: SAKRALITÄT UND LEGITIMATION IN ENGLAND}

In England war das Verhältnis des Monarchen zur Kirche seit der Reformation besonders komplex. Die Trennung von Rom war im Namen eines unbegrenzten königlichen Kirchenregimentes, das unter Heinrich VIII. durchaus caesaro-papistische Züge annahm, vollzogen worden. Der englische Protestantismus trug seit den 1530er Jahren stark erastianische und dezidiert antiklerikale Züge. Potentiell konnte sich dieser Antiklerikalismus durchaus auch gegen protestantische Prälaten - wie die Bischöfe des 16. und 17. Jahrhunderts - oder gegen die theokratischen Ordnungsvorstellungen radikaler Presbyterianer oder anderer strenger Calvinisten richten. Gerade die Position des Monarchen als Verteidiger einer gereinigten und von Laien dominierten Kirche gegen klerikale Übergriffe, verlieh dem Königtum eine besondere religiöse Legitimation. ${ }^{7}$ Allerdings stand dem die Tatsache gegenüber, dass Maria die Katholische zwischen 1553 und 1558 die Sache der Reformation und das Erbe ihres Vaters gewissermaßen verraten hatte, um England in den Schoß der Römischen Kirche zurückzuführen. Unter englischen Protestanten hatten die marianischen Verfolgungen ein dauerhaftes Trauma geschaffen; der gottesfürchtige Monarch mochte als Werkzeug der Vorsehung gesehen werden, aber allzu leicht, so schien es, konnten die Herrscher dieser Welt auch in den Dienst der Mächte der Finsternis und der „Hure Babylon“ treten. Jedenfalls wurden die Verfolgungen der 1550er Jahre vom Martyrologen John Foxe und anderen durchaus auch in einer eschatologischen Perspektive gedeutet. ${ }^{8}$

Das Vertrauen der militanteren Protestanten mochte daher einzelnen Monarchen gelten, kaum je der Monarchie als Institution an sich. Vorbehalte gegenüber einem Herrscher, der für sich eine sakrale Legitimation in Anspruch nahm, wurden durch bestimmte Tendenzen im Calvinismus noch verstärkt. Zwar wäre es falsch, dem Calvinismus eine generelle und uneingeschränkte Tendenz zur ,Entzauberung' der Welt - unter gleichzeitiger Betonung der radikalen Transzendenz Gottes - zuzuschreiben, wie dies ja oft geschieht. Aber die Sichtbarkeit und Greifbarkeit des Sakralen in

7 Geoffrey Bernard: The King's Reformation: Henry VIII and the Remaking of the English Church, New Haven, Conn. 2007.

8 Wichtig dafür war vor allem die Martyrologie von John Foxe, siehe Christopher Highley (Hrsg.): John Foxe and his World, Aldershot 2002. 
dieser Welt, die Möglichkeit, es räumlich oder auch in materiellen Objekten zu verorten, wurde durch eine Frömmigkeit, die ganz auf das Wort ausgerichtet war, doch deutlich in Frage gestellt. ${ }^{9}$ Das Gleiche galt für die Zuschreibung einer performativen Kraft von Ritualen oder symbolischen Handlungen, denen wie bei der Eucharistie tendenziell nur noch eine zeichenhafte Bedeutung zukam. Konnte die Legitimation monarchischer Herrschaft namentlich in einer Monarchie wie der englischen, die im Mittelalter durchaus ihre eigene religion royale parallel $\mathrm{zu}$ den Verhältnissen in Frankreich entwickelt hatte, ohne solche Elemente auskommen, wurde damit der Herrschaftsanspruch des Königs nicht gänzlich entzaubert? Das war zumindest ungewiss.

Es waren daher nicht nur Vorbehalte gegenüber dem militanten Aktivismus des radikalen Protestantismus und seinen außenpolitischen Implikationen, die die Stuarts im frühen 17. Jahrhundert, also Jakob I. und Karl I., dazu bewogen, eher den Schulterschluss mit jenen Kräften innerhalb der englischen Kirche zu suchen, die die Kontinuität mit der mittelalterlichen Kirche - wenn auch keineswegs die Verbindung zum tridentinischen Katholizismus - betonten, und konfessionell eher auf eine via media zwischen Genf und Rom und nicht auf den theologischen, aber unter Umständen auch bewaffneten Konfessionskrieg um jeden Preis setzten. Die sogenannten Conformists innerhalb der englischen Kirche, die Vertreter dieser via media, betonten meist zugleich, dass das von den Presbyterianern abgelehnte Bischofsamt eine Einrichtung göttlichen Rechtes - iure divino sei, ja dass auch die einzelnen Bischöfe ihr Amt von Gott erhalten hätten und auch in der Church of England in einer apostolischen Sukzession

9 Edward Muir (Ritual in Early Modern Europe, Cambridge 1997) bietet eine ausgewogene Analyse des Verhältnisses des Protestantismus zu religiösen Symbolen und Ritualen. Muir weist darauf hin, dass der Protestantismus nicht auf den einfachen Nenner einer Entzauberung der Welt gebracht werden kann, aber die Bedeutung des Wortes sehr viel stärker betonte als bisher und die Kraft performativer Handlungen an den Glauben der Beteiligten band (ebd., S. 185198.). Vgl. auch Bob Scribner: Reformation and Desacralization: From Sacramental World to Moralised Universe, in: ders./Ronnie Po-Chia Hsia (Hrsg.): Problems in the Historical Anthropology of Early Modern Europe, Wiesbaden 1997, S. 75-92, hier S. 85; Robert Zaller: Breaking the Vessels: The Desacralization of Monarchy in Early Modern England, in: Sixteenth Century Journal 29 (1998), S. 757-778 sowie Alexandra Walsham: The Reformation and „The Disenchantment of the World“ Reassessed, in: Historical Journal 51 (2008), S. 497-528. 
stünden, sie also keineswegs nur vom König eingesetzte geistliche Amtsträger seien. ${ }^{10}$

Eine solche Lehre richtete sich zumindest vor 1642 weniger gegen das Kirchenregiment des Königs, sondern gegen den Versuch, die Kirche ganz dem Parlament respektive dem King-in-Parliament zu unterstellen und sie ihrer Autonomie zu berauben. Eine von Bischöfen iure divino gelenkte Kirche konnte letztlich nur von einem König kontrolliert werden, der eine persona mixta, selber ein halber Geistlicher war. Das Kirchenregiment fiel damit auch weitgehend in den Bereich der reinen Prärogativgewalt des Herrschers. Gerade dies waren freilich Doktrinen, die in England bei militanten Protestanten auf starke Ablehnung stießen, wenn sie nicht generell als Vorboten einer Re-Katholisierung des Landes galten.

Der Kampf um die Gestalt der Kirche und ihre Verfassung muss zu den wesentlichen Ursachen des englischen Bürgerkrieges gerechnet werden, in dessen Verlauf die Bischofskirche zusammen mit dem Königtum unterging, um erst 1660 im Zuge der Wiederbelebung der monarchischen Ordnung wiederhergestellt zu werden. Karl II. und erst recht sein Anfang der 1670er Jahre zum Katholizismus konvertierter Bruder hatten zur Church of England freilich ein eher gespanntes Verhältnis. Aggressiver als vor 1640 verteidigten die Bischöfe ihre kirchenpolitischen Positionen nun auch gegen den König selber, dessen uneingeschränktes Kirchenregiment von vielen Prälaten mit deutlichen Vorbehalten gesehen wurde, da man sich auf die Loyalität der regierenden Dynastie gegenüber der church by law established nicht mehr glaubte verlassen zu könne. $\mathrm{Zu}$ sehr sympathisierten die

10 Vgl. Ronald G. Asch: No bishop no king oder cuius regio eius religio. Die Deutung und Legitimation des fürstlichen Kirchenregiments und ihre Implikationen für die Genese des ,Absolutismus' in England und im protestantischen Deutschland, in: ders./Heinz Duchhardt (Hrsg.): Der Absolutismus - ein Mythos? Köln 1996, S. 79-124, bes. S. 92-95; Peter Lake: Lancelot Andrewes, John Buckeridge and Avant-garde Conformity at the Court of James I, in: Linda Levy Peck (Hrsg.): The Mental World of the Jacobean Court, Cambridge 1991, S. 113-133; Charles W.A. Prior: Defining the Jacobean Church. The Politics of Religious Controversy, 1603-1625, Cambridge 2005; Kenneth Fincham (Hrsg.): The Early Stuart Church, 1603-1642, Basingstoke 1993; Anthony Milton: The Creation of Laudianism. A New Approach, in: Thomas Cogswell u.a. (Hrsg.): Politics, Religion and Popularity in Early Stuart Britain. Essays in Honour of Conrad Russell, Cambridge 2002, S. 162-184; Lori A. Ferrell: Government by Polemic. James I, the King's Preachers and the Rhetoric of Conformity, Stanford, Cal. 1998. 
späteren Stuarts zeitweilig mit der Idee einer zumindest begrenzten Toleranz einerseits und einer Förderung des Katholizismus andererseits.

Unter Karl II. wurde darüber hinaus die deutlich sichtbare religiöse Indifferenz des Monarchen zunehmend zum Problem. Die Verfestigung der konfessionellen Gegensätze und der Zugriff der rivalisierenden konfessionellen Richtungen auf das Gewissen des Einzelnen verlangten vom Monarchen stärker als früher als Gläubiger glaubhaft den Eindruck der Aufrichtigkeit zu erwecken, der bloße Vollzug ritueller Handlungen - kein englischer Monarch vollzog so viele Wunderheilungen wie Karl I, wohl an die 100.000 in seiner 25jährigen Regierungszeit - wirkte nicht mehr hinreichend überzeugend. ${ }^{11}$ Die Zuwendung der Herzogs von York, des späteren Jakobs II. zum Katholizismus kann auch als ein Versuch gesehen werden, außerhalb des Protestantismus jene konfessionelle Eindeutigkeit zu finden, die die anglikanische Kirche so nicht zu bieten vermochte. ${ }^{12}$ Die Rolle des sakralen Monarchen nur zu spielen, wie sein Bruder, reichte Jakob II. nicht mehr aus, sie sollte ihr Fundament in seiner eigenen religiösen Überzeugung finden, auch wenn diese nicht zum Bekenntnis der Staatskirche passte. Indem Jakob II. seine eigene persönliche Überzeugung, die weit über einen bloß konventionellen Barockkatholizismus hinausging, zur Basis seines Handelns machte, und diese religiöse Aufrichtigkeit bewusst öffentlich inszenierte - womit er sich freilich den Weg zu einem Kompromiss mit der Staatskirche und den eigentlich königstreuen anglikanischen Tories verbaute - handelte er durchaus modern, wenn es denn stimmt, dass ,the entire world of liberal modernity can be usefully understood in terms of the tropes of sincerity“, wie der amerikanische Soziologe Adam Seligman zusammen mit anderen Autoren dies in einer

11 Ronald Hutton: The Religion of Charles II, in: R. Malcolm Smuts (Hrsg.): The Stuart Courts and Europe: Essays in Politics and Political Culture, Cambridge 1995, S. 228-246; John Miller: After the Civil Wars: English Politics and Government in the Reign of Charles II, Harlow 2000; John Spurr: The Restoration Church of England, 1646-1689, New Haven, Conn. 1991; Anna Keay: The Magnificent Monarch: Charles II and the Ceremonies of Power, London 2008, S. 115-118 und 211-213 zu den Wunderheilungen.

12 Vgl. zu Jakob II.: John Miller: James II. A Study in Kingship, London 1978; John Callow: The Making of King James II. The Formative Years of a Fallen King, Stroud 2000; ders.: King in Exile. James II: Warrior, King and Saint, Stroud 2004. 
Abhandlung über ritual and sincerity formuliert hat. ${ }^{13}$ Zugleich war Jakob II. aber sicherlich vom französischen Modell sakraler Herrschaft beeinflusst, das unter Ludwig XIV. seine größten Triumphe feierte. Seine eigene Kirchenpolitik, die trotz religiöser Treue zu Rom stark auf der Autonomie Englands bestand, war eher gallikanisch als ultramontan, oder man könnte auch sagen, dass Jakob II. seine Position als supreme governor der englischen Kirche, ein Erbe der Reformation Heinrichs VIII., in einem gallikanischen, also katholisch nationalkirchlichen Sinne umdeutete. ${ }^{14}$

\section{Der Monarch in KonkURRenz zUR Kirche: SAKRALITÄT UND LEGITIMATION IN FRANKREICH}

Allerdings war die religiöse Basis der Herrschaft des Sonnenkönigs, den Jakob II. augenscheinlich bewunderte und nachzuahmen suchte, nicht so stabil, wie es auf den ersten Blick scheinen mochte. Zwar hatte noch Bossuet in seiner Politik tirées de propres paroles de l'ecriture sainte in den 1670er Jahren die Gottesebenbildlichkeit des Monarchen, seine Position als imago dei, im Sinne einer repräsentativen Theokratie betont. ${ }^{15}$ Aber das neo-platonische Weltbild, das in seiner Annahme einer durchgehenden Analogie und engen Verbindung zwischen den himmlischen und irdischen Hierarchien solchen Strategien der Legitimation überhaupt erst ihre Plausibilität und Glaubwürdigkeit verlieh, wurde zunehmend von einer rationalistischen Theologie unterminiert, zu deren Verfechtern auch Bossuet selber gehörte. Die Mystik, die in der französischen Kirche nach den Religionskriegen noch einmal eine große Blüte erlebt hatte, verkümmerte gegen Ende des 17. Jahrhunderts zunehmend, oder zumindest wurden ihre Vertreter und Fürsprecher wie der Erzbischof Fenelon an den Rand der

13 Adam B. Seligman: Ritual and its Consequences. An Essay on the Limits of Sincerity, Oxford 2008, S. 118.

14 Vgl. Jacqueline Rose: Godly Kingship in Restoration England: The Politics of the Royal Supremacy 1660-1688, Cambridge 2011, S. 169-170 sowie S. 185.

15 Vgl. Jacques-Bénigne Bossuet: Politique tirée des propres parole de l'écriture sainte, hrsg. von Jacques Le Brun, Genf 1967. Vgl. Lothar Schilling: Bossuet, Die Bibel und der „Absolutismus“, in: Kai Trampedach/Andreas Pečar (Hrsg.): Die Bibel als Politisches Argument. Voraussetzungen und Folgen biblizistischer Herrschaftslegitimation in der Vormoderne. Beiheft der Historischen Zeitschrift, Bd. 43, München 2007, S. 349-370. 
Kirche gedrängt. ${ }^{16}$ Aber auch der Versuch, dem Königtum eher durch Bezug auf die antike Mythologie und ihre Bilderwelt eine transzendente Dimension außerhalb des Christentums zuzuschreiben, verlor an Plausibilität. Mythologische Figuren traten zwar noch als Schmuckelemente auf, aber eine Identifikation des Königs mit Halbgöttern und Helden wie Herkules oder Alexander, die ihn für den Betrachter wirklich zur lebenden Verkörperung dieser Figuren werden ließ, trat seit den 1680er Jahren und der sogenannten querelle des anciens et des modernes zurück hinter der Darstellung seiner Taten als individueller, nicht austauschbarer historischer Person. Der „,corps mystique“ des Herrschers, die Idee des Königtums, ging jetzt ganz in dieser Person auf. ${ }^{17}$ Verlor damit das Königtum letztlich seine religiöse und transzendente Dimension? Sicherlich nicht, aber sie zu begründen und darzustellen wurde schwieriger, wie vielfach betont worden ist.

Allerdings gab es auch gegenläufige Tendenzen. Konfessionell wurde das Profil des französischen Königtums seit den 1680er trotz der Konflikte mit dem Papst deutlich schärfer; die Vertreibung der Hugenotten wurde wie ein Kreuzzug inszeniert, sicherlich auch als Kompensation für das Prestige als Sieger über die Ungläubigen, das die mit den Bourbonen rivalisierenden Habsburger 1683 erworben hatten; vielleicht auch um den späteren Anspruch auf die spanische Krone zu begründen. ${ }^{18}$ Das spanische Modell eines durch Glaubenseifer legitimierten Königtums ohne Salbung und Krönung und ohne Wunderheilungen, aber unter deutlicher Betonung der konfessionellen Militanz gewann jedenfalls zunehmend Einfluss auf Frank-

16 Vgl. Yves Durand: Mystique et politique au XVIIe siècle. L'influence du pseudo-Denys, in: Dix-septième siécle 173 (1991), S. 323-50; ders.: L'Ordre du monde. Idéal politique et valeurs sociales en France du XVIe au XVIIIe siècle, Paris 2001, S. 135-136; Jean-Marie Le Gall: Le Mythe de Saint Denis entre Renaissance et Révolution, Seyssel 2007, S. 216-269. Siehe auch Louis Cognet: Crépuscule des mystiques. Bossuet-Fénelon, 2. Aufl., Paris 1991.

17 Nicolas Milanovic: Du Louvre à Versailles. Lecture des grands décors monarchiques, Paris 2005, S. 229. Vgl. Sabatier: Versailles, 1999, S. 560-565; ferner: Chantal Grell/Christian Michel/Pierre Vidal-Naquet: L'École des princes ou Alexandre disgracié: essai sur la mythologie monarchique de la France absolutiste, Paris 1988; Jean-Pierre Néraudau: L'olympe du roi-soleil. Mythologie et idéologie royale au Grand Siècle, Paris 1986.

18 Maral, Roi-Soleil, 2012, S. 190-208; Jean Orcibal: Les „supercroisades“ de Louis XIV (1683-1689), in: Janet van Bavel (Hrsg.): Jansénius et le Jansénisme dans les Pays-Bas, Louvain 1982, S. 138-147. 
reich. ${ }^{19}$ Es sollte die französische Monarchie auch über die Regierungszeit Ludwigs XIV. hinaus prägen. Der Sonnenkönig selber ließ sich in den letzten beiden Jahrzehnten seiner Regierung auch weniger als Held und Sieger feiern, sondern eher als demütiger Christ, der dem Erlöser auch auf seinem Leidensweg folgte. Jedenfalls waren manche Hofpredigten während des wenig erfolgreichen Spanischen Erbfolgekrieges auf ein solches Modell sakraler Herrschaft hin ausgerichtet. ${ }^{20}$ Vor seinem Tode konnte der exilierte Jakob II. von England, dessen Frömmigkeit zunehmend obsessive, wenn nicht gar bigotte Züge annahm, für Ludwig XIV. sogar zum Vorbild des rechtgläubigen leidenden Herrschers, der zugleich König und Heiliger war, werden, oder zumindest erweckten manche Predigten diesen Eindruck.

Ludwig XIV. sah sich freilich mit dem Problem konfrontiert, dass jene Strömung, die innerhalb der französischen Kirche am meisten nach einer Verinnerlichung des Glaubens strebte, die Jansenisten, kirchenpolitisch nur schwer integrierbar war, oder zumindest faktisch nicht integriert, sondern eher ausgegrenzt wurde. Auch das machte das Modell sakraler Herrschaft, das er seinem Nachfolger hinterließ, anfechtbar, wie sich sehr bald zeigen sollte. Immerhin gelang in den 1690er Jahren ein Ausgleich mit dem Papsttum, der einen Höhepunkt in der gemeinsamen Verfolgung der Jansenisten und der Bulle Unigenitus von 1713 fand. ${ }^{21}$ Die jansenistische Opposition blieb freilich virulent und fand gerade nach 1715 Rückhalt im Pariser Parlement, das die gallikanischen Freiheiten und die Autonomie der Kirche nun gegen die Krone selber verteidigte. Den Richtern des Parlement ging es einerseits darum, den Anspruch des Königs zurückzuweisen, in Glau-

19 Jean-Fréderic Schaub: La France espagnole: les racines hispaniques de l'absolutisme français, Paris 2003; Gérard Sabatier/Margarita Torrione (Hrsg.): ¿Louis XIV espagnol? Madrid et Versailles, images et modèles, Versailles 2009.

20 Martha Mel Stumberg Edmunds: Piety and Politics. Imagining Divine Kingship in Louis XIV's Chapel at Versailles, Newark, Del. 2002, S. 228-229, Vgl. auch: Maral, Roi-Soleil, 2012, S. 214-219; Jacques-Paul Migne (Hrsg.): Collection intégral et universelle des orateurs sacrés, du premier ordre, vol. XXVIII, Paris 1847, Predigt von Charles de la Rue S. J., zweiter Advent 1690, Sp. 301ff., 301 sowie 314, vgl. ebd., Sp. 243, Predigt von Charles de la Rue, Tous les Saints 1709. Zu Jakobs Bild als reuiger Sünder und Märtyrer vgl. ebd., vol. XXI, Sp. 179-204, Leichenpredigt auf Jakob II. Von Père Antoine Anselme, 8 Nov. 1702, vgl. Callow, King in Exile, 2004, S. 378-384.

21 Vgl. Catherine-Laurence Maire: De la cause de Dieu à la cause de nation: le Jansénisme aus XVIIIe siècle, Paris 1998, S. 58-67; Lucien Ceyssens: Le Sort de la Bulle Unigenitus, Louvain 1992; Emile Jacques: Jansenisme et antijansenisme. Acteurs, auteurs et temoins, Brüssel 1988. 
bensfragen richtungsweisende Entscheidungen treffen zu können, da eine solche Autorität nur der Kirche selber zukam. Andererseits wurde die päpstliche Entscheidungskompetenz letztlich ebenso zurückgewiesen zugunsten eines möglichen Nationalkonzils, in dem dann auch einfache Geistliche wenn nicht sogar Laien eine Stimme gehabt hätten, nicht nur die Hierarchie. ${ }^{22}$ Das Parlament wurde damit zum Sammelpunkt eines kirchenpolitischen Konstitutionalismus, der auch die Regierungspraxis der Monarchie in nichtkirchlichen Fragen zum Gegenstand der Kritik machen konnte.

\section{Die englische Monarchie im Wandel}

Man hat den Jansenismus das ,schlechte Gewissen des französischen Absolutismus“،23 genannt, eine eigentlich königstreue Bewegung, die in Gegensatz zu einem Königtum geriet, das scheinbar die sakralen Grundlagen seiner Herrschaft, aber auch die gallikanischen Freiheiten der französischen Kirche verraten hatte. Vergleichbar ist diese Situation mit der allerdings sehr viel dramatischeren Lage in England in den Jahren 1687 und 1688, als die eigentlich royalistischen Bischöfe der anglikanischen Kirche, die jedes aktive Widerstandsrecht ablehnten, in Opposition zu einem König traten, der sowohl durch seinen Katholizismus wie auch durch seine Toleranzpolitik die Fundamente der Staatskirche angriff. ${ }^{24} \mathrm{Ihm}$ wurde das Modell einer kirchlichen Hierarchie entgegengesetzt, die sich einer Beherrschung durch die weltliche Obrigkeit kraft ihrer göttlichen Vollmacht entzog. ${ }^{25}$ Das alte Bündnis zwischen Bischöfen iure divino und einem sakralen

22 Olivier Chaline: Des parlementaires Jansénistes?, in: Gauthier Aubert/Olivier Chaline (Hrsg.): Les parlements des Louis XIV. Opposition, coopération, autonomisation? Rennes 2010, S. 277-292 sowie David Feutry: Le parquet du parlement de Paris à la fin du règne de Louis XIV: une cohésion familiale et doctrinaire à l'epreuve des choix du roi, in: ebd. S. 33-47, bes. S. 39-44. Zum Jansenismus vgl. Maire, De la cause de Dieu, 1998 sowie Dale K. Van Kley: The Religious Origins of the French Revolution. From Calvin to the Civil Constitution, 1560-1791, New Haven, Conn. 1996.

23 Catherine Maire: Aux sources politiques et religieuses de la Révolution française. Deux modeles en discussion, in: Le Débat 130 (2004), S. 133-153, hier: S. 147.

24 William Gibson: James II and the Trial of the Seven Bishops, Basingstoke 2009. Vgl. Tim Harris: Revolution: The Great Crisis of the British Monarchy, 16851720, London 2006, S. 260-264.

25 Rose, Godly Kingship, 2011, S. 267-275. 
Monarch von Gottes Gnaden zerbrach 1687/88, und erst dadurch war der Weg frei für die Glorious Revolution. Vor allem aber ließen die Umbrüche der Jahre 1685 bis 1688 noch einmal recht deutlich die strukturellen Konflikte zwischen sacerdotium und imperium, hervortreten, die die Geschichte der englischen Kirche seit der Reformation begleitet hatten. Wie etwa Geoffrey Collins in seiner großen Studie über Thomas Hobbes betont hat, besaßen diese Konflikte in England im 17. Jahrhundert durchaus noch eine aktuelle Bedeutung und waren weitaus mehr als nur eine mittelalterliche Reminiszenz. ${ }^{26}$ Eine Feststellung, die mit Blick auf die 1680er Jahre freilich auch für Frankreich gültig wäre, denn in dieser Epoche kam es zwischen Rom und Versailles zu einem erbitterten Streit über kirchliches Recht. Der Papst war nicht mehr weit von einer Exkommunikation Ludwig XIV. entfernt, und vor der Beilegung des Konfliktes waren zahlreiche französischen Bistümer vakant, da der Papst sich weigerte, der Investitur der königlichen Kandidaten zuzustimmen. ${ }^{27}$

In England hatte vor allem der Bürgerkrieg die Spannungen zwischen den Vertretern eines dualistischen Autoritätsmodells - für das geistliche und weltliche Obrigkeit jeweils ihren eigene Kompetenzbereich hatten, der nur in der Person des sakralen Monarchen zusammenfiel - und eines monistischen Modells, das alles dem weltlichen Staat unterordnete, so wie Thomas Hobbes es vertrat, deutlicher als in der Vergangenheit hervortreten lassen. Erst nach 1714 sollten sich diese Konflikte mit dem Sieg einer rein erastianischen Auffassung vom Kirchenregiment auflösen. Da die Convocation, das Parlament der Kirche, nach 1717 nicht mehr einberufen wurde, setzte sich die Kontrolle des King-in-Parliament über die Kirche vollständig durch, und die Konflikte der Vergangenheit traten in den Hintergrund. ${ }^{28}$ Bis dahin hatten namentlich die Whigs - die Gegner einer autoritären und intoleranten High Church - einen neuen episkopalen

26 Vgl. Jeffrey R. Collins: The Allegiance of Thomas Hobbes, Oxford 2005, S. 279. Vgl. auch: ders.: The Restoration Bishops and the Royal Supremacy, in: Church History 68 (1999), S. 549-580.

27 Joseph Bergin: Crown, Church and Episcopate under Louis XIV, New Haven, Conn. 2004, S. 238-245.

28 Andrew Starkie: The Church of England and the Bangorian Controversy, 17161721, Woodbridge 2007; Justin Champion: „My Kingdom is not of this world”: the Politics of Religion after the Revolution, in: Nicholas Tyacke (Hrsg.): The English Revolution 1590-1720. Politics, Religion and Communities, Manchester 2007, S. 185-202. 
Klerikalismus als erhebliche Gefahr angesehen. Das beeinflusste auch ihre Haltung zur Monarchie als Institution. Ihre Kritik an absolutistischen Tendenzen verband sich zumindest bei manchen Whigs mit der Neigung, der Monarchie als Institution durchaus eine sakrale Autorität zuzuschreiben, denn nur eine Sakralmonarchie war stark genug, eine kirchliche Hierarchie zu kontrollieren, die sich ihrerseits auf eine göttliche Vollmacht berief. So zumindest schien es, oder wie Mark Goldie es formuliert hat:

„Erastianism became a permanent counterbalance within Whiggism to the country ideal of distrust of the state. It helps explain the readiness of post-revolution Whiggism to sanctify and defend state power, and so explains the longevity in England of the idea of a national church. ${ }^{629}$

Allerdings musste die sakrale Dimension monarchischer Herrschaft nach dem Sturz Jakobs II. doch ganz neu definiert werden. Dem niederländischen Calvinisten Wilhelm III. lag es ebenso fern, sich als rex et sacerdos zu definieren wie nach 1714 Georg I., der ja von Haus aus Lutheraner war. Wilhelm III. inszenierte sich aber durchaus als heroischer Retter seiner niederländischen Heimat und der britischen Monarchie vor den Mächten der Finsternis, Rom und Versailles, und trat mit einem entsprechenden Sendungsbewusstsein auf. Der Monarch war nun weniger Priesterkönig als Glaubensheld, eine Rolle, die ja bereits Elisabeth I. zugeschrieben worden war. ${ }^{30}$ Es war der Ratschluss der Vorsehung, der religiös die Herrschaft des Königs legitimierte, nicht seine Fähigkeit, Wunder zu vollbringen, denn die traditionellen Skrofelheilungen vollzog Willhelm III. nicht mehr. Lediglich seine Nachfolgerin Königin Anna sollte sie noch einmal beleben, bevor sie in England 1714 ganz ihr Ende fanden. Zugleich konnte der Monarch auch als Vorkämpfer gegen eine anmaßende Priesterherrschaft in jedweder, also nicht notwendigerweise nur römischer Gestalt, dargestellt werden. Dieses Herrscherbild war für militante Pro-

29 Mark Goldie: Civil Religion and the English Enlightenment, in: Gordon J. Schochet (Hrsg.): Politics, Politeness and Patriotism, Washington DC 1993, S. 31-46, hier: S. 44.

30 Ulrich Niggemann: Herrschermemoria als Norm und Symbol. Zum Umgang mit der Erinnerung an Wilhelm III. im England des frühen 18. Jahrhundert, in: Zeitschrift für historische Forschung 29 (2012), S. 1-36, hier: S. 5-7 und Craig Rose: England in the 1690s: Revolution, Religion and War, Oxford 1999, S. 2427 sowie Tony Claydon: William III. and the Godly Revolution, Cambridge 1996. 
testanten, die sich auf das antiklerikale Erbe der Reformation beriefen, ebenso akzeptabel wie für Anwälte einer post-konfessionellen civil religion, die sich vom traditionellen Christentum, vor allem aber von jedweder Form von kirchlicher Hierarchie, entfernt hatte. ${ }^{31}$

Jedoch trat die heroische und providentielle Dimension des Königtums unter den Hannoveranern eher wieder zurück. Am Ende war der Monarch weniger der gottesfürchtige Führer der Gläubigen, ein neuer David, wie es Wilhelm III. für seine Anhänger gewesen war, sondern eher ein individueller Christ mit freilich spezifischer Vorbildfunktion. Abgeschlossen war diese Transformation erst unter Georg III., also nach 1760, zumal Georg I. und Georg II. sich für diese Rolle nicht in gleicher Weise eigneten, aber in den zahlreichen politischen Predigten des frühen 18. Jahrhunderts wurden solche Aspekte, wie der finnische Historiker Pasi Ihalainen gezeigt hat, doch schon früher nachdrücklich betont. Die Monarchie musste sich stärker einem Verständnis von Religion anpassen, für das der Glaube an eine Dimension der individuellen Erfahrung gebunden war - dass eine Nation als solche im Kollektiv, von wenigen Außenseitern abgesehen, gottesfürchtig und fromm sein könne, schien nun eine eher abwegige Annahme. Aufgabe des Monarchen war es daher, weniger das Seelenheil seiner Untertanen zu fördern und sie vor den Verlockungen der Idolatrie zu schützen, sondern eher die kirchlichen Institutionen zu stärken und selber den wahren Glauben vorzuleben. Oder wie Pasi Ihalainen es formuliert hat: ,the monarch was no longer seen as a God-sent deliverer of an oppressed Protestant people, but rather as fellow Christian who had particular duties in showing his subjects how they should lead virtuous and pious lives. ${ }^{\text {، } 32}$

31 Vgl. Justin A. Champion: The Pillars of Priestcraft Shaken. The Church of England and its Enemies 1160-1730, Cambridge 1992, S. 170-175; ders.: Republican Learning: John Toland and the Crisis of Christian Culture, 16961722, Manchester 2003, S. 91-115.

32 Pasi Ihalainen: Protestant Nations Redefined: Changing Perceptions of National Identity in the Rhetoric of the English, Dutch, and Swedish Public Churches, 1685-1772, Leiden 2005, S. 348; vgl. ebd., S. 347: „It was private religion which was rising to a key position in discussion side by side with public protestantism, which reflects the increasingly individualistic understanding of religion at the time of the european-wide pietistic movement and enlightenment theology." Vgl. aber mit anderer Akzentuierung: Jonathan C. D. Clark: English Society 1660-1832. Religion, Ideology and Politics During the Ancien Regime, Cambridge 2000, S. 256-283 und S. 300-317. 
Karl I. und Jakob II. hatten sich noch an einem Modell der sacerdotal kingship orientiert, waren zugleich weltliche Herrscher und Inhaber einer quasi priesterlichen, jedenfalls genuin geistlichen Autorität gewesen. Davon waren die Hannoveraner weit entfernt, eine solche Auffassung von Herrschaft wäre allerdings auch mit dem lutherischen konfessionellen Erbe ihrer Dynastie kaum verträglich gewesen. Der sakrale Charakter der Monarchie im engeren Sinne des Wortes war schon nach 1688 zurückgetreten, nach 1714 schwächte sich auch die Rolle des Monarchen als providentieller gottgesandter Erretter ab, aber die religiöse und dezidiert konfessionelle Dimension der Monarchie als Institution blieb dennoch stark, gerade in den Jahrzehnten zwischen 1714 und 1745, als eine katholische Thronfolge immer noch eine mögliche Option blieb und wohl erneut nach Ausbruch der Französischen Revolution, als eine religiöse Erneuerung für viele das Mittel zu sein schien, sich gegen die Gefahr des politischen Radikalismus zu verteidigen. Das Einfallstor der Transzendenz in den Alltag der Politik war jetzt aber eher das Gewissen des Monarchen, seine religiösen Überzeugungen, oder das anderer politischer Amtsträger, sehr viel weniger dagegen performative Handlungen mit stark religiöser Dimension, von der Krönung über die Trauerfeierlichkeiten bis hin zu den Wunderheilungen von Kranken.

\section{DER Verlust der sakralen Legitimation IN FRANKREICH}

In Frankreich hingegen, ich habe es bereits angedeutet, blieb der Monarch auch nach 1715, nach dem Tode Ludwig XIV. zumindest dem Anspruch nach rex et sacerdos. Zugleich wurde der Papst, in den 1680er Jahren noch ein gefährlicher Gegner der Autorität der Krone, in geistlichen Angelegenheiten zunehmend zum wichtigsten Verbündeten der Krone im Kampf gegen die Jansenisten. Zumindest bis zur Mitte des 18. Jahrhunderts war dabei die Kritik, die die Jansenisten an der Monarchie übten, die zugleich als papsthörig und als verweltlicht erschien, vermutlich wirkungsvoller als die einer eher säkularisierenden Aufklärung. ${ }^{33}$

33 Vgl. Van Kley, Origins, 1996 sowie ders.: The Religious Origins of the French Revolution, in: Peter R. Campbell (Hrsg.): The Origins of the French Revolution, Basingstoke 2006, S. 160-190; Wolfgang Mager: Die Anzweiflung 
Die streng von der Monarchie kontrollierte Kirche verlor dabei zunehmend an spiritueller Ausstrahlung, auch weil sie sich der Subjektivierung und Individualisierung von Frömmigkeit verschloss, aus der der Jansenismus seine Kraft bezog. Die Monarchie selber beanspruchte aber bis zuletzt eine stark sakrale Autorität, eine rein innerweltliche Legitimation politischer Herrschaft war bis zur Revolution kaum vorstellbar. Das Ritual der Wunderheilungen geriet allerdings unter Ludwig XV. in eine Krise, weil der Monarch aufgrund seines beständigen Ehebruches nicht mehr zur Messe zugelassen wurde. Die Tatsache, dass die Geistlichen, die im 18. Jahrhundert als Beichtväter des Königs amtierten, kaum noch die Politik des Monarchen kritisierten, wie dies im 17. Jahrhundert durchaus vorgekommen war, sondern sich ganz auf die Rolle konzentrierten, die persönliche Moral des Königs zu überwachen, machte es schwerer als vor 1715, mit den Mitteln der Kasuistik persönliche Verfehlungen des Herrschers zu relativieren. ${ }^{34}$

Überdies konnte fehlende Glaubwürdigkeit des Königs als gottesfürchtiger Herrscher nur partiell durch die demonstrative Frömmigkeit anderer, oft weiblicher Mitglieder der regierenden Dynastie kompensiert werden. Dennoch stieß die Revolution auf eine Monarchie mit immer noch starker sakraler Tradition; die Zerstörung der Königsgräber in Saint Denis und andere Akte des Ikonoklasmus wären sonst kaum verständlich. Gerade weil sie dieses Sakralkönigtum ersetzen musste, verschrieb sich die Revolution einer neuen Form von civil religion. Der Staat selbst, die Republik, wurden sakralisiert - eine Tendenz, die mit der Wendung zur Laizität in der dritten Republik ihren Höhepunkt erreichte und die sich in einem Kanon heiliger Texte ebenso manifestierte wie in politischen Festen und Ritualen. ${ }^{35}$ Eine

des oberhirtlichen Kirchenregiments im Widerstand des jansenistischen Lagers gegen die Anerkennung der Bulle Unigenitus (1713) in Frankreich. Ein Beitrag zur Entstehungsgeschichte des modernen Konstitutionalismus, in: Neithart Bulst (Hrsg.): Politik und Kommunikation. Zur Geschichte des Politischen in der Vormoderne, Frankfurt a.M. 2009, S. 147-249.

34 Den Hinweis auf die sich wandelnde Rolle der Beichtväter verdanke ich einem unveröffentlichten Aufsatz von Nicole Reinhardt (Durham).

35 Vgl. Van Kley, Origins, 1996, S. 187; Michel Vovelle: La Révolution contre l'église. De la raison à l'être suprême, Brussels 1988 sowie Michael Burleigh: Earthly Powers: The Clash of Religion and Politics in Europe, from the French Revolution to the Great War, London 2005, S. 67-112. Vgl. ebenso den Beitrag von Daniel Schulz: Das Sakrale im Zeitalter seiner politischen Reproduktion. 
solche civil religion, die ihre eigene Form politischer Transzendenz entwickelt, lässt, wenn sie, wie in Frankreich, im Konflikt mit traditionellen Formen von Religion entstanden ist, für autonome religiöse Gemeinschaften in der Öffentlichkeit wenig Raum, mögen diese nun christlich oder neuerdings islamisch bestimmt sein. Gerade weil Republikanismus und Kult der Menschenrechte schon in sich eine transzendente Dimension haben, ist für eine anders bestimmte Transzendenz in der Politik kein Raum. In diesem Sinne unterscheidet sich die politische Kultur Frankreich bis heute grundlegend von der vieler anderer europäischer Länder, ganz besonders aber von der politischen Kultur der angelsächsischen Länder. In England hingegen verband sich die Subjektivierung des Religiösen tendenziell nach 1688 mit einer neuen Form von ,,civil religion“, ${ }^{36}$ die den reformatorischem und aufklärerischen Antiklerikalismus durch einen relativ unspezifischen aber dennoch wirkungsmächtigen Glauben an die Bedeutung der göttlichen Vorsehung als Legitimationsgrundlage politischer Herrschaft ergänzte. Etwas von dieser politischen Grundeinstellung, die im providential deism des aufgeklärten 18. Jahrhunderts ${ }^{37}$ ebenso wurzelt wie im älteren mit der Prädestinationslehre verbundenen Providentialismus des Puritanismus, lebt, wenn schon nicht in Großbritannien, so doch zumindest in Amerika bis heute fort, mag nun auch an die Stelle der Auserwähltheit des Monarchen als Werkzeug der Vorsehung endgültig die Auserwähltheit der Nation als Instrument des Heils getreten sein. ${ }^{38}$

Die Französische Revolution zwischen Verfassungsfest und Missionierungskrieg, in diesem Band.

36 Justin A. Champion: The Pillars of Priestcraft Shaken. The Church of England and its Enemies 1160-1730, Cambridge 1992, S. 173, 207, 221-222. Wie Champion betont, ging es Republikanern wie John Toland um 1700 darum, eine Einheit von Staat und Religion (letztlich im Sinne eines Staatskultes) auf der Basis einer neuen „civic theology“ herzustellen, für die die virtus des Bürgers wichtiger war als die traditionellen Dogmen des Klerus.

37 Charles Taylor: A Secular Age, Cambridge M.A. 2007, S. 221-234.

38 Über „civil religion“ in Amerika siehe Robert N. Bellah: The Broken Covenant. American Civil Religon in Time of Trial, 2. Aufl., Chicago 1992; ders.: Civil Religion in America [1967], in: Daedalus 134 (2005), S. 40-55. Siehe auch: George Washington International Law Review 41 (2010) 4 (special issue: Civil Religion in the United States and Europe), bes. den allerdings skeptischen Beitrag von Frederick Gedicks: American Civil Religion: An Idea Whose Time is Past, S. 891-908. 



\title{
Politische Tugenden bei Hobbes
}

\author{
Alessandro PinZANi
}

Es wird häufig angenommen, dass Hobbes' Hauptinteresse beim Verfassen des Leviathans der Rechtfertigung einer absoluten Staatsmacht als einziger stabiler Regierungsform gelte. ${ }^{1}$ Ihm ginge es mit anderen Worten ausschließlich um die Stabilität des Staatswesens, um deren willen er bereit sei, die individuelle Freiheit des Einzelnen zu opfern. Diese Annahme ist nicht schlichtweg falsch oder inkorrekt, aber sie kann zu einer partiellen Lektüre dieses Werkes, allgemein von Hobbes' politischer Philosophie führen. Zweifellos geht es diesem Autor in erster Linie um die Stabilität des Staatsgebildes und des durch dessen Tätigkeit garantierten Friedens, aber es wäre irreführend, die Gesamtheit von Hobbes' durchaus komplexer Position auf diesen einzigen Aspekt zurückzuführen. Zwar scheint die Sicherung des inneren und äußeren Friedens gegen äußere und vor allem innere Feinde der dominierende Gedanke des ganzen Buchs zu sein, aber dies darf nicht dazu verleiten, weitere Elemente zu übersehen, die auch eine wichtige Rolle spielen und dem obersten Ziel der Friedenssicherung seinen eigentlichen Sinn erst verleihen, wie z.B. die Tatsache, dass die Menschen nicht nur ein sicheres, sondern auch ein bequemes Leben führen wollen. Ein solches, häufig übersehenes Moment besteht in der politischen Ethik, die vorwiegend in den Kapiteln 14 und 15 vorgestellt wird, und um die es im vorliegenden Aufsatz geht. Im Folgenden werde ich zunächst auf die Unter-

1 Dieser Aufsatz basiert auf dem Hobbes-Kapitel meines Buchs: An den Wurzeln moderner Demokratie, Berlin 2009, S. 88-145, genauer: er stellt eine stark überarbeitete Fassung von einem Teil des 3. Kapitels dar. Ich möchte mich bei Werner Euler für die freundliche Hilfe bei der sprachlichen Korrektur dieses Textes bedanken. 
scheidung von Ethik und Moral bei Hobbes eingehen (1), aus der sich der politische Charakter der in den besagten Kapiteln behandelten Tugenden ableiten lässt (2). Ich werde dann kurz auf die Rolle der Religion in dieser politischen Ethik und auf den politisch-theologischen Katechismus hinweisen, dessen Verbreitung Hobbes als Aufgabe des Souveräns ansieht (3). Schließlich werde ich mich mit der Frage von Hobbes' liberaler bzw. republikanischer Haltung aufgrund der vorausgegangenen Analysen ansatzweise auseinandersetzen (4).

\section{ETHIK UND MORALPHILOSOPHIE}

Hobbes benutzt die Begriffe von Ethik und Moralphilosophie, um zwei unterschiedliche Wissenschaften zu bezeichnen. Erstere wird als die „Wissenschaft aus den Folgen der menschlichen Leidenschaften “"2, letztere als die „Wissenschaft von dem, was im Verkehr und in der Gesellschaft gut und böse ist ${ }^{\star 3}$, definiert. Schon aus diesen Definitionen wird klar, dass für Hobbes Ethik mit der individuellen Privatmoral, Moralphilosophie mit der öffentlichen Moral zu tun hat. Dementsprechend werden beide „Wissenschaften“ an verschiedenen Orten behandelt: Ethik in De homine, Moralphilosophie in De cive und Leviathan.

Dabei ist Vorsicht geboten. Wenn er ,von dem, was im Verkehr und in der Gesellschaft gut und böse ist" spricht, so meint Hobbes nicht, dass der Maßstab von Gut und Böse, von Tugend und Laster in den Werten einer bestimmten Gesellschaft liegt: er vertritt keineswegs eine relativistische Position. Es ist vielmehr der sich durch die Gesetze ausdrückende souveräne Wille, der einen solchen Maßstab setzt. Hobbes behauptet zwar, der Gegenstand der Moralphilosophie seien die natürlichen Gesetze. Er betont jedoch gleichzeitig, dass sie eigentlich keine Gesetze, sondern nur Weisungen der Vernunft sind, ${ }^{4}$ die erst durch ihre Umwandlung in positive rechtliche Normen durch den Souverän zu wahren Gesetzen werden. ${ }^{5}$ Das bedeutet wiederum nicht, dass die Moralphilosophie als ihren Gegenstand die positiven Gesetze hat, sondern nur, dass sie ihren Maßstab in diesen findet. Und

2 Vgl. Thomas Hobbes: Leviathan, hrsg. von Iring Fetscher, Frankfurt a.M. 1984, S. 65.

3 Ebd., S. 122.

4 Vgl. ebd.

5 Vgl. ebd., S. 205. 
es bedeutet weiter, dass der Gegenstand der Moralphilosophie und der Gegenstand der gesetzgebenden Tätigkeit des Souveräns mindestens zum Teil gleichwertig sind und beide mit dem friedlichen Zusammenleben der Untertanen innerhalb der zivilen Gesellschaft zu tun haben.

Außerdem zählt in der schon erwähnten Tafel der Wissenschaften die Moralphilosophie offensichtlich zur umfassenderen Wissenschaft der Politik: Sie bildet nämlich den Zweig dieser Wissenschaft, der sich mit den „Folgen aus der Einsetzung von Staaten für Pflicht und Recht der Untertanen "6 befasst. Nun: welche Pflichten und welche Rechte den Untertanen zukommen, ist etwas, das nur ,im Verkehr und in der Gesellschaft“ (sprich: durch den Souverän und dessen Gebrauch der eigenen Vernunft) festgesetzt werden kann - wie im Fall der Definition der Maßstäbe von Gut und Böse. Somit spricht Hobbes der Moralphilosophie von vornherein unmittelbar politischen Charakter zu.

Hobbes' Position wird noch klarer, wenn man seine Polemik gegen Aristoteles und die ,andere[n] heidnische[n] Philosophen“ beobachtet. Die Moralphilosophie des Stagiriten und der anderen klassischen Denker der Antike stelle für den Staat eine Gefahr dar, da sie „Gut und Böse durch die Triebe der Menschen“ definierten - was eigentlich nur für die Personalmoral (also, für das, was Hobbes als Ethik bezeichnet) richtig ist. Dabei bemerkt Hobbes, dass die Bestimmung von Gut und Böse durch Berufung auf die triebhafte Natur des Menschen zwar sinnvoll sein kann, aber nur ,solange wir davon ausgehen, dass jeder von seinem eigenen Gesetz beherrscht wird. Denn befinden sich die Menschen in dem Zustand, in dem sie kein anderes Gesetz kennen als ihre eigenen Triebe, so kann es keine allgemeine Regel für gute und böse Handlungen geben. “7

Im Staat ist jedoch eine solche Voraussetzung vollkommen falsch: „,nicht der Trieb von Privatleuten, sondern das Gesetz, das Willen und Trieb des Staates darstellt, ist der Maßstab“" ${ }^{\text {8 }}$ von Gut und Böse. Würden die Menschen tatsächlich ,die Güte oder Schlechtigkeit ihrer eigenen Handlungen, die Handlungen anderer und die Handlungen des Staates selbst nach ihren Leidenschaften“ beurteilen, so wäre dies ,nicht nur sinnlos, sondern auch verhängnisvoll für das öffentliche Staatswesen“`9 Dann würde nämlich der

\footnotetext{
6 Ebd., S. 65.

7 Ebd., S. 518f.

8 Ebd., S. 519.

9 Ebd.
} 
Krieg der Meinungen wieder ausbrechen, der nach Hobbes die Hauptursache menschlicher Konflikte darstellt. Dazu bemerkt Hobbes, dass sich die Menschen, auch wenn sie über ihre gemeinsamen Ziele einig wären, über die Mittel zu ihrer Erreichung streiten würden, denn verschiedene Menschen beurteilen auf verschiedene Weise, „was bei den Handlungen des täglichen Lebens mit der Vernunft übereinstimmt oder nicht. Ja, ein und derselbe Mensch hat zu verschiedenen Zeiten verschiedene Ansichten [...]. Daraus entstehen Zank, Streitigkeiten und zuletzt Krieg." ${ }^{\text {(10 }}$ Sogar wenn das Ziel allen Menschen gemeinsam wäre, wie im Fall vom Frieden, so werden sie nicht alle einen und denselben Frieden wollen, sondern jeder würde seine eigene Vorstellung von Frieden und bürgerlicher Gesellschaft realisieren wollen. Konflikte sind daher möglich sogar im Namen des Friedens, wie schon Augustinus beobachtet hatte: „Auch die, welche den Frieden, in dem sie leben, stören wollen, hassen ja nicht den Frieden als solchen, sondern wollen nur einen anderen, der ihren Wünschen entspricht. “11

Eintracht unter den Bürgern wird somit zu einer Hauptbedingung für den inneren Frieden und das Weiterbestehen eines jeglichen politischen Wesens. Ihre Sicherung wird daher zu einer Hauptpflicht des Souveräns, der dafür die Meinungen kontrollieren muss (diese Kontrolle der zugelassenen Meinungen und Lehren ist eines der auffälligsten, am meisten diskutierten Momente der Hobbes'schen Souveränitätslehre, und darauf werden wir noch eingehen müssen). Gleichzeitig bilden alle Haltungen, die diese Eintracht bedrohen, negative Eigenschaften, deren Gedeihen unter den Bürgern auf jeden Fall vermieden werden muss. Wie wir sehen werden, beziehen sich viele der von Hobbes erwähnten „Laster“ eben auf solche Haltungen. Hobbes' politische Morallehre und seine Souveränitätslehre sind somit von vornherein miteinander verquickt, da beide in ihr Zentrum die Errichtung eines politischen Zustandes rücken, in dem das friedliche Zusammenleben möglich ist. Dies erklärt die Definition der Moralphilosophie als Wissenschaft vom dem, was im Verkehr und in der Gesellschaft

10 Ebd., S. 122. Vgl. auch S. 246f., wo das bürgerliche Gesetz als „Maß der guten und bösen Handlungen“ und der Gesetzgeber als „Richter“ darüber bezeichnet werden.

11 Aurelius Augustinus: Vom Gottesstaat, hrsg. von Wilhelm Thimme, Bd. II, Zürich 1955, S. 553. 
als gut bzw. böse gilt, denn es ist in der letzten Instanz der Souverän, der die moralischen Maßstäbe für seine Untertanen durch die Gesetze setzt.

In De homine (1658) vertritt Hobbes noch einmal diese Position und ergänzt sie durch einen Hinweis auf die moralisch neutralen Haltungen bzw. Handlungen. Alles, was nicht durch die Gesetze festgesetzt ist, bleibt dem Individuum frei: Es ist weder gut noch böse, bzw. es gilt dafür die Maxime „soviel Menschen, soviel verschiedene Regeln für Tugend und Laster““12. Es gibt deshalb keine Moralwissenschaft außerhalb des Staates bzw. der bürgerlichen Gesellschaft, denn ohne den sicheren Maßstab der Gesetze ist keine genaue Bestimmung von ,gut und böse“, daher keine Wissenschaft, sondern nur ein ,leeres Gerede“13 möglich.

Dieser Behauptung scheint das zu widersprechen, was Hobbes in der Tafel von Kapitel 9 des Leviathan behauptet hatte, nämlich dass die Ethik doch eine Wissenschaft sei, und zwar die, welche aus den Folgen der Leidenschaften resultiert. In der Tat spricht er ihr in De homine mitnichten Wissenschaftlichkeit ab. Er bestreitet lediglich, dass die Beschreibung der Folgen der Leidenschaften die Basis für normative Aussagen in Bezug auf das Gute und das Böse sein kann. Die Tatsache, dass ein Individuum aus bestimmten Anlagen den entsprechenden Charakter entwickeln kann, darf nicht als gut oder böse bezeichnet werden, solange dies das friedliche gesellschaftliche Zusammenleben nicht beeinträchtigt (in diesem Fall würde dies in den Bereich der Moralphilosophie fallen und politische Relevanz annehmen). Mit anderen Worten: Geiz, Freundlichkeit, Liebe usw. sind moralisch gesehen neutral, obwohl sie ethischen Charakter besitzen; als individuelle Eigenschaften können sie weder als gut noch als böse bezeichnet werden (dies würde vom Gebrauch abhängen, den man von ihnen im Verkehr mit den Mitbürgern machen würde). Aber man kann durchaus eine wissenschaftliche Beschreibung von ihnen anbieten (das ist eben Aufgabe der Ethik, die in De homine dargelegt wird). Billigkeit, Rachsucht oder Bereitschaft zum Verzeihen sind hingegen Eigenschaften, die von vornherein die Beziehung mit den Mitbürgern betreffen und daher das friedliche Gesellschaftsleben fordern bzw. bedrohen können; daher werden sie als gut bzw. böse bezeichnet, denn man verfügt hier über einen sicheren Maßstab,

12 Thomas Hobbes: Vom Menschen/Vom Bürger, hrsg. von Günter Gawlick, Hamburg 1959, S. 41.

13 Ebd. 
nämlich: den Willen des Souveräns, der die natürlichen Gesetze implementiert.

Mit anderen Worten: Ethik befasst sich mit den Folgen menschlicher Leidenschaften für das einzelne Individuum, nicht für die Gesellschaft. Sie zielt auf die Frage, was gut bzw. schlecht (nicht aber: böse) für die Einzelmenschen als private Individuen, nicht als Bürger bzw. Untertanen, ist. Sie bezieht sich auf einen nicht-politischen Bereich, in dem die Individuen frei sind, sich Handlungsrichtlinien und Lebensweisen beliebig auszusuchen, solange sie den Frieden nicht bedrohen. Ein Beispiel davon ließe sich im Kapitel 6 des Leviathan und in den Kapiteln 11-13 von De homine finden, in denen Hobbes die Folgen der menschlichen Leidenschaften beschreibt, ohne sie aus einer moralischen Perspektive zu beurteilen. Andererseits scheint Hobbes auch dieses personale Verhalten dem natürlichen Gesetz zu unterstellen, wie z.B. wenn er von den Dingen spricht, ,die zur Vernichtung von einzelnen Menschen führen wie Trunksucht und alle andere Arten von Unmäßigkeit, die man deshalb ebenfalls zu den Dingen rechnen kann, die das natürliche Gesetz verboten hat ${ }^{\text {"14 }}$.

Hier eröffnet sich anscheinend eine gewisse Asymmetrie: Einerseits haben die natürlichen Gesetze mit der öffentlichen Sphäre des friedlichen $\mathrm{Zu}$ sammenlebens zu tun, andererseits erstrecken sie sich mindestens auf Teile der privaten Lebensführung. Wie ist diese Diskrepanz zu interpretieren?

Die Schwierigkeit kann gelöst werden, wenn man den Charakter der Moral bei Hobbes genauer betrachtet. Hobbes gründet seine Moral (die persönliche wie die öffentliche) ${ }^{15}$ auf eine prudentielle Basis. ${ }^{16}$ Dabei verwirrt er den Leser durch zwei unterschiedliche Definitionen der natürlichen Gesetze: Am Anfang von Kap. 14 des Leviathan definiert er ein Gesetz der Natur als

14 Hobbes, Leviathan, 1984, S. 120 (Hervorhebung AP).

15 Entgegen der sogenannten Taylor und Warrender-Thesis (vgl. dazu Alfred E. Taylor: The Ethical Doctrine of Hobbes, in: Philosophy 13 (1938), S. 406-424; Howard Warrender: The Political Philosophy of Hobbes, His Theory of Obligation, Oxford 1957; Stuart M. Brown jr.: Hobbes. The Taylor Thesis, in: The Philosophical Review 68 (1959), S. 303-323). Die Literatur zu dieser These ist fast unendlich. Leicht gekürzte deutsche Fassungen der Aufsätze von Taylor und Brown finden sich bei Wolfgang Kersting (Hrsg.): Thomas Hobbes, Leviathan oder Stoff, Form und Gewalt eines bürgerlichen und kirchlichen Staates, Berlin 1996.

16 John W.N. Watkins: Hobbes' System of Ideas: A Study in the Political Significance of Philosophical Theories, London 1965. 
„eine von der Vernunft ermittelte Vorschrift oder allgemeine Regel [a Precept or generall Rule fund out by Reason], nach der es einem Menschen verboten ist, das zu tun, was sein Leben vernichten oder ihn der Mittel zu seiner Erhaltung berauben kann, und das zu unterlassen, wodurch es seiner Meinung nach am besten erhalten werden kann"“17;

am Ende von Kap. 15 schreibt er hingegen:

„Diese Weisungen der Vernunft [dictates of Reason] werden von den Menschen gewöhnlich als Gesetze bezeichnet, aber ungenau. Sie sind nämlich nur Schlüsse oder Lehrsätze [Conclusions, or Theoremes], die das betreffen, was zur Erhaltung und Verteidigung der Menschen dient. “18

Während in der ersten Definition der imperativische Charakter des Gesetzes zur Geltung kommt, spricht die zweite den natürlichen Gesetzen jeglichen imperativischen Grundzug ab. Hinzu kommt eine berühmte Stelle, die zu den meist zitierten im Leviathan zählt: „,Die natürlichen Gesetze verpflichten in foro interno, das heißt sie verpflichten zu dem Wunsch, dass sie gelten mögen, aber in foro externo, das heißt zu ihrer Anwendung, nicht immer." 19

Sie verpflichten also nicht zu ihrer uneingeschränkten Befolgung; sie verpflichten nicht einmal, an ihre uneingeschränkte Gültigkeit zu glauben, sondern nur zu dem Wunsch, sie mögen gelten. Das lässt sich mit einer imperativischen Auffassung kaum in Einklang bringen, ist jedoch mit einer prudentiellen Lesart durchaus vereinbar: Da die natürlichen Gesetze Vorschriften bezüglich der Selbsterhaltung sind, soll ich wenigstens wünschen, dass sie ihr Ziel erreichen.

Dass Hobbes von Verpflichtung im Zusammenhang mit Wünschbarkeit spricht, ist irritierend - aber nur wenn man eine imperativistische Auffassung der Normativität der Naturgesetze hat. Bei Hobbes kommen sie vielmehr hypothetischen Imperativen gleich, um die Kantische Terminologie zu benutzen: Sie schreiben bestimmte Handlungen oder Verhaltensweisen vor, aber nur unter der Voraussetzung, dass man sich ein Ziel setzt, zu dessen Erreichung jene Handlungen oder Verhaltensweisen die notwendigen Mittel sind. Sie alle betreffen die Erreichung eines bestimmten Zieles, näm-

17 Hobbes, Leviathan, 1984, S. 99.

18 Ebd., S. 122.

19 Ebd., S. 121 (Hervorhebung im Original). 
lich Selbsterhaltung. Entgegen einer verbreiteten Auffassung ist jedoch Selbsterhaltung für Hobbes kein höchstes Gut, nach dem alle Menschen streben. Unser Philosoph wehrt sich ausdrücklich gegen die Existenz eines solchen letzten Ziels oder höchsten Gutes. ${ }^{20}$ Die Neigung zur Selbsterhaltung, obwohl sie eine entscheidende Rolle beim Ausgang aus dem Naturzustand spielt (sie bietet schließlich die einzige Motivation dafür), kann wie alle Neigungen durch eine andere ersetzt werden. Die Menschen können ihre Selbsterhaltung selbst gefährden, und zwar nicht nur als Folge einer Fehleinschätzung der Mittel zur Erreichung des Zwecks der Selbsterhaltung, sondern auch aus anderen Gründen, z.B. aus Furcht vor Schande, ${ }^{21}$ aus militärischer Tapferkeit oder aus bloßer Unmäßigkeit. ${ }^{22}$ Auch in Hobbes' Definition eines Gesetzes der Natur kommt ein subjektives Moment zum Ausdruck (,[...] das zu unterlassen, wodurch es seiner Meinung nach am besten erhalten werden kann“'23), das den Raum für eine persönliche Moral (sprich: für Ethik) öffnet, in der nur die subjektiven Meinungen zählen und kein objektiver Maßstab vorhanden ist, um zu entscheiden, welche Handlungen unterlassen werden sollten (etwa ein maßloses Trinken, um ein Lieblingsbeispiel von Hobbes zu erwähnen).

Wenn ich mir nun - wie es zu erwarten ist, obwohl dies keine Notwendigkeit ist - das Ziel der Selbsterhaltung setze, muss ich den entsprechenden Vorschriften der Vernunft (d.h. den Naturgesetzen) Gehorsam leisten; und ich muss hoffen, dass alle anderen dasselbe tun. Das ist der Sinn der Verpflichtung zum Wunsch, jene Gesetze mögen Geltung haben. Verpflichtung darf also hier nur dann in einem moralischen Sinne verstanden werden, wenn man mit Hobbes als ,moralisch“ alles das definiert, was im Rahmen menschlichen Zusammenlebens zur Friedenserhaltung (d.h. auch zur Selbsterhaltung) dient. Das bedeutet allerdings weder, dass ,prudentiell' und ,moralisch`Synonyme seien, noch dass die Bereiche des Prudentiellen und des Moralischen gleichwertig sind. Es gibt nämlich prudentiell gebotene Handlungen, die moralisch neutral sind, da sie weder das friedliche Zusammenleben noch die Selbstvernichtung der Individuen betreffen.

20 Vgl. ebd., S. 75.

21 Vgl. ebd., S. 71.

22 Vgl. ebd., S. 120.

23 Ebd., S. 99 (Hervorhebung AP). 
Eine letzte Bemerkung zum systematischen Platz der Ethik im Leviathan und insbesondere in Hobbes' Tabelle der Wissenschaften: Wenn er von den ,,andere[n] Dinge[n]“ spricht, ,die zur Vernichtung von einzelnen Menschen führen“, fügt Hobbes hinzu: „Es ist aber weder nötig, sie ausdrücklich zu erwähnen, noch gehören sie unbedingt in diesen Zusammenhang “24. Dass sie nicht in diesen Zusammenhang gehören, wird offensichtlich, wenn man Folgendes beachtet: Das natürliche Gesetz verbietet - wie betont - einem Menschen, ,das zu tun, was sein Leben vernichten kann oder ihn der Mittel zu seiner Erhaltung berauben kann, und das zu unterlassen, wodurch es seiner Meinung nach am besten erhalten werden kann“'25; darunter fallen selbstverständlich Haltungen und Handlungen wie Trunkenheit, unnötiges Sich-tödlichen-Gefahren-aussetzen usw., und insofern hat Hobbes recht, wenn er sagt, man brauche ,diese Dinge“ nicht ausdrücklich zu erwähnen. Es handelt sich eben um Handlungen und Lebensweisen, welche die Selbsterhaltung ,von einzelnen Menschen" bedrohen, nicht jedoch den sozialen Frieden, um den es nur ,in diesem Zusammenhang“ geht: daher kann man sie ruhig bei Seite lassen. Es gibt deshalb in Hobbes' Leviathan keinen Platz für die persönliche Moral als Lehre der für Individuen gebotenen Lebensführung, da sich das Werk zum Ziel setzt, eine Friedenslehre zu entwickeln. ${ }^{26}$ Daher wird die Personalmoral als „Ethik“ in der Tafel von Kapitel 9 als ein Zweig der Physik eingetragen, nämlich als jener Zweig, der die Folge der menschlichen Leidenschaften studiert. ${ }^{27}$ Und daher ist sie Gegenstand von De Homine, nicht von De Cive oder von Leviathan.

\section{Natürliche Gesetze und Tugenden}

Gegenstand der natürlichen Gesetze sind Handlungen (aber auch Haltungen, wie wir sehen werden), die dem Zweck der Errichtung eines friedlichen Zustandes unter den Menschen dienen. Hobbes erwähnt neunzehn

24 Ebd., S. 120.

25 Ebd., S. 99.

26 Auch die ersten Kapitel stellen keine Zusammenfassung von Hobbes' philosophischem System dar, sondern befassen sich mit genau jenen Elementen des Systems, die als Bausteine für den Aufbau der angestrebten Friedenslehre vonnöten sind: was Sprache ist, was Vernunft ist, welches die Beweggründe menschlichen Handelns sind, usw.

27 Vgl. ebd., S. 65. 
solche Gesetze, denen jedoch mindestens ein zwanzigstes hinzugefügt werden muss. Die ersten zwei Gesetze sind die grundlegendsten und werden getrennt im Kapitel 14 behandelt. Das erste besagt: „Jedermann hat sich um Frieden zu bemühen, solange dazu Hoffnung besteht ${ }^{\text {‘2 }}$, oder in einer kürzeren Formulierung „Suche Frieden und halte ihn ein" ${ }^{\text {“29. Alle }}$ anderen Gesetze werden aus diesem abgeleitet, denn sie sind nur dessen Explikationen: sie spezifizieren, welche Handlungsweisen geboten bzw. verboten sind, um Frieden zu erhalten. Sie alle entsprechen der oben angeführten allgemeinen Definition eines Naturgesetzes, da sie alle bestimmte Handlungen oder Handlungsweisen gebieten bzw. verbieten (ich benutze hier die Ausdrücke ,Gebot' und ,Verbot' bzw. ,gebieten` und ,verbieten im oben erwähnten hypothetisch-imperativischen Sinn). Das zweite Gesetz besagt: ,Jedermann soll freiwillig, wenn andere ebenfalls dazu bereit sind, auf sein Recht auf alles verzichten, soweit er dies um des Friedens und der Selbstverteidigung willen für notwendig hält. “30

Die ersten zwei Gesetze führen zum Abschluss des Gesellschaftsvertrages und zur Errichtung des Staates. Im Kapitel 15 stellt Hobbes die anderen Gesetze der Natur vor. Jedem Gesetz lässt er eine Tugend bzw. deren entgegengesetztes Laster entsprechen. Dies ist ziemlich problematisch: Wie findet der Übergang von objektiven Gesetzen zu subjektiven, persönlichen Einstellungen statt?

Hobbes' natürliche Gesetze sind allerdings keine eigentlichen Gesetze, sondern prudentielle Weisungen der Vernunft, die an sich zwar normative Kraft besitzen (als hypothetische Imperative), jedoch nicht immer über genügend motivierende Kraft verfügen. Die Menschen weichen im Gegenteil von diesen Weisungen häufig ab und verhalten sich nicht rational, sei es aus falscher Berechnung (Rationalität ist schließlich bei Hobbes ein Vermögen des Kalküls), sei es, weil sie eher ihren Leidenschaften folgen. Im ersten Fall lassen sie sich von ihrer Vernunft verleiten, im zweiten Fall verzichten sie komplett auf ihren Gebrauch oder sie setzen sie nur mit dem Ziel an, den eigenen Leidenschaften zu besserer Durchsetzung zu verhelfen.

28 Ebd., S. 99.

29 Ebd., S. 100.

30 Ebd. 
Dies ist ein gutes Beispiel von Hobbes' typischer Vorgehensweise: Anscheinend übernimmt er einfach traditionelle Begriffe wie Naturgesetz oder Naturrecht, deutet sie jedoch anders als die Tradition so, dass er ihnen manchmal eine entgegensetzte Bedeutung gibt. In diesem Fall hören die natürlichen Gesetze auf, unveränderliche Normen mit absoluter, vor- und überpositiver Geltung zu sein. Sie werden zu bloßen Weisungen, die nur zum Wunsch verpflichten, sie mögen gelten, und nehmen erst durch die gesetzgebende Tätigkeit des Souveräns (der sie in positive Gesetze umwandeln muss) Gesetzescharakter an. Damit gibt Hobbes den Anschein, er folge der Tradition und vertrete keine besonders heterodoxe Lehre, setzt sich jedoch in der Tat komplett von ihr ab. Er benutzt die Begrifflichkeit der naturrechtlichen Tradition, um eben dieser Tradition den Boden unter den Füßen zu entziehen: waren die natürlichen Gesetze im jus naturalis ein Kriterium, um das Handeln des Souveräns zu beurteilen, und gleichzeitig ein Grund, um Ungehorsam gegen ihn zu rechtfertigen, so werden sie jetzt zu rein prudentiellen Ratschlägen, die die Autorität des Souveräns sogar brauchen, um normativen Charakter im starken Sinne zu bekommen.

Damit wird klar, warum für Hobbes den natürlichen Gesetzen bestimmte Tugenden entsprechen: die Weisungen der Vernunft können erst dann ihren Zweck erreichen, wenn sie nicht bloß ein einziges Mal, sondern immer wieder befolgt und letztlich verinnerlicht werden, damit der Zustand des Friedens und der Sicherheit dauerhaft garantiert wird. Hier weist Hobbes eine gewisse Nähe zu dem von ihm sonst immer wieder kritisierten Aristoteles auf: Moralisch (und das heißt bei Hobbes immer: moralischpolitisch) gute Handlungen müssen so lange wiederholt werden, bis sie zu einem Habitus geworden sind und fast automatisch durchgeführt werden. Ließe die Befolgung der Weisungen der Vernunft nach, so wäre bald der friedliche Zustand gefährdet, und man würde langsam aber sicher zurück in den Naturzustand abrutschen. Daher lässt Hobbes jedem Gesetz der Natur eine Tugend entsprechen, auch wenn er sie nicht in jedem Falle ausdrücklich erwähnt. Diese Tugenden werden von Hobbes positiv oder negativ (d.h. als Verbote einer bestimmten Einstellung bzw. eines bestimmten Lasters) formuliert.

Die von Hobbes geforderten Tugenden bzw. verbotenen Laster sind die folgenden (in Klammern das jeweilige natürliche Gesetz): 1) die Friedsamkeit (die wichtigste Tugend aus einer Perspektive, in der die Sicherung von Frieden die Hauptaufgabe des Staates darstellt), 2) das Verbot des 
,Trittbrettfahrens' bzw. die Bereitschaft, sich für die Herstellung und Erhaltung von Frieden und Sicherheit zu engagieren, 3) die Gerechtigkeit (als Tugend, nicht einfach als Gerechtigkeit der Handlungen ${ }^{31}$ ), 4) die Dankbarkeit ${ }^{32} 5$ ) die Bereitschaft zum Entgegenkommen (Hobbes spricht sich dabei ausdrücklich für einen Ausschluss der unverbesserlichen Störenfriede aus der Gesellschaft aus), 6) eine bedingte Bereitschaft zum Verzeihen (nämlich immer dann, wenn dadurch Frieden gewährt werden kann), 7) das Verbot, ,eine Bestrafung in anderer Absicht zu verhängen als der der Besserung des Täters und der Anleitung anderer “333, also das Verbot der Grausamkeit (die entsprechende Tugend wäre die Menschlichkeit und Angemessenheit beim Bestrafen - daher, nicht Menschlichkeit im allgemeinen), 8) das Verbot der Beleidigung, 9) das Verbot des Hochmuts, 10) das Aufweisen von Bescheidenheit und Anmaßung, 11-20) ${ }^{34}$ das Gebot der Billigkeit bzw. das Verbot der Begünstigung in Bezug auf verschiedene Gebiete (Privateigentum, Justizverwaltung usw.).

Diese Gesetze sind - wie gesagt - einfache „Weisungen der Vernunft“. Würden sie befolgt, würden die Menschen in Frieden und Sicherheit leben (wobei Sicherheit mehr als die bloße Erhaltung des Lebens ist, sondern alles einschließt, was einem angenehmen Leben dient). Wenn sie aber verletzt werden, können sie zur Ursache von gewalttätigen Konflikten werden. Sie können insgesamt als Vorschriften gelesen werden, die alle Bürger er-

31 Vgl. ebd., S. 114 sowie S. 260.

32 Es lohnt sich hier die Stelle genauer unter die Lupe zu nehmen, da sie Entscheidendes zur Beantwortung der Frage von Hobbes' angeblich egoistischem Menschenbild beitragen kann. Hobbes schreibt: „Empfängt jemand von einem anderen einen Vorteil aus reiner Gunst, so soll er sich bemühen, dass der Schenker keinen vernünftigen Grund hat, seinen guten Willen zu bereuen.“ (ebd., S. 116) Dann fügt er sofort hinzu: „Denn niemand schenkt etwas ohne die Absicht, sich dabei selbst ein Gut zu verschaffen." Hier scheint Hobbes den Menschen jegliche Selbstlosigkeit abzusprechen. Gegen diese Interpretation ist einzuwenden, dass Hobbes altruistische Motive durchaus annimmt, auch wenn er sie im Sinne seiner mechanistischen Anthropologie deutet. Hier scheint er eher von der Annahme altruistischer Motive nicht ausgehen $z u$ wollen, denn eine solche Annahme wäre eine schwer zu beweisende anthropologische Voraussetzung. Man muss nach Hobbes' Meinung auch dann dankbar sein, wenn der andere aus selbstbezogenen Motiven gehandelt hat, denn Undankbarkeit schmälert die Kooperationsbereitschaft und lässt das Misstrauen wachsen.

33 Ebd., S. 117.

34 Das 20. Gesetz wird erst im 26. Kapitel eingeführt, wo Hobbes sagt, dass es dem Gesetz der Natur widerspricht, „einen Unschuldigen zu bestrafen“ (ebd., S. 213). 
füllen sollten, damit der Staat, in dem sie leben, erhalten bleibt. Daher kann die Befolgung dieser Vorschriften keine einmalige Handlung sein. Sie müssen vielmehr verinnerlicht werden, so dass man letztlich von politischen oder gar von Bürgertugenden sprechen kann: Die Bürger müssen gerecht, dankbar und entgegenkommend sein; sie müssen bereit sein zu verzeihen und auf Grausamkeit verzichten; sie dürfen die anderen Bürger nicht beleidigen; sie dürfen sich weder hochmütig noch anmaßend, sondern bescheiden geben; und sie müssen immer die Vorschriften der Gerechtigkeit befolgen.

Eine bloße Befolgung der Naturgesetze reicht also nicht aus. Mit ihr sollte vielmehr eine Internalisierung der Weisungen der Vernunft einhergehen. Selbstinteresse allein kann unmöglich Kooperation garantieren, da der Mensch immer wieder selbstzerstörenden Leidenschaften wie Ruhmsucht und Hochmut unterliegt; ${ }^{35}$ außerdem sind die konkreten Fähigkeiten eines Souveräns, den Krieg der Meinungen endgültig zu beseitigen, ziemlich eingeschränkt: er kann nicht überall sein, um das Verhalten der Untertanen zu kontrollieren und abweichendes Benehmen zu bestrafen. Daher müssen die Untertanen die Weisungen der Vernunft internalisieren, auch unabhängig von ihrer Übersetzung in positive Gesetze (die zwar eine stärkere normative und motivationale Kraft besitzen, jedoch leicht zu verletzen sind, wenn die Kontrolle der politischen und rechtlichen Mächte nicht vollkommen ist).

Dass sich Hobbes der Grenzen der souveränen Macht sehr bewusst war, zeigt eindeutig seine Rekonstruktion des englischen Bürgerkriegs im Behemoth. Dort bezeichnet A (der Dialogteilnehmer, der als Augenzeuge dem jüngeren B die Geschichte der Wirrungen erzählt) Karl I. als einen König, der nicht nur mit voller Legitimität seine Macht ausübte, ${ }^{36}$ sondern darüber

35 Ich möchte nochmals betonen, dass Hobbes' Argument gegen den Einwand der Narren zwar zeigt, dass es unvernünftig ist, sich prinzipiell der Kooperation durch List zu entziehen, es besagt jedoch nicht, dass sich die Menschen deswegen immer vernünftig verhalten.

36 Selbstverständlich legitimiert A diese Macht durch Bezug auf das historische Recht von Karl I. als Nachfolger in einer ununterbrochenen Linie von Herrschern, und nicht durch ein hypothetisches Argument wie im Leviathan: Hier geht es nicht nur darum, die Notwendigkeit souveräner Macht schlechthin zu zeigen (diese Lehre sollte eher aus den furchtbaren Ereignissen des Krieges als aus einem philosophischen Argument resultieren), sondern auch die Legitimität von Karls Titel und Besitz des Amtes aufzuweisen. 
hinaus voller Tugenden war und seinen Aufgaben pflichtbewusst nachging. Das hat ihm aber nichts genutzt, da er die Meinungen seiner Untertanen nicht genügend kontrollierte. Interessant ist die Reaktion des zweiten Dialogteilnehmers B auf die Analyse von A: Bei einem Volk, das so veranlagt war, sei der König schon aus der Regierung ausgeschlossen; es sei daher eigentlich gar nicht notwendig gewesen, dass jenes die Waffen gegen diesen erhebe, denn es sei nicht zu sehen, wie der König einem Volke widerstehen könne, das gegen ihn dermaßen aufgebracht sei. Für Hobbes war es also offensichtlich, dass auch ein legitimer und guter Souverän nicht imstande ist, seinem Zweck (d. h. Erhaltung der Sicherheit des Volkes) nachzugehen, wenn ein relevanter Teil des Volkes selbst dessen Autorität nicht bedingungslos anerkennt oder wenn es sie sogar anzweifelt. Die bloße Gewalt reicht also nicht aus, um die Herrschaft zu behalten.

Man muss daher die Bereitschaft der Untertanen voraussetzen, die eigenen Leidenschaften auch unabhängig von der Gewaltandrohung des Gesetzes zu unterdrücken und eine Haltung anzunehmen, die dem Krieg abschwört und einen stabileren Frieden unter ihnen ermöglicht. Deswegen ist die Behauptung erlaubt, dass von den Hobbes'schen Untertanen erwartet wird, dass sie die natürlichen Gesetze so weit verinnerlichen, dass sie zu Tugenden werden. Wie Peter Berkowitz beobachtet: „Virtue lubrificates the joints and moving parts of Hobbes's complex political machine. ${ }^{\text {(37 }}$ Ohne die erwähnten Tugenden würde das politische Modell von Hobbes nicht funktionieren. Deshalb identifiziert Hobbes die wissenschaftliche Kenntnis der natürlichen Gesetze (d. h. der Weisungen der Vernunft) mit der „wahren und einzigen Moralphilosophie“, verstanden als „die Wissenschaft von dem, was im Verkehr und in der Gesellschaft gut und böse ist“38.

Ich möchte hier einige Bemerkungen bezüglich der Beziehung Hobbes' zu Aristoteles einführen. Vorher war von einer gewissen Nähe unter den beiden Autoren die Rede; dies muss insofern verwundern, als sich Hobbes von Aristoteles ausdrücklich distanziert. Wo soll also die Nähe zu Aristoteles liegen - außer in der erwähnten Idee, eine moralisch gute Handlung solle so häufig wiederholt werden, bis sie zu einer Haltung, also zu einer

37 Peter Berkowitz: Virtue and the Making of Modern Liberalism, Princeton 1999, S. 39.

38 Hobbes, Leviathan, 1984, S. 122 (Hervorhebung im Original). 
Tugend geworden ist? Die Beantwortung dieser Frage wird uns helfen, manche Eigenschaften von Hobbes' Tugendauffassung besser zu verstehen.

Man könnte behaupten, dass eine gewisse Analogie zwischen dem teleologischen Tugendverständnis des Aristoteles und dem prudentiellen Tugendverständnis von Hobbes bestehe. Für beide Autoren sind Tugenden die Mittel zur Erreichung eines Ziels. Für Aristoteles ist allerdings dieses Ziel ein naturgegebenes telos, das jedes Individuum gemäß seiner Fähigkeiten und Charakteristiken realisieren soll. Hobbes identifiziert hingegen das Ziel mit einem Zustand von Frieden, Geselligkeit und Bequemlichkeit, zu dem alle Menschen neigen, und den der Einzelne nur in Zusammenarbeit mit den Anderen erreichen kann. Aristoteles' Tugenden sind vornehmlich individuelle Tugenden, nur sekundär mit Bezug auf ihre Auswirkungen auf die Mitmenschen und auf die Gesellschaft zu bewerten, da jedes Individuum die eigene Vollkommenheit, das eigene telos verfolgt. Hobbes' Tugenden sind hingegen ausschließlich politischer Natur: Sie dienen allgemeinen politischen Zwecken (Frieden und ein angenehmes Leben) und betreffen das Zusammenleben der Individuen. Sie sind soziale Tugenden, die nicht von isolierten Individuen kultiviert werden können - im Gegensatz zu vielen (wenngleich nicht zu allen) aristotelischen Tugenden, allen voran den dianoëtischen.

Dem Philosophen aus Stagira wirft Hobbes andererseits vor, „die Tugend in die Mitte zwischen den Leidenschaften“ zu legen, ,als ob nicht der Grund, sondern der Grad des Wagens die Tapferkeit und nicht der Grund, sondern die Größe der Gabe die Freigiebigkeit ausmachte! ‘39. Es bliebe dahingestellt, ob diese - eigentlich nicht neue - Kritik die aristotelische Tugendlehre wirklich trifft. Festzuhalten ist auf jeden Fall, dass für Hobbes Aristoteles eine falsche Definition der Tugend angab, der er seine eigene entgegenstellt: Tugenden sind „Mittel zu einem friedlichen, geselligen und bequemen Leben“ ${ }^{\star 40}$. Interessanterweise nimmt Hobbes hier eine Bemerkung Kants vorweg: Der moralische Wert einer Haltung hängt vom Grund

39 Ebd.

40 Ebd. Insofern ist Berkowitz sicher zuzustimmen, wenn er behauptet: „Hobbes’ Leviathan is firmly grounded in reflections on the virtues that conduce to peace" (Berkowitz, Virtue and the Making of Modern Liberalism, 1999, S. 38), während gleichzeitig Mary Dietz' Behauptung, der Leviathan sei ,a tract on civic virtue" (Mary G. Dietz: Hobbes's Subject as Citizen, in: dies. (Hrsg): Thomas Hobbes and Political Theory, Lawrence 1990, S. 91-119, hier: S. 92) als etwas übertrieben angesehen werden muss. 
des Subjekts (bei Kant: vom Motiv), nicht von den inneren Merkmalen der Haltung ab. Tapferkeit bei einem Friedensstörer ist sicher keine Tugend, so wenig wie Freigiebigkeit bei einem reichen Mann, der dadurch politischen Einfluss zu gewinnen hofft, um die legitime Macht auszuhöhlen. Diese Position kommt in De homine sehr klar zum Ausdruck, und zwar an einer Stelle, wo noch einmal von den Bürgertugenden die Rede ist, die hier von den Tugenden unterschieden werden, die nur für den Menschen als Individuum gut sind. Dabei nimmt Hobbes als Beispiel drei Tugenden, die nicht nur zusammen mit der Gerechtigkeit (die hingegen eine politische Tugend ist, da sie im „Befolgen der Gesetze“ besteht) die vier traditionellen Kardinaltugenden ausmachen, sondern im politischen Aristotelismus wie im Republikanismus als primäre Bürgertugenden gelten: Tapferkeit, Besonnenheit und Mäßigkeit. ${ }^{41}$ Hobbes' Meinung ist eindeutig: Sie sind „nicht Tugenden der Bürger als Bürger sondern als Menschen; denn sie sind nicht so sehr dem Staate als den einzelnen Menschen selbst, die sie besitzen, nützlich“42. Hobbes rechtfertigt seine Position durch das schon erwähnte Argument der unterschiedlichen Gebräuche dieser Tugenden: „Ein Staat nämlich wird zwar erhalten nur durch Tapferkeit, Besonnenheit und Mäßigkeit der guten Bürger, zerstört aber wird er wiederum nur durch Tapferkeit, Besonnenheit und Mäßigkeit der Feinde.،“43

Jene Eigenschaften, die bei den eigenen Bürgern die Kraft eines Staates ausmachen, können also, wenn sie auch bei den Feinden zu finden sind, sein Ende bedeuten. Damit meint Hobbes nicht, diese Qualitäten seien für den Staat negativ, sondern bloß, dass sie für ihn neutral sind. Sie können für das Heil des Staates entweder gut oder böse sein, je nach den Umständen (und den Trägern solcher Eigenschaften). An sich dienen sie nur den Menschen, die sie haben - besonders Mäßigkeit, da sie „ein Nichtvorhandensein der Laster" ist, und die Laster schädigen ,weniger den Staat als vielmehr den einzelnen Menschen ${ }^{\text {‘4 }}$.

Hobbes gibt in diesem Werke folgende Zusammenfassung seiner Tugendlehre: „Gute Anlagen sind solche, die geeignet sind, eine staatliche Gemeinschaft zu bilden; ein guter Charakter, d. h. sittliche Tüchtigkeit, ist ein solcher, durch den die Gemeinschaft, wenn sie gebildet ist, am besten

41 Vgl. Hobbes, Vom Menschen, 1959, S. 42.

42 Ebd.

43 Ebd.

44 Ebd. 
erhalten werden kann. “45 Er zieht dann folgenden Schluss: „Alle Tugenden aber sind enthalten in Gerechtigkeit und Liebe ${ }^{\text {c } 46}$, d. h. im Befolgen der staatlichen Gesetze bzw. der natürlichen Gesetze. Soweit also der Bürger die positiven Gesetze seines Staates befolgt, handelt er aus Gerechtigkeit, nicht aus Liebe. Hält er sich jedoch an die natürlichen Gesetze, unabhängig von ihren positiven Eigenschaften, dann ist das Motiv seiner Handlung die Liebe. Somit übersetzt Hobbes die christliche Tugend der Nächstenliebe in die Befolgung der Weisungen der Vernunft (Friedfertigkeit, Bereitschaft zum Verzeihen, Dankbarkeit usw.). Man darf jedoch nicht denken, diese Liebe sei für den Staat nur soweit notwendig, bis der Souverän die Wiesungen in die positive Gesetzgebung aufgenommen hat. Auch wenn die bürgerlichen Gesetze eine positive Fortführung der natürlichen darstellen, so können sie nur die entsprechenden Handlungen, nicht jedoch die entsprechenden Haltungen gebieten bzw. verbieten. Von den Bürgern ist also gefordert, dass sie jene Haltungen aus Liebe einnehmen.

Diese Liebe darf allerdings nicht mit Vaterlandsliebe oder Liebe zu den Landesgenossen verwechselt werden. In Hobbes' Theorie gibt es für solche Gefühle keinen Platz. Und keinen Platz gibt es auch für Begriffe wie Vaterland oder Nation. Der Staat entsteht nicht aufgrund des Vorhandenseins einer durch gemeinsame Geschichte, Sprache und Kultur vereinigten Gruppe von Menschen: Wir dürfen nicht vergessen, dass vor der Errichtung des Leviathan das Volk nicht existiert. Der Staat ist vielmehr ein künstlicher Zusammenschluss von Individuen auf der Suche nach Frieden und Sicherheit. Wenn der Souverän nicht mehr imstande ist, diese zu garantieren, haben sie das Recht, sich von jeglicher Verpflichtung ihm (daher dem Staat) gegenüber frei zu fühlen, und sind autorisiert, sich einen neuen Herrscher zu suchen, denn ,Zweck des Gehorsam ist Schutz“, wie es im Leviathan heißt. ${ }^{47}$ Im „Rückblick und Schluss“ dieses Werkes wird es noch deutlicher wiederholt: Jedermann ist zwar ,,von Natur aus verpflichtet, soweit es in seiner Macht steht, im Krieg die Autorität [nicht: seine Mitbürger oder sein Vaterland, AP] zu schützen, durch die er in Friedenszeiten geschützt wird“, doch besiegt ein Eroberer den Inhaber dieser Autorität, so sind die Menschen autorisiert, sich ihm zu unterwerfen. ${ }^{48}$ Diese Lehre (und

45 Ebd., S. 42f.

46 Ebd., S. 43.

47 Hobbes, Leviathan, 1984, S. 171 sowie S. 254.

48 Vgl. ebd., S. 536f. 
seine Position über die Beziehung von Staat und Religion) brachte Hobbes starke Feindseligkeit beim Exilhof ein; gleichzeitig jedoch erleichterte sie seine Rückkehr nach England, da sie eine Legitimationsbasis für die wieder eingesetzte Autorität der Stuarts anbot. ${ }^{49}$

\section{Religion Und politische ERZIEHUNG}

Im Leviathan wird der Religion ein weitaus größerer Platz als der Politik eingeräumt: ${ }^{50}$ Diesem Thema sind zwei der vier Teile des Buches und einige Kapitel in den beiden anderen Teilen (die sich jeweils mit Anthropologie und mit dem Staat beschäftigen) gewidmet. Das verwundert nicht angesichts der Entstehungsgeschichte des Werkes, das Hobbes unter anderem darum verfasste, um Position zu beziehen im damals in England entflammten Streit über die Beziehung zwischen Staat und Kirche. Wie gesagt, war es zum Teil seine Auffassung dieser Beziehung, die ihm die Missgunst der Geistlichen um den im Exil lebenden Karl II. und die Ungnade von Stuart selbst einbrachten, so dass sich Hobbes gezwungen sah, aus dem französischen Exil Hals über Kopf in sein Heimatland zu flüchten. Nach der Rückkehr des Königs nach England musste Hobbes dann um sein Leben fürchten, da mehrmals eine Anklage wegen Ketzerei gegen ihn erhoben wurde. Seine Gönner konnten ihn aber immer wirksam gegen seine Feinde, allen voran Edward Hyde, verteidigen. Was war so ketzerisch an Hobbes' Auffassung?

Für Hobbes ist Religion ein instrumentum regni, ein Mittel zur Machtausübung. Dabei reiht er sich in eine lange Tradition politischer Denker ein, zu denen z.B. Machiavelli gehört. Hobbes' Analyse der Religion kommt derjenigen des Florentiners sehr nahe, obwohl der Engländer auf das Thema nicht nur aus einer rein politischen Perspektive eingeht. Er behandelt es nämlich schon im ersten Teil des Leviathans, welcher der Natur des Menschen gewidmet ist. In Kapitel 12, „Von der Religion“, interpretiert Hobbes diese als anthropologisches Phänomen. Im Unterschied zu Tieren sind Menschen immer auf der Suche nach der Ursache der von ihnen wahrgenommenen Ereignisse und entwickeln dabei die Fähigkeit, über die

49 Vgl. dazu Hans-Dieter Metzger: Thomas Hobbes und die Englische Revolution 1640-1660, Stuttgart 1991.

50 Vgl. zu dieser Frage Michael Großheim: Religion und Politik. Die Teile III und IV des „Leviathan“, in: Kersting, Thomas Hobbes, 1996, S. 283-316. 
Zukunft nachzudenken: Sie erinnern sich nämlich bei ihrer Beobachtung der Ursachen an vergangene Beobachtungen und ziehen daraus Schlüsse über die Zukunft. Solche Eigenschaften (Neugierde über die Ursachen der Ereignisse und Fähigkeit, an die Zukunft zu denken) bewirken Angst, da sich der Mensch unvermeidlich Sorge über seine Zukunft macht. Da die Angst aus keinem sichtbaren Gegenstand entspringt, schreiben die Menschen Glück und Unglück einer unsichtbaren Macht zu. Die Götter sind somit ,von der menschlichen Furcht geschaffen worden“" ${ }^{\text {"51 }}$. Kaum war mit den Göttern die Religion erschaffen, kamen prompt einige Menschen auf die Idee, sich derselben für ihre Machtzwecke zu bedienen: Dabei handelten manche zwar ,auf Grund göttlichen Befehls und göttlicher Weisung“, wie z.B. Abraham und Moses; andere jedoch nach eigener Erfindung, und das waren nach Hobbes, der in diesem Punkt mit Machiavelli übereinstimmt, ,alle Staatsgründer und heidnischen Gesetzgeber“. Unabhängig davon, ob diese Menschen auf Gottes Befehl oder auf eigene Faust handelten, verfolgten sie alle ,die Absicht, die Menschen, die sich ihnen anvertrauten, zu Gehorsam, Befolgung von Gesetzen, Frieden, Nächstenliebe und zur bürgerlichen Gesellschaft zu erziehen“52. Deshalb achteten sie alle darauf, ,den Glauben auszuprägen, die von ihnen erlassenen religiösen Vorschriften seien keine eigene Erfindung, sondern Weisungen eines Gottes“, und legten großen Wert darauf,

„den Glauben zu erwecken, dass dieselben Dinge, die durch Gesetz verboten waren, auch den Göttern missfielen. Drittens waren sie auf die Einführung von Zeremonien, Bittgebeten, Opfern und Festen bedacht, wodurch die Menschen dazu gebracht werden sollten, zu glauben, der Zorn der Götter könnte besänftigt werden. “53

Abraham, Moses und die anderen, welche auf Gottes Befehl gehandelt haben, gingen nicht anders vor, auch wenn - so führt Hobbes aus - die von ihnen erlassenen Gesetze tatsächlich Vorschriften Gottes waren und er durch Zeremonien zur Gnade wirklich bewegt werden konnte.

Die Folgen einer solchen Auffassung von Religion werden im 31. und letzten Kapitel des zweiten, dem Staat gewidmeten Teils, ,Vom natürlichen Reich Gottes“, gezogen. Hier scheint sich Hobbes zunächst der traditionellen Auffassung christlicher Denker anzuschließen, nach der die Gehorsams-

51 Hobbes, Leviathan, 1984, S. 83.

52 Ebd., S. 85.

53 Ebd., S. 88f. 
pflicht der Untertanen dort endet, wo die Befehle des Souveräns den göttlichen Gesetzen widersprechen. ${ }^{54}$ Diese Behauptung wird jedoch im Folgenden abgeschwächt und erlebt eine Interpretation, die Empörung und Wut der englischen Geistlichen auf sich ziehen sollte, und ein weiteres Beispiel der schon erwähnten Vorgehensweise ist, die darin besteht, anscheinend aus der Tradition übernommene Positionen umzukehren: Die göttlichen Gesetze entsprechen nämlich nach Hobbes den bürgerlichen, vom Souverän erlassenen Gesetzen. Hobbes bekräftigt zunächst die traditionelle Position, nach der die Menschen, ob sie es wollen oder nicht, immer der göttlichen Gewalt unterstehen, da Gott allmächtig ist. Hätte es im Naturzustand einen Menschen unwiderstehlicher Gewalt gegeben, wäre kein Gesellschaftsvertrag notwendig gewesen, denn er hätte die alleinige Herrschaft über alle anderen Menschen errungen. Die Menschen sind jedoch gleich geschaffen, ${ }^{55}$ daher kommt die alleinige Herrschaft nur Gott zu.

Hobbes verringert jedoch sofort die Tragweite der Behauptung, Gott regiere über alle Menschen: Sie sei nur bildlich zu verstehen, „denn das Wort ,regieren' passt nur für den, der seine Untertanen durch sein Wort und durch Versprechen von Belohnungen für die Gehorsamen und Bedrohungen für die Ungehorsamen mit Strafe lenkt ${ }^{456}$. Daher erstreckt sich Gottes Reich nur auf diejenigen, die an einen Gott glauben, da sie seine Vorschriften verstehen können - im Unterschied zu Sachen und unvernünftigen Lebewesen und im Unterschied zu Atheisten, die kein Wort als göttlich anerkennen. Die Atheisten kommen jedoch nicht so einfach davon: Sie sind als Feinde (scil. des Staates und des Friedens) anzusehen und als solche zur Tötung freigegeben.

Gott befiehlt also durch Worte, wie jeder andere Souverän. Dabei gibt es drei Erscheinungsformen des göttlichen Wortes. Die erste findet Ausdruck in den Vorschriften der natürlichen Vernunft, den natürlichen Gesetzen der Kapitel 14 und 15, die wir durch rechte Vernunft wahrnehmen. Die zweite besteht in einer Offenbarung und wird durch übernatürliche Wahrnehmung erfahren, wird aber von Hobbes bei Seite gelassen, weil dadurch keine allgemeinen Gesetze jemals erlassen wurden. Die dritte wird durch die Stimme eines Propheten verkündet und fordert

54 Vgl. ebd., S. 271.

55 Vgl. ebd., S. 94.

56 Ebd., S. 271. 
den Glauben daran. Gott kann man demnach Herrschaft in einem doppelten Reich zuschreiben: Im natürlichen Reich herrscht er mittels der natürlichen Vernunft über den Teil der Menschheit, der seine Vorsehung anerkennt, und in dem prophetischen herrschte er mittels positiver Gesetze über das jüdische Volk. ${ }^{57}$

Somit stellt Hobbes die göttliche Gesetzgebung mit der natürlichen, durch rechte Vernunft erkannten Gesetzgebung gleich: Die göttlichen Gesetze und die Vorschriften der natürlichen Vernunft sind ein und dasselbe; ${ }^{.5}$ sie betreffen zunächst „die gegenseitigen Pflichten der Menschen“, wie sie in den Kapiteln 14 und 15 dargestellt wurden: sie entsprechen somit den dort erwähnten moralischen Tugenden wie Billigkeit, Gerechtigkeit, Demut, Dankbarkeit usw. Es gibt ferner Gesetze, die als „Regeln der Ehre und Verehrung der göttlichen Majestät den Menschen allein von ihrer natürlichen Vernunft vorgeschrieben werden, ohne andere göttliche Worte ${ }^{\text {“59 }}$.

Hier wendet Hobbes noch einmal die Strategie an, zunächst traditionelle Auffassungen zu vertreten, um sie dann mittels einer strengen Begriffsanalyse so umzugestalten, dass sie eine entgegensetzte Bedeutung annehmen. Um Gottes Gunst zu gewinnen, loben, verherrlichen und preisen ihn die Menschen selig. Dabei kann die Zuschreibung jedes positiven Attributes - außer dem der Existenz ${ }^{60}$ - nur als Ausdruck unserer Bewunderung für ihn verstanden werden, ${ }^{61}$ da wir durch unsere Vernunft keine positive Kenntnis über ihn haben können. Somit ist jeder Streit über seine Eigenschaften eine Entehrung Gottes. ${ }^{62}$ Wenn wir nichts über Gott sagen können, außer dass er existiert, dann können wir ihm sogar keinen Willen zuschreiben - was das Beten als Versuch, Gottes Willen zu bewegen, zwecklos und Lob, Verherrlichung und Seligpreisung zu Ausdrücken einer auf Furcht basierenden Anerkennung seiner unwiderstehlichen Gewalt, seiner Allmacht, macht. Die größte aller Ehrbezeugungen ist letztlich der Gehorsam gegen seine Gesetze, die Gesetze der Natur, ${ }^{63}$ da nur dieser Gehorsam über ein einfaches Lippenbekenntnis zur Anerkennung von

57 Vgl. ebd., S. 272.

58 Vgl. ebd., S. 274.

59 Ebd.

60 Vgl. ebd., S. 276.

61 Vgl. ebd., S. 277.

62 Vgl. ebd., S. 278.

63 Vgl. ebd., S. 279. 
Gottes Autorität hinausgeht. Nicht zufällig nennt Hobbes im Kapitel 43 nur zwei Bedingungen, die für die Aufnahme ins himmlische Reich erfüllt werden müssen: den Glauben an Christus und den Gehorsam gegen die Gesetze. ${ }^{64}$ Da aber der erstere ,innerlich und unsichtbar“, somit Privatsache der Menschen ist, ${ }^{65}$ konzentriert sich Hobbes nur auf den letzteren, d.h. auf den Punkt, der ihn wirklich interessiert.

Wir haben schon gesehen, wie die Gesetze Gottes mit den Gesetzen der Natur gleich sind. Das wichtigste Naturgesetz (offensichtlich nachdem wir den Naturzustand schon verlassen haben) ist, ,dass wir unsere Treuepflicht nicht verletzen sollen, das heißt ein Gebot, unseren bürgerlichen Souveränen zu gehorchen, die wir über uns durch gegenseitigen Vertrag [...] eingesetzt haben“"66. Der Gehorsam ,gegen alle bürgerliche Gesetze, in denen auch alle Gesetze der Natur enthalten sind, das heißt alle göttlichen Gesetze ${ }^{67}$, ist somit alles, was zur Errettung der Seele notwendig ist wohl bemerkt: neben dem innerlichen, unsichtbaren und privaten Glauben an Christus. Schrittweise ist Hobbes zur Behauptung gelangt, die Befehle des Souveräns, welche die Form bürgerlicher Gesetze annehmen, seien göttliche Befehle und als solche zu befolgen! Die Religion ist daher in erster Linie eine staatliche Religion, bei welcher der bürgerliche Souverän als „der oberste Priester“68 ${ }^{\text {"d }}$ über Kultus und Formen der Verehrung Gottes entscheidet. Darüber hinaus findet hier eine Identifikation des Kultus Gottes mit dem Kultus des Souveräns statt; seine Befehle sind nicht einfach Ausdruck seines Willens, sondern gleichzeitig Ausdruck des Willens Gottes. Wer dem Souverän nicht gehorcht, macht sich des Ungehorsams gegen Gott schuldig.

Hobbes hat Machiavellis Idee der Religion als instrumentum regni konsequent angewandt und dem bürgerlichen Souverän einen Gott ähnlichen Stellenwert in den Augen der Untertanen zugeschrieben. Der Untertan soll nicht nur zur Erfüllung seiner bürgerlichen Pflichten durch Hinweis auf abgelegte Eide oder durch Androhung göttlichen Zorns bzw. Versprechen göttlicher Gunst bewegt werden; seine Verpflichtungen gegenüber dem

64 Vgl. ebd., S. 447.

65 Vgl. ebd., S. 458.

66 Ebd., S. 448.

67 Ebd., S. 457.

68 Ebd., S. 449. 
Staat sollen ihm vielmehr als Verpflichtungen gegenüber Gott präsentiert werden. Wer sie nicht erfüllt, verliert sein Seelenheil.

Die Religion stellt daher ein wichtiges Instrument für den Souverän dar, um die Meinungen der Untertanen besser zu kontrollieren, und um sich ihren Gehorsam zu sichern: Nicht zufällig stellt das berühmte Titelblatt des Leviathan diesen als einen Riesen dar, der in den Händen die Zeichen weltlicher und geistlicher Macht, nämlich ein Schwert und einen Bischofsstab, hält. Der Souverän zwingt durch beide Mittel die Untertanen zu gehorchen: Er droht ihnen mit der irdischen Strafe seiner unwiderstehlichen Gewalt und mit der jenseitigen Strafe durch Gottes Urteil. Wer glaubt, der Bestrafung durch den Souverän entkommen zu sein, wird im Jenseits eine bittere Enttäuschung erleben.

Der Rekurs auf die Religion als instrumentum regni ist eine notwendige Folge von Hobbes' prudentiellem Ansatz. Die Macht des Souveräns beim Zügeln seiner Untertanen und bei der Kontrolle ihrer Handlungen und ihrer Meinungen ist beschränkt. Die Vernunft zeigt uns zwar, wie wir deshalb bestimmte Tugenden entwickeln müssen, aber ihre Macht auf die Menschen ist begrenzt: Zwar werden vernünftige Menschen und Individuen mit gutem Charakter ihren Weisungen folgen, aber es wird immer genügend Störenfriede geben. Daher bleibt nur der Rekurs auf Gott, vor dem sich alle fürchten, denn seine Gewalt ist im Unterschied $\mathrm{zu}$ derjenigen des Souveräns uneingeschränkt und sein Urteil unfehlbar. Hobbes' Theorie der Religion stellt daher ein notwendiges Moment seines Modells dar, und es ist erstaunlich, dass ihr in dieser Form viele Interpreten nur wenig Aufmerksamkeit schenken. Nicht erstaunlich ist es im Gegenteil, dass die Frage der politischen Rolle der Religion und ihrer eventuellen Notwendigkeit für die politische Gemeinschaft immer noch ein wichtiges Thema ist.

Im Zusammenhang der politischen Bedeutung der Religion soll auch die extrem wichtige Rolle, die Hobbes der Erziehung des Volkes durch den Souverän zumisst, erwähnt werden. Sie gilt sogar als eine seiner Hauptaufgaben. Fast das gesamte 30. Kapitel, das der „Aufgabe der souveränen Vertretung“ gewidmet ist und einen regelrechten Fürstenspiegel darstellt, beschäftigt sich mit jenem Problem. Diese Erziehung ist notwendig, denn nur von ihr ist die Ausrottung der Ursachen des Krieges der Meinungen zu erwarten. Er entsteht, wie erwähnt, entweder aus der Ambition und Bösartigkeit mancher Individuen, oder aus der politischen Ignoranz der Massen heraus, meistens jedoch aus der Kombination der beiden Ursachen. Wird 
die zweite beseitigt, verliert die erste an Bedeutung, da die Unruhestiftenden nicht mehr darauf zählen können, die Masse an sich ziehen zu können.

Hobbes' Position erweist sich als weniger misstrauisch gegenüber den intellektuellen Fähigkeiten des gemeinen Volkes als die vieler anderer klassischer Autoren. Er stellt fest, dass sich viele „von dem bestechenden Wort ,Freiheit‘ leicht täuschen“ lassen, und „dieser Irrtum noch durch die Autorität von Leuten, die wegen ihrer Schriften über diesen Gegenstand berühmt sind, bestärkt" wird. Es ist also „kein Wunder, wenn daraus Aufruhr und Staatsumwälzungen entstehen “69. Allerdings schreibt Hobbes den Irrtum weniger dem Volk, als vielmehr den reichen und gebildeten Untertanen zu. Dabei übernimmt er Argumente der republikanischen Tradition, allen voran die Gefahr der Abhängigkeit der Armen von den Reichen:

„Mächtige Menschen verdauen kaum etwas, das eine Macht zur Zügelung ihrer Begierden errichtet, und Gelehrte nichts, was ihre Irrtümer aufdeckt und dadurch ihre Autorität schmälert, während der Verstand des gemeinen Volkes, wenn er nicht durch die Abhängigkeit von Mächtigen befleckt oder mit den Ansichten ihrer Doktoren vollgekritzelt ist, einem reinen Papier gleicht, dazu geeignet alles aufzunehmen, was ihm von der öffentlichen Gewalt aufgedrückt wird.“70

Hobbes führt hier kein richtiges Argument ein, sondern bedient sich eher rhetorischer Mittel. So fragt er: Wenn nun „ganze Völker dazu gebracht“ werden, „die großen Mysterien der christlichen Religion hinzunehmen, die über der Vernunft stehen“; oder wenn Millionen Menschen dazu gebracht werden, Sachen zu glauben, die der Vernunft gar widersprechen; wie sollte es denn nicht möglich sein, ,durch gesetzlich geschützte Lehre die Anerkennung dessen zu bewirken, was mit der Vernunft so sehr übereinstimmt, dass es jeder vorurteilslose Mensch schon lernt, wenn er es nur hört?"“11

Es ist nicht so, als habe Hobbes die Zweifel vergessen, die er in den vorangegangenen Kapiteln in Bezug auf die Rationalität der Menschen und auf die Kraft der Vernunft geäußert hatte: Er glaubt nicht, die Individuen könnten dazu gebracht werden, die Weisungen der Vernunft von sich selbst aus anzuerkennen - wie im Fall der gläubigen Massen. Er meint jedoch, das

69 Ebd., S. 167.

70 Ebd., S. 257.

71 Ebd. 
Gesetz sei imstande, diese Anerkennung zu bewirken. Wie soll das geschehen?

Erstens durch das Verbot der „falschen“" Lehren. Und zweitens durch die ständige Behauptung der „,wahren“ Lehre: Wird eine Lehre lang genug und mit Autorität wiederholt, wird sie auch von den Menschen als Wahrheit angenommen. Nicht dass Hobbes meint, alle Menschen werden dadurch zu „vorurteilslosen“ Richtern; er glaubt vielmehr, sie würden sich einfach durch Gewohnheit (eine durch Wiederholung hergestellte Gewohnheit) von der Wahrheit der offiziellen Lehre überzeugen lassen. Was Hobbes auf diesen Seiten anbietet, ist ein regelrechter politischer Katechismus in Form eines Fürstenspiegels. Er weist dem Souverän den Weg, um die Untertanen jene Lehre anerkennen zu lassen, die Friede, Sicherheit und Stabilität garantiert. Und er macht aus solcher erzieherischen Tätigkeit eine Pflicht für den Souverän, ${ }^{72}$ denn würde er jene vernachlässigen, würde der Boden für den Krieg der Meinung (also für das Ende des Friedens) wieder fruchtbar.

Der politische Katechismus enthält zehn Artikel. Diese werden von Hobbes als „Gebote“ bezeichnet, obwohl sie eher Verbote darstellen. Diese Bezeichnung resultiert aus Hobbes' Absicht, sie auf die biblischen zehn Geboten zu modellieren (dies betont noch einmal die enge Beziehung von Religion und Politik) und zwar nach dem folgenden Muster:

- Bibel: Du sollst keine anderen Götter neben mir haben!

Hobbes: Verbot des Vergleichs des eigenen politischen Systems mit demjenigen der Nachbarvölker.

- Bibel: Du sollst dir kein Bildnis ... machen!

Hobbes: Verbot der übermäßigen Ehrung von Individuen oder Gruppen (Hobbes spricht von Versammlungen und denkt wahrscheinlich ans englische Parlament) bzw. Verbot der Gleichsetzung dieser Individuen oder Gruppen mit dem Souverän.

- Bibel: Du sollst den Namen des HERRN ... nicht missbrauchen! Hobbes: Verbot der Kritik des Souveräns.

- Bibel: Gedenke des Sabbattages, dass du ihn heiligest!

Hobbes: Gebot der Teilnahme an Versammlungen, ,in denen das Volk nach Gebeten und Lobpreisungen Gottes, des Souveräns aller

72 Vgl. ebd. 
Souveräne, Vorträge über seine Pflichten anhören kann““73; kurz: Gebot der Teilnahme an Sitzungen des politischen Katechismus.

- Bibel: Du sollst deinen Vater und deine Mutter ehren!

Hobbes: Gebot der Dankbarkeit den Eltern gegenüber, da diese die

Fürsorge für die erste Unterrichtung der Kinder haben, somit verantwortlich dafür sind, dass die Kinder Gehorsamkeit lernen.

- Bibel: Du sollst nicht töten!

Hobbes: Verbot des Mordes und der Verstümmelung sowie der Privatrache.

- Bibel: Du sollst nicht ehebrechen!

Hobbes: Verbot der Verletzung der ehelichen Ehre.

- Bibel: Du sollst nicht stehlen!

Hobbes: Verbot der Verletzung fremden Eigentums durch Raub und Betrug.

- Bibel: Du sollst nicht falsch Zeugnis reden!

Hobbes: Verbot der Bestechung von Richtern oder Zeugen.

- Bibel: Du sollst nicht begehren ... alles, was dein Nächster hat!

Hobbes: Verbot aufrührerischer Pläne und Absichten (,Ungerechtigkeit besteht ebenso sehr in der Niedrigkeit des Willens wie in der Rechtswidrigkeit der Handlung،"74).

Die im Namen des sterblichen Gottes Leviathan erlassenen zehn Gebote sollen von Geistlichen und Gelehrten verkündet werden. Diese beziehen jedoch ihr Wissen von ,den Universitäten, den Juristenschulen oder den Büchern, die von hervorragenden Leuten dieser Schulen und Universitäten veröffentlicht wurden “75. Es ist daher zur Erziehung des Volkes notwendig, die Erziehung an den Universitäten zu kontrollieren, um sicher zu sein, dass dort nur die Lehren vertreten werden, welche die staatliche Stabilität sichern. Verboten wird hingegen das Lehren jener Theorien, die „mit der Natur des Staates unverträglich sind“676 und im Kap. 29 aufgelistet werden. Verbunden mit der Frage der Volkserziehung ist schließlich die Frage nach der Religion, wie wir schon gesehen haben.

73 Ebd., S. 259.

74 Ebd., S. 260.

75 Ebd., S. 261.

76 Ebd., S. 248. 


\section{Ein Republikanischer HobBes?}

Dass bei Hobbes politische oder gar Bürgertugenden aufzufinden sind, lässt die Frage entstehen, ob und inwieweit er als republikanischer Denker angesehen werden kann (gegen eine weit verbreitete Lesart, die aus ihm einen proto-liberalen Denker macht ${ }^{77}$. Ein Vergleich mit klassischen Republikanern mag dabei helfen. Alle diese Autoren - von Cicero bis Machiavelli und später Rousseau - halten bekannterweise Bürgertugenden für ein entscheidendes Moment für die Stabilität der Republik. Sie vertreten dabei genau wie Hobbes die Auffassung, der Staat dürfe auf das Privatleben der Bürger soweit Einfluss nehmen, wie es für die Sicherheit der Republik selbst notwendig ist. Sie sehen jedoch den Hauptzweck solcher Tugenden darin, die Liebe zur Freiheit zu fördern - Freiheit als Unabhängigkeit von der Willkür anderer. Durch die Entwicklung ziviler Tugenden lernen die Bürger ihre politische Unabhängigkeit zu schätzen - was eher im Widerspruch zu Hobbes' Position zu stehen scheint, nach der die erste Tugend der Untertanen die Gehorsamkeit gegenüber dem Willen des Souveräns sein sollte. ${ }^{78}$ In der Tat ist der Widerspruch weniger stark als angenommen: Bei Hobbes werden die Untertanen aufgefordert, auch andere Tugenden als die der Gehorsamsbereitschaft zu entwickeln - und zwar aus wohlüberlegtem Eigeninteresse, nicht aus bloßem Respekt vor der souveränen Autorität und deren Befehlen.

Hobbes scheint andererseits genuin liberal zu sein, wenn er behauptet, der Souverän dürfe auf keinen Fall den Untertanen bestimmte innere Haltungen gebieten: Seine Macht beschränkt sich vielmehr auf die (äußeren) Handlungen. Damit geht Hobbes über Machiavellis einfache Alternative ,Politik vs. Moral' hinaus und führt eine wichtige Unterscheidung zwischen Recht und Moral ein, die später bei Kant seine eindeutigste Theoretisierung finden wird (um dann bei Hegel durch die Annahme einer unterschiedlichen Perspektive partiell wieder aufgehoben zu werden). Zwar ließen sich

$77 \mathrm{Zu}$ Hobbes als Republikaner vgl. Quentin Skinner: Hobbes and Republican Liberty, Cambridge 2008.

78 Das entspricht auch der Meinung von Dietz: „Insofar as the virtues of Hobbes' citizen cultivate a disposition toward obedience to Leviathan, they conspire to deprive the citizen of precisely the sort of liberty that distinguished classical republicanism.“" (Dietz, Hobbes's Subject as Citizen, 1990, S. 113) Sie betont gleichzeitig auch, dass ,the argument for civic virtues needs not to be the exclusive possession of the classical republican“ (ebd., S. 114). 
politische oder soziale Handlungen nicht durch die herkömmlichen (allen voran: christlichen) moralischen Maßstäbe beurteilen: wer z.B. gemäß dem Gebot der Nächstenliebe im Naturzustand leben möchte, würde sofort zugrunde gehen, weil ihn die Mitmenschen vernichten würden (und das gilt umso mehr für den Souverän in den Beziehungen zu anderen Souveränen, denn damit würde er das Leben seiner eigenen Untertanen ins Spiel setzen). Daher sind all die natürlichen Gesetze, die ein friedliches Zusammenleben fordern, einfache Weisungen der Vernunft, die zunächst nur zum Wunsch verpflichten, sie mögen gelten, sprich: allgemeine Akzeptanz und Befolgung finden. Sie werden zu moralischen Normen nur im Moment, in dem die Individuen den Naturzustand verlassen und sich in die zivile Gesellschaft begeben: dann werden sie durch den Willen des Souveräns zu Gesetzen und somit zu Kriterien des Guten und des Bösen - und zwar im moralischen, sprich: sozio-politischen, nicht im ethischen: sprich: individualistischen Sinne. Durch diese Unterscheidung von Moral und Ethik wird jener Unterschied angesprochen, den Machiavelli zwischen Politik und Moral, Kant zwischen Recht und Ethik treffen. Es geht mit anderen Worten um zwei Bereiche menschlicher Handlungen, die Normen unterschiedlicher Art unterstehen, daher jeweils andere Bewertungsmaßstäbe haben. Hobbes' politische Tugenden stellen somit keineswegs ein unerlaubtes Eindringen moralischer Werte in die Politik, sondern eine Übersetzung traditioneller moralischer Tugenden ins Politische dar, die gleichzeitig deren vollkommene Umwandlung bedeutet: sie hören auf, moralische Haltungen zu sein und werden zu zentralen Elementen des politischen Lebens, das seinerseits keinen anderen Zweck kennt, als ein sicheres, angenehmes Leben für die Individuen zu garantieren, ohne an ihrer ethischen Vervollkommnung im geringsten interessiert zu sein.

Liberale und republikanische Momente gehen somit bei Hobbes ineinander über (ein Beweis, dass die strikte Trennung beider Denktraditionen nur um den Preis von idealisierenden Verallgemeinerungen möglich ist, denen in der Geschichte des politischen Denkens kaum ein konkretes Beispiel entspricht). Die Untertanen müssen zwar Bürgertugenden entwickeln, aber nur weil dies für die Erhaltung von Frieden und für ein angenehmes Leben erforderlich ist. Der Staat kümmert sich um ihre Meinungen nur insoweit, als diese den inneren Frieden beeinträchtigen. In jeder anderen Hinsicht bleiben sie frei, gemäß den eigenen ethischen Werten zu leben. Die Bürgertugenden sind andererseits nicht bloß ein zusätzliches Moment 
eines gelungenen politischen Zusammenlebens, sondern bilden einen notwendigen Bestandteil davon. Deswegen sieht Hobbes ein weiteres Instrument vor, um die Untertanen dazu zu bewegen, solche Tugenden zu entwickeln, nämlich: eine staatlich kontrollierte Form der Religion. Somit werden Themen aufgegriffen, die bis heute die politisch-theoretische Debatte beschäftigen. Dies beweist, wie aktuell das Denken eines klassischen Autors wie Hobbes auch nach 350 Jahren sein kann. 



\title{
Zur Kritik liberaler Ordnungsentwürfe
}

\author{
Bernard de Mandeville, Adam Smith, \\ Karl Marx und Alexis de Tocqueville
}

Julia SCHulze WeSSEL

Eitelkeit, Luxus und überflüssiger Reichtum gelten in politischen Ordnungen gemeinhin nicht als vorzugswürdige Eigenschaften. Vom Gegenteil war Bernard de Mandeville überzeugt, der 1705 über die Tugendhaftigkeit des Lasters schrieb und damit für große Empörung sorgte. Die in dieser Zeit als schädlich und untugendhaft geltenden, lediglich durch den egoistischen Eigensinn motivierten Handlungen erklärte Mandeville zu den produktiven Prinzipien einer neuen politischen Ordnung. Wenn auch in kritischer Distanz zu Mandeville, so übernahm Adam Smith die Idee, das egoistische und Eigeninteressen verfolgende Individuum zum Motor der Dynamik und des Wohlstandes der Nationen zu machen. Dagegen sahen Karl Marx und Alexis de Tocqueville den Individualismus als Gefahr demokratischer Ordnung an.

In diesem Aufsatz möchte ich im ersten Teil zeigen, wie Mandeville und Smith den zeitgenössischen Tugenddiskurs zum Interessendiskurs verschieben. Dabei greifen sie auf die Transzendenzfigur von der Natur des Menschen zurück, um das Individuum als dynamisches Prinzip einer marktrationalen Gesellschaft behaupten zu können. Die kurze Rekonstruktion dieser Argumentation dient als Kontrastfolie für den zweiten Teil des Aufsatzes: Karl Marx und Alexis de Tocqueville haben unterschiedlich auf diese Einführung des marktrational handelnden Individuums als Ausgangspunkt der Ordnungslegitimation reagiert. Ihre Kritik an den Geltungsbehauptungen dieser von Smith und Mandeville entworfenen Ordnung wird 
im zweiten Teil dargestellt. Beide unterstreichen die Brüchigkeit einer auf die Rationalität des Marktes und auf das egoistische Individuum ausgerichteten Ordnung, die allein keine dauerhaften Bindungen hervorzubringen imstande seien. Mit Verweis auf Transzendenzfiguren wie die Geschichte, das Wesen des Menschen, seine Autonomie und Gott demontieren sie die liberalen Geltungsbehauptungen. Gleichzeitig aber begründen sie mit genau diesen Argumenten neue Ordnungsarrangements. Die Marktordnung tritt ihren Vorrang an eine radikaldemokratische Ordnung (Marx) beziehungsweise eine liberal-demokratische Rechtsordnung (Tocqueville) ab.

\section{Bernard de MANDEVILLE Und AdAm Smith: DAS INDIVIDUUM ALS DYNAMISCHES PRINZIP DER GESELLSChAFT}

Bernard de Mandeville veröffentlicht die Bienenfabel in einer Zeit, als sich in London verschiedene Organisationen zur „Reformation of Manners“"1 etablieren. Sie entspringen dem Wiedererwachen religiöser Lehren, die im Glauben das Fundament der Gesellschaft erblicken. Laster wie Stolz, Habgier und Luxus galten als Sünde, die den gesellschaftlichen Zusammenhalt unterminierten. ${ }^{2}$ Mandeville entwirft mit seiner Bienenfabel ein Gegenmodell zu diesem Tugenddiskurs. Dabei setzt er sich mit der Metapher des Bienenstocks von verschiedenen Traditionen ab, um eine Gesellschaft zu entwerfen, in der die Laster in Tugenden und die Tugenden in Laster umgewertet werden. Hatte Aristoteles noch die Gemeinsamkeit zwischen Menschen und Bienen herausgestrichen, indem er beiden ein soziales Aufeinanderbezogensein attestiert, ${ }^{3}$ so wendet sich bereits Hobbes gegen diese Tradition und behauptet, gegen Aristoteles gerichtet, die antisoziale Ausrichtung des Menschen. Hobbes stellt den Menschen gegen die Bienen und Ameisen und führt den Menschen als Konkurrenzwesen ein, der im ständigen Wettkampf mit seinesgleichen liegt. Die Handlungen des Menschen sind in diesem Sinne immer egoistische, auf sich bezogene Handlungen. Im Gegensatz zum Menschen lässt sich Privatwohl und Gemein-

1 Thomas A. Horne: The Social Thought of Bernard Mandeville. Virtue and Commerce in Early Eighteenth-Century England, New York 1978, S. 1.

2 Ebd., S. 1-5.

3 Aristoteles: Politik, 4. Aufl., übersetzt und hrsg. von Eugen Rolfes, Hamburg 1981, S. 4 (1253 a). 
wohl bei Bienen und Ameisen nicht trennen: „[D]a sie [die Bienen, JSW] von Natur aus ihr privates Wohl anstreben, fördern sie dadurch das Gemeinwohl."4 Diese Idee übernimmt Mandeville in der Bienenfabel und überträgt sie auf die menschliche Gesellschaft. Er führt den Menschen als ein von Natur aus mit Selbstliebe ausgestattetes Wesen ein, das sein Leben dem Kosten-Nutzen Kalkül unterwirft. Die Natur des Menschen wird bei ihm so zur präpolitischen Voraussetzung, von der aus die Gesellschaftsordnung abzuleiten ist. Der Behauptung des menschlichen Sollens stellt er die Behauptung des menschlichen Seins gegenüber: „Einer der Hauptgründe, warum so wenige Menschen über sich selbst im klaren sind, ist der, daß die meisten Schriftsteller ihnen immer nur auseinandersetzen, wie sie sein sollen, und sich kaum jemals darum kümmern, ihnen zu sagen, wie sie in Wirklichkeit sind. "5 Mandevilles Ausgangspunkt ist also die Transzendenzfigur der menschlichen Natur, der „Menschen schlechthin“6 ${ }^{\text {, }}$, die ihm als das Grundmovens aller menschlichen Tätigkeiten erscheint. ${ }^{7}$

Mandeville stellt der These von der Natur des Menschen, die auf der Anerkennung der privaten Nutzenmaximierung basieren soll, die Künstlichkeit der republikanischen und christlichen Tugendanforderungen entgegen. ${ }^{8}$ Diese werden von ihm als Trick der herrschenden Klasse dargestellt. Deren Ziel sei es, die Gesellschaft zu zivilisieren und zu ihrem eigenen Vorteil leichter regieren zu können. ${ }^{9}$

Mandeville demontiert in der Bienenfabel die hohen Tugenderwartungen an die Bürger und kehrt die vorherrschende Meinung über gemeinsinnsfördernde Tugenden und gemeinsinnszerstörende Laster in ihr Gegenteil. Denn keineswegs sei es so, dass Tugenden förderliche Wirkungen er-

4 Thomas Hobbes: Leviathan. Oder Stoff, Form und Gewalt eines kirchlichen und bürgerlichen Staates [1651], hrsg. von Iring Fetscher, Neuwied/Berlin 1966, S. 133.

5 Bernard de Mandeville: Die Bienenfabel oder private Laster, öffentliche Vorteile [1705-1714], eingeleitet von Walter Euchner, 2. Aufl., München 1980, S. 93 (Hervorhebung im Original).

6 Ebd., S. 93.

7 Heinz-Gerd Schmitz: Das Mandeville-Dilemma. Untersuchungen zum Verhältnis von Politik und Moral, Köln 1997, S. 74.

8 Horne, Social Thought, 1978, S. 14.

9 „Daraus erhellt, daß die ersten Ansätze von Sittlichkeit geschickten Politikern zu verdanken sind, die danach strebten, die Menschen sich gegenseitig nützlich sowie überhaupt lenkbar zu machen, damit nämlich die Ehrgeizigen Vorteil daraus ziehen und größere Mengen von ihnen bequemer und sicherer regieren könnten.“ (Mandeville, Bienenfabel, 1980, S. 98) 
zeugten: „Übergroße Nächstenliebe fördert meist Trägheit und Müßiggang und leistet kaum etwas für ein Staatswesen, als Nichtstuer hervorzubringen und den Fleiß zu zerstören.“" ${ }^{\text {10 }}$ Das individuelle Eigeninteresse wird hingegen bei Mandeville zum produktiven Prinzip der ökonomischen Ordnung gewendet: Das nutzenmaximierende egoistische Kalkül des Individuums erscheint als neue Tugend; nicht mehr die ,alten` Tugenden, sondern die Laster wirken bei Mandeville produktiv für den Wohlstand der Nation; der Drang nach Luxus, die Habgier des Menschen, sein Neid und sein Drang, von anderen Menschen anerkannt und geachtet zu werden, wirken nicht mehr gemeinschaftszerstörend. Sie bilden nun die neuen tugendhaften Voraussetzungen einer wirtschaftlich blühenden Nation.

Laster suchten nach mittelalterlicher Metaphorik das Dunkel, Tugenden das Licht. Es war Zeichen einer guten Obrigkeit, dass sie nichts im Verborgenen halten musste. ${ }^{11}$ Mandeville kehrt die Begriffe in ihr Gegenteil und demontiert so den Tugenddiskurs. Die guten, tugendhaften Regierungen werden bei ihm zur schlechten Regierung, die sich selbst lediglich als tugendhaft behaupten, um ihre wahren Interessen im Verborgenen zu halten. Das Licht der Tugenden führt bei Mandeville zur Verblendung. Der Vorteil und der Wohlstand der Nation entspringt grenzenlosen Wünschen und Luxusstreben, ${ }^{12}$ die durch eine kluges Institutionenarrangement und eine kluge Regierung gesteuert und eingehegt werden. ${ }^{13}$ Damit greift Mandeville in den damalig herrschenden Auseinandersetzungen um den Glauben , in government from the hand of God ${ }^{\text {“14 }}$ der Jacobiten und einen vorpolitischen Tugenddiskurs der Whigs ein. Dem stellt er die Funktionalität von Herrschaft gegenüber. ${ }^{15}$

Während Mandeville diese Diskursverschiebung mit ironischen, teilweise sarkastischen Elementen begleitet, verfolgt Smith einen anderen An-

10 Ebd., S. 250.

11 Lucian Hölscher: Öffentlichkeit, in: Otto Brunner/Werner Conze/Reinhart Koselleck (Hrsg.): Geschichtliche Grundbegriffe. Historisches Lexikon der politischsozialen Sprache in Deutschland, Bd. 4, Stuttgart 1978, S. 413-467, hier: S. 416.

12 Thomas A. Horne: Envy and Commercial Society. Mandeville and Smith on ,Private Vices, Public Benefits', in: Political Theory 9 (1981) 4, S. 551-569, hier: S. 557.

13 Mandeville, Bienenfabel, 1980, S. 222f. und S. 377.

14 John A.W. Gunn: Beyond Liberty and Property. The Process of SelfRecognition in Eighteenth-Century Political Thought, Québec 1983, S. 102.

15 Gunn, Beyond Liberty and Property, 1983, S. 102. 
satz. So greift er zum einen durch seine moralphilosophische Abhandlung der Moral Sentiments und seiner nationalökonomischen Schrift The Wealth of Nations in die damaligen Diskurse über Tugend und Moral ein und behauptet zum anderen gleichzeitig die Interessenorientierung des Individuums als unverfügbare Legitimationsgrundlage einer marktrationalen Gesellschaft. Im Gegensatz zu Mandeville verbindet Adam Smith Moralphilosophie und Gesellschaftstheorie. Der erste Satz der Theorie der ethischen Gefühle richtet sich indirekt gegen Mandevilles Entwurf vom egoistischen Menschen: „Mag man den Menschen für noch so egoistisch halten, es liegen doch offenbar gewisse Prinzipien in seiner Natur, die ihn dazu bestimmen, an dem Schicksal anderer Anteil zu nehmen, und die ihm selbst die Glückseligkeit dieser Anderen zum Bedürfnis machen. “16 Die Umkehrung von Lastern in Tugenden hat Smith einer deutlichen Kritik unterzogen, indem er die Transzendenzfigur der menschlichen Natur umdeutet. Der Mensch ist bei ihm nicht nur von Natur aus interessengeleitet, sondern ebenso immer auch auf den anderen bezogen.

Zum einen ist bei ihm ein rein funktionales Bezogensein auf den Anderen in der Idee der allseitigen Abhängigkeit der nutzenmaximierenden homines oeconomici zu finden. Das führt er vor allem im Wohlstand der Nationen aus. Zum anderen gibt es jedoch auf der individuellen Ebene den Wunsch nach Zustimmung und Anerkennung durch die Mitmenschen. ${ }^{17}$ So entdeckt Smith ebenso im Menschen eine grundsätzliche Fähigkeit, mit Anderen mitzufühlen und ein grundsätzliches Bedürfnis, von Anderen anerkannt zu sein. Er zieht daraus den normativen Schluss, dass „,der Mensch nur in Gesellschaft bestehen“"18 kann. Der Gemeinschaft wird damit ein anderes Fundament verliehen als bei Mandeville. Diese Bezogenheit auf den Anderen fasst Adam Smith in seinen Begriffen der „Sympathie“ und des ,unparteiischen Beobachters“. In der Theorie der ethischen Gefühle verweist Smith auf die dem Vorstellungsvermögen ${ }^{19}$ entspringende Fähig-

16 Adam Smith: Theorie der ethischen Gefühle [1790], hrsg. von Horst O. Brandt, Hamburg 2010, S. 5.

17 Albert O. Hirschman: Leidenschaften und Interessen. Politische Begründungen des Kapitalismus vor seinem Sieg, 2. Aufl., Frankfurt a.M. 1984, S. 118.

18 Weiter heißt es bei Smith, Ethische Gefühle, 2010, S. 137: „Alle Mitglieder der menschlichen Gesellschaft bedürften des gegenseitigen Beistandes.“

19 Michael Aßländer: Die moralphilosophischen Grundlagen der Ökonomie bei Adam Smith, in: Wolfgang Kersting (Hrsg.): Freiheit und Gerechtigkeit. Die moralischen Grundlagen der sozialen Marktwirtschaft, Frankfurt a.M. u.a. 2010, 
keit des Menschen, den Standpunkt eines anderen Menschen übernehmen zu können. ${ }^{20}$ Diese Fähigkeit verbindet die Menschen untereinander, denn sie führt zum Mitgefühl, zur Sympathie, die ,in keinem Sinne als ein egoistisches Prinzip betrachtet werden" kann. ${ }^{21}$ Durch sie gelangen die Menschen zu Werturteilen über die Angemessenheit von Handlungen, Meinungen und Gefühlen. ${ }^{22}$

Auch Smith rekurriert auf den unverfügbaren Bezugspunkt der menschlichen Natur, um die wechselseitige Abhängigkeit der Menschen zu unterstreichen. Die Transzendenzfigur der ,Natur des Menschen', auf die ebenfalls Mandeville zurückgriff, wird durch die Transzendenzfigur, Gott ${ }^{*}$ bei Smith noch verstärkt. Denn der für den Menschen gut eingerichteten Ordnung legt Smith das Telos des planenden Schöpfergottes zugrunde. Die Glückseligkeit der Menschen als Gottes Endzweck wird der menschlichen Gestaltbarkeit entzogen. Sie wird zur Handlungsmotivation, an der alle Menschen durch ihr Verhalten beitragen sollten, so dass jeder zum „Mitarbeiter der Gottheit“" wird. ${ }^{23}$

Im Wohlstand der Nationen systematisiert er das in der Theorie der ethischen Gefühle bereits angelegte zweite Prinzip der menschlichen Natur: das Eigeninteresse. ${ }^{24}$ Es steht jedoch nicht im Gegensatz zur Sympathie, sondern beide Prinzipien der menschlichen Natur tragen zum Telos der Glückseligkeit bei. ${ }^{25}$ Smith führt das individuelle Streben nach Reichtum und Wohlstand als eine zentrale Eigenschaft des Menschen ein, die zum Gewinn Aller führe. Gleichzeitig ersetzt er die negativ konnotierten Begriffe von Leidenschaft und Laster durch Vorteil und Interesse. ${ }^{26}$ Das

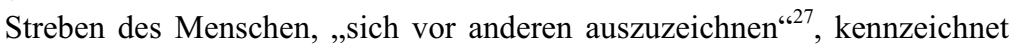

S. 117-138, hier: S. 120. Siehe auch: Horst Claus Recktenwald: Würdigung des Werkes, in: Adam Smith: Der Wohlstand der Nationen. Eine Untersuchung seiner Natur und seiner Ursachen [1789], hrsg. von Horst Claus Recktenwald, München 1978, S. XV-LXXIX, hier: S. XXXVIf.

20 Smith, Ethische Gefühle, 2010, S. 5-13.

21 Ebd., S. 519.

22 Karl Ballestrem: Adam Smith, München 2001, S. 60.

23 Smith, Ethische Gefühle, 2010, S. $264 \mathrm{f}$.

24 Aßländer, Moralphilosophische Grundlagen, 2010, S. 126.

25 Ebd., S. 125.

26 Hirschman, Leidenschaften, 1984, S. 27 und S. 118-122; Wolf Prieß: Vom Zweck des Nutzens. Sinn und Grenzen des Eigennutz-Paradigmas und das Rationale der Nützlichkeit, Norderstedt 2010, S. 91.

27 Smith, Ethische Gefühle, 2010, S. 292. 
Smith ähnlich wie Mandeville als Motor dieser Entwicklung. Der Marktmechanismus der Konkurrenz um das beste Produkt ist damit bei Smith nicht allein auf den Markt bezogen, sondern wird zum Prinzip der gesellschaftlichen Beziehungen der Menschen untereinander. Der Marktrationalität ,wohnt ein Versprechen inne“628, ein Versprechen auf einen sich selbst regulierenden, den Menschen der Verfügung entzogenen und zum Vorteile aller wirkenden Mechanismus, der die gesamte Gesellschaft umfasst. Somit entspricht die Gesellschaftsordnung der Ordnung des Marktes, die Marktrationalität ist auch bei Smith das vorherrschende Prinzip, das die Gesellschaft insgesamt strukturiert.

Auch bei Smith ist das individuelle Streben der interessengeleiteten Nutzenmaximierer das produktive Prinzip der marktrationalen Gesellschaft. ${ }^{29}$ Dabei kehrt Smith nicht wie Mandeville das Verhältnis zwischen Tugend und Laster um, sondern er entkoppelt die Konsequenzen aus tugendhaftem und aus lasterhaftem Verhalten. Tugendhaftes Verhalten bringt ebenso wenig per se eine gute Gesellschaft hervor, wie lasterhaftes Verhalten eine schlechte. Keine funktionierende Gesellschaft ist allein vom gemeinwohlorientierten und altruistischen Verhalten abhängig. ${ }^{30}$

Die egoistische Verfolgung der Interessen produziert so einen Überschuss, der der Allgemeinheit zugutekommt, ohne von den einzelnen Individuen beabsichtigt zu sein. Auf dieser Koppelung der individuellen Einstellung mit dem Wohlstand der Gesellschaft beharrten noch Hutcheson und Shaftesbury. ${ }^{31}$ Hutcheson führte die Lehre des „moral sense“ ein und verlegte die Anlage zur Gemeinschaftsbildung in das einzelne Subjekt, die zur Verfolgung der egoistischen Privatinteressen in Konkurrenz trat. ${ }^{32}$ Smith setzt sich von dieser Richtung der schottischen Aufklärung ebenso ab wie von Mandeville: von Hutcheson, weil er das individuelle Interesse

28 Harald Bluhm/Karsten Malowitz: Märkte denken, in: Berliner Debatte Initial 18 (2007) 6, S. 4-25, hier: S. 5.

29 Smith, Wohlstand der Nationen, 1978, S. 17f.

30 „Wohltätigkeit ist die Verzierung, die das Gebäude verschönt, nicht das Fundament, das es trägt und darum war es hinreichend, sie dem einzelnen anzuempfehlen, keineswegs jedoch nötig, sie zwingend vorzuschreiben." (Smith, Ethische Gefühle, 2010, S. 138)

31 Siehe dazu z.B.: Nicholas Phillipson: Adam Smith. An Enlightened Life, New Haven u.a 2010, S. 46-47 und S. 50.

32 Hölscher, Öffentlichkeit, 1978, S. 442. 
negiere, von Mandeville, der es überbetone. ${ }^{33}$ Dagegen setzt Smith die Figur der ,unsichtbaren Hand‘.

Die Metapher der unsichtbaren Hand war in seiner Zeit ein viel gebrauchtes geflügeltes Wort und war Ausdruck religiöser Überzeugungen, ${ }^{34}$ war also, bei vielen Bedeutungsverschiebungen seit der Antike, auch ,theologisch konnotiert ${ }^{* 35}$. Smith benutzt lediglich an zwei Stellen die Denkfigur der unsichtbaren Hand, beide Male in ökonomischen Kontexten. ${ }^{36}$ In der Theorie der ethischen Gefühle will er begründen, warum egoistisches Verhalten, Gewinnsucht und Streben nach Ruhm der Gesellschaft insgesamt Nutzen bringen. Die unsichtbare Hand verwandelt das Laster in eine Tugend, ohne dass das Individuum aus diesem Prozess als tugendhaft hervorgehen müsste: Die Reichen, die „nur ihre eigene Bequemlichkeit vor Augen haben, obwohl der einzige Zweck [...] die Befriedigung ihrer eigenen eitlen und unersättlichen Begierden ist", teilen dennoch

„mit den Armen den Ertrag aller Verbesserungen, die sie in die Landwirtschaft einführen. Von einer unsichtbaren Hand werden sie dahin geführt, beinahe die gleiche Verteilung der zum Leben notwendigen Güter zu verwirklichen, die zustandegekommen wäre, wenn die Erde zu gleichen Teilen unter alle ihre Bewohner verteilt worden wäre; und so fördern sie, ohne es zu beabsichtigen, ja ohne es zu wissen, das Interesse der Gesellschaft und gewähren die Mittel zur Vermehrung der Gattung. ${ }^{\text {(37 }}$

Damit ersetzt Smith nicht das Gemeinwohl durch das Eigeninteresse. Stattdessen bringt das Eigeninteresse, geleitet von der unsichtbaren Hand, das Gemeinwohl und den Wohlstand der Nationen erst hervor. Sie leistet damit das, was dem Zugriff des Einzelnen entzogen ist. Der unsichtbare Marktmechanismus bekommt ,übermenschliche Qualität ${ }^{\text {‘38. }}$. Dieser Denkfigur liegt der Glaube an den menschlichen Fortschritt zugrunde. Denn es

33 Horne, Envy and Commercial Society, 1981, S. 560.

34 D. David Raphael: Adam Smith, Frankfurt a.M. 1991, S. 86. Siehe auch: Aßländer, Moralphilosophische Grundlagen, 2010, S. 131.

35 Bluhm/Malowitz, Märkte denken, 2007, S. 7.

36 Insgesamt im Werk an drei Stellen. Vgl. Thomas Rommel: Das Selbstinteresse von Mandeville bis Smith. Ökonomisches Denken in ausgewählten Schriften des 18. Jahrhunderts, Heidelberg 2000, S. 300. Im Essay The History of Astronomy ist diese Metapher noch eindeutig religiös aufgeladen.

37 Smith, Ethische Gefühle, 2010, S. 296 f.

38 Rommel, Selbstinteresse, 2000, S. 299. 
profitieren alle vom egoistischen Streben, weil es immer einen Überschuss gibt, der wiederum allen zugutekommt: ${ }^{39}$ Wenn jeder einzelne

„es vorzieht, die nationale Wirtschaft anstatt die ausländische zu unterstützen, denkt er eigentlich nur an die eigene Sicherheit und [...] strebt [...] lediglich nach eigenem Gewinn. Und er wird in diesem wie auch in vielen anderen Fällen von einer unsichtbaren Hand geleitet, um einen Zweck zu fördern, den zu erfüllen er in keiner Weise beabsichtigt hat. “40

Die unsichtbare Hand wird hier zum Prinzip der Gerechtigkeit und wirkt als transzendentes, unsichtbares Prinzip einer harmonischen Weltordnung hinter dem Rücken der Menschen. ${ }^{41}$ Sie ist das Gegenüber der sichtbaren Hand, die bei Smith mit konkreter Planung, mit Absichten und Lenkung verbunden ist. Der unsichtbare Marktmechanismus steht der „sichtbaren Hand des politischen Körpers" gegenüber. ${ }^{42}$

Die unsichtbare Hand kompensiert Tugend und Moral, kompensiert die negativen Auswirkungen der egoistischen Interessen. Die positiven gemeinwohlfördernden Ergebnisse individueller Handlungen stellen sich bei Smith jenseits des Wollens und Wissens der Handelnden her. Eine gut eingerichtete Gesellschaft macht sich so von der Einstellung ihrer Mitglieder unabhängig. Mit der unsichtbaren Hand beschreibt Smith die geheimen Wirkmechanismen einer freien Marktwirtschaft; einem verborgenen Lenker gleich, macht sie die Selbstregulation der Gesellschaft möglich. Aber anders als Mandeville hält Smith noch an „Restbeständen von Tradition, Moral und Religion“ als ,individuelle[s] Verhaltenskorrektiv“, ,,als Notnagel gesellschaftlicher Kohäsion" fest, ${ }^{43}$ allerdings sind sie ihrem transzendenten Überschuss des republikanischen und christlichen Tugenddiskurses entkleidet. In der marktrationalen Gesellschaft wirken für Smith

39 „Gerade das Streben nach seinem eigenen Vorteil ist es, das ihn ganz von selbst oder vielmehr notwendigerweise dazu führt, sein Kapital dort einzusetzen, wo es auch dem ganzen Land den größten Nutzen bringt." (Smith, Wohlstand der Nationen, 1978, S. 369)

40 Ebd., S. 371.

41 Aßländer, Moralphilosophische Grundlagen, 2010, S. 132.

42 Bluhm/Malowitz, Märkte denken, 2007, S. 8.

43 Hans Vorländer: Institution und Tugend. Zur Dialektik des Liberalismus, in: Joachim Fischer (Hrsg.): Kunst, Macht und Institution. Studien zur philosophischen Anthropologie, soziologischen Theorie und Kultursoziologie der Moderne. Festschrift für Karl-Siegbert Rehberg, Frankfurt a.M. 2003, S. 317-330, hier: S. 325. 
Tugenden wie Ö1 und Laster wie Rost. ${ }^{44}$ Das Laster sei immer auf die Störung, die Tugend auf die Aufdauerstellung und Sicherung der gemeinschaftlichen Ordnung ausgerichtet. ${ }^{45}$

Mit Mandeville und Smith kann also die gewichtige Diskursverschiebung vom Tugend- zum Interessendiskurs deutlich gemacht werden. Beide stellen die ökonomische, und nicht politische oder religiöse, Rechtfertigung politischer Ordnung in den Mittelpunkt ihrer Theorie. ${ }^{46}$ Der bewusst tugendhaft handelnde Bürger wird bei beiden durch den homo oeconomicus ersetzt, der seine Individualinteressen verfolgt und nicht tugendhaft zu handeln braucht, um dennoch zum Allgemeinwohl beizutragen. Smith führt dabei die Figur der „unsichtbaren Hand“, der „Sympathie“ und des „unbeteiligten Beobachters" ein, während Mandeville ungleich radikaler die den Tugenddiskurs tragenden Argumente in ihr Gegenteil verkehrt. Beide entwerfen eine auf Marktrationalität beruhende gesellschaftliche Ordnung, die durch das Individuum und seine Natur legitimiert ist. Während die klassischen republikanischen Theorien den Markt der Politik unterordneten, kehren beide dieses Verhältnis um. Der Markt setzt die Selbstregulierungskräfte der Gesellschaft frei.

Gegen die Ableitung der politischen Ordnung aus der Annahme eines einzelnen, rational und interessenorientiert handelnden Individuums haben sowohl Alexis de Tocqueville als auch Karl Marx ihre Demokratietheorie gestellt. Als Beobachter bereits etablierter demokratischer Ordnungen reagieren sie in ihren Schriften auf die Unverfügbarstellung des Individuums und seiner Natur bei Mandeville und Smith.

\section{KRITIK AN DER ZERSTÖRERISCHEN DYNAMIK DER INDIVIDUALISIERTEN GESELLSCHAFT: ALEXIS DE TOCQUEVILLE UND KARL MARX}

Während Mandeville und Smith den interessenorientierten Bürger noch mit hohem Aufwand theoretisch rechtfertigen, um sich von einem normativ aufgeladenen Tugenddiskurs abzusetzen, beschreiben und kritisieren Toc-

44 Smith, Ethische Gefühle, 2010, S. 517.

45 Ebd., S. 516-520.

46 Für Adam Smith siehe: Hirschman, Leidenschaften, 1984, S. 109. 
queville und Marx ${ }^{47}$ eine Gesellschaft, die bereits eine an den Interessen des Einzelnen ausgerichtete Ordnung sei. Tocqueville und Marx gehören zu den Beobachtern der liberalen Demokratie, an der beide die Gefahr atomisierter, privatistisch und egoistisch agierender Individuen betonen, in der jede Gemeinsinnsorientierung zu verschwinden droht und damit die Bindungszusammenhänge demokratischer Gesellschaften problematisch werden. Beiden gemein ist die Kritik an einer Gesellschaft, die in Individualinteressen gespalten ist und in der jeder Einzelne sein privates Glück zu finden versucht. Sie sehen durch den Individualismus die Gesellschaft einer Dynamik unterworfen, die selbstzerstörerisch ist.

Tocqueville und Marx teilen die Kritik an einer Gesellschaft, die durch die egoistische Interessenverfolgung der einzelnen Individuen geprägt ist. Beide sehen eine an der Marktrationalität ausgerichtete Gesellschaft einer gewaltigen Dynamik ausgesetzt. So begreift Tocqueville zwar auch die Möglichkeit des Aufstiegs als ein produktives Prinzip der neuen politischen Ordnung, kehrt jedoch auch die zerstörerischen Elemente heraus: „In der politischen Welt ist alles im Fluß, umstritten, ungewiß ${ }^{\text {*48 }}$, die tradierten Bande haben sich aufgelöst und setzen die Menschen der Gefahr des Individualismus aus. ${ }^{49}$

Diese Dynamik, wird sie nicht in Grenzen gehalten, wirke auf die Gesellschaft zerstörerisch. Hier ist sich Tocqueville mit Marx einig. Denn dessen Kritik gilt der sinnlosen Kapitalakkumulation, die die „Bourgeoisie über die ganze Erdkugel ${ }^{* 50}$ jagt. Durch die ständige Veränderung der Produktionsverhältnisse werden alle gesellschaftlichen Verhältnisse fortwährend revolutioniert, und so sieht Marx das Kennzeichen der bürgerlichen Gesellschaft in ebendieser unruhigen, prozesshaften und stürmischen Dynamik: „Die fortwährende Umwälzung der Produktion, die ununterbrochene Erschütterung aller gesellschaftlichen Zustände, die ewige Unsicherheit und Bewegung zeichnet die Bourgeoisepoche vor allen anderen aus. ${ }^{\text {“51 }}$

47 Für Karl Marx werden hier die Frühschriften herangezogen.

48 Alexis de Tocqueville: Über die Demokratie in Amerika [1835/1840], hrsg. von Jacob P. Mayer, 2. Aufl., München 1984, S. 50.

49 Ebd., S. 585-588.

50 Karl Marx/Friedrich Engels: Das Manifest der kommunistischen Partei [1848], in: MEW, Bd. 4, Berlin 1959, S. 465-493, hier: S. 465.

51 Ebd. 
In dieser Dynamik entdecken Marx und Tocqueville gleichermaßen die Gefahr der Angleichung, die Gefahr einer Despotie der Normierung, des Gleichmachens und Einebnens aller Differenzen, der Abspaltung der Individuen von der Gesellschaft. Tocqueville hat im Gegensatz zu Marx innerhalb der Demokratie die Möglichkeit gesehen, die Dynamik in Grenzen zu halten. Dementsprechend unterschiedlich sind ihre Perspektiven auf die liberale demokratische Ordnung. Während Tocqueville nach neuen Begründungen dieser Ordnung sucht und innerhalb der Demokratie bestimmte Prinzipien für unverzichtbar hält, um Freiheit zu stabilisieren, ist Marx der distanzierte Beobachter dieser Begründungen, die er durch seine Kritik gleichzeitig überwinden und deren Geltungsbehauptungen er demontieren will.

\subsection{Marx und die demokratische Ordnung}

\subsubsection{Die Demontage der Geltungsbehauptungen liberaler Demokratie}

Marx nennt Mandeville einen „ehrlichen Mann und hellen Kopf ${ }^{\text {‘52 }}$, ,der unendlich kühner und ehrlicher als die philisterhaften Apologeten der bürgerlichen Gesellschaft ${ }^{453}$ gewesen sei, denn er habe die Geltungsgründe der liberalen Gesellschaft wie kein Zweiter offen gelegt. Marx unternimmt es in seinen Frühschriften, diese Geltungsgründe liberaler Ordnungen radikal zu kritisieren. Als legitimatorischer Kern liberaler Ordnung erscheint Marx der „Individualismus“" ${ }^{\text {(54 }}$, der vereinzelte, von anderen getrennte Mensch. Für ihn ist dieser vereinzelte Mensch in der bürgerlichen Gesellschaft ein begründendes Prinzip der Gesellschaftsordnung, das, so die Kritik von Marx, in allen anderen Bereichen der Gesellschaft nur als bourgeois, und nicht als citoyen repräsentiert wird.

52 Karl Marx: Das Kapital. Kritik der politischen Ökonomie [1867], Bd. 1, Berlin 1989, S. 643.

53 Karl Marx: Abschweifung über produktive Arbeit [1862/1863], in: MEW, Bd. 26/1, S. 363-391, hier: S. 364.

54 Karl Marx: Kritik des Hegelschen Staatsrechts [1843], in: MEW, Bd. 1, Berlin 1957, S. 203-333, hier: S. 285. 
Zwar erkennt Marx die verbrieften liberalen Freiheiten als einen Fortschritt an, ${ }^{55}$ kritisiert sie jedoch auch als Privilegienrechte, die de facto nur dem Bürgertum zugutekommen, ${ }^{56}$ und unterzieht sie einer Fundamentalkritik. Dem bürgerlichen Recht insgesamt liegt die Behauptung zugrunde, die Mandeville noch versucht hatte zu etablieren, dass sich das Wesen des Menschen überhistorisch und gesellschaftlich unabhängig als das eines egoistischen Individuums bestimmen ließe. ${ }^{57}$ Das auf sich selbst zurückverwiesene Individuum sei der wahre Bestimmungsgrund der bürgerlichen $\mathrm{Ge}$ sellschaft. ${ }^{58}$ Die einzige zwischenmenschliche Beziehung, die die bürgerliche Gesellschaft den Menschen zu bieten habe, sei „das nackte Interesse, als die gefühllose , bare“ Zahlung“59.

Die Letztbegründung liberaler Demokratien findet Marx in der französischen Erklärung der Menschen- und Bürgerrechte paradigmatisch repräsentiert. In seinem Aufsatz Zur Judenfrage arbeitet er drei grundlegende Menschenrechte heraus, die allen anderen Rechten vorgängig seien und das ideologische Fundament der modernen Ordnungen bildeten: das Menschenrecht auf Freiheit, das Menschenrecht auf Gleichheit, das Menschenrecht auf Sicherheit. Freiheit meint nicht mehr als die Freiheit des Einzelnen, des von anderen abgesonderten Individuums. Die Gleichheit ist eine Gleichheit der Trennung von anderen Menschen und das Recht auf Sicherheit interpretiert Marx als „die Versicherung ihres Egoismus“60. Diese drei Rechte benennen Marx zufolge den einzigen Geltungsgrund der bürgerlichen Gesellschaft, dass nämlich, ,jeder Mensch gleichmäßig als solche auf sich ruhende Monade betrachtet wird. [...] Es ist das Recht dieser Absonderung, das Recht des beschränkten, auf sich beschränkten Individuums."61 Für Marx liegt hier das zentrale Kennzeichen der bürgerlichen Gesellschaft und

55 Karl Marx: Zur Judenfrage [1844], in: MEW, Bd. 1, Berlin 1957, S. 347-377, hier: S. 356.

56 Harald Bluhm: Freiheit in Marx' Theorien, in: Ingo Pies (Hrsg.): Karl Marx' kommunistischer Individualismus, Tübingen 2005, S. 57-80, hier: S. 60.

57 „Das egoistische Individuum der bürgerlichen Gesellschaft mag sich in seiner unsinnlichen Vorstellung und unlebendigen Abstraktion zum Atom aufblähen, d.h. zu einem beziehungslosen, selbstgenügsamen, bedürfnislosen, absolut vollen, seligen Wesen.“ (Karl Marx: Die heilige Familie [1845], in: MEW, Bd. 2, S. 7-223, hier: S. 127, Hervorhebung im Original)

58 Marx, Zur Judenfrage, 1957, S. 369 (Hervorhebung im Original).

59 Marx/Engels, Das Manifest, 1959, S. 464.

60 Marx, Zur Judenfrage, 1957, S. 365, 364, 366 (Hervorhebung im Original).

61 Ebd., S. 365, 364, 366 (Hervorhebung im Original). 
das sie strukturierende Prinzip. Denn der besitzindividualistische Egoismus findet seine funktionalen Äquivalente in den unterschiedlichen Institutionen der bürgerlichen Gesellschaft. ${ }^{62}$

Für Marx dienen sowohl der Gleichheits- als auch der Freiheitsbegriff nur der Verschleierung realer Unfreiheit und Ungleichheit. Es habe zwar noch nie eine Gesellschaft gegeben, die frei und gleich war, aber die bürgerliche Gesellschaft unterscheide sich von den vorangegangenen Ordnungen durch die behauptete Autonomie und Freiheit der Menschen, schaffe jedoch erneut Institutionen und Strukturen der Unfreiheit und Ungleichheit. Freiheit und Gleichheit werden bei Marx als „handlungsleitende Kategorien dechiffriert, die Teil der Selbstbeschreibung der bürgerlichen Gesellschaft sind“63. Er wendet die Idee einer von Gott abgeleiteten Volkssouveränität kritisch als Transzendenzbehauptung liberalen Denkens, das das Individuum zum höchsten Wesen erklärt habe:

„Christlich ist die politische Demokratie, indem in ihr der Mensch, [...] jeder Mensch, als souveränes, als höchstes Wesen gilt, aber der Mensch in seiner unkultivierten, unsozialen Erscheinung, [...] der Mensch, wie er durch die ganze Organisation unserer Gesellschaft verdorben, sich selbst verloren, veräußert, unter der Herrschaft unmenschlicher Verhältnisse und Elemente gegeben ist, mit einem Wort, der Mensch, der noch kein wirkliches Gattungswesen ist. “64

Die Spaltung zwischen dem irdischen Dasein und dem himmlischen Versprechen auf Erlösung wird in der bürgerlichen Gesellschaft in der Spaltung zwischen dem isolierten Bourgeois und dem allgemeinen Citoyen aufrechterhalten. ${ }^{65}$

62 Ansgar Klein: Zivilgesellschaft und Sozialkapital. Herausforderungen politischer und sozialer Integration, Wiesbaden 2004, S. 104. Claude Lefort (Politisches Denken im Angesicht der Menschenrechte, in: Trivium. Deutsch-Französische Zeitschrift für Geistes- und Sozialgeschichte 3 (2009), S. 1-13, hier: S. 13) hat der Marx'schen Interpretation der Menschenrechte als isolierende Rechte entgegengehalten, dass in diesen überhaupt erst die Möglichkeit begründet liegt, mit anderen in der Öffentlichkeit in Kontakt zu treten und sich damit über Normen und Werte, über den Gemeinsinn der politischen Ordnung zu verständigen. Menschenrechte, so sein Gegenentwurf zu Marx, sind immer auf den Anderen bezogene und somit gemeinschaftskonstituierende Rechte.

63 Bluhm, Freiheit, 2005, S. 59.

64 Marx, Zur Judenfrage, 1957, S. 360 (Hervorhebung im Original).

65 Ebd., S. 355 (Hervorhebung im Original). 


\subsubsection{Der Mensch als Gattungswesen}

In seiner Kritik an den liberalen Geltungsgründen wendet sich Marx demnach zum einen auf der inhaltlichen Ebene gegen den Versuch, den Menschen als egoistisches, interessengeleitetes Individuum zu bestimmen und zum anderen auf formaler Ebene gegen eine überhistorische natürliche oder wesensmäßige Bestimmung des Menschen. Er setzt dieser Behauptung das historisch Gewordene entgegen und zwar in doppelter Hinsicht. Denn so wie die Bestimmung der Natur immer abhängig war von dem jeweiligen gesellschaftlichen und politischen Kontext, so ist auch ,der Mensch“ eingebettet in die gesellschaftlichen Verhältnisse. Indem Marx die Behauptung einer essentialistischen Bestimmung des Menschen selbst als historisches Konstrukt darstellt, bricht er mit der Vorstellung, überhaupt über das Wesen des Menschen etwas aussagen zu können. ${ }^{66}$ Dagegen bindet er die liberale Argumentation an die historisch besondere Situation zurück. „Warum wird das Mitglied der bürgerlichen Gesellschaft ,Mensch', Mensch schlechthin, warum werden seine Rechte Menschenrechte genannt? Woraus erklären wir dies Faktum? Aus dem Verhältnis des politischen Staats zur bürgerlichen Gesellschaft, aus dem Wesen der politischen Emanzipation. “67

Die Marx'sche Kritik richtet sich gegen die Behauptung einer unverfügbaren Wesensbestimmung des Menschen schlechthin, denn ,in seiner Wirklichkeit ist es [d.h.: das Individuum, JSW] das Ensemble der gesellschaftlichen Verhältnisse“68. Mit dieser Kritik behauptet Marx den Menschen zunächst als historisch kontingentes Wesen. Was Mandeville noch versuchte, die Natur des Menschen als Argument gegen die bestehende Ordnung einzuführen, um sie der Debatte zu entziehen, macht Marx durch die Umkehrung wieder zu einem verfügbaren Gegenstand. Der Natur des Menschen als letztem, unverfügbarem Grund stellt Marx die grundsätzliche Historizität von Normen gegenüber. ${ }^{69}$ Menschenrechte spiegeln deswegen nicht die Natur des Menschen, sondern die konkrete historische Situation

66 Siehe dazu auch Andrea Maihofer: Das Recht bei Marx. Zur dialektischen Struktur von Gerechtigkeit, Menschenrechten und Recht, Baden-Baden 1992, S. $96 f$.

67 Marx, Zur Judenfrage, 1957, S. 365 (Hervorhebung im Original).

68 Karl Marx: Thesen über Feuerbach [1845], in: MEW, Bd. 3, Berlin 1969, S. 5-7, hier: S. 6. Siehe auch: Maihofer, Recht, 1992, S. 102f.

69 Vgl. dazu: ebd., S. 54f. 
der bürgerlichen Gesellschaft. ${ }^{70}$ Marx kehrt die liberale Argumentation in ihr Gegenteil: Nicht die Natur bestimmt die Ordnung, sondern die Ordnung behauptet die Natur zu ihrem eigenen Nutzen. Marx beharrt auf dem historischen Gewordensein dieser Geltungsgründe, die sich mit dem Wandel der Ordnung selbst wieder verändern.

Diese von Marx aufgerissene Lücke, seine radikale Öffnung liberaler Ordnungsbegründung, wird bei ihm jedoch selbst durch die Einführung des Begriffs des menschlichen Gattungswesens wieder geschlossen, das als Maßstab seiner Kritik an der bürgerlich individualisierten Gesellschaft fungiert. Dem egoistischen Menschen der bürgerlichen Gesellschaft wird ein Menschenbild gegenübergestellt, das Individualität und das Bezogensein auf andere in sich vereinigt:

„Das von Marx bekämpfte Missverständnis besteht darin, die Freiheit des Einzelnen als Freiheit von der Gesellschaft zu denken, als die Freiheit einer Monade, als eine Freiheit, die durch Isolation von anderen konstituiert wird. Marx hielt dagegen, dass es Freiheit nur in der und durch die Gemeinschaft mit anderen Menschen gibt.“"71

Bereits Smith hatte dies in seiner Morallehre angedeutet. Marx geht jedoch über Smith hinaus und hebt in seiner Demokratiekritik die liberale Trennung zwischen Individuum und Gemeinschaft auf:

„Erst wenn der wirkliche individuelle Mensch den abstrakten Staatsbürger in sich zurücknimmt und als individueller Mensch in seinem empirischen Leben, in seiner individuellen Arbeit, in seinen individuellen Verhältnissen, Gattungswesen geworden ist, erst wenn der Mensch seine ,forces propres` als gesellschaftliche Kräfte erkannt und organisiert hat und daher die gesellschaftliche Kraft nicht mehr in der Gestalt der politischen Kraft von sich trennt, erst dann ist die menschliche Emanzipation vollbracht. “72

Denn durch sie werden erst die Bezüge des Menschen zu sich selbst und zur Außenwelt hergestellt. Bei der entfremdeten Arbeit ist dieser Bezug gestört und unterbrochen: Sowie der Mensch seinen Bezug zu seinem

70 Menschenrechte sind die „Rechte des Mitglieds der bürgerlichen Gesellschaft, d.h. des egoistischen Menschen, des vom Menschen und vom Gemeinwesen getrennten Menschen.“ (Marx, Zur Judenfrage, 1957, S. 365, Hervorhebung im Original)

71 Ingo Pies: Einleitung, in: ders. (Hrsg.): Karl Marx' kommunistischer Individualismus, Tübingen 2005, S. 1-33, hier: S. 2.

72 Marx, Zur Judenfrage, 1957, S. 370. 
Produkt und seiner Tätigkeit verliert, so ist er ebenso dem Gattungswesen als auch den anderen Menschen entfremdet. ${ }^{73}$ Im Begriff des Gattungswesens kann das mit sich und der Gesellschaft versöhnte Individuum niemals isoliert, sondern immer nur auf den anderen bezogen gedacht werden. Die Arbeit, der Marx auch einen intrinsischen Wert für den Einzelnen beimisst, ${ }^{74}$ dient ebenso diesem bestimmten Zweck.

Marx will den Dualismus zwischen dem liberalen Menschenbild eines egoistischen, primär interessengeleiteten homo oeconomicus und der Rousseau'schen Entäußerung des Individuums an das Kollektiv durchbrechen, denn sie bedeuten beide Selbstverleugnung. ${ }^{75}$ Er setzt an diese Stelle die Verschränkung der Individualität und Gemeinschaftlichkeit. Sie ist unhintergehbarer Ausgangspunkt seiner Gesellschaftskritik. Marx durchbricht hier die Grundlagen liberalen Denkens, wie sie in erster Linie Mandeville aber auch Smith mitentworfen haben. Diese Demontage der Idee eines sich selbst genügenden, seine egoistischen Interessen verfolgenden Menschen prägt Marx' radikale Kritik an der bürgerlichen Gesellschaft, weil sie bloße politische Emanzipation, aber keine vollständige menschliche Emanzipation sei, die alle Bereiche des Lebens umfasst. ${ }^{76}$

Marx ersetzt die Marktordnung durch den Entwurf einer ,demokratischen ${ }^{77}$ Gemeinschaft, für die nicht der Egoismus, sondern die Freiheit des Individuums in der Gemeinschaft konstitutiv ist. Die liberale Transzendenzstellung des einzelnen Menschen verschiebt Marx zu der Unverfügbarkeitsbehauptung, dass der Mensch nur in Gemeinschaft zu sich selbst komme:

73 „Überhaupt, der Satz, daß der Mensch seinem Gattungswesen entfremdet ist, heißt, daß ein Mensch dem andern, wie jeder von ihnen dem menschlichen Wesen entfremdet ist. Die Entfremdung des Menschen, überhaupt jedes Verhältnis, in dem der Mensch zu sich selbst [steht], ist erst verwirklicht, drückt sich aus in dem Verhältnis, in welchem der Mensch zu d[em] andren Menschen steht." (Karl Marx: Ökonomisch-philosophische Manuskripte [1844], in: MEW, Bd. 40, Ergbd. 1, S. 465-588, hier: S. 518) Zum Entfremdungsbegriff bei Marx siehe Jaeggi, Entfremdung, 2005, bes. S. 30-35.

74 Rahel Jaeggi: Entfremdung. Zur Aktualität eines sozialphilosophischen Problems, Frankfurt a.M. 2005, S. 31.

75 Karl Marx: Deutsche Ideologie [1845f.], in: MEW, Bd. 3, Berlin 1969, S. 5-530, hier: S. 230.

76 Raymond Aron: Über die Freiheiten. Essay, Stuttgart 1981, S. 23.

77 Zum Demokratiebegriff bei Marx siehe z.B. Hermann Ebeling: Der Begriff ,Demokratie ' in den sozialistischen Ideologien. Marx, Lassalle, Engels, Heidelberg 1964, S. 17-38. 
„Die unselige sinnliche Wirklichkeit kümmert sich nicht um seine [d.h. die des liberalen Individuums, JSW] Einbildung, jeder seiner Sinne zwingt es, an den Sinn der Welt und der Individuen außer ihm zu glauben, und selbst sein profaner Magen erinnert es täglich daran, daß die Welt außer ihm nicht leer, sondern das eigentlich Erfüllende ist." 78

Der Bezug zum Anderen selbst, die Gemeinschaftlichkeit des Menschen wird zur Transzendenzfigur im Marx'schen Werk. Diese Idee vom Menschen hat bei Marx sinnkonstitutive Bedeutung für seinen, wenn auch vage bleibenden, Gegenentwurf zur bürgerlichen Gesellschaft. Marx demontiert zwar auf der einen Seite die Behauptung einer überhistorischen Wesensbestimmung des Menschen, bestimmt jedoch gleichzeitig selbst einen Wesenskern des Menschen. Damit ist auch der Begriff des Gattungswesens seiner Historizität entzogen.

\subsection{Demokratie und Rechtsordnung bei Tocqueville}

\subsubsection{Demokratie als Versprechen}

Während Marx noch grundsätzlich am Wesenskern des Menschen zur Begründung von Ordnung festhält, verabschiedet sich Tocqueville von dieser Argumentation. Tocqueville greift in seiner Demokratietheorie auf die Transzendenzfigur, Gott‘ zurück, lässt sie jedoch gleichzeitig wieder verschwinden. An ihre Stelle tritt die Autonomie des Menschen, die Freiheit bedeuten kann, als neue ordnungsbegründende transzendente Figur.

Tocqueville macht für die Entwicklung der Demokratie zwei entscheidende religiös-transzendente Wendepunkte aus: Der erste Wendepunkt ist die Geburt Jesu als Menschwerdung Gottes. Sie gilt Tocqueville als Zeichen der Gleichheit aller Menschen: „Jesus Christus“, so Tocqueville, „,musste auf die Welt kommen, um zu lehren, daß alle Angehörigen des Menschengeschlechts von Natur dieselben und einander gleichgestellt seien“79. Durch Jesus ist das Versprechen, dass Gott die Menschen als Gleiche geschaffen habe, sichtbar geworden. Die Demokratie gleicht dem auf die Erde geholten radikalen Gleichheitsversprechen von Gott an die Menschen.

78 Marx, Die heilige Familie, 1957, S. 127 (Hervorhebung im Original).

79 Tocqueville, Über die Demokratie, 1984, S. 499. 
Neben der Ableitung der Gleichheit aus dem göttlichen Versprechen führt Tocqueville die Gleichheit ebenso als unverfügbares, geschichtliches Prinzip ein. In seinen revolutionstheoretischen Schriften Die gesellschaftlichen und politischen Zustände in Frankreich vor und nach 1789 und Der alte Staat und die Revolution stellt Tocqueville die These auf, dass die Idee der Gleichheit schon lange vor der Französischen Revolution in die Sitten und Gebräuche der Gesellschaft eingesickert war, bevor dann in der Revolution lediglich die alten Hüllen des feudalen Systems abgeschafft wurden. Er setzt sich damit gegen die Deutung der Revolution als radikalen Umbruch, die zur damaligen Zeit sowohl von den Befürwortern, wie ihren Gegnern geteilt wurde. ${ }^{80}$ Die Revolutionäre werden in Tocquevilles Revolutionsdeutung zu Ausführenden eines unaufhaltsamen geschichtlichen Prozesses, der ohnehin abgelaufen wäre. Die Revolution hat einzig die Funktion, die alten Institutionen den neuen politischen Strukturprinzipien anzupassen. ${ }^{81}$ Die Transzendenzfiguren ,Gott' und ,Geschichte' dienen hier Tocqueville zur Begründung der neuen demokratischen Ordnung.

Neben der Gleichheit gilt dies auch für den Freiheitsbegriff Tocquevilles, der im Kern die Autonomie des Menschen meint. Dieser ist das zweite Versprechen Gottes an die Menschen und der zweite entscheidende Wendepunkt in der Geschichte der Menschheit. Während die Menschwerdung Jesu nicht nur auf das Versprechen der Gleichheit der Menschen weist, entspricht die göttliche Ebenbildlichkeit dem Potential menschlicher Schöpfungskraft und damit das Versprechen an die Menschen, über seine Lebensbedingungen selbst bestimmen zu können:

80 So z.B. Olympe de Gouges: Erklärung der Rechte der Frau und der Bürgerin [1791], in: dies.: Die Rechte der Frau und andere Schriften, hrsg. von Gabriela Wachter, Berlin 2006, S. 51-68, hier: S. 55; Marquis de Condorcet: Darlegung der Prinzipen und Gründe des Verfassungsentwurfs [1791], in: ders.: Freiheit, Revolution, Verfassung. Kleine politische Schriften, hrsg. von Daniel Schulz, Berlin 2010, S. 173-213; Edmund Burke: Reflections on the Revolution in France [1790], hrsg. von Jonathan Charles Douglas Clark, Stanford 2001.

81 Alexis de Tocqueville: Die sozialen und politischen Verhältnisse Frankreichs vor und nach 1789 [1836], in: ders.: Kleine politische Schriften, hrsg. von Harald Bluhm, Berlin 2006, S. 81-109; Marcel Gauchet: Tocqueville, Amerika und wir. Über die Entstehung der demokratischen Gesellschaften, in: Ulrich Rödel (Hrsg.): Autonome Gesellschaft und libertäre Demokratie, Frankfurt a.M. 1990, S. 123-206, hier: S. 126. 
„Der modernen, demokratischen, und ich wage zu sagen, der richtigen Freiheitsauffassung zufolge ist jeder Mensch [...] von Geburt an Träger eines gleichen und unantastbaren Rechts, in allem, was nur ihn selbst betrifft, unabhängig von seinesgleichen zu leben und sein eigenes Los so zu gestalten, wie er es beabsichtigt. “ ${ }^{82}$

Hier wird deutlich, dass diese von Gott geschenkte Freiheit im Kern die Autonomie des Menschen meint. Diese Autonomie des Menschen schlägt sich im Prinzip der Volkssouveränität nieder, durch die sich „das Volk [selbst] regiert ${ }^{\text {‘ } 83}$.

Auch wenn oftmals festgestellt wurde, dass Tocqueville seinen Demokratiebegriff nie systematisch entfaltet hat, ${ }^{84}$ so ist er doch im Wesentlichen zusammengesetzt aus diesen zwei miteinander verwobenen Prinzipien: der Gleichheit und der Autonomie des Menschen als die Freiheit der Verfügung über die eigenen Angelegenheiten. Beide lassen sich in den Vereinigten Staaten als gesellschaftsstrukturierende Prinzipien beobachten. ${ }^{85}$

Ebenso wie den Gleichheitsbegriff verlängert Tocqueville auch die Idee dieser Autonomie als Freiheit, sich die Welt selbst schaffen zu können, in die Geschichtlichkeit, denn ,der Grundsatz der Volkssouveränität“ liege bereits immer schon „den menschlichen Einrichtungen zugrunde“ ${ }^{\text {“66 }}$. Jede Institution ist von den Menschen selbst geschaffen und spiegelt damit bereits Momente der von Gott auf den Menschen übertragenen Schöpferkraft, die sich in dem Geschenk der Autonomie ausdrückt und erst in der modernen Demokratie zur vollen Entfaltung kommt. Tocqueville verbindet somit seinen argumentativen Bezug auf Gott mit den Begriffen von Gleichheit und Freiheit.

\subsubsection{Die menschliche Freiheit}

Marcel Gauchet und Raymond Aron kritisieren die theologische Ableitung der Demokratie bei Tocqueville, weil er hier die Legitimationslücke, die die

82 Aron, Über die Freiheiten, 1981, S. 14.

83 Tocqueville, Über die Demokratie, 1984, S. 65.

84 Aron, Über die Freiheiten, 1981, S. 11.

85, ,D]as Dogma der Volkssouveränität [ist] das letzte Glied einer Kette von Meinungen $[\ldots]$, welche die ganz angloamerikanischen Welt umspannt." (Tocqueville, Über die Demokratie, 1984, S. 461)

86 Ebd., S. 63. 
Demokratien aufgerissen habe, sofort wieder schließen würde. ${ }^{87}$ Und in der Tat scheint durch die religiös-transzendente Ableitung bei Tocqueville ein Prinzip bestehen zu bleiben, das die Gesellschaft von innen beherrscht und dessen Abschaffung oder Einführung nicht in der menschlichen Macht steht. Gauchet hatte noch Tocqueville in diesem Sinne kritisiert, dass er durch die religiöse Aufladung seines Demokratiebegriffs an einem alles erklärenden und alles strukturierenden Prinzip festhalte und damit die Freiheit menschlichen Handelns verleugne. Er entdeckt in dieser unverfügbaren Schließung der Legitimationslücke ein totalitäres Moment im Demokratiebegriff Tocquevilles, denn die monovalente Ableitung eines Ordnungssystems und die Vorstellung einer zu sich selbst gekommenen und in diesem Sinne harmonischen Gesellschaft sei zentrales Kennzeichen totalitärer Ordnungen. Für Gauchet beschreibt der Gleichheitsbegriff das der demokratischen Gesellschaft zugrundeliegende Prinzip, aus dem alles weitere abgeleitet wird und in das jedes Gesellschaftsmitglied einstimmen muss. ${ }^{88}$

Es ist zwar richtig, dass die demokratische Ordnung als solche bei Tocqueville der menschlichen Verfügung entzogen wird, ihre Gestaltung ist es jedoch nicht. Ganz im Gegenteil muss Tocqueville den Demokratiebegriff offen halten, um die neue Ordnung radikal zu einer menschlichen Angelegenheit zu machen. Denn hier, in der volkssouveränen Bestimmung über die Gesellschaft und ihre politischen Einrichtungen, liegt die von Gott gegebene Freiheit als Autonomie der Menschen verborgen: „Nicht um den Wiederaufbau einer aristokratischen Gesellschaft handelt es sich also, sondern darum, aus dem Schoß der demokratischen Gesellschaft, in der Gott uns leben heißt, die Freiheit hervorgehen zu lassen. “89

Die durch Gott auferlegte Freiheit des Menschen wird allein an den unzähligen Variationen des Gleichheitsbegriffs deutlich. Denn die Gleichheit kann eine freie demokratische Ordnung ebenso begründen, wie eine despotische: ${ }^{90}$ Was der Mensch aus dem Gleichheitsversprechen macht, ist

87 Aron, Über die Freiheiten, 1981; Gauchet, Tocqueville, 1990, S. 123-206.

88 Ebd., S. 129.

89 Tocqueville, Über die Demokratie, 1984, S. 818.

90 Siehe dazu auch: Wilhelm Hennis: Tocquevilles ,Neue politische Wissenschaft', in: Justin Stagl (Hrsg.): Aspekte der Kultursoziologie. Aufsätze zur Soziologie, Philosophie, Anthropologie und Geschichte der Kultur. Zum 60. Geburtstag von Mohammed Rassem, Berlin 1982, S. 385-407, hier: S. 393. „Die Nationen unserer Tage können nicht bewirken, daß bei ihnen die gesellschaftlichen Bedingungen nicht gleich seien; von ihnen jedoch hängt es ab, ob die Gleichheit sie in 
damit durch die von Gott gegebene Freiheit ganz ihm zur Verfügung gestellt. Indem er das Unverfügbare (Gott) direkt wieder invisibilisiert, drückt er seine Überzeugung aus, dass die Ausgestaltung demokratischer Ordnung ganz dem Menschen selbst aufgegeben ist. Gott zieht sich somit aus der durch ihn gegebenen Ordnung wieder zurück, um den Menschen Freiheit und Autonomie zu geben. Somit ist paradoxerweise die gottgewollte Welt Tocquevilles gottverlassen, die Menschen sind wie „vaterlose Kinder ${ }^{\varkappa 91}$. Gleichheit und Volkssouveränität sind bei Tocqueville radikal den Menschen zur Verfügung gestellt: „Das Volk beherrscht die amerikanische politische Welt wie Gott das All. Es ist Ursprung und Ziel aller Dinge; aus ihm geht alles hervor, und zu ihm kehrt alles zurück." ${ }^{\text {"92 }}$ So wie Gott hier als der unbewegte Beweger und das höchste Ziel allen Lebens vorgestellt wird, so werden diese Gotteseigenschaften auf das demokratische Volk übertragen.

Tocqueville legt so das Gelingen der Ordnung ganz in die Verantwortung der Menschen. Es gibt keine göttlichen Prinzipien mehr, die die Struktur der Ordnung genau vorgeben, keine Harmonie einer von Gott erdachten Ordnung und der menschlich gemachten Welt. Es gibt damit niemanden mehr, der die Gesellschaft leitet und führt, denn Gott hat nur sein Versprechen gegeben. Das Versprechen kann von der Gesellschaft angenommen werden, indem sie sich immer wieder dieses eingelösten Versprechens versichert. Die religiöse Transzendenz als Legitimationsgrundlage der Ordnung ist bei Tocqueville damit zunächst innerhalb der Demokratie aufgelöst.

Wenn also Demokratie nicht als schließendes ,universalhistorisches Prinzip“933 verstanden wird, sondern nur das Versprechen der Gleichheit und Freiheit die Vergangenheit, Zukunft und Gegenwart verbindet, dann werden die Grundprinzipien zu einem immer wieder neu zu konstituierenden Moment der Gesellschaft. ${ }^{94}$ Die Demokratie wird bei Tocqueville

die Knechtschaft oder in die Freiheit, zur Gesittung oder in die Barbarei, zum Wohlstand oder ins Elend führt.“ (Tocqueville, Über die Demokratie, 1984, S. 830)

91 Tocqueville, Über die Demokratie, 1984, S. 10.

92 Ebd., S. 65.

93 Werner Conze u.a.: Demokratie, in: Otto Brunner/Werner Conze/Rainer Koselleck (Hrsg.): Geschichtliche Grundbegriffe. Historisches Lexikon zur politisch-sozialen Sprache in Deutschland, Bd. 1, Stuttgart 1972, S. 821-899, hier: S. 882.

94 Vgl. Jacques Derrida: Schurken. Zwei Essays über die Vernunft. Aus dem Französischen von Horst Brühmann, Frankfurt a.M. 2003, S. 111-133. 
durch die Loslösung von Gott zu einem Prozessbegriff. Sie kann niemals mit sich selbst, mit ihren Grundprinzipien zur Übereinstimmung kommen. Denn die Gleichheit in Freiheit setzt immer voraus, dass die Gesellschaft durch Diskurse und Praktiken, durch die Religion, die öffentliche Teilhabe, durch den Rechtsgeist, durch das politische Leben, durch das gemeinsame Handeln, durch Erfahrung und Erziehung, sich ihrer Grundprinzipien immer wieder neu versichert. Demokratie wird damit bei Tocqueville auch zu einer Ordnung, die ihre Geltungsgrundlagen fortwährend aus sich selbst heraus schafft und schaffen muss. Und diese Ordnung findet Tocqueville nicht im Markt, sondern in der Demokratie.

Die Leerstelle, die Gott hinterlässt, schließt und öffnet Tocqueville also in einer Doppelbewegung. Durch die Bezugnahme auf Gott schließt er eine andere Ordnung als die Demokratie aus und öffnet damit gleichzeitig den Raum für die politische Freiheit und Selbstbestimmung. Im Gegensatz zu Marx gibt es bei Tocqueville „,keine adäquate Determination der politischen Herrschaftsordnung“"95, denn sie kann liberal oder despotisch sein, die Möglichkeiten der Entwicklung sind vielfältig und können niemals abgeschlossen sein. Mit dieser Öffnung wird die Demokratie zur radikal anderen Ordnungsform als die vorangegangenen Ordnungen. Um diesen Bruch deutlich zu machen, hat Tocqueville seine Wissenschaft als neue Wissenschaft verstanden: „Eine völlig neue Welt bedarf einer neuen politischen Wissenschaft." 96

Während sich dieser Begründungsversuch als Reaktion auf den Konflikt in Frankreich deuten lässt, ${ }^{97}$ invisibilisiert Tocqueville das Gottesversprechen in einer etablierten demokratischen Ordnung, in der die Grundprinzipien nicht mehr zur Disposition stehen. Damit dient ihm der Gottesbezug vor allem in Krisenzeiten dazu, die neuen Prinzipien der Diskussion zu entziehen. Er hält sie denjenigen entgegen, die versuchen, sich ihnen entgegenzustellen.

95 Aron, Über die Freiheiten, 1981, S. 20.

96 Tocqueville, Über die Demokratie, 1984, S. 9.

$97 \mathrm{Vgl}$. für die theologischen Bezüge gerade auch im Hinblick auf die Krisensituation in Frankreich: „Alle Menschen haben das Ihre dazu beigetragen, die, welche ihren [der Demokratie, JSW] Erfolg fördern wollten, wie jene, die ihm keineswegs zu dienen beabsichtigten; [...] alle wurden auf den gleichen Weg geschoben, und alle haben gemeinsam gearbeitet, die einen wider Willen, die andern ohne ihr Wissen, alle als blinde Werkzeuge in Gottes Hand.“ (ebd., S. 8) 
Aber in der Freiheit, selbst über sein Leben bestimmen zu können, liegt die Gefahr der Unfreiheit verborgen und so sucht Tocqueville nach Merkmalen der Demokratie, die dem Gemeinsinn verpflichtete Freiheit auf Dauer stellen zu können.

\subsubsection{Stabilisierung der Freiheit}

In Abgrenzung zu Denkern wie Mandeville und Smith betont Tocqueville die Gefahr des Individualismus, der Absonderung von Anderen, der reinen Selbstbezogenheit, der „Einsamkeit seines eigenen Herzens“ ${ }^{\text {“98 }}$. Der Individualismus stellt für Tocqueville somit eine Gefahr für die Stabilität der Ordnung dar. Anders als Mandeville sieht Tocqueville die reine Selbstbezogenheit, die „den Quell der öffentlichen Tugenden trocken ${ }^{\text {“99 } 99}$ legt, als destruktives Moment in der demokratischen Ordnung. Er stellt sich hier nicht wie Marx gegen das ökonomisch und egoistisch agierende Individuum an sich, sondern gegen die Reduzierung des Menschen auf den nutzenmaximierenden homo oeconomicus, wie ihn vor allem Mandeville entworfen hatte. ${ }^{100}$ Die republikanische Tradition einer lebendigen Bürgergesellschaft aufgreifend, betont er die Wichtigkeit der Öffentlichkeit, die Freiheit sichernde Freiheit auf Assoziation ${ }^{101}$ und damit die Bedeutung einer partizipierenden Bürgergesellschaft, die dem Selbstbezug Schranken aufweist. Denn mit der öffentlichen Partizipation wird der Bürger daran erinnert, dass „er in Gesellschaft lebt“102. Insofern kann die lebendige Bürgergesellschaft das zerschnittene hierarchische Band der Adelsgesellschaft durch ein neues, egalitäres, gemeinsinnstiftendes Band, das Freiheit stabilisiert, hervorbringen.

98 Ebd., S. 587.

99 Ebd., S. 585.

100 Siehe dazu auch: Hans Vorländer: Alexis de Tocqueville. Über die Demokratie in Amerika (1835/1840), in: Manfred Brocker (Hrsg.): Geschichte des politischen Denkens. Ausgewählte Werkanalysen, Frankfurt a.M. 2007, S. 419-433, hier: S. 424.

101 Bluhm bezeichnet die Assoziation als die ,wichtigste Kunst in der Demokratie" bei Tocqueville. Siehe Harald Bluhm: Das Verständnis von Assoziation bei Alexis de Tocqueville und Karl Marx, in: ders./Karsten Fischer/Marcus Llanque (Hrsg.): Ideenpolitik: Geschichtliche Konstellationen und gegenwärtige Konflikte. Festschrift für Herfried Münkler zum 60 . Geburtstag, Berlin 2011, S. 243-266, hier: S. 244.

102 Tocqueville, Über die Demokratie, 1984, S. 593. 
Dabei gibt Tocqueville nicht die Mandevillesche Idee des Eigennutzes auf, deutet sie jedoch neu und verweist auf die gemeinsinnsstärkende Kraft. Der wohlverstandene Eigennutz, die ,aufgeklärte Selbstliebe“, führt zu einer gegenseitigen Hilfsbereitschaft durch die Erkenntnis, dass beide Seiten von dieser Hilfe profitieren. ${ }^{103}$ Die Amerikaner, so Tocqueville, ,zeigen selbstzufrieden, wie die aufgeklärte Selbstliebe sie ständig dazu drängt, sich gegenseitig zu helfen, und für das Wohl des Staates bereitwillig einen Teil ihrer Zeit und ihres Reichtums zu opfern."“104

Insofern stellt der wohlverstandene Eigennutz ein Funktionsäquivalent für den überkommenen Tugendbegriff dar. ${ }^{105}$ Tocqueville nimmt dem alten Tugendbegriff jeden transzendenten Überschuss, indem er seine Funktionalität hervorhebt: „In den Vereinigten Staaten sagt man kaum, die Tugend sei schön. Man versichert, daß sie nützlich ist, und beweist es täglich.“106 Er zeigt den reziproken Gewinn eines tugendhaften Verhaltens, um dann direkt zum wohlverstandenen Eigennutz überzuleiten. Tocqueville setzt gegen die republikanische Tugendlehre die Einfachheit seines Tugendbegriffs (,sie erstrebt keine großen Ziele“"107, „,öst keine großen Opfertaten aus “6108) und macht sie mit den menschlichen Schwächen vereinbar. ${ }^{109}$ Allerdings besitzt die Lehre vom wohlverstandenen Eigennutz für Tocqueville kein ausreichendes Integrationspotential für die moderne demokratische Gesellschaft. ${ }^{110}$

Anders als Mandeville, der das kluge Institutionen- und Regierungsarrangement als einzigen Garanten für die Stabilität der Gesellschaft her-

103 Insofern ist die Einschätzung Bauszus nicht richtig, wenn er dem wohlverstandenen Eigennutz gänzlich abspricht, ein Gefühl der Zusammengehörigkeit hervorzubringen. Detlef David Bauszus: Religion, Politik und die demokratische Republik in der Analyse Alexis de Tocquevilles ,Über die Demokratie in Amerika', in: Ines-Jacqueline Werkner u.a. (Hrsg.): Religionen und Demokratie. Beiträge zu Genese, Geltung und Wirkung eines aktuellen politischen Spannungsfeldes, Baden-Baden 2009, S. 17-28, hier: S. 21.

104 Tocqueville, Über die Demokratie, 1984, S. 611.

105 Hans Vorländer: Hegemonialer Liberalismus. Politisches Denken und politische Kultur in den USA 1776-1920, Frankfurt a.M. 1997, S. 133.

106 Tocqueville, Über die Demokratie, 1984, S. 610.

107 Ebd., S. 612.

108 Ebd.

109 Damit wird die Tugendorientierung auch für eine hohe Zahl an Einwohnern in der Demokratie möglich, erklärt Tocqueville (ebd., S. 610ff.).

110 Siehe Bauszus, Religion, 2009, S. 21; Tocqueville, Über die Demokratie, 1984, S. 615. 
vorhebt, beharrt Tocqueville vielmehr darauf, dass die Demokratie von den Sitten der Menschen, von ihren Einstellungen, Mentalitäten, Ideen, den „habits of the heart" ${ }^{\star 111}$, kurz: der politischen Kultur abhängig ist. ${ }^{112}$ Er ist überzeugt, dass „das Reich der Freiheit nicht ohne das der guten Sitten zu errichten und die guten Sitten nicht ohne den Glauben zu festigen " sei. ${ }^{113}$

Die Religion ist ein wichtiges Element bei Tocqueville, denn sie gilt ihm als eine Quelle der Stabilität, der Orientierung, des ethischen Gefüges moderner demokratischer Gesellschaften. Eine Zivilreligion im Sinne Rousseaus hätte Tocqueville abgelehnt. ${ }^{114}$ Deswegen können die grundlegenden christlichen Überzeugungen in diesem Sinne durchaus als die „vorpolitische, moralische Grundverfassung des Gemeinwesens"115 bezeichnet werden. Politische Freiheit macht Tocqueville unmittelbar abhängig von der sittlichen Verfasstheit der Gesellschaft. Insofern gibt es bei Tocqueville ein positives Kooperationsverhältnis zwischen Religion und Politik, auch wenn diese beiden Sphären bei ihm strikt getrennt werden. ${ }^{116}$ Religiöse Überzeugungen dienen also als Reservoir gemeinsinniger Selbst-

111 Robert N. Bellah u.a.: Habits of the Heart. Individualism and Commitment in American Life, Berkely u.a. 1985.

112 Siehe dazu auch Vorländer, Alexis de Tocqueville, 2007, S. 422. Tocqueville (Über die Demokratie, 1984, S. 356) schreibt: „Es sind also vor allem die Sitten, welche die Amerikaner der Vereinigten Staaten als einzige unter allen Amerikanern zum Ertragen der demokratischen Herrschaft befähigen." Im Anschluss an Tocqueville: Robert D. Putnam: Demokratie in Amerika am Ende des 20. Jahrhunderts, in: Friedrich Wilhelm Graf (Hrsg.): Soziales Kapital in der Bürgergesellschaft, Stuttgart 1999, S. 21-70.

113 Tocqueville, Über die Demokratie, 1984, S. 14.

114 Der Glaube gehört für Tocqueville zum menschlichen Leben, es gibt keine Entscheidung für ihn oder gegen ihn (vgl. ebd., S. 623). Als Begründung dient Tocqueville die Natur des Menschen. Im religiösen Bedürfnis entdeckt Tocqueville einen entscheidenden Unterschied zum Tier: „Als einziges unter allen Wesen“ bekunde der Mensch ,einen natürlichen Widerwillen gegen das Dasein und ein unermessliches Verlangen, dazusein; er verachtet das Leben und fürchtet das Nichts. Diese verschiedenen Triebe drängen seine Seele unaufhörlich zur Betrachtung der anderen Welt, und die Religion ist es, die ihn dorthin führt.“ (ebd., S. 343) Die Religiosität des Menschen selbst zumindest bedarf bei Tocqueville also keiner weiteren Begründung, denn sie entspringt dem menschlichen Leben selbst. Für ihn gibt es ein ,metaphysisches Bedürfnis des Glaubens“, der Glaube entspricht damit dem „menschlichen Instinkt“ (Oliver Hidalgo: Unbehagliche Moderne. Tocqueville und die Frage der Religion in der Politik, Frankfurt a.M. 2006, S. 277).

115 Bauszus, Religion, 2009, S. 19.

116 Tocqueville, Über die Demokratie, 1984, S. 344. 
beschreibungen und Praktiken in einer freiheitlichen Demokratie und bewahren auf unterschiedliche Weise vor der despotischen Spielart, die aus dem puren Egoismus und der reinen Selbstbezogenheit resultiert. ${ }^{117}$

Religion in diesem Sinne bedeutet Begrenzung und den Schutz vor dem demokratischen ,Übermut' und den Allmachtsphantasien, die durch die Übergabe der Freiheit und Souveränität an die Menschen demokratische Ordnungen als ständige Gefahr begleitet. Ihre Achtung bietet Schutz vor individueller Willkür. ${ }^{118}$ Eine der wichtigsten Funktionen der Religion sieht Tocqueville daher in der Selbstbeschränkung: „Und was soll man tun mit einem Volk, das als Herr seiner selbst nicht Gott untertan ist?“"119 Diese Selbstbeschränkung findet Tocqueville ebenso bei den Rechtsgelehrten der amerikanischen Demokratie. Sie stehen für das Gegenüber der dynamisch gewordenen Gesellschaft, die auch die Rechtsgelehrten „mitreißt“" ${ }^{\text {“20 }}$. Die Rechtsgelehrten verkörpern die unverfügbaren Momente der dynamischen Demokratie, denn sie stehen für den „starren Geist“, für das Bewahren des „Bestehenden“, für die konservierende Haltung, „keine Neuerungen“ einführen zu wollen. Sie stehen für die Spannung zwischen Konstitutionalismus und Demokratie. ${ }^{121}$

Insofern wird bei Tocqueville die Marktordnung nicht nur durch die demokratische Ordnung, sondern auch durch die Rechtsordnung ersetzt. Ebenso wie Tocqueville für die Religion zwischen festen „Hauptüberzeugungen“ und den sich verändernden ,Glaubenssätzen“ unterscheidet, ${ }^{122}$ so findet er das Äquivalent in der Rechtsordnung in dem Verhältnis zwischen Verfassung und den aus ihr abgeleiteten Gesetzen. Während die Verfassung

117 Siehe dazu auch: Bauszus, Religion, 2009, S. 21f.; Herbert Dittgen: Politik zwischen Freiheit und Despotismus. Alexis de Tocqueville und Karl Marx, Freiburg i.B. 1986, S. 60; Karlfriedrich Herb: Staat und Religion. Die politische Vernunft in den Grenzen des Glaubens, in: ders./Oliver Hidalgo (Hrsg.): Alter Staat, neue Politik. Tocquevilles Entdeckung der modernen Demokratie, Baden-Baden 2004, S. 83-95, hier: S. 86f.

118 Tocqueville, Über die Demokratie, 1984, S. 338.

119 Ebd., S. 340.

120 Ebd., S. 311.

121 Hans Vorländer: Die Suprematie der Verfassung. Über das Spannungsverhältnis von Demokratie und Konstitutionalismus, in: Wolfgang Leidhold (Hrsg.): Politik und Politeia. Formen und Probleme politischer Ordnung. Festgabe für Jürgen Gebhardt, Würzburg 2000, S. 373-383.

122 Während die Hauptüberzeugungen, „stets fest bleiben, was immer der besondere Geist einer Zeit sei“, können sich die Glaubenssätze ändern (Tocqueville, Über die Demokratie, 1984, S. 510). 
für Tocqueville unantastbare Prinzipien enthält, sind die Gesetze der ständigen Veränderung unterworfen. Denn es gebe „,bei politischen Einrichtungen zwei Arten der Unbeständigkeit, die man nicht miteinander verwechseln darf ${ }^{\text {c123 }}$. Während die einen verändert und immer wieder neu diskutiert werden, bleibt die Verfassung in ihren Prinzipien unangetastet. In der Verfassung also findet Tocqueville die Grundlagen eines übergreifenden Konsenses, der als unverfügbar behauptet werden muss, um Freiheit zu stabilisieren: Die Unverfügbarkeit der Verfassung und ihrer Prinzipien stellt Tocqueville hier gegen die zerstörerische Dynamik einer demokratischen Gesellschaft. ${ }^{124}$ Das heißt, dass die Gesellschaft durch Gleichheit und Volkssouveränität eine dynamische Ordnung geworden ist, deren Grundlagen jedoch der Verfügbarkeit entzogen sein sollen, um nicht in einem neuen Despotismus zu enden. ${ }^{125}$

\section{SCHLUSS}

Während Mandeville und Smith zum einen in Ablehnung gegen den vorherrschenden Tugenddiskurs, zum anderen in Abgrenzung und seiner Weiterentwicklung eine auf marktrationalen Kriterien aufruhende und vom homo oeconomicus ausgehende Gesellschaftsordnung zu entwickeln versuchen, gehören Tocqueville und Marx zu den Kritikern dieser marktrationalen Gesellschaftsordnung. So wie Mandeville den Diskurs vom Tugenddiskurs zum Interessendiskurs verschoben hat, von der Gemeinschaftsverpflichtung zur egoistischen Interessenverfolgung, so behauptet Marx dagegen den Menschen als ein Wesen, das nur in und durch die Gemeinschaft seine Freiheit entfalten kann. Individuelle Freiheit wird bei ihm da-

123 Ebd., S. 462.

124 „Die Amerikaner ändern die Gesetze häufig, die Grundlage der Verfassung bleibt unangetastet. [...] [D]as Übel, das sich aus der Unbeständigkeit der untergeordneten Gesetze ergibt, würde dann den Bestand der grundlegenden Gesetze in Frage stellen und mittelbar eine Revolution herbeiführen." (ebd., S. 462f.). Siehe dazu auch: Donald Maletz: The Union as Idea: Tocqueville on the American Constitution, in: History of Political Thought 19 (1998) 4, S. 599-620.

125 ,[D]ie eine [Unbeständigkeit] hängt mit untergeordneten Gesetzen zusammen; diese kann lange in einer wohlgefestigten Gesellschaft herrschen; die andere rüttelt unaufhörlich an den Grundlagen der Verfassung selbst und greift die Prinzipien an, aus denen die Gesetze hervorgehen. Diese hat stets Wirren und Revolutionen zur Folge; das Volk, das ihr ausgesetzt ist, befindet sich in einem heftig erregten Übergangszustand.“(Tocqueville, Über die Demokratie, 1984, S. 462) 
mit sozial kontextuiert. Marx ersetzt den Begriff des egoistischen Individuums durch den Begriff des Gattungswesens. Anders als Marx wiederum rekurriert Tocqueville nicht allein auf die Natur des Menschen, sondern auf das göttliche Versprechen von Freiheit und Gleichheit und entzieht somit die Prinzipien der neuen politischen Ordnung der Verfügung der Menschen, um die Demokratie allerdings gleichzeitig radikal zur menschlichen Angelegenheit zu machen. Im Gegensatz zu Marx, der die Demokratie nur als Übergang zur „wahren Demokratie“ ansieht, sucht Tocqueville innerhalb der Demokratie nach gemeinsinnsstiftenden Elementen, die die Freiheit des Menschen auf Dauer stellen. Mit dem Begriff des wohlverstandenen Eigennutzes deutet Tocqueville den marktrationalen Individualismus, wie ihn Mandeville entworfen hatte, um. Denn er prägt diesen Begriff neu, indem er seinen gemeinsinnsstiftenden Überschuss hervorhebt. Damit löst er den Eigennutz von der Mandevilleschen Isolierung ab. Tocqueville und Marx stimmen in ihrer Kritik an der Isolation der Menschen im liberalen demokratischen Staat überein. Tocqueville betont in der Auseinandersetzung mit dem gemeinsinnstiftenden Engagement des amerikanischen Demos, dass durch die Teilhabe am Politischen der Bürger immer wieder daran erinnert wird, „daß er in Gesellschaft lebt ${ }^{\text {“126 }}$. Tocqueville entwickelt in seinen Werken verschiedene Funktionsäquivalente für die zerbrochenen gesellschaftlichen Bande. So muss auch der Gemeinsinn, ebenso wie die Freiheit, immer wieder neu durch politisches Handeln hervorgebracht werden. Durch das öffentliche Engagement versichert sich der Bürger also ebenso seiner eigenen Abhängigkeit von der Anerkennung des Anderen als Gleicher wie er sich selbst als Gleicher anerkannt fühlt. Nur in der lebendigen, gemeinsinnsfördernden Gesellschaft politisch engagierter Bürger können Freiheit und damit die demokratische Republik im Unterschied zur demokratischen Despotie erhalten bleiben.

126 Tocqueville, Über die Demokratie, 1984, S. 593. 



\title{
Naturerzählungen und republikanische Geltungsbedingungen bei Rousseau
}

\author{
DANIEL SCHULZ
}

\section{Rousseaus Fragestellung}

Rousseaus Fragestellung ist die der klassischen Wissenschaft von der Politik: Was ist die für die Freiheit beste Verfassung, wie kann sie errichtet und dauerhaft erhalten werden? Was also ist das Gesetz, und was kann ihm Geltung verleihen? ${ }^{1}$ Als zentrale Leitfrage kann damit das Problem der Unverfügbarstellung einer politisch-konstitutionell verfügbaren Ordnung identifiziert werden. Mit diesem theoriegeleiteten Zugriff werden einige Aspekte reformuliert, die in der Rousseauforschung zwar für sich genommen präsent sind, aber kaum je systematisch aufeinander bezogen werden. Der politische Theoretiker Rousseau ist damit sehr viel weiter gefasst, als es in

1 In den Confessions heißt es: ,J'avois vu que tout tenoit radicalement à la politique [...]; ainsi cette grand question du meilleur Gouvernement possible me paroissoit se reduire à celle-ci. Quelle est la nature de Gouvernement propre à former un Peuple plus vertueux, le plus éclairé, le plus sage, le meilleur enfin à prendre ce mot dans son plus grand sens. [...] Quel est le Gouvernement qui par sa nature se tient toujours le plus près de la loi? De là, qu'est-ce que la loi?"“ (OC I, Confessions, S. 404f.) Rousseaus Schriften werden als OC zitiert nach der fünfbändigen Pléiade-Ausgabe der Euvres complètes, hrsg. von Bernard Gagnebin und Marcel Raymond, Paris 1961ff. Der Contrat Social wird in der deutschen Übersetzung der Reclam-Ausgabe Stuttgart 1986 zitiert als CS. Zur Freiheit als Rousseaus Fragestellung vgl. auch Wilhelm Hennis: Tocquevilles „Neue politische Wissenschaft", in: ders.: Politikwissenschaft und politisches Denken, Tübingen 2000, S. 297-330, hier: S. 310; außerdem das zentrale Kapitel bei Iring Fetscher: Rousseaus politische Philosophie. Zur Geschichte des demokratischen Freiheitsbegriffs, Frankfurt a.M. 1975, Kap. IV („Voraussetzungen für die Errichtung und Mittel zur Erhaltung der Republik“). 
der Deutung als Vertragstheoretiker oder auch als Souveränitätstheoretiker „radikaler“ Demokratie zum Ausdruck kommt. ${ }^{2}$ Die alternative Lesart als Denker der (Zivil-)Religion hat zwar den Vorteil, den Interpretationsrahmen bis hin zu den Geltungsbedingungen der republikanischen Ordnung zu ziehen, allerdings erfasst auch sie nur einen - den religionsbezogenen Teil dessen, was als die Transzendenzproblematik bei Rousseau beschrieben werden kann. ${ }^{3}$

Der vorliegende Text will zeigen, wie mit dem analytischen Instrumentarium des kulturwissenschaftlichen Transzendenzbegriffs zentrale Zusammenhänge im Rousseau'schen Begründungs- und Verstetigungsversuch einer egalitären, auf bürgerlicher Teilhabe beruhenden politischen Ordnung klarer herausgestellt werden können. Dabei soll mit dem Begriff der Transzendenz auf zwei miteinander verbundene Dimensionen politischer Ordnung verwiesen werden: Zum einen geht es um die Behauptung von Unverfügbarkeit der Ordnung, zum anderen um den ordnungslegitimierenden symbolischen Überschuss, der auch als Unberührbarkeit suggerierende Sakralisierung bezeichnet werden kann. Keine radikale Neuinterpretation eines weithin bekannten Werkes also - aber dennoch kann gezeigt werden, wie das Rousseausche Euvre in all seinen Widersprüchen und Ambivalenzen durch die Frage nach der (Un)Verfügbarkeit politischer Ordnung verbunden wird.

Eine besondere Rolle spielt dabei der Naturbegriff: Obgleich Rousseaus Begrifflichkeiten weit verzweigte Bezüge zur Denktradition des jus naturalis aufweisen, ${ }^{4}$ so lässt er sich doch nicht ohne weiteres als Theoretiker des modernen Naturrechts einreihen: Trotz der Analogien in der staatsrechtlichen Dogmatik, allen voran die Souveränitätskonzeption, nimmt Rousseaus Naturbegriff im Unterschied zu seinen Vorgängern -

2 Vgl. zur Vertragstheorie: Wolfgang Kersting: Die politische Philosophie des Gesellschaftsvertrags, Darmstadt 1994; zur Volkssouveränität und Demokratietheorie: Ingeborg Maus: Über Volkssouveränität. Elemente einer Demokratietheorie, Frankfurt a.M. 2011. Die Vertrags- und Souveränitätskonzepte stehen auch im Mittelpunkt der Monographie von Karlfriedrich Herb: Rousseaus Theorie legitimer Herrschaft, Würzburg 1989.

3 Einschlägig dazu die Diskussion von Rousseaus Zivilreligion bei Hermann Lübbe: Religion nach der Aufklärung, Graz/Wien/Köln 1986, S. 306f. sowie Michaela Rehm: Bürgerliches Glaubensbekenntnis. Moral und Religion in Rousseaus politischer Philosophie, München 2006.

4 Vgl. zu den naturrechtlichen Bezügen die klassische Studie von Robert Derathé: Jean-Jacques Rousseau et la science politique de son temps, Paris 1950. 
seien es Grotius, Pufendorf, Burlamaqui, Barbeyrac oder Althusius - und auch im Vergleich zu den englischen Vertragstheoretikern Hobbes und Locke in seiner politischen Theorie eine recht eigentümliche Stellung ein. Die Natur dient hier gerade nicht als unverfügbarer Bezugspunkt für die Stabilisierung einer bestimmten, aus dem Naturzustand abgeleiteten Ordnung. In ihrer Offenheit schweigt sich die Natur über die gute Verfassung weitgehend aus und enthüllt damit die politische Ordnungsfrage in ihrer ganzen Radikalität. ${ }^{5}$ In einer normativen Verschärfung dieser Analyse hatte bereits Leo Strauss in seiner Verteidigung des Naturrechts gegen die Moderne Rousseau der substantiellen und normativen Entleerung des Naturrechts beschuldigt. ${ }^{6}$ Für Strauss war Rousseau mit einem Liberalismusverdacht belegt, der mit seinen individualistischen Prämissen und seiner vertragsrechtlichen Positivierung politischer Ordnung nicht unwesentlich zur Krise des Naturrechtsdenkens beigetragen hatte.

Wenngleich das Straus'sche Verdikt in seiner normativen Ablehnung der Moderne gründet, so ist doch zumindest seine Analyse bedenkenswert, die auch von Blumenbergs Einschätzung gestützt wird: Der Naturzustand ist in der Tat gerade aufgrund seiner Unbestimmtheit das Vehikel, das die politische Ordnung verfügbar stellt. War die Natur für den Proto- und Frühliberalismus eines Thomas Hobbes oder John Locke noch der negative

5 Vgl. Hans Blumenberg: Arbeit am Mythos, Frankfurt a.M. 1996, S. 247f.: „Wirksam an den gesellschaftlichen Mythen der Aufklärung war nicht die Definition von Erwartungen, sondern die Fiktion von Erinnerungen. Die von Rousseau erfundene Urgeschichte des Menschen als jenes unbedürftigen Naturwesens war, trotz der ausdrücklichen Feststellung ihres Autors von der Unwiederholbarkeit des Naturzustandes, die Proklamierung der Kontingenz jedes je gegenwärtigen kulturellen und politischen Zustandes. Darin war sie vor allem die Antithese vom status naturalis als dem Inbegriff der Vernunftzwänge zur Begründung staatlicher Herrschaft.“

6 Vgl. Leo Strauss: Naturrecht und Geschichte, Frankfurt a.M. 1977, S. 306f.: „Die Vorstellung, daß das gute Leben in der Rückkehr zum Naturzustand auf der Ebene der Humanität besteht, [...] führt mit Notwendigkeit zu der Konsequenz, daß das Individuum eine derartig große Freiheit von der Gesellschaft beansprucht, daß sie jedes bestimmten menschlichen Inhalts entbehrt. Dieser grundsätzliche Mangel des Naturzustandes als Ziel menschlichen Strebens war aber in Rousseaus Augen seine vollkommene Rechtfertigung: gerade die Unbestimmtheit des Naturzustandes als Ziel menschlichen Strebens machte diesen Zustand zum idealen Vehikel der Freiheit. [...] Es war die ideale Basis dafür, sich von der Gesellschaft auf etwas Unbestimmtes und Unbestimmbares zu berufen, auf ein letztes Heiligtum des Individuums als Individuum, unerlöst und ungerechtfertigt." 
Maßstab, aus der sich der Ausgang in die vernünftige Ordnung gewissermaßen automatisch (bei Hobbes) bzw. autonom (bei Locke) wie von selbst ergab, so ist Rousseau hier der politischere Denker: Ebenso wie bei seinem republikanischen Gesprächspartner Machiavelli sind es die Geltungsbedingungen, die sozio-moralischen, den kognitiv-rationalen Elementen politischer Entscheidung vorausgehenden Aspekte, die durch kluge politische Einrichtungen zwar begünstigt, nicht jedoch unter allen Umständen - also naturgemäß - garantiert werden können. Zwar gilt auch für Rousseau, was Jean Starobinski mit Blick auf dessen Zeitgenossen formuliert hat: Wer im 18. Jahrhundert recht haben will, ruft die Natur an. ${ }^{7}$ Der status naturalis aber erscheint uns nach Rousseau für die eigentliche Begründung der republikanischen Ordnung absolut unverfügbar und entzogen. Weder lässt er Raum für die Freiheit der Selbstkonstitution, noch fielen wir nach dem Tod des Leviathans in ihn zurück. ${ }^{8}$ Bei Rousseau wird die Natur damit aufgrund ihrer Entzogenheit deutungsoffen und entlässt uns in die Freiheit des politischen Handelns. Rousseaus Naturnarrativ setzt aus seinen transhistorischen Ursprüngen eine geradezu notwendige Verfügbarkeit über die politische Ordnung frei, die nun in ihrer Konstitution selbst zugänglich erscheint. Diese Verschiebung wird auch im Verfassungsbegriff selbst angezeigt: Bezeichnet er vor Rousseau noch die Physis des politischen Körpers und damit seine natürliche Gestalt, so wird die denaturierte Verfassung nun zum verfügbaren Gegenstand politischen Gestaltungswillens, zu einem „cybernetical political body ${ }^{\star 9}$.

7 Vgl. Jean Starobinski: Die Erfindung der Freiheit 1700-1789, Frankfurt a.M. 1988, S. 115. Zur Natur als Standard für das Gute, Schöne, Gerechte und Wertvolle vgl. Lorraine Daston/Fernando Vidal: Doing What Comes Naturally, in: dies. (Hrsg.): The Moral Authority of Nature, Chicago 2004, S. 1-20. Der Begriff der „Naturalisierung“ beschreibt demnach die moralische Autorität der Natur in menschlichen Dingen: „Naturalization imparts universality, firmness, even necessity - in short, authority - to the social.“ (ebd., S. 3)

8 Rousseau unterscheidet allerdings zwischen dem reinen und dem korrupten Naturzustand: Ersterer ist die transhistorisch entzogene Natur des Ursprungs, letzteres ist lediglich eine Chiffre für die depravierte politische Ordnung, die nicht republikanisch-gesetzesbasiert ist. Vgl. zur Unterscheidung der Naturzustände: OC III, Sur l'origine de l'inégalité, S. 191.

9 David William Bates: States of War. Enlightenment Origins of the Political, New York 2012, S. 171ff.; diese Transformation wird auch durch die metaphorologische Zwischenstellung Rousseaus angezeigt, der sowohl die - das naturalisierende Moment anzeigende - Körpermetapher ebenso wie die - auf das Artifizielle verweisende - Maschinenmetapher gleichermaßen verwendet. Gleichwohl bleiben die metaphorologischen Vexierspiele der Aufklärung uneindeutig, 
In einem ersten Schritt sollen die Naturnarrative der Transzendenz bei Rousseau in dreifacher Hinsicht entfaltet werden: als Stimme (und sehr viel seltener: als Buch) der Natur (2.1), als imaginärer Raum der Selbsttranszendenz (2.2) sowie als schweigende Natur (2.3). Dieser erste Schritt zeigt, wie aus der vielfältigen Transzendenz der Natur zunächst nur deren Offenheit für die politische Selbstkonstitution abgeleitet wird. Der zweite Schritt dokumentiert, mit welchen Mitteln der Schließung Rousseau auf die Kontingenz der politischen Ordnung zu reagieren versucht. Zentral ist dabei eine Strategie politischer Sakralisierung, die vom Gesetzgeber (3.1) über die Zivilreligion (3.2) bis hin zu einer politischen Festkultur reicht (3.3). Damit aber wird letztlich die Grenze einer Re-Naturalisierung des Gemeinwesens berührt.

\section{Naturnarrative}

Die Natur als handlungsleitende Einheits- und Orientierungsmetapher ist auf drei Ebenen für die soziale und politische Ordnung relevant: Als „Stimme der Natur" diktiert sie die unverfügbaren Grundzüge der Familienordnung, als Buch der Natur offenbart sie die Grundlagen der natürlichen Religion (2.1). Diese Transzendenz der Natur wird jedoch nicht unmittelbar für die politische Ordnungsgründung in Anspruch genommen. Als Gegenstand und Medium existentieller Einheitserfahrung dient die unverfügbare Natur zudem der Versicherung personaler Identität als Naturwesen (2.2), aber auch dieser Transzendenzbezug liefert keine Begründungsleistung für die Republik. In der Frage nach der guten politischen Ordnung sind wir allein mit dem Schweigen einer radikal entzogenen Natur konfrontiert (2.3).

steht doch Voltaire zufolge hinter dem unverfügbaren Ursprung der Natur wieder nur ein göttlicher Feinmechaniker. Schon für Descartes - und auch für Hobbes - waren natürliche Körper letztlich nichts anderes als komplexe Maschinen, ebenso künstlich wie natürlich. Erst im achtzehnten Jahrhundert begann sich dieser Komplex langsam aufzulösen in einen mechanistischen Materialismus (La Mettrie) und dessen biologisch-organisches Gegenstück (Diderot). Vgl. dazu Ernst Cassirer: Philosophie der Aufklärung [1932], Hamburg 2007, S. $37 \mathrm{ff}$. („Natur und Naturerkenntnis im Denken der Aufklärungsphilosophie“). Zur Veränderung des Verfassungsbegriffs auch: Wolfgang Schmale: Art. „Constitution, Constitutionnelle“, in: Rolf Reichardt/Jürgen Lüsebrink (Hrsg.): Handbuch politisch-sozialer Grundbegriffe in Frankreich 1680-1820, München 1992, S. 31-63. 


\subsection{Die Stimme der Natur}

Die Leitmetapher der sprechenden Natur erscheint immer dort, wo Rousseau die Liebe zwischen Mann und Frau sowie die Liebe und die Autorität der Eltern gegenüber den Kindern der reinen Konvention entziehen will. ${ }^{10}$ Aus der Stimme der Natur spricht für Rousseau die Unverfügbarkeit der natürlichen Familienordnung, die notwendig in den von der Natur induzierten Bedürfnissen gründet. Die höchste Form der natürlichen Gemeinschaft ist die gegenseitige Transparenz der Herzen: ${ }^{11}$ In der Offenbarung des Ich im Anderen liegt für Rousseau ein sakrales Moment, die Herzenseinheit gilt ihm als Möglichkeit und Ausdruck einer radikal unvermittelten Beziehung. Ort dieser natürlichen Herzenstransparenz ist die Familie, neben die Liebe aber tritt gleichberechtigt auch die Freundschaft - die deshalb so wichtig ist, weil sie die durch Bedürfnisentsagung realisierte Tugend in der Sphäre des Privaten darstellt. ${ }^{12}$ Um sich von den politischen Theorien paternalistisch begründeter Autorität abzusetzen, unterstreicht Rousseau die Differenz, die zwischen der natürlichen Familienordnung und der politischen Ordnung des Staates besteht. In seinem Enzyklopädie-Artikel zur politischen Ökonomie stellt er diese klassische Unterscheidung zwischen den Handlungssphären heraus: Während der Vater nur den natürlichen Neigungen des Herzens folgen muss, hat der Magistrat hingegen genau diesen Neigungen zu widerstehen und darf nur den Gesetzen folgen. ${ }^{13}$

Dennoch ist die Stimme der Natur auch für die politische Theorie von Bedeutung: Die natürliche Einheitserfahrung im vorpolitischen Raum der Freundschaft und der Familie ähnelt mit ihrem unvermittelten Transparenz-

10 „La voix de la nature est la plus forte. Le moyen de lui resister quand elle s'accorde à la voix du coeur?" (OC II, La Nouvelle Héloïse, S. 53) Ebendort erinnert Saint-Preux „la voix de la nature“ an seinen Vater (OC II, La Nouvelle Héloïse, S. 73), und die erste Fassung des Contrat Social nennt explizit „l'autorité naturelle d'un Pére de famille“ (OC III, Contrat Social première version, S. 297).

11 Vgl. zum Leitmotiv der Transparenz: Jean Starobinski: Jean-Jacques Rousseau: La transparence et l'obstacle, Paris 1971.

12 Dieser Topos wird vor allem in der Nouvelle Héloüse entfaltet, in der Clarens den vergänglichen Moment gelungener Vergemeinschaftung darstellt. Vgl. ebd., S. $102 \mathrm{ff}$.

13 „Si la voix de la nature est le meilleur conseil que doive écouter un bon pere pour bien remplir ses devoirs, elle n'est pour le magistrat qu'un faux guide qui travaille sans cesse à l'écarter des siens, et qui l'entraîne tôt ou tard à sa perte et à celle de l'état, s'il n'est retenu par la plus sublime vertu." (OC III, Discours sur l'économie politique, S. 243) 
anspruch der Einheit der Herzen mit dem Gesetz, das als das Eigene erkannt wird und aufgrund dieser Identitätssuggestion Geltung entfalten kann. In dieser gegenseitigen Durchdringung von Herz und Gesetz berühren sich daher bei Rousseau Natur und Konvention. Der zweite Berührungspunkt von politischer Ordnung und Naturoffenbarung besteht in der natürlichen Religion: Rousseau bedient sich im Glaubensbekenntnis des savoyardischen Vikars der Metapher vom offenen Buch der Natur, das als heilige Schrift jenseits der kirchlichen Vermittlungsinstitutionen einen wahrhaften, konfessions- und religionsübergreifenden Glauben, einen Kult der Herzen begründet. Für die politische Ordnung relevant ist diese Naturoffenbarung, weil mit dem hier gestifteten Glauben auch die bürgerliche Tugend- und damit die politische Bindungsfähigkeit gestärkt wird. ${ }^{14}$

Hinzu kommt drittens die natürliche Empathiefähigkeit, die pitié, die schon im zweiten Diskurs über die Ungleichheit thematisiert wird. ${ }^{15}$ Angesichts des enormen Erfolgs der Nouvelle Hélö̈se beim französischen Lesepublikum des achtzehnten Jahrhunderts hat Lynn Hunt den kulturellen Überschlagsprozess intensiver und leidenschaftlicher Romanlektüre beschrieben, der bei der Genese der politischen und sozialen Gleichheitsvorstellungen durch ein neues, imaginäres Narrativ geholfen hatte. Über diese kulturelle Vermittlung von individueller Subjekterfahrung, Herzensbindung und schützenswerter Innerlichkeit haben Mitleidensfähigkeit und Einfühlungsvermögen als imaginäre Geburtshelfer unverfügbarer natürlicher Rechte fungieren können. ${ }^{16}$ Gleichwohl liefert keines dieser Naturnarrative eine unverfügbare Begründung republikanischer Ordnung.

\section{2 „être ce que la nature a voulu“}

Ein weiteres, vor- bzw. transpolitisches Naturnarrativ liefern die Rêveries $d u$ promeneur solitaire. Sie entwerfen die Naturerfahrung als Rückzugsraum des Ich und zugleich als voluntaristische Selbsttranszendierung. Das

14 „C'est dans ce grand et sublime livre que j'apprends à servir et adorer son divin auteur. Nul n'est excusable de n'y pas lire, parce qu'il parle à tous les hommes une langue intelligible à tous les esprits.“ (OC IV, Émile, S. 625); „Le culte essentiel est celui du Coeur.“ (ebd., S. 627); „sans la foi nulle véritable vertu n'existe.“ (ebd., S. 632)

15 OC III, Sur l'origine de l'inégalité, S. 219.

16 Vgl. Lynn Hunt: Inventing Human Rights. A History, New York 2007. Zu Rousseau vgl. das Kapitel 1: „Torrents of Emotion“: Reading Novels and Imagining Equality. 
Gefühl der eigenen Existenz blendet über in die Einheit mit der Natur. Diese literarisch vermittelte Selbsterfahrung als Naturwesen, das Glück der Botanisiertrommel und der Rückzug in die Natureinsamkeit bedeuten eine Flucht vor der Gesellschaft, vor dem Blick der Anderen. Der republikanische Denker Rousseau hatte diesen Blick für den unwahrscheinlichen Fall einer guten Verfassung zwar stets als Garant einer tugendhaften Gemeinschaft gepriesen, aus der korrumpierten Gesellschaft seiner Zeitgenossen hingegen zieht sich der Autor Rousseau ebenso wie das literarische Subjekt Jean-Jacques in den Schutzraum der inneren und äußeren Natur zurück. ${ }^{17}$ Durch die meditative Versenkung in die Natur bleibt das innerste Selbst dem sozialen Zugriff entzogen. Dieser gesellschaftlich und politisch unverfügbare, natürliche Persönlichkeitskern wird von Rousseau mit unterschiedlichen Begriffen bezeichnet: Seele, Gewissen, Selbst etc. Die Träumereien bilden damit eine paradoxe Erzählung eines Subjekts, das sich für Andere unverfügbar beschreibt und sich in der ekstatischen Überschreitung zur Natur selbst als Naturwesen offenbar wird. Zugleich wird dieses Transzendenzerlebnis dem literarischen Publikum in seiner erzählerischen Form verfügbar gemacht. Die träumerische Versenkung in das Selbst erzeugt Selbsttranszendenz, ein natürliches Einheitsempfinden durch Weltentzug. Dieser Kontemplation in die eigene Endlichkeit als unverfügbare Dimension der eigenen Existenz dient daher die Natur als Medium der Sinnstiftung. Diese Idee der Selbsttranszendenz verweist einerseits zurück auf Elemente der Mystik, andererseits nimmt sie frühe Motive der radikal individuierten Existenzphilosophie vorweg. Auch von diesem Transzendenznarrativ führen jedoch nur sehr verzweigte Pfade zurück zum Politischen. ${ }^{18}$

\subsection{Die schweigende Natur}

Das ursprüngliche Problem der Republik gründet im Schweigen der Natur. Auch wenn Rousseau zahlreiche naturalisierende Familienmetaphern und -

17 „Je suis ce qu'il plait aux hommes tant qu'ils peuvent agir sur mes sens; mais au prémier instant de relache je redeviens ce que la nature a volou, c'est là quoi qu'on puisse faire mon état le plus constant et celui par lequel je me sens constitué.“ (OC I, Rêveries, S. 1084)

18 Vgl. Heinrich Meier: Über das Glück des philosophischen Lebens. Reflexionen zu Rousseaus Rêveries in zwei Büchern, München 2011; dort auch der problematische Versuch, die transzendente Naturerfahrung wieder an die politische Philosophie zurückzubinden. 
analogien für die politische Ordnung verwendet, so ist es doch nicht der natürliche Mensch, sondern der durch künstliche Bindungen und denaturierende Institutionen geschaffene Bürger, der im Zentrum seines politischen Denkens steht. ${ }^{19}$ Der Gründungsakt einer guten Verfassung muss demnach als Denaturierungsstrategie begriffen werden. Öffnet die Natürlichkeit in den intimen Beziehungen der Menschen einen Raum der unmittelbaren Herzensbindung, so verschleiert sie in politischer Hinsicht nur den Bedarf an künstlichen Bindungen, die durch die Gesetze erst gestiftet werden müssen. Gerade weil die Struktur der individuellen Bedürfnisse sich nicht ohne weiteres in die republikanische Ordnung des Gemeinwohls übersetzen lässt - ein Problem, das Rousseau mit seiner komplizierten Willensmechanik von Einzel- und Allgemeinwillen eher bezeugt als löst -, scheidet die Natur als unfehlbare Weisungsinstanz für die politische Verfassunggebung aus. ${ }^{20}$ Eine von der Natur diktierte politische Ordnung bleibt damit eine bloße Chimäre - und sie wäre auch keine Ordnung der Freiheit mehr, weil sie den Bedürfnissen und ihrer Befriedigung einen unangemessenen Stellenwert einräumen müsste. ${ }^{21}$ Somit ist auch die Vorstellung einer natürlichen Freiheit problematisch. Anstelle der Stimme der Natur tritt damit die Stimme des Gesetzes. ${ }^{22}$ Im Gesetz, so die Suggestion der volonté générale, sprechen die Menschen nicht als Naturwesen, sondern als Bürger zu sich selbst. Aus diesem Bruch mit der Natur entsteht die Freiheit zur konstitutionellen Verfügbarkeit der politischen Ordnung. Aus

19 „C'est qui fait la misère humaine est la contradiction qui se trouve entre notre état et nos désirs, entre nos devoirs et nos penchans, entre la nature et les institutions sociales, entre l'homme et le citoyen; rendez l'homme un vous le rendez heureux autant qu'il peu l'être. Donnez-le tout entier à l'etat ou laissez-le tout entier à lui-même, mais si vous partagez son coeur, vous le déchirez." (OC III, Fragments politiques, S. 510) Vgl. zu dieser Unterscheidung: Robert Spaemann: Rousseau - Mensch oder Bürger. Das Dilemma der Moderne, Stuttgart 2008, der damit allerdings zugleich den radikalen Vergesellschaftungs- und Politisierungsschub der Moderne als Absolutheitsanspruch problematisiert.

20, ,[L]a douce voix de la nature n'est pour nous un guide infaillible.“ (OC III, Contrat Social première version, S. 283)

21, ,[C]e prétendu traité social dicté par la nature est une véritable chimére; puisque les conditions en sont toujours inconnues ou impraticables, et qu'il faut necessairement les ignorer ou les enfreindre." (OC III, Contrat Social première version, S. 284)

22 Rousseau sagt über das Gesetz: „C'est cette voix céleste qui dicte à chaque citoyen les préceptes de la raison publique, et lui apprend à agir selon les maximes de son prope jugement, et à n'être pas en contradiction avec luimême.“ (OC III, Discours sur l'économie politique, S. 248) 
dieser selbstbezüglichen Struktur der Gesetzesherrschaft jedoch entsteht auch ein grundsätzliches Problem, das durch den Wegfall der Natur als Unverfügbarkeitsgenerator nur noch verschärft wird: Wie kann die einmal verfügbar gestellte Ordnung in eine dauerhaft geltende Verfassung überführt werden? Wenn das Gesetz die Garantie der Freiheit ist, was kann ihm Geltung verschaffen?

\section{Die UNVERFÜGBARKEIT DER POLITISCHEN ORDNUNG}

Der Akt der Verfassunggebung bedeutet das Knüpfen künstlicher Bande, die dort ansetzen, wo die Natur schweigt: Die politische Ordnung kann für Rousseau nicht nach dem Vorbild der natürlichen Einheit der Herzen gedacht werden, sondern nur auf der Grundlage der Gesetze. Damit diese künstlichen Bande jedoch einen Verpflichtungszusammenhang entfalten können, bedarf es darüber hinaus jener Ressourcen, die sich der unmittelbaren Verfügung durch den Gesetzgeber entziehen. Da die Natur hier wegfällt, sind es für Rousseau die Sitten und Gewohnheiten, die zwar kurzfristig der Verfügung entzogen sind, auf lange Sicht jedoch als ad hoc unverfügbare Stabilitätsgarantie in Form von sentimens de sociabilité, Gemeinsinn und Tugend politisch verfügbar gemacht werden können.

Tugend und Gemeinsinn sind demnach für Rousseau die eigentlichen Transzendenzressourcen, die in einer republikanischen Ordnung das Dilemma der Unverfügbarkeitsstiftung in einem freiheitsbasierten Gemeinwesen leisten können. Was aber zeichnet diese Tugend aus? Rousseaus Kritik der Wissenschaft und der Künste gibt uns einen Hinweis, wenn wir sie nicht vorschnell als bloße Dekadenztheorie sondern als eine aufklärende Kritik der Aufklärung, als Selbstaufklärung über den Ort der Transzendenz in der politischen Ordnung lesen. Die zentrale Aussage des ersten Diskurses lautet: Der Sinn der menschlichen Praxis erschließt sich als Einheit nur im Vollzug bürgerlicher Teilhabe, er bleibt jedoch theoretisch unverfügbar. ${ }^{23}$ Tugend besteht also nicht im Wissen, sondern im Handeln. Nicht die entzogen bleibenden, unmöglichen Kenntnisse über die letzten Dinge, die moralphilosophische Spekulation oder die repräsentative Darstellung des

23 „Nous avons des Physiciens, des Géometres, des Chymistes, des Astronomes, des Poetes, des Musiciens, des Peintres; nous n'avons plus des citoyens.“ (OC III, Discours sur les sciences et les arts, S. 26) 
Schönen und Guten in der Kunst, sondern die aktive Teilhabe an der politischen Gemeinschaft entwickelt einen einheitlichen Sinnzusammenhang, für den die Chiffre „Tugend“ steht. Wissenschaftliche und künstlerische Reflexion lösen den Einzelnen aus dem sozialen Kontext und führen deshalb in einen Zustand der Selbstentfremdung. ${ }^{24}$ Das Gute und Schöne erschließt sich erst über gemeinsinnige Teilhabe. Man kann so nach Rousseau nicht für sich selbst tugendhaft sein, sondern nur im Kontext sozialer und politischer Beziehungen, also im nicht-instrumentellen bzw. bedürfnisgeleiteten Umgang mit anderen. Die gelungene politische Praxis ist damit zugleich Ausgangspunkt als auch das Ziel der Tugend. Der Idealfall eines perpetuum mobile, eines aus sich selbst heraus angetriebenen Gemeinwesens taugt jedoch auch nach Rousseau nicht für die Praxis: Es bedarf demnach weiterer Faktoren, um diesen Mechanismus der in der bürgerlichen Praxis generierten Transzendenzproduktion von außen in Bewegung zu setzen und um ihm Dauer zu verleihen. Rousseau entwirft dazu drei Wege, um mit diesem Unverfügbarkeitsdilemma umzugehen: Das Problem des Anfangs soll durch die Ausnahmepersönlichkeit des Gesetzgebers überwunden werden (3.1). Das Problem der Dauer hingegen wird durch die Zivilreligion (3.2) und eng damit verbunden durch eine politische Festkultur (3.3) bewältigt.

\section{1 "Comment arriver aux coeurs?" Die Figur des Gesetzgebers}

Das Problem des Anfangs einer guten Verfassung hat sich Rousseau nicht nur im Gesellschaftsvertrag gestellt. Was im bekannten Kapitel über den Gesetzgeber theoretisch ausgeführt wird, hat in seinen Verfassungsentwürfen für Korsika und für Polen eine praxisnahe Form angenommen. Die Frage der Verfügbarstellung der politischen Ordnung wird so bei Rousseau noch nicht explizit als Revolution begriffen, sondern als gesetzgeberischer

24 Damit nimmt Rousseau hier einen zentralen Topos der philosophischen Anthropologie und der Institutionentheorie Gehlens vorweg: Dauerreflexion destabilisiert die Grundlagen sozialer Ordnung. Vgl. dazu Karl-Siegbert Rehberg: Natur und Sachhingabe. Jean-Jacques Rousseau, die Anthropologie und, das Politische“ im Deutschland des 20. Jahrhunderts, in: Herbert Jaumann (Hrsg.): Rousseau in Deutschland. Neue Beiträge zur Erforschung seiner Rezeption, Berlin/New York 1994, S. 221-266. Zur „Reflexionsfeindlichkeit beider Dauerreflektierer": ebd., S. 239. 
Akt nach den großen Vorbildern Moses, Lykurg und Solon. Die zentrale Frage dabei ist nicht die nach der Verfügung über die Gesetze, sondern über die Sitten und Gewohnheiten, der Verfügung über die Herzen - ein Problem, das Rousseau selbst als die politische Quadratur des Kreises beschrieben hat. ${ }^{25}$ Wie also kann eine Nation vom Gesetzgeber geformt werden? $?^{26}$

Zur Gesetzgebung „,bedürfte es einer höheren Vernunft, die alle Leidenschaften der Menschen sieht und selbst keine hat, die keinerlei Ähnlichkeit mit unserer Natur hat und sie dabei von Grund auf kennt [...]; es bedürfte der Götter, um den Menschen Gesetze zu geben“'27. Was für ein Gott also wäre der ideale Gesetzgeber? Rousseau hat hier einen deistischen Schöpfergott im Sinn, einen unbewegten Beweger, der sich mit vollbrachtem Schöpfungsakt aus seiner Schöpfung zurückzieht. Nun ist aber der Gesetzgeber kein Gott, sondern imitiert ihn nur in seiner Schöpfung, bis hin zur Schöpfung einer Natur. Hat ein Gott die menschliche Natur kreiert, so muss der Gesetzgeber gewissermaßen eine neue Natur jenseits der natürlichen Natur des Menschen formen. ${ }^{28}$ Der politische Schöpfungsakt gleicht somit einer künstlichen Denaturierung, der Formung einer zweiten, künstlichen Natur. $^{29}$

25 „Mettre la loi au-dessus de l'homme est un problème en politique, que je compare à celui de la quadrature du cercle en géometrie. [...] Il n'y aura jamais de bonne constitution que celle où la loi régnera sur les coeurs des citoyens. Tant que la force législative n'ira pas jusques là, les loix seront toujours éludées. Mais comment arriver aux coeurs?" (OC III, Pologne, S. 955) Der Contrat Social unterscheidet dazu vier Arten von Gesetzen: Staatsgesetze, bürgerliche Gesetze, Strafgesetze: „Zu diesen drei Arten von Gesetzen fügt sich eine vierte, die wichtigste von allen, die weder auf Marmor noch auf Erz, sondern in die Herzen der Bürger geschrieben wird; in ihr liegt die eigentliche Verfasstheit des Staates." (CS, S. 60)

26 Die Aufgabe lautet: ,former la nation pour le gouvernement“(OC III, Corse, S. 901).

27 CS, S. 43.

28 „Wer sich daran wagt, ein Volk zu errichten, muß sich imstande fühlen, sozusagen die menschliche Natur zu ändern [...]; die Verfaßtheit des Menschen zu ändern, um sie zu stärken“ (CS, S. 43f.); ,Je mehr die natürlichen Kräfte absterben und vergehen, desto stärker und dauerhafter werden die erworbenen." (CS, S. 44)

29 Für Korsika hingegen wandelte Rousseau diese Aufgabe in das kaum weniger paradox erscheinende Ziel einer künstlich erhaltenen Natürlichkeit. Die Korsen haben noch nicht die Laster, aber die Vorurteile der anderen Nationen übernommen: „ce sont ces préjugés qu'il faut combattre et détruire pour former un bon établissement“ (OC III, S. 902), „il faut les policer“ (ebd.). Die sozio-moralischen Grundlagen des Gemeinwesens werden daher durch Gesetze auf Dauer gestellt und konserviert (ebd., S. 903). Rousseau beschreibt das Paradox der 
Worauf aber gründet die Macht des Gründers? Auf einer Transzendenzbehauptung: Die „Heiligkeit seines Werkes“, seine Unantastbarkeit, beruht auf einer „Autorität anderer Ordnung“, die „ohne Gewalt mitreißen und ohne zu überreden überzeugen kann““. ${ }^{30}$ Die Gesetzgeber müssen „Zuflucht zum Himmel als Mittler“ nehmen, um „mit ihrer Weisheit die Götter zu schmücken“31. Rousseau bezieht sich dabei direkt auf Machiavellis historische Beobachtung in den Discorsi und verleiht ihr eine Wendung ins Normative. Der Gesetzgeber Rousseaus ist ein Transzendenzerzähler: Er leistet Arbeit am Mythos des Staates. Man kann in diesem Akt der Gründung in erster Linie eine Instrumentalisierung der Religion erblicken, und Rousseau selbst sagt offen, dass die Religion der Politik hier als Werkzeug dienen solle. ${ }^{32}$ Aber der Bezug auf die Religion allein reicht für Rousseau nicht aus. Er ist gewissermaßen eine aus der Not geborene, aber noch keine hinreichende Maßnahme für die erfolgreiche Geltungsstiftung - und er ist auch nicht für jedermann verfügbar, denn

„nicht jedem Menschen ist es gegeben, die Götter sprechen zu lassen oder Glauben zu finden, wenn er sich als ihr Deuter bezeichnet. Die große Seele des Gesetzgebers ist das eigentliche Wunder, das seine Sendung beweisen muss. Jeder Mensch kann auf Steintafeln schreiben oder ein Orakel kaufen oder eine geheime Verbindung zu irgendeiner Gottheit heucheln oder einen Vogel abrichten, damit er ihm ins Ohr singt [...]. Wer nicht mehr vermag als das, kann zwar durch Zufall vielleicht einen Haufen von Verrückten sammeln, er wird aber niemals ein Reich gründen [...]. Eitle Blendwerke bilden ein vergängliches Band, nur die Weisheit macht es dauerhaft.“33

Verfügung über das Unverfügbare: „Les Corses sont presque encore dans l'état naturel et sain, mais il faut beaucoup d'art pour les y maintenir. [...] Noble peuple, je ne veux point vous donner des loix artificielles et systématiques inventées par des hommes mais vous ramener sous les seules loix de la nature et de l'ordre qui commandent aux coeurs et ne tyrannisent point les volontés." (OC III, S. 950) Rousseaus Anspruch der Sittenbewahrung weist gleichwohl die Anzeichen eines gesetzgeberischen Verfügbarkeitsphantasmas auf: „Il s'agit de faire adopter au peuple la pratique de ce système, de lui faire aimer l'occupation que nous voulons lui donner, d'y fixer ses plaisirs, ses desirs, ses gouts, d'en faire géneralement le bonheur de la vie, et d'y borner les projets de l'ambition.“ (OC III, S. 918)

30 CS, S. 44 und S. 46.

31 CS, S. 46.

32 CS, S. 47. Zur Instrumentalisierung der Religion vgl. Rehm, Bürgerliches Glaubensbekenntnis, 2006, S. 135.

33 CS, S. 47. 
Ersetzen wir die „Weisheit“ durch das „Charisma“, so bietet Rousseau eine erstaunlich nahe Definition dessen, was Max Weber sehr viel später als einen zentralen Legitimitätstypus identifizierte. Der Kern dieser Geltungsstiftung, die „Weisheit des Gesetzgebers“ oder seine charismatische Fähigkeit, Menschen an die von ihm gestiftete Verfassung glauben zu lassen, entzieht sich damit für Rousseau der Verfügbarkeit, da „Weisheit“ ebenso wie Charisma nicht ohne weiteres produziert werden kann, sondern auf sozialen Zuschreibungen beruht. In einer republikanischen Ordnung ist das Charisma zudem alleine für den Akt des in Geltung Setzens einer guten und angemessenen Verfassung relevant. In der Verfassung selbst ist nach Rousseau kein Platz für einen charismatischen Herrscher, der in eine asymmetrische Sakralitätskonkurrenz zu den Gesetzen treten würde und deren mühsam erzeugte, entpersonalisierte Heiligung wieder zunichte machte. Die transzendente Aufladung der Gesetze dient gerade dazu, jegliche Form der personalen Herrschaft und des charismatischen Ausnahmeherrscher überflüssig zu machen. Es bedarf also charismatischer, geheiligter Gesetze; einer Transformation personaler Sakralität des Stifters in die Sakralität des Gesetzestextes. Im Medium der Gesetze erscheint die von der politischen Aufklärung postulierte Vernunft in einem charismatischen Kleid. ${ }^{34}$ Sakralität aber will geglaubt werden - daher ist es nicht verwunderlich, wenn Rousseau auf der Rückseite des Kapitelmanuskriptes über den Gesetzgeber das korrespondierende Kapitel über die Zivilreligion geschrieben hat. ${ }^{35}$ Beide Kapitel stellen spiegelbildlich die zwei Seiten des systematischen Begründungsproblems dar. Dessen Bearbeitung bei Rousseau erscheint aber erst mit der Rolle der politischen Festkultur vollständig.

34 Max Weber schreibt dazu am Ende seiner Geschichte des Charismas: „die charismatische Verklärung der ,Vernunft' (die ihren charakteristischen Ausdruck in ihrer Apotheose durch Robespierre fand), ist die letzte Form, welche das Charisma auf seinem schicksalsreichen Wege überhaupt angenommen hat" (Max Weber: Wirtschaft und Gesellschaft. Die Wirtschaft und die gesellschaftlichen Ordnungen und Mächte, Herrschaft, MWG I/22-4, hrsg. von Edith Hanke, Tübingen 2009, S. 216).

35 Vgl. die Hinweise des Herausgebers Robert Derathé in der Einleitung zum Genfer Manuskript des Contrat Social (OC III, S. LXXXVIIIf. sowie in den Anmerkungen S. 1427). 


\section{2 "L'autorité la plus absolue“ - Die Zivilreligion}

Nach der charismatisch überhöhten Gründung folgt das eigentlich größere Problem: Wie kann die Verfassung auf Dauer gestellt werden? Wie kann die Bindung der Bürger an die Verfassung gesichert werden? Nach Rousseau lautet das erste Gesetz einer Republik, dass die Gesetze zu respektieren sind. ${ }^{36}$ Ein Gesetz, das seine eigene Befolgung regeln will, stößt jedoch auf logische Probleme und praktische Widerstände. Das Gebot der Gesetzesbefolgung kann daher für Rousseau nicht auf derselben Ebene liegen wie die Gesetze selbst, sondern zielt auf die Möglichkeit, die normativen Praxisformen gefügig zu machen. Um den Geltungsglauben der Bürger an den Gesetzen auszurichten, bedient sich Rousseau daher der Religion als Stabilisierungsinstrument. ${ }^{37}$ Wenngleich eine allgemein verstandene Religiösität ganz grundlegend die Glaubensfähigkeit und damit die Fähigkeit zur Herzensbindung garantiert, so erfüllen doch nicht alle religiösen Formen in gleichem Maße die politische Integrationsfunktion. Den Katholizismus verwirft Rousseau als Priesterreligion, die aufgrund eines eigenen Herrschaftsanspruchs der Gesetzesbindung der Bürger diametral widerstrebt. Die christliche Offenbarungsreligion in ihrer protestantischen Ausrichtung wirkt aber ebenfalls nicht integrierend, weil ihr universalistischer Horizont vom Gemeinwesen distanziert. Die „Religion des Bürgers" nach antiken Vorbildern dagegen ist zu partikularistisch, ihr fehlt die Transzendenzdimension. Übrig bleibt Rousseaus Zivilreligion als ein Syntheseversuch, der den Glauben an Gott und an die politische Verfassung miteinander vereint.

Für die Verfassung Korsikas hatte Rousseau einen Bürgerschwur auf die Verfassungsgrundsätze geplant, und auch in der ersten Version des Contrat social war noch der explizite Schwur eines Glaubensbekenntnisses aller Bürger enthalten. ${ }^{38}$ Auch wenn die Zeremonie in der endgültigen

36 „La premiere des lois est de respecter les lois.“ (III, Economie politique, S. 249)

37 „Sitôt que les hommes vivent en société il leur faut une Religion qui les y maintienne. Jamais peuple n'a subsisté ni ne subsistera sans Religion et si on ne lui en donnoit point, de lui-même il s'en feroit une ou seroit bientôt détruit.“ (OC III, Contrat Social première version, S. 336)

38 OC III, Contrat Social première version, S. 340f.; OC III, Corse, S. 943. Die Bekenntnisformel lautet: „Au nom de Dieu tout puissant et sur les saints Evangiles par un serment sacré et irrévocable je m'unis de corps, de biens, de volonté et de toute ma puissance à la nation corse pour lui appartenir en toute proprieté, moi et tout ce qui dépend de moi. Je jure de vivre et mourir pour elle, d'observer 
Fassung nicht mehr erwähnt wird, so bleibt doch die sanktionsbewehrte Verpflichtung der Bürger durch den Souverän auf die Dogmen der Zivilreligion erhalten: die Existenz Gottes, ein Leben nach dem Tode sowie die Heiligkeit des Gesellschaftsvertrags und der Gesetze; als negatives Dogma abgelehnt werden muss die Intoleranz, in weltlicher wie in religiöser Hinsicht. Ob das bürgerliche Glaubensbekenntnis in öffentlich-ritualisierter Form gedacht wird, oder auch in der schwächeren Form einer bloßen Verhaltenskonformität: es bleibt für den öffentlichen Verrat an der geheiligten Verfassung die Todesstrafe. ${ }^{39}$ Auch wenn über die Verräter am Geist der Gesetze wenig gesagt wird: Gemeint sind doch in erster Linie Übergriffe auf die symbolisch-sakrale Dimension der Konstitution, in denen ihr heiliger Verpflichtungscharakter in Frage gestellt wird - eine Art republikanischer lèse-majesté, eine Verletzung des künstlich-symbolischen Körpers der Verfassung, die für jedermann sichtbar die Transzendenzbehauptung in Frage stellt und die daher ebenso sichtbar bestraft werden muss, um die Verletzung des Souveräns wieder zu heilen. Problematisch ist dabei die staatliche Deutungshoheit über einen solchen Verrat, der bei weiter Auslegung mit jeglichem Gesetzesverstoß identisch wäre, zudem Rousseau nur ungenau zwischen Verfassungsgesetzen und einfachen Gesetzen differenziert. In diesem sanktionsbewehrten Verfügungswillen über das Glaubensbekenntnis liegt daher die Illiberalität der ganzen Konstruktion.

Rousseau selbst war sich der Problematik jedoch im Ansatz bewusst. Zwar könne der Souverän die Dogmen festlegen, den Glauben aber kann er letztlich nicht erzwingen. ${ }^{40} \mathrm{Ihm}$ ist daher klar, dass nur das äußere Verhalten sanktioniert werden kann. ${ }^{41}$ Freilich führen diese Zweifel nicht zu einer Abkehr vom politischen Verfügbarkeitsglauben. Die Regierung eines konstituierten Gemeinwesens habe zahlreiche Mittel, die „sentimens de

les loix et d'obeir à ses chefs et magistrats légitimes en tout ce qui sera conforme aux loix. Ainsi Dieu me soit en aide en cette vie et fasse misericorde à mon ame. Vive à jamais la liberté, la justice et la République des Corses. Amen.“

39 OC III, Contrat Social première version, S. 341.

40 „Les Magistrats, les Rois n'ont aucune autorité sur les ames, et pourvu qu'on soit fidelle aux Loix de la société dans ce monde, ce n'est point à eux de se mêler de ce qu'on deviendra dans l'autre, où ils n'ont aucune inspection." (OC III, Lettres ecrits de la Montagne, S. 711)

41 Vgl. OC III, Fragments politiques, S. 555: „La loi n'agit qu'en dehors et ne règle que les actions; les moeurs seules pénétrent intérieurement et dirigent les volontés.“ 
sociabilité“ ${ }^{42} \mathrm{zu}$ fördern: Sie ist der Garant der Verfassung und besitzt „mille moyens de la faire aimer“. Sie muss die Herzen gewinnen, denn zu ihren essentiellen Aufgaben gehört der Erhalt der Sitten. ${ }^{43}$ Fraglich ist die mögliche Eingriffstiefe in den inneren sozio-moralischen und sozio-emotionalen Haushalt der Bürger. Hier und nicht in der Stärke des äußeren militärischen oder anderweitig gewaltsamen Zwangs zeigt sich für Rousseau die größte politische Macht und wahre Regierungskunst. ${ }^{44}$ Nicht die Sitten formen die Gesetze, wie Montesquieu gezeigt hatte, sondern die Gesetze sollen die Sitten formen. Es bedarf daher einer Praxis der Habitualisierung, der affektiven Einübung der Gesetze, mit denen zugleich die notwendigen gemeinsinnigen Verhaltensdispositionen der Bürger gestärkt werden. Dazu sind nach Rousseau gleichermaßen kognitive wie affektiv-emotionale Aspekte zu beachten: Die Bürger müssen die Gesetze kennen, wozu ähnlich des Studiums der Heiligen Schrift eine regelmäßige gemeinsame Lektüre der Gesetze notwendig ist. ${ }^{45}$ Aus diesem Grund allerdings müssen die Gesetze klar und einfach bleiben, sie dürfen die Kapazität der normalen Bürger nicht überschreiten. Das in Rousseaus Augen wirksamste Mittel praktizierter Gesetzesverehrung liegt aber in einer republikanischen Festkultur.

\section{3 ,jeux d'enfans“ - Politische Festkultur}

Politische Feste schaffen Räume der Transzendenz, in denen der zwanglose Zwang zum öffentlichen Bekenntnis wirksam und die im Alltäglichen unverfügbare Herzenseinheit der Bürger mit dem Gemeinwesen erfahrbar

42 OC III, S. 469 (CS, S. 151).

43 OC III, S. 250. Auch: OC III, Fragments politiques, S. 485 („maintenir les moeurs").

44 „S'il est bon de savoir employer les hommes tels qu'ils sont, il vaut beaucoup mieux encore les rendre tels qu'on a besoin qu'ils soient; l'autorité la plus absolue est celle qui pénétre jusque'à l'inérieur de l'homme, et ne s'excerce pas moin sur la volonté que sur les actions. Il est certain que les peuples sont à la longue ce que le gouvernement les fait être." (OC III, Economie politique, S. 251) „Formez donc des hommes si vous voulez commander à des hommes; si vous voulez qu'on obéisse aux lois, faites qu'on les aime." (OC III, Economie politique, S. 251f.)

45 „La seul étude qui convienne à un bon Peuple est celle de ses Loix. Il faut qu'il les médite sans cesse pour les aimer.[...] Tout Etat où il y a plus de Loix que la mémoire de chaque citoyen n'en peut contenir est un Etat mal constitué, et tout homme qui ne sait pas par coeur les loix de son pais est un mauvais Citoyen.“ (OC III, Fragments, S. 492) 
werden sollen. Feste sind Transzendenzgeneratoren, ihr Erfolg aber entzieht sich der Verfügung. Als organisierte Spontaneität und geregelte Ausnahme verkörpern sie eine widersprüchliche Praxis - genau daher aber sind sie die angemessene Form der Rousseau'schen Quadratur des Kreises, um das instrumentelle Regelwerk der Verfassung zur Herzenssache der Bürger zu machen. Auch hier ist sich Rousseau der Paradoxie zögernd bewusst, betont er doch in seinem Fest und Spektakel gewidmeten Brief an D'Alembert die Unverfügbarkeit des individuellen Glaubens, der von außen nicht zu beurteilen ist. ${ }^{46}$ Dennoch zeigt sich auch hier, wie repräsentationsfeindlich Rousseaus politische Theorie bis in die Grundlagen hinein ist und wie sehr sie die unvermittelte Teilhabe an der politischen Einheit betont. ${ }^{47}$ D'Alembert hatte in seinem Enzyklopädie-Artikel zu Genf für die bislang fehlende Einrichtung eines Theaters plädiert, um die Sitten zu stärken. Rousseau jedoch attackierte diesen Vorschlag als politischer Theoretiker vehement: Ein Theater diene nicht dem Gemeinsinn, da es stärker vereinzele als es vergemeinschafte.$^{48}$ Es reduziere die Bürger auf das passive, von einander isolierte Zuschauen. Der Bürger spielt buchstäblich keine Rolle. ${ }^{49}$ Ebenso wie in der politischen Ordnung lehnt er die darstellend-repräsentative Dimension des Theaters ab, weil sie Distanz statt Nähe schafft. ${ }^{50}$

Ganz anders dagegen das republikanische Bürgerfest, das Rousseau als Alternative preist: Es verspricht eine inklusive, aktive Vergesellschaftung ohne anderes Ziel und Inhalt als die öffentliche Teilhabe selbst. Damit verkörpert es ein praktisches Symbol gemeinsamer Freiheit. ${ }^{51}$ Die politischen

46 „Qui sais mieux que moi ce que je crois ou ne crois pas, et à qui doit-on s'en rapporter là-dessus plustôt qu'à moi même? [...] je suis l'ami de toute Religion paisible, où l'on sert l'Etre éternel selon la raison qu'il nous a donné. Quand un homme ne peut croire ce qu'il trouve absurde, ce n'est pas sa faute, c'est celle de sa raison." (OC V, Lettre à D'Alembert, S. 10f.)

47 Die in der Ablehnung des Theaters manifeste Repräsentationskritik Rousseaus diskutiert demokratietheoretisch jetzt Juliane Rebentisch: Die Kunst der Freiheit. Zur Dialektik demokratischer Existenz, Berlin 2012, S. $271 \mathrm{ff}$.

48 „L'on croit s'assembler au Spectacle, et c'est là que chacun s'isole; c'est là qu'on va oublier ses amis, ses voisins, ses proches.“ (OC V, Lettre à D'Alembert, S. 16)

49 „Il n'a point de rôle a jouer; il n'est pas Comédien.“ (ebd., S. 24)

50 „Plus j'y reflechis, et plus je trouve que tout ce qu'on met en représentation au théatre, on l'approche pas de nous, on l'éloigne." (ebd.)

51 ,[D]onnez les Spectateurs en Spectacle; rendez-les acteurs eux-mêmes; faites que chacun se voye et s'aime dans les autres, afin que tous en soient mieux unis." (ebd., S. 115) 
Tugenden und der Gemeinsinn müssen den Bürgern buchstäblich vor Augen gehalten werden. ${ }^{52}$ Die politische Präsenzkultur der Tugend und der Bürgerpflichten gleicht daher einem erzieherischen Projekt, in dem Rousseau dem Gemeinwesen die Rolle der Mutter zuweist und den Bürgern die Rolle der Kinder. ${ }^{53}$ Für seine Heimatstadt Genf schlägt Rousseau neben diesen politischen Freiluftfesten auch gesellschaftliche Debütantenbälle vor, auf denen die jungen Unvermählten mit ihren Familien zum Zwecke der Heiratsanbahnung zusammenkommen. Diese republikanische Partneragentur soll die Reproduktion der grundlegenden Familienstruktur garantieren, die der politischen Ordnung zuträglich ist. ${ }^{54}$ Gleiches hat er für Korsika im Sinn, wenn er das Bürgerrecht nur für diejenigen Männer vorbehalten wollte, die bis $\mathrm{zu}$ ihrem vierzigsten Lebensjahr geheiratet haben und Vater zweier Kinder sind. ${ }^{55}$ So ist es kaum erstaunlich, dass an denselben Stellen auf die störende Wirkung von Fremden und Ausländern hingewiesen wird. ${ }^{56}$

52 „Ne négligez point une certaine décoration publique; qu'elle soit noble, imposante, et que la magnificience soit dans les hommes plus que dans les choses. On ne sauroit croire à quel point le coeur du peuple suit ses yeux. Cela donne à l'autorité un air d'ordre et de régle qui inspire la confiance et qui écarte les idées de caprice et de fantaisie attachées à celle du pouvoire arbitraire." (OC III, Pologne, S. 964)

53 „Par où donc émouvoir les coeurs, et faire aimer la patrie et ses loix? L'oserai-je dire? Par des jeux d'enfans; par des institutions oiseuses aux yeux des hommes superficiels, mais qui forment des habitudes cheries et des attachemens invincibles“ (OC III, Pologne, S. 955); „Beaucoup de jeux publics où la bonne mere patrie se plaise à voir jouer ses enfants. Qu'elle s'occupe d'eux souvent afin que'ils s'occupent toujours d'elle. [...] il faut inventer des jeux, des fêtes, des solemnités.“ (OC III, Pologne, S. 962)

$54,[$ C] ]es Bals [...] ressembleroient moins à un Spectacle public qu'à l'assemblée d'une grande famille, et du sein de la joye et de plaisirs naitroient la conservation, la concorde et la prospérité de la République." (OC V, Lettre à D'Alembert, S. 120) Hier und an anderer Stelle zeigt sich, dass Bevölkerungswachstum für Rousseau ein zentraler Indikator für die gute Konstitution des Gemeinwesens ist.

55 OC III, Corse, S. 919: „posant la loi fondamental sur la nature de la chose“, sowie ebd., S. 941.

56 Für Genf: ,je suis persuadé, quand à moi, que jamais étranger n'entra dans Genève qu'il n'y ait fait plus de mal que de bien.“(OC V, Lettre à D'Alembert, S. 120) Für Korsika gilt zwar das Bürgerrecht qua Geburt, aber nur alle fünfzig Jahre einmal kann ein einziger Fremder eingebürgert werden - „Sa reception sera une fête générale dans toute l'Isle." (OC III, Corse, S. 941) Auch für Polen gilt diese patriotische Exklusion: ,affectionner les Polonois à leur pays“ et „leur donner une répugnance naturelle à se mêler avec l'étranger“ (OC III, Pologne, S. 962). 


\section{Der Ort der Transzendenz}

Rousseaus ursprünglicher Anspruch, die politische Ordnung der Republik auf dem Schweigen der Natur zu errichten, führt mitten hinein in die doppelte Bewegung der Transzendenz: Jenseits der unverfügbaren und heiligen Natur wird die politische Ordnung verfügbar. Zugleich bedarf es jedoch zur Begründung und Stabilisierung der neuen Republik einer quasinatürlichen Rückbindung an entzogene Quellen der Transzendenz. Rousseaus Stabilitätsverlangen geht dabei soweit, letztlich auch über diese Quellen der Unverfügbarkeit verfügen zu wollen. Wie wir gesehen haben, berührt dieser Verfügbarkeitsanspruch neben der Kreation einer künstlichen Natur am Ende die natürlichen Grundlagen des Gemeinwesens selbst: Die Familienmetaphorik der politischen Gemeinschaft verlässt hier ihre Bildlichkeit und geht über in die natürlichen Produktionsbedingungen der Staatsbürger. Damit ist der Rückzug der Natur bei Rousseau nicht so vollständig, wie es seine politische Denaturierungsstrategie vorgibt. Als natürliche Familienordnung und in der existenziellen Selbsterfahrung als Naturwesen stellt die Natur immer noch eine transzendente Geltungsressource zur Verfügung, die im Rahmen einer denaturierten politischen Ordnung zu komplexen Spannungen führt. Hinzu kommt der Versuch, die natürliche Genese der Generationenfolge auch für die Stabilisierung politischer Ordnungsvorstellungen in den Dienst zu nehmen. Es ist daher kein Zufall, dass auch die Französische Revolution sich mit ihren politischen Geltungsansprüchen stets in diesem Spannungsfeld von Denaturalisierung und Renaturalisierung bewegte, aus dem eine dynamische Transformation der transzendenten Bezugsmöglichkeiten hervorging. Zwischen den Polen einer Vergesellschaftung der natürlichen Ordnung oder einer Naturalisierung der Gesellschaft wurden hier neue, komplexe Konstellationen der Unverfügbarkeit erprobt, die den Ort der Transzendenz in der Schwebe zu halten versuchten. Dass die Revolution diesen Ort am Ende mit dem Heiligen Jean-Jacques selbst besetzen wollte, wäre demnach mehr als nur eine ironische Pointe. Heilen konnte die Wunde auch derjenige nicht, der sie einst diagnostiziert hatte. 


\title{
Die Tugend, der Markt, das Fest und der Krieg
}

\author{
Über die problematische Wiederkehr vormoderner
}

Gemeinsinnserwartungen in der Postmoderne

\section{HERFRIED MÜNKLER}

\section{Gier, GeIZ UND ,NEUe BÜRgerLICHKEIT‘}

Es war im evolutionstheoretisch grundierten Selbstverständnis moderner Gesellschaften nicht vorgesehen, dass man wieder auf die Vorstellungen von rechtem Maß und Anstand, Angemessenheit und Zurückhaltung zurückgreifen würde, um einen größeren Teil der wirtschaftlichen Eliten an den sozialmoralischen Zügel zu nehmen. Der Diskurs über Tugend und Laster, Maß und Maßlosigkeit gehörte der Vormoderne an, und die sozialwissenschaftlichen Theorien, von der Ökonomie über die Soziologie bis zur Politikwissenschaft, hatten versichert, dass institutionelle Arrangements und rechtliche Verfahren die Aufgaben übernommen hätten, die in der vormodernen Gesellschaft von sozialmoralischen Regulationssystemen bearbeitet worden waren ${ }^{1}$ - von der Beichte und der Gemeindedisziplin bis zu

$1 \mathrm{Zu}$ diesen sozialmoralischen Regulationssystemen gehörten sowohl das aristokratische Ethos, wie es Baldassare Castiglione paradigmatisch in seinem Libro del Cortegiano beschrieben hat (vgl. dazu Peter Burke: Die Geschichte des „Hofmann“. Zur Wirkung eines Renaissance-Breviers über angemessenes Verhalten, Berlin 1996), als auch die sehr genauen Verhaltenserwartungen, die das Leben der Handwerker, Bergmänner usw. bestimmten (vgl. Edward P. Thompson: Plebeische Kultur und moralische Ökonomie. Aufsätze zur englischen Sozialgeschichte des 18. und 19. Jahrhunderts, Frankfurt a.M./Berlin 1980). Auch das bäuerliche Zusammenleben war sozialmoralisch reguliert, etwa 
den politischen Verhaltenslehren der Fürstenspiegel. ${ }^{2}$ Und schließlich wurde auch der liberale Charakter der modernen Gesellschaft in Abhängigkeit davon beschrieben, dass sich Politik und Staat aus dem heraushielten, was längst zu einer Frage der individuellen Moral geworden war. Sicherlich ist dieser Rückzug der Tugenderwartung aus den Feldern von Staat und Gesellschaft nicht mit einem Mal und auf einen Schlag erfolgt, sondern schrittweise. Dabei hat es Avantgarden und Arrièregarden gegeben, liberale und mehr oder weniger konservative Sichtweisen, aber zuletzt haben doch die Liberalen und deren politische Verbündete die Marschrichtung vorgegeben, und die Konservativen sind deren Vorgaben gefolgt.

Aber dann brach im Jahre 2008 unter dem Eindruck der Banken- und Finanzkrise eine bis heute anhaltende, periodisch an- und abschwellende Gierdebatte los, in der eines der alten Laster, das in der Vormoderne eine wesentliche Rolle bei der adhortativen Steuerung der Gesellschaft gespielt hatte, die avaritia, die Habgier, zur sozialmoralischen Erklärung der Finanz- und Wirtschaftskrise avancierte. Die Mächtigen und Reichen, so die sich unter dem Eindruck platzender Finanzblasen schnell ausbreitende ,Gierdebatte', hätten jedes Ziel und Maß verloren. ${ }^{3}$ Vor allem Banker und Manager gerieten in den Fokus der Kritik: Sie zeigten ein Zockerverhalten, bei dem sie mit dem wirtschaftlichen Schicksal der Menschen spielten, missachteten obendrein das Gebot der Nachhaltigkeit, und eigentlich gehe

in der Art, dass in Krisenzeiten familiale und nachbarschaftliche Solidarität den Bewegungen der Marktpreise entgegenzuwirken hatte (vgl. dazu Giovanni Levi: Das immaterielle Erbe. Eine bäuerliche Welt an der Schwelle zur Moderne, Berlin 1986, bes. S. 75ff.).

2 Hierzu Hans-Otto Mühleisen/Theo Stammen (Hrsg.): Politische Tugendlehre und Regierungskunst. Studien zum Fürstenspiegel der Frühen Neuzeit, Tübingen 1990; über die Verhaltenssteuerung des Herrschens durch die Gewissenserforschung in der Beichte vgl. exemplarisch Ernst-Albert Seils: Die Staatslehre des Jesuiten Adam Contzen, Beichtvater Kurfürst Maximilians I. von Bayern, Lübeck-Hamburg 1968.

3 Die ,Gierdebatte', d.h. der Vorwurf, an den jüngsten Krisen der kapitalistischen Ordnung seien nicht systemische Ursachen, sondern die Maßlosigkeit einiger Wirtschaftssubjekte in maßgeblichen Positionen schuld, ist in mancher Hinsicht eine Umkehrung der ,Neiddebatte', in der den Kritikern der Vermögensunterschiede vorgehalten worden war, die Motive ihrer Kritik lägen in persönlichen Neidempfindungen. Neid wie Gier sind gleichermaßen Laster (vgl. Wolfgang Sofsky: Das Buch der Laster, München 2009, S. 116ff. und S. 154ff.), aber nur Neid ist ein Gefühl (vgl. Christoph Demmerling/Hilge Landweer: Philosophie der Gefühle. Von Achtung bis Zorn, Stuttgart 2007, S. 195-217), während Gier/Habgier habituelle Dispositionen sind. 
es ihnen nur darum, ohne jeden Sinn fürs Gemeinwohl möglichst große Gewinne für sich selbst einzustreichen. „Akkumuliert! Akkumuliert! Das ist Moses und die Propheten“ - Marx’ polemische Zuspitzung der handlungsleitenden Maxime im Kapitalismus scheint sich nun wirklich durchgesetzt zu haben. ${ }^{4}$ Dabei hatte sich Marx überhaupt nicht für die individuellen Verhaltensdispositionen der Kapitalisten interessiert und von deren Änderung auch keine Effekte für die gesellschaftliche Ordnung erwartet im Unterschied zu Werner Sombart, dem ersten Historiker des Kapitalismus, der in der „Wirtschaftsgesinnung“ einen ausschlaggebenden Faktor des ökonomischen Geschehens gesehen hat. ${ }^{5}$ Marx dagegen wandte sich den systemischen Mechanismen zu, von denen er annahm, dass sie das individuelle Verhalten steuerten. Aber auch in der Wirtschaftssoziologie, von der, wie etwa bei Max Weber, die Entstehung des modernen Kapitalismus aus religiösen Einstellungen und Mentalitäten heraus erklärt wurde, spielten nicht Gier oder Habsucht die erklärende Rolle, sondern Askese und Disziplin, durch die, so Weber, das Akkumulationsstreben der Menschen verstetigt und deren Rückfall in eine neofeudale Wirtschaftsgesinnung verhindert wurde. ${ }^{6}$ Das ist die eigentliche Pointe der ,Gierdebatte ${ }^{6}$ : dass sie auf die Vorstellungswelten der Vormoderne zurückgreift, indem sie eine moralische Disposition, die in der Vormoderne als Laster bezeichnet wurde, für die Krise der wirtschaftlichen Ordnung verantwortlich macht.

Aber es ist keineswegs bloß die Gierdebatte, in der sich die Wiederkehr einer sozialmoralischen Gesellschaftsdiagnostik und Verhaltensregulation manifestiert, sondern ebenso ist dies die Diskussion über eine ,neue Bürgerlichkeit', die hierzulande seit etwa einem Jahrzehnt geführt wird und in der sich die Idee der Rückkehr eines sozialmoralischen Habitus äußert, in dem die Dispositionen des Bürgertums im 19. und frühen 20. Jahrhundert wieder aufleben ${ }^{7}-$ einer sozialen Figuration, die wie keine andere Schicht

4 Karl Marx: Das Kapital, Bd. 1, MEW, Bd. 23, Berlin 1968, S. 621.

5 Werner Sombart: Der moderne Kapitalismus. Historisch-systematische Darstellung des gesamteuropäischen Wirtschaftslebens von seinen Anfängen bis zur Gegenwart, 3 Bde. in 6 Teilbdn., Berlin 1902.

6 Max Weber: Die protestantische Ethik. Eine Aufsatzsammlung, hrsg. von Johannes F. Winckelmann, Hamburg 1972, sowie Max Weber: Wirtschaftsgeschichte. Abriss der universalen Sozial- und Wirtschaftsgeschichte, hrsg. von Sigmund Hellmann und Melchior Palyi, Berlin 1958, S. 300f.

7 Vgl. Heinz Bude/Joachim Fischer/Bernd Kauffmann (Hrsg.): Bürgerlichkeit ohne Bürgertum. In welchem Land wohnen wir?, München 2010. 
der Gesellschaft die Verfolgung ihrer Eigeninteressen mit der Orientierung am Gemeinwohl verbunden hat und die soziale Trägerschicht des Gemeinsinns gewesen ist. ${ }^{8}$ Die ,neue Bürgerlichkeit' wird als Rückgewinnung oder Wiederherstellung der sozialmoralischen Dispositionen des Bürgertums begriffen, ohne dass dies jedoch mit einer entsprechenden Rekonstruktion der einstigen sozio-ökonomischen Grundlagen des Bürgertums verbunden ist. Dies ist nicht bloß eine soziologische Beobachtung, für die man empirische Belege wie Gegenbeispiele beibringen kann, sondern damit sind auch politische Erwartungen verbunden. Das zeigt sich darin, dass die ,neue Bürgerlichkeit‘ als Antwort auf eine als bedrängend wahrgenommene Herausforderung verstanden wird: die des Zusammenhalts einer Gesellschaft, deren zentrifugale Kräfte immer stärker werden. Bürgerlichkeit, alt oder neu, wird als sozialmoralisches Dispositiv der gesellschaftlichen Zentripetalität ins Spiel gebracht. Neid und insbesondere Gier werden dagegen als Faktoren einer Zentrifugalität begriffen, die den gesellschaftlichen Zusammenhalt in Frage stellt und auf die Dauer zerstören wird.

Die konstatierte oder auch bloß imaginierte ,neue Bürgerlichkeit" ist in der ihr zugeschriebenen Gemeinsinndisposition und einer generösen Offenheit für Gemeinwohlerfordernisse aber auch der Antipode zu einer den Unterschichten attestierten Wirtschaftsmoral unter dem Werbeslogan „Geiz ist geil“". Während die Gierdebatte im Gestus eigener Honorigkeit direkt an die Tugend- und Lastervorstellungen der Vormoderne anknüpft und diese wieder in Erinnerung bringt, wird in der Propagierung des Geizes das Verhältnis von Tugend und Laster umgekehrt und aus dem einstigen Laster $^{9}$ eine Verhaltensdisposition gemacht, mit der jeder seine eigenen Interessen am besten und effektivsten verfolgt. Man könnte auch sagen: Das Wirtschaftsverhalten des rationalen Nutzenmaximierers wird in diesem und anderen Slogans (,Ich bin doch nicht blöd“) im Lichte einer als altbacken erscheinenden Moral als Gestus der Rebellion dargestellt, bei dem es geradezu sinnliche Freude bereitet, wenn man ihn un-verschämt auslebt. Die Suche nach dem günstigsten Preis-Leistungsverhältnis, so wird suggeriert, werde gesellschaftlich immer noch als das Verhalten derer angesehen,

8 Dazu Manuel Frey: Vom Gemeinwohl zum Gemeinsinn. Das Beispiel der Stifter und Mäzene im 19. und 20. Jahrhundert, in: Herfried Münkler/Harald Bluhm (Hrsg.): Gemeinwohl und Gemeinsinn. Historische Semantiken politischer Leitbegriffe, Berlin 2001, S. 275-301.

9 Vgl. Sofsky, Das Buch der Laster, 2009, S. $128 \mathrm{ff}$. 
die sich nichts rechtes leisten können und darum auf das Billigste angewiesen sind. Dagegen meldet der Slogan entschiedenen Protest an: gegen die Vorstellungen von Status und Distinktion, gegen das System der „feinen Unterschiede“"10 wird die Suche nach dem niedrigsten Preis als neues Wertesystem für die Cleveren propagiert, das der herkömmlichen Orientierung an einem Mittleren oder der gesellschaftlichen Erwartung des Angemessenen ${ }^{11}$ entgegentritt und das Unterste (hier: den niedrigsten Preis) als das Lustvollste präsentiert. Die im Werbeslogan verheißene Lust erwächst dabei nicht nur aus dem eingesparten Geld, sondern auch aus dem Bruch mit der herrschenden bzw. als herrschend behaupteten Moral. Das wird deutlich in der Betonung der körperlichen Lust, die aus einer offensiven Präsentation des Geizes erwächst.

Nun lässt sich gegen diese Beobachtungen und ihre Deutung einwenden, dass es sich bloß um Werbeslogans handele; in ihnen poliere ein Elektro- und Elektronikdiscounter sein Image dadurch auf, dass er seinen Kunden Cleverness und Marktübersicht als antibürgerlichen Habitus attestiert, während den genuinen Trägern bürgerlicher Werte eine altbackene und längst überholte Einstellung zugeschrieben wird. Diese traditionelle Bürgerlichkeit, so der Einwand gegen den gesellschaftsdiagnostischen Gehalt des Werbeslogans, sei ein bloßer Popanz, der aufgebaut werde, um der Sparsamkeit einen möglichst dümmlichen Widerpart zu verschaffen und sie so $\mathrm{zu}$ entstigmatisieren. - Doch was auch immer die hinter der Werbestrategie stehenden Motive sein mögen: Im Slogan spiegelt sich eine Auseinandersetzung um die moralische Ordnung der Gesellschaft, ein Konflikt um die Beantwortung der Frage, ob für den Zusammenhalt der Gesellschaft das reibungslose Funktionieren der Marktmechanismen genügt oder ob dazu sozialmoralische Dispositionen der Bürger, zumindest bei einem relevanten Teil, unerlässlich sind. Dabei geht es nicht um Verfassungstreue und Rechtsliebe, also genuin politische Tugenden, die nach republikanischer Auffassung für eine demokratisch-partizipatorische Ordnung unverzichtbar sind, sondern um Gemeinsinn und Gemeinwohlorientierung als genuin zivilgesellschaftliche Dispositionen, also sozialmoralische Erwartungen, die

10 Pierre Bourdieu: Die feinen Unterschiede. Kritik der gesellschaftlichen Urteilskraft, Frankfurt a.M. 1982.

11 Dazu Herfried Münkler: Mitte und Maß. Der Kampf um die richtige Ordnung, Berlin 2010. 
sich keineswegs bloß an die Elite, sondern an eine breite Mehrheit der Bürger richten.

Die bis ins 18. Jahrhundert zurückreichende Debatte über die Ersetzbarkeit sozialmoralischer Dispositionen durch institutionelle Arrangements ist die ideengeschichtliche Grundierung der aktuellen Auseinandersetzung zwischen der Beschreibung einer ,neuen Bürgerlichkeit` und den damit verbundenen Erwartungen sowie den marktradikalen Parolen der Werbung, mögen sie nun „Geiz ist geil“ oder „Unterm Strich zähl' ich“ lauten. Es ist dies eine Auseinandersetzung darum, welche Verhaltenserwartungen in der Gesellschaft hegemonial sind und wer über diese Erwartungen verfügt. Die Vorstellung einer ,neuen Bürgerlichkeit' ist vor allem ein sozialmoralisches Projekt, bei dem es jenseits von Marktgesetzen und Rechtsordnung auf Werte und Normen ankommt, ohne die eine Gesellschaft selbstdestruktiv wird oder bloß noch soziale Kälte ausstrahlt. Diese sozialmoralische Erwartungsstruktur kann und will Markt und Staat nicht ersetzen, aber diese sollen komplementär ergänzt werden, was zu ihrem besseren, ebenso effektiveren wie humaneren Funktionieren beiträgt. ${ }^{12}$

Dass die ,neue Bürgerlichkeit‘ sowie die Suche nach dem ,Sozialkapital' einer Gesellschaft nicht bloß Chimären einiger Soziologen und Philosophen sind, zeigt sich paradigmatisch an der Zunahme des Stiftungswesens, dem beachtlichen Wachstum des Stiftungskapitals, aber auch der Bürgerstiftungen, über die nicht nur Geld, sondern auch persönliches Engagement in das Gemeinwesen eingebracht wird. ${ }^{13}$ Dabei sind Stiftungen keineswegs purer Gemeinsinn, also ein Verzicht auf Eigensinn zu Zwecken

12 Die Arbeiten Robert Putnams (Making Democracy Work. Civic Tradition in Modern Italy, Princeton 1993; ders.: Bowling Alone. The Collapse and Revival of American Community, New York 2000) drehen sich unter dem Begriff des „Sozialkapitals“ um die sozialmoralischen Ressourcen einer Gesellschaft und zeigen die Effizienzverluste, die Gesellschaften mit geringem Sozialkapital hinnehmen müssen. Der Kommunitarismus ist ein weiteres Projekt auf der Suche nach den sozialmoralischen Bindekräften einer Gesellschaft, das diese zu erhalten und zu stärken sucht; vgl. Walter Reese-Schäfer: Was ist Kommunitarismus?, Frankfurt a.M. 1994.

13 Zur jüngeren Entwicklung des Stiftungswesens vgl. Helmut K. Anheier: (Hrsg.): Stiftungen für eine zukunftsfähige Bürgergesellschaft. Gedanken für eine Generation von Erben. Beiträge zu einer Tagung der Wirtschaftsgilde e.V. und des Arbeitskreises Evangelischer Unternehmer in Deutschland e.V., Regionalgruppe Württemberg am 6. Juni 1998 in der Evangelischen Akademie Bad Boll, München 1998. 
des Gemeinwohls. Im Gegenteil: Dem Staat wird ein Teil des Steuervolumens, über das er zur Erfüllung seiner sozialpolitischen Verpflichtungen verfügen könnte, entzogen, um unter der Dispositionsgewalt des Stifters und seiner Präferenzen zu verbleiben ${ }^{14}$ - und zwar über den Tod des Stifters hinaus, weswegen Stiftungen auch als ,Diktatur der toten Hand“ bezeichnet werden. Kurzum: Stiftungen sind eine juridisch konstruierte Verbindung von Eigeninteresse und Gemeinsinn, in der die persönlichen Präferenzen des Stifters und jene Aufgaben der Gemeinschaft, die der Staat nicht oder aus Sicht des Stifters nur unzureichend wahrnimmt, von der Zivilgesellschaft übernommen werden. Stiftungen sind Ausdruck der Sorge einzelner für das Gemeinwesen, und sie folgen darin gerade nicht den Antriebsmomenten der (kapitalistischen) Marktgesellschaft. ${ }^{15}$

Die ,neue Bürgerlichkeit‘ und ein wachsendes Stiftungswesen sind in der Debatte über die sozialmoralischen Ressourcen moderner Gesellschaften die Antipoden der Gier- und Raffmentalität, die Bankern, Brokern und Managern attestiert wird. Versteht sich der Hinweis auf eine um sich greifende Gier- und Raffmentalität als sozialmoralisches Warnsignal, als Thematisierung einer Entwicklung, die gestoppt und umgekehrt werden muss, so werden ,neue Bürgerlichkeit‘ und wachsendes Stiftungswesen als Indiz dafür ins Feld geführt, dass es keineswegs nur bergab geht, sondern in Konkurrenz zu einem wachsenden Egoismus auch Gemeinsinn und Gemeinwohlorientierungen im Wachsen begriffen sind. Ein erstes Resümee könnte also lauten: Es gibt durchaus Grund zu Besorgnis, aber keinen Anlass zur Panik: Was der Gesellschaft auf der einen Seite an sozialmoralischen Ressourcen abhanden kommt, wächst ihr auf der anderen Seite wieder zu. Die Verteilung verändert sich, aber die Gesamtbilanz bleibt stabil.

Im Weiteren soll es um die Beantwortung der Frage gehen, ob wir uns mit diesem Bescheid zufrieden geben können. Um das herauszubekommen, soll zunächst der Diskurs über die politische Tugend von der Antike übers Mittelalter bis in die Frühe Neuzeit umrissen und dabei ein genauerer Blick auf die ideengeschichtliche Thematisierung von Krisen der sozialmora-

14 Dazu Herfried Münkler: Anstifter, Unruhestifter. Wie Stiftungen Veränderungen bewegen, in: Merkur 61 (2007) 3, S. 200-209.

15 Zur Geschichte des Stiftungswesens grundlegend Rupert Graf Strachwitz: Die Stiftung - ein Paradox? Zur Legitimität von Stiftungen in einer politischen Ordnung, Stuttgart 2010; zur Rolle von Stiftungen in der Zivilgesellschaft vgl. ebd., S. $163 \mathrm{ff}$. 
lischen Ausstattung einer Gesellschaft geworfen werden. Dabei ist zunächst freilich vonnöten, die Geschichtsvorstellung von Wachstum, Scheitelpunkt und Verfall politischer Ordnungen in Augenschein zu nehmen, also jene zyklischen Geschichtsmodelle zu thematisieren, die mit dem Tugenddiskurs aufs engste verwoben sind. Es kommt nämlich nicht von ungefähr, dass die Ablösung des Tugenddiskurses durch den Interessendiskurs ${ }^{16}$ etwa zu derselben Zeit erfolgt ist, als auch die zyklische Geschichtsauffassung durch das Modell eines kontinuierlichen Fortschritts des Menschengeschlechts abgelöst wurde. ${ }^{17}$ Nur in der genuin politischen Geschichte findet das Zyklenmodell bis heute Anwendung: Buchtitel über Aufstieg und Niedergang der großen Reiche sind nach wie vor en vogue, ${ }^{18}$ und das erst recht, seitdem sich viele fragen, ob wir gegenwärtig der Verlagerung des weltwirtschaftlichen Zentrums aus dem atlantischen in den pazifischen Raum beiwohnen und Zeugen des Aufstiegs Chinas und des Niedergangs Europas und der USA werden. Die publizistische Debatte ist durch solche Vorstellungen von Aufstieg und Niedergang geprägt. In der klassischen Politiktheorie hat dieses zyklische Geschichtsmodell eine zentrale Rolle gespielt, und als dessen Antriebsmoment wurde die politische Tugend bzw. deren Erosion herausgestellt. Damit eng verbunden ist die Frage nach der Selbsttranszendenz politischer Ordnungen; gemeint ist damit die Fähigkeit politischer Ordnungen, die Determination ihres Geschicks durch Zyklus oder Niedergang zu sprengen und zu überschreiten.

\section{Die Erneuerung der Gesellschaft durch DAS EKSTATISCH-ORGIASTISCHE FEST}

Wie uns Ethnologen und Religionstheoretiker belehren, waren die archaischen Gesellschaften von einer großen Sorge beherrscht: der des Alterns der Welt und vor allem des Alterns der sozialen Verbände, so dass es, woll-

16 Vgl. Hartmut Neuendorff: Der Begriff des Interesses. Eine Studie zu den Gesellschaftstheorien von Hobbes, Smith und Marx, Frankfurt a.M. 1973.

17 Dazu Johannes Rohbeck: Die Fortschrittstheorie der Aufklärung. Französische und englische Geschichtsphilosophie in der zweiten Hälfte des 18. Jahrhunderts, Frankfurt a.M./New York 1987.

18 Am bekanntesten ist das Werk von Paul Kennedy: Aufstieg und Fall der großen Mächte. Ökonomischer Wandel und militärischer Konflikt von 1500 bis 2000, Frankfurt a.M. 1987. 
te man nicht dem Siechtum mit schließlichem Tod zum Opfer fallen, eines Regenerationsmechanismus' bedurfte, durch den die physische Welt und die soziale Ordnung verjüngt wurden und alles wieder von vorn beginnen konnte. ${ }^{19}$ Der Fortgang der Zeit wurde in diesen biologisch-organologischen Vorstellungen als Verfall und Ermattung begriffen, und im Unterschied zum Einzelmenschen, der sich dieser Entwicklung nicht entziehen konnte, wurde dem Sozialverband ein Neuanfang durch das Zurückdrehen der Zeit zugetraut. ${ }^{20}$ Als Mittel zu dieser Selbsttranszendenz, zu diesem sozial initiierten kosmologischen Wunders, dienten Riten und Mythen, aber auch orgiastische Exzesse und Gewalteruptionen, die als Formen der Verjüngung und Erneuerung imaginiert wurden. All diesen Mechanismen der politischen und sozialen Regeneration war gemeinsam, dass in ihnen die sonst geltenden Gebote des Zusammenlebens auf den Kopf gestellt und durch einen regelrechten Zwang zur Verbotsübertretung abgelöst wurden. Diese archaische Vorstellung hat sich in den griechischen Dionysien oder den römischen Saturnalien bis in die antiken Gesellschaften und darüber hinaus in die des Mittelalters fortgeerbt, und man kann einen späten Nachklang dessen im rheinischen Karneval oder der alemannischen Fasnacht erkennen - zurückgenommen freilich auf ein Treiben, dem niemand im Ernste mehr eine sozial regenerative Funktion zuschreiben würde. In der spielerischen Erstürmung der Rathäuser und der Machtübernahme durch die Narren jedoch zittert noch etwas nach von der Idee einer Erneuerung durch die Umkehrung des Gewohnten und Regulären. Das zeitlich begrenzte Auf-den-Kopf-Stellen der sozialen Welt und der politischen Ordnung sollte die Energie verfügbar machen, die erforderlich war, damit die Gemeinschaft in einen neuen Lebenszyklus eintreten konnte. Es war ein Kraftholen für die Bewältigung der Ordnung durch deren zeitlich begrenzte Außerkraftsetzung. Insofern war die Idee der Erneuerung von Anfang an mit dem Versuch einer Ausnutzung des Paradoxen verbunden.

Die orgiastischen Feste der archaischen Gesellschaften waren freilich alles andere als Äußerungsformen gesellschaftlicher oder politischer Tu-

19 Exemplarisch Mircea Eliade: Kosmos und Geschichte. Der Mythos der ewigen Wiederkehr, Reinbek bei Hamburg 1966, S. 46ff. sowie ders.: Mythos und Wirklichkeit, Frankfurt a.M. 1988, S. 48ff.

$20 \mathrm{Zu}$ modernen Varianten dieser archaischen Vorstellung vgl. Karsten Fischer (Hrsg.): Der Neustart des Weltlaufs. Fiktion und Faszination der Zeitwende, Frankfurt a.M. 1999. 
gend; sie waren im Gegenteil Akte der Entfesselung und Durchbrechung der im Alltag herrschenden Formen der Selbstdisziplin. Dienten diese der Verbannung der Gewalt aus dem Innern der Gemeinschaft, ${ }^{21}$ so war das große Fest in der Form des Paroxysmus ein Sammeln von Kraft, um in einem neuen Zyklus den mit ihm verbundenen Anforderungen an Disziplin und Askese genügen zu können. Roger Caillois, George Bataille und René Girard haben das eingehend beschrieben ${ }^{22}$ : Die Immanenz der regulären Ordnung war, sollte sie stabil und dauerhaft sein, auf die zyklisch wiederkehrende Transzendenzinszenierung des großen Festes angewiesen, weswegen das Fest auch als ,heilig' und seine Dauer als ,heilige Zeit" begriffen wurden, inbegriffen die Meutengewalt und die Akte ritueller Opferung von Erstgeborenen, Königen und Sklaven.

Aber die Entfesselung der Gewalt war gefährlich, und deswegen musste sie in streng zu befolgenden Riten an die Transzendenz gebunden, dazu zeitlich begrenzt und dem Belieben derer entzogen werden, die sie praktizierten. Vor allem die Tötungsgewalt, von der, den mythischen Erzählungen zufolge, die stärkste Kraft der Erneuerung ausging, wurde in den Riten des Opfers einem strikten Reglement unterworfen. Nur wo die dem Heiligen verbundenen Verfluchungen ernst genommen wurden, konnte sich die Gemeinschaft den Exzess von Sexualität und Gewalt als Modus der Selbstregeneration leisten. Wohingegen die Furcht vor dem Heiligen schwand und frühe Formen der Aufklärung um sich griffen, durch die die Riten in Frage gestellt und die Selbstbindungen gelockert wurden, geriet das orgiastisch-ekstatische Fest zu einem Tanz auf dem Vulkan. Was es verhindern sollte, kam nun gerade zum Durchbruch: die innergesellschaftliche Gewalt, die Rebellion gegen die Ordnung, deren Umsturz und schließlich der Bürgerkrieg. Das Fest drohte zu entgleisen. Das Projekt der

21 Norbert Elias hat in seinem Werk Über den Prozeß der Zivilisation (2 Bde., Basel 1939, Frankfurt a.M. 1976) die Domestizierung und Sublimierung von Gewalt als Kernelement der Zivilisierung von Gesellschaften beschrieben. Entscheidend ist dabei die Verwandlung von Fremdzwang in Selbstzwang. Diesem Ansatz folgend, kann das Fest als eine zeitlich begrenzte Lockerung oder Aufhebung der Selbstzwangs angesehen werden - mit dem funktionalen Effekt, danach den Selbstzwang wieder umso konsequenter in Wirkung zu setzen.

22 Roger Callois: Der Mensch und das Heilige. Durch drei Anhänge über den Sexus, das Spiel und den Krieg in ihren Beziehungen zum Heiligen erweiterte Ausgabe [1950], München/Wien 1988; Georges Bataille: Theorie der Religion [1947], hrsg. und mit einem Nachwort von Gerd Bergfleth, München 1997; René Girard: Das Heilige und die Gewalt [1972], Frankfurt a.M. 1992. 
Erneuerung schlug, sobald sich erste Zweifel an der mythischen Evokation der Transzendenz und deren Vergegenwärtigung im Ritus ausbreiteten, um in einen Akt der Selbstzerstörung. Gesellschaften, die auf soziale Regeneration durch das große Fest angewiesen sind, sind darum nicht säkularisierbar und aufklärungsfähig. Schon die ersten Anfänge von Aufklärung hebeln die Grundlagen dieser Gesellschaften aus und geben sie der Selbstzerstörung preis. Das erklärt den heftigen Widerstand, den diese Gesellschaften gegen ihre Selbstaufklärung leisten: Sobald die funktionalen Effekte ritueller Selbstbindung durchschaut sind, haben sie ihre bindende Kraft verloren und können auch nicht durch Lug und Trug einer Priesterund Schamanenkaste aufrecht erhalten werden. Transzendenzschwund, gar Transzendenzverlust führten bei diesen Gesellschaften entweder in die soziale und politische Katastrophe, oder das Fest wurde zu einer Form der Unterhaltung, in der die potentiell rebellischen Schichten und Gruppen einer Gesellschaft ,stillgestellt‘ wurden, wie das in den römischen Zirkusspielen und Gladiatorenkämpfen der Fall war. Zwar floss noch immer Blut, aber nicht mehr zu Zwecken der sozialen Erneuerung und politischen Revitalisierung, sondern als Abwechslung von einem tristen Alltag und als Ablenkung von Armut und Not. ${ }^{23}$ Aus dem Akt der Erneuerung war ein Herrschaftsinstrument der Mächtigen geworden.

Die politische Tugend, die in den einschlägigen Texten von der Antike bis in die Frühe Neuzeit beschrieben und gepriesen wird, kann als eine säkularisationsresistente Kompensation für die Erosion der religiösen Riten beim orgiastisch-ekstatischen Treiben während des heiligen Fests begriffen werden. Die politische Tugend tritt an die Stelle des großen Festes. Sie ist kein Akt ekstatischer Erneuerung, sondern der Entschleunigung, wenn nicht gar des Anhaltens von Niedergang und Verfall. Bürgerschaftliche Tugend ist im Sinne von Norbert Elias eine Form der Verwandlung rituellen Fremdzwangs in habituell gewordenen Selbstzwang. Damit eröffnete sie die Möglichkeit, mit der Lockerung der Riten im Gefolge der ethnologischen Aufklärung im sechsten vorchristlichen Jahrhundert politisch umzugehen. Eine andere bestand darin, das Fest von allen sozialen und politischen Regenerationserfordernissen zu entlasten und es zum bloßen

23 Vgl. Paul Veyne: Brot und Spiele. Gesellschaftliche Macht und politische Herrschaft in der Antike, Frankfurt/New York 1988 sowie Tobias Wiedemann: Kaiser und Gladiatoren. Die Macht der Spiele in der Antike, Darmstadt 2002. 
Statthalter der Transzendenz im Diesseits zu machen. Das war die Lösung, die das Christentum anzubieten hatte. Die aber war mit dem Preis verbunden, dass die Energie der Menschen von der Politik abgezogen und auf ein wie auch immer angelegtes Jenseits gerichtet wurde, wie dies die Kritiker des Christentums monierten. Niccolò Machiavelli etwa hat in der Ausbreitung des Christentums die Ursache dafür gesehen, dass es, wie er meinte, in der Antike mehr Republiken gegeben habe als in seiner Zeit. ${ }^{24}$ Die Transzendenz hatte hier nicht nur die Immanenz entwertet, sondern überließ diese auch sich selbst. Sie war, so Machiavellis Diagnose zu Beginn des 16. Jahrhunderts, nicht länger Grund und Halt der bestehenden Ordnung bzw. als deren kurzzeitige Entfesselung ein Modus ihrer Regeneration, sondern die Ordnung der Welt war den christlich Tugendhaften gleichgültig, insofern die christliche Tugend nicht auf die politische Ordnung, sondern auf die Verlässlichmachung des Jenseits gerichtet war. Der subkutane Neopaganismus bei vielen frühneuzeitlichen Politiktheoretikern ist durch die Sorge um die politische Tugend als Lebenselixier der republikanischen Freiheit gespeist, und die Erosion der politischen Tugend durch die Trennung des Religiösen vom Politischen hat aus ihrer Sicht, um noch einmal Machiavelli aufzugreifen, die politische Welt den Bösewichtern ausgeliefert. ${ }^{25}$ Der Diskurs über die Bindekraft der politischen Tugend war somit einer, der sich um die Relationierung von Transzendenz und Immanenz drehte. Zunächst aber noch einmal zurück zur Degeneration des großen Fests zum Bürgerkrieg.

\section{Die Debatte Über die Regeneration deR TUGEND IM KRIEG UND IHRE BEWÄHRUNG IM FRIEDEN}

In seiner Darstellung des fünften Kriegsjahres im Ringen zwischen Athen und Sparta, einer der großartigsten und wichtigsten Textpassagen der politischen Theorie, hat der griechische Historiker Thukydides die Auflösung der sozio-politischen Ordnung in Kerkyra beschrieben, nachdem dort die Konkurrenz zwischen der demokratischen und der oligarchischen Partei in of-

24 Niccolò Machiavelli: Discorsi. Gedanken über Politik und Staatsführung, eingeleitet und erläutert von Rudolf Zorn, Stuttgart 1966, S. 172 (II, 2).

25 Ebd. 
fene Gewalt umgeschlagen war. ${ }^{26}$ Die Konflikte zwischen den sozialen Gruppen und politischen Parteiungen, die in der alten Ordnung durch das große Fest kanalisiert worden waren, eskalierten nun zum offenen Bürgerkrieg. Die siegreiche Partei der Demokraten, so Thukydides, habe jeden gemordet, den man für einen Gegner gehalten habe:

„Schuld gaben sie ihnen, daß sie die Volksherrschaft stürzen wollten, aber manche fielen auch als Opfer persönlicher Feindschaft, wieder andere, die Geld ausgeliehen hatten, von der Hand ihrer Schuldner. Der Tod zeigte sich da in jederlei Gestalt, wie es in solchen Zeiten zu gehen pflegt [...]. Erschlug doch der Vater den Sohn, manche wurden von den Altären weggezerrt oder dort selbst niedergehauen, einige auch eingemauert im Heiligtum des Dionysos, daß sie verhungerten. “27

Es ist das Merkmal des Bürgerkriegs, dass das Heilige, welches Zuflucht und Asyl bietet, nicht mehr zählt. ${ }^{28}$ Der Exzess der Gewalt durchbricht deren Begrenzungslinien, die solange verbindlich waren, wie die Riten das Fest durch das Faszinosum des Heiligen bändigten. Aber auch im großen Fest waren die Verbote - zeitweilig - außer Kraft gesetzt worden, und insofern lässt sich die These vertreten, innergesellschaftlichen Gewaltkonflikten komme eine dem Fest analoge Funktion zu: Wenn der Rausch der Gewalt verflogen sei und die Menschen sähen, was sie angerichtet hatten, werde die Ordnung wieder hergestellt, die Parteien versöhnten sich miteinander und für lange Zeit sei die Gemeinschaft durch die Erinnerung an die schrecklichen Ereignisse, die im Rahmen des Festes stattgefunden hatten, gegen Gewaltausbrüche im Innern gefeit. ${ }^{29}$ Der Bürgerkrieg war danach bloß ein entfesseltes Fest, und der in ihm erfahrene Schrecken führte zur Regeneration der politischen Tugend, deren Zerfall ja gerade im

26 Thukydides: Geschichte des Peloponnesischen Krieges, hrsg. und übertragen von Georg Peter Landmann, München 1973, S. 244-253 (III, 69-85).

27 Ebd., S. 249f. (III, 81).

28 Ausdrücklich geht es hier um den innergesellschaftlichen und nicht um den zwischenstaatlichen Krieg. Soweit ich sehe, ist der Zusammenhang zwischen der Entgleisung des Festes und der Eskalation der Gewalt zum Bürgerkrieg weder in den sozial- noch in den kulturwissenschaftlichen Arbeiten zum Bürgerkrieg thematisiert worden. Vgl. etwa Heinrich-W. Krumwiede/Peter Waldmann: (Hrsg.), Bürgerkriege: Folgen und Regulierungsmöglichkeiten, Baden-Baden 1998 sowie Sabine Ferhadbegović/Brigitte Weiffen (Hrsg.): Bürgerkriege erzählen: Zum Verlauf unziviler Konflikte, Konstanz 2011.

29 In diesem Sinne Caillois, Der Mensch und das Heilige, 1988, S. 217ff. sowie Bataille, Theorie der Religion, 1997, S. 50ff. 
Bürgerkrieg deutlich geworden war. Besser noch war es freilich, den Bürgerkrieg durch einen äußeren Krieg zu vermeiden, dem dieselbe sozialtherapeutische und tugendregenerative Funktion zugesprochen wurde. Die politische Tugend im Sinne einer Zurückstellung von Parteiinteressen gegenüber dem Gesamtinteresse und egoistischen Dispositionen gegenüber dem Gemeinwohl werde durch den Krieg im Sinne einer nach außen gekehrten Gewalt nachhaltig regeneriert und trage zu einem neuerlichen Aufstieg des Gemeinwesens bei. Hegel hat in seiner Rechtsphilosophie diesem Gedanken breiten Raum gegeben ${ }^{30}$, und das ,Augusterlebnis' des Jahres 1914, das nicht auf Deutschland beschränkt war, aber hier eine besonders intensive Form annahm, kann als eine Verbindung von Fest und Krieg begriffen werden. ${ }^{31}$

Thukydides hingegen war dezidiert nicht der Auffassung, dass dem Krieg eine dem Fest vergleichbare Funktion der sozialen Regeneration zukomme, und einer der Gründe dafür war für ihn die Erosion des Heiligen, die den Krieg im Innern vom großen Fest unterschied. Während das Heilige als das der politischen Gemeinde Unverfügbare im Fest bestätigt und aufs Neue verbindlich gemacht wird, wird es im Bürgerkrieg weiter aufgezehrt. Der Bürgerkrieg ist in dieser Sicht eine Folge von Transzendenzerosion, und er beschleunigt noch den Verlust der Transzendenz. „Untereinander verbürgte ihnen die Treue weniger das göttliche Recht als gemeinsam begangenes Unrecht“, heißt es bei Thukydides:

30 „Der Krieg als der Zustand, in welchem mit der Eitelkeit der zeitlichen Güter und Dinge, die sonst eine erbauliche Redensart zu sein pflegt, Ernst gemacht wird, ist hiermit das Moment, worin die Idealität des Besonderen ihr Recht erhält und Wirklichkeit wird; - er hat die höhere Bedeutung, daß durch ihn, wie ich es anderwärts ausgedrückt habe, ,die sittliche Gesundheit der Völker in ihrer Indifferenz gegen das Festwerden der endlichen Bestimmtheiten erhalten wird, wie die Bewegung der Winde die See vor der Fäulnis bewahrt, in welche sie eine dauernde Ruhe, wie die Völker ein dauernder oder gar ein ewiger Friede versetzen würde'. - [...] Daß die Idealität, welche im Kriege als einem zufälligen Verhältnisse nach außen liegend, zum Vorschein kommt, und die Idealität, nach welcher die inneren Staatsgewalten organische Momente des Ganzen sind, - dieselbe ist, kommt in der geschichtlichen Erscheinung unter anderen in der Gestalt vor, daß glückliche Kriege innere Unruhen verhindert und die innere Staatsmacht befestigt haben." (Georg Wilhelm Friedrich Hegel: Grundlinien der Philosophie des Rechts, hrsg. von Johannes Hoffmeister, Hamburg 1967, S. 280f.)

31 Zum ,Augusterlebnis‘ in Berlin vgl. Modris Eksteins: Tanz über Gräben. Die Geburt der Moderne und der Erste Weltkrieg, Reinbek bei Hamburg 1990, S. $93 \mathrm{ff}$. 
„Eide, falls noch irgendein Vergleich auf die Art bekräftigt wurde, waren geleistet in der Not, wenn beide sich nicht mehr anders zu helfen wussten, und galten für den Augenblick; wer aber bei günstiger Gelegenheit zuerst wieder Mut faßte, wenn er eine Blöße entdeckte, der nahm seine Rache lieber durch Verrat als in offenem Kampf, [...].“

Infolgedessen wurden die Laster freigesetzt, und keinerlei Tugend vermochte mehr ihre Wirkung zu blockieren. „Die Ursache von dem allem war die Herrschsucht mit ihrer Habgier und ihrem Ehrgeiz [...]. ${ }^{\text {(32 }}$

Der Bürgerkrieg stellt in Thukydides' Sicht also die sozialmoralischen Grundlagen der Ordnung nicht wieder her, sondern zerstört sie von Grund auf; er schafft nicht die Voraussetzungen für die Wiederherstellung des Friedens, sondern macht eine Rückkehr zum Frieden noch schwieriger:

„Denn im Frieden und Wohlstand ist die Denkart der Menschen und der ganzen Völker besser, weil keine aufgezwungenen Notwendigkeiten sie bedrängen; aber der Krieg, der das leichte Leben des Alltags aufhebt, ist ein gewalttätiger Lehrer und stimmt die Leidenschaften der Menge nach dem Augenblick. “33

Der Krieg, so die Diagnose des griechischen Historikers, setzt nicht nur die gewaltlimitierenden und dadurch die regenerative Gewalt erst ermöglichenden Riten als Statthalter der Transzendenz außer Geltung, sondern konsumiert auch die Tugendhaftigkeit der Bürgerschaft, die sich in der Zeit des Friedens entwickelt hat, und setzt an deren Stelle das Ausleben unmittelbarer Impulse und Triebe sowie die Orientierung an kurzfristigen Interessen - kurzum: das Leben im Augenblick. Dieses Zusammenschnurren der Zeitperspektive, das Einklappen des Erwartungshorizonts auf den Erfahrungsraum, um es mit Reinhart Koselleck zu formulieren, ${ }^{34}$ ist mithin typisch für Bürgerkriegskonstellationen. ${ }^{35}$ Das sind nicht die Voraussetzungen, unter denen sich bürgerschaftliche Tugend entwickeln kann. Politische Tugend ist auf längere Zeiträume angewiesen, sie entfaltet sich in der

32 Thukydides, Der Peloponnesische Krieg, 1973, S. 251f. (III, 82).

33 Ebd., S. 250 (III, 82).

34 Reinhart Koselleck: ,Erfahrungsraum' und ,Erwartungshorizont' - zwei historische Kategorien, in: ders.: Vergangene Zukunft. Zur Semantik geschichtlicher Zeiten, Frankfurt a.M. 1979, S. 349-375.

35 Vgl. hierzu die großartige Analyse des angolanischen Bürgerkriegs der 1970er und 1980er Jahre bei Rýszard Kapuściński: Wieder ein Tag Leben. Innenansichten eines Bürgerkriegs, Frankfurt a.M. 1984, bes. S. 90-94. 
Dauer und nicht im Augenblick. Deswegen ist dieser Sichtweise zufolge nicht nur der Bürgerkrieg, sondern auch das große Fest kein Ort der politischen Tugend. Weder soziale noch bürgerschaftliche Tugend lassen sich durch das ekstatisch-organische Fest oder den Bürgerkrieg als Modi sozialmoralischer Regeneration stabilisieren oder erneuern. Allenfalls dem äußeren Krieg kann diese Funktion zukommen. In der politischen Theorie des 19. und 20. Jahrhunderts freilich haben das große Fest, das inzwischen nicht als Ekstase und Auflösung der Ordnung, sondern als feierliche $\mathrm{Zu}-$ sammenkunft der Bürger gedacht wurde, ${ }^{36}$ und der Krieg (der freilich als ein zeitlich wie räumlich begrenzter Krieg entworfen wurde) um die Funktion des Tugendregenerators konkurriert. Und wenn man dem politischen Fest die Aufgabe zusprach, in Zeiten des Friedens und der Normalität einen im Jahresrhythmus wiederkehrenden Beitrag zur sozialmoralischen Selbstverpflichtung des Bürgers zu leisten, so war der Krieg die große Inpflichtnahme der Bürger in einer in jeder Hinsicht außergewöhnlichen und außeralltäglichen Situation.

In Thukydides' Sicht dagegen konnten beide, die Gemeinschaft im Zustand der Ekstase und die Bürgerschaft im Zustand des tödlichen Gemetzels, kein tugendhaftes Handeln hervorbringen, ja, sie konnten tugendhaftes Handeln nicht einmal honorieren. Ganz im Gegenteil: Thukydides beschreibt, wie sich die Identifizierbarkeit der Tugend, die semantische Unterscheidbarkeit von Tugend und Untugend, im Verlauf des Krieges mehr und mehr auflöste:

„Und den bislang gültigen Gebrauch der Namen für die Dinge vertauschten sie nach Willkür: unbedachtes Losstürmen galt nun als Tapferkeit und gute Kameradschaft, aber vordenkendes Zögern als aufgeschmückte Feigheit, Sittlichkeit als Deckmantel einer ängstlichen Natur, Klugheit bei jedem Ding als Schlaffheit zu jeder Tat; tolle Hitze rechnete man zu des Mannes Art, aber behutsames Weiterberaten nahm man als ein schönes Wort zur Verbrämung der Abkehr. ${ }^{37}$

Üblicherweise werden diese Passagen dahingehend verstanden, dass die Semantik als Grundlage verständigungsorientierten Handelns der Dynamik

36 Vgl. Dieter Düding/Peter Friedemann/Paul Münch: Öffentliche Festkultur. Politische Feste in Deutschland von der Aufklärung bis zum Ersten Weltkrieg, Reinbek bei Hamburg 1988 sowie Manfred Hettling/Paul Nolte (Hrsg.): Bürgerliche Feste. Symbolische Formen politischen Handelns im 19. Jahrhundert, Göttingen 1993.

37 Thukydides, Der Peloponnesische Krieg, 1973, S. 250f. (III, 82). 
des Bürgerkriegs zum Opfer fällt. Die Bezeichnungen werden willkürlich, sie folgen den Parteiinteressen oder den gewalttätigen Aufwallungen der Menge. Die Semantik verliert ihre Transzendenz gegenüber der Jeweiligkeit und Augenblicklichkeit des Begehrens. Die Begriffe sind dann nicht mehr als rechtfertigende Bezeichnungen dessen, was man gerade will und tut. Im Umkehrschluss heißt das: Politische Ordnung gibt es nur dort, wo die Willkür des Augenblicks durch eine dem Einzelnen wie den Parteien unverfügbare, also transzendente Semantik getilgt worden ist. Die politisch unverfügbare Semantik dient als Statthalter der Zukunft in der unmittelbaren Gegenwart und zugleich als Anwalt der Gegenseite im eigenen Lager. Es gibt weder politische Tugend noch politische Vernunft ohne eine solche den Faktionen unverfügbare Semantik.

Einen Beleg für diese These liefert die Ermittlung der persönlichen wie politischen Tugenden (aretai) in Aristoteles' Politik sowie seiner Nikomachischen Ethik, wo die sprachlich genau bezeichneten Extreme möglichen Verhaltens die Orientierungsmargen bilden, zwischen denen, in der Regel in ihrer Mitte, das Verhalten gefunden wird, das dann als Tugend ausgezeichnet werden kann. ${ }^{38}$ Tapferkeit ist danach die Mitte zwischen Feigheit und Tollkühnheit, Freigebigkeit die Mitte zwischen Geiz und Verschwendungssucht. Aber es geht nicht nur um das Finden der richtigen Tugend, sondern auch um deren zutreffende Bezeichnung, die eine unverzichtbare Orientierung bei der Suche nach dem Guten und Rechten ist. Dass sie in der Mitte zwischen den Extremen liegt, kommt nicht von Ungefähr: Nie ist diese Mitte stärker gefährdet als in Zeiten des Bürgerkriegs. ${ }^{39}$ Die wohlgeordnete Verfassung bietet den Rahmen für eine auf längere Zeit angelegte Selbstdisziplinierung der Bürger, bei der diese ihr Verhalten durch die Beobachtung von Abweichung kontrollieren und korrigieren können. Die gute Verfassung macht solche Tugenden möglich, ist dabei aber auf eine zuverlässige Semantik angewiesen. Wenn dies gewährleistet ist, ist die Wahrscheinlichkeit groß, dass tugendhafte Bürger in hinrei-

38 Aristoteles: Die Nikomachische Ethik, übersetzt und hrsg. von Olof Gigon, München 1972, S. 96f. (II, 8); Aristoteles: Politik, übersetzt und hrsg. von Olof Gigon, München 1973, S. 153f.(IV, 11); dazu Münkler, Mitte und Maß, 2010, S. $82 \mathrm{ff}$.

39 So berichtet Thukydides über die Bürgerkriegswirren in Kerkyra: „Und die Mittelschicht der Bürger wurde, weil sie nicht mitkämpfe oder aus Neid, daß sie davonkäme, von beiden Seiten her ausgemordet.“ (Der Peloponnesische Krieg, 1973, S. 252 (II, 82)) 
chender Zahl heranwachsen. Diese Vorstellung des Aristoteles wurde zur Grundlage der politischen Tugendmodelle, die durch ihre Zentrierung um die Tugend der Gerechtigkeit für die Verwirklichung des Gemeinwohls sorgen sollten - gleichgültig, ob einer, einige oder viele die Regierungsgewalt inne haben. Der Zustand, in dem sich diese Tugend entfaltete, war der Frieden, und die Aufrechterhaltung des Friedens war der Lohn für tugendhafte Politik. Ambroggio Lorenzetti hat das auf seinen drei Fresken in der Sala della pace des Palazzo Pubblico von Siena dargestellt. ${ }^{40}$ An die Stelle einer sozialmoralischen Regeneration durch den Krieg tritt hier die offenkundig auf Dauer angelegte Verbindung von Gemeinwohlorientierung und Frieden. Der Frieden ist die Voraussetzung für die wirtschaftliche Prosperität der Stadt, die sich auf Lorenzettis Fresko über die Folgen der guten Regierung im regen Treiben in der Stadt und in der Sicherheit auf dem Lande zeigt; im Frieden sind immer wieder auch kleine Feste möglich, die im Reigen der jungen Frauen im Vordergrund des Freskos gezeigt werden, während die Herrschaft der Laster, wie das Fresko über die Folgen der schlechten Regierung zeigt, zu Gewalt im Innern und zu Verfall führen. An die Stelle der biologisch-organologischen Vorstellung von Alter und Verfall ist in der performativen Konstellation der Fresken - sie befinden sich in einem Raum, in dem die Sieneser Regierung tagte - die pädagogisch-adhortative Idee getreten: Tugenden verfallen nicht von selbst, sondern werden von den Regierenden missachtet; deswegen werden diese durch die Bilder zu tugendhaftem Regieren ermahnt. An die Stelle der Beobachtung von Mechanismen und Funktionen ist die Sorge um die Intentionalität der Regierenden getreten: Solange diese tugendhaft sind, sind Gemeinwohl und Gerechtigkeit gesichert.

40 Für eine Interpretation des Freskos und der in es eingegangenen aristotelischen Rechts- und Politikvorstellungen vgl. Hasso Hofmann: Bilder des Friedens oder Die vergessene Gerechtigkeit, München 1997 sowie Alois Riklin: Ambrogio Lorenzettis politische Summe, Bern/Wien 1996; für eine Klärung der politischen Aussage der Fresken durch ihren Vergleich mit dem Titelkupfer zu Thomas Hobbes' Leviathan vgl. Herfried Münkler: Politische Bilder, Politik der Metaphern, Frankfurt a.M. 1994, S. 50ff. 


\section{Die ZYKLIZITÄT DER Geschichte UND DIE REGENERATIVE FUNKTION DES INSTITUTIONALISIERTEN KONFLIKTS}

Aber das aristotelische Modell einer an die Intentionalität der Regierenden gebundenen Tugend ist eines für krisenfreie Zeiten, das auf die beschriebene Herausforderung des zyklischen Niedergangs keine Antwort parat hat. Es ist ein Politikmodell, mit dem sich ein Stadtstaat möglichst lange im oberen Segment der Entwicklungskurve eines Gemeinwesens halten lässt, doch sobald die Erosionsprozesse der politischen und moralischen Ordnung in Gang kommen, ist er diesen tendenziell hilflos ausgeliefert. Die Schwäche dieses Modells ist, dass es alles auf die Tugenden der Regierenden setzt, aber keine Mechanismen zur Verfügung hat, die greifen, wenn diese Tugenden abhanden gekommen sind. Im Prooemium seiner Schrift Über die Verschwörung des Catilina hat der römische Historiker Sallust ein Alternativmodell geliefert, das vom Verfall der politischen Tugend ausgeht und Möglichkeiten auslotet, diesem Verfall entgegenzuwirken. Danach ist ein langer Frieden für die Tugend der Bürger bedrohlich, während das Vorhandensein eines äußeren Feindes und der von ihm ausgehende Zwang zur Anspannung aller Kräfte dem Tugendverfall entgegenwirken. Nach Gründung der Republik habe Rom immer wieder mit seinen Nachbarn im Krieg gelegen und das habe dazu geführt, dass ,die Jugend, sobald sie wehrfähig war, im Feldlager unter Anstrengung das Kriegshandwerk“ erlernte und ,mehr Vergnügen an prächtigen Waffen und Streitrossen [...] als an Dirnen und Gelagen“" hatte, so Sallust. ${ }^{41}$ Wenn man miteinander stritt, dann um den Ruhm und die Ehre, als erster am Feind gewesen zu sein und seine Altersgenossen an Heldentaten zu übertreffen. „Darin lag für sie Reichtum, darin guter Ruf und hoher Adel. Nach Anerkennung waren sie gierig, mit Geld freigebig, Ruhm wollten sie ungeheuer viel, an Reichtum nur den sittlich gerechtfertigten. ${ }^{\text {“42 }}$

Es sind die Siege, die von diesen Männern errungen wurden, und die durch diese Siege bewirkte Expansion der römischen Macht, in deren Folge es zur Tugenderosion in Rom kommt:

41 Sallust: Werke, Lat.-Dt. von Werner Eisenhut und Josef Lindauer, München/ Zürich 1985, S. 15.

42 Ebd. 
„Als sich aber der Staat durch ihre Anstrengung und Rechtlichkeit aufgeschwungen hatte, als mächtige Könige im Krieg bezwungen, wilde Stämme und große Völker gewaltsam unterjocht waren, Karthago, die Rivalin der römischen Macht, bis auf den Grund vernichtet war und nun alle Meere und Länder offenstanden, da begann das Schicksal (fortuna) zu wüten und alles durcheinanderzubringen. “43

Mit dem Frieden halten nämlich die Laster, die Geldgier (cupido pecuniae), die Herrschgier (cupido imperii), die Habgier (avaritia) und die Ehrsucht (ambitio) in das Gemeinwesen Einzug. Was Thukydides als Folge des Bürgerkriegs angesehen hatte, wird von Sallust als Ergebnis eines langen imperialen Friedens angesehen:

„Seitdem der Reichtum allmählich Ehre einbrachte und Ruhm, Herrschaft und Macht im Gefolge hatte, da begann die moralische Kraft (virtus) zu erlahmen, Armut als Schande zu gelten, Redlichkeit als Böswilligkeit ausgelegt zu werden. Infolge des Reichtums riß dann bei der Jugend Genusssucht (luxuria) und Habgier (avaritia) sowie Überheblichkeit (superbia) ein: man raubte, verschwendete, schätzte den eigenen Besitz gering, begehrte fremden, hielt Ehrgefühl und Sittlichkeit, göttliche wie menschliche Ordnung für belanglos, hatte keine Gewichtungen und Maßstäbe mehr.““4

Der Verlust der Maßstäbe und die Herrschaft der Laster werden von Sallust zwar nicht explizit auf einen Verlust der semantischen Ordnung zurückgeführt, wie das bei dem feinsinnigen Thukydides der Fall ist, aber in Sallusts Beschreibung des Sittenverfalls wird doch deutlich, dass die Benennung der Laster und Tugenden keine moralische Orientierungswirkung mehr hat. Die Folge dessen ist - auch in Umkehrung der Ursache-Wirkungsverhältnisse bei Thukydides - der Bürgerkrieg in Rom.

Was den Analysen von Caillois und Bataille zufolge in archaischen Gesellschaften das Fest war, ist bei Sallust der Krieg gegen äußere Feinde: Die Ehre, etwas für die Gemeinschaft zu tun, ist das höchste Ziel, und die Verlockungen des Reichtums kommen gegen sie nicht an. So wirken den zentrifugalen Tendenzen der Gesellschaft, dem Reichtum und den Lastern in seinem Gefolge, die Orientierung an Ruhm und Ehre als zentripetale Faktoren der gesellschaftlichen Ordnung entgegen. Aus sozialwissenschaftlicher Sicht ist dieses Modell nicht zuletzt darum interessant, weil es, im

43 Ebd., S. 17f.

44 Ebd., S. 21. 
Unterschied zur Moralphilosophie, nicht auf der Intentionalität des Handelns insistiert, sondern die funktionalen Effekte von Tugenden und Lastern ins Auge fasst: Nicht der gute Wille, sondern die positiven Effekte der äußeren Bedrohung sind letzten Endes ausschlaggebend. Ohnehin folgt Sallust bei seiner Thematisierung von Tugend und Laster nicht den Vorgaben der Moralphilosophie, sondern unterwirft sie einer Evaluation unter funktionalen Gesichtspunkten: Die Gier nach Ruhm und Ehre, die in seiner Sicht die Zentripetalität der Ordnung sicherstellt, ist schließlich keine Tugend, sondern eher deren Gegenteil. Der Krieg, der Streit, der Konflikt sind die Mechanismen, die den engen Rahmen des intendierten Guten überschreiten und das, was bei der Betrachtung des Einzelnen ein Laster ist, wird im Hinblick auf die politische Ordnung in ein gemeinwohlförderndes Verhalten verwandelt. Der Krieg, der, wie die Strategieanalytiker versichern, ohnehin ein Raum der Paradoxien ist, ${ }^{45}$ wird zur Agentur der Versittlichung, und gleichzeitig kann er im Anschluss an Sallust als ein Mechanismus der Verjüngung und Erneuerung begriffen werden, der den Alterungs- und Erschlaffungsprozessen der Gesellschaft entgegenwirkt. Die Beobachtungs- bzw. Beschreibungsmodelle von Paradoxie und Funktionalität sorgen dafür, dass der Fortbestand des politischen Verbandes von dem sozialmoralischen Habitus der Regierenden wie der Bürger unabhängig gemacht und als ein Mechanismus zu deren Wiederherstellung gedacht werden kann.

Dieser hier paradigmatisch am Beispiel des Sallust entwickelte Gedanke ist von Machiavelli, diesem Theoretiker der politischen Paradoxie, aufgegriffen und weitergeführt worden. Dabei ist vorwegzuschicken, dass auch Machiavelli der Vorstellung von den selbstdestruktiven Effekten militärischer Erfolge und politischer Macht verpflichtet ist, also ebenfalls einem zyklischen Geschichtsmodell folgt, das nicht durch die Tugendhaftigkeit der Akteure gesteuert werden kann. In der Vorrede zum fünften Buch seiner Istorie Fiorentine schreibt er:

„In ihrem Kreislauf pflegen die meisten Staaten von der Ordnung zur Unordnung überzugehen, um dann von der Unordnung zur Ordnung zurückzukehren. [...] Denn Kraft erzeugt Ruhe, Ruhe Trägheit, Trägheit Unordnung, Unordnung Zerrüttung,

45 So Edward Luttwak: Strategie. Die Logik von Krieg und Frieden, Lüneburg 2003, S. 17ff. 
wie hier wieder aus der Zerrüttung Ordnung entsteht, aus der Ordnung Kraft, aus der Kraft Ruhm und Glück."“6

Dementsprechend attestiert auch Machiavelli dem Krieg eine verjüngende und erneuernde Funktion, ${ }^{47}$ geht aber noch einen Schritt weiter, wenn er die Institutionalisierung des inneren Konflikts als politischen Jungbrunnen des Gemeinwesens begreift. ${ }^{48}$ Die verfassungstechnische Institutionalisierung des Streits der Parteien soll als politische Regenerationsmaschine wirken und gleichzeitig dafür sorgen, dass dieser Streit nicht zum Bürgerkrieg eskaliert. An die Stelle dessen, was von Lorenzetti und seinen philosophischen Beratern der Tugend als Orientierungsrahmen der Regierenden zugeschrieben worden ist, tritt bei Machiavelli der in der Verfassung verankerte Konflikt. Er ist die institutionelle Garantie für die politische virtù der Bürger eines Gemeinwesens. Die Verfassungsordnung des institutionalisierten Konflikts der sozialen und politischen Gruppierungen ist darauf ausgelegt, die mit naturgesetzlicher Notwendigkeit auftretende Kraft des Zentrifugalen in Zentripetalität zu transformieren. Ethische Tugenden im Sinne einer Intendierung des Sittlichen und Guten spielen für Machiavelli hier keine Rolle, ja er beschreibt verschiedentlich sogar deren dysfunktionalen Effekte: die Großzügigkeit und Großherzigkeit eines Politikers hat zur Folge, dass er, um die Tugend der magnificientia finanzieren zu können, das Volk mit Steuern und Abgaben belegt, die auf Dauer viel lästiger sind, als seine gelegentlich erwiesenen Wohltaten angenehm waren. Deswegen ist es für ein Gemeinwesen besser, wenn sein Herrscher bzw. die Regierenden knausrig und geizig sind, statt großzügig und freigebig. Was im klassischen Tugendkatalog als Laster angesehen wurde, entpuppt sich

46 Niccolò Machiavelli: Geschichte von Florenz. Mit einem Nachwort von Kurt Kluxen, Zürich 1986, S. 285.

47 Dazu mit Nachweisen Herfried Münkler: Machiavellis Theorie des Krieges, in: Thomas Jäger/Rasmus Beckmann (Hrsg.): Handbuch Kriegstheorien, Wiesbaden 2011, S. 169-177.

48 In einer kühnen Wendung kehrt Machiavelli die bisher hinter der Mischverfassung stehende Vorstellungen von Interessenausgleich und Gewaltenteilung um, indem er die Zusammenführung von monarchischen, aristokratischen und demokratischen Elementen als institutionalisierten Konflikt begreift, der dafür sorgen soll, dass die negativen Effekte des inneren Friedens nicht überhand nehmen. 
unter Machiavellis funktionalistischer Betrachtungsweise als politische Wohltat. $^{49}$

Die Idee von der Produktivität des Konflikts als Alternative zu einer an den ethischen Tugenden der Elite hängenden Ordnung ist von modernen Konflikttheoretikern, wie Georg Simmel, Lewis Coser und Ralf Dahrendorf, aufgegriffen und weiterentwickelt worden. Nicht die zelebrierte Gemeinsinnigkeit der Elite und der Bürgerschaft, so deren Credo, sondern der Konflikt der Eliten mitsamt der daraus resultierenden Elitenzirkulation sorgt für die Stabilität wie Regenerationsfähigkeit einer Gesellschaft, jedenfalls dann, wenn er in geregelten Bahnen gehalten und auf Dauer gestellt, also institutionalisiert wird. Was die Riten für die Ordnung des Festes waren, sind hier die verfassungsmäßigen Grenzen, die der stets möglichen Eskalation des Konflikts entgegenwirken. Aber wie die Riten die ekstatische Umkehrung der Ordnung zwar begrenzen, aber nicht unterbinden sollen, so haben bei den Konflikttheoretikern die Institutionen die Aufgabe, die Konflikte zu regulieren, aber nicht zu verhindern. Riten wie Institutionen sollen also gleichzeitig zulassen und begrenzen. Sie wirken wie Kanäle, die dem Gemeinwesen neue Kraft zuführen und destruktive Energien entsorgen. Im Unterschied zur Ritualität ist die Institutionalität jedoch eine politische und gesellschaftliche Regulationsform, die nicht auf Transzendenz als Legitimationsreserve angewiesen ist; gegenüber dem großen Fest hat der institutionelle Konflikt den Vorzug, ohne Transzendenz auskommen zu können.

Der Konflikt dient im politischen Dauerbetrieb somit als Transzendenzdispensator, und das tut er, indem er kontinuierlich und zuverlässig politische Tugend generiert. Dabei bildet die politische Tugend den Rohstoff eines politischen Betriebs, der über funktionale Effekte gesteuert wird. Diese Form der politischen Ordnung ist also unabhängig von den guten Zielen und Absichten der Regierenden. In diesem Sinne ist der Konflikt sowohl ein Transzendenz- als auch ein Intentionalitätsdispensator: Er bringt tüchtige Menschen hervor, die aber keine im moralischen Sinn guten Menschen sein müssen. Das Wunder des Konflikts ist, dass sie dennoch als tugendhaft gelten dürfen. Der klassische Tugendkatalog wird außer kraft gesetzt, die Laster können sich entfalten - und indem sie dies tun, wird die

49 Niccolò Machiavelli: Der Fürst/Il Principe, übersetzt und hrsg. von Rudolf Zorn, Stuttgart 1972, S. 64ff. 
Ordnung der Gesellschaft gestärkt und erneuert. Der Effekt des Konflikts ist, dass die Laster, teilweise zumindest, als politische Tugenden wirken. Freilich: Was für den Konflikt im Innern gilt, kann nicht auf den Krieg als große Form der Regeneration übertragen werden, denn ebenso wenig wie das Fest kann der Krieg auf Dauer gestellt werden. Er ist die Ausnahme von der Normalität des Friedens, wie das Fest das Außeralltägliche gegenüber dem alltäglichen Leben darstellt.

\section{DAS SCHEITERN DES REVOLUTIONÄREN TUGENDPROJEKTS UND DIE NIEDERgangsResistenten ProblemLÖser MARKT UND VERFASSUNG}

Was mit Konflikt und Krieg begonnen hatte, endete mit Markt und Verfassung, durchaus auch in Fortschreibung des Projekts, die Ordnung des Gemeinwesens vom Vorhandensein politischer und gesellschaftlicher Tugend unabhängig zu machen. Dagegen insistierte der jakobinische Strang der Französischen Revolution bis zum Thermidor auf der politischen Tugend gemäß der Vorstellung, dass ohne tugendhafte Bürger die Republik auf Dauer keinen Bestand haben werde. Der Sturz der Monarchie, das Ende der alten korrupten Despotenherrschaft, so wurde Robespierre nicht müde zu versichern, werde nur dann von dauerhaftem Erfolg gekrönt sein, wenn es gleichzeitig gelinge, die Tugend der Bürger wiederherzustellen. Alle Laster stünden auf Seiten der Tyrannen, und

„die Republik hat nur die Tugenden auf ihrer Seite. Die Tugenden sind einfach, bescheiden, arm, oft unwissend, zuweilen ungeschliffen; sie sind das Leibgedinge der Unglücklichen, das Erbteil des Volkes. Die Laster sind von allen Schätzen umgeben, mit allen Reizen der Wollust und allen Lockungen der Treulosigkeit geziert; sie werden von allen gefährlichen Talenten begleitet, die im Verbrechen geübt sind." 50

In der revolutionären Situation, so Robespierre, braucht die Tugend Unterstützung im Kampf gegen die Laster, und diese Unterstützung bekommt sie

50 Maximilien Robespierre: Über die Prinzipien der revolutionären Regierung (25. Dezember 1793), in: Reden der Französischen Revolution, hrsg. und übersetzt von Peter Fischer, München 1974, S. 336. 
durch den gegen die Anhänger der Tyrannei gerichteten Schrecken, den Terror: „So wie im Frieden die Triebfeder der Volksregierung die Tugend ist, so ist es in einer Revolution die Tugend und der Schrecken zugleich; die Tugend, ohne welche der Schrecken verderblich, der Schrecken, ohne den die Tugend ohnmächtig ist. ${ }^{\text {(51 }}$

Robespierre konstatiert, dass die Tugend, nachdem so viele Menschen bereits aus Ehrsucht oder Geldgier von der Republik abgefallen und zur Konterrevolution übergelaufen seien, die einzig wirkliche Bastion gegen die Angriffe der Tyrannei sei. Deswegen müsse die Tugend durch die Politik des Terrors geschützt werden.

„Glücklicherweise ist die Tugend, trotz der aristokratischen Vorurteile, eine natürliche Eigenschaft des Volkes. Eine Nation ist wirklich verdorben, wenn sie allmählich ihren Charakter und ihre Freiheit verliert und von der Demokratie zur Aristokratie und zur Monarchie übergeht; dies ist der Tod des politischen Körpers nach einem hohen und abgelebten Alter.“ ${ }^{52}$

Gegen diese zum Tod des Gemeinwesens führende Entwicklung will Robespierre ankämpfen, und in diesem Sinne ist ihm die Revolution als exzessiver Tugendgenerator ein Mittel der Verjüngung und Erneuerung Frankreichs. Die Revolution ist ein großes Fest, aus dem das Gemeinwesen gestärkt und erneuert hervorgehen wird. Robespierres Revolutionsrhetorik versammelt die im republikanischen Diskurs enthaltenen Überlegungen zum Fest und zum Krieg und verbindet sie mit dem Prozess der Revolution. Im Mittelpunkt aber steht die Insistenz auf der bürgerschaftlichen Tugend.

Bei diesem Projekt konnte sich Robespierre auf so unterschiedliche Denker wie Montesquieu und Rousseau berufen, die beide die Tugend, vertù, als die unverzichtbare sozialmoralische Grundlage der Republik herausgestellt hatten. Ohne die Wiedergewinnung der Tugend werde sich die despotische Ordnung nach einiger Zeit von selbst zurückmelden, denn die Menschen strebten entweder nach Ruhe und Sicherheit und kehrten sich von der freiheitlichen Verfassung ab, weil diese ihnen zu viel Mühe und Engagement abverlange, wie Etienne de la Boétie in seinem großen Essay

51 Maximilien Robespierre: Über die Prinzipien der politischen Moral (5. Februar 1794), in: Reden der Französischen Revolution, 1974, S. 349.

52 Ebd., S. 347. 
De la servitude volontaire erklärt hatte,$^{53}$ oder sie rebellierten gegen die tugendhafte Republik, weil diese in ihren Augen zu streng und zu langweilig war und keinen Spielraum ließ, den Lüsten zu folgen und die Triebe auszuleben. Das war die Funktion des großen ekstatisch-orgiastischen Festes gewesen, aber derlei war unter den Bedingungen der Tugendrepublik nicht möglich. Die republikanische Freiheit auf der Grundlage politischer Tugend und die liberale Freiheit der individuellen Selbstverwirklichung kollidierten hier miteinander. Die einschlägige Erzählung dazu stammt aus altrömischer Zeit; sie ist im Geschichtswerk des Titus Livius überliefert, und der Maler Jacques-Louis David, ein überzeugter Parteigänger der Revolution, hat sie zu Beginn der revolutionären Veränderungen gemalt. ${ }^{54}$ In ihr wird das Gegenteil des großen Festes für verbindlich erklärt. Das Bindeglied ist einmal mehr Machiavelli, der die Erzählung aus der altrömischen Geschichte auf die prägnante Formel gebracht hat: Wer die Republik verteidigen will, muss die Söhne des Brutus töten. ${ }^{55}$

Nach der Selbsttötung der Lucretia hatten Brutus und andere beherzte Männer den König Tarquinius Superbus und seine Familie aus Rom vertrieben und anstelle der Monarchie eine Republik errichtet. Das fiel leicht,

53 Etienne de La Boétie: Von der freiwilligen Knechtschaft, übersetzt und hrsg. von Horst Günther, Frankfurt a.M. 1980.

54 Neben dem Brutusbild von 1789 ist Davids Schwur der Horatier als ein weiteres Bild zu nennen, das die römische Geschichte aufruft, um über sie in die Gegenwart hineinzuwirken.

55 In den Discorsi ist Machiavelli (1966) mehrfach auf die Exekution der BrutusSöhne zu sprechen gekommen. In I, 16 macht er als die größten Vorzüge der republikanischen Ordnung geltend, dass man in ihr ,frei und ohne Sorgen sein Eigentum genießen kann, daß man nicht für die Ehre seiner Frau und seine Kinder zu bangen und nicht für seine eigene Person zu fürchten braucht" (ebd., S. 58). Um eine solche Republik gegen ihre inneren Feinde zu sichern, „gab es kein durchschlagenderes, wirksameres, heilsameres und notwendigeres Mittel, als die Söhne des Brutus umzubringen“" (ebd.). In III, 3 kommt Machiavelli auf die Hinrichtung der Brutussöhne zurück und spitzt dies zu der Alternative zu: „Wer sich zum Alleinherrscher aufwirft und den Brutus nicht tötet, oder wer einen Freistaat (repubblica) gründet und die Söhne des Brutus nicht beseitigt, wird sich nicht lange halten." (ebd., S. 281) Machiavelli verweist darauf, dass die Republik Florenz, deren Beamter er gewesen ist, daran gescheitert sei, dass deren führender Politiker diesem Imperativ nicht genügt habe: Piero Soderini „glaubte, nach der Wiederherstellung der alten Regierung [der Republik] mit Geduld und Güte den Ehrgeiz, von dem die Söhne des Brutus erfüllt waren, überwinden zu können; doch er täuschte sich“ (ebd.). „So verlor er, weil er dem Brutus nicht zu gleichen wusste, gleichzeitig mit seiner Heimat Herrschaft und Ansehen.“ (ebd., S. 282) 
weil die Königsfamilie nach zahlreichen Übergriffen und Gewalttaten unter den Bürgern keine Anhänger mehr hatte. Die eigentliche Herausforderung war dagegen die Verteidigung der Republik gegen diejenigen, die ihrer schon bald überdrüssig wurden. ${ }^{56}$ Unter ihnen spielten die Söhne des Brutus eine wichtige Rolle. Als sie das republikanisch sittenstrenge Leben zunehmend als Einschränkung empfanden, trafen sie sich mit den Söhnen des gestürzten Königs Tarquinius außerhalb Roms, um ihr früheres abwechslungsreiches Leben wieder aufzunehmen, und schon bald konspirierten sie mit den Königssöhnen, um die gerade errichtete Republik wieder zu stürzen. Brutus, zu diesem Zeitpunkt Konsul, erfuhr davon. Er ließ seine Söhne festnehmen, zum Tode verurteilen, auspeitschen und anschließend hinrichten. Er stellte damit die Verpflichtungen gegenüber der Republik höher als die Vaterliebe zu seinen Söhnen. Und er war bereit, um des zu statuierenden Exempels willen seine Familie im Mannesstamm auszulöschen.

Politisch ging es dabei nicht einmal konkret um seine Söhne. Es musste vielmehr ein Exempel statuiert werden, das klar machte, dass die Republik sich zu verteidigen wusste; es ging um den Schrecken, der von der Hinrichtung der Brutussöhne ausging. Daran hat Robespierre angeknüpft, als er in seiner Rede Über die Prinzipien der politischen Moral vom 5. Februar 1794 davon sprach, die Tugend sei ohnmächtig, wenn ihr nicht der Schrecken zur Seite stehen würde: Wer die Republik schützen wolle, müsse die Tugend schützen, und dabei dürfe er auch vor Familie und Freunden nicht zurückschrecken. Diesem Grundsatz gemäß hat Robespierre die Guillotine arbeiten lassen. Er handelte im Horizont der klassischen Bildung, in den er durch seine Erziehung hineingestellt worden war. ${ }^{57}$ Die Folge war der große Terreur, durch den die politische Tugend als unerlässliche Voraussetzung der Republik folgenreich desavouiert worden ist. Seitdem ist sie im politischen Diskurs ins zweite Glied zurückgetreten. In den liberaldemokratischen Verfassungen der westlichen Staaten spielt sie nur noch als Korruptionsresistenz politischer Eliten eine Rolle.

Der Verzicht auf die Tugend als Lebenselixier der Republik fiel um so leichter, als im Vorfeld der Französischen Revolution bereits Kompensa-

56 Livius: Römische Frühgeschichte, Bd. 1: Roms Königszeit und der Kampf um die Vorherrschaft in Mittelitalien, ausgewählt und übertragen von Josef Feix, München 1970 (Buch II, Kap. 5).

57 Vgl. Max Gallo: Robespierre, Stuttgart 1989, S. $27 \mathrm{ff}$. 
tionen ,entdeckt ${ }^{\natural}$ worden waren, die das Erfordernis der Tugend zumindest relativierten. Es waren dies der Markt und die Verfassung. Über den Markt bemerkt Adam Smith in seinem Wealth of Nations, er befördere das gemeine Wohl, selbst wenn alle nur ihr Eigeninteresse verfolgten: der Bäcker nur an sich selbst denke, der Brauer nur an sich selbst denke usw. Die Konkurrenzmechanismen des Marktes und der Ausgleich zwischen Angebot und Nachfrage würden wie durch eine unsichtbare Hand dafür sorgen, dass jeder seine Bedürfnisse befriedigen könne und so das allgemein Beste herauskomme. ${ }^{58}$ Die Gemeinsinn-Zumutung war im Wirtschaftsleben nicht vonnöten, wenn man nur für das freie Spiel der Kräfte am Markt sorgte. Und wie war das in der Politik?

Vermutlich hatte Kant den auf das Erfordernis der Tugend abhebenden Einwand gegen die Erfolgschancen bei der Errichtung einer Republik schon viele Male gehört: „Es müsse ein Staat von Engeln sein, weil Menschen mit ihren selbstsüchtigen Neigungen einer Verfassung von so sublimer Form nicht fähig wären.“59 Kants listiges Gegenargument lautet, es seien die selbstsüchtigen Neigungen selbst, die der als ohnmächtig gedachten Vernunft zur Hilfe kämen, und zwar dann, wenn es gelinge, die Kräfte der selbstsüchtigen Neigungen so gegeneinander zu richten, ,daß eine die andere in ihrer zerstörenden Wirkung aufhält, oder diese aufhebt: so daß der Erfolg für die Vernunft so ausfällt, als wenn beide gar nicht da wären, und so der Mensch, wenngleich nicht ein moralisch-guter Mensch, dennoch ein guter Bürger zu sein gezwungen wird.“60

58 Adam Smith: Der Wohlstand der Nationen. Eine Untersuchung seiner Natur und seiner Ursachen, hrsg. von Horst Claus Recktenwald, München 1978, S. 17: „Nicht vom Wohlwollen des Metzgers, Brauers und Bäckers erwarten wir das, was wir zum Essen brauchen, sondern davon, dass sie ihre eigenen Interessen wahrnehmen. Wir wenden uns nicht an ihre Menschen-, sondern an ihre Eigenliebe, und erwähnen nicht die eigenen Bedürfnisse, sondern sprechen von ihrem Vorteil.“ Das war das Programm zur Ablösung der letzten Reste der Moralökonomie durch die Marktökonomie.

59 Immanuel Kant: Zum Ewigen Frieden; in: ders.: Werke, hrsg. von Wilhelm Weischedel, Bd. 9, Darmstadt 1970, S. 223 (Hervorhebung im Original).

60 Ebd., S. 224. Kant folgt hier derselben Intention wie Machiavelli, aber während dieser die moralische von der politischen Tugend trennte, als er zeigte, dass Laster (wie der Geiz) politisch positive Effekte haben können, vermag Kant an einer klaren Semantik von Tugend und Laster festzuhalten, weil er die mit den Lastern (oder dem Bösen) verbundenen Effekte externalisiert und an den „Mechanism der Antagonismen“ in der Verfassung überweist. Im Unterschied dazu hat Machiavelli auf dem Erfordernis bürgerschaftlicher Tugend bestanden 
Selbst mit einem Volk von Teufeln ist also eine Republik zu gründen, wenn dieser Mechanismus der Natur die Anlage der Verfassung bestimmt, vorausgesetzt nur, dass die Teufel Verstand haben, also ihre Interessen rational verfolgen und an der Maximierung ihres Nutzens orientiert sind. Das Erfordernis der Tugend tritt zurück, wenn die Verfassung gut und richtig geordnet ist. Es sind die institutionellen Arrangements des Marktes und der Verfassung, die vom altrepublikanischen Zwang zur Mobilisierung politischer Tugend als Voraussetzung republikanischer Freiheit entlasten. Es bedarf weder des Festes, noch des Schreckens, noch des Krieges als der großen Erneuerer, sondern nur des zuverlässigen Wirkens der Institutionen, damit die Republik Bestand hat.

Die Suggestivität dieser Überlegungen ist - neben der Unterstellung der Akteursrationalität - freilich dem Umstand geschuldet, dass die biologischorganologische Semantik der Aufgabenbeschreibung durch eine mechanische Semantik ersetzt worden ist, ${ }^{61}$ so dass sich das Problem des Alterns und das Erfordernis der Revitalisierung nicht mehr stellen. Durch die Umstellung der Semantik (bzw. Metaphorik) ist ein Problem zum Verschwinden gebracht worden, mit dem sich die republikanische Theorie zuvor immer wieder beschäftigt hat: das Problem von Altern, Niedergang und Zerfall. Die mechanistische Semantik war gegen den Einbruch der Zeit immun. Allenfalls ging es um ein Nachjustieren der Mechanik, und im Notfall mussten verschlissene Teile ausgetauscht oder repariert werden. Damit war auch das Erfordernis von Transzendenz verschwunden, denn sowohl das Funktionieren als auch die Reparatur der Mechanik sind Vorgänge des Alltags, für die weder der Schauder des Heiligen noch die Idee der Unverfügbarkeit als Funktionsvoraussetzung vonnöten sind. War

und die Verfassung mit der Aufgabe betraut, für deren Reproduktion zu sorgen. Kant hingegen verabschiedet mit Blick auf die politische Ordnung das Erfordernis politischer Tugend.

61 Vgl. zum Übergang von biologisch-organologischen zu mechanischen Gesellschaftsmodellen Franz Borkenau: Der Übergang vom feudalen zum bürgerlichen Weltbild [1934], Darmstadt 1971 sowie Hendryk Grossmann: Die gesellschaftlichen Grundlagen der mechanistischen Philosophie und die Manufaktur, in: Zeitschrift für Sozialforschung 4 (1935), S. 161-231. Hans Blumenberg hat in mehreren Arbeiten (zuletzt Quellen, Ströme, Eisberge, hrsg. von Ulrich von Bülow, Berlin 2012) gezeigt, auf welche Weise Problemwahrnehmung und Problembeschreibung durch Semantik und Metaphorik beeinflusst werden. Bei der Beschreibung politischer Verbände als Körper oder aber Maschinen bzw. Apparate handelt es sich um Metaphoriken im Sinne Blumenbergs. 
für Thukydides die Verwirrung der Semantik das Problem, so wurde die Umstellung der Semantik für Smith und Kant zu dessen Auflösung.

Ebenso wichtig wie die Umstellung der politischen Metaphorik von der Organologie auf die Mechanik war deren geschichtsphilosophische Rückendeckung, die Kant durch den Aufstieg der Fortschrittsvorstellungen gegenüber dem Zyklenmodell zugute kam. Damit nämlich war das Problem der Selbstdestruktion des erfolgreichen Aufstiegs, das seit Polybios und Sallust wie ein Damoklesschwert über der politischen Geschichtsschreibung hing, verschwunden. Fortschritt hieß, dass es einen kontinuierlichen Aufstieg des Menschengeschlechts zum Besseren gab und dass dieser Fortschritt nicht, wie in der Zyklentheorie, die Ursache eines anschließenden Niedergangs war. Auch die Zyklentheorie bestritt ja keineswegs, dass es Fortschritte und politische Aufstiege gab, aber sie sah darin die Ursache für anschließenden Niedergang und Verfall und dadurch war die Vorstellung eines kontinuierlichen und irreversiblen Fortschritts unmöglich gemacht. Ein solcher kontinuierlicher und irreversibler Fortschritt war im Europa des 18. Jahrhunderts zunächst für die Kultur- und sodann für die Wissenschafts- und Technikgeschichte gedacht worden; unter dem Eindruck der Französischen Revolution hat Kant die Fortschrittsidee dann auf die politische Geschichte übertragen. ${ }^{62}$ Das war ein weiterer Grund, warum sich für ihn das Problem des Verfalls und das Erfordernis der Regeneration nicht mehr stellte.

Im Großen und Ganzen hat die politische Geschichte des 19. Jahrhunderts in Europa gehalten, was das Fortschrittsparadigma des Liberalismus versprochen hat. Erst der Erste Weltkrieg hat diese Zuversicht erschüttert - sei es, dass er als Rettung aus dem ,Sumpf des Materialismus“ durch die Opferbereitschaft der in Helden verwandelten Bürger im Krieg gedeutet, sei es, dass er als ,Rückfall in die Barbarei“ begriffen wurde - mit der Folge, dass man sich auf die Zivilisierungsgewährleistung nicht verlassen konnte. Diese Zweifel wurden durch den Zusammenbruch der Weimarer Republik, die Naziherrschaft in Deutschland und den Zweiten Weltkrieg mitsamt dem Völkermord an den Juden weiter verstärkt. Nach dem Ende der als ,Diktatur ' oder ,Tyrannei‘ bezeichneten Nazi-Herrschaft tauchte das aus der politischen Ideengeschichte vertraute Ensemble der

62 Immanuel Kant: Der Streit der Fakultäten, in: ders.: Werke, hrsg. von Wilhelm Weischedel, Bd. 9, Darmstadt 1970, S. 357-360. 
Erneuerung, Selbstreinigung und politischen Läuterung wieder auf, nur dass es nicht mehr im Kontext einer zyklischen Geschichtsauffassung gedacht wurde, sondern als Voraussetzung dafür, dass Deutschland wieder Anschluss an die zivilisierte Welt fand. Vor allem aber war es mit der Vorstellung eines einmaligen Zivilisationsbruchs verbunden und wurde nicht als ein repetitives Erfordernis politischen Lebens begriffen. Nach einiger Zeit setzte sich dann die Vorstellung durch, Bonn sei nicht Weimar (und auch Berlin würde es nicht werden), und so konnte die liberale Vorstellung vom kontinuierlichen Fortschritt oder zumindest doch der Erreichung eines festen und stabilen Zustands ohne selbstdestruktive Elemente wieder aufgenommen werden. Aber können wir uns auf die Versicherung einer solchen Stabilität, wenn nicht gar eines beständigen Fortschritts wirklich verlassen? Oder sind die Debatten über Gier und Geiz und das Projekt einer ,neuen Bürgerlichkeit', von denen eingangs die Rede war, Indikatoren dafür, dass das Gespenst der Selbstdestruktion durch Erfolg, das doch eigentlich gebannt zu sein schien, zurückgekehrt ist?

\section{DAS ERNEUERTE ERFORDERNIS VON TUGEND UND GEMEINSINN UND DER EINBRUCH DES POPULISMUS IN DIE POLITISCHE ORDNUNG}

Es hätte alles gut bleiben können, so erscheint es in der Retrospektive, wenn es nicht die Liberalisierung der Märkte, die Prozesse der ökonomischen Globalisierung, den Aufstieg Ostasiens, die Ausweitung Europas in alle Richtungen und vieles andere mehr gegeben hätte. Auf den ersten Blick sieht es so aus, als hätten der Erfolg und sein Versprechen, dass die bislang beschrittenen Wege richtig seien und bloß energisch weitergegangen werden müssten, zu dem nunmehrigen Umschlag in wirtschaftliche und politische Krisen geführt. Und schon ist die alte Frage wieder da: Wer schützt die Institutionen, wenn sie in Notlagen außer Kraft gesetzt, Verpflichtungen relativiert und dem Eigeninteresse die Zügel freigegeben werden? Managergehälter, Bankerboni, plagiierte Dissertationen, korrupte politische Klassen - mit einem Mal stand die Frage der politischen Tugend wieder auf der Tagesordnung. Dort wird sie vermutlich sehr lange unbeantwortet stehen bleiben, denn sie ist nun nicht mehr bloß an autoritäre bzw. totalitäre Regime adressiert, sondern betrifft den demokratischen Rechtsstaat in seinem Kernbestand. Und damit ist auch das Problem der 
Regeneration bzw. Revitalisierung wieder da, über das in der Geschichte des politischen Denkens mehr als 2000 Jahre nachgedacht worden ist. Legt man dieses Nachdenken zugrunde, so ist der Slogan „Geiz ist geil“" mehr als eine bloße Form geschickter Werbung, sondern Bestandteil eines Kampfes um die Deutungshoheit über die Semantik einer Gesellschaft. Womöglich ist es aber auch schon das Ergebnis dessen, dass die um den Eigennutz orientierten Gruppen bereits eine semantische Verwirrung angerichtet haben, die gesellschaftlich destruktive Folgen haben wird. Das bleibt abzuwarten.

Daneben gibt es aber noch ein mit der Erosion der politischen Tugend zusammenhängendes genuin politisches Problem: Es geht um das schwindende Engagement der Bürger in den politischen Parteien und seine Verwandlung in zivilgesellschaftliches Engagement, das im Unterschied zum politischen Engagement thematisch punktuell und zeitlich eng begrenzt ist: Auf der kommunalen Ebene sind inzwischen mehr Sitze in den Vertretungskörperschaften zu vergeben, als es Bewerber um diese Sitze gibt. Die Demokratie trocknet von unten her aus bzw. Profis treten an die Stelle von Amateuren. Der Anstieg des bürgerschaftlichen Engagements in der Zivilgesellschaft hat zu einem Rückgang des Engagements im politischen System geführt. Der Demokratie kommen zwar nicht die Demokraten, aber die zum politischen Engagement bereiten Bürger abhanden. In der Folge schottet sich die politische Klasse mehr und mehr ab, und Wahlen werden zu dem, als was sie die ökonomische Demokratietheorie schon immer gedacht hat: eine Auswahl zwischen zwei Produktanbietern. ${ }^{63}$ Das ist im Wesentlichen eine Folge veränderter Engagementspräferenzen, bei denen die Orientierung an den eigenen Interessen zunehmend an die Stelle der Bereitschaft tritt, sich durchs Gemeinwohl konsumieren zu lassen. Damit steht die Frage nach der politischen Tugend wieder ganz oben auf der Tagesordnung. Das Projekt einer, neuen Bürgerlichkeit‘ ist eine der Antworten auf das Problem, aber insofern die ,neue Bürgerlichkeit‘ selbst ein Element der Verwandlung genuin politischen in zivilgesellschaftliches Engagement ist, ist sie nicht nur Lösung, sondern auch Bestandteil des Problems.

63 Vgl. die Darstellung der Demokratie bei Joseph Schumpeter: Kapitalismus, Sozialismus und Demokratie, Bern 1950; Anthony Downs: An Economic Theory of Democracy, New York 1957. 
Aber die Gier- und Geizdebatte, in der sich der neue Tugenddiskurs in Deutschland äußert, ist nicht bloß ein sozialmoralisches Aufbäumen gegen die sozio-ökonomischen Effekte des Finanzkapitalismus, dem man nur, selbst wenn man am Erfolg dessen zweifelt, innerlich zustimmen kann, sondern hat auch ihre politisch problematischen Seiten, die in einer Remoralisierung der Gesellschaftsanalyse und der damit verbundenen Politikvorstellungen ihren Niederschlag finden. Solange sich dies in einer wellenförmigen Stärkung und Schwächung kommunitarischer Ideen und Initiativen ausdrückt, ist dagegen nichts einzuwenden, im Gegenteil, aber das ändert sich, sobald der neue Tugenddiskurs zum Antriebsmoment rechts- wie linkspopulistischer Politikvorstellungen wird. ${ }^{64}$ Nun lässt sich gegen eine alarmistische Dramatisierung dieser Herausforderung sicherlich einwenden, dass populistische Bewegungen immer auch einer Abschottung der politischen Klasse entgegenwirken und ein gerade in Demokratien unverzichtbares Gegengewicht zu einer sich ausdehnenden Bürokratie, Technokratie und Expertokratie darstellen. Insofern sind sie - auch - Formen demokratischer Revitalisierung. Dieses Argument zur Rechtfertigung zyklisch auftauchender Populismen kann durchaus an den klassischen Tugenddiskurs anschließen: Populistische Bewegungen und Parteien sind danach als Revitalisierungsformen der Demokratie zu begreifen. Aber wie das ekstatischorgiastische Fest, der äußere Krieg und der revolutionäre Schrecken ist auch der Populismus mit einer Reihe von Risiken verbunden, die aus den mit dem Tugenddiskurs verbundenen Gesellschaftsvorstellungen erwachsen.

Das Gesellschaftsbild des politischen Tugenddiskurses ist nämlich im Kern antagonistisch, indem es den Tugendhaften die Lasterhaften bzw., im frühneuzeitlichen Diskurs von Machiavelli bis Montesquieu und Rousseau, denen mit Tugend die ohne Tugend gegenüberstellt. Populistisch wird diese Gegenüberstellung dann, wenn die Tugend mit dem, Volk' und das Laster mit den Herrschenden, den Eliten, jedenfalls denen , da oben' verbunden wird. Das antagonistische Gesellschaftsbild wird dadurch moralisch aufgeladen und bekommt, sobald noch apokalyptische Untergangsszenarien ins Spiel kommen, einen ausgesprochen manichäischen Charakter.

64 Ich folge hier weitgehend den Überlegungen von Karin Priester: Rechter und linker Populismus. Annäherung an ein Chamäleon, Frankfurt a.M./New York 2012, bes. S. $205 f f$. 
Die Gierdebatte sowie die mit ihr verbundene Attac-Organisation und die Occupy-Bewegung haben sich inzwischen unübersehbar in diese Richtung bewegt: Der großen Anzahl derer, die hart arbeiten und eher bescheiden leben, also den Guten und Tugendhaften, steht eine kleine Gruppe frivoler Nutznießer des Finanzkapitalismus gegenüber, die das Wirtschaftssystem mit List und Tücke für ihren ,schamlosen Egoismus' ausnutzen und es obendrein zu ihrem Vorteil manipuliert haben. Die Gierdebatte gipfelt in der Aufforderung, ihrem ,schamlosen Treiben' Einhalt zu gebieten, mit welchen Mitteln auch immer. Der publizistische Erfolg, den Stéphane Hessels kleiner Essay Empört Euch! erzielt hat ${ }^{65}$ zeigt an, in welchem Maße eine die Komplexität der Gesellschaft und die paradoxalen Funktionsketten der Politik berücksichtigende Analyse inzwischen von einem Moraldiskurs überlagert ist, der alles klar und überschaubar macht: Die für die Wirtschafts- und Finanzkrise sowie die daraus resultierende Verarmung und Verelendung Verantwortlichen sind identifizierbar und werden auch als solche benannt. Die Analyse von Paradoxien und funktionalen Verkehrungen ist durch eine Betrachtung überlagert worden, in der Ergebnisse unmittelbar auf Absichten und Pläne zurückgeführt werden können: Im Prinzip haben wir es danach mit einer Verschwörung korrupter, gemeinwohlaverser Eliten gegen das, gute Volk' zu tun. Aber inzwischen, so die Botschaft weiter, haben moralische Gegeneliten anstelle des desorientierten Volkes damit begonnen Widerstand zu leisten, der von demonstrativen Platzbesetzungen bis zu Sabotageaktionen reicht. ${ }^{66}$ Sie legitimieren sich durch die politische Tugendhaftigkeit, die sie sich selbst attestieren.

Komplementär dazu sind die Tugendvorstellungen zu sehen, die in die Euro-Debatte und den Vorstellungen zur Bewältigung der Fiskalkrise in der Europäischen Union um sich gegriffen haben: Danach stehen den ,fleißigen und sparsamen' Deutschen (und denen, die ihnen ähnlich sind) die, faulen und verwöhnten' Südländer gegenüber, die sich ihr dolce far niente von den anderen bezahlen lassen wollen, um bei sich selbst keine Abstriche machen zu müssen. Der Gegensatz von Tugend und Laster ist hier keiner von ,Volk' und Elite, sondern einer nationaler Mentalitäten, die zur Erklärung der unterschiedlichen Entwicklung im Euroraum bemüht werden. Der von

65 Stéphane Hessel: Empört euch!, 5. Aufl., Berlin 2011.

66 Aufschlussreich ist hier das von einem „Unsichtbaren Komitee“ verfasste Pamphlet: Der kommende Aufstand [2007], Hamburg 2010. 
diesem neuen Tugenddiskurs gemachte Lösungsvorschlag läuft darauf hinaus, dass die im Süden entweder umgehend so tugendhaft werden wie die im Norden oder beide sich voneinander trennen. Komplexe politische und ökonomische Fragen werden hier zu einfachen Absichten und Vorhaben. Politisches Handeln wird von diesem populistischen Tugenddiskurs unter Rechtfertigungs- und Handlungszwang gesetzt. Selbstverständlich ist darin immer auch der Appell an die nationalen wie europäischen Technokratien enthalten, sich mehr an den Erwartungen und Bedürfnissen der Bürger zu orientieren, aber der Gestus der Rebellion gegen die institutionelle Ordnung Europas ist in diesen Tugendpopulismus immer eingeschlossen. - Man kann in ihm aber auch eine durchaus angemessene Reaktion auf eine rein outputorientierte Form der politischen Legitimation sehen: die Hypertrophie der Tugenderwartungen, mit denen die Politik zur Zeit konfrontiert ist, ist die ,Strafe‘ für die Defizite an Inputlegitimationen, mit denen Europa gebaut worden ist. 



\section{DEMOKRATISCHE ORDNUNGEN IN GRÜNDUNGS-, KRISEN- UND UMBRUCHSZEITEN}





\title{
Das Sakrale im Zeitalter seiner politischen Reproduktion
}

\author{
Die Französische Revolution zwischen
}

Verfassungsfest und Missionierungskrieg

\section{DANIEL SCHULZ}

Moderne Revolutionen haben durch ihren erfolgreich durchgesetzten politischen Widerspruch die bestehende Ordnung zum Alten Regime degradiert. In der Form des Widerspruchs aber produzieren sie auf der Ebene der Ordnungsbegründung Paradoxien, deren Bearbeitung, wie gerade am Beispiel der Französischen Revolution augenfällig wird, ein gewaltiges symbolisches Dispositiv notwendig macht. Diese Bewältigungsstrategien sind keine „bloß“ symbolischen Verdeckungen realer gesellschaftlicher Widersprüche, oder willfährige Instrumente im politischen Kampf. Sie sind Teil der politischen Wirklichkeit und der Auseinandersetzung darüber, wie die politische Ordnung zu deuten sei. Der phänomenologische Befund der Revolution verweist auf die zentrale Bedeutung dieser symbolischen Paradoxien des Gründungsmoments, die sich dem Zugriff der politischen Akteure nur teilweise unterwerfen. Die Wahl der symbolischen Waffen im politischen Kampf ist nicht beliebig, ihre Produktion entzieht sich der unmittelbaren Verfügung. Gleichwohl besteht ein großer Teil der revolutionären Aktivität darin, sich in Diskursen und Praktiken diese unverfügbaren Geltungsressourcen anzueignen und zur Legitimation einer neuen Ordnung einzusetzen.

Die Grundstruktur der revolutionären Paradoxie kann als Dreischritt beschrieben werden: Auflösung, Neugründung, Bindung. Die Phasen durch- 
dringen und überlagern sich, laufen mitunter in umgekehrter Reihenfolge ab. An erster Stelle steht die Auflösung der bisherigen Ordnung, die damit zur alten Ordnung entwertet wird. Mit dem Auflösen wird die politische Ordnung verfügbar. Im Prozess der Auflösung gelingt es, die „,versteinerten Verhältnisse dadurch zum Tanzen zwingen, dass man ihnen ihre eigene Melodie vorsingt“" . Dies gilt auch für die Französische Revolution, die doch immer wieder betonte, es gehe nicht um eine Neukonstruktion, sondern um das Auffinden der Ursprünge, das Wiederentdecken der verschütteten Grundlagen. Dies betrifft schon den zweiten Schritt: das Neugründen, und sei es auch als Wiederbegründen. Entscheidend jedoch ist der dritte Schritt, das Binden, welches unmittelbar an den Gründungakt gekoppelt ist. Im Moment der Gründung stellt sich bereits die Frage, wie über den Moment hinaus die neu geschaffene Ordnung eine bindende und verpflichtende Kraft entfalten kann. Wie kann - und hierin besteht nun die Paradoxie - die neu gegründete Ordnung also der Verfügbarkeit wieder entzogen werden, die sie doch erst ermöglicht hatte? Dem ersten revolutionären Akt der „Ent-transzendierung“ entspricht also eine Retranszendierung der politischen Ordnung, mit der die zwischen diesen beiden Akten aufscheinende Kontingenz wieder unsichtbar gemacht wird. Der Gründungsmoment enthält alle drei Dimensionen in nuce: Die Gründung setzt im gleichen Moment ein Ende und einen Neuanfang, sie ist Entbindung und Neubindung zugleich. Im Moment des Gründens also treffen Geltungsbehauptungen aufeinander, die mit dem Akt der Verfügbarmachung politischer Ordnung auch deren symbolische Transzendierung erzeugen.

Im Folgenden werden unterschiedliche Erscheinungsformen revolutionärer Transzendenz an drei Beispielen illustriert. Das Material ist exemplarisch ausgewählt, um die Formenvarianz der Transzendenzbehauptungen aufzeigen zu können. Zunächst gilt es jedoch, den Transzendenzbegriff anhand zweier Dimensionen genauer zu umreißen: Vorerst kann mit dem Begriff die Frage nach der Verfügbarkeit und der Unverfügbarkeit von Ordnung bezeichnet werden. Ordnungen sind begründungsbedürftig - das gilt auch und gerade für den Fall, wenn sie als unbegründbar und selbstevident dargestellt werden, aus sich selbst heraus existierend. Auch diese Selbstevidenz, die Unhinterfragbarkeit ist symbolisch verfasst und beruht

1 Karl Marx: Kritik der Hegelschen Rechtsphilosophie, Einleitung, in: MEW, Bd. 1, Berlin 1983, S. 378-391, hier: S. 381. 
auf komplexen Mechanismen der Geltungsstabilisierung. Auch dort, wo anstelle der (vermeintlich vormodernen) unhinterfragbaren, nicht-reflexiven Begründung die (vermeintlich moderne) diskursive, explizite und räsonierende Begründungsform tritt, kommt dem Bezug auf Unverfügbares, der Begründung Vorausliegendes oder sie Übersteigendes eine zentrale Bedeutung zu - sei es in Gestalt der unhintergehbaren Lebenswelt, sei es durch die universelle Macht der Vernunft oder des Diskurses selbst.

Zugleich lässt sich auch jene Dimension politischer und sozialer Ordnung als transzendent begreifen, die durch einen Bezug auf überschießendes symbolisches Potential - in Gestalt der Heiligkeit, des Außeralltäglichen - ausgewiesen ist. Ordnungen werden so mit einem symbolischen Anschein der besonderen Bedeutung, der Sakralität belegt, der zugleich ihre Unantastbarkeit garantieren soll. Beide Dimensionen des Transzendenzbegriffs hängen daher eng miteinander zusammen: Unverfügbar gilt eine Ordnung, ein Geltungsanspruch insofern, als er durch seine besondere symbolische Form einer umfassenden Sinnstiftung oder eines Heilsversprechens dem Zugriff entzogen scheint. Unverfügbares muss als besonders bewahrenswert, als unantastbar dargestellt, inszeniert werden oder auch durch die Verdeckung, durch Invisibilisierung des Gemachten, des Kontingenten und Zufälligen mit Notwendigkeit und Dauer aufgeladen werden. Das Heilige, symbolisch überschießende, Außeralltägliche kann von den betroffenen Akteuren als unverfügbar gedeutet werden, insofern es als Erfahrung eines Einbruchs von außen in die Lebenswelt, in den alltäglichen Erfahrungshorizont begriffen wird.

Mithilfe eines solchermaßen gefassten Transzendenzbegriffs kann nun gezeigt werden, wie die Französische Revolution das Problem der politischen Neugründung zu bewältigen versuchte. Am Beispiel der politischen Feste wird der Versuch einer Sakralisierung politischer Ordnung offenbar, den Moment der revolutionären Einheit durch zeremonielle und rituelle Formen zu stabilisieren. Diese symbolische Verstetigung steht zudem in einem engen Bezug zu den verschiedenen Phasen der Verfassunggebung, in denen die Frage der transzendenten Überhöhung besonders dringlich gestellt wird. Die destabilisierenden Kräfte des revolutionären Transzendenzdiskurses liegen dagegen in der Kriegsdebatte zu Tage. Obgleich alle drei Aspekte - Festkultur, Verfassunggebung, Kriegsdebatte - eng miteinander verbunden sind, werden sie zunächst analytisch getrennt behandelt, um die jeweilige Transzendenzdimension herauszuarbeiten. An- 
schließend kann dann jedoch gezeigt werden, dass alle drei Dimensionen miteinander verbunden werden, weil es sich um verschiedene Artikulationsformen einer durch Sakralisierung der Verfügbarkeit entzogenen Ordnung handelt.

\section{Revolutionsfeiern UND SAKRALITÄTSVERSCHIEBUNGEN}

Die Revolutionsfeste sind von der Revolutionsgeschichtsschreibung als zentrale Orte der Selbstartikulation revolutionären Handelns beschrieben worden. ${ }^{2}$ Ihre Vielfalt in allen Phasen der Revolution und auch ihre räumliche Verbreitung in allen Teilen Frankreichs über die Hauptstadt hinaus lädt dazu ein, mit der Formulierung Mona Ozoufs nicht nur von den Festen der Revolution, sondern von der Revolution als Fest, gar als einem großen revolutionären Fest zu sprechen. Das Fest markiert damit den politischen Ausnahmezustand als prekäres Ineinander von sich auflösenden Bindungen ebenso wie den Bedarf an neuen Bindungsstiftungen und ihrer symbolischen Bestärkung. Als rites de passages sind Feste stets eingeübte Form der kulturellen Bearbeitung von Wandel - sei er gesellschaftlicher, natürlicher oder politischer Art. Gerade die Revolution machte intensiven Gebrauch von dieser kulturellen Verarbeitungsform des Kontinuitätsbruchs. In der symbolischen Rahmung des außeralltäglichen Momentes sollte der revolutionären Neugründung Dauer verliehen und zugleich die destruktive Macht gebändigt werden, die weiterhin von ihr auszugehen schien.

Am eindrücklichsten belegt wird dieser Anspruch durch die Fête de la fédération vom 14. Juli 1790 auf dem Pariser Marsfeld. Die vielschichtigen Bedeutungen, die von diesem Ereignis ausgehen, verweisen letztlich alle auf die Integration der neuen, freien und gleichen Gesellschaft durch die symbolische Wiederholung ihres Gründungsereignisses, dem Sturm auf die Bastille. Dieser memoriale Verstetigungsversuch geschieht zu einem Zeitpunkt, als zwar mit der Menschen- und Bürgerrechtserklärung von 1789

2 Vgl. die klassischen Studien der Revolutionshistoriographie von FrançoisAlphonse Aulard: Le culte de la Raison et le culte de l'Être suprême, Paris 1892 sowie sein Schüler Albert Mathiez: Les origines des cultes révolutionnaires, Paris 1904; dagegen vor allem Mona Ozouf: La fête révolutionnaire 1789-1799, Paris 1976 sowie Michel Vovelle: 1793. La Révolution contre l'Église, Paris 1988. 
bereits das Gründungsdokument vorliegt, der Prozess der eigentlichen Verfassunggebung aber noch nicht abgeschlossen ist. Während also die integrative Wirkung einer neuen Verfassung auf sich warten lässt und zudem aufgrund der ungeklärten konstitutionellen Grundfragen immer mehr Konfliktpotential offenbart, übernimmt das Föderationsfest die Bedeutung eines symbolischen Integrationsversuches. Die revolutionäre Ordnungsverletzung soll durch die festlich inszenierte Gemeinschaftserfahrung geheilt werden, das wiederholte Gründungsereignis in einer theatralischen Inszenierung nur noch als verbindendes Hoffnungszeichen im Gedenken präsent sein, nicht mehr als Einbruch des Realen. Dabei beginnt die Teilhabe am Sakralen schon mit den Aufschüttungen der Tribünen und des Altars auf dem Marsfeld - die Vorbereitung des Festes, seine Genese, nimmt zudem in den Darstellungen einen prominenten Platz ein und galt für alle nachfolgenden Interpreten stets als Beleg für seine Spontaneität. ${ }^{3}$ Der Moment des Festes am 14. Juli selbst bildet nach Ozouf so nur den Scheitelpunkt von sehr viel weiterreichenden Feierlichkeiten, die bereits im Herbst 1789 einsetzen und den ganzen Winter über bis in das Jahr 1790 reichen. Der Grund für die vom Fest der Föderation ausgehende Transzendenzerfahrung, die zum Vorbild aller nachfolgenden Kulte werden sollte, liegt daher weniger im Fest selbst, sondern in der Dynamik vor und nach dem Ereignis. Bereits die Anreise der Teilnehmer aus allen Teilen des Landes wird zu einer heiligen Wallfahrt der Revolution, die durch ihren Ausnahmecharakter für alle Beteiligten zum ersten Mal die Einheit der Nation zur erfahrbaren Größe werden lässt. Mit dem durchquerten Territorium wächst auch der kleinräumige Erfahrungsraum zum großräumigen Erwartungshorizont, der die zum Fest abgeordneten Bürger wahrhaft zum Teil einer revolutionären Raumerfahrung werden lässt. Die Föderierten betraten Paris und das Marsfeld wie heilige, geweihte Orte, die Beteiligten aus der Provinz beschrieben das Ereignis später als eine Wallfahrt, deren Reliquie das Banner der Föderierten stellt. ${ }^{4}$ Um das Datum des 14. Juli herum häufen sich zudem in Paris zahlreiche Spektakel und Volksfeiern, die den Charakter des Außergewöhnlichen im Erlebnis der Teilnehmer nur noch verstärken. Das Ereignis selbst wirkt demgegenüber schon fast zu statisch inszeniert, um jene transzendente Wirkung freizusetzen, die man sich von ihm erhofft. Der Einzug der Teilnehmer auf das Festgelände folgt nach einem langen

3 Ozouf, La fête révolutionnaire, 1976, S. 47.

4 Ebd., S. 71. 
Paradezug über die Champs Elysées und zieht sich ereignisarm über viele Stunden. Um den vaterländischen Altar herum stehen in einem ersten Kreis die militärischen Vertreter der Nationalgarden. In einem zweiten Kreis finden sich Amtsträger und Notabeln, und erst jenseits dieser privilegierten Gruppen finden sich einfache Bürger. ${ }^{5}$ Die topographische Ordnung des Festes entspricht der neuen, emphatischen Einheitserfahrung daher nur bedingt. Zudem beruht der festliche Integrationsversuch ebenso auf der Figur des Gegenüber - der Aristokrat garantiert als unsichtbarer Ausgeschlossener die verborgene Sinnstiftung des Rituals, und auch das Volk wird nur als symbolisch anwesend vorgestellt, bleibt als soziale Kategorie jedoch abwesend.

Demgegenüber entfaltet das Ereignis die neue sakrale Bindungswirkung in seiner ganzen Tragweite erst auf der Rückreise der Föderierten durch das ganze Land, die den realpräsenten Beweis des neuen Gemeinwesens anschaulich demonstriert. Der Schwur der Einheit, der auf dem Marsfeld den Zusammenhalt garantieren sollte, wurde jenseits von Paris unzählige Male wiederholt, die neuen Bande der Nation, die Verpflichtung der Bürger über ihren unmittelbaren lokalen Handlungshorizont hinaus werden zum ersten Mal fassbar und konkret anhand der Delegationen, die das geweihte Banner der Föderierten in ihre Heimat zurückbringen. Durch diese vermittelte Transzendenzerfahrung politischer Einheit stiftet das Ereignis des Festes ein neues, nationales Gedächtnis, in dem der revolutionäre Gründungsmoment ebenso wie seine festliche Vergegenwärtigung präsent gehalten werden.

Der Kult der Vernunft stellt einen ähnlichen Integrationsversuch der neuen Ordnung dar, der durch seine explizit antireligiöse Transzendenzbehauptung noch radikalisiert wird. Die Umwidmung von Kirchen in Tempel der Philosophie, der Vernunft, der Freiheit sowie die Analogien in der Liturgie lassen auf einen Erfolg des neuen Rituals durch Ähnlichkeit zu überkommenen, aber als sinnentleert erfahrenen Formen schließen - wobei offen bleibt, ob es sich um die Belebung einer Idee durch das Ritual oder um die Wiederbelebung des Rituals durch eine Idee handelt. Ursprung des Vernunftkultes ist die auch als Fête de la Régénération bekannte Verfassungsfeier am 10. August 1793 - dem Moment, als Hérault de Séchelles auf den Ruinen der Bastille unter Anrufung der souveränen Natur den Text

5 Ebd., S. 74. 
der neuen, jakobinisch geprägten Verfassung verkündet. ${ }^{6}$ Symbolisch steht die Neugeburt des Gemeinwesens im Mittelpunkt: Die Place de la Bastille beherrscht eine riesige antike Göttin Isis, aus deren überdimensionierten Brüsten das reinigende Wasser als Symbol für den Ursprung des Lebens fließt und das den anwesenden Abgeordneten der Primärversammlungen als allegorischer Trank gereicht wird. Mit diesem Anklang an das Inaugurationsritual der ägyptischen Pharaonen präsentiert sich die Nation in Gestalt ihrer Stellvertreter als ebenso göttlich wie ewig. Auf den Verfassungsaltären im Land wird die neue Verfassung nicht nur in Gestalt mosaischer Gesetzestafeln, sondern mitunter mit neugeborenen Kindern als konstitutionelles tableau vivant inszeniert, anstelle des Gottesdienstes tritt die erläuternde Lesung der Gesetze. ${ }^{7}$ Erst zu diesem Zeitpunkt schlägt die bisherige, wenn auch mitunter durchaus aggressive Strategie der revolutionären Einbindung von Klerus und Kirche in eine radikale Konkurrenz um - einen Verdrängungsversuch, der einen offensiv antichristlichen, rationalistischen Staatskult als neues, bürgerliches Glaubensbekenntnis etablieren will. Nur schwer jedoch kann man diesen neuen Kult einen Monismus der Vernunft nennen, denn gleichberechtigt wird auch an andere Gottheiten appelliert: am häufigsten an die Göttin der Freiheit, aber auch der Wahrheit, der Philosophie oder der Natur. Die genaue Identität scheint dabei im Verständnis der Akteure keineswegs immer gesichert zu sein. ${ }^{8}$ Auch handelt es sich nicht so sehr um eine zentral gesteuerte politische Instrumentalisierung, wenngleich in Paris die Hébertisten den atheistischen und antiklerikalen Impetus des Kultes am radikalsten verkörpern. Der Kult setzt sich mehrheitlich im ganzen Land, wenn auch mit regionalen Schwerpunkten durch.

Der Übergang zum Kult des Höchsten Wesens ist trotz des hierarchischen Implementationsversuches eher gleitend als abrupt, dessen Dominanz bedeutet keineswegs das Verschwinden des Vernunftkultes. Vielmehr kann eine Koexistenz bis hin zum Thermidor beobachtet werden. ${ }^{9}$ Der Wandel beginnt mit der Fête de l'Être suprême, die auf dem Pariser Marsfeld am 8. Juni 1794 gefeiert wird. Der in seinem Kern deistische Kult geht auf die Initiative Robespierres zurück und ist bekanntermaßen

6 Vovelle, La Révolution, 1988, S. 28 f.

7 Ozouf, La fête révolutionnaire, 1976, S. 100.

8 Vovelle, La Révolution, 1988, S. 157ff.; zu den Mehrdeutigkeiten der symbolischen Praxis im Vernunftkult: ebd., S. 182; zur Entwicklung der Allegorien vgl. Maurice Agulhon: Marianne au Combat, Paris 1979, S. 38ff.

9 Vovelle, La Révolution, 1988, S. 160f. 
inspiriert von Rousseaus Glaubensbekenntnis des Savoyischen Vikars aus dem Emile, aber mindestens im gleichen Maße durch Rousseaus Lob der republikanischen Festkultur. ${ }^{10}$ Zwar wurde er erst im Frühjahr 1794 zu einem offiziellen Kult erhoben, jedoch figuriert das Höchste Wesen bereits bei den Freimaurern in verschiedenen Kontexten und ist auch in der Präambel der Menschen- und Bürgerrechtserklärung von 1789 als Garant einer Letztbegründung explizit präsent: „l'Assemblée Nationale reconnoît et déclare, en présence et sous les auspices de l'Être Suprême, les droits suivans de l'Homme et du Citoyen." Zudem hatte das Höchste Wesen auch im vielstimmigen Konzert des Vernunftkultes eine Stimme - nun allerdings sollte an die Stelle der Deutungsoffenheit eine begriffliche und symbolische Verengung treten, die mit dem Versuch der politischen Kontrolle zusammenhängen mag. Hinter dem Namen des Höchsten Wesens sollte so die Toleranz unter atheistischen Vorzeichen verschwinden, und gleichzeitig eine Abschwächung der antichristlichen Stoßrichtung stattfinden. Anders als der Vernunftkult wurde der Kult des höchsten Wesens auch sehr viel stärker von Paris aus durchgesetzt, wobei Robespierre eine maßgebliche Rolle gespielt hat. ${ }^{11}$

Robespierre ließ sich bei seinem Einsatz für den neuen Kult nicht zuletzt von seiner Gegnerschaft zu den konkurrierenden radikalen Strömungen innerhalb des jakobinischen Lagers leiten. Der kosmopolitische Extremismus eines Anacharsis Cloots, der zugleich einer der wesentlichen Unterstützer des Vernunftglaubens war, konnte so zusammen mit dem Hébertismus durch den Bezug auf das Höchste Wesen im Kampf um die Deutungshoheit verdrängt werden. Das Höchste Wesen markiert dabei den Versuch, die Gegner des moralzersetzenden Atheismus zu bezichtigen, ohne zugleich durch den offenen Bezug auf die religiöse Transzendenz eine Annäherung mit den Formen institutionalisierter Religion zu markieren. Das Höchste Wesen erlaubt es der Revolution und den Jakobinern im Besonderen, die symbolischen Transzendenzressourcen des tief verwurzelten Glaubens abzuschöpfen, ohne freilich dadurch ihre Eigenständigkeit zu riskieren. In seinem Referat vor dem Nationalkonvent am 7. Mai 1794 legt

10 Vgl. dazu meinen Beitrag: Naturerzählungen und republikanische Geltungsbedingungen bei Rousseau, in diesem Band.

11 Vovelle, La Révolution, 1988, S. 189. Die Dechristianisierungswelle der Revolution kann daher weder als reine Volksbewegung noch als eine instrumentell gesteuerte Agenda verstanden werden, sondern bewegt sich ambivalent zwischen diesen beiden Polen (ebd., S. 269). 
Robespierre ausführlich seine Beweggründe dar, die ihn zur Begründung des Kultes bewogen haben. Die ,leidenschaftlichen Apostel des Nichts“, die „fanatischen Missionare des Atheismus“ haben für Robespierre die Revolution in den Bürgerkrieg gestürzt und damit das Gegenteil dessen erreicht, was ein öffentlicher Kultus leisten sollte. Ganz in der Spur seines Mentors Rousseau entwirft er die notwendige Stabilisierung der politischen Ordnung durch eine starke sozio-moralische Verankerung der Verfassung. Nur die reine und wahrhaftige Tugend der Bürger kann als Garant der Republik dienen, daher bedarf es eines stützenden Ritus, der diese Tugendressourcen regeneriert und zum Ausdruck bringt. Ebenso wie Rousseau sieht er diesen Transzendenzbedarf unter vorwiegend funktionalen Gesichtspunkten, wenn er die kultischen Inhalte von jeglichen metaphysisch oder theologisch zu begründenden Wahrheitsansprüchen entlastet: „ihr braucht diese Probleme weder als Metaphysiker noch als Theologen zu betrachten. In den Augen des Gesetzgebers ist alles, was für die Welt nützlich und für die Praxis gut ist, auch zugleich die Wahrheit."12 Und weiter: „was der Unzulänglichkeit der menschlichen Autorität abhilft, ist das religiöse Gefühl, das in den Seelen die Vorstellung erzeugt, eine über den Menschen stehende Macht könne die Vorschriften der Moral sanktionieren. ${ }^{\text {(13 }}$ Der atheistische Kult ist daher verderblich, weil er es versäumt, die Menschen an ihre Institutionen zu binden. Um also die neue Ordnung dauerhaft an die Herzen zu binden, bedarf es einer künstlichen Transzendenz: „Wir sollten die Moral auf ewige und heilige Grundlagen stellen; wir sollten dem Menschen eine religiöse Achtung für seinesgleichen und ein tiefes Gefühl für seine Pflichten eingeben; das ist die einzige Garantie für das allgemeine Glück.“"14 Die nationalen Festlichkeiten unter der Schutzherrschaft des Höchsten Wesens sind demnach die angemessene Form, um ein solches Bindungs- und Verpflichtungsgefühl dauerhaft zu generieren, „um die Liebe zum Vaterland und die Achtung vor den Gesetzen zu fördern“"15. Für Robespierre scheint es gerade die offene Bedeutung dieses symbolischen Zentrums zu sein, aus der seine sinnstiftende

12 Maximilien Robespierre: Über die Beziehungen der religiösen und moralischen Ideen zu den republikanischen Grundsätzen, und über die nationalen Feste, in: ders., Ausgewählte Texte, übersetzt von Manfred Unruh, eingeleitet von Carlo Schmid, Hamburg 1971, S. 633-696, hier: S. 674.

13 Ebd., S. 675.

14 Ebd., S. 687.

15 Ebd., S. 690. 
Wirkung hervorgeht: Das Höchste Wesens steht zugleich für die Natur, für die Freiheit, die Gleichheit, die Menschlichkeit und das Menschengeschlecht in seiner Gänze. ${ }^{16}$ Damit ist der von Robespierre entworfene republikanische Kult ein Versuch, stabilisierende und integrierende Transzendenzvorstellungen miteinander zu verbinden, die zueinander in einem offenem Verweisungszusammenhang stehen und durch diese relative Deutungsoffenheit die Identifikation mit den kultischen Inhalten erleichtern. Das höchste Wesen erscheint damit als zugleich religiös und säkular, als weltlich-politisch und zugleich das rein Profane Transzendierende.

Neben den unterschiedlichen Ausprägungen im Detail kann das revolutionäre Fest daher im übergreifenden Verständnis als Heiligungsversuch der Gemeinschaft gelesen werden, einer Integration durch Transzendenz, die den Gründungsmoment symbolisch überhöht zum Ausgangspunkt der gemeinschaftlichen Bindungen macht. Den zugehörigen Kulten liegt die Verstetigungsabsicht des singulären Festereignisses zugrunde, das durch seine rituelle Wiederholung zu einer erzieherischen, bewusstseins- und habitusprägenden Instanz weit über den Festtag hinaus wird. Verdeckt wird im Fest wie im Kult die Devianz, diejenigen, die nicht teilhaben und so die Gemeinschaft durch ihre Exklusion konstituieren, durch den Ausschluss des Unreinen. ${ }^{17}$ Mona Ozouf bezeichnet die Gemeinsamkeit der Revolutionsfeste so als „Sakralitätstransfer“, durch die die neue Ordnung selbst symbolisch überhöht und der neuerlichen Verfügung entzogen wird. ${ }^{18}$ Der Begriff des Transfers impliziert jedoch, dass beim Umbruch vom Ancien Regime zur demokratischen Ordnung die politische Sakralität selbst keine Veränderung erfährt. Um dem Missverständnis einer solchen nicht-transformierbaren Sakralität vorzubeugen, empfiehlt es sich, an dieser Stelle nicht von einem Transfer, sondern von einer Verschiebung, einer Transformation sakraler Legitimierung zu sprechen, die unter demokratischen Vorzeichen zudem eine ganz andere Funktion erfüllen muss: Während in den monarchischen Ordnungen die Person des Königs als zentrale Sakralitätsverkörperung zur Verfügung steht, muss der demokratische Verfassungsstaat gerade mit dieser Leerstelle des politischen Körpers symbolisch umgehen. Die politischen Feste und Transzendenzsymboliken der Revolution

16 Ebd., S. 690f.

17 Vgl. Mary Douglas: Reinheit und Gefährdung. Eine Studie zu Vorstellungen von Verunreinigung und Tabu, Frankfurt a.M. 1988.

18 Ozouf, La fête révolutionnaire, 1976, S. $317 \mathrm{ff}$. 
reagieren daher genau auf diese Herausforderung, die politische Einheit des Gemeinwesens darstellbar und damit verfügbar zu machen.

Jedoch zeigt gerade die massive Revolutionsdynamik mit ihren immer neuen Ordnungsentwürfen und Verfassungen, dass nach der Enttranszendierung der alten Ordnung diese Stillstellung nicht gelingen will. Die sakrale Heilssemantik stiftet neue Erwartungshorizonte, die mit ihrer handlungsmobilisierenden Kraft die politische Ordnung immer wieder über sich hinaustreibt. Die vorläufige Rückkehr zu einem auf die Volkssouveränität umgestellten Kaiserkult mit der Selbstsakralisierung Napoleons mag in diesem Sinne auch als Teil eines symbolischen Überbietungswettbewerbs verstanden werden, der bei den republikanischen Ordnungsformen angesichts der über Jahrhunderte ausdifferenzierten und habituell eingeübten Formensprachen von Thron und Altar ein nicht unwesentliches Manko sichtbar werden lässt. ${ }^{19}$

Die übergreifende Funktion der Festkultur für die Revolution in all ihren Tendenzen und Gruppierungen liegt so in einem kollektiven Versuch der Selbsttranszendierung: „c'est de montrer la transcendance du genre humain à l'homme même et d'instituer l'humanité en son humanité. “20 Jean Starobinski charakterisiert das Föderationsfest im Selbstverständnis der Akteure als ,heilige Handlung [...], durch die die Lebenden ihren Gehorsam gegenüber den ewigen Prinzipien erklären." Es handelt sich um eine „teilhabende Unterwerfung. [...] Der Mensch ehrt eine Macht, die über ihn hinausgeht, ohne ihm fremd zu sein, eine Macht, von der ihn nichts trennt, vor der er sich nicht zu demütigen braucht. [...] Die in jeden Menschen von Geburt an gesenkte Göttlichkeit tritt sichtbar in Erscheinung, wenn die Menge sich einmütig versammelt.، ${ }^{21}$

Die bisherige Transzendenzsymbolik hatte ihre Bedeutung verloren und musste durch eine Verschiebung, eine Übertragung wiederbelebt werden:

„Die unbeweglichen Bilder vergangener Autoritäten - die Statuen Christi, der Jungfrau Maria, der Heiligen, der Könige von Frankreich - wurden von der revolutionären Bilderstürmerei zerschlagen oder geköpft; man erkannte darin nicht mehr die

19 Dabei muss es sich nicht um einen von der alten Integrationslehre so häufig vorgebrachten Wesensnachteil der republikanischen Ordnung handeln, sondern nur um mangelnde Erfahrung.

20 Ozouf, La fête révolutionnaire, 1976, S. 338.

21 Jean Starobinski: 1789. Die Embleme der Vernunft, München 1988, S. 57. 
Gegenwart des Heiligen. [...] Der revolutionäre Glaube wählte als Ersatzembleme Wesen aus Fleisch und Blut oder lebende Objekte: junge Bäume, auf den Altar gesetzte Kinder, von Schauspielerinnen dargestellte Göttinnen. ‘22

Starobinski betont damit die gewollte Bindungswirkung des revolutionären Festes, das als eine Inszenierung eines kollektiven Eides verstanden wird: „Das revolutionäre Fest läuft wie ein Stiftungsakt ab; es stellt den Einsetzungsakt eines Seelenbündnisses dar.“ Der hier abgenommene Eid „nimmt ein Zukünftiges in die Pflicht und bindet Kräfte zusammen, die sich ohne ihn zerstreuen würden“ “23. Auch wenn dieser Selbstbindungsakt sich von der Weihezeremonie der Könige wesentlich unterscheidet, ${ }^{24}$ so bleibt dennoch bei allen Unterschieden im Bezug der Unverfügbarkeitsbehauptung eine Ähnlichkeit in der Form: ,die Bewegung der menschlichen Solidarität ist begleitet von einem Anruf der beschützenden Transzendenz. “25 Sowohl Starobinski als auch Ozouf haben damit die fundamentale Bedeutung erkannt, die den symbolischen Formen im Umbruch der politischen Ordnung auch von den Akteuren zugesprochen wurde und die auch für das Verständnis konstitutioneller Gründung zentral war.

\section{Die Heiligung der Verfassung}

Die Form der ,schützenden“ Transzendenzbehauptung begleitet auch den Prozess der Verfassunggebung. Nicht nur die integrative Gemeinschaftsstiftung der neuen Ordnung greift auf die Selbstverpflichtung der Eidesformel zurück, auch der Verfassungsprozess hat an seinem Ursprung einen Eid: Der Ballhausschwur vom 20. Juni 1789 markiert die symbolische Wurzel des revolutionären Einheitsbewusstseins. Bereits einige Tage zuvor hatte sich die Versammlung des Dritten Standes auf Vorschlag von Sieyès durch einen Akt der Umbenennung in „Assemblée nationale“ die Macht zugeschrieben, für das gesamte Gemeinwesen sprechen zu können. Im Machtkonflikt mit dem König, der daraufhin die Versammlung durch den

\footnotetext{
22 Ebd., S. 57f.

23 Ebd., S. 59.

24 „Die Weihungszeremonie der Salbung verlieh dem Monarchen durch einen Eingriff von oben im Namen eines transzendenten Gottes die übernatürlichen Insignien seiner Macht. Der Revolutionseid schafft die unumschränkte Herrschaft - während der Monarch sie vom Himmel empfing." (ebd.)

25 Ebd., S. 61.
} 
Entzug ihres Sitzungsraumes buchstäblich auszusperren versuchte, gelingt es nun, durch den Schwur der Abgeordneten eine neue Bindung zu schaffen und sich unabhängig von der Macht des Königs als repräsentative Körperschaft mit eigenem Verfassungsauftrag zu konstituieren. ${ }^{26}$ Schon am 7. Juli 1789 bildet so die neue Nationalversammlung einen Verfassungsausschuss.

Dieses Versprechen der Einheit wurde von den verschiedenen Revolutionsverfassungen aber immer nur unzureichend verkörpert, und das Gefälle von imaginierter Einheit und konstitutioneller Realität mag mit dafür verantwortlich sein, warum die konstitutionellen Behauptungen von Dauer letztlich immer prekär geblieben sind. Nur die unmittelbar aus diesem Eid hervorgegangene Erklärung der Menschen- und Bürgerrechte hat eine symbolische Macht entfaltet, in der die mit ihr verbundene Unverfügbarkeitsbehauptung auch zur Geltung gebracht wurde. ${ }^{27}$ Wie stark diese Geltung war, zeigt sich besonders deutlich in dem Augenblick, da die Erklärung von 1789 in die Verfassung von 1791 integriert werden soll. In der Diskussion über die Deklaration der Menschen- und Bürgerrechte von 1789 beschreibt der Berichterstatter Thouret aufschlussreich, warum das Verfassungskomitee keine Änderung der Erklärung gewagt hatte und man sie daher in unberührter Form in die neue Verfassung übernahm:

„Elle est exactement telle qu'elle a été décrété. Les comités n'ont pas cru qu'il leur fût permis de vous proposer d'y faire aucun changement. Ils croient même qu'il ne serait pas bon qu'il fût fait aucun changement. Cette déclaration a, en quelque sorte acquis un caractère sacré et religieux. Elle est depuis deux ans devenue le symbole de tous les Français, elle est imprimée dans tous les formats; elle se trouve en placards dans tous les lieux publics et jusque dans les habitations des habitants des campagnes: elle a servi et sert à apprendre à lire aux enfants. Il serait très dangereux d'établir en parallèle de cette déclaration, une seconde déclaration différente, non seulement différente par le fond des choses qu'elle pourrait contenir, mais même différente en rédaction. On ne connaîtrait plus qu'elle est la vértable déclaration des droits de l'homme et du citoyen. [...] nous croyons donc qu'il est absolument inutile

26 Archives Parlementaires de 1787 à 1860. Première série (1787 à 1799), t. 8, du 5 mai au 15 septembre 1789, Paris 1875, S. 138.

27 Vgl. Marcel Gauchet: Die Erklärung der Menschenrechte. Die Debatte um die bürgerlichen Freiheiten 1789, Reinbek bei Hamburg 1995. 
de faire aucun changement à cette déclaration, et, comme je le dirais, il serait dangereux de le faire. ${ }^{\text {‘28 }}$

Die detaillierte Wiedergabe dieser umfangreichen Passage zeigt deutlich, wie sehr sich der Charakter der Erklärung der Menschen- und Bürgerrechte seit ihrer Verabschiedung gewandelt hat. Bereits zwei Jahre nach der Abfassung ist dieser Text - ,le veritable acte constitutionnel“ - der Verfügung entzogen, ja es wäre sogar gefährlich, ihn auch nur anzutasten - eine Formulierung, mit der sich die wirksame Sakralisierung verrät. ${ }^{29}$ Die im Erklärungstext festgeschriebenen Inhalte und Leitideen sind damit nicht mehr unabhängig von ihrer konkreten Form. Die Versuche, die Erklärung in einigen Aspekten zu korrigieren, zu erweitern oder zu verbessern, stoßen bereits auf den Widerstand des sakralen Dokuments, das dem unmittelbaren Zugriff in der Wahrnehmung der konstitutionellen Akteure entzogen bleibt. Der wirksame Geltungsgrund dieser Transzendenz verrät sich in den Ausführungen Thourets: Die soziale Praxis hat sich des Textes bemächtigt und behandelt ihn als Grundlage des Gemeinwesens. Er ist universal präsent im Erfahrungshorizont der Bürger und stiftet ein gemeinsames Glaubensbekenntnis.

Aus der mittelbar über die Erklärung erfolgten Sakralisierung der Verfassung resultiert jedoch zugleich eine extrem hohe Hürde für deren Änderung. In der Diskussion über die Änderbarkeit der Verfassung (Titre VII: De la revision des décrets constitutionnels) kommt die Spannung zum Ausdruck, die sich zwischen der Ermächtigung des Souveräns und dessen

28 Archives Parlementaires de 1787 à 1860. Première série (1787 à 1799), t. 29, du 29 juillet au 27 août 1791, Paris 1888, S. 266f.

29 Zum Verhältnis von Sakralität und Angst schon Rudolf Otto: Das Heilige [1917], München 2004. Paradoxerweise wurden Änderungen von anderer Seite nur vorgeschlagen, um den Ewigkeitsanspruch noch $\mathrm{zu}$ verstärken. Der Abgeordnete Dupont: „Il faut que la Déclaration des droits, qui est le véritable acte constitutionel, car tout le reste n'en est que le commentaire, il faut qu'elle ait la brièveté impériale; il faut qu'elle ait la clarté philosophique; il faut qu'elle ait la pronfondeur des idées et la justesse de l'expression. Je vous demande de la relire, et vous verrez qu'il y manque beaucoup de ces choses-là.“ (Archives Parlementaires de 1787 à 1860 . Première série (1787 à 1799), t. 29, du 29 juillet au 27 août 1791, Paris 1888, S. 267) Begründet wird der Änderungsbedarf mit dem zeitlichen Geltungsanspruch: „Mais, Messieurs, il ne s'agit pas d'une déclaration des droits qui doive durer un jour. Il s'agit de la loi fondamental, des lois de votre nation et de celles d'autres nations qui doivent durer autant que les siècles. Je demande, Messieurs, que le portique soit en tout digne de l'édifice." (ebd., S. 268) 
Bindung aufbaut: Zum einen wird die Verfassung und die Rechteerklärung als geheiligtes Dokument betrachtet, zum anderen wird die Freiheit der französischen Nation unterstrichen, sich jederzeit eine neue Verfassung geben zu können oder die vorliegende Verfassung zu ändern. Die hohe Hürde für Verfassungsänderungen hat so vermutlich genau das Gegenteil dessen befördert, wozu sie ursprünglich gedacht war: Der Weg, eine neue Verfassung zu geben, war angesichts der starren Regelungen stets der einfachere. Anstatt also eine partielle Verfügbarstellung der Verfassung zu erlauben und damit die konstitutionelle Bindungswirkung durch ihre politische Dynamisierung und Anpassungsfähigkeit zu erhöhen, wurde mit der starren Regelung letztlich die permanente Verfügbarkeit der gesamten politischen Ordnung erleichtert.

Einen ganz anderen, jedoch nicht weniger aufschlussreichen Versuch, die neue Ordnung in einem jenseits ihrer selbst liegendem Geltungsgrund zu verankern, zeigt die Diskussion über die Voraussetzungen des Wahlrechts. Darin zeigt sich, dass zwar zum einen die Verfassungstexte durch symbolische Überhöhung dem Zugriff entzogen werden sollen, zum anderen aber dieser Akt der Unverfügbarstellung selbst wiederum an eine Transzendenzbehauptung rückgebunden bleibt. Der Abgeordnete Malouet, der am 8. August 1791 über die Verfassungsakte spricht, verortet sowohl die Garantie der Vernunft als auch der Verfassung selbst im Besitz. ${ }^{30}$ Wählbar als Abgeordnete sollten daher nur Eigentümer sein, da sie ein Interesse an der Wahrung der bestehenden Ordnung haben. Nichteigentümer hingegen sind von der Leidenschaft getrieben und wollen alles ändern: „Le gouvernement le mieux ordonné est donc celui dans lequel les propriétaires seuls influent, car ils ont, comme les non-propriétaires, un intérêt égal à la sûreté et à la liberté individuelle, et ils ont de plus un intérêt éminent au bon régime des propriétés." ${ }^{31}$ Damit ist dies die verallgemeinerte physiokratische Argumentation, in der sich Rationalität und Grundbesitz gegenseitig bedingen, in der also geradezu im konkretesten Sinne die Ordnung durch den Grundbesitz als letzten Grund begründet wird. ${ }^{32}$

Der Überhöhung des Eigentums zur transzendenten Garantie der Verfassung hält Robespierre in der Diskussion die Tugend als letzte Bindung

30 Ebd., S. 274ff.

31 Ebd., S. 276.

32 Das Argument findet sich prominent beim Quesnay-Schüler Turgot ebenso wie beim frühen Condorcet. 
der guten Ordnung entgegen: Die Garantie der Reinheit und Unabhängigkeit der Wahlabsichten liegt nicht im Vermögen, sondern in der Moral. Daher ist ein einfacher Arbeiter oder Handwerker unabhängiger als ein Reicher,

„parce que ses désirs et ses besoins sont encore plus bornés que sa fortune, parce qu'il n'est point accablé de toutes ces passions ruineuses, enfants de l'opulence. Ces idées sont morales, sans doute; mais elles n'en sont pas moins dignes d'être présentées à l'Assemblée nationale. [...] Les plus grands législateurs sont ceux qui ont fondé la législation sur la morale. ${ }^{\text {‘33 }}$

Nicht durch seine Qualität als Eigentümer, sondern als Mensch und Bürger verdient jeder das Vertrauen seiner Mitbürger. Mit dieser Erkenntnis, mit der die alte republikanische Bedeutung der Tugend in Form der Moral in den modernen Verfassungsstaat gerettet werden soll, legt Robespierre die Grundlage für die jakobinische Agenda der Diktatur, die zugleich zu einer Entwertung der geschriebenen Verfassung führte. Die Verfassungsdiskussion von 1793 sah daher zum einen die zunehmende Aktivierung eines ekstatischen, antiinstitutionellen Volksbegriffs, in der das Volk zu einem kollektiven Heiland stilisiert wurde. Zum anderen wurde versucht, das Problem der revolutionären Unverfügbarstellung auch diesseits der großen Transzendenzbehauptungen zu lösen. So unternahm Condorcet den Versuch einer Verfügbarmachung des Volkes durch die Vermittlung konstitutioneller Institutionen, ohne auf das ekstatische Moment einer unvermittelten Präsenz zurückzugreifen. ${ }^{34}$ Zudem gibt er einem genuin republikanischen Pessimismus gegenüber den Ewigkeitspostulaten der antiken Verfassunggeber Ausdruck, die danach strebten ,à rendre éternelles les constitutions qu'ils présentaient, au nom des dieux, à l'enthousiasme du peuple" und auf diese Weise bereits einen ,germe de destruction profonde“ in die konstitutionelle Ordnung einfügten. ${ }^{35}$ Diese Skepsis gegenüber den jenseits von Zeit und Geschichte stehenden Ewigkeitsansprüchen menschlicher Ordnung - die bei den Republikanern Machiavelli und Rousseau grundlegend war - fügt sich in die Überlegungen, wie die neuen

33 Ebd., S. 360f.

34 Dazu Pierre Rosanvallon: La démocratie inachevée. Histoire de la souveraineté du peuple en France, Paris 2000; Daniel Schulz: Condorcet und die Theorie der repräsentativen Demokratie, in: Marquis de Condorcet: Freiheit, Revolution, Verfassung, hrsg. von Daniel Schulz, Berlin 2010, S. 11-50.

35 Zitiert nach: Ozouf, La fête révolutionnaire, 1976, S. 339. 
Verfassungsgesetze in Einklang mit den Sitten, Gewohnheiten und den Urteilen, kurz: der politischen Kultur, gebracht werden könnte. Condorcet stellt sich diesem Problem mit der Frage der Erziehung, die einem Versuch der reflektierenden Unverfügbarstellung gleichkommt. In seinem Erziehungsprojekt, vorgetragen in der Nationalversammlung am 20. April 1792, wird die allgemeine Schulbildung zur Grundvoraussetzung für eine freie Gesellschaft. Sie beinhaltet auch eine Erziehung in den Prinzipien der Moral und der Politik, setzt jedoch andere Akzente als die jakobinische Vorstellung der patriotischen Tugenderziehung und ihr Versuch einer Verfügbarmachung der Volksmoral. Condorcets Projekt zielt vielmehr auf die Formierung politischer Urteilskraft. Wenngleich sich dieser Entwurf aus den der Radikalaufklärung eigenen Transzendenzbehauptungen einer natürlichen Vernunft speist, so rechnet er doch mit der Unverfügbarkeit des individuellen Subjekts gegenüber eines direkten mobilisierenden politischen Zugriffs:

„Chaque dimanche l'instituteur ouvrira une conférence publique à laquelle assisteront les citoyens de tous les âges: nous avons vu dans cette institution un moyen de donner aux jeunes gens celles des connaissances nécessaires qui n'ont pu cependant faire partie de leur première éducation. On y développera les principes et les règles de la morale avec plus étendue, ainsi que cette partie des lois nationales dont l'ingnorance empêcherait un citoyen de connaître ses droits et de les exercer. Ainsi dans ces écoles les vérités premières de la science sociale précéderont leurs applications. Ni la Constitution française, ni même la Déclaration des Droits ne seront présentées à aucune classe des citoyens, comme des tables descendues du ciel, qu'il faut adorer et croire. Leur enthousiasme ne sera point fondé sur les préjugés, sur les habitudes d'enfance; et on pourra leur dire: ,Cette Déclaration des Droits qui vous apprend à la fois ce que vous devez à la société et ce que vous êtes en droit d'exiger d'elle, cette Constitution que vous devez maintenir aux dépens de votre vie ne sont que le développement de ces principes simples, dictés par la nature et par la raison dont vous avez appris, dans vos premières années, à reconnaître l'êternelle vérité. ' Tant qu'il y aura des hommes qui n'obéiront pas à leur raison seule, qui recevront leurs opinions d'une opinion étrangère, en vain toutes les chaînes auraient été brisées, en vain ces opinions de commande seraient d'utiles vérités; le genre humaine n'en resterit pas moins partagées en 2 classes, celle des 
hommes qui raisonnent et celle des hommes qui croient, celle des maîtres et celle des ésclaves. “36

Dagegen erscheint bei Robespierre das Volk als corpus mysticum. Zwar offenbart es sich im Moment der Verfassunggebung, kann jedoch konstitutionell nicht auf Dauer gestellt werden. In der nie in Kraft getretenen jakobinischen Verfassung ging es so in erster Linie um die Abschöpfung des transzendenten Gründungsmoments ohne institutionelle Verstetigungsabsicht. ${ }^{37}$ In den appellativ erweckten Leidenschaften, den ,,passions“ als transzendierendes Moment jenseits der bloßen Vernunft und des Interesses liegt der mobilisierende Mechanismus, der ein ekstatisches Transzendieren des Individuums in die Gemeinschaft, ein Erlebnis der Einheit unter Führung der jakobinischen Elite möglich machen soll. ${ }^{38}$ Auch bei Saint-Just zeigt sich schon 1791 die Betonung des unvermittelten Moments, des heiligen Feuers der Leidenschaft, das sich kaum auf Dauer stellen lässt: „La calme est l'âme de la tyrannie, la passion est l'âme de la liberté. Le premier est un feu qui couve, le second un feu qui se consume; [...] on n'est verteux qu'une fois. ${ }^{\text {“39 }}$ Echte Tugend existiert daher nur im Ausnahmezustand der Revolution. Die Verfassung kann dagegen lediglich ein Spiegel dieser Tugend sein, ,l'image sacrée de la liberté, elle n'est point la liberté même“40 Damit mag die Verfassung zwar bestimmte Prinzipien und Prozeduren der politischen Verfügbarkeit entziehen - aber die als letzte Garantie gedachten, ungleich stärkeren Transzendenzbehauptungen des jakobinischen Tugenddiskurses wirken schließlich nicht mehr als ergänzende Stütze des Rechts, sondern setzen - mindestens als Prätention - die unvermittelte,

36 Archives Parlementaires de 1787 à 1860 . Première série (1787 à 1799), t. 42, du 17 avril 1792 au matin, au 4 mai 1792 au matin, Paris 1893, S. 192 (Hervorhebung DS). Damit zeichnet sich hier der paradoxe und durchaus moderne Versuch ab, eine Dauerreflektion der politischen Ordnung auf feste Grundlagen zu stellen.

37 Vgl. zur Verfassungsdiskussion: Daniel Schulz: Verfassung und Nation. Formen politischer Institutionalisierung in Deutschland und Frankreich, Wiesbaden 2004, S. $57 \mathrm{ff}$.

38 Vgl. zur Analyse der jakobinischen Rhetorik Lucien Jaume: Le discour jacobin et la démocratie, Paris 1989.

39 Louis-Antoine-Léon de Saint-Just: Théorie politique, hrsg. von Alain Liénard, Paris 1976, S. 51.

40 Louis-Antoine-Léon de Saint-Just: Discours sur la constitution de la France, Sitzung des Konvent, 24. April 1793, in: ders.: Théorie politique, 1976, S. 181230, hier: S. 190. 
direkte Erfahrung des Gemeinwohls und der Volkssouveränität an dessen Stelle.

\section{3 ÜBerschiessende GeLtungsSymbolik IN DER KRIEGSDISKUSSION}

Die institutionelle Verstetigung des Gründungsmoments wurde auch durch die Dynamik der Kriegsdiskussion erschwert. In dieser Debatte kam zudem eine ganz eigene Transzendenzsemantik zum Ausdruck: Die Deklaration universaler Menschenrechte generierte im Kontext der Revolution eine entgrenzende Dynamik, die den mit ihr verbundenden Handlungsauftrag alsbald von der Nation auf die Menschheit übertrug. In der Revolution verband sich die alte, republikanische Tradition, in der Krieg als soziomoralische Integrationsinstanz des Gemeinwesens thematisiert wurde, ${ }^{41}$ mit diesem neuen, säkularen Universalismus in Form von Vernunft und Menschenrechten und erzeugte ein spannungsreiches Amalgam.

Politisch übertrug sich dieses Spannungsverhältnis in einen Konflikt zwischen radikalen Universalisten wie Anacharsis Cloots, die zur Herstellung der Weltrepublik auch vor Missionierungskriegen nicht zurückschreckten, und den klassischen - jedoch in ihrer Beziehung zur Gewalt nicht weniger radikalen - Republikanern, die in der emotionalen Gemeinschaft der Nation das Ziel und zugleich die Grenze jeder Politik sahen. Der Krieg dient hier in erster Linie der Verteidigung der Republik, der Terror nach innen jedoch ist unabdingbares Mittel zum Zweck der Integration.

Die Sprengkraft eines universalistisch aufgeladenen Republikanismus kommt bei den Kriegsbefürwortern der Gironde am deutlichsten zum Ausdruck. Hier verbinden sich die im republikanischen Denken so präsente sozio-moralische Reinigungs- und Integrationsfunktion des Krieges mit dem universalistischen Geltungsanspruch der Menschenrechte, die vom Liberalismus der Aufklärung betont wurde und die in ihrer explosiven Mischung den revolutionären Befreiungskampf gegen die Tyrannen der

41 Vgl. nur zum neo-harringtonianischen Republikanismus in der schottischen Aufklärung und besonders bei Adam Ferguson: Matthias Bohländer: Die Poetik der Schlacht und die Prosa des Krieges. Nationalverteidigung und Bürgermiliz im moralphilosophischen Diskurs der schottischen Aufklärung, in: Johannes Kunisch/Herfried Münkler (Hrsg.): Die Wiedergeburt des Krieges aus dem Geist der Revolution. Studien zum bellizistischen Diskurs des ausgehenden 18. und 19. Jahrhunderts, Berlin 1999, S. 17-41. 
Welt befeuerten. Was im Ursprung lediglich die Abwehr einer vermeintlichen oder echten Bedrohung der Revolution durch das feindliche Ausland gewesen war, gewann durch die radikale, handlungsleitende Transzendenzsemantik schnell an expansiver Dynamik. Diese Semantik lässt sich an einigen Beispielen aus den Kriegsdebatten in der Nationalversammlung aufzeigen:

Der Abgeordnete Isnard, neben Brissot eine der zentralen Befürworter des Krieges, bedient sich dieser neuen Pathosformeln einer sakralen Rechtssprache: „Le Français est devenue le peuple le plus marquant de l'univers [...]. Qui sont en effet les adversaires qui nous menacent? Ce sont les ennemis de notre constitution sacrée. “42 Aber:

„Mais non, dussent tous les nobles de la terre nous assaillir, ce temple ne s'écroulera pas; du haut de cette tribune, nous électreriserons tous les Français; les plus froids s'embraseront des flammes de notre patriotisme; tous, versant d'une main leur or, et tenant le fer de l'autre, combattront cette race orgueilleuse et la forceront d'endurer le supplice de l'égalité. L'égalité et la liberté sont devenues aux Français aussi nécessairess que l'air qu'il respire. Souffririez-vous, Messieurs, que quelque puissance au monde les lui ravit??“ [...] ,Elevons nous, dans cette circonstance, à toute la hauteur de notre mission. ${ }^{، 43}$

Einen ähnlichen Geist atmet die Rede Brissots am 16. Dezember 1791:

„Die Kraft der Überlegung und der Tatsachen hat mich davon überzeugt, dass ein Volk, das nach 10 Jahrhunderten der Sklaverei die Freiheit errungen hat, Krieg führen muß. Es muß Krieg führen, um die Freiheit auf unerschütterliche Grundlagen zu stellen; es muß Krieg führen, um die Freiheit von den Lastern des Despotismus rein zu waschen, und es muß schließlich Krieg führen, um aus seinem Schoß jene Männer zu entfernen, die die Freiheit verderben könnten. Segnet den Himmel, dass

42 Rede von Isnard vom 29. November 1791. Zitiert nach: Archives Parlementaires de 1787 à 1860 . Première série $(1787$ à 1799), t. 35 , du 11 novembre au 10 décembre 1791, Paris 1890, S. 442 (deutsche Teilübersetzung bei Wilhelm Grab (Hrsg.): Die Französische Revolution, München 1973, S. 124ff.).

43 Ebd., S. 441f. Isnard hat ein Jahr nach dem Konkordatsschluss von Napoleon mit dem Vatikan eine Abhandlung De l'immortalité de l'âme (Paris 1802) verfasst: „En retablissant ses rapports avec Dieu, la France cimente ses traités avec divers puissances, et se remet en harmonie avec toutes les autres peuples qui ne peuvent plus lui refuser l'admiration que commande sa gloire." (1f.) 
er selber dafür gesorgt und euch Zeit gegeben hat, eure Verfassung auf feste Grundlagen zu stellen. “44

„Wenn ihr mit einem einzigen Streich die Aristokratie, die eidverweigernden Priester und die Missvergnügten austilgen wollt, dann müsst ihr Koblenz in Schutt und Asche legen. Das Oberhaupt der Nation wird dann genötigt sein, gemäß der Verfassung zu regieren, sein Heil nur in seiner Verfassungstreue zu erblicken und sein Verhalten einzig und allein nach ihr auszurichten. “45

Die konsequente Spitze erreicht diese Totalrevision politischer Ordnung im Lichte einer radikalen Transzendenz mit dem Ziel der universellen Weltrepublik, vertreten von Anacharsis Cloots, dem „Redner des Menschengeschlechts“, der sich wie kaum ein anderer Akteur der Revolution einer republikanisch-säkularen, von zahllosen Totalitäts- und Einheitsansprüchen durchsetzten Sprache des Heiligen bedient und zudem einer der eifrigsten Verfechter des Vernunftkultes war. Am 21. April 1792 hält Cloots in der Nationalversammlung sein Plädoyer für den Krieg und für die universale Republik, das aufgrund seiner sakral aufgeladenen Semantik ein herausragendes Beispiel für die Transzendenzdimension dieser Debatte liefert und daher ausführlich zitiert zu werden verdient:

„Législateurs, le désespoir de la tyrannie européenne force une nation généreuse et libre à joindre les armes de la guerre aux armes de la raison. [...] C'est ici la crise de l'univers: le sort du genre humain est entre les mains de la France. Nous combattons pour les droits de l'homme; et nos victoires ajouteront un nouvel éclat à la dignité humaine: nous frapperons les despotes, et nous déliverons les hommes. Chaque tyran renversé dans la poussière fera sortir tout un peuple de l'esclavage. Dieu débrouilla le chaos primitif, les Français débrouilleront le chaos féodal. Dieu est puissant, et il a voulu; nous sommes puissant et nous voulons. Les hommes libres sont les dieus de la terre, et le genre humain sera plus fort que les satrapes. [...] nous faisons une guerre sainte“, mit einem Sieg für „la liberté universelle“. „Les tyrannes apprendront que avec effroi que les citoyens de la France et les citoyens du monde se disposent aux plus grands sacrifices pour le succès d'une cause qui intéresse vivement tous les hommes. Oui, nous saurons nous réduire à une nourriture gros-

44 Zitiert nach Walter Markov (Hrsg.): Revolution im Zeugenstand. Frankreich 1789-1799, Bd. 2, Leipzig 1982, S. $198 \mathrm{ff}$.

45 Ebd., S. 200. 
sière, à la sauce noire des Spartiates pour soutenir une guerre qui sera suivie de la paix perpétuelle [...].“46

Die spartanische Askese wird zum Sieg führen, die Freiheit wird die Bürger mobilisieren:

„Le culte de la liberté exigerait-il moins d'obligations que les cultes superstitieux? Le chef-lieu de l'indépendance n'aurait-il pas ses pélerins et ses ex-voto, comme le chef-lieu des chrétiens ou des musulmans? La religion des droits de l'homme inspirerait-elle moins de vertu, de zèle et d'enthousiasme que la religion des faux prophètes? L'or, l'argent et les pierreries sont accumulés par la superstition universelle, à Rome, à la Mecque, à Jagrenad; et l'amour universel de la liberté ne remplirerait-il pas le Trésor de la France, le trésor du genre humain d'offrandes libératrice? Législateurs, je dépose dans ce sanctuaire, en présence de mes Iares et de mes pénates, dans le sanctuaire du dieu constitutionnel, la somme de 12.000 livres pour habiller, équiper, armer et solder 40 à 50 combattants dans la guerre sacrée des hommes contre les couronnes. C'est en consacrant ma fortune et mes travaux à l'amélioration de l'espèce humaine que je serai toute ma vie l'orateur du genre humain. “47

Dagegen hatte Robespierre im Jakobinerclub bereits am 2. Januar 1792 gegen den Krieg und den exaltierten Universalismus Stellung bezogen. Gegen Brissot, Isnard und Cloots wendet er ein: „Niemand mag bewaffnete Missionare. “48

„Die Erklärung der Rechte ist keinesfalls das Licht der Sonne, das allen Menschen gleichermaßen leuchtet; sie ist nicht der Blitz, der alle Throne gleichzeitig trifft. Es

46 Archives Parlementaires de 1787 à 1860 . Première série (1787 à 1799), t. 42, du 17 avril 1792 au matin, au 4 mai 1792 au matin, Paris 1893, S. 252ff.

47 Ebd., S. 253 (Hervorhebung DS). Bei dieser Gelegenheit übergab Cloots der Nationalversammlung auch sein Werk La république universelle, in der die neue Ordnung skizziert wird. Französisch wird die universale Sprache der Menschheit sein, Paris das Zentrum des Universums und Sitz der gemeinsamen Versammlung - „Paris est le Vatican de la raison.“ (Anacharsis Cloots: La République universelle ou adresse au tyrannicides, in: ders., Ecrits révolutionnaires, présentés par Michèle Duval, S. 243-318, hier: S. 261) Zu Cloots vgl. Selma Stern: Anarcharsis Cloots der Redner des Menschengeschlechts als Mitglied des Nationalkonvents, Berlin 1914; Roland Mortier: Anacharsis Cloots, ou, L'utopie foudroyée, Paris 1995. Zur Diskussion von Cloots und Kant vgl. Pauline Kleingeld: Kant and Cosmopolitanism. The Philosophical Ideal of World Citizenship, Cambridge 2012, S. 40-71.

48 Zitiert nach: Grab (Hrsg.), Die Französische Revolution, 1973, S. 129. 
ist leichter, sie auf ein Blatt Papier zu schreiben, oder in Erz zu gravieren, als ihre heiligen Lettern, die durch die Unwissenheit, die Leidenschaften und den Despotismus ausgelöscht wurden, wieder in die Herzen der Menschen einzugraben. “49

Damit artikuliert Robespierre die nach innen gerichtete Integrationsperspektive des republikanischen Denkens, wenngleich auch er mit seinem Kult des höchsten Wesens die universale Dimension der Revolution betont und seine kritische Haltung gegenüber den Revolutionskriegen eher aus strategischen Gründen zu erklären ist. Während er die sozio-moralischen Geltungsvoraussetzungen für eine demokratische Verfassung außerhalb Frankreichs nicht gegeben sieht, so sind es doch eben jene Voraussetzungen, die auch in Frankreich selbst durch die Tugenddiktatur erst wieder hergestellt werden sollen. Die politische Gewalt der Guillotine wird so als radikaler Verfügbarkeitsglaube gerechtfertigt, die terreur erscheint als reinigender Integrationsmechanismus der prekären revolutionären Gemeinschaft. ${ }^{50}$

\section{TRANSZENDENZBEHAUPTUNGEN ZWISCHEN StABILISIERUNG UND DESTABILISIERUNG}

Die revolutionäre Praxis in der Zeit nach 1789 hat in vielfältiger Weise Transzendenzbehauptungen hervorgebracht, mit denen der Gründungsmoment auf Dauer gestellt werden sollte. Gerade die Kriegsdiskussion aber hat gezeigt, dass die entfesselte Semantik des Heiligen nicht allein stabilisierend wirkte, sondern mindestens ebenso sehr für die radikale Handlungsdynamisierung verantwortlich gemacht werden kann, die sich der

49 Ebd., S. 130.

50 In der Folge von François Furet (Art. „terreure“, in: ders./Mona Ozouf (Hrsg.): Dictionnaire critique de la Révolution française, Paris 2007, S. 293-316) sowie von Mona Ozouf (Guerre et Terreur dans le discours révolutionnaire 1792-1794, in: Paul Viallaneix/Jean Ehrard (Hrsg.): La Bataille, l'Armée et la Gloire 17451871, Bd. 1, Paris 1985, S. 283-297), die gegen die neojakobinische Erklärung des terreurs durch die Kriegsumstände mit der inneren Logik der revolutionären Deutungsmuster argumentieren, vgl. Hans-Ulrich Thamer: „Freiheit oder Tod“. Zur Heroisierung und Ästhetisierung von Krieg und Gewalt in der Ikonographie der Französischen Revolution, in: Kunisch/Münkler, Die Wiedergeburt des Krieges aus dem Geist der Revolution, 1999, S.75-91; Elisabeth Fehrenbach: Die Ideologisierung des Krieges und die Radikalisierung der Französischen Revolution, in: Dieter Langewiesche (Hrsg.): Revolution und Krieg. Zur Dynamik historischen Wandels seit dem 18. Jahrhundert, Paderborn 1989, S. 57-66. 
kontrollierenden Verfügung durch institutionelle Entscheidungs- und Verantwortungsmechanismen letztlich entzogen hat.

In der Zusammenschau wird deutlich, dass die Artikulation der revolutionären Transzendenzbehauptungen zum einen maßgeblich durch eine performativ-rituelle Dimension gekennzeichnet ist. Diese Dimension zielt auf eine Geltungsstabilisierung der neuen revolutionären Gemeinschaft durch symbolische Präsenz. Die Praktiken des Transzendierens bedienen sich der Formen des Rituals, des Festes, der direkten öffentlichen Rede, der Mobilisierung von Gefolgschaft durch unmittelbare Anwesenheit. Es handelt sich um eine performative Verfügbarmachung einer doch stets der Erfahrung entzogenen Einheit durch eine Mobilisierung überschießenden Sinns, die jenseits ihres ursprünglichen Erscheinens nur durch die direkte rituelle Verkörperung auf Dauer gestellt werden kann, aber auf Distanz zu jeglicher Vermittlung geht, mit der die Transzendenzintensität nur geschwächt würde. Die jakobinische Tugendsemantik, die revolutionäre Festkultur, die volkspädagogischen Mobilisierungen im Krieg und die zahlreichen Versuche, den revolutionären Ausnahmezustand der Erhebung auf Dauer zu stellen, sind Beispiele, in denen diese Dimension besonders ausgeprägt zu sein scheint. ${ }^{51}$

Neben diesen performativen Praktiken steht eine Semantik der unverfügbaren Rechte, die zum einen zwar den Festen und präsenzkulturellen Formen als inhaltliche Orientierung zugrunde liegt, zum anderen aber gerade in ihrer individualistischen Form deutlich über die Einheits- und Gemeinschaftsinszenierungen hinaus geht. Damit aber entsteht ein Spannungsverhältnis zwischen den performativen Elementen der Präsenzerzeugung, mit denen die proklamierte Einheit des politischen Gemeinwesens insofern verfügbar gemacht wird, als sie die realpräsente Anwesenheit der sakralen Einheit zum Ziel hat. Die solchermaßen geheiligten individuellen Rechte aber sind es gerade, die den Einzelnen dem Zugriff der politischen Gemeinschaft doch wiederum entziehen wollen. Das Rechtsverständnis der Französischen Revolution, das noch deutlich zwischen einem traditionellrepublikanischen, gemeinschaftlichen und einem liberal-individuellen Frei-

51 Der Marquis de Sade hat diesen performativen, efferveszenten Überbietungsgestus unter Umkehrung der normativen Vorzeichen auf die Spitze getrieben: „Français, encore un effort si vous voulez être républicains.“ (La Philosophie dans le boudoir ou Les Instituteurs immoraux [1795], dt.: Die Philosophie im Boudoir oder Die lasterhaften Lehrmeister, Köln 1995, S. 275) 
heitsverständnis schwankt, spiegelt diese Konstellation wider, die auch durch die verschiedenen Verfassunggebungen nicht überwunden wird. Dennoch wird die Entzogenheit zentraler Ordnungsprinzipien durch die zahlreichen Vermittlungsversuche zum Ausdruck gebracht und ist besonders deutlich in den liberalen Strömungen der Revolution vorhanden, die der unmittelbaren Mobilisierung der Volksmacht durch die ekstatische, performative Proklamation misstrauen. Die Versuche, über konstitutionelle Mechanismen eine Transzendenz der politischen Ordnung zu garantieren, bis hin zu den späten Überlegungen einer neutralen Macht (Constant) oder einer Verfassungsgerichtsbarkeit (Sieyès) gehen in diese Richtung.

Gleichwohl sind doch auch die konstitutionellen Transzendierungsversuche darauf angewiesen, dass die von ihnen proklamierte Unverfügbarkeit liberalen Rechts wiederum in Praktiken und Diskursen verankert ist, die das Bewusstsein für die quasi-sakrale Unantastbarkeit aufrecht erhalten. Darauf zielt die institutionelle Konstitution von Praktiken, in denen die unverfügbar gestellten Rechte durch die bürgerliche Teilhabe in Geltung gesetzt werden. Eine solche Verbindung der performativ-praktischen und der institutionellen Dimension von konstitutioneller Transzendenz zeigt sich beispielsweise im Verfassungsentwurf von Condorcet, der in diesem Sinne als ein ,liberaler Rousseauismus “ ${ }^{\text {"52 }}$ verstanden werden kann, weil er paradoxerweise vom Volk als unverfügbarer Geltungsvoraussetzung der Verfassung ausgeht, die aber gleichzeitig von der Verfassung mittels institutioneller Mechanismen prozedural verfügbar gestellt wird - also auf die konstitutionell gestifteten politischen Praktiken der rituellen Gewöhnung vertraut, die jedoch niemals in eine volle Präsenz des transzendenten politischen Subjektes münden können. Damit gehen die performativ-rituelle und die institutionelle Dimension eine hybride Spannungsbalance unterschiedlicher Transzendenzbehauptungen ein. Sie unterstreichen solchermaßen die Notwendigkeit konstitutioneller Formen ebenso wie deren soziomoralische Einbettung in eine nicht unmittelbar verfügbare demokratische Kultur des esprit public.

52 Rosanvallon, La démocratie inachevée, 2000, S. 61. 



\title{
Verfassung, Vertrag und Monarchie
}

\author{
Der Prozess der Verfassunggebung in Württemberg
}

(1815-1819)

\section{JAN RÖDER}

\section{EinLeitung}

In der Moderne beruhen Gründung und Geltung politischer Ordnungen auf der Bewältigung einer ,dreifachen Zumutung'. „[Abgenabelt] von allen Heilsplänen" sind moderne politische Gesellschaften und ihre Mitglieder zu allererst herausgefordert, ,in Selbstbestimmung eine politische Autorität zu gründen und begründen".' An die Stelle einer religiösen Sanktion weltlicher Autorität tritt die Vorstellung einer autonomen Gestaltbarkeit menschlichen Zusammenlebens und damit die „aktivistische Zumutung “'2 neue Geltungsgrundlage politischer Ordnung (be)gründen zu müssen. Die revolutionären (Neu)Gründungen der Vereinigten Staaten und Frankreichs im ausgehenden 18. Jahrhundert gelten in dieser Hinsicht als tiefgreifende Zäsur und als Ausdruck dieser Entwicklung. Zugemutet wird den Gesellschaften zudem und zugleich, ,ein symbolisches Band“ zwischen den einzelnen Mitgliedern zu knüpfen, ,diese sozial [zu] integrieren“ bzw. einen gemeinsamen, von möglichst vielen Bürgern geteilten Sinnhorizont entstehen zu lassen. ${ }^{3}$ Hinzu tritt schließlich eine dritte Zumutung, die nicht selten übersehen wird: Moderne Gesellschaften sind herausgefordert, die im Konstituierungsakt offensichtlich werdende Kontingenz menschlichen Ent-

1 Günter Frankenberg: Die Verfassung der Republik. Autorität und Solidarität in der Zivilgesellschaft, Baden-Baden 1996, S. 71 und S. 58.

2 Ebd., S. 57.

3 Ebd., S. 58. 
scheidens zu verarbeiten, um Geltung zu behaupten und Stabilität dauerhaft sicher zu stellen. Keine politische Ordnung, so kann angenommen werden, ist der Notwendigkeit enthoben, sich als selbstverständliche, so-und-nichtanders-mögliche Ordnung zu begründen und als eine solche auch zu erscheinen, will sie nicht Geltungskraft und Geltungsanspruch verlieren. ${ }^{4}$ Konstitutiv wirkt in diesem Zusammenhang ein spezifischer Modus politischer Kommunikation: die Transzendierung bzw. Unverfügbarstellung. Die Begründung der neuen Ordnung erfolgt, indem diese selbst und ihre konkrete historische Entstehungssituation transzendiert werden. ${ }^{5}$ Sie werden verabsolutiert, überhöht, unverfügbar gestellt oder gar geheiligt. Beobachtbar ist dabei zumeist ein argumentativer Rekurs auf Begriffe und symbolische Formen, die als nicht-kontingentes, allgemein geteiltes Wissen behandelt werden und denen nicht selten selbst ein quasi-sakraler Charakter zugesprochen wird. ${ }^{6}$ Damit ergibt sich ein paradoxales Spannungsverhältnis: autonome (Be)Gründung und Sozialintegration auf der einen Seite und Kontingenzverarbeitung mittels Transzendierung bzw. Unverfügbarstellung auf der anderen Seite. Dem soll im Folgenden am Beispiel des

4 Die Formulierung ist angelehnt an Ernst-Wolfgang Böckenförde (Die verfassunggebende Gewalt des Volkes. Ein Grenzbegriff des Verfassungsrechts, in: ders.: Staat, Verfassung, Demokratie. Studien zur Verfassungstheorie und zum Verfassungsrecht, Frankfurt a.M. 1991, S. 90-112, hier: S. 91). Dort heißt es: „Keine geltende Rechtsordnung ist der Notwendigkeit enthoben, sich aus vorrechtlichen Gegebenheiten zu begründen und zu legitimieren; andernfalls verliert sie Geltungskraft und Geltungsanspruch.“ Vgl. zum Problem der Kontingenz den Überblick bei Michael Makropoulos: Modernität als Kontingenzkultur. Konturen eines Konzeptes, in: Gerhart von Graevenitz/Odo Marquard (Hrsg.): Kontingenz. Poetik und Hermeneutik, Bd. 17, München 1998, S. 55-79.

5 Vgl. in diesem Sinne Karl-Siegbert Rehberg: Institutionen als symbolische Ordnungen. Leitfragen zur Theorie und Analyse institutioneller Mechanismen, in: Gerhard Göhler (Hrsg.): Die Eigenart der Institutionen. Zum Profil politischer Institutionentheorie, Baden-Baden 1994, S. 47-84, hier: S. 63-65. Außerdem grundlegend: Hans Vorländer: Einleitung, in: ders. (Hrsg.): Transzendenz und Gemeinsinn. Themen und Perspektiven des Dresdner Sonderforschungsbereiches 804, Dresden 2011, S. 6-15, hier: S. 9-11.

6 Vgl. in diesem Sinne auch Thorsten Bonacker: Die Kontingenz des politischen Handelns. Adorno, Arendt und die Legitimationsprobleme in der politischen Gesellschaft, in: Dirk Auer/Julia Schulze Wessel/Lars Rensmann (Hrsg.): Arendt und Adorno, Frankfurt a.M. 2003, S. 286-310, hier: S. 290f. Dort heißt es: „Deshalb stützt sich kontingentes politisches Handeln auf Geltungsgründe, mit denen sich die politische Gesellschaft als solche konstituiert hat und die sie als nichtkontingent behandelt, obwohl sie natürlich - wie die Verfassung historisch kontingent sind." 
Königreichs Württemberg nachgegangen werden. Der württembergischen Verfassung und ihrer Genese kommt dabei mit Blick auf die deutsche Verfassungsgeschichte des 19. Jahrhunderts eine besondere Bedeutung zu. In der sogenannten ersten Verfassungswelle in Deutschland war sie nicht nur die erste und einzige paktierte Verfassung, sondern auch jene, deren Entstehung als am heftigsten umkämpft galt und die zudem als nacheifernswertes Muster angesehen wurde. ${ }^{7}$

Das Streben nach einer Verfassung hatte sich in Württemberg in der epochalen Umbruchs- und Krisenphase um 1800 verstärkt. In den Jahren zwischen 1815 und 1819 unternahmen die württembergischen Eliten unter den Augen einer engagierten Öffentlichkeit zahlreiche Versuche, eine neue Ordnung zu konstituieren, um auf diesem Wege die von Frankreich ausgehenden revolutionären und napoleonischen Umwälzungen evolutionär zu verarbeiten. Wie bereits in den Vereinigten Staaten und im revolutionären Frankreich war dabei das Ziel, den inneren Zusammenhalt des Landes herzustellen bzw. abzusichern und die (neu bzw. wieder erlangte) äußere Selbstständigkeit und Souveränität zu bewahren, ein entscheidender Grundimpuls der Verfassunggebung. Die Reformen ,von oben', wie sie 1803/06 in Folge der Auflösung des Alten Reiches und nach der Erhebung des Herzogtums zum Königreich bei gleichzeitigem Beitritt zum Rheinbund erfolgt waren, erschienen hierfür nicht ausreichend. Im Gegenteil: Die einseitige Aufhebung der alten, landständisch verfassten Ordnung Württembergs im Dezember 1805 hatte sich destabilisierend ausgewirkt. Darüber hinaus befürchtete der württembergische König, Friedrich I., eine Einschränkung

7 Vgl. Manfred Hettling: Reform ohne Revolution. Bürgertum, Bürokratie und kommunale Selbstverwaltung in Württemberg von 1800 bis 1850, Göttingen 1990, S. 115. Zum zeitgenössischen Bewusstsein der Mustergültigkeit: Joachim Gerner: Vorgeschichte und Entstehung der württembergischen Verfassung im Spiegel der Quellen 1815-1819, Stuttgart 1989, S. 246. Zum Begriff der „Verfassungswellen“: Wilhelm van Calker: Die Verfassungsentwicklung in den deutschen Einzelstaaten, in: Gerhard Anschütz/Richard Thoma (Hrsg.): Handbuch des Deutschen Staatsrechts, Bd. 1, Tübingen 1931, S. 49-63, hier: S. 49ff. Daran anknüpfend: Dieter Grimm: Deutsche Verfassungsgeschichte 1776-1866. Vom Beginn des modernen Verfassungsstaates bis zur Auflösung des Deutschen Bundes, Frankfurt a.M. 1988. Er unterscheidet zwei Verfassungswellen (18131819/24 und 1830ff.). Vgl. auch Hans Gangl: Der deutsche Weg zum Verfassungsstaat im 19. Jahrhundert. Eine Problemskizze, in: Ernst-Wolfgang Böckenförde (Hrsg.): Probleme des Konstitutionalismus im 19. Jahrhundert, Berlin 1975, S. 23-58, hier: S. 50ff. Er unterscheidet drei Wellen (1816-20, 1830-33 und 1848-50). 
seiner Souveränität durch den seit September 1814 tagenden Wiener Kongress. Notwendig erschien daher eine konstitutionelle Integration im Inneren. ${ }^{8}$ Besonders dringlich war dies mit Blick auf die großen territorialen Zugewinne, die infolge von Säkularisation und der Mediatisation zu verzeichnen waren. ${ }^{9}$ So verdoppelten sich Württembergs Staatsgebiet und dessen Bevölkerung. Verbunden war damit zugleich das Aufweichen der vergleichsweise homogenen - da primär protestantischen - Konfessionsstruktur (Alt)Württembergs, da die Mehrheit der hinzugetretenen Neuwürttemberger Katholiken waren. Schließlich muss auch die Finanznot Friedrichs I. als Kernfaktor der Konstitutionalisierung genannt werden. Wie bereits in Frankreich 1788/89 forcierten die notwendige Schuldenkonsolidierung und Kreditsicherung, welche nur mit Hilfe und Zustimmung der Stände erfolgen konnten, die verfassungspolitischen Bemühungen. ${ }^{10}$

Es stellt sich die Frage, wie die württembergischen Eliten vor diesem Hintergrund versuchten, diese ordnungspolitischen Herausforderungen zu bewältigen. Wie versuchten sie den politisch-konstitutionellen Umbruch zu verarbeiten und die Gründung Württembergs als modernen Verfassungsstaat $\mathrm{zu}$ rechtfertigen? Im Zentrum der Betrachtungen steht dabei die Selbstwahrnehmung und Selbstbeschreibung der Akteure, d.h. der zeitgenössische Selbstverständigungsprozess, eingebettet in den spezifischen

8 Zur Annahme eines zweifachen Integrationsprozesses von Reform und Verfassunggebung vgl. Ina Ulrike Paul: Württemberg 1797-1816/19. Quellen und Studien zur Entstehung des modernen württembergischen Staates, München 2005, S. 51-77; Hettling, Reform, 1990, S. 34f. Paul Nolte (Staatsbildung als Gesellschaftsreform. Politische Reformen in Preußen und den süddeutschen Staaten 1800-1820, Frankfurt a.M./New York 1990, S. 169) hält die Reformen insbesondere im Hinblick auf die süddeutschen Staaten für ,die Bedingung der Möglichkeit“ der Verfassungen. Unklar ist, inwieweit bereits die Reformen als „Präkonstitutionalismus“ gelten können. Vgl. hierzu Arthur Schlegelmilch: Die Alternative des monarchischen Konstitutionalismus. Eine Neuinterpretation der deutschen und österreichischen Verfassungsgeschichte des 19. Jahrhunderts, Bonn 2009, S. 26-37. Zum Wiener Kongress: Gerner, Vorgeschichte, 1989, S. 9f.

9 Vgl. zum Überblick Hermann Schmid: Die Säkularisation und Mediatisation in Baden und Württemberg, in: Württembergisches Landesmuseum Stuttgart (Hrsg.): Baden und Württemberg im Zeitalter Napoleons, Bd. 2, Stuttgart 1987, S. 135-156.

10 Vgl. Herbert Obenaus: Finanzkrise und Verfassungsgebung. $\mathrm{Zu}$ den sozialen Bedingungen des frühen deutschen Konstitutionalismus, in: Gerhard A. Ritter (Hrsg.): Gesellschaft, Parlament und Regierung. Zur Geschichte des Parlamentarismus in Deutschland, Düsseldorf 1974, S. 244-265. 
württembergischen Gründungskontext. In einem ersten Abschnitt soll dieser Kontext anhand eines kurzen Überblicks über den Verlauf des württembergischen Verfassungskonflikts skizziert werden (2).

Im Mittelpunkt steht sodann die inhaltliche Dimension des Konfliktes insbesondere die Auseinandersetzungen um die Verfassung als solche. Innerhalb der historischen Konstitutionalismusforschung ist in diesem $\mathrm{Zu}$ sammenhang immer wieder deren herausragende Bedeutung hervorgehoben worden. Das 19. Jahrhundert war nicht nur ,ein Jahrhundert der Verfassungsfragen, der Verfassungsschöpfung und Verfassungskämpfe“", sondern vor allem auch ,ein Jahrhundert des Verfassungsglaubens“. ${ }^{11}$ Reinhard Blänkner hat an verschiedenen Stellen auch vom „Vorrang der Verfassung“ gesprochen. In diesem Sinne etablierte sich die ,konstitutionelle Verfassung“ - zumindest zwischen 1770 und 1840 - nicht nur zur entscheidenden „Leitdifferenz der Ordnung des Politischen“, sondern war darüber hinaus auch der Ausdruck einer ,aufgeklärt-liberalen politischen Theologie“, mit der sich eine spezifische „Zivilreligion“ verband. ${ }^{12}$

Wie zu zeigen sein wird, bestätigt dies der Blick auf den Ordnungsdiskurs in Württemberg. Dass die Neugründung des Königreichs, die Vereinigung von Alt- und Neuwürttemberg und die Wiederherstellung eines Rechtszustandes nur auf dem Weg der Verfassunggebung und damit ausschließlich in Form einer Verfassung erfolgen könne, bestritt keiner der beteiligten Akteure. Die Idee der Verfassung wurde damit als Teil jenes oben angesprochenen, nicht-kontingenten, allgemein geteilten Wissen be-

11 Gangl, Der Deutsche Weg, 1975, S. 24f.

12 Vgl. u.a. Reinhard Blänkner: Der Vorrang der Verfassung. Formierung, Legitimations- und Wissensformen und Transformation des Konstitutionalismus in Deutschland im ausgehenden 18. und frühen 19. Jahrhundert, in: ders./Bernhard Jussen (Hrsg.): Institutionen und Ereignis. Über historische Praktiken und Vorstellungen gesellschaftlichen Ordnens, Göttingen 1998, S. 295-325; ders.: Historizität, Institutionalität, Symbolizität. Grundbegriffliche Aspekte einer Kulturgeschichte des Politischen, in: Barbara Stollberg-Rilinger (Hrsg.): Was heißt Kulturgeschichte des Politischen?, Berlin 2005, S. 71-96; ders.: Tugend, Verfassung, Zivilreligion. Normative Integration im aufgeklärten Liberalismus, in: Hubertus Buchstein/Rainer Schmalz-Bruns (Hrsg.): Politik der Integration. Symbole, Repräsentation, Institution. Festschrift für Gerhard Göhler zum 65. Geburtstag, Baden-Baden 2006, S. 339-367. Auch Hans Vorländer (Die Geltung gesatzter Ordnung. Vormoderne und moderne Verfassung im Vergleich, in: Anette Kehnel/Franz Felten/Stefan Weinfurter (Hrsg.): Institution und Charisma. Festschrift für Gert Melville zum 65. Geburtstag, Köln/Weimar/Wien 2009, S. 47-54, hier: S. 53) spricht von der Verfassung als „Teil einer konstitutionellen Zivilreligion". 
handelt. Als solche bildete sie den entscheidenden Ausgangspunkt für die Transzendierung bzw. Unverfügbarstellung der politischen Ordnung. Was jedoch ,Verfassung' oder ,Constitution' meine, was hierunter zu verstehen sei, was eine solche umfasse und nicht zuletzt wie diese überhaupt zustande kommen solle oder ob diese gar schon bestanden habe, dies war vehement umstritten und der Hauptstreitpunkt im Verlaufe des gesamten Konfliktes. Verkürzt lautete er: Wiederherstellung der altwürttembergischen, Verfassung' oder Herstellung einer Neuen?

Gerade die von allen Akteuren als selbstverständlich angenommene Verfassung, ihr quasi-sakraler Status, brachte es mit sich, dass beide Seiten, sowohl König als auch Stände, bestrebt waren, die Deutungshoheit über den Verfassungsbegriff zu gewinnen. Zu beobachten ist dabei, wie beide Konfliktparteien - bewusst oder unbewusst - auf unterschiedliche Weise versuchten, ihr eigenes politisches Ordnungsmodell der Verfügung des Gegners zu entziehen, es für allgemein verbindlich zu erklären und das der Gegenseite zu destruieren. Letztlich verbanden damit beide die Absicht, ihre jeweiligen Vorstellungen vom neuen Württemberg als Verfassungsordnung durchzusetzen. In den Abschnitten 3 und 4 soll dies näher betrachtet werden. Darauf folgend werden mit dem Vertrag und der Monarchie jene Ordnungsvorstellungen in den Mittelpunkt der Betrachtungen gestellt, die schließlich von den Akteuren als entscheidende Kompromissformeln eingesetzt wurden, um den Konflikt zu beenden und eine Einigung herbeizuführen (5 und 6 ).

\section{DeR WÜRTtembergische VERFASSUNGSKONFLIKT (1815-1819)}

Der Verfassunggebungsprozess, aus dem schließlich im September 1819 die Verfassung des Königreichs Württemberg hervorging, erstreckte sich mit zahlreichen Unterbrechungen über einen Zeitraum von vier Jahren. ${ }^{13}$

13 Vgl. zum württembergischen Verfassungskonflikt: Albrecht Liste: Der Kampf ums gute alte Recht (1815-1819) nach seiner ideen- und parteigeschichtlichen Seite, Tübingen 1913; Erwin Hölzle: Das alte Recht und die Revolution. Eine politische Geschichte Württembergs in der Revolutionszeit 1789-1805, Berlin 1931; ders.: Württemberg im Zeitalter Napoleons und der deutschen Erhebung. Eine deutsche Geschichte der Wendezeit im einzelstaatlichen Bereich, Stuttgart/Berlin 1937; Walter Grube: Der Stuttgarter Landtag 1457-1957: Von den Landständen zum demokratischen Parlament, Stuttgart 1957, S. 489-508; 
Typisch für die vom Primat des Monarchen geprägte Erscheinungsform des monarchischen Konstitutionalismus wurde dieser Prozess vom württembergischen König, Friedrich I., und dessen Staatsräten initiiert. ${ }^{14}$ Sie unternahmen den Versuch, den umrissenen Neuordnungsbedarf in Form eines einseitigen Verfassungsoktrois zu befriedigen. ${ }^{15}$ Die Verfassung sollte als königlicher Gnadenakt in Geltung gesetzt werden. Zu diesem Zweck berief Friedrich I. am 15. März 1815 eine hierzu gewählte Ständeversammlung ein, die dieser von Friedrich bereits beschworenen Verfassung zustimmen sollte. Eine vorherige Beratung oder gar Mitwirkung war - dem Vorbild der französischen Charte Constitutionnelle bzw. Charte octroyée von 1814 folgend $^{16}$ - hierfür nicht vorgesehen. Das Vorhaben scheiterte. Die große Mehrheit der Stände verweigerte noch am gleichen Tag ihre Zustimmung nicht zuletzt weil sich bereits im Vorfeld der Einberufung eine breite Front gegen eine neue, einseitig zu erlassene Verfassung herausgebildet hatte. Das verfassungsrechtliche Fundament eines erweiterten Württembergs konnte nach Ansicht der überwiegenden Mehrheit der Ständeversammlung und der meinungsführenden, von einer breiten Öffentlichkeit unterstützten ,Altrechtler' keine andere sein als die wiederherzustellende, nur partiell zu

Hartwig Brandt: Parlamentarismus in Württemberg 1819-1870. Anatomie eines deutschen Landtags, Düsseldorf 1987, S. 19-32; ders.: Von den Verfassungskämpfen der Stände zum modernen Konstitutionalismus: Das Beispiel Württemberg, in: Martin Kirsch/Pierangelo Schiera (Hrsg.): Denken und Umsetzung des Konstitutionalismus in Deutschland und anderen europäischen Ländern in der ersten Hälfte des 19. Jahrhunderts, Berlin 1999, S. 99-108; Rolf Grawert: Der württembergische Verfassungsstreit 1815-1819, in: Christoph Jamme/Otto Pögger (Hrsg.): „O Fürstin der Heimath! glückliches Stutgard““. Politik, Kultur und Gesellschaft, Stuttgart 1988, S. 35-54. Unverzichtbar: Gerner, Vorgeschichte, 1989.

14 Vgl. zum ,monarchischen Konstitutionalismus“: Martin Kirsch: Monarch und Parlament im 19. Jahrhundert. Der monarchische Konstitutionalismus als europäischer Verfassungstyp - Frankreich im Vergleich, Göttingen 1999.

15 Vgl. zum Nachfolgenden: Gerner, Vorgeschichte, 1989.

16 Hartwig Brandt (Von den Verfassungskämpfen der Stände zum modernen Konstitutionalismus. Das Beispiel Württemberg, in: Martin Kirsch/Pierangelo Schiera (Hrsg.): Denken und Umsetzung des Konstitutionalismus in Deutschland und anderen europäischen Ländern in der ersten Hälfte des 19. Jahrhunderts, Berlin 1999, S. 99-108, hier: S. 99) spricht von der Charte Constitutionnelle als dem „Prototyp des nachrevolutionären Verfassungssystems“, Schlegelmilch (Alternative, 2009, S. 175) vom „Charte-Konstitutionalismus“ als „kontinentaleuropäischen Verfassungsstandard“. Vgl. detailliert: Kirsch, Monarch und Parlament, 1999, S. 299-304. Zum Begriff der charte octroyée: Schlegelmilch, Alternative, 2009, S. 38. 
modifizierende, alte gute Verfassung', wie sie vor 1805 bestanden hatte. Angesichts dieser konträren Vorstellungen über den Weg und die Ausgestaltung der neuen Ordnung scheiterten erste Verhandlungen zwischen Ständen und königlicher Regierung.

Einen wichtigen Einschnitt bedeutete der Tod Friedrichs am 30. Oktober 1816 und die Inthronisierung seines Sohnes, nun Wilhelm I. Dieser beschloss, einen neuen, eigenen Verfassungsentwurf zu entwickeln. Über dessen Annahme konnte aber wiederum innerhalb der inzwischen gespaltenen Ständeversammlung keine Einigkeit erzielt werden. Anfang Juni 1817 lehnte vielmehr eine Mehrheit der Stände auch diesen königlichen Verfassungsentwurf ab. Wilhelm I. reagierte mit der Auflösung der Versammlung.

Es folgte der Versuch Wilhelms, seinen Verfassungsentwurf durch eine Befragung der württembergischen Amtsversammlungen quasi plebiszitär in Geltung zu setzen, sowie jener, die Verfassungsfrage einheitlich auf der Ebene des Deutschen Bundes zu lösen. Auch diese scheiterten. Wilhelm I. beschloss deshalb, verschiedene seiner Vorhaben auf dem Reformweg und mittels zahlreicher Verwaltungsedikte durchzusetzen.

Erst zwei Jahre nach Auflösung der Ständeversammlung initiierte Wilhelm I. schließlich einen weiteren gemeinsamen Verhandlungsversuch mit den Ständen. Er berief die hierzu neu gewählte Ständeversammlung ein. Auf der Grundlage des (modifizierten) königlichen Entwurfes von 1817 erarbeitete sodann eine gemeinsame Kommission aus königlichen und ständischen Bevollmächtigten einen neuen Verfassungsentwurf. Erst anschließend begannen die Verfassungsberatungen innerhalb der Ständeversammlung, die innerhalb kurzer Zeit ohne weitere Verzögerungen und ohne grundsätzliche Auseinandersetzungen abgeschlossen wurden. Am 23. September 1819 nahmen die Stände die Verfassung einstimmig an. Zwei Tage später erfolgte im Ludwigsburger Schloss der feierliche Austausch der Verfassungsurkunden. 


\section{3 „VON DEM HOHEN BEDÜRFNISSE EINER FESTEN STAATS-CONSTITUTION"“17}

Eine ,eigene gemäßigtere und besonders für die Zukunft nothwendig werdende Monarchische Verfassung“ zu errichten, schrieb Friedrich I. an seinen Staatsminister Mandelslohe noch während des Wiener Kongress ' im Oktober 1814, sei schon immer seine Absicht gewesen. Besonders die Eigenständigkeit derselben hob er dabei hervor. Als „Richtschnur“ hätten demnach weder die bundesdeutschen Konstitutionspläne des Freiherrn von Stein noch jene des liberal-demokratisch gesinnten „Rheinischen Merkurs“ gedient. Darüber hinaus beruhe sie weder auf der englischen noch auf der französischen Verfassung, und ,am allerwenigsten“ auf den „obsoleten altwürttembergischen Carrikaturen von Verfassung“. ${ }^{18}$ Stattdessen unterstrich er in der Präambel seines Verfassungsentwurfes den Anspruch, ,in der Ueberzeugung von dem hohen Bedürfnisse einer festen Staats-Constitution“ eine solche in Form einer „Verfassungs-Urkunde“" zu geben. ${ }^{19}$

Wenngleich hiermit erstmals in der württembergischen Geschichte ein systematisches und geschlossenes Verfassungsdokument mit dem Anspruch einer umfassenden und universalen rechtlichen Bindung vorgelegt wurde, verband Friedrich I. damit keinen herrschaftskonstituierenden Akt. Vielmehr wird die neue „Staats-Constitution“ vom Staat aus gedacht. Sie sei der „Schlussstein zu dem Gebäude des Staates“, somit der Abschluss der seit 1805 einseitig vom König durchgeführten Reformen und in dieser Form nach Aussage des Innenministers Reischach - ein Akt der ,,Selbstbeschränkung seiner Gewalt“. ${ }^{20}$ Sieht man einmal von der inhaltlichen Ausgestal-

17 [Verfassungsentwurf vom 15.03.1815], in: Horst Dippel (Hrsg.): Verfassungen der Welt vom späten 18. Jahrhundert bis Mitte des 19. Jahrhunderts. Quellen zur Herausbildung des modernen Konstitutionalismus, Bd. 3/6: Deutsche Verfassungsdokumente 1806-1849, München 2008, S. 265.

18 Brief Friedrich I. an Mandelslohe vom 03.10.1814, zitiert nach: Gerner, Vorgeschichte, 1989, S. 9.

19 [Verfassungsentwurf vom 15.03.1815], in: Dippel, Verfassungen der Welt, 2008, S. 265.

20 Friedrich I., Abt. 1, S. 14. Die Angaben verweisen stets auf die Druckausgabe der Protokolle der Ständeversammlung bei Friedrich Schott/Willibald Feuerlein (Hrsg.): Verhandlungen in der Versammlung der Landstände des Königreichs Würtemberg, Heidelberg/Stuttgart 1815-1819 (Sigle: [Name des Sprechers], Abt. [Nummer], S. [Nummer]). Ebenso: Karl von Reischach: [Rede], in: Königlich privilegierte Stuttgarter Zeitung. Nr. 43, 16.03.1815, S. 214f. Vgl. hierzu: Grimm, Verfassungsgeschichte, 1988, S. 111. 
tung dieser „Monarchischen Verfassung“ ab, die aus diesem Verfassungsverständnis hervorging ${ }^{21}$, so ist eines deutlich erkennbar: die Verfassunggebung sollte als Innovation und, was noch viel wichtiger ist, als königlicher Gnadenakt erscheinen.

Genau hierin muss der (einzige) Versuch Friedrichs gesehen werden, die von ihm oktroyierte Verfassung zu begründen, sie unverfügbar zu stellen und sie weiteren Diskussionen zu entziehen. Diese Begründung erfolgte eben im und durch den Akt der Verfassunggebung als Gnadengeschenk. Sie sollte nicht weniger als den Willen „Friderich[s], von Gottes Gnaden“, wie die Präambel der Verfassungsurkunde verkündet, ausdrücken. Sie - und nur sie - könne daher die Grundlage der politischen Ordnung des Königreichs bilden. Einzig auf ihrer Basis - und erst nach ihrer unbedingten Anerkennung durch die Ständeversammlung - könne bei Bedarf und auf dem verfassungsrechtlich dafür vorgesehenen Weg, nämlich dem Petitionsweg, über Modifikationen derselben gesprochen werden. ${ }^{22}$

In der Eröffnungszeremonie der Ständeversammlung findet sich diese Vorstellung symbolisch verdichtet wieder. Wie zuletzt Rainer Schmidt überzeugend herausgearbeitet hat, beruhte diese Zeremonie - deren Verlauf dem Vorbild der Verkündung der französischen Charte vom 4. Juni 1814 folgte $^{23}$ - allein auf dem höfischen Zeremoniell als dem traditionellen monarchischen Kommunikationsmodus. Indes lief diese symbolische Praxis der königlichen Verfassungsverkündung und -beeidung ins Leere. Die Stände hatten sich, organisiert und koordiniert durch Eberhard Friedrich Georgii, bereits im Vorfeld darauf verständigt, die Verfassung nicht anzunehmen. Sie wohnten dem Zeremoniell lediglich mit Distanz bei und entzauberten damit die Inszenierung des Besonderen und Außeralltäglichen, deren konstitutive Bedeutung doch gerade darin bestehen sollte, den Monarchen zu erhöhen, und vor allem die neue (monarchische) Ordnung symbolisch in Geltung zu setzen. ${ }^{24}$

21 Vgl. u.a. Brandt, Parlamentarismus, 1987, S. 25.

22 Vgl. z.B. Friedrich I., Abt. 1, S. 61.

23 Vgl. Gerner, Vorgeschichte, 1989, S. 68 Fn. 9. Zum Verlauf des Zeremoniells: ebd., S. 68-71.

24 Vgl. Rainer Schmidt: Verfassungskultur und Verfassungssoziologie. Politischer und rechtlicher Konstitutionalismus in Deutschland im 19. Jahrhundert, Wiesbaden 2012, S. 93 Aus Sicht der Stände: Bolley/Klüpfel, Abt. 8, S. 80: „Die Ehrerbietung verbot den Ständen, diesen Königlichen Akt auf irgendeine Weise zu unterbrechen; aber sobald Se. Majestät der König den Stände-Saal verlassen hatten, so erinnerten sich die Stände an die Pflichten, welche sie für das Volk zu 
Bemerkenswert ist zudem ein zweiter, für die neue Ordnung Friedrichs konstitutiver, symbolischer Akt. Der württembergische König berief die Stände nicht ins alte Ständehaus - dem Symbol der altwürttembergischen Verfassungs- und Repräsentationstradition - ein. Stattdessen wurde ein ehemaliges Wohnhaus eines Staatsrats zum Beratungsort bestimmt. ${ }^{25}$ Dies entsprach der grundlegenden Zäsurvorstellung Friedrichs. Er negierte den Bestand einer württembergischen Verfassung. Diejenige Altwürttembergs, betonte Friedrich, sei schließlich 1805 ,,in sich selbst zusammen[gefallen] ${ }^{\text {‘26 }}$. Ohnehin sei diese schon immer mangelhaft und unanwendbar gewesen. Ihr müsse der Rang einer Verfassung schlichtweg abgesprochen werden. Nicht umsonst bezeichnete sie Friedrich auch als „obsolete altwürttembergische Carrikatur von Verfassung“. Er begründete damit seine eigene Verfassung negativ - in Abgrenzung zur , alten Verfassung ‘ ${ }^{27}$ Darüber hinaus habe das um die neuen Länder erweiterte Württemberg noch nie eine gemeinsame Verfassung besessen. Die Verfassunggebung bedeute somit nichts anderes als eine Neugründung, und ,Verfassung“ meine nichts anderes als eine neue Verfassung. Diese müsse wiederum oktroyiert werden. Den Vertragsgedanken, die Idee, die Verfassung könne durch eine Übereinkunft vereinbart werden, lehnte Friedrich I. ab. Stattdessen verkündete Friedrich während seiner Rede zur Eröffnung der Ständeversammlung vom Thron herab: „Ich [gebe] Meinem Volk eine Verfas-

erfüllen hatten [...].“ Vgl. zur Präsenz und zeitgenössischen Aktualität des höfischen Zeremoniells (als Kontinuität, Wiederaufnahme oder brüchige Zitation) zuletzt: Horst Carl: Erinnerungsbruch als Beginn der Moderne? Tradition und bewusste Neuorientierung bei Hof und Zeremoniell nach 1800, in: Andreas Klinger/Hans-Werner Hahn/Georg Schmidt (Hrsg.): Das Jahr 1806 im europäischen Kontext. Balance, Hegemonie und politische Kulturen, Köln u.a. 2008, S. 169-184. Zu Württemberg: ebd., S. 178f. Prägnant zur konstitutiven Bedeutung symbolischer Praxis und Form: Barbara Stollberg-Rilinger: Des Kaisers alte Kleider. Verfassungsgeschichte und Symbolsprache des Alten Reiches, München 2008, S. 9-12.

25 Vgl. hierzu Grube, Stuttgarter Landtag, 1957, S. 491. Das alte Ständegebäude war von königlichen Behörden belegt und nicht frei gegeben worden.

26 Friedrich I.: Rede im Staatsrathe vom 11.01.1815, in: Karl Heinrich Ludwig Pölitz (Hrsg.): Die europäischen Verfassungen seit dem Jahre 1789 bis auf die neueste Zeit, Bd. 1: Die gesammten Verfassungen des teutschen Staatenbundes enthaltend, 2., neugeordnete, berichtigte und ergänzte Aufl., Hildesheim/ Zürich/New York 1999 [1832], S. 363.

27 Kronprinz Wilhelm wird wenig später die Stände als „Kranke oder Hypochondristen“ bezeichnen, „die fixe Idee[n] hätten“. Zitiert nach Gerner, Vorgeschichte, 1989, S. 109. 
sung, wie Ich sie den Bedürfnissen und dem Wohl desselben für angemessen halte. ${ }^{628}$

\section{Die „ALte Verfassung“ ALS dAS AN UND FÜR SICH ,HEILIGE‘, ,HÖCHSTE‘ UND ,SEIENDE‘}

Wie anders der Standpunkt der Stände: die Basis der politischen Ordnung eines vergrößerten Württembergs - darin waren sich diese (mit wenigen Ausnahmen) einig - könne keine andere sein als die , alte Verfassung' der Erblande bzw. das hierzu synonym gebrauchte, (gute) alte Recht'. Doch was verstanden die Stände darunter? In einer von den Abgeordneten Heinrich Bolley und Heinrich Klüpfel entworfenen und verfassten Adresse vom Juni 1815 wird dies expliziert. Dort heißt es:

„In Württemberg sind die Verhältnisse zwischen dem Regenten und den Unterthanen durch ausdrückliche, durch oft wiederholte, durch sehr ausdrückliche Verträge bestimmt. Den Inbegriff dieser Verträge nannte man die Verfassung Württembergs. - Diese Verfassung war der Stolz Württembergs; sie wurde überall als das Muster einer gesellschaftlichen Ordnung gepriesen $[\ldots]]^{، 29}$

Die „Verfassung [Alt-]Württembergs“ wurde damit keineswegs als ein systematisches, geschlossenes Rechtsdokument gedacht. Gemeint waren vielmehr jene „schriftlich fixierten Verfassungsverbürgungen“, die, um eine treffende Metapher Dilchers aufzugreifen, ,gleich Inseln, zum Teil auch gleich Felsblöcken im Meer des Herkommens schwammen “30. ,Verfassung' als Erfahrungs-, Zustands- und Seins-Begriff umschrieb also

28 Friedrich I., Abt. 1, S. 14 (Hervorhebungen JR). Vgl. auch: ders.: Königliches Manifest vom 11.01.1815, in: Pölitz, Die europäischen Verfassungen, 1999, S. 362f. sowie die Präambel der Verfassungsurkunde von 1815, abgedruckt in: Dippel, Verfassungen der Welt, 2008, S. 265 (,Wir haben [...] Unseren lieben und getreuen Unterthanen Unsern Entschluß kund gethan, Unserem Königreiche eine ständische Verfassung zu geben.").

29 Bolley/Klüpfel, Abt. 8, S. 78 (Hervorhebung JR). Vgl. auch: Weishaar, Abt. 9, S. 223 (,einzelne Theile unserer Verfassung, obgleich in verschiedenen, zu verschiedenen Zeiten errichteten Vertragsurkunden zerstreut").

30 Gerhard Dilcher: Vom ständischen Herrschaftsvertrag zum Verfassungsgesetz, in: Der Staat 27 (1988), S. 161-193, hier: S. 171. Umfassend zur Begriffsgeschichte des Verfassungsbegriffs: Heinz Mohnhaupt/Dieter Grimm: Verfassung. Zur Geschichte des Begriffs von der Antike bis zur Gegenwart. Zwei Studien, 2. Aufl., Berlin 2002. 
jenen sich aus Verträgen, Grundgesetzen, Manifesten, Reskripten, Landtagsabschieden und Gravamina zusammensetzenden staatsrechtlichen Rahmen, der spätestens seit dem 18. Jahrhundert zu einer spezifisch württembergischen Verfassungstradition im Sinne einer ancient constitution mythisiert worden war und unter dessen Geltung die altwürttembergischen Stände bis dato gelebt hatten. ${ }^{31}$ Dass dieser gleichwohl in die neue Zeit überführt werden musste, erschien zunächst unstrittig. Entsprechend dachte die große Mehrheit die , alte Verfassung' stets als , die alte (zu modifizierende) Verfassung،. ${ }^{32}$ Ihre Veränderung wurde als unumgänglich, gar selbstverständlich angesehen, und auch die Form der Verfassungsurkunde wurde, wenngleich nicht zum notwendigen Merkmal erklärt, zumindest nicht zurückgewiesen.

Der Begriff der ,Verfassung' blieb entsprechend allein der , alten Verfassung 'vorbehalten. In Bezug auf die vom König zu erlassene Verfassung sprach man lediglich von der „Urkunde“, die zurückzuweisen sei. ${ }^{33}$ Andere beriefen sich ausschließlich auf die ,alte Verfassung', die nicht aufgegeben werden könne, ohne die neue Verfassung expressis verbis zu erwähnen oder als solche zu bezeichnen. Man kann dies als Ausdruck einer plakativen Ignoranz auffassen oder aber als einen subtilen Versuch, den Bereich des Sagbaren einzugrenzen. ${ }^{34}$ Selbst die Agnaten, hier die Brüder Friedrich I., sprachen in Bezug auf die königliche Verfassung lediglich von „Grundlinien“ und zeigten sich verwundert, dass diese von Seiten des Königs als „ganz neue Verfassung“ bezeichnet worden war. ${ }^{35}$

Neben dieser semantischen Ebene versuchten die Stände - wie bereits die Regierung - gleich zu Beginn des Konfliktes die Deutungshoheit über den Verfassungsbegriff auf symbolischer Ebene zu erringen, um den Vor-

31 Vgl. allgemein zu Ursprüngen und Verbreitung der Rede vom „alten Recht“: Dietmar Willoweit: Vom alten guten Recht. Normensuche zwischen Erfahrungswissen und Ursprungslegenden, in: Jahrbuch des Historischen Kollegs, München 1997, S. 23-52. Grundlegend und unverzichtbar zur Tradition einer ancient constitution als Kern der , politischen Kultur' Altwürttembergs: Laurence W. Dickey: Hegel: Religion, Economics, and the Politics of Spirit 1770-1807, Cambridge 1989, S. 113-137.

32 Vgl. z.B. Fetzer, Abt. 3, S. 48 („Nothwendigkeit einer modifizierten Wiederherstellung der vormaligen Verfassung und deren Ausdehnung auf ganz Würtemberg").

33 Bolley, Abt. 1, S. 85; ebenso: Fischer, Abt. 7, S. 82f.; Knapp, Abt. 7, S. 89f.

34 Vgl. z.B. Waldeck, Abt. 2, S. 3ff.

35 Friedrich Wilhelm/Heinrich Friedrich Carl v. Württemberg, Abt. 2, S. 34. 
rang der , alten Verfassung ' zu unterstreichen und jede ordnungspolitische Bedeutung der königlichen „Urkunde“ zu leugnen.

Vom Scheitern des königlichen Verfassunggebungszeremoniells wurde in diesem Zusammenhang bereits berichtet. Demgegenüber steht der Erfolg der Stände, denen es gelungen war, die Deutungshoheit über die symbolische Dimension dieses Aktes zu erobern. In den Mittelpunkt gerückt wurden dabei das Datum der Landtagseröffnung, der 15. März, und die Person des zwischen 1550 und 1568 regierenden Herzogs Christoph, der als eigentlicher Urheber der , alten Verfassung' galt. Wenngleich nicht bekannt ist, warum Friedrich I. den 15. März als Eröffnungstag wählte, erkannten die Stände darin nur eines: die königliche Anerkennung der fortwährenden Geltung und damit der Unantastbarkeit und Unverfügbarkeit der ,alten Verfassung ${ }^{6}{ }^{36}$ Schließlich war der 15. März der Namenstag Christophs und dieser - wie allgemein bekannt - die Verkörperung des ,guten alten Rechts“ und dessen mythischer Gesetzgeber. ${ }^{37}$ Welche andere Basis als die ,alte Verfassung' konnte angesichts dessen die Grundlage der Verfassunggebung bilden?

Dies versuchten die Stände zu unterstreichen. Die ,alte Verfassung wurde an und für sich als einzig denkbare Basis der politischen Ordnung Württembergs dargestellt. Sie konnten in dieser Hinsicht auf frühere Bemühungen zurückgreifen. Bereits für die Zeit vor 1815 lassen sich solche Versuche nachweisen. Und bereits damals war damit stets die Idee der ,Wiederherstellung' und der ,Erneuerung ' verbunden. So heißt es schon in einer anlässlich des sogenannten Reformlandtags vom Historiker Ludwig Timotheus Spittler 1796 verfassten Flugschrift:

36 Vgl. zeitgenössisch bes. Waldeck, Abt. 2, S. 4 und S. 7ff., passim. Zum Überblick: Grube, Stuttgarter Landtag, 1957; Volker Press: Der württembergische Landtag im Zeitalter des Umbruchs 1770-1830, in: Zeitschrift für Württembergische Landesgeschichte 42 (1983), S. 255-281, hier: S. 266.

37 Die allgemeine Anerkennung dieser Ursprungslegende spiegelt sich vor allem in einer Vielzahl volkstümlicher Praktiken wider, die sich allesamt der Mythisierung Christophs widmeten. Das Anbringen eines Bildes Christophs an das Gewand oder den Hut soll eine ebenso weit verbreitete Praxis gewesen sein, wie das Tragen eines in Silber geprägten Bildes am Fingerring oder an der Gürtelschnalle. Es ist auch von einer Bebilderung von Krügen, Schüsseln und Blumentöpfen die Rede. Großer Beliebtheit erfreuten sich zudem Trinksprüche, die zur Unterstützung der Altrechtler auf das ,gute, alte Recht“ ausgebracht wurden. Vgl. hierzu: Grube, Stuttgarter Landtag, 1957, S. 492ff. sowie Württembergisches Landesmuseum Stuttgart (Hrsg.): Baden und Württemberg im Zeitalter Napoleons, Bd. 1.1, Stuttgart 1987, S. 340f. 
„Wir sind mit der bisherigen Verfassung und Regierung unsers Landes so wohl zufrieden, daß wir durchaus keine wesentliche Veränderung verlangen, sondern nur Wiederherstellung der wahren Konstitution, bei der unsere Vorväter so glücklich gewesen sind, und die allmählich im Laufe der Zeiten gelitten zu haben scheint.“38

Gleich zu Beginn des Verfassungskonflikts im Jahr 1815 griffen die Stände diesen Gedanken wieder auf. Der Zweck ihre Einberufung sei kein anderer als die „Begründung eines gemeinschaftlichen Vereins“ durch die „modifizierte Wiederherstellung der vormaligen Verfassung und deren Ausdehnung auf ganz Würtemberg““ ${ }^{39}$ Schließlich passe „,der Geist derselben für alle Zeiten und alle Umstände“"40. Sie habe demnach einen wahren, unantastbaren Kern und eine überzeitliche Geltung. Hinzu trat der Gedanke der Vollkommenheit. Die , alte Verfassung' sei - ganz im Gegensatz zur königlichen „Urkunde“ - ,das Ideal einer musterhaften Verfassung“, wie sich Klüpfel in einem Adressentwurf äußerte, und als solche auch ,allgemein“ anerkannt. ${ }^{41}$ Sie bzw. das hierzu synonym gebrauchte ,alte Recht“ sei folgerichtig - so die immer wiederkehrende Formulierung - „heilig“. Die ,alte Verfassung ' wurde somit dezidiert sakralisiert. ${ }^{42}$ Über sie zu verfügen, sollte unmöglich erscheinen. Kein Wunder, dass der Abgeordnete

38 Zitiert nach Ewald Grothe: Der württembergische Reformlandtag, in: Zeitschrift für Württembergische Landesgeschichte 48 (1998), S. 159-200, hier: S. 166 (Hervorhebung JR). Es findet sich im Übrigen auch zu dieser Zeit bereits die Delegitimierung der alten, „wahren Konstitution“, wie eine - damals unveröffentlicht gebliebene - Überlegung Hegels aus dem Jahr 1798 zeigt: „Wie blind sind diejenigen, die glauben mögen, daß Einrichtungen, Verfassungen, Gesetze, die mit den Sitten, den Bedürfnissen, der Meinung der Menschen nicht mehr zusammenstimmen, aus denen der Geist entflohen ist, länger bestehen, daß Formen, an denen Verstand und Empfindung kein Interesse mehr nimmt, mächtig genug seien, länger das Band eines Volkes auszumachen! Alle Versuche, Verhältnissen, Teilen einer Verfassung, aus welchen der Glaube entwichen ist, durch großsprechende Pfuschereien wieder Zutrauen zu verschaffen, die Totengräber mit schönen Worten zu übertünchen, bedecken nicht nur die sinnreichen Erfinder mit Schande, sondern bereiten einen viel fürchterlicheren Ausbruch. Wenn eine Veränderung geschehen soll, so muß etwas verändert werden.“ (zitiert nach: ebd., S. 167)

39 [Waldeck], Abt. 2, S. 18; Fetzer, Abt. 3, S. 48. Vgl. ebenso: Waldeck, Abt. 1, S. 105 sowie Bolley, Abt. 1, S. 76.

40 Weishaar, Abt. 9, S. 16. Ebenso: Waldeck, Abt. 2, S. 3 („,ür ewige Zeiten gegründete Verfassung").

41 Klüpfel, Abt. 7, S. 39.

42 Vgl. Waldeck, Abt. 7, S. 155; Griesinger, Abt. 8, S. 25; Zahn, Abt. 8, S. 45; Bolley/Klüpfel, Abt. 8, S. 66; Weishaar, Abt. 9, S. 16 und S. 223; Forstner von Dambenois, Abt. 9, S. 45. 
Bolley im April 1815 - die Rückkehr Napoleons und den Krieg vor Augen - pointiert formulieren konnte:

„Für alle Unterthanen, die neuen wie die alten, hat der Name ,alte Verfassung' eine magische Kraft; und nichts kann das Vaterland gegen das Gift der gefährlichen Grundsätze, welche jetzt wieder, wie vor 25 Jahren, von Frankreich verbreitet werden, so gewiß sicher stellen, als die Anhänglichkeit an diese Verfassung. “43

Und noch ein Weiteres wurde hinzugefügt, was diese Verfassung unverfügbar erscheinen lassen sollte: sie habe sich selbst hervorgebracht. ${ }^{44}$ Sie wurde somit - mit den Worten aus Hegels Rechtsphilosophie von 1821 - als das ,schlechthin an und für sich Seiende, das darum als das Göttliche und Beharrende und als über der Sphäre dessen, was gemacht wird“", dargestellt. ${ }^{45}$

Es finden sich überdies einige Anzeichen dafür, dass die Stände zumindest in Ansätzen die auf diese Weise gestaltete Überhöhung der ,alten Verfassung' reflektiert haben. Dies wird an drei Stellen deutlich: Erstens an jenen, an denen die ständische Mehrheit die Zusammenfassung ihrer Kernargumente als „Glaubensbekenntnisse“ titulierte. ${ }^{46}$ Bemerkenswert ist ferner der Ausruf des Abgeordneten Cottas, der es - zweitens - als das erste Interesse der Ständeversammlung ansah, „das Wahre, sich selbst Rechtfertigende anzubieten“, um die „öffentliche Meinung“ für ihre Ordnungsvorstellungen zu gewinnen. ${ }^{47}$ Und drittens zeigt sich dieses Bewusstsein bei den Versuchen der Abgeordneten Gleich und Kessler, diesen überhöhten Status der , alten Verfassung' als bloßen naiven Glauben ironisch zurückzuweisen und diese als solche und als Basis der konkreten Verfassungsverhandlungen als politisch veränder- und revidierbar erscheinen zu lassen.

43 Bolley, einstimmig angenommener Adressentwurf als Antwort auf das königliche Reskript vom 16.04.1815, Abt. 3, S. 111 (Hervorhebung JR). Pikant war an dieser Adresse, dass die Stände damit die Zustimmung zur Rüstungsfinanzierung, die angesichts des neuerlichen Kriegsausbruchs in Folge der Rückkehr Napoleons unerlässlich war, an die Wiederherstellung der alten Verfassung knüpfte.

44 Zahn, Abt. 8, S. 45.

45 Georg Wilhelm Friedrich Hegel: Grundlinien der Philosophie des Rechts oder Naturrecht und Staatswissenschaft im Grundrisse [1821], hrsg. von Eva Moldenhauer und Karl Markus Michel, Frankfurt a.M. 1970, S. 439 (\$272).

46 [Protokollant], Abt. 1, S. 66; Waldeck, Abt. 1, S. 72; Mayer, Abt. 3, S. 52; Bolley u.a., Abt. 3, S. 109; Mayer, Abt. 7, S. 29; Varnbüler, Abt. 8, S. 5.

47 Cotta, Abt. 7, 1815, S. 139 (Hervorhebung JR). 
Maximilian Heinrich Gleich, von Beruf Rentbeamter und Abgeordneter für die ehemalige Reichsstadt (nun Oberamt) Aalen, zielte als erstes Mitglied der Ständeversammlung darauf, die ,alte Verfassung ‘ von ihrem ständisch konstruierten Altar zu stürzen. ${ }^{48}$ Entsprechend wandte er sich dezidiert den entscheidenden Punkten zu: er sei keineswegs davon überzeugt, dass die Grundgesetze der Erblande den Gipfel der Vollkommenheit erreicht hätten; er jedenfalls könne ,in der besagten Verfassung nicht das Non plus ultra aller Konstitutionen“ erkennen; dies sei schlicht fern jeder Wirklichkeit. Würde man all ihre Mängel beseitigen - und dies sei unbedingt nötig -, so sei ihr Äußeres nichts weiter mehr als ein ,überphysiognomisirtes Flickwerk“. Überhaupt müsse man endlich einsehen, dass ,,keine menschlichen Einrichtungen für die Ewigkeit gemacht" sind. Kurzum: Die Mehrheit der Stände sei „unter den Gehorsam des Glaubens gefangen“. Es müsse deshalb endlich „,eine andere Bahn“ betreten werden. Und dies könne nur durch eine neue ,heilsame und das Wohl des Landes sichernde Staatsverfassung“ erreicht werden, die auf der Basis weniger „materielle[r] und nicht bestreitbare[r] Forderungen“" auszuhandeln sei und die letztlich die ,ungebundene Willkührherrschaft“ beseitigen solle. Auch der Abgeordnete und der Parteiung der ,Bürgerfreunde“ angehörende Heinrich Kessler argumentierte später auf diese Weise. Die Annahme der Altrechtler, die alte Verfassung könne fortexistieren, sei nichts als Einbildung. „Eben so leicht kann ich mir aber auch einbilden, daß man in Stuttgart am babylonischen Turm baue.“ „Alter Plunder“ sei daher die zutreffendere Bezeichnung für das „gute alte Recht“. Überhaupt kritisierte Kessler, dass die Altrechtler ,ihre politische Meinung zur Sache der Pietät machen, und Jeden für gottlos ausschreien, der für ihr Evangelium keinen Glauben hat“ “49

48 Vgl. zum Folgenden: Gleich, Abt. 7, S. 118-130, bes. S. 119, 121f., 125, 127 und S. 130. Der Abgeordnete Mayer hatte in Reaktion auf dessen Rede betont, dass „solche Ideen“ auch ,außer der Versammlung zu stark zirkulierten“ (Abt. 7, S. 85).

49 Heinrich Keßler, in: Für und Wider. Eine politische Zeitschrift für Württemberg, 1 (1817), S. 178f. und S. $173 f$. 


\section{Der Verfassungsvertrag als Forderung DER Geschichte UND DER VeRnUNFT}

Trotz dieser grundlegenden Differenzen, die sich im Laufe des Konfliktes innerhalb der Ständeversammlung herauskristallisierten, blieb eines unumstritten: Eine Verfassung müsse und könne ausschließlich auf dem Weg eines Vergleichs und in Form eines freien Vertrags vereinbart werden. Oder wie es der Abgeordnete Cotta als Unmöglichkeitsaussage formulierte: „Keine Verfassung, auch die beste, [kann] nicht gegeben werden, sondern [muß] zwischen Regenten und Volk verglichen werden. “50 Dieser Rekurs auf die Idee der paktierten Verfassung ${ }^{51}$ ist das Axiom der Stände in Hinblick auf die Möglichkeit der Konstitution und Stabilität einer politischen Ordnung. Er war zudem neben dem Verweis auf die fortwährende Geltung der alten Verfassung das Kernargument für die Ablehnung bzw. Mißachtung der königlichen Verfassungsurkunde vom 15. März.

Bemerkenswert sind wiederum die Begründungsformeln, derer sich die Akteure in diesem Zusammenhang bedienten. Sie rekurrierten dabei vor allem auf Argumentationsfiguren, die jeweils als Heteronomien, die Autonomie der Entscheidungsträger einschränkende Instanzen, erscheinen sollten. Willibald Steinmetz hat in diesem Zusammenhang von , unpersönlichen Agenten' gesprochen, von denen in bestimmten Sprechhandlungssituationen behauptet wird, sie seien die eigentlich handelnden Subjekte. ${ }^{52}$ Die Akteure suggerierten demnach, dass diese das Handeln determinieren und allmächtig lenken würden. Handlungsalternativen erschienen so weder denkbar noch sagbar. Es handelte sich also stets um Notwendigkeitsaussagen, in denen sowohl der angegebene Zwang als auch dessen Herkunft und Ursache evident erscheinen sollten. Der ohnehin schon an und für sich heilige Vertrag - und damit auch die (alte) Verfassung - wurden zusätzlich zum Objekt jener ,unpersönlichen Agenten' erklärt. Verwiesen wurde in diesem Sinne etwa auf das ,Volk', den ,Volksgeist', den ,Zeitgeist‘, aber vor allem auf die ,Geschichte' und die ,Vernunft‘. Diese letzten

50 Cotta, Abt. 7, S. 138; ebenso: [Agnaten], Abt. 2, S. 34.

51 Vgl. Thomas Würtenberger: Die Idee der paktierten Verfassung in der Neuzeit bis zum 19. Jahrhundert, in: Okko Behrends/Christian Starck (Hrsg.): Gesetz und Vertrag I, Göttingen 2004, S. 107-123, bes. S. 113-117.

52 Vgl. Willibald Steinmetz: Das Sagbare und das Machbare. Zum Wandel politischer Handlungsspielräume. England 1780-1867, Stuttgart 1993, S. 38f. 
beiden Beispiele gilt es in Bezug auf das Begriffsfeld ,Verfassung' und ,Vertrag' näher in den Blick zu nehmen.

Eine herausragende Bedeutung kam historischen Begründungsformeln zu. Schon immer seien die Grundgesetze Württembergs - d.h. die Verfassung - der „Inbegriff“ von Verträgen, im Sinne freier Übereinkünfte zwischen Regent und Volk gewesen. Dies zeige unzweifelhaft die Geschichte des Herzogtums. Die herausragende Bedeutung, die diesem Gedanken zugesprochen wurde, offenbart sich bereits in der ersten Rede von Seiten der Stände, nachdem die Versammlung vom König im März 1815 eröffnet worden war. Es ist Graf von Waldeck der dieses Narrativ von der württembergischen Verfassungsgeschichte als Geschichte von Verträgen pointiert ausformulierte. In ihrem Mittelpunkt stand der Tübinger Vertrag von 1514 als die „magna charta“ Württembergs sowie der Erbvergleich von 1770, welcher die jüngste vertragliche Übereinkunft und damit das „Hauptfundament der Würtembergischen innern Staatsverfassung“ bilde. Die Stoßrichtung dieses Narrativs war es unzweifelhaft, die königliche, nichtvertraglich erlassene Verfassungsurkunde zu delegitimieren und ihre implizite Nicht-Annahme zu begründen. ${ }^{53}$ Gleiches gilt auch für die zahlreichen Verweise auf die Weltgeschichte. Gerade sie zeige, wie etwa Ludwig Friedrich Griesinger im April 1815 in der Ständeversammlung ausführte, dass der ,souverainste Monarch der Welt seinen feierlich eingegangenen und beschworenen Verträgen“ wie ,,auch ein Gott [dem Verhängnisse des Schicksals] nicht entgehen könne“. Den Kaisern Hadrian und Anastasius sei dies ebenso gewiss gewesen wie den gotischen und den persischen Königen. $^{54}$

Auch mit Blick auf die vertrags- bzw. vernunftrechtliche Begründung des Verfassungsvertrags lässt sich eine ähnlich strukturierte Argumentation nachvollziehen. Am elaboriertesten ausgearbeitet, findet sich diese - ebenfalls an einer hervorgehobenen Stelle - in der ständischen Adresse vom 26. Juni 1815, die von den Abgeordneten Bolley und Klüpfel entworfen und beinahe einstimmig angenommen worden war. Gehe man nur von ,allgemeinen Prinzipien“, das heißt der Vernunft, aus, so „,beruhet die Constitution auf einem Vertrag“ - genauer zwei Verträgen: einem „VereinigungsVertrag“ und einem „Unterwerfungs-Vertrag“. „Paziscenten“, also Ver-

53 Vgl. Waldeck, Abt. 2, S. 3-20; später: Bolley, Abt. 1, S. 75, 81 und S. 85; Waldeck, Abt. 1, S. 104; Bolley/ Klüpfel, Abt. 8, S. 77f.

54 Griesinger, Abt. 8, S. 30f. 
tragsteilnehmer, könnten dabei ,keine andern seyn, als diejenigen, denen die höchste Gewalt übertragen ist, auf der einen, und die gesammte Nation auf der andern Seite“. Im ersten Vertrag einige man sich darauf, wer die höchste Staatsgewalt ausübe und in welchem rechtlichen Rahmen diese wirken soll. Wie noch zu zeigen sein wird, könne dies kein anderer als der Monarch sein. Der „Unterwerfungs-Vertrag“ bedeute schließlich nichts weiter, ,als daß jene [Vereinbarung] in der Würklichkeit dargestellt werde“ ${ }^{\text {c55 }}$. Die Vernunft zeige darüber hinaus ein Weiteres: Es sei unmöglich, wie selbst Blackstone und Locke in seltener Einigkeit erklärt hätten, dass der Verfassungsvertrag von einem Paziszenten einseitig aufgelöst oder verändert werde. ${ }^{56}$ Schließlich entsage eine Nation niemals (freiwillig) ihrem Mitspracherecht; ,dadurch würde sie sich in Sklaverei hingeben, und nicht blos der sinnlichen Glückseligkeit, sondern der moralischen Menschennatur entsagen“- was undenkbar sei.

\section{Monarchie und Verfassungsvertrag}

Bereits zu Beginn des Verfassungskonfliktes ist die allgemeine und unwidersprochene Anerkennung der Monarchie als die einzig denkbare Regierungsform Württembergs zu beobachten. Sowohl König als auch Stände verbinden ihre Vorstellung von ,Verfassung' mit jener der Monarchie. Die ,monarchische Verfassung' bzw. die ,constitutionelle Monarchie' sind unbestrittene Grundsätze.

So enthält die königliche Verfassungsurkunde vom 15. März 1815 dementsprechend sowohl das großgeschriebene Wir, den pluralis majestatis, als auch die übliche Gottesgnadentumsformel ${ }^{57}$ sowie weitere Hinweise auf die

55 Hier wie im Folgenden: Bolley/Klüpfel, Abt. 8, S. 68f. Ohne darauf hinzuweisen, zitieren Bolley und Klüpfel hier aus der zeitgenössisch viel rezipierten Schrift Der Anti-Leviathan von Friedrich Eberhard Georgii. Vgl. hierzu: Friedrich Eberhard Georgii: Anti-Leviathan oder über das Verhältnis der Moral zum äussern Recht und zur Politik, Göttingen 1807, S. 192-194. Zu dieser Schrift: Hölzle, Württemberg, 1937, S. 142f. Der Anti-Leviathan habe ,den Mittelpunkt der damaligen politischen Philosophie württembergischer Prägung dargestellt".

56 Vgl. ebd.; ebenso: Klüpfel, Abt. 7, S. 31-39; Griesinger mit Verweis auf Grotius, Sidney und Reyneval, Abt. 8, S. 32 und S. 34.

57 Jenseits dieser Formel rekurrieren weder König (bzw. Regierung) noch Stände auf „Gott“, um die Monarchie oder das ,monarchische Prinzip' zu begründen. Vgl. zur Bedeutung der Formel vom Gottesgnadentum in den Verfassungen des 
königliche Gnade, als deren Geschenk diese Verfassung erscheinen sollte. Aber auch die Stände bekennen sich immer wieder zur Monarchie.

„[D]er gute teutsche Mann [sey] viel zu verständig, hochherzig, fromm und edel, als $\mathrm{da}$ er einen so heiligen Zweck selbstsüchtig und leichtsinnig aus dem Auge verlieren, und seine angebohrene Liebe zu seinem Regentenstamm und Vaterland, oder seine, aus der Hand der Vorsehung empfangene Pflicht, neuen Regenten zu gehorchen, frevelhaft aufgeben und verletzen könnte. ${ }^{\text {(58 }}$

Sie sprechen von einer unerschütterlichen „Anhänglichkeit“ gegenüber dem Regenten, vom ,innigste[n] Pflichtgefühl“ als ihrer ,einzige[n] Triebfeder“, von ihrer unbedingten, ,dem Menschen ins Herz gegossene[n]“ und „dem Regenten schuldige[n] Ehrfurcht“ sowie von ihrer „heilige[n] Pflicht“" ${ }^{59}$ Andere erkennen in der Monarchie den ,natürlichen Staat“60. Dem Abgeordneten Massenbach erscheint der König gar als „ein überirdisches, wie ein der Gottheit ähnliches Wesen, [...] der von der Höhe des Thrones herab Worte des Friedens spricht ${ }^{\text {661 }}$.

Die darin erkennbare Selbstverständlichkeit der Monarchie im politischen Ordnungsdenken der beteiligten Akteure manifestierte sich auch in den beiden Verfassungsentwürfen der Jahre 1816 und 1817. Sowohl im ständischen als auch im königlichen Entwurf findet sich im ersten bzw. zweiten Kapitel („Von dem Könige“) das monarchische Prinzip als Verfassungsformel. Dass der König das „Haupt des Staates“ sei, ,in sich alle Rechte der Staatsgewalt“ vereinige und als Person „heilig und unverletzlich" sei, galt als allgemein geteilter Konsens. ${ }^{62}$

Außer Frage stand aber auch, dass die Monarchie verfassungsrechtlich (selbst)begrenzt und beschränkt werden müsse. Die Untertanen seien

19. Jahrhunderts: Otto Brunner: Vom Gottesgnadentum zum monarchischen Prinzip, in: ders.: Neue Wege der Verfassungs- und Sozialgeschichte, 3. Aufl., Göttingen 1980, S. 160-186, hier: S. 181-183.

58 Mayer, Abt. 7, S. 25.

59 Zahn, Abt.1, S. 98; Waldeck, Abt. 1, S. 104; Knapp, Abt. 7, S. 41; Fischer, Abt. 7, S. 67; Bolley/ Klüpfel, Abt. 8, S. 80.

60 Heinrich Keßler, in: Für und Wider. Eine politische Zeitschrift für Württemberg, 4 (1817), S. 32.

61 Massenbach, Abt. 38, S. 212. Vgl. auch die Hinweise bei List, Kampf, 1912, S. 13.

62 Vgl. [Verfassungsentwurf Wilhelm I. vom 03.03.1817], in: Pölitz, Die europäischen Verfassungen, 1999, S. 377f. sowie [o.A.]: Entwurf des zu erneuernden württembergischen Verfassungs-Vertrags nach den Beschlüssen des Ständischen Instructions-Comité, [o.O.] 1816. 
schließlich, wie Bolley schon zu Beginn der Verhandlungen hervorgehoben hatte, „nur zu verfassungsmäßigem Gehorsam verpflichtet“63. Und überhaupt liege im Begriff „Souveränität“ keineswegs die „Idee der absoluten Machtvollkommenheit“. Vielmehr seien alle Verträge sowie bestimmte Rechte unantastbar. Beides beweise nicht nur die Geschichte, sondern es sei vernunftgemäß gar nicht anders denkbar. ${ }^{64}$ Kurzum: die ,constitutionelle Monarchie" wird an und für sich als alternativlos dargestellt. Sie war in der Perspektive der Akteure dem Bereich des politisch Entscheid- und Veränderbaren entzogen. Auf diesem Topos gründeten schließlich auch der Kompromiss und der Verfassungsvertrag vom September 1819. Auch dieser enthielt die bekannte Formel des monarchischen Prinzips. So erklärte Staatsminister Groß die ,constitutionelle Monarchie` zur unbedingten Forderung „der vorgeschrittenen Aufklärung des Zeitalters“665.

Integriert wurde diese Vorstellung innerhalb eines im zeitgenössischen Denken fest verankerten und weit verbreiteten historisch-organischen Entwicklungsmodells. Im Mittelpunkt stand dabei die Metapher der politischen Ordnung als ein lebendiger Organismus bzw. als ein ,pflanzenhaft wachsendes Naturwesen“" (Stolleis), dessen Werden und Vergehen das Verständnis der beteiligten Akteure nachhaltig prägte. ${ }^{66}$ Hieran knüpfte vor allem der Abgeordnete von Theobald an. ${ }^{67} \mathrm{Ihm}$ gelang es damit sowohl die Unantastbarkeit der ,alten Verfassung' weiter zu behaupten als auch die neue Verfassung für alternativlos zu erklären. Die ,constitutionelle Monarchie‘ bildete hierbei den Fixpunkt und das entscheidende Bindeglied. Sie wurde zum Ziel- und Erwartungsbegriff.

63 Bolley, Abt. 1, S. 85.

64 Griesinger, Abt. 4, S. $20 \mathrm{ff}$. sowie ders., Abt. 6, S. 125, 133, $140 \mathrm{ff}$. und S. 156.

65 Groß, Rede im Geheimen Rat, den durch gemeinschaftliche Commission entworfene Verfassungsentwurf betreffend, zitiert nach: Gerner, Vorgeschichte, 1989, S. 476.

66 Vgl. hierzu pointiert Michael Stolleis: Geschichte des öffentlichen Rechts in Deutschland, Bd. 2: Staatsrechtslehre und Verwaltungswissenschaft, 1800-1914, München 1992, S. 123-126. Ausführlich: Gerhard Dohrn-van Rossum/ ErnstWolfgang Böckenförde: Organ, Organismus, Organisation, politischer Körper, in: Otto Brunner/Werner Conze/Reinhart Koselleck (Hrsg.): Geschichtliche Grundbegriffe. Historisches Lexika zur politisch-sozialen Sprache in Deutschland, Bd. 4, Stuttgart 2004, S. 519-622, bes. S. 604ff.

67 Zum Folgenden: Theobald, Abt. 42, S. 92f. (Hervorhebungen JR). Die Rede wurde noch einmal, am Tage der Endabstimmung (!), in der Zeitschrift Die Tribüne (Nr. 75 [1819], S. 299f.) veröffentlicht. 
Die ,,alte ehrwürdige Verfassung“, führte von Theobald in der Ständeversammlung Mitte September 1819 aus, enthalte nichts anderes als den „Keim einer constitutionellen Ordnung“. Insofern könne man diese nur gutheißen, sie als ,das Heiligthum unseres Volks“ ehren, ihren Verteidigern huldigen und ihren Gegnern nichts als „Abscheu“ entgegenbringen. Doch auch die neue Verfassung enthalte nichts anderes als „,das ganze Wesen der constitutionellen Monarchie“ - dies sei nicht widerlegbar und damit wahr. Davon ausgehend gelang es von Theobald, die entscheidende Kompromissformel zu formulieren. Denn er schlussfolgerte:

„Die constitutionelle Monarchie, wenn sie in Würtemberg eingeführt wird, ist mir weiter nichts, als eine höhere Entwicklung, die schöne Blüthe der altwürtembergischen Verfassung. Durch diese Monarchie geht daher diesem Lande nicht nur kein altes Recht verloren, sondern jedes alte gute Recht wird vielmehr durch sie auf's Neue bestätigt, erweitert, gesteigert und veredelt."

Er erklärt damit die neue Verfassung als Inbegriff der ,constitutionellen Monarchie' zum unaufhaltsamen und notwendigen Ergebnis der natürlichen Fortentwicklung und zum Symbol des natürlichen Fortschritts. Ihre Ursprünge und ihre Geschichte gingen damit keineswegs verloren. Im Gegenteil: Die ,alte Verfassung' sei ihr Keim, sie die Blüte.

Gerade der Blick auf die königliche Regierung bestätigt die Bedeutung dieser Äußerung als entscheidende Kompromissformel. Auch hier finden wir den gleichen Gedanken wieder. Mit dem ausgearbeiteten Verfassungsentwurf, betonte Staatsminister Groß im Geheimen Rat, anlässlich seiner Rede zur Arbeit und den Ergebnissen der gemeinsamen Verfassungskommission - an der auch von Theobald mitgewirkt hatte -, sei ,dasjenige, was den Geist und das wahre Wesen der altwürttembergischen Verfassung ausmacht [...], zu neuem wirksameren Leben gerufen“" worden. Schließlich habe „in ihr schon früher“ der „Keim einer constitutionellen Monarchie“ gelegen. ${ }^{68}$ Es handle sich somit bei der neuen Verfassung um ein quasi naturgesetzliches Fortschreiten in die Richtung einer konstitutionellen Monarchie. Bei Groß wird damit erneut das uns bereits vertraute Argument der Wiederherstellung des wahren Verfassungsgeistes erkennbar. Wiederum werden Assoziationen zur biblischen Idee geweckt, eine gestörte Ord-

68 Zitiert nach Gerner, Vorgeschichte, 1989, S. 476 (Hervorhebung im Original). 
nung müsse wiederhergestellt werden ${ }^{69}$ Staatsminister Groß identifizierte diesen „Geist“ nun mit der ,constitutionellen Monarchie“ als einer scheinbar ewigen, sich natürlich fortentwickelnden Idee.

Abschließend sei kurz auf eine zweite Variante dieses historisch-organischen Entwicklungsdenkens verwiesen. Erneut findet sich die Idee eines quasi natürlichen und deshalb unaufhaltsamen Wachstums und Fortschritts. Im Mittelpunkt stehen in diesem Fall der Begriff der,(Un)Vollkommenheit‘ und der damit implizierte Prozess der Vervollkommnung. Vor allem der Abgeordnete Weishaar, Vizepräsident und Meinungsführer der Versammlung und ebenfalls Mitglied jener Kommission, die die Verfassung von 1819 entworfen hatte, entwickelte diese Idee.

Im Grundsatz hatte sich die Ausgangsposition der Jahre 1815 und 1817 nicht verändert. Auch der Verfassungsentwurf des Jahres 1819 wurde über alle Akteursgrenzen hinweg als unvollkommen wahrgenommen. Die Mängelliste war weiterhin lang: Nicht zuletzt das von Seiten der Regierung und den ständischen Bevollmächtigten als „nothwendig“ etikettierte Zweikammersystem, das seit 1816 im Mittelpunkt der öffentlichen Auseinandersetzungen gestanden hatte und immer noch von der großen Mehrheit innerhalb und außerhalb der Versammlung abgelehnt wurde, veranschaulicht dies. Doch anders als noch zwei Jahre zuvor, hielt es nun die Mehrheit mit dem Abgeordneten und Landtagssekretär Johann Christian Schott, der seine Zustimmung zur Verfassung mit den Worten begründete: lieber eine „unvollkommene Verfassung als keine“ ${ }^{\text {“70 }}$. Auf dieser Basis gelang es nun, die neue Verfassung trotz oder gerade wegen ihrer Unvollkommenheit zu begründen und sie schließlich in Geltung zu setzen.

Die Idee der unvermeidlichen, da vorbestimmten Unvollkommenheit allen menschlichen Handelns entwickelt Weishaar in zwei Abschlussreden in der Ständeversammlung. Er bedient sich dabei den Worten Benjamin Franklins, der seinerseits im Verlaufe des amerikanischen Verfassunggebungsprozesses im Konvent von Philadelphia bereits versucht hatte, auf dieser Grundlage die amerikanische Bundesverfassung zu rechtfertigen. Die Unvollkommenheit alles von Menschenhand Erdachten und Geschaffenen sei der Natur gemäß. Aber auch der Fortschritt sei dies.

69 Vgl. hierzu Wolfgang Reinhard: Geschichte der Staatsgewalt. Eine vergleichende Verfassungsgeschichte Europas von den Anfängen bis zur Gegenwart, München 1999, S. 282.

70 Schott, Abt. 44, S. 4. 
„[L]iegt nicht“, fragte Weishaar, ,vielmehr in der Verfassungs-Urkunde der Keim, der sich zu größerer Vervollkommnung entwickeln kann, entwickeln wird, entwickeln $m u \beta$ ?“71

Formuliert wird eine Notwendigkeitsaussage in Form einer quasi-natürlichen Gesetzmäßigkeit. Erneut wird das organische Verfassungsverständnis deutlich.

Einige Abgeordnete nahmen dieses Argument als Kernpunkt ihrer Zustimmungsbegründung explizit auf. So betonte auch der Prälat von Schmid in seiner Abschiedsrede die natürliche Unvollkommenheit menschlichen Wirkens wie auch die zur Vervollkommnung angelegten „Keime“. Gleiches gilt für den Präsidenten der Ständeversammlung, Fürst Maximilian von Waldburg zu Zeil und Trauchburg, wenn er die ,Aufrechterhaltung, die Vervollkommnung und Verbesserung“ der Verfassung als „heilige Pflicht“ bezeichnete. ${ }^{72}$ Schließlich findet sich der Gedanke der „Unvollkommenheit, die sie [die Verfassung, JR] mit jedem menschlichen Werke theilt", des „Keims“ und des Fortschritts in Wilhelms Thronrede anlässlich der Übergabe der Verfassungsurkunde sowie im Verkündungsmanifest wieder.

„Möge die Vorsehung Unsere Bemühungen für das Glück Unsers Volks segnen; mögen alle Keime des Guten, welche in die Verfassung gelegt sind unter der sorgsamen Pflege treuer Diener des Staats und würdiger Stände des Königreichs gedeihen; mögen“, schloss Wilhelm seine Rede, ,künftige Geschlechter die Früchte der Anstrengungen genießen. “73

\section{ResümeE}

Das Ziel dieses Beitrages war es, darzulegen, wie die handelnden und deutenden Eliten den politisch-konstitutionellen Umbruch von 1815/19, die

71 Weishaar, Abt. 45, S. 25 (Hervorhebung JR). Es ist bemerkenswert, dass die Kehrseite dieser naturalen Wachstumsmetaphorik, die dieser per definitionem inhärenten Vorstellung eines Zyklus' und damit auch der Unentrinnbarkeit des Verfalls, nicht thematisiert und ausgeblendet wurde. Die darin sichtbar werdende Zukunftsbezogenheit dieses historisch-organischen Denkens bringt es also mit sich, dass die Möglichkeit des Nicht-Keimens und damit des Scheiterns der Verfassung - kurz: deren Kontingenz - unausgesprochen und verdeckt bleibt.

72 Vgl. Schmidt, Abt. 45, S. 84; Zeil, Abt. 45, S. 75; ebenso: John, Abt. 45, S. 39.

73 Wilhelm I., Abt. 45, S. 90 und S. 95. Er nennt den „Geist der Mäßigung, der Ordnung und der Wahrheit" sowie ,wahre Vaterlandsliebe [und] ächter Bürgersinn" als Grundvoraussetzungen für diese Verbesserung. 
Gründung Württembergs als modernen Verfassungsstaat, begründet und auf Dauer zu stellen versuchten. Es sollte damit exemplarisch gezeigt werden, wie das paradoxale Spannungsverhältnis zwischen autonomer (Be)Gründung sowie Sozialintegration auf der einen Seite und Kontingenzverarbeitung mittels Transzendierung bzw. Unverfügbarstellung auf der anderen Seite, als zentrale Herausforderung moderner politischer Ordnungen, bewältigt wurde.

Die konstitutive Bedeutung der Transzendierung bzw. Unverfügbarstellung als spezifischer Modus politischer Kommunikation konnte somit deutlich herausgearbeitet werden. Erinnert sei noch einmal an den gescheiterten Versuch Friedrich I., im März 1815 eine Verfassung zu oktroyieren. Ihm war es nicht gelungen, diese als einseitigen voluntaristischen Gnadenakt („Wir Friderich, von Gottes Gnaden“) unverfügbar zu stellen. Das Zeremoniell zur Eröffnung der Ständeversammlung führte dies symbolisch verdichtet vor Augen. Sein Versuch scheiterte nicht zuletzt deshalb, weil es den Ständen zunächst gelungen war, die Deutungshoheit zu gewinnen, die Geltungsgrundlage dieser neuen Verfassung verfügbar zu halten und die Behauptung von einer fortwährenden Gültigkeit der , alten Verfassung' als den Fixpunkt der (alt)württembergischen Ordnungstradition durchzusetzen bzw. aufrecht zu erhalten. Daraufhin hatte sich ein Dualismus von alter und neuer Verfassung ausgebildet, der bis 1819 immer wieder aktualisiert wurde.

Gleichwohl stand am Ende dieses konfliktiven Aushandlungsprozesses die erfolgreiche Neukonstitution Württembergs. Damit gelang nicht nur die verfassungsmäßige Vereinigung der alten und neuen württembergischen Lande, sondern ebenso die evolutionäre Verarbeitung jener außerordentlichen Herausforderungen, die durch die Französische Revolution und die napoleonischen Umwälzungen entstanden waren. Dies glückte durch das Festhalten an der ,alten Verfassung' (im Sinne eines wiederherzustellenden Ideals) bei gleichzeitiger Bejahung eines neuen, nun schriftlich in einer Urkunde kodifizierten Verfassungsvertrags - einer, neuen alten Verfassung '. Sie galt den Akteuren als Kern der politischen Ordnung Württembergs als einer vertraglich verfassten, constitutionellen Monarchie‘. Die Grundlage und Möglichkeit dieses Kompromisses ist in fünf Punkten zusammenzufassen:

Erstens beruhte dieser Kompromiss auf der zeitgenössischen Selbstverständlichkeit, dass die Ordnungsbegründung einzig und allein auf dem Weg 
der Verfassunggebung und in Form einer Verfassung erfolgen könne. Das württembergische Beispiel veranschaulicht damit die herausragende Stellung der Verfassung im Ordnungsdiskurs des frühen 19. Jahrhundert, in dem diese zur ,ideenpolitischen Erwartung der Zeit" avancierte. ${ }^{74}$

Eine ähnlich hervorgehobene Stellung nahm zweitens die Monarchie ein, die als einzige sag- und denkbare Regierungsform erschien und erscheinen sollte. Während des gesamten Konfliktes blieb diese Annahme über alle Akteursgrenzen hinweg unwidersprochen. Entsprechend gebrauchten die Akteure den Ziel- und Erwartungsbegriff der ,constitutionellen Monarchie auch als entscheidende Kompromissformel am Ende der Auseinandersetzung.

Das dritte Kernelement des Verfassungskompromisses ist der Rekurs auf die altrechtliche Idee des Vertrages bzw. auf die traditionelle „Erzählung des Vertragsschlusses““75. Die politische Ordnung Württembergs wurde als vertraglich verfasste, constitutionelle Monarchie' begründet und in Geltung gesetzt. Dabei erscheint die gängige und viel rezipierte Deutung Ernst-Wolfgang Böckenfördes, wonach die aus dem Verfassungsvertrag hervorgehende konstitutionelle Monarchie als „Ausdruck eines institutionalisierten politischen Kompromisses“ gelten müsse, in zweifacher Hinsicht in einem anderen Licht. ${ }^{76}$

Zum einen muss sie in erster Linie als das Ergebnis der ständischen Bemühungen angesehen werden, den ,Verfassungsvertrag' als traditionelle Ordnungsform in Württemberg - auch gegen Widerstand - aufrecht erhalten und dessen Aura der Unverfügbarkeit und Heiligkeit erfolgreich behauptet zu haben. Zum anderen zeigt sich hier erneut, dass die konstitutive Bedeutung der vertraglich verfassten ,constitutionelle Monarchie‘ als

74 Vgl. Thomas Nipperdey: Deutsche Geschichte 1800-1866. Bürgerwelt und starker Staat, München 1998, S. 273.

75 Vgl. Hans Vorländer: Gründung und Geltung. Die Konstitution der Ordnung und die Legitimität der Konstitution, in: Gert Melville/Hans Vorländer (Hrsg.): Geltungsgeschichten. Über die Stabilisierung und Legitimierung institutioneller Ordnungen, Köln/Wien/Weimar 2002, S. 243-263, hier: S. 245. Dilcher (Herrschaftsvertrag, 1988, S. 191) hat aber explizit darauf hingewiesen, dass es sich hier um eine Kontinuitätslinie handelt. Angeknüpft (und fortgesetzt) wird an das altrechtliche Vertragsdenken, nicht an die Idee des Gesellschaftsvertrages. Vgl. auch: Würtenberger, Die Idee der paktierten Verfassung, 2004.

76 Vgl. Ernst-Wolfgang Böckenförde: Geschichtliche Entwicklung und Bedeutungswandel der Verfassung, in: ders.: Staat, Verfassung, Demokratie. Studien zur Verfassungstheorie und zum Verfassungsrecht, Frankfurt a.M. 1991, S. 2952, hier: S. 37. 
Kompromissformel nicht zuletzt auf ihrer begrifflichen Unschärfe, Vieldeutigkeit und damit auf der ihr inhärenten Deutungsoffenheit beruhte.

Auf dieses Merkmal ist viertens auch die integrative Kraft dieser Begründungsfiguren zurückzuführen. Sie muss als weitere Grundlage der Neukonstituierung Württembergs genannt werden. Sowohl ,Verfassung ' als auch ,Verfassungsvertrag' und ,constitutionelle Monarchie " wurden nicht nur als Leit- und Schlüsselwörter, sondern zugleich auch als „Fahnenwörter" (Hermanns) gebraucht. Sie wurden gemeinsinnig aufgeladen, signalisierten, wie eine Fahne, Gemeinschaft und Zugehörigkeit und erschienen den Akteuren schließlich als das integrative Zentrum, das einigende Band der politischen Gemeinschaft der Württemberger. ${ }^{77}$

Als grundlegend erwies sich schließlich fünftens ein historisch-organisches Entwicklungsdenken mit einer spezifischen Zukunftsgerichtetheit, das innerhalb der Debatte in unterschiedlichen Ausprägungen - vor allem in der Metapher eines fortschreitenden Vervollkommnungsprozesses oder eines pflanzengleichen Wachstums (,alte Verfassung“ als „Keim“, neue Verfassung als ihre „Blüte“) zu finden ist. Verbunden ist damit am Ende der Auseinandersetzungen die Vorstellung einer sich aus sich selbst heraus fortentwickelnden Verfassung, der ihre natürliche Unvollkommenheit eingeschrieben ist, die aber genauso einen neuen Keim der Vervollkommnung in sich trägt.

Die Gründung bzw. der Neuanfang wird somit durch den gleichzeitigen Verweis auf Vergangenheit und Zukunft negiert und verklärt. Man begründete vor allem „,das Neue im Lichte des Vergangenen“ und bediente sich in erster Linie „des Verweises auf das Immer-schon-Dagewesene“, dem hierzu eine Aura der Heiligkeit, Notwendigkeit und ewigen Geltung

77 Vgl. zu den theoretischen Implikationen dieser Vieldeutigkeit und Deutungsoffenheit am Beispiel der Verfassung: André Brodocz: Chancen konstitutioneller Identitätsstiftung. Zur symbolischen Integration durch eine deutungsoffene Verfassung, in: Hans Vorländer (Hrsg.): Integration durch Verfassung, Wiesbaden 2002, S. 101-119, bes. S. 110. Zu den „Fahnenwörtern“ vgl. Fritz Hermanns: Schlüssel-, Schlag- und Fahnenwörter: zu Begrifflichkeit und Theorie der lexikalischen ,politischen Semantik"; erste Fassung eines Überblicksartikels zum Forschungsstand in Sachen Schlüsselwort- und Schlagworttheorie und -forschung für den Ergebnisband des Teilprojekts C5 „Bedeutungskonstitution im Dialog" des Sonderforschungsbereichs 245 ,Sprache und Situation", Heidelberg 1994, S. 15f. Er versteht darunter aber nicht, wie hier, ein gruppenübergreifendes, sondern ein auf einzelne Parteiungen beschränktes Erkennungszeichen. 
zugesprochen wurde. ${ }^{78}$ Dabei ging es den handelnden und deutenden Eliten, d.h. den Mitgliedern der Ständeversammlung und der Regierung, die hier im Fokus standen, eben darum, das „Neue als Erneuerung des Immerschon-Dagewesenen" sichtbar zu machen. ${ }^{79}$

Damit wird die aus der rückblickenden Beobachterperspektive offensichtlich werdende Kontingenz des Gründungsaktes verarbeitet. Anstatt das „mögliche Anderssein“ ${ }^{60}$ der Ordnung und ihrer Gründung offen zulegen, ließen die Akteure diese als so-und-nicht-anders-möglich erscheinen. Davon ausgehend war die (konstitutionelle und monarchische) Verfassung des frühen 19. Jahrhunderts tatsächlich, wie bereits Reinhard Blänkner festgestellt hat, die ,gleichsam kompensatorische Kehrseite der Säkularisierung für die Entflechtung von Politik und Religion“" ${ }^{\text {(81 }}$. Sie bildete damit die adäquate Antwort der Zeitgenossen auf die einleitend umrissene, dreifache Zumutung' moderner Ordnungsbegründung.

78 Vgl. zur Verklärung, Verabsolutierung, Heiligung und Mythisierung des Neuanfangs: Vorländer, Gründung und Geltung, 2002, S. 246f.

79 Wenngleich mit gänzlich anderen historischen Bezugspunkten zeigt sich hier auf den ersten Blick eine erstaunliche Analogie zu den revolutionären Ordnungsbegründern am Ende des 18. Jahrhunderts. Vgl. zu Frankreich und den USA: ebd., S. $247 \mathrm{f}$.

80 Niklas Luhmann: Soziale Systeme. Grundriß einer allgemeinen Theorie, 2. Aufl., Frankfurt a.M. 1989, S. 152.

81 Blänkner, Historizität, 2005, S. 85. 



\title{
Der Volksstaat als Selbstverständlichkeit
}

\author{
Friedrich Naumann und die Begründung
}

der Weimarer Republik

\section{JAN RÖDER}

\section{Einleitung}

Die Gründung einer politischen Ordnung ist, wie immer wieder betont wurde, ,eine der größten, kompliziertesten und verwickeltsten Aufgaben, die es geben kann"“1. Nicht zuletzt deshalb handelt es sich um ein Kernproblem der politischen Theorie und Ideengeschichte. ${ }^{2}$ Ein Aspekt, der dabei im Zentrum steht und hier besonders hervorgehoben werden soll, ist die Frage der Kontingenzbewältigung ${ }^{3}$ : Wie kann die Kontingenz des Gründungsaktes verarbeitet werden?

1 Hier von Friedrich Naumann: Die Demokratie in der Nationalversammlung [1919], in: ders.: Werke, Bd. 2: Schriften zur Verfassungspolitik, hrsg. von Theodor Schieder, bearbeitet von Wolfgang J. Mommsen, Köln/Opladen 1964, S. 537-557, hier: S. 545.

2 Einen systematischen Überblick vermittelt hierzu Hans Vorländer: Gründung und Geltung. Die Konstitution der Ordnung und die Legitimation der Konstitution, in: Gert Melville/Hans Vorländer (Hrsg.): Geltungsgeschichten. Über die Stabilisierung und Legitimierung institutioneller Ordnungen, Köln/Wien/ Weimar 2002, S. 243-263.

3 Der Begriff der Kontingenzbewältigung (allerding mit einem dezidierten Bezug auf die Religion) wurde geprägt von Hermann Lübbe: Kontingenzerfahrung und Kontingenzbewältigung, in: Gerhart von Graevenitz/Odo Marquard (Hrsg.): Kontingenz. Poetik und Hermeneutik, Bd. 17, München 1998, S. 35-47. Vgl. zur grundlegenden Bedeutung des Kontingenzbegriffs als kulturwissenschaftliche Schlüsselperspektive: Andreas Reckwitz: Die Kontingenzperspektive der ,Kultur'. Kulturbegriffe, Kulturtheorien und das kulturwissenschaftliche For- 
Gründungsphasen zeichnen sich nämlich gerade dadurch aus, dass in ihnen der Raum des politisch Möglichen und Gestaltbaren weit geöffnet wird. ${ }^{4}$ Die Akteure unternehmen (zumeist unter Zeitdruck, Konkurrenz und Konflikt) den Versuch, die politische Ordnung neu zu denken, zu entwerfen und zu errichten. Dabei sind zwei gegenläufige Phänomene zu beobachten: Einerseits verbindet sich damit der Anspruch, das Fundament und die Prinzipien der alten Ordnung zu negieren, zu delegitimieren oder zu modifizieren - kurz: über diese zu verfügen. Auf der anderen Seite wird aber auch stets versucht, den politischen Möglichkeitsraum wieder zu begrenzen, um so eine neue Ordnung zu etablieren und sie der Verfügung wieder zu entziehen. Die Kontingenz des Umbruchs, seine Offenheit und sein „mögliches Anderssein" ${ }^{\text {, }}$, wird somit bewältigt, indem die neue Ordnung als etwas Selbstverständliches, Notwendiges, eben So-und-nicht-anders-mögliches dargestellt wird. Kennzeichnend und grundlegend ist hierbei ein spezifischer Modus politischer Kommunikation: die Transzendierung bzw. Unverfügbarstellung. Die Begründung der neuen Ordnung erfolgt, indem diese selbst und ihre konkrete historische Entstehungssituation transzendiert werden. ${ }^{6}$ Sie werden verabsolutiert, überhöht, unverfügbar gestellt

schungsprogramm, in: ders.: Unscharfe Grenzen. Perspektiven der Kultursoziologie, Bielefeld 2008, S. 17.

4 Rüdiger Graf (Die Zukunft der Weimarer Republik. Krisen und Zukunftsaneignungen in Deutschland 1918-1933, München 2008, S. 60) hat diesen Aspekt gerade vor dem Hintergrund der Erfahrungen des Ersten Weltkrieges und der Revolution für das Umbruchsjahr 1918/19 hervorgehoben. Die Zukunft, so Graf, sei über die Grenzen der politischen Lager hinweg ,als immer offenerer Möglichkeitsraum“ erschienen. Grundsätzlich zur Konzeption des Politischen als Raum vgl. Gesa Bluhm: Diskursiver Wandel und der Raum des Politischen, in: Achim Landwehr (Hrsg.): Diskursiver Wandel, Wiesbaden 2010, S. 177-209, hier: S 186-196.

5 Niklas Luhmann: Soziale Systeme. Grundriß einer allgemeinen Theorie, 2. Aufl., Frankfurt a.M. 1989, S. 152. Dort heißt es weiter: „Kontingent ist etwas, was weder notwendig ist noch unmöglich ist; was also so, wie es ist (war, sein wird), sein kann, aber auch anders möglich ist.“ (ebd.) Grundlegend ist ferner Bernhard Waldenfels Bemerkung, wonach Kontingenz nicht nur impliziere, „daß etwas innerhalb einer Ordnung anders sein kann, sondern daß die Ordnung selbst variabel ist" (Grenzen der Normalisierung. Studien zur Phänomenologie des Fremden 2, Frankfurt a.M. 1998, S. 53).

6 Vgl. in diesem Sinne Karl-Siegbert Rehberg: Institutionen als symbolische Ordnungen. Leitfragen zur Theorie und Analyse institutioneller Mechanismen, in: Gerhard Göhler (Hrsg.): Die Eigenart der Institutionen. Zum Profil politischer Institutionentheorie, Baden-Baden 1994, S. 47-84, hier: S. 63-65. Außerdem grundlegend: Hans Vorländer: Einleitung, in: ders. (Hrsg.): Transzendenz und 
oder gar geheiligt. Beobachtbar ist dabei zumeist ein argumentativer Rekurs auf Begriffe und symbolische Formen, die als nicht-kontingentes, allgemein geteiltes Wissen behandelt werden und denen nicht selten selbst ein quasisakraler Charakter zugesprochen wird. ${ }^{7}$

Diese konzeptionellen Vorüberlegungen sollen im Folgenden am Beispiel Friedrich Naumanns und den Debatten der Umbruchszeit von 1918/19 veranschaulicht werden. Gefragt wird danach, wie diejenigen, die für die Weimarer Republik eintraten, diese und deren Prinzipien begründeten, um ihnen Geltung zu verleihen. Wie setzte sich insbesondere Naumann mit der alten Ordnung, dem Kaiserreich, auseinander? Welche Versuche unternahm er, die Republik unverfügbar erscheinen zu lassen? Auf welche Ordnungsvorstellungen und symbolische Formen wurde dabei rekurriert?

Friedrich Naumann war 1918/19 zweifelsohne einer der bekanntesten und bestvernetzten liberalen Publizisten und Politiker. ${ }^{8}$ Als solcher - und nicht als ,Klassiker" - ist er hier von Interesse. Naumann gehörte im Sinne Detlef Peukerts der „Wilhelminischen Generation“ an, das heißt zu jenen, die vor der Reichsgründung geboren, im Kaiserreich sozialisiert wurden und bereits vor 1918/19 auf eine politische Karriere zurückblicken konnten. ${ }^{9}$ Nach dem Zusammenbruch der Monarchie infolge von Weltkriegsniederlage und Revolution nahm Naumann trotz andauernden gesundheitlichen Problemen am Prozess der Neuordnung aktiv teil. Neben seiner fortwährenden publizistischen Tätigkeit (insbesondere in der von ihm gegrün-

Gemeinsinn. Themen und Perspektiven des Dresdner Sonderforschungsbereiches 804, Dresden 2011, S. 6-15, hier: S. 9-11.

7 Vgl. in diesem Sinne auch Thorsten Bonacker: Die Kontingenz des politischen Handelns. Adorno, Arendt und die Legitimationsprobleme in der politischen Gesellschaft, in: Dirk Auer/Julia Schulze Wessel/Lars Rensmann (Hrsg.): Arendt und Adorno, Frankfurt a.M. 2003, S. 286-310, hier: S. 290f. Dort heißt es: „Deshalb stützt sich kontingentes politisches Handeln auf Geltungsgründe, mit denen sich die politische Gesellschaft als solche konstituiert hat und die sie als nichtkontingent behandelt, obwohl sie natürlich - wie die Verfassung historisch kontingent sind."

8 Vgl. zu Friedrich Naumann: Theodor Heuss: Friedrich Naumann. Der Mann, das Werk, die Zeit, Stuttgart/Berlin 1937 sowie Peter Theiner: Sozialer Liberalismus und deutsche Weltpolitik. Friedrich Naumann im Wilhelminischen Deutschland (1860-1919), Baden-Baden 1983. Zuletzt auch, wenngleich mit Skepsis gegenüber der Beschreibung Naumanns als Liberalen: Frank Fehlberg: Protestantismus und Nationaler Sozialismus. Liberale Theologie und politisches Denken um Friedrich Naumann, Bonn 2012.

9 Vgl. Detlef Peukert: Die Weimarer Republik. Krisenjahre der Klassischen Moderne, Frankfurt a.M. 1987, S. 25-31. 
deten Zeitschrift ,Die Hilfe', in welcher er nach dem Weltkrieg fast 70 Artikel veröffentlichte ${ }^{10}$ ) sowie seinen Auftritten als öffentlicher Redner wirkte Naumann auch unmittelbar als gewählter Abgeordneter der Weimarer Nationalversammlung und als Mitglied des Verfassungsausschusses an der Entstehung der Reichsverfassung mit. ${ }^{11}$ In dieser Funktion hatte er hierbei nachdrücklich den Anspruch und das Ziel formuliert, „den Staat selbst in seiner Größe und Festigkeit und Selbstverständlichkeit ${ }^{\star 12}$ hervorgehen zu lassen.

Dem soll im Folgenden nachgegangen werden. Im Mittelpunkt stehen dabei die Rekonstruktion und die Einordnung der konkreten Begründungsversuche Naumanns in den Jahren 1918/19. Fokussiert werden vor allem die argumentativen Verweise auf den ,Volksstaat" sowie die ,Nation' und das ,Volk' (2 und 3), aber auch auf verschiedene entwicklungsgeschichtliche Annahmen und den Topos der ,neuen Zeit' (4). Ein weiterer Abschnitt widmet sich schließlich Naumanns „Versuch volksverständlicher Grundrechte" als spezifische symbolische Form der Ordnungsbegründung (5).

\section{2 „RePUblik Oder MONARCHIE?“13 Der VolKsstaAt ALS ,SEMANTISCHE BRÜCKE‘}

Im Mittelpunkt der Argumentation Naumanns stand die Idee des, deutschen Volksstaates'. Diese war als Modell und Programm politischer Ordnung bereits vor dem Ersten Weltkrieg in den innenpolitischen Debatten des Kaiserreichs - auf Seiten der Sozialdemokratie und des Linksliberalismus -

10 Daneben publizierte Naumann u.a. auch im Berliner Tageblatt, in der Vossischen Zeitung sowie in der Zeitschrift Der Beobachter.

11 Vgl. zum Verfassunggebungsprozess: Reinhard Rürup: Entstehung und Grundlage der Weimarer Verfassung, in: Eberhard Kolb (Hrsg.): Vom Kaiserreich zur Weimarer Republik, Köln 1972, S. 218-243; Christoph Gusy: Die Weimarer Reichsverfassung, Tübingen 1997, S. 55-79 sowie Heiko Bollmeyer: Der steinige Weg zur Demokratie. Die Weimarer Nationalversammlung zwischen Kaiserreich und Republik, Frankfurt a.M. 2007. Zum Wirken Naumanns in Weimar: Heuss, Friedrich Naumann, 1937, S. 594-631 sowie Theiner, Sozialer Liberalismus, 1983, S. 289-296.

12 Naumann, Die Demokratie in der Nationalversammlung, 1964, S. 544.

13 Überschrift des 2. Kapitels von Friedrich Naumann: Der Kaiser im Volksstaat, Berlin-Schöneberg 1917. 
eingebracht worden. ${ }^{14}$ Zusätzliche Bedeutung gewann sie vor allem in den Debatten der Kriegsjahre, in denen die deutschen Eliten über die ,ideale Ordnung der Nation“ (Graf) diskutierten. ${ }^{15}$ Mit dem ,Volksstaat" verbanden sich unterschiedliche Entwürfe einer demokratischen Verfassungsordnung, die sich allesamt gegen den ,Obrigkeitsstaat' wandten und sich für eine grundlegende Demokratisierung, Parlamentarisierung sowie Unitarisierung des Deutschen Reichs einsetzten, ohne aber zunächst die Monarchie als Staatsform infrage zu stellen. ${ }^{16}$

Friedrich Naumann hatte bis Ende 1918 am Gedanken festgehalten, dass Deutschland nur eine Monarchie sein könne. ${ }^{17}$ Die aus seiner Sicht

14 Kurz zur Begriffsgeschichte: Steffen Bruendel: Volksgemeinschaft oder Volksstaat. Die „Ideen von 1914“ und die Neuordnung Deutschlands im Ersten Weltkrieg, Berlin 2003, S. 106.

15 Vgl. hierzu: ebd.; Jeffrey Verhey: Der „Geist von 1914“ und die Erfindung der Volksgemeinschaft, Hamburg 2000 sowie auch Marcus Llanque: Demokratisches Denken im Krieg. Die deutsche Debatte im Ersten Weltkrieg, Berlin 2000. Zum engen Zusammenhang von ,Volksstaat' und ,Republik': Detlef Lehnert: Die Weimarer Republik, Stuttgart 2009, S. $12 \mathrm{f}$.

16 Vgl. zum Überblick: Bruendel, Volksgemeinschaft oder Volksstaat, 2003, S. 102-132 und S. 238-288. Die Vertreter dieses Ordnungsmodells waren jedoch in der Minderheit. Die Mehrheit vertrat korporative, sehr viel weniger partizipationsorientierte Reformmodelle, in deren Mittelpunkt die ,Volksgemeinschaft ${ }^{\text {‘ }}$ und die ,Ideen von 1914“ standen. Vgl. zum Ordnungsentwurf der ,Volksgemeinschaft‘: ebd., S. 110-132 und S. 258-289. Das Verhältnis von ,Volksstaat ' und ,Volksgemeinschaft' wird innerhalb der Forschung unterschiedlich bewertet. Llanque (Demokratisches Denken, 2000, bes. S. 81f.) und Bruendel (Volksgemeinschaft oder Volksstaat, 2003) betonen die (unvereinbare) Gegensätzlichkeit beider Ordnungsvorstellungen. Wolfram Pyta (Antiliberale Ideenwelt in Europa bei Kriegsende, in: Christoph Gusy (Hrsg.): Demokratie in der Krise: Europa in der Zwischenkriegszeit, Baden-Baden 2008, S. 86-104, hier: S. 93) hat demgegenüber dafür plädiert, beide als „Zwei unterschiedliche akzentuierte Varianten derselben Kernidee“ aufzufassen, „die sich in der politischen Ideenlandschaft nicht unversöhnlich gegenüberstanden, sondern erhebliche politische Schnittmengen aufwiesen“. Vgl. ebenso: Thomas Mergel: Führer, Volksgemeinschaft und Maschine. Politische Erwartungsstrukturen in der Weimarer Republik und dem Nationalsozialismus 1918-1936, in: Wolfgang Hardtwig (Hrsg.): Politische Kulturgeschichte der Zwischenkriegszeit 1918-1939, Göttingen 2005, S. 91-128, hier: S. 99 Fn. 32 sowie Michael Wildt: Volksgemeinschaft und Führererwartung in der Weimarer Republik, in: Ute Daniel u.a. (Hrsg.): Politische Kultur und Medienwirklichkeiten in den 1920er Jahren, München 2010, S. 181-204, hier: S. 186 (,semantische Überschneidungen und Korrespondenzen").

17 Beispielhaft für Naumanns monarchiebejahende Haltung: Friedrich Naumann: Demokratie und Kaisertum. Ein Handbuch für innere Politik, Berlin-Schöneberg 1900; ders.: Die Politik des Kaisers [1908], in: ders.: Werke, Bd. 5: Schriften 
notwendige Vereinigung von „Demokratie und Kaisertum“ stand im Mittelpunkt seines politischen Wirkens seit der Jahrhundertwende. Er verfolgte dabei das Ziel, die Monarchie als spezifisch deutsche Form des „demokratischen Volksstaates" neu zu begründen, um so ihren zukünftigen Bestand zu sichern. Dass der Volksstaat, dieser ,wirkliche Staat der ganzen Nation“, nur eine Monarchie sein könne, führte Naumann zum einen auf die „deutsche Geschichte“ zurück, „die nun einmal nicht ohne ihre kleinen und großen Könige gedacht werden kann“ ${ }^{18}{ }^{18}$ Darüber hinaus erschien ihm das Kaisertum als Verkörperung des industriegesellschaftlichen Fortschritts sowie vor allem als unverzichtbare Integrationsinstanz, die die fragmentierte deutsche Gesellschaft zusammenhielt. ${ }^{19}$ Demgegenüber erachtete Naumann die Republik als Staatsform nicht für befähigt, die „Ziele der Nation“ zu erfüllen. ${ }^{20}$ Sie sei keineswegs identisch mit dem „Volkstaat“. Dieser enthalte „einerseits mehr andererseits weniger als die Bezeichnung Republik“. Das Weniger erkannte Naumann in dessen Unschärfe als staatsrechtlichem Begriff, das Mehr aber im ,nationalen Inhalt“, der ihm fest eingeschrieben sei.

„Während nämlich die Idee Republik letztlich auf der Vorstellung von lauter unorganisierten Einzelnen beruht, die erst durch einen Vertrag (contrat social) zu Staatsmitgliedern werden, so setzt der Volksstaat das Volk als eine gewachsene und gewordene Naturgröße voraus. Das Volk ist größer, wichtiger und älter als alle seine

zur Tagespolitik, hrsg. von Theodor Schieder, bearbeitet von Alfred Milatz, Köln/Opladen 1964, S. 402-408, hier: S. 403 (,Wir denken nicht daran, die Republik für von vornherein besser zu halten als die Monarchie, denn wir kennen die Geschichte der vorhandenen Republiken gut genug, um von aller falschen Schwärmerei für die Verfassung monarchiefreier Länder uns fernzuhalten.“); ders.: Demokratie und Monarchie [1912], in: ders., Werke, Bd. 2: Schriften zur Verfassungspolitik, 1964, S. 439-444, hier: S. 443 (,Wir wollen keine Generaldebatte über Monarchismus und Republik. Das hat praktisch gar keinen Sinn!"); ders., Der Kaiser im Volksstaat, 1917.

18 Ebd., S. 5.

19 Vgl. pointiert zu dieser funktionalen Begründung des deutschen Kaisertums: Thomas Hertfelder: „Meteor aus einer anderen Welt“. Die Weimarer Republik in der Diskussion des Hilfe-Kreises, in: Andreas Wirsching/Jürgen Eder (Hrsg.): Vernunftrepublikanismus in der Weimarer Republik: Politik, Literatur, Wissenschaft, Stuttgart 2008, 29-56, hier: S. 31f. Zur Auseinandersetzung Naumanns mit der wilhelminischen Staats- und Gesellschaftsordnung: Gangolf Hübinger: „Maschine und Persönlichkeit“. Friedrich Naumann als Kritiker des Wilhelminismus, in: Rüdiger vom Bruch (Hrsg.): Friedrich Naumann in seiner Zeit, Berlin/New York 2000, S. 167-188, hier: S. 182-187.

20 Vgl. hier wie im Folgenden: Naumann, Der Kaiser im Volksstaat, 1917, S. 18-29. 
einzelnen Glieder. Der Einzelne stirbt, das Volk lebt. Wir alle sind nur Wassertropfen, das Volk aber ist quellende Flut.، ${ }^{\text {(21 }}$

Das Volk und die Nation - beide Begriffe wurden weitestgehend synonym gebraucht - seien schließlich der Grund, weswegen eine staatliche Ordnung überhaupt geschaffen wird. Entsprechend schlussfolgert er: „Was bei uns das Volk will, ist nicht Republik.“22

Mit dem Umbruch von 1918/19 und nicht zuletzt vor dem Hintergrund des Bolschewismus, den er als alternatives Ordnungsmodell überaus ernst nahm und als Bedrohung empfand, revidierte Naumann diese Einschätzung. ${ }^{23}$ Dass der Krieg die Monarchie destruiert hatte, weil diese „,innerlich nicht stark genug“" gewesen war, stand für ihn nun außer Frage. ${ }^{24}$ Selbstkritisch hielt er fest, dass das, „womit wir früher, auch ich, die Monarchie begründet haben [...] nicht eingetroffen“" sei. Gleichwohl nutzte Naumann weiterhin den Kernbegriff seiner damaligen Ordnungsbegründung: den Begriff des ,deutschen Volksstaates'. Er verwendete diesen als ,semantische Brücke' (Graf) und behauptete nun in der Folgezeit die Identität von Volkstaat, Republik und Demokratie. ${ }^{25}$ Die Begriffe wurden zu Synonymen. Naumann übertrug damit die soeben angedeutete Rechtfertigung der Monarchie auf die neue republikanische Ordnung und entwickelte darauf beruhend ein Narrativ ordnungspolitischer Kontinuität. Entsprechend blieben auch weiterhin vor allem zwei Konzepte für Friedrich Naumanns Rhetorik konstitutiv: Volk und Nation.

21 Ebd., S. 22.

22 Friedrich Naumann: Die Monarchie im Krieg, in: Die Hilfe 23 (1917) 20, S. 357. Gleichwohl erkannte er schon damals in der stetig an Bedeutung gewinnenden republikanischen „Weltmeinung“, die sich längst in einem „,republikanischen Weltsprachgebrauch" manifestiert hatte, eine ernstzunehmende Herausforderung. Vgl. Naumann, Der Kaiser im Volksstaat, 1917, S. 19.

23 Vgl. unter vielen: Friedrich Naumann: Europäische Revolution?, in: Die Hilfe 24 (1918) 6/7, S. 66f.

24 Friedrich Naumann: Demokratie als Staatsgrundlage [1919], in: ders.: Werke, Bd. 2: Schriften Zur Verfassungspolitik, Köln/Opladen 1964, S. 557-573, hier: S. 560 (auch das folgende Zitat). Vgl. auch ders.: [Rede im Verfassungsausschuss am 31.03.1919], in: Verhandlungen der verfassungsgebenden Deutschen Nationalversammlung, Bd. 336, Nr. 391: Bericht des Verfassungsausschusses, Berlin 1920, S. 176-181, hier: S. 179.

25 Vgl. bereits Hertfelder, Meteor, 2008, S. 33. Am deutlichsten wird dies bei Naumann, Demokratie als Staatsgrundlage, 1964, S. 562. Dort heißt es: „Beides wirkt zusammen [...], daß das Wort Republik, Volksstaat, zur Notwendigkeit wird.“ 


\section{VolK UND NATION ALS „NOTWENDIGKEIT VOR SICH SELBST“}

Fragt man danach, wie die neue politische Ordnung Deutschlands nach 1918/19 von denjenigen, die für diese eintraten, begründet wurde, fällt sofort der argumentative Rekurs auf die einheits-, gemeinschafts- und partizipationsverbürgenden Begriffe von ,Volk' und ,Nation` auf. Deren Bedeutung ist immer wieder herausgearbeitet worden. ${ }^{26}$ Insbesondere ihre „ubiquitäre Verbreitung“ - nicht zuletzt in der Weimarer Nationalversammlung - wurde dabei betont. ${ }^{27}$ Aufgrund ihrer Vieldeutigkeit und semantischen Unschärfe zeigten sie sich lager- und parteiübergreifend anschlussfähig. Entsprechend unterschieden sich aber ihre inhaltlichen Ausdeutungen. Vehement wurde darüber gestritten, was im Sinne der Nation oder der Wille des Volkes sei. ${ }^{28}$ Entscheidend ist, dass auch von Seiten der republikbejahenden Eliten versucht wurde, die neue Verfassungsordnung zu diesen Schlüsselbegriffen affirmativ in Beziehung zu setzen. Obwohl die Verweise im Einzelfall durchaus unterschiedlich strukturiert waren, ist allen gemein, dass ,Volk‘ und ,Nation“ stets als vorgängige, überkonstitutionelle, vorstaatliche und scheinbar überzeitlich wirksame Instanzen

26 Vgl. etwa Reinhart Koselleck: Volk, Nation, Nationalismus, Masse, in: Otto Brunner/Werner Conze/Reinhart Koselleck (Hrsg.): Geschichtliche Grundbegriffe, Bd. 7, Stuttgart 2004, S. 141-431, hier: S. 389ff.; Bruendel, Volksgemeinschaft oder Volksstaat, 2003; Pyta, Antiliberale Ideenwelt, 2008; Mergel, Führer, 2005.

27 Vgl. Bollmeyer, Der Steinige Weg, 2007, S. 255-270 und S. 320-326.

28 Vgl. etwa Sven Oliver Müller: Die umkämpfte Nation. Legitimationsprobleme im kriegsführenden Kaiserreich, in: Jörg Echternkamp (Hrsg.): Die Politik der Nation. Deutscher Nationalismus in Krieg und Krisen 1760-1960, München 2002, S. 149-171. Treffend heißt es dort: „Die politischen Kontrahenten sprachen nicht dieselbe, aber die gleiche nationale Sprache - und verstanden sich deshalb nicht.“ (ebd., S. 169) Zur konfliktverschärfenden Wirkung des Nationalismus in der Vor- und Nachkriegszeit: Moritz Föllmer/Andrea Meissner: Ideen als Weichensteller? Polyvalenzen, Aneignung und Homogenitätsstreben im deutschen Nationalismus 1890-1933, in: Lutz Raphael (Hrsg.): Ideen als gesellschaftliche Gestaltungskraft im Europa der Neuzeit. Beiträge für eine erneuerte Geistesgeschichte, München 2006, S. 313-335, hier: S. 314f. Naumann hatte diese Auseinandersetzung um das Nationale im Rahmen der Abstimmung über den Versailler-Vertrag, wie folgt, reflektiert: „Wenn wir unterschrieben hätten, dann wäre die Vertretung des deutschen Zukunftsgedankens, des nationalen Gedankens glatt in die Hände der Rechten hinübergekommen.“ (zitiert nach: Theiner, Sozialer Liberalismus, 1983, S. 302) 
erscheinen bzw. in der politischen Auseinandersetzung als solche erscheinen sollten. $^{29}$

Dies zeigt sich sehr deutlich bei Friedrich Naumann. Auch ihm galt „das deutsche Volk, die deutsche Nation [als] eine Notwendigkeit vor sich selbst und vor der Geschichte und vor dem Unsichtbaren und Höheren““30. Er erkannte darin etwas, ,was der Religion außerordentlich verwandt ist", das ,alle besitzen und pflegen [müssen]“" und aufgrund dessen es gelte, „untereinander die Ordnung aufzurichten“. Die argumentative Bedeutung der Begriffe ,Volk' und ,Nation“ beruhte dabei auf zwei handlungsleitenden Ordnungsvorstellungen der Zeit: mit ihnen verband sich zum einen die Erwartung von Einheit, Gemeinschaft und Integration sowie zum anderen das Versprechen von Selbstbestimmung und Partizipation.

\subsection{Volk und Nation als Inbegriffe für Einheit, Gemeinschaft und Integration}

Das allgemeine Verlangen nach nationaler Einheit und Gemeinschaft sowie sozialer Integration ist kennzeichnend für die unmittelbare Nachkriegszeit wie auch für die Weimarer Gesellschaft. ${ }^{31}$ Die Narrationen vom ,Augusterlebnis', vom ,Geist von 1914' und von der ,(Heimat)Frontgemeinschaft ‘ versprachen die Möglichkeit nationaler Geschlossenheit auch nach 1918. Die Erfahrung einer fragmentierten Gesellschaft in den Kriegsjahren und in der Revolution forcierte diese Sehnsucht. Hierfür stehen die über die Lagerund Parteigrenzen wirksamen Ordnungsreformprogramme der ,Volksgemeinschaft' und des ,Volksstaates', die nicht zuletzt als Utopien und Zukunftsvisionen zu verstehen sind. ${ }^{32}$ Die Einheit des deutschen Volkes als Nation wurde zum Telos erklärt. Entsprechend musste die neue Ordnung darauf ausgerichtet sein, um Geltungsglauben erzeugen zu können.

29 Vgl. hierzu etwa Koselleck, Volk, 2004, S. 389f. sowie Müller, Die umkämpfte Nation, 2002, S. 152f.

30 Naumann, Die Demokratie in der Nationalversammlung, 1964, S. 552f. (auch die folgenden Zitate).

31 Vgl. unter vielen: Paul Nolte: Die Ordnung der deutschen Gesellschaft. Selbstentwurf und Selbstbeschreibung im 20. Jahrhundert, München 2000, S. $169 f$. Insbesondere zum , demokratischen Nationalismus' weiterhin grundlegend: Jürgen C. Heß: „Das ganze Deutschland soll es sein“. Demokratischer Nationalismus in der Weimarer Republik am Beispiel der Deutschen Demokratischen Partei, Stuttgart 1978.

32 Vgl. bes. Bruendel, Volksgemeinschaft oder Volksstaat, 2003, S. 93 und S. 219. 
Auch Naumann brachte dieses Streben nach Einheit und Gemeinschaft zum Ausdruck. Dass man nach dem Krieg „,noch nicht eigentlich Nation geworden“ und dass auch das „Gift der Klassenherrschaft noch nicht genügend ausgewachsen ${ }^{\text {“33 }}$ sei, diagnostizierte er kritisch. Gerade deshalb brauche „das Vaterland die volle Durchführung der nationalen Idee“334. Im republikanischen Volksstaat erkannte Naumann hierfür den richtigen Ort. Er erschien ihm als Garant und Inbegriff dieser nationalen Einheit. Die Begründung der neuen republikanischen Ordnung erfolgte also mit der Behauptung, sie sei mit dem übergeordneten Wert des deutschen Volkes als vereinter Nation untrennbar verbunden. ${ }^{35}$

Naumann leitete diese Verbundenheit von Republik und Volk/Nation noch auf eine andere Art und Weise her. So konzeptualisierte er die Gründung der Republik auch als Bestandteil eines übergeordneten Entwicklung: dem Prozess der Nationwerdung und des (Wieder)Aufstiegs des deutschen Volkes. Die Republik, so das Argument, sei notwendig, um die nationale Einheit herzustellen bzw. die Nation zu vervollkommnen und zu festigen. Um dies zu beschreiben, griff Naumann an verschiedenen Stellen auf die religiös konnotierte Metapher der „Auferstehung“ zurück. Deutschland sei durch die Kriegsniederlage und die Revolution gestorben, in Form des „deutschen Volksstaat“ werde es wieder auferstehen. ${ }^{36}$

33 Friedrich Naumann: Europäische Revolution?, in: Die Hilfe 24 (1918) 6/7, S. 67. Vgl. auch: ders.: Deutsche Demokratie, in: Die Hilfe 25 (1919) 32, S. 418 („Lasset uns deutsch sein in den schwersten Tagen unseres Volkes!“).

34 Friedrich Naumann: Europäische Revolution?, in: Die Hilfe 24 (1918) 6/7, S. 66f., hier: S. 67. Dass es sich bei Deutschland nicht um ,verschiedene Nationalitäten“, sondern um ein „einheitliches Volk“ handle, stand für Naumann außer Frage. Vgl. etwa ders.: Die deutsche Einheit [1918], in: ders., Werke, Bd. 5: Schriften zur Tagespolitik, 1964, S. 645-647, hier: S. 647.

35 Naumann (Deutsche Demokratie, 1919, S. 418, Hervorhebung im Original) schreibt: „Der Geist, der von Riga bis Straßburg, von Schleswig bis Bozen alle Deutschen verbindet, der steht jetzt erst recht auf. Ihm dient, und für ihn wirbt die deutsche Demokratie. Um aber gute Deutsche sein zu können, sind wir gute Republikaner."

36 Vgl. Friedrich Naumann: Der Volksstaat kommt, in: Die Hilfe 24 (1918) 41, S. 480. Außerdem: ders.: Auferstehung, in: Die Hilfe 25 (1919) 18, S. 199f.; ders.: Fichtes Glaube, in: Die Hilfe 25 (1919) 28, S: 365; ders., Die Demokratie in der Nationalversammlung, 1964, S. 555. 


\subsection{Volk und Nation als Inbegriffe für Selbstbestimmung und Partizipation}

Wie bereits angedeutet, erfuhr die Verbindung von Nation und Volk im Ersten Weltkrieg eine Aufwertung. Mit ihr verbanden sich grundlegende Implikationen in Bezug auf die Legitimität der politischen Ordnung. „Die Nation war nun untrennbar mit der Vorstellung eines zu politischer Teilhabe berechtigten ,Volkes' verknüpft - ,Nation` zu sagen ohne ,Volk' und damit demokratisch begründete Partizipation mitzudenken, blieb nunmehr allein den konservativen Verächtern egalitärer politischer Teilhabe vorbehalten.“37 ,Volk' und ,Nation“ waren nicht allein Konzepte, die den Wunsch nach Einheit und Gemeinschaft ausdrückten, sondern ebenso der Inbegriff eines Partizipationsversprechens, dass nicht zuletzt aus den Erfahrungen des Weltkrieges hergeleitet wurde. Das deutsche Volk als nationale Willensgemeinschaft wurde zur zentralen Legitimationsinstanz, zum Souverän und aktiven Gestalter erklärt. ${ }^{38}$ Gerade für diejenigen, die 1918/19 für die Republik eintraten, war es auf dieser Grundlage möglich, sowohl über die alte Ordnung zu verfügen und sie zu delegitimieren als auch die Republik zu rechtfertigen und unverfügbar zu stellen.

Die Forderung autonomer Selbstbestimmung findet sich entsprechend auch bei Friedrich Naumann. „Das deutsche Volk soll sich jetzt seinen Staat zurechtzimmern"“39, heißt es in Demokratie als Staatsgrundlage. In gleicher Weise hatte er in der Weimarer Nationalversammlung postuliert, dass die Republik ,aus dem Volk heraus auf Grund des Volkswillens unvermittelt aufzurichten“" ${ }^{* 40}$ sei. Die Verfassung der Republik wurde somit auf das Volk, dessen Willen bzw. das ,gegenwärtige Volksbedürfnis“41 zurückgeführt. Sie sollte als Ausdruck dieses Volkswillens, als die „Ver-

37 Pyta, Antiliberale Ideenwelt, 2008, S. 92.

38 Vgl. ebd., S. 97. Müller (Die umkämpfte Nation, 2002, S. 158-169) hat in diesem Zusammenhang die Bedeutung der Debatten über die Abschaffung des preußischen Dreiklassenwahlrechts betont. An dieser hatte Naumann aktiv teilgenommen und sich vehement für die Abschaffung eingesetzt. Vgl. hierzu: Theiner, Sozialer Liberalismus, 1983, S. 258ff.; Bruendel, Volksgemeinschaft oder Volksstaat, 2003, S. 249-251.

39 Naumann, Demokratie als Staatsgrundlage, 1964, S. 559. Dort heißt es auch: „Stehe auf [Volk, JR], mach dir deinen Staat“ und „Du Volk, setz dich hin, schick deine Vertreter und mache mit ihnen den Staat!“ (ebd., S. 560)

40 Naumann, Die Demokratie in der Nationalversammlung, 1964, S. 543.

41 Naumann, Rede im Verfassungsausschuss, 1920, S. 179 (auch die folgenden Zitate). Vgl. auch: ders., Demokratie als Staatsgrundlage, 1964, S. 567. 
körperung des Nationalgeistes“ nicht nur legitim, sondern vielmehr alternativlos erscheinen. Der republikanische Volksstaat sei eben „nicht mehr Organisation der oberen und herrschenden Klassen und Autorität zur Leistung [sic!] und Versorgung der übrigen Masse“, sondern „Ausdruck der lebendigen Organisation des Volkes“. Als solcher wurde er zum „nationalen Volksstaat“ und zum Inbegriff des „,nationalen Gedankens“ erklärt. Er erschien mithin als jene Ordnung, in der sich, wie von Naumann gefordert, ,der deutsche Geist und der deutsche Wille tatsächlich verwirklichen“442 können.

Damit verbindet sich ein grundlegender Topos, der sich auch bereits im Ordnungsdiskurs der Kriegszeit findet: die Idee der ,deutschen Demokratie bzw. des ,deutschen Volkstaates'. Die nationale Attribution brachte nicht nur den Wunsch der Einheit zum Ausdruck, sondern verwies auch auf die immer wieder hervorgehobenen Eigen- und Besonderheiten der Deutschen, auf die Behauptung eines besonderen ,Wesens' bzw. ,Charakters'. Dieses Argument wurde zumeist gebraucht, um sich gegenüber den westlichen Demokratien Frankreichs, Großbritanniens und der Vereinigten Staaten abzugrenzen und das nationale Selbstbestimmungsrecht der Deutschen zu unterstreichen. Naumann hat in diesem Sinne wiederholt von der „deutschen Demokratie“ gesprochen. ${ }^{43}$ Er war zuversichtlich, ,daß unser deutsches Volk sich seine eigene lebendige Art von deutschen Volksstaat zurechtmacht“. Es sei allein diese „volkstümliche Staatsform der Republik“, die die deutschen Eigen- und Besonderheiten des ,in politischer Mystik viel gebundenen, alten, früher zerspaltenen, dann mühsam norddeutsch geeinigten deutschen Volks“444 zum Ausdruck bringen könne.

Zusammenfassend ist festzuhalten, dass im begründungsrhetorischen Schlüsselbegriff des ,deutschen Volksstaates' beide hier besprochenen Dimensionen enthalten und gebündelt waren: Einheit und souveräne Selbstbestimmung. „Als Staat des Volkes symbolisierte der Begriff ,Volksstaat" die nationale Einheit und als Staat des Volkes die Volksfreiheit im Sinne einer Selbstregierung des Volkes. ${ }^{“ 45}$ Die Idee des ,Volksstaates“ implizierte sowohl ein Integrations- als auch ein umfassendes Partizipationsversprechen. Vor diesem Hintergrund hat Thomas Mergel zutreffend von einer

42 Naumann, Die Demokratie in der Nationalversammlung, 1964, S. 544.

43 Naumann, Deutsche Demokratie, 1919, S. 418 (auch die folgenden Zitate).

44 Naumann, Demokratie als Staatsgrundlage, 1964, S. 563.

45 Bruendel, Volksgemeinschaft oder Volksstaat, 2003, S. 106 (Hervorhebung im Original). 
„Politik der Verheißung“46 gesprochen. Nicht zuletzt hierin liegt die Bedeutung des Volksstaatsbegriffs und der mit ihm verbundenen Begriffe ,Volk“ und ,Nation“ für die Ordnungsbegründung in der Umbruchszeit von 1918/19.

\section{Der VolksstaAt als „Neue Zeit“, ENTWICKLUNGSGESCHICHTLICHE NOTWENDIGKEIT UND ZUKUNFTSPROGRAMM}

Friedrich Naumann behauptete die Selbstverständlichkeit und Notwendigkeit des republikanischen Volksstaates nicht nur mit dem Verweis auf die Entitäten von Volk und Nation. Vielmehr unternahm er ebenso den Versuch, den neuen Staat als das Ergebnis einer unaufhaltsamen ,geschichtlichen Bewegung “47, als Ausdruck einer „,neuen Periode“ und einer „neuen Zeit $^{\text {“48 }}$ erscheinen zu lassen. Er diagnostizierte in diesem Sinne ein „Bedürfnis der Zeit", das etwas Neues fordere und das in der neuen Verfassung zum Ausdruck gebracht werden müsse. ${ }^{49}$ Auch diese Topoi ermöglichten es wiederum, einerseits das Kaiserreich als nicht mehr zeitgemäße Ordnung zu delegitimieren und andererseits die Republik als Symbol und Produkt einer entwicklungsgeschichtlichen Notwendigkeit unverfügbar zu stellen.

Den Anbruch dieser ,neuen Zeit' beschrieb Naumann aber keineswegs emphatisch. Er sprach vielmehr von einem „grauen Morgen“. Die Republik sei zunächst im „Hauskleide“ erschienen. ${ }^{50}$ Ebenso wenig deutete er diese ,neue Zeit‘ als revolutionären Bruch. Zum Ausdruck kommt hier vielmehr erneut ein dezidiertes Kontinuitätsdenken, indem die Zeitenwende als längerfristiger Transformationsprozess konzeptualisiert wurde. ${ }^{51}$ „Auch in

46 Mergel, Führer, 2005, S. 97.

47 Naumann, Deutsche Grundrechte, 1919, S. 141 (auch das folgende Zitat).

48 Naumann, Demokratie als Staatsgrundlage, 1964, S. 560 und S. 566. Vgl. ebenso: ders.: Sozialisierung, in: Die Hilfe 25 (1919) 11, S. 125.

49 Naumann, Rede im Verfassungsausschuss, 1920, S. 181. Die Rede von einer „,neuen Zeit“, einem „,neuen Zeitalter“ oder vom „,neuen Deutschland“ hatte bereits während des Ersten Weltkrieges Konjunktur; vgl. die Beispiele bei Bruendel, Volksgemeinschaft oder Volksstaat, 2003, S. 102f., 238 und 248 sowie bei Graf, Zukunft, 2008, S. 142f.

50 Vgl. Friedrich Naumann: Wie wir gesund werden?, in: Die Hilfe 25 (1919) 18, S. 213.

51 Vgl. hierzu: Graf, Zukunft, 2008, S. 135-250, bes. S. $211 \mathrm{ff}$. und S. 225-232. Graf arbeitet sehr überzeugend heraus, dass ,das Bewusstsein, an einer epochalen Wende zu stehen, in der Weimarer Republik keinesfalls auf die 
großen Revolutionen“, so Naumann im Februar 1919, „geht alles schrittweise, weil die Natur selber keine Sprünge macht. ${ }^{\text {“52 }}$ Für dieses Entwicklungsdenken sind drei Argumente von grundlegender Bedeutung: erstens eine Theorie historischer Zeiten, zweitens die Vorstellung vom Wirken eines Entwicklungsgesetzes hin zur Demokratie (verbunden mit der Kategorie des Schicksals und einer Naturmetaphorik) sowie schließlich drittens - insbesondere nach der Verabschiedung der Weimarer Reichsverfassung die Konzeption des Volksstaates als sich weiterentwickelndes Zukunftsprogramm.

Die Annahme ,verschiedener geschichtlicher Zeiten“"53 hatte für Naumann axiomatische Bedeutung. Es sei „der Charakter früherer Zeiten [gewesen], mehr monarchisch zu sein“ und genauso sei es „der Charakter neuerer, technischer Zeiten, mehr republikanisch-demokratisch zu sein“ “. ${ }^{54}$ Flankiert wurde diese Annahme von einer Theorie der ,unvermeidlichen Demokratisierung ${ }^{655}$. Naumann hielt „die Entwicklung zur großen Demokratisierung [für] notwendig“. Er gebrauchte in diesem Zusammenhang auch den Begriff des Schicksals. ${ }^{56}$ Nur wenige Wochen nach dem Ende des Krieges wurde der demokratische Volksstaat damit zu etwas, „was nach menschlicher Wahrscheinlichkeit irgendeinmal sowieso gekommen wä-

extremistische Rechte und Linke oder gar die Nationalsozialisten beschränkt war. Die rhetorische Formel der Zeitenwende, des fundamentalen Bruchs oder Umbruchs, war vielmehr auch in republikanischen Kreisen anschlussfähig und erwies sich nach dem Ersten Weltkrieg als omnipräsentes Schlagwort“ (ebd., S. 202). Vgl. auch: Dieter Langewiesche: Liberalismus in Deutschland, Frankfurt a.M. 1988, S. 252.

52 Naumann, Sozialisierung, 1919, S. 125.

53 Naumann, Demokratie als Staatsgrundlage, 1964, S. 562.

54 Ebd. Dieses Argument war auch bereits in der Weltkriegsdebatte virulent: Vgl. Bruendel, Volksgemeinschaft oder Volksstaat, 2003, S. 242. Vor allem Hugo Preuß erkannte in der Demokratie den ,,allgemeinen Typus moderner politischer Entwicklung unseres Zivilisationskreises" (zitiert nach: ebd.). Ebenso: Naumann, Sozialisierung, 1919, S. 125 („,man [kann] unter entwicklungsgeschichtlichem Gesichtspunkt überzeugt sein, daß wir eben an einem Meilenstein der Kultur- und Zivilisationsbahn vorübergegangen sind").

55 Naumann, Demokratie als Staatsgrundlage, 1964, S. 560, 565 sowie S. 561 (auch das folgende Zitat). Vgl. bereits früher: Friedrich Naumann: Der Gesellschaftsvertrag [1912], in: ders.: Werke, Bd. 5: Schriften zur Tagespolitik, 1964, S. 481-486, hier: S. 482 und S. 484.

56 Friedrich Naumann: Der Weg zum Volksstaat [1918], in: ders., Werke, Bd. 2: Schriften zur Verfassungspolitik, 1964, S. 521-536, hier: S. 522; ders., Die Demokratie in der Nationalversammlung, 1964, S. 543. 
$\mathrm{re}^{6557}$. Naumann erklärte ihn vor diesem Hintergrund zur ,zeitgemäßen Form“. Volksstaat und Republik erschienen somit als das „Notwendige, Unvermeidliche“658, das sich so oder so durchgesetzt hätte. Die 1918/19 zu beobachtenden Entwicklungen wurden somit als Kulmination eines langen, gleichwohl zielgerichteten evolutionären Prozesses beschrieben - nicht aber als Revolution. Zum Ausdruck kam dies auch in einer Naturmetaphorik, auf die Naumann an verschiedenen Stellen zurückgriff. ${ }^{59}$ So beschrieb er den „demokratischen Freistaat Deutschland“ als „Notwendigkeit“, die „hervorgewachsen“ sei. Der demokratische Entwicklungsprozess, im Ganzen gesehen, wird zum „Naturvorgang“, der ihn an früherer Stelle gar an den „Wechsel geologischer Perioden“ erinnerte, wie er „,einst in dunkler Vorzeit" vor sich gegangen sei. ${ }^{60}$ In diesem Zusammenhang sprach sich Naumann geradezu selbst prophetische Gaben zu. Er betonte, dass der Umbruch von 1918/19 seine Prognose, die er in seiner Schrift Demokratie und Kaisertum bereits aufgestellt hatte, bestätigt habe. Das damals bereits Beschriebene sei schlichtweg ,eine geschichtlich richtige Konstruktion dessen [gewesen], was irgendwie und irgendwann aus der Natur der Dinge sich ergeben mußte“. Dass diese Entwicklung keineswegs abgeschlossen sei, unterstrich Naumann ebenso deutlich. Er war davon überzeugt, dass die „deutsche Demokratie“ ein „Programm“ sei. ${ }^{61}$ Es handle sich um „etwas täglich erst Werdendes, ein aus der Gegenwart in die Zukunft hineinwachsendes großes Werk des Neubaus“.

Welche Vorstellungen verband Naumann mit der von ihm diagnostizierten und weiter im Werden befindlichen ,neuen Zeit'? In erster Linie begriff er diese als ein „soziales Zeitalter ${ }^{\text {‘62 }}$. Diese Diagnose des Neuen

57 Naumann, Der Weg zum Volksstaat, 1964, S. 522 (auch das folgende Zitat).

58 Naumann, Demokratie als Staatsgrundlage, 1964, S. 562.

59 Vgl. zum Folgenden: Naumann, Rede im Verfassungsausschuss, 1920, S. 179; ders., Der neue Parlamentarismus, in: Die Hilfe 25 (1919) 9, S. 100.

60 Naumann, Der Volksstaat kommt!, in: Die Hilfe 24 (1918) 41, S. 480-481, hier: S. 480 (auch das folgende Zitat). Hertfelders (,Nur die Demokratie kann Deutschland wieder aufrichten“. Staat und Demokratie im Hilfe-Kreis, 19181933, in: Philippe Alexandre/Reiner Marcowitz (Hrsg.): Die Zeitschrift „Die Hilfe": 1894-1944. Ein Ideenlabor in Deutschland, Bern u.a. 2011, S. 277-316, hier: S. 283) Deutung dieser Textpassage als bloßer Ausdruck eines allgemein verbreiteten „Fatalismus“ greift dagegen zu kurz und übersieht die ordnungskonstitutive Bedeutung des Arguments.

61 Naumann, Deutsche Demokratie, 1919, S. 418 (auch das folgende Zitat).

62 Naumann, Rede im Verfassungsausschuss, 1920, S. 177 und S. 180. Er sprach auch vom ,jetztbeginnenden sozialistischen Zeitalter in Deutschland“ bzw. vom 
korrespondierte mit jener des Niedergangs. Dem behaupteten Anbruch eines „sozialen Zeitalters“ setzte Naumann das Ende des „Zeitalter des Individualismus "63 entgegen. Sollte jenes in der neuen republikanischen Verfassung seinen Ausdruck finden, ordnete Naumann dieses dem Symboldatum „1848“ und der gescheiterten Paulskirchen-Verfassung zu. Damit verband sich ein lager- und parteiübergreifender Konsens, wonach nicht mehr der Einzelne als Individuum im Mittelpunkt der Betrachtungen stehen sollte, sondern die Gemeinschaft und das Kollektiv. ${ }^{64}$ Das Entscheidende, so Naumann in Rekurs auf frühere Überlegungen, seien „Gemeinschaftsgedankengänge ${ }^{\text {‘65 }}$. An die Idee vom Durchbruch eines neuen ,sozialen Zeitalters' knüpfte er entsprechend auch die Vorstellung eines ,neuen Menschen“. Er erklärte den „Verbandsmensch“ zum „Normalmensch der Gegenwart“. Es sei der „sozialisierte, gruppierte Mensch“, der „sich verfassungsmäßig einen Ausdruck [sucht] "66. Insbesondere „der neue Massenmensch, der Arbeiter", suche ,sein Recht innerhalb der Staatsgemeinschaft ${ }^{{ }^{667}}$. Bereits seit der Jahrhundertwende hatte Naumann immer wieder darauf hingewiesen, dass Verbände und andere Zwischenorganisationen nicht nur zu den entscheidenden wirtschaftlichen Kräften geworden seien, sondern auch zu jenen politischen Instanzen, die das politische Handeln der großen Mehrzahl der Bürger bestimmten und prägten. ${ }^{68}$ Aufgrund dessen

„Sozialismus“ als „Hauptidee des Zeitalters“ (ders.: Das Schicksal des Sozialismus, in: Die Hilfe, 02.01.1919, S. 4f.) und vom „Zeitalter der kommenden Arbeiterschicht“" (ders., Rede im Verfassungsausschuss, 1920, S. 180).

63 Naumann, Rede im Verfassungsausschuss, 1920, S. 177. Vgl. auch: ders.: Gattungsleben, in: Die Hilfe 25 (1919) 1, S. 15.

64 Vgl. hierzu: Marcus Llanque: Der Untergang des liberalen Individuums. Zum Fin de siècle des liberalen Denkens in Weimar, in: Karsten Fischer (Hrsg.): Neustart des Weltlaufs? Fiktion und Faszination der Zeitenwende, Frankfurt a.M. 1999, S. 164-183, hier: S. 168-171; ders.: Friedrich Naumann und das Dilemma des politischen Liberalismus, in: Richard Faber (Hrsg.): Liberalismus in Geschichte und Gegenwart, Würzburg 2000, S. 131-149. Ebenso: Nolte, Ordnung, 2000, S. 167. Auch Llanque (Untergang, 2000, S. 133) übersieht die grundlegende Bedeutung dieses Arguments für die Begründung der neuen politischen Ordnung, wenn er hierin allein die „Entfremdung des politischen Liberalismus von seinen normativen Wurzeln" zu erkennen meint.

65 Friedrich Naumann: Wie soll es werden?, in: Die Hilfe 24 (1918) 49, S. 583584, hier: S. 583. Ebenso: ders., Gattungsleben, 1919, S. 14 f.

66 Naumann, Rede im Verfassungsausschuss, 1920, S. 180.

67 Naumann, Deutsche Grundrechte, 1919, S. 142.

68 Vgl. Friedrich Naumann: Neudeutsche Wirtschaftspolitik [3. Aufl., 1917], in: ders.: Werke, Bd. 3: Schriften zur Wirtschafts- und Gesellschaftspolitik, 1964, S. 71-534, hier: S. 529-531; ders.: Kann man Liberale organisieren?, in: Die 
sprach er 1919 nicht nur vom „Verbandsmenschen“, sondern konzeptualisierte auch das Volk als Gesamtheit von „Gruppenindividuen“ und nicht von einzelnen Staatsbürgern. ${ }^{69}$

Hierin spiegeln sich zweifellos die Erfahrungen und die gemeinschaftssowie einheitszentrierten Debatten des Ersten Weltkrieges wider, wie sie oben bereits angedeutet worden sind. Grundlegend ist in diesem Zusammenhang aber vor allem die Vorstellung eines spezifischen nationalen Sozialismus, der während und nach dem Ersten Weltkrieg - nicht zuletzt in Konzepten der Gemeinwirtschaft ${ }^{70}$ - Wirkungskraft entfaltet hatte.

Daneben darf aber nicht übersehen werden, dass Naumanns Idee vom national-sozialen, auf Gruppenindividuen beruhenden Volkstaat ebenso durch die Konzepte der Sozialreformbewegung seit der Jahrhundertwende geprägt war. ${ }^{71}$ Spätestens mit der Gründung des National-Sozialen Vereins 1896 und der Zeitschrift Die Hilfe hatte er als wichtiger Akteur und Multiplikator dieser Bewegung jene Entwicklung angedeutet und zu forcieren versucht. Dies entsprach seiner Grundsatzkritik an der Wilhelminischen Gesellschaftsordnung und seinem aktiven Eintreten für eine reformistische Sozialpolitik, die sich zunächst für den wohlfahrtsstaatlichen Interventionismus Bismarcks aussprach, über den grundlegenden strukturellen Wandel von Wirtschaft und Gesellschaft aufzuklären versuchte und vor allem für die „Industrieverfassung“, das Prinzip der Tarifpartnerschaft und damit für die Sicherung und Ausweitung der Koalitionsrechte sowie der Mitwirkungsrechte der Arbeitnehmerseite vehement eintrat. Naumann verband damit stets das politische Ziel, Liberalismus und Sozialdemokratie $\mathrm{zu}$ verbinden sowie Bürgertum und Arbeiterschaft $\mathrm{zu}$ versöhnen. Es ging ihm letztlich angesichts der Herausforderungen des gesellschaftlichen Wandels darum, soziale Integration zu fördern und Gemeinschaft zu stiften.

Hilfe 19 (1913) 8, S. 114f.; ders.: Das Blaue Buch von Vaterland und Freiheit. Auszüge aus seinen Werken, Königstein i.T./Leipzig 1913, S. 206 („Der moderne Mensch ist der Verbandsmensch."); ders.: Die politischen Parteien, Berlin 1910, S. 43f.

69 Naumann, Rede im Verfassungsausschuss, 1920, S. 180.

70 Vgl. hierzu etwa Mergel, Führer, 2005, S. 98.

71 Vgl. Hübinger, „Maschine und Persönlichkeit“, 2000; Inho Na: Sozialreform oder Revolution. Gesellschaftspolitische Zukunftsvorstellungen im NaumannKreis 1890-1903/04, Marburg 2003; Rüdiger vom Bruch: Bürgerliche Sozialreform im deutschen Kaiserreich, in: ders. (Hrsg.): Weder Kommunismus noch Kapitalismus. Bürgerliche Sozialreform in Deutschland vom Vormärz bis in die Ära Adenauer, München 1985, S. 61-179. 
Davon unberührt blieb aber Naumanns Glauben an den Kapitalismus und dessen Zukunftsfähigkeit, der kurz nach der Jahrhundertwende unter dem Einfluss Werner Sombarts und Max Webers zu einem tragenden Pfeiler seines Ordnungsdenkens geworden war. ${ }^{72}$ Gerade hierin gründete seine Sensibilität für jene „,modernen Probleme“"73, von denen er behauptete, sie könnten am ehesten im demokratischen Volksstaat entschärft und gelöst werden. Dieser erschien ihm somit nicht zuletzt als die Antwort auf die Suche nach einer adäquaten politischen Ordnung unter den Bedingungen des Kapitalismus, den Naumann bereits 1911 als die alles prägende ,überstaatliche Lebensgemeinschaft" beschrieben hatte. ${ }^{74}$

\section{NAUMANNS „VERSUCH VOLKSVERStÄNDLICHER GRUNDRECHTE“}

Wie bisher gezeigt wurde, beruhte Friedrich Naumanns Begründung der neuen politischen Ordnung zu allererst auf dem Begriff des Volksstaates. Inhärent war diesem der Verweis auf das Volk und die Nation als Bürgen für Einheit und Integration sowie Demokratie und Partizipation. Hinzu trat mit der Rede vom neuen, unvermeidlichen und sich weiterentwickelnden sozialen Zeitalter die Vorstellung vom sozialen Volksstaat.

Im Zuge der Weimarer Verfassunggebung unternahm Naumann den Versuch, diese ordnungsbegründenden „Grundideen“, wie er diese selbst

72 Vgl. hierzu: Traugott Jähnichen: Neudeutsche Kultur- und Wirtschaftspolitik. Friedrich Naumann und der Versuch einer Neukonzeptualisierung des Liberalismus im Wilhelminischen Deutschland, in: Rüdiger vom Bruch (Hrsg.): Friedrich Naumann in seiner Zeit, Berlin/New York 2000, S. 151-166, hier: S. 151156; Gangolf Hübinger: Kapitalismus und Kulturgeschichte, in: Rüdiger vom Bruch/Friedrich Wilhelm Graf/Gangolf Hübinger (Hrsg.): Kultur und Kulturwissenschaften um 1900. Krise der Moderne und Glaube an die Wissenschaft, Stuttgart 1989, S. 25-83 sowie ders., „Maschine und Persönlichkeit“, 2000, S. 181. Naumann selbst verband mit seiner Rede vom „Verbandsmenschen“ auch eine Entwicklungsstufentheorie des Kapitalismus. Während er den „Einzelmensch" für einen Ausdruck einer ersten Stufe des Kapitalismus hielt, erklärte er den „Verbandsmensch“ zum Abbild einer neuen Entwicklungsstufe. Diese Unterscheidung war dezidiert national konnotiert. Während die alte Form des Kapitalismus als „westlich“ beschrieben wurde, wurde die neue Entwicklungsstufe als spezifisch „deutsch“ gekennzeichnet. Vgl. Friedrich Naumann: Mitteleuropa, Berlin 1915, S. $104 f$.

73 Naumann, Rede im Verfassungsausschuss, 1920, S. 178.

74 Friedrich Naumann: Kulturgeschichte und Kapitalismus, in: Die neue Rundschau 22 (1911), S. 1337-1348, hier: S. 1342. 
nannte, in eine herausgehobene symbolische Form zu bringen, um auf diese Weise die Geltung der neuen politischen Ordnung zu begründen. Er wählte hierfür den Grundrechtsteil der Verfassung. ${ }^{75}$ Der dreizehn Artikel umfassende Grundrechtsentwurf, den Naumann im März 1919 in den Verfassungsausschuss der Nationalversammlung einbrachte und rechtfertigte, ${ }^{76}$ bildete somit den Versuch, die symbolische Lücke des „Übersinnlichen, Mythischen“ zu schließen, die er nach dem Zusammenbruch der Monarchie zu erkennen geglaubt hatte. ${ }^{77}$ Es spricht einiges dafür, dass Naumann in ihm genau jene entscheidenden Elemente aufgehoben sah, die er bis dato vermisst hatte: das „Historisch-Dramatische“, „die Mystik der Staatsgeburt“" sowie den ,überwältigende[n] Trieb einer Offenbarungszeit““. ${ }^{78}$ Mit

75 Zur herausgehobenen symbolisch-integrativen Bedeutung der Grundrechte: Hans Vorländer: Integration durch Verfassung? Die symbolische Bedeutung der Verfassung im politischen Integrationsprozess, in: ders. (Hrsg.): Integration durch Verfassung, Wiesbaden 2002, S. 9-40, hier: S. 16. Zeitgenössisch bereits: Carl Schmitt: Verfassungslehre, Berlin 1928, S. 157-182 sowie Rudolf Smend: Verfassung und Verfassungsrecht, München 1928, S. 260-268. Insbesondere Smend (ebd., S. 166f.) hob Naumanns ,politischen Scharfsinn“ hervor, weil dieser jenen „Grundgedanken“ - die Bedeutung des Symbolisch-Integrativen erkannt hatte. In diesem Sinne attestierte er ihm „doch im Vergleich zu der wesentlich technischen Verfassungstheorie von M. Weber und H. Preuß eine ungleich tiefere Einsicht“". Gleichzeitig lehnte er die konkrete Form von Naumanns Grundrechtsentwurf aber ab (,unglücklich, halb liturgisches Alterswerk“).

76 Vgl. Naumann, Rede im Verfassungsausschuss, 1920. Zur Grundrechtsdebatte in der Nationalversammlung: Thomas Wirth: Der Unterausschuß für die Grundrechte und seine Arbeit in der Weimarer Nationalversammlung, in: Jahrbuch der Hambach-Gesellschaft 2 (1989), S. 129-201; Ludwig Richter: Kirche und Schule in den Beratungen der Weimarer Nationalversammlung, Düsseldorf 1996, S. 412-429; Friedhelm Köster: Entstehungsgeschichte der Grundrechtsbestimmungen des zweiten Hauptteils der Weimarer Reichsverfassung in den Vorarbeiten der Reichsregierung und den Beratungen der Nationalversammlung, Göttingen 2003 sowie Walter Pauly: Grundrechtslaboratorium Weimar. Zur Entstehung des zweiten Hauptteils der Reichsverfassung vom 14. August 1919, Tübingen 2004. $\mathrm{Zu}$ Naumanns Grundrechtsentwurf vor allem: Ernst Rudolf Huber: Friedrich Naumanns Weimarer Grundrechts-Entwurf. Der Versuch eines Modells der Grundwerte gegenwärtigen Daseins, in: Okko Behrends (Hrsg.): Festschrift für Franz Wieacker zum 70. Geburtstag, Göttingen 1978, S. 384-398 sowie Dieter Beese: Staatsbekenntnis und Volkskatechismus. Friedrich Naumann und die Weimarer Verfassungsberatung, in: Günter Brakelmann (Hrsg.): Auf dem Weg zum Grundgesetz: Beiträge zum Verfassungsverständnis des neuzeitlichen Protestantismus, Münster 1999, S. 55-76.

77 Vgl. Naumann, Rede im Verfassungsausschuss, 1920, S. 179.

78 Naumann, Der neue Parlamentarismus, 1919, S. 100. 
ihm sollte es gelingen, die scheinbar ,unvermeidliche Nüchternheit" ${ }^{\text {*79 }}$ des Weimarer Verfassunggebungsprozess zu überwinden.

Gerade deshalb konzipierte er den Grundrechtsteil der Verfassung dezidiert als ein „Staatsgrundbekenntnis“ ${ }^{\text {“80 }}$. Als solches sollte es im etatistischen Sinne dem Volk darüber Aufschluss geben, ,was der Staat nun [...] zu den Problemen von heute [sagt]“. Es sollte sich um ein staatsoffizielles, werbendes Verfassungsprogramm der, jetzt beginnenden deutschen Republik“ handeln. Damit verband sich das Ziel, das allgemein verbreitete Bedürfnis nach Orientierung und Sinnstiftung zu befriedigen. Naumann beabsichtigte, einen ,,verfassungsmäßigen Ausdruck für den Charakter der neuen Periode“" in der Form des Grundrechtekatalogs zu finden und zu fixieren. In ihm sollten sich die „Grundideen“ und die „leitenden Grundgedanken“ in ihrer ordnungsbegründenden Qualität niederschlagen. So findet sich der nationale Volksstaat, die Idee vom Vorrang nationaler Einheit und Gemeinschaft, etwa in Artikel 28 wieder, wenn es heißt: „Alle Deutschen sind vor dem Gesetz gleich. [...] Jeder Deutsche ist ein Wertgegenstand der Nation, solange er seines Volkes würdig bleibt. “81 Das grundlegende demokratische Element seiner Volksstaatskonzeption schrieb Naumann in Artikel 29 im Satz „Die Staatsgewalt liegt beim Volke. Mehrheit entscheidet" nieder. Darüber hinaus fand insbesondere die Idee des sozialen Volksstaates an zahlreichen Stellen seinen Ausdruck. ${ }^{82}$

Darauf aufbauend wies Naumann dem Grundrechtekatalog eine zweite Funktion zu. Er verstand ihn als ein ,sich von selbst darbietenden Volkskatechismus“, der diejenige „Gesinnung“ herbeiführen sollte, ,,auf der der

79 Ebd.

80 Naumann, Rede im Verfassungsausschuss, 1920, S. 179. Alle folgenden Zitate: ebd., S. 176-181.

81 Vgl. hier wie im Folgenden: Naumann, Rede im Verfassungsausschuss, 1920, S. 171-173.

82 Vgl. Art. 33ff. Beispiele sind: ,Jede ehrliche Arbeit ist gleichen Rechtes und gleicher Würde.“, „Die Arbeitskraft gilt als das oberste menschliche Gut“, „Wer nicht arbeiten will, soll auch nicht essen!“”, „Zum demokratischen Industriestaat gehört Industrieparlamentarismus“ (Art. 35). Die Forschung hat vor allem die Bedeutung dieser sozialen Grundrechte in den Mittelpunkt gerückt. Entsprechend häufig findet sich auch eine auf diesen Aspekt zentrierte Interpretation des Grundrechtsentwurfs als Sozialverfassung und damit insbesondere als Antwort auf die nach der Revolution virulente Frage der Sozialisierung. Vgl. etwa: Lothar Albertin: Liberalismus und Demokratie am Anfang der Weimarer Republik. Eine vergleichende Analyse der Deutschen Demokratischen Partei und der Deutschen Volkspartei, Düsseldorf 1972, S. 297-301. 
Staat beruht". Er sollte die Erziehung des Volkes zu Staatsbürgern der Republik anleiten und letztlich zur Verinnerlichung der Republik und der ihr zugrunde liegenden Kernprinzipien führen. Grundlegend war hierfür eine adäquate Sprache, mit der gesichert sein sollte, dass die Grundrechte volksverständlich waren, um schließlich als Grundlage eines kollektiven Bekenntnisses zur republikanischen Verfassungsordnung dienen zu können. ${ }^{83}$

Zum Ausdruck kam hier nicht nur die bildungspolitische „Gestaltungseuphorie der Zeit" und der damit verbundene Glauben, den Einzelnen und die Gemeinschaft zur ,neuen Zeit' erziehen zu können. ${ }^{84}$ Bemerkenswert sind ebenso die Kontinuitäten in Naumanns politischem Denken und Handeln. Insbesondere auf die Gattungsform des Katechismus hatte Naumann bereits früher zurückgegriffen: sei es mit dem Arbeiterkatechismus von 1889 oder dem neun Jahre später veröffentlichten Nationalsozialen Katechismus. Die darin erkennbare kulturprotestantisch geprägte, liberale „Bildungsemphase und Bildungsreligiösität ${ }^{\star 85}$ kennzeichnete grundsätzlich Naumanns politisches Wirken. Wiederholt hatte er sich dem Problem der politischen Bildung zugewandt. ${ }^{86}$ Dabei war er stets davon ausgegangen, dass Gründung und Geltung ,Staatsbürgerbewusstsein“ und ,Gesinnung“ voraussetzen. Die beste Verfassung, so Naumann bereits 1909, sei ohne eine adäquate „Gesinnungserziehung“, ohne „Gesinnungslehre“ bzw. ohne „Gesinnungszucht“ wertlos. Erforderlich sei eine „Pädagogik großen Stils“ mit dem Ziel, eine ,allgemeine Atmosphäre fortschrittlicher Gesinnungs-

83 Zeitgenössisch hat vor allem der SPD-Abgeordnete Hugo Sinzheimer ([Rede im Verfassungsausschuss am 31.03.1919], in: Verhandlungen der verfassungsgebenden Deutschen Nationalversammlung, Bd. 336, Nr. 391: Bericht des Verfassungsausschusses, Berlin 1920, S. 183) hierin den Wert des Grundrechtsentwurfs gesehen. „Für uns“, so Sinzheimer, „kommt es darauf an, nicht nur eine papierene Republik zu errichten; wir wollen dem Volke eine lebendige republikanische Gesinnung geben. Das ist aber nur möglich, wenn es sie [die Verfassung, JR] lesen kann." Vgl. auch Beese, Staatsbekenntnis, 1999, S. 57 sowie Huber, Grundrechts-Entwurf, 1978, S. 387. Letztlich scheiterte Naumanns Grundrechtsantrag aber nicht zuletzt an dessen Form und Sprache, die sich explizit gegen juristische Sprachkonventionen wandte.

84 Vgl. Graf, Zukunft, 2008, S. 194 (mit weiteren Hinweisen).

85 Vgl. Hübinger, „Maschine und Persönlichkeit“, 2000, S. 177; grundlegend: ders.: Kulturprotestantismus und Politik. Zum Verhältnis von Liberalismus und Protestantismus im wilhelminischen Deutschland, Tübingen 1994.

86 Vgl. zu Friedrich Naumann und der politischen Bildung: Norbert Friedrich: Friedrich Naumann und die politische Bildung, in: Rüdiger vom Bruch (Hrsg.): Friedrich Naumann in seiner Zeit, Berlin/New York 2000, S. 345-360. 
ansichten“ entstehen zu lassen, ,von der der einzelne mit bewegt wird“ ${ }^{87}$ In diesem Sinne initiierte und unterstützte er verschiedene politische Bildungsprojekte. Hierzu zählte die Gründung des Nationalvereins für das liberale Deutschland von $1907^{88}$ sowie die Planung für ein Deutsches Staatslexikon, das Naumann nicht zuletzt auch als Erziehungsmittel und als Beitrag zur Erwachsenenbildung verstanden wissen wollte. ${ }^{89}$ Es folgte die Gründung der Staatsbürgerschule im Jahr 1918, aus der schließlich nach dem Tod Naumanns die Deutsche Hochschule für Politik hervorging. ${ }^{90}$ Diesen Projekten und insbesondere auch seinem „Versuch volksverständlicher Grundrechte" lag letztlich die Idee zugrunde, die Bürger durch Bildung im und zum Volksstaat zu erziehen. Er zielte auf die Herstellung eines demokratischen Gemeinsinns. ${ }^{91}$

\section{SChLUSSBEtRACHTUNGEN}

Die leitende Fragestellung dieses Beitrages war, welche Versuche Friedrich Naumann unternahm, Geltung und Stabilität der Weimarer Republik zu begründen. Gefragt wurde insbesondere danach, wie er sich mit der alten Ordnung des Kaiserreichs auseinandersetzte und wie er versuchte, die Republik unverfügbar erscheinen zu lassen. Von besonderem Interesse war zudem, auf welche Ordnungsvorstellungen und symbolischen Formen Naumann diesbezüglich rekurrierte. Ausgegangen wurde dabei von der Annahme einer grundsätzlichen Begründungsbedürftigkeit politischer Ordnungen, vom Problem der Kontingenzbewältigung sowie vom damit einhergehenden paradoxalen Spannungsverhältnis von Verfügbarkeit auf der einen

87 Friedrich Naumann: Liberalismus und Protestantismus [1909], in: ders.: Werke, Bd. 1: Religiöse Schriften, hrsg. von Walter Uhsadel, Köln/Opladen 1964, S. 773-801, hier: S. 793.

88 Vgl. Werner Link: Der Nationalverein für das liberale Deutschland (1907-1918), in: Politische Vierteljahresschrift 5 (1964), S. 422-444.

89 Vgl. hierzu: Helen Müller: Im Zeitalter der Sammelwerke. Naumanns Projekt eines „Deutschen Staatslexikons“ (1914), in: Rüdiger vom Bruch (Hrsg.): Friedrich Naumann in seiner Zeit, Berlin/New York 2000, S. 189-208. Ebenso: Hübinger, Kulturprotestantismus, 1994, S. 303-305.

90 Vgl. Erich Nickel: Politik und Politikwissenschaft in der Weimarer Republik, Berlin 2004; Manfred Gangl: Die Gründung der „Deutschen Hochschule für Politik“, in: ders. (Hrsg.): Das Politische. Zur Entstehung der Politikwissenschaft während der Weimarer Republik, Frankfurt a.M. 2008, S. 77-96, hier: S. 83-85; Theiner, Sozialer Liberalismus, 1983, S. 271f.

91 Vgl. auch: Hertfelder, Meteor, 2008, S. 48. 
Seite und Unverfügbarkeit auf der anderen Seite. Eine herausragende Bedeutung wurde in diesem Zusammenhang der Transzendierung bzw. Unverfügbarstellung als einem spezifischen Modus politischer Kommunikation zugesprochen. Am Beispiel Friedrich Naumanns und der Begründung der Weimarer Republik sollte dies veranschaulicht werden.

Als besonders wichtig erwies sich dabei vor allem der Rekurs auf den Begriff des ,Volksstaates‘. Inhärent war diesem der Verweis auf das ,Volk“ und die ,Nation‘. Beide wurden als selbstevident und als Teil eines nichtkontingenten, allgemein geteilten Wissens behandelt. Mit ihnen verband sich zudem, wie gezeigt werden konnte, das Versprechen auf Einheit und Integration sowie auf demokratische Selbstbestimmung und Partizipation. Mit der Rede von der ,neuen Zeit', vom Eintritt in ein neues ,soziales Zeitalter' und vom ,neuen Menschen' traten weitere Begründungsargumente hinzu. Allen genannten ist gemein, dass sie zum einen die Möglichkeit eröffneten, über die alte Ordnung des Kaiserreichs zu verfügen und diese zu delegitimieren. Auf der anderen Seite konnten sie dazu herangezogen werden, die Kontingenz des Gründungsmoments zu verarbeiten und die Republik jenseits des Bereichs des politisch Verfügbaren zu verorten. So war es nun die neue republikanische Ordnung, von der Naumann im Gegensatz zum alten Kaiserreich behauptete, zur Einheit der deutschen Nation zu führen, dem Willen des Volkes zu entsprechen oder auch der Ausdruck der ,neuen Zeit‘ zu sein.

Der Rekurs auf diese Argumentationsfiguren ermöglichte es Naumann aber nicht nur, den neuen Volksstaat auf diese Art und Weise zu rechtfertigen und als etwas Selbstverständliches und Notwendiges erscheinen zu lassen. Er unternahm so auch den Versuch, den revolutionären Umbruch von $1918 \mathrm{zu}$ invisibilisieren oder zumindest zu relativieren. Anstatt die radikale Ablösung des Alten dezidiert hervorzuheben, betonte Naumann die Kontinuitäten. Zentral ist hier wiederum das umfassende, bereits vor 1918/19 entwickelte Konzept des Volksstaates. Aber auch seine Deutung des Umbruchs als Ergebnis eines langfristigen, unaufhaltsamen und sich weiter fortsetzenden Transformationsprozesses kann hierfür angeführt werden.

Schließlich konnte gezeigt werden, wie Friedrich Naumann mit seinem „Versuch volksverständlicher Grundrechte“, einer Mischform aus Katechismus und Grundrechtekatalog, ein ideengeschichtlich wirkungsmächtiges Symbol zu aktualisieren versuchte, um so der neuen Ordnung einen quasi- 
sakralen Charakter zu verleihen. Gerade der Verfassung der neu geschaffenen Republik wurde in diesem Zusammenhang eine herausragende Bedeutung zugesprochen. Sie sollte, wie Gustav Radbruch 1919 in expliziter Anlehnung an Naumann zusammenfassend festhielt, das ,,wichtigste Volksund Schulbuch“ und der „,weltliche Katechismus deutscher Nation“ sein. ${ }^{92}$ Insbesondere sie sollte dazu beitragen, die Weimarer Republik als Volksstaat zur Selbstverständlichkeit werden zu lassen.

92 Gustav Radbruch: Reichsverfassung und staatsbürgerliche Erziehung [1919], in: ders.: Gesamtausgabe, Bd. 13: Politische Schriften aus der Weimarer Zeit II, bearbeitet von Alessandro Baratta, Heidelberg 1993, S. 176-179, hier: S. 176. Vgl. zum Briefwechsel zwischen Naumann und Radbruch in dieser Angelegenheit: Theiner, Sozialer Liberalismus, 1983, S. 292, Fn. 59. In der Weimarer Reichsverfassung wurde diese Lehrbuchfunktion in Art. 148 selbst institutionell verankert. 


\section{Rechtsgeltung}

\section{Dekonstruktion und Konstruktion in den Umbrüchen nach}

\section{3 und 1945}

\section{STEVEN SCHÄLLER}

\section{Einleitung}

Warum gilt Recht? Dieser Problematik widmeten sich neben der Staatsund Rechtslehre schon so verschiedene Disziplinen, wie die Soziologie, Philosophie, Ökonomie oder auch die Politikwissenschaft. Die Antworten sind so vielfältig wie die Disziplinen selbst. Die Beschäftigung mit dieser Frage legt zumindest die zentrale Stellung des Rechts in modernen Gesellschaften offen. Recht gilt als das Steuerungsmedium schlechthin. Es stabilisiert Institutionen, reduziert Komplexität durch Erwartungssicherheit, senkt Transaktionskosten, transformiert ethische und moralische Zumutungen in allgemeinverbindliche Normen. Und immer bleibt die Frage, warum das Recht diese zentrale Stellung in politischen Ordnungen einnehmen soll.

Für den juristischen Positivismus ist die Geltungsfrage des Rechts eine Übung in metaphysischer Enthaltsamkeit. Die Begründung der Geltung einer Rechtsnorm verweist so nur auf eine - dem Recht - immanente Stufenordnung, die mit Kelsen die „Grundnorm“" als letzten Geltungsgrund annimmt. Die Funktion der Grundnorm besteht dann darin, die gesamte Rechtsordnung in Geltung zu setzen, ohne dem Recht eine weltanschaulich vorausgehende Vorherbestimmung einzuschreiben. Verweist geltendes

1 Hans Kelsen: Reine Rechtslehre. 2., vollständig überarbeitete und erweiterte Aufl., Wien 1960, S. 200-209; vgl. außerdem Horst Dreier: Rechtslehre, Staatssoziologie und Demokratietheorie bei Hans Kelsen, Baden-Baden 1990, S. 2756. 
Recht auf sich selbst, hat dies für den Juristen einerseits und die Rechtsunterworfenen andererseits verschiedene Folgen: Der Jurist wird von Spekulationen über die metaphysischen Gründe der Rechtsgeltung entlastet, weil die Norm innerhalb der Legeshierarchie zustande gekommen ist. Der Versuch, dennoch die Rechtserkenntnis hinter die Letztbegründung der Legeshierarchie zu verlängern, ist mit Kelsens eindrücklicher Formulierung vom Entgegenstarren des „Gorgonenhaupte[s] der politischen Macht ${ }^{\text {“2 }}$ beantwortet worden. Gerade die metaphysische Enthaltsamkeit des juristischen Positivismus verschiebt die Geltungsfrage des Rechts in den politischen Raum und steht dort dem demokratischen Diskurs offen. Im liberal-demokratischen Verfassungsstaat werden die Geltungsgründe des Rechts so aus dem Spannungsverhältnis von Politik und Recht generiert. ${ }^{3}$

Hier erst zeigt sich die integrative Stärke des liberal-demokratischen Pluralismus: Die Geltung des Rechts kann aus ganz verschiedenen philosophischen, weltanschaulichen oder religiösen Gründen angenommen werden, ohne dass mit dem subjektiven Geltungsglauben der Rechtsunterworfenen ein staatlicher Sanktionsmechanismus einhergeht. Die Geltungsgründe des Rechts sind demokratisch-diskursiv verhandelbar. ${ }^{4}$

Im Methodenstreit der Weimarer Staatsrechtslehre boten diese beiden Merkmale des Rechtspositivismus ideale Angriffsflächen. Die metaphysische Enthaltsamkeit einer Letztbegründung des Rechts allein in der Legeshierarchie wurde als inkonsistente Begründung einer herrschenden, sich selbst genügenden Lehre denunziert, während der liberal-demokra-

2 Zitiert nach Bernd Rüthers: Entartetes Recht. Rechtslehren und Kronjuristen im Dritten Reich, München 1989, S. 34.

3 Vgl. dazu Hans Vorländer: Die Suprematie der Verfassung. Über das Spannungsverhältnis von Demokratie und Konstitutionalismus, in: Wolfgang Leidhold (Hrsg.): Politik und Politeia. Formen und Probleme politischer Ordnung. Festgabe für Jürgen Gebhardt zum 65. Geburtstag, Würzburg 2000, S. 373-383.

4 Die Integrationskraft des demokratischen Prozesses für die Einheit der politischen Ordnung und für den Geltungsglauben in die Rechtsordnung wurde nicht nur allein von den Vertretern des juristischen Positivismus verteidigt. Vgl. Rudolf Smend: Verfassung und Verfassungsrecht [1928], in: ders.: Staatsrechtliche Abhandlungen und andere Aufsätze. 3., wiederum erweiterte Aufl., Berlin 1994, S. 119-276; Hans Vorländer (Hrsg.): Integration durch Verfassung, Wiesbaden 2003; Marcus Llanque: Die politische Theorie der Integration: Rudolf Smend, in: André Brodocz/Gary S. Schaal (Hrsg.): Politische Theorien der Gegenwart I. Eine Einführung, 2., erweiterte und aktualisierte Aufl., Opladen 2006, S. 313-340; Kathrin Groh: Demokratische Staatsrechtslehrer in der Wiemarer Republik. Von der konstitutionellen Staatslehre zur Theorie des modernen demokratischen Verfassungsstaats, Tübingen 2010. 
tische Pluralismus subjektiver Geltungsgründe als Werterelativismus einer substanzlosen Gesellschaft gedeutet wurde. Zusammengenommen wurden diese beiden Punkte zu einer Krisen- und Verfallsdiagnose des liberalen Rechtsstaates verdichtet. ${ }^{5}$

Im Kontext der späten Weimarer Republik sah sich der Rechtspositivismus daher konkurrierenden Erzählungen von den Geltungsgründen des Rechts ausgesetzt. Diese Gegendiskurse verorteten den letzten Geltungsgrund des Rechts außerhalb des Zusammenhangs von Politik und Recht. Die Frage der Rechtsgeltung wird damit dem liberal-demokratischen Rechtsdiskurs entzogen, indem die Geltungsgründe - bereits metaphysisch verankert - nicht mehr verhandelbar sind. So werden neben dem ,Volk‘ auch das ,Gemeinschaftserlebnis‘ und schließlich das ,Blut' als konkurrierende Transzendenzfiguren ins Spiel gebracht. Der auf immanente Geltungsgründe rekurrierende Rechtspositivismus wird mit diesen metaphysischen, das Recht transzendierenden Verweisen ausgehebelt.

Der vorliegende Text analysiert daher zunächst die Umbruchsituation von 1933, insbesondere die Phase nach der nationalsozialistischen Machtergreifung. Der Positivismusstreit der Weimarer Republik geht hier in die Verlängerung, allerdings ohne Beteiligung der Vertreter des juristischen Positivismus. Aus dem Feld der Akteure wurden drei maßgeblichen Autoren ausgewählt. ${ }^{6}$ Dies sind Carl Schmitt, Otto Koellreutter und Reinhard Höhn. Zudem wird eine zweite Umbruchsituation komparativ herangezogen, die ebenfalls die Auseinandersetzung mit dem juristischen Positivismus sucht und diesen in den Kontext krisenhafter Auflösungserscheinungen stellt. Es handelt sich dabei um die Phase nach 1945 bis in die späten 1950er Jahre hinein, und zwar in der sowjetischen Besatzungszone und der späteren Deutschen Demokratischen Republik. Hier findet eine Auseinandersetzung mit einem ,bürgerlichen“ Rechtsverständnis sowohl aus der Weimarer Zeit als auch der konkurrierenden Bundesrepublik statt.

5 Vgl. Christoph Gusy (Hrsg.): Demokratisches Denken in der Weimarer Republik, Baden-Baden 2000.

6 Vgl. dazu Bernd Rüthers: Reinhard Höhn, Carl Schmitt und andere - Geschichten und Legenden aus der NS-Zeit, in: Neue Juristische Wochenschrift 39 (2000), S. 2866-2871; ders., Entartetes Recht, 1989; Diemut Majer: Rechtstheoretische Funktionsbestimmungen der Justiz im Nationalsozialismus am Beispiel der, völkischen Ungleichheit‘, in: dies. (Hrsg.): Nationalsozialismus im Lichte der Juristischen Zeitgeschichte. Ideologie - Staat - Besatzungsregime in Europa 1939-1945, Baden-Baden 2002, S. 3-20. 
Mit Karl Polak findet sich ein Staatsrechtslehrer, der das sozialistische Staatsrecht der DDR geprägt hat.

Der Prozess der diskursiven Umstellung von immanenten auf transzendente Geltungsgründe des Rechts soll mit den vier Autoren analysiert werden. Die diskursiven Strategien aller vier Autoren eint eine besondere Eigenschaft, die den erkenntnistheoretischen Hintergrund der Jurisprudenz als Rechtswissenschaft abbildet. So erhielten alle vier Autoren ihre akademische Prägung in der Spätphase des juristischen Positivismus. Gemeinsam ist ihnen die Revolte gegen diesen Positivismus, ohne aber dessen Verständnis von Wissenschaftlichkeit hinter sich lassen zu können, welches auf der konstruktiven Methode, der Logik der juristischen Begriffe und der rein formalen Analyse normativer Zusammenhänge aufruhte. ${ }^{7}$ Für das öffentliche Recht fanden diese methodischen Anforderungen für den Rechtswissenschaftler ihre gültige Formulierung bereits durch Laband: „Die wissenschaftliche Aufgabe der Dogmatik eines bestimmten positiven Rechts liegt aber in der Konstruktion der Rechtsinstitute, in der Zurückführung der einzelnen Rechtssätze auf allgemeinere Begriffe und andererseits in der Herleitung der aus diesen Begriffen sich ergebenden Folgerungen." 8

Die zu analysierenden Texte sind daher in einer markanten Hinsicht alle in einem juristischen Stil verfasst, der sich auch noch in der Auflösung des Rechtspositivismus dessen wissenschaftlichen Denkformen verpflichtet sieht. ${ }^{9}$ Die Verdrängung der immanenten Geltungsgründe des Rechts durch nicht mehr verhandelbare transzendente Geltungsgründe operiert als diskursive Strategie gerade mit der juristischen Methode der Konstruktion. Diese folgt bei jedem der hier vorgestellten Autoren einem analytisch zu unterscheidenden Dreischritt. Im Mittelpunkt der Abhandlungen steht jeweils die juristische Konstruktion einer neuen Rechtsordnung. Dieser Konstruktion geht jedoch als erstem Schritt eine ebenso streng juristische Dekonstruktion der immanenten Geltungsbehauptungen des Positivismus voraus. Schließlich wird drittens die neue Rechtsordnung als gültig ausgewiesen, wobei

7 Vgl. dazu Michael Stolleis: Geschichte des öffentlichen Rechts in Deutschland, Bd. 2: Staatsrechtslehre und Verwaltungswissenschaft 1800-1914, München 1992, S. 276-278.

8 Paul Laband: Das Staatsrecht des Deutschen Reiches, Bd. 1, 4., neu bearbeitete Aufl., Tübingen 1901, S. IX.

9 Die Wahrung der Formen rechtswissenschaftlicher Auseinandersetzung beobachtet auch Majer, Rechtstheoretische Funktionsbestimmungen, 2002, S. $6 \mathrm{f}$. 
der transzendente Geltungsgrund ein nicht mehr verhandelbarer Verweis auf Metaphysisches bleibt.

\section{Carl Schmitt Und die Gerechtigkeit KONKRETER ORDNUNGEN}

\subsection{Dekonstruktion: Der Begriff der Rechtssicherheit}

Die Dekonstruktion des Positivismus beginnt bei Schmitt mit der Unterscheidung von Recht und Gesetz. Dem liberal-demokratischen Rechtsstaat unterstellt er, dass dieser kein Rechtsstaat ist, sondern ein Gesetzesstaat. Recht und Gesetz treten als Gerechtigkeit und als positive Norm auseinander. Der Gerechtigkeitsbegriff des liberalen Rechtsstaates als Gesetzesstaat reduziere sich auf die Rechtssicherheit.

„Soweit dieser Positivismus eine rechtsphilosophische Begründung gibt, führt er in die Gedankengänge eines individualistischen Rechtssicherheits-Interesses und beruft sich darauf, daß es ungerecht wäre, die durch das Gesetz hervorgerufene Erwartung der Rechtsgenossen, [...] das ,Vertrauen', zu enttäuschen. “10

Die Rechtssicherheit avanciert zur zentralen Gerechtigkeitskategorie, weil das Individuum dem Staat entgegengesetzt ist und diesen durch das Recht berechenbar machen will. Die Machtfülle des Staates gilt aus liberaler Perspektive als potentiell bedrohlich für das Individuum. Daher wird der Einzelne mit Abwehrrechten ausgestattet und so eine Konfliktsituation geschaffen, die vor den Gerichten nur scheinbar juristisch ausgetragen wird. Denn das Individuum, das durch den Begriff der Rechtssicherheit meint, den Staat und seine Handlungen berechenbar zu halten, wird vor Gericht feststellen müssen, dass seine Erwartungen an die Rechtssicherheit nicht immer erfüllt werden. Schmitt führt die Auseinandersetzung mit diesem Gedankengang direkt in eine Paradoxie des Positivismus: Danach ist staatliches Handeln zwar nur dann legal und für das Individuum berechenbar, wenn es sich durch eine positive Norm rechtfertigen lässt. Gleichzeitig aber schöpfen die Richter als Justizbeamte des Staates in ihren Entscheidungen neues Recht, welches gerade nicht durch eine bereits

10 Carl Schmitt: Über die drei Arten des rechtswissenschaftlichen Denkens, Berlin 1934, S. 27 (Hervorhebung im Original). 
bestehende positive Norm zu rechtfertigen ist. ${ }^{11}$ Schmitt spielt hier auf die Kodifikationsproblematik des modernen Rechtsstaates an, die nach positivistischer Rechtsvorstellung durch die axiomatische Annahme einer lückenlosen Rechtsordnung aufgelöst werden soll. Faktisch aber entstehe dadurch für den liberalen Gesetzesstaat das logische Problem, dass einerseits staatliches Handeln nur dann legitim sein soll, wenn es sich allein durch eine positive Norm rechtfertigen lässt und andererseits staatliches Handeln auch dann legitim sein soll, wenn es sich gerade nicht durch eine positive Norm rechtfertigen lässt. Diese theoretische Inkonsistenz zeige ganz klare praktische Wirkungen, die dem positivistischen Rechtsverständnis den Boden für seinen zentralen Geltungsgrund des Rechts entzieht: Im Richterrecht finde sich ein Einfallstor für die herrschaftliche Willkür des Justizbeamten, vor dem der liberale Rechtsstaat durch die Opposition von Individuum und Staat den Einzelnen gerade bewahren wolle. Sicherheit und Berechenbarkeit entfallen somit als Geltungsgrund des Rechts im liberalen Rechtsstaat. $^{12}$

\subsection{Konstruktion: Konkretes Ordnungsdenken und das Lebensrecht des Volkes}

1933 erscheint die Schrift Staat, Bewegung, Volk - Die Dreigliederung der politischen Einheit. In diesem Text beschäftigt sich Schmitt mit der neuen Lage nach der Machtergreifung der Nationalsozialisten. Im Mittelpunkt stehen Fragen der Legitimität der neuen Ordnung, ihrer Einheitsverkörperung sowie das Verhältnis von Führertum und nationalsozialistischem Recht. Einerseits arbeitet Schmitt die Legitimität der neuen Ordnung heraus. Diese gründe nicht auf der Legalität eines Übergangs von einer Ordnung in die andere durch das Ermächtigungsgesetz, sondern auf der Legitimität des in den Reichstagswahlen sichtbar gewordenen Willens des deutschen Volkes, Adolf Hitler als Führer zu bestimmen. ${ }^{13}$ Schmitt zapft damit die partizipatorische Quelle der Legitimität an, die in der Verknüpfung von Volk und Führer einerseits die Notwendigkeit einer politischen Führerherrschaft bejaht, andererseits aber diese an die Zustimmung des

11 Vgl. Carl Schmitt: Staat, Bewegung, Volk - Die Dreigliederung der politischen Einheit [1933], Hamburg 1993, S. 40.

12 Vgl. Schmitt, Über die drei Arten, 1934, S. 20-24.

13 Vgl. Schmitt, Staat, Bewegung, Volk, 1993, S. 7. 
Volkes knüpft. ${ }^{14}$ Die Legitimität der neuen Ordnung bestimmt sich daher nicht durch das Recht, auch nicht durch das Verfassungsrecht, sondern durch das Politische. Das Politische geht, so ist mit Schmitts erstem Satz aus Der Begriff des Politischen von 1927 zu reformulieren, den rechtlichen Organisationsformen eines Volkes voraus. Daher ist jedes Recht situativ, es ist kontextgebunden, und es ist jedenfalls nicht mit jenem abstrakten Ewigkeitswert identisch, den ihm der Positivismus verleihe. „Wir wissen nicht nur gefühlsmäßig, sondern aufgrund strengster wissenschaftlicher Einsicht, daß alles Recht das Recht eines bestimmten Volkes ist."15 Andererseits deutet sich in dieser Rechtsauffassung bereits die besondere Stellung des Juristen an. Schmitts quis judicabit, die Frage also, wer über das Recht eines Volkes entscheidet, verlegt das akademische Konfliktfeld über den richtigen Weg der Rechtsinterpretation. Recht kann nicht, so Schmitt, durch objektive Methoden der Auslegung, die sogenannte juristische Methode, erkannt werden. Dies führe zu abstrakten Leerformeln, mit denen das Recht eines Volkes verfehlt werde. Es ist stattdessen die Artgleichheit als Bestimmungsfaktor der Zugehörigkeit zu einem Volk, die sich im Prinzip des Führertums ausdrückt und zur richtigen Rechtserkenntnis führt. „Der richtige Richter ist daher einer, der in seiner seinsmäßigen, artbestimmten Weise an der rechtschöpfenden Gemeinschaft teil hat und existenziell ihr zugehört."16

Damit eröffnen sich zwei Fragen der Rechtsgeltung: Erstens bleibt offen, wo dieses Recht eines Volkes herkommt, oder juristisch formuliert, was ist eine Rechtsquelle unter der Herrschaft der Nationalsozialisten? Und zweitens bleibt offen, welche Stellung diejenigen einnehmen, die sich mit dem Recht beruflich in Wissenschaft und Justiz beschäftigen. Beide Fragen werden überwölbt von dem Problem des Verhältnisses von Recht und Politik, das Schmitt zugunsten der Politik auflöst.

Schmitts Auffassung von der Kontextgebundenheit jeden Rechts mündet 1934 in das konkrete Ordnungsdenken. ${ }^{17}$ Er grenzt das konkrete Ordnungsdenken von einem normativistischen Regelndenken einerseits und einem dezisionistischen Entscheidungsdenken andererseits ab. So ist das

14 Vgl. Wolfram Pyta: Antiliberale Ideenwelt in Europa bei Kriegsende, in: Christoph Gusy (Hrsg.): Demokratie in der Krise: Europa in der Zwischenkriegszeit, Baden-Baden 2008, S. 86-104, hier: S. 93.

15 Schmitt, Staat, Bewegung, Volk,1993, S. 45.

16 Ebd.

17 Vgl. Schmitt, Über die drei Arten, 1934. 
konkrete Ordnungsdenken erstens nicht dazu bereit, Recht als reine Regeln zu begreifen, die, losgelöst von dem Volk, das unter ihnen leben soll, ein normativistisches Eigenleben entfalten. Für die positivistische Rechtslehre aber schwebten die reinen Regeln ,über jeder konkreten Lage und jedem konkreten Tun; [...] das Sollen bleibt vom Sein unberührt und behält seine für das normativistische Denken unverletzbare Sphäre.“"18 Gegen solche Entfremdungsprozesse von Volk und Recht richte sich das konkrete Ordnungsdenken.

Zweitens kann das konkrete Ordnungsdenken gegen das dezisionistische Entscheidungsdenken nur insoweit Bedenken geltend machen, als der Dezisionismus im 19. Jahrhundert jene eigentümliche Verbindung mit dem normativistischen Regelndenken einging, die als juristischer Positivismus bezeichnet wird. War daher für den Carl Schmitt der Jahre vor 1933 das dezisionistische Denken der große Gegenspieler zum Positivismus Stichwort: Ausnahmefall und Normalsituation -, rückte der Dezisionismus jetzt in eine unterstützende Position ein, um die Paradoxien des juristischen Positivismus aufzulösen. So halte der Dezisionismus das Recht auch dann noch entscheidungsfähig, wenn der Ausnahmezustand - sprich: die Kodifikationslücke - eintrat und der Richter regellos entscheiden musste.

Während das normativistische Regelndenken sein Verhältnis zur Rechtsordnung dadurch bestimmt, dass die Ordnung lediglich die Summe aller Regeln darstellt, kehrt sich dieses Verhältnis im konkreten Ordnungsdenken um. Ausgangspunkt ist hier immer die konkrete Situation eines Volkes, das sich situativ sein Recht gibt. Die Norm ist daher nur ein Instrument zur Regelung bestimmter, begrenzter Sachverhalte. Sie kann deswegen auch nicht in den ,heiligen', über allem schwebenden Status gelangen, den sie im Normativismus inne hat. Sie ist ein Instrument der Ordnung. Der Begriff der Rechts-Ordnung bestimmt sich vom letzteren her: Es handelt sich um das konkrete - nicht abstrakte - Recht einer konkreten Ordnung. „Die Norm oder Regel schafft nicht die Ordnung; sie hat vielmehr nur auf dem Boden und im Rahmen einer gegebenen Ordnung eine gewisse regulierende Funktion mit einem relativ kleinen $\mathrm{Ma} ß$ in sich selbständigen, von der Lage der Sache unabhängigen Geltens. “19

Damit ist das konkrete Recht einer konkreten Ordnung an diese zurückgebunden und in seinem allgemeinen Geltungsanspruch beschränkt.

18 Ebd., S. 16.

19 Ebd., S. 11. 
In ihm drückten sich keine Normen mit einem abstrakt-allgemeinen Geltungsanspruch aus, sondern die gegenwärtigen, volatilen und von vorpolitischen individuellen Schutzräumen befreiten Regelungsbedürfnisse eines Volkes. ${ }^{20}$ Es stellt sich daher erneut die Anschlussfrage, was diese Regelungsbedürfnisse inhaltlich ausmacht und auf welche Weise sie befriedigt werden können. Die Antwort auf diese Frage führt zum einen auf das quis judicabit der eingangs formulierten Problematik zurück und zum anderen weist sie bereits auf die sich in radikaler Intensität steigernden Schriften Schmitts nach den Ereignissen vom Juni 1934.

Das quis judicabit ist für Schmitt deswegen eine relevante Frage, weil die Auseinandersetzung mit dem juristischen Positivismus und seinen Auslegungsmethoden keine akademische, sondern eine politische Frage sei. Der juristische Positivismus ist der politische Feind. Die Gesetzeslage ist nach 1933 weitestgehend gleich geblieben, nun aber mit einem vollkommen neuen Denken zu bearbeiten. Richteten sich die Bemühungen nationalsozialistischer Rechtslehrer für ein Recht der konkreten Ordnung dabei allein auf die Auslegungsmethoden des juristischen Positivismus, käme ein nationalsozialistisches Rechtsdenken nicht zu sich selbst. Deswegen erweitert Schmitt die Zielbestimmung für eine nationalsozialistische Rechtswissenschaft: „Es kommt für uns heute nicht darauf an, die alte normativistische Methode zu korrigieren, sie elastischer zu machen, um sie dadurch womöglich zu retten und sie noch eine zeitlang am Leben zu erhalten, sondern wir kämpfen für einen neuen Typus des deutschen Juristen. “21

Ein solcher deutscher Jurist soll an dem geschult werden, was Schmitt konkrete Ordnung bezeichnet. Er soll das Recht jenen vorfindbaren Ordnungen nur noch entnehmen, denen er sich selbst als Angehöriger des deutschen Volkes zugehörig fühlt. Methodisches Einfallstor für diesen Zweck sind die sogenannten Generalklauseln, mit denen den Gesetzen der Weimarer Republik eine Bedeutung im Sinn der konkreten Ordnung des deutschen Volkes einzuschreiben sei. „Sobald Begriffe wie ,Treu und Glauben', gute Sitten“ usw. nicht auf die individualistische bürgerliche Verkehrsgesellschaft bezogen werden, ändert sich in der Tat das gesamte

20 Die Rückverweisung von Recht und Politik auf das Volk thematisiert auch Michael Th. Greven: Der substanzhafte und metaphysische Ansatz des politischen Schriftstellers Carl Schmitt bis 1934, in: Rainer Eisfeld (Hrsg.): Gegen Barbarei. Essays Robert W. Kempner zu Ehren, Frankfurt a.M. 1989, S. 131-152.

21 Carl Schmitt: Nationalsozialistisches Rechtsdenken, in: Deutsches Recht 4 (1934) 10, S. 225-229, hier: S. 228. 
Recht, ohne das ein einziges ,positives' Gesetz geändert zu werden brauchte. ${ }^{\text {“22 }}$ Frei von den Bindungen einer juristischen Methode, die noch jede vorpositivistische Erwägung aus dem Rechtserkenntnisprozess ausschließen möchte, hält Schmitt nun fest: „Wir denken die Rechtsbegriffe um. [...] Wir sind auf der Seite der kommenden Dinge. “23

Die ,kommenden Dinge' und das ,Umdenken von Rechtsbegriffen“ stellen Schmitt spätestens mit den Ereignissen vom Juni 1934 vor eine große Herausforderung. In dem Text Der Führer schützt das Recht rechtfertigte Schmitt das, was die nationalsozialistische Propaganda als Abwehr eines Putsches apostrophierte und was als politische Morde an Gegnern und Konkurrenten Hitlers in die Geschichte einging. Schmitt zitiert zunächst Hitlers Rechtfertigung für die Röhm-Morde, wonach dieser im Augenblick höchster Gefahr Verantwortung für das deutsche Volk übernommen habe und damit „des Deutschen Volkes oberster Gerichtsherr' ${ }^{\text {‘24 }}$ war. Zweifel an dem in dieser Behauptung steckenden Durchbrechen der Gewaltenteilung werden als „Rechtsblindheit des liberalen Gesetzesdenkens“،25 denunziert. Denn „,[a]us dem Führertum fließt das Richtertum“ “26. Habe daher in einem liberalen Rechtsstaat der ,Verbrecher' einen Anspruch auf Rechtssicherheit und Berechenbarkeit der Justiz, verkehre sich dieser subjektive Anspruch in einen Nachteil für das Volk, das sein Bedürfnis nach Gerechtigkeit nicht gestillt sieht. Daher habe der Führer jenseits des positiven Gesetzesstaates der Gerechtigkeit zu ihrem Recht verholfen. „In Wahrheit war die Tat des Führers echte Gerichtsbarkeit. Sie untersteht nicht der Justiz, sondern war selbst höchste Justiz.“27

Die Aufhebung der Gewaltenteilung und die Außerkraftsetzung der Rechtsordnung rechtfertigt Schmitt mit einem höheren Grund. Im Ausnahmezustand habe der Führer nicht unrecht oder rechtlos gehandelt, sondern vielmehr höherem, vorpositiven Recht zur Geltung verholfen. „Das Richtertum des Führers entspringt derselben Rechtsquelle, der alles Recht jedes Volkes entspringt. [...] Alles Recht stammt aus dem Lebensrecht des

22 Schmitt, Über die drei Arten, 1934, S. 49.

23 Schmitt, Rechtsdenken, 1934, S. 229.

24 Carl Schmitt: Der Führer schützt das Recht, in: Deutsche Juristen-Zeitung 39 (1934) 15, S. 945-950, hier: S. 946.

25 Ebd., S. 947.

26 Ebd.

27 Ebd. 
Volkes.“28 Damit verweist Schmitt schließlich auch auf die Rechtsquelle des nationalsozialistischen Rechts, dem sich seine Geltung verdankt.

\subsection{Geltungsgrund des Rechts: Gerechtigkeit}

,Höheres Recht‘ und ,Bedürfnis nach Gerechtigkeit‘ sind die entscheidenden und letztbegründenden Formeln für Schmitts Behauptung der Geltung nationalsozialistischen Rechts. Auch dieses gilt nicht aus sich selbst heraus. Es verweist auf eine überpositive Rechtsordnung. Schmitt ist Vertreter einer materiellen Rechtsauffassung im „Geist des Nationalsozialismus“29. Nationalsozialistisches Recht ist nur dann legitim, wenn es eine Funktion erfüllt. Dies soll nicht mehr die positivistische Leerformel von der Rechtssicherheit sein. Die Funktion nationalsozialistischen Rechts sei Gerechtigkeit. Die Gerechtigkeit entspringt dem Lebensrecht des Volkes und seinen konkreten Ordnungen.

In dieser Perspektive lautet die Reihe der Letztbegründungen folgendermaßen: die nationalsozialistische Rechtsordnung ist legitim, weil das deutsche Volk seinen Wunsch nach Führertum durch plebiszitäre Zustimmung zum Ausdruck gebracht hat. Das Recht des Führers gilt, weil es in vollständiger Abkehr vom liberalen Recht des positiven Gesetzesstaates gegeben wird. Es artikuliert das „Lebensrecht des Volkes“630. Dieses Recht ist jenseits der Verformungen positivierten Rechts das gerechte Recht der Deutschen. Es fließt aus einer Rechtsquelle, die Schmitt als die Bewegung identifiziert. Das Programm der NSDAP hat diese Rechtsquelle konkretisiert. Juristisch-wissenschaftlich reformuliert, ist dieses Lebensrecht des Volkes als Recht konkreter Ordnungen zu bezeichnen und damit das Gegenteil liberalen Gesetzesrechtes. Das Recht konkreter Ordnungen gilt, weil es die Ordnungen bereits vorpositiv verfasst hat und von den Mitgliedern der konkreten Ordnung schon vor jedem Kodifikationsversuch als „,inneres Eigenrecht“31 akzeptiert ist. Eine Positivierung dieses Rechts der konkreten Ordnungen ist nicht mehr notwendig. Erfolgt sie dennoch, hat sie vor allem notariellen Charakter mit einem nur begrenzten normativen Geltungsbereich für die positivierten Normen. Das Recht der konkreten

28 Ebd.

29 Carl Schmitt: Nationalsozialismus und Rechtsstaat, in: Juristische Wochenschrift 63 (1934) 12/13, S. 713-718, hier: S. 717.

30 Schmitt, Der Führer schützt das Recht, 1934, S. 947.

31 Schmitt, Über die drei Arten, 1934, S. 42. 
Ordnungen ist gerecht, weil es der Lebenslage des deutschen Volkes in seinen ständischen Gliederungen zum Ausdruck verhilft und das Rechtsgefühl umfänglich widerspiegelt. Es gilt, weil es gerecht ist; weil mit ihm Recht und Gerechtigkeit wieder vereint sind.

\section{Otto KoellReutter UND die Gemeinschaft DER FRONTSOLDATEN}

\subsection{Dekonstruktion: Individualismus und völkische Lebensnotwendigkeiten}

Koellreutters Dekonstruktion des positivistischen Rechtsbegriffes und seiner Geltungsgründe ist wesentlich weniger ambitioniert als bei Schmitt. Zum Teil trägt er auch dessen Schlüsse nicht mit, wenn er die Rechtssicherheit als einen zentralen Wert der Idee des Rechts annimmt und nicht wie Schmitt als die spezifische Denkform der liberalen Rechtslehre. Koellreutter wirft dem liberalen Rechtsstaatsverständnis zunächst vor, die „Sicherung der individualistischen Position“32 gegenüber den Bedürfnissen der völkischen Gemeinschaft zu stark zu betonen. Dem liberalen Rechtsstaat „gilt eben als höchster Wert der Schutz des individuellen Anspruchs. Hier liegt das Gerechtigkeitsideal des bürgerlichen Rechtsstaates, demgegenüber auch die nationalen Existenzfragen verblassen. ${ }^{\text {‘33 Konsequenz }}$ sei eine Schwächung der völkischen Lebensordnung, die mit einem individualistisch gewendeten fiat justitita, pereat mundus zum Zusammenbruch von Recht und Staat führen muss. Wendet sich aus dieser inneren Logik der Rechtsgestaltung heraus der liberale Rechtsstaatsbegriff gegen die Interessen der völkische Gemeinschaft, so zeige die Realität der Weimarer Republik bereits genau diese Verfallsprozesse.

Koellreutters Kritik am liberalen Rechtsbegriff ist daher zugleich auch zeitgeschichtliche Verfallsdiagnose. So sei jedes Recht und jeder Staat das Produkt einer spezifischen und zu ihrer Zeit dominanten Staatsidee. Der liberale Rechtsstaat und der juristische Positivismus entspringen der liberalen Staatsidee. Sie bringen insbesondere einen Gegensatz zwischen dem vermeintlich gefährdeten Individuum und dem vermeintlich gefähr-

32 Otto Koellreutter: Der nationale Rechtsstaat, Tübingen 1932, S. 6.

33 Ebd., S. 14. 
lichen Staat hervor. Solange eine Staatsidee dominant genug ist, um die Einheit der politischen Gemeinschaft sicherzustellen, solange befinden sich auch Staat und Recht in Übereinstimmung mit den grundlegenden Überzeugungen der Zeit. Die liberale Staatsidee habe jedoch keine geistige Kraft mehr. Ihre Eliten begreifen den Staat nur noch als Instrument zur Unterdrückung neuer Staatsideen. Fehlt daher dem liberalen Recht die Übereinstimmung mit der dominanten Staatsidee, kann liberales Recht auch nicht mehr als gerechtes Recht begriffen werden. Die gegenwärtige Staatsform zu Beginn der 1930er Jahre kennzeichnet Koellreutter deshalb als liberalen Machtsstaat. Die neue, dominant gewordene Staatsidee, die letztendlich zur Ablösung des Weimarer Systems geführt hat, ist die völkische Staatsidee. Aufgrund ihrer besonderen Herkunft aus dem gemeinschaftsbildenden Frontkämpfererlebnis bedeutet sie eine faktische Verschiebung im Verhältnis von Individuum und Gemeinschaft. ${ }^{34}$

\subsection{Konstruktion: Die nationale Lebensordnung und das Erlebnis der Volksgemeinschaft}

Direkt nach der nationalsozialistischen Machtergreifung beginnt Koellreutter mit der Konstruktion der Geltungsgründe für ein neues Rechtsverständnis. Ausgangspunkt ist der „Ewigkeitswert des Rechtsstaats““35. Auf ihm gründe auch der ,nationale Rechtsstaat ${ }^{6}$ des Nationalsozialismus. ${ }^{36}$ Nur der nationale Rechtsstaat leiste den notwendigen Ausgleich zwischen individuellen „Forderungen nach Gerechtigkeit wie den nationalpolitischen Lebensnotwendigkeiten“"37. Diese Position steht in zweifacher Weise konträr zu Schmitt. Erstens versteht Schmitt Gerechtigkeit nicht als individuel-

34 Vgl. ebd.

35 Otto Koellreuter: Der nationale Rechtsstaat, in: Deutsche Juristen-Zeitung 38 (1933) 8, S. 517-524, hier: S. 517.

361933 gebraucht Koellreutter noch den Begriff des nationalen Rechtsstaates. Er schwenkt 1935 auf den Begriff des nationalsozialistischen Rechtsstaates um. Dem war ein polemischer, explizit gegen Koellreutter gerichteter Text Schmitts vorausgegangen sowie eine kontroverse Rezension Forsthoffs zu Koellreutters Schrift ,Der Deutsche Führerstaat', Tübingen 1934. Vgl. dazu Schmitt, Nationalsozialistisches Rechtsdenken, 1934 sowie Ernst Forsthoff: Otto Koellreutter, Der Deutsche Führerstaat, in: Juristische Wochenschrift 9 (1934), S. 538 und Hans Helfritz: Rechtsstaat und nationalsozialistischer Staat, in: Deutsche Juristen-Zeitung 39 (1934) 7, S. 425-433.

37 Koellreutter, Der nationale Rechtsstaat, 1933, S. 517. 
len Anspruch, der in einem Gegensatz zum „Lebensrecht des Volkes ${ }^{\text {‘38 }}$ steht. Vielmehr erwächst der Gerechtigkeitsbegriff bei Schmitt gerade aus der konkreten Ordnung eines Volkes. Somit kann Schmitt zweitens aus dem Rechtsgefühl des Volkes jenen Gerechtigkeitsbegriff herausarbeiten, der für ihn den letzten Geltungsgrund einer Rechtsordnung darstellt. Indem Koellreutter einen subjektiven Gerechtigkeitsbegriff entwickelt, der lediglich als Rechtsposition des Individuums gegen die Gemeinschaft gedacht wird, entfällt der Gerechtigkeitsbegriff als externer Bezugspunkt für die Geltung der Rechtsordnung. Wäre diese ,nur' gerecht, würde sie den Fehler der liberalen Rechtsordnung wiederholen und die Ansprüche des Individuums über Bedürfnisse der völkischen Gemeinschaft stellen. Der nationale Rechtsstaat aber ist ,die bewußte politische Form einer volklichen Lebensordnung [...]. Daraus ergibt sich nur, daß der primäre Rechtswert in ihm in der rechtlichen Gestaltung und Sicherung unserer nationalen Lebensordnung besteht. ${ }^{\text {(39 }}$ Daher gelten individuelle Schutzpositionen nur noch unter dem Vorbehalt der Lebensnotwendigkeiten der völkischen Gemeinschaft. ${ }^{40}$ Hier findet sich ein erstes funktionales Motiv für die Geltungsgründe einer Rechtsordnung.

Entfällt damit für Koellreutter in einer nationalen Rechtsordnung der Geltungsgrund der Gerechtigkeit, so ist zunächst zu fragen, was für ein Recht, das nicht gerechtes Recht zu sein braucht, auf welche Weise zustande kommt? Und warum soll dieses Recht gelten, wenn es nicht als gerechtes Recht zu verstehen ist? Auch hier führen diese Fragen zum Problem der Rechtsquellen.

Koellreutter begreift die Rechtsordnung nur noch als „Funktion des völkischen Lebens “41, in der ein Normativismus des Rechts einen geringeren Raum einnimmt als in einer liberalen Rechtsordnung. Genau wie die staatliche Organisation kann dem Recht somit nur noch ein „bedingte[r] Eigenwert ${ }^{\star 42}$ zugesprochen werden. Rechtliche und staatliche Ordnung gewinnen ihre Legitimität allein durch ihre Bezogenheit auf die völkische Gemeinschaft. Gleichzeitig beharrt Koellreutter aber im Gegensatz zu

38 Schmitt, Der Führer schützt das Recht, 1934, S. 947.

39 Koellreutter, Der nationale Rechtsstaat, 1933, S. 517 (Hervorhebung StS).

40 Vgl. ebd., S. 519.

41 Otto Koellreutter: Der nationalsozialistische Rechtsstaat, in: Hans Heinrich Lammers/Hans Pfundtner (Hrsg.): Die Verwaltungsakademie. Bd. 1 [Loseblattsammlung], Berlin 1935, S. 1-15, hier: S. 3.

42 Ebd. 
Schmitts Konzeption des absoluten Vorrangs der Politik vor dem Recht auf dem „Eigenwert des Rechtsstaats“ auch für eine völkische Gemeinschaft:

„Die politische Dynamik allein vermag in normalen Zeiten das völkische Leben nicht zu gestalten. Es bedarf dazu der Rechtsnormen, die den Ablauf des völkischen Lebens und des Lebens der Volksgenossen in der Gemeinschaft berechenbarer Gestaltung garantieren. Deshalb erweist sich der Rechtsstaat als Notwendigkeit für die Gestaltung und Entwicklung des völkischen Gemeinschaftslebens. “43

Die Rechtsquellen des völkischen Gemeinschaftslebens weichen jedoch von denen eines liberalen Rechtsstaates ab. So kenne der liberale Rechtsstaat nur formale Rechtsquellen, auf denen eine Rechtsordnung gründe, „die nach der Auffassung des individualistischen Liberalismus nur ein Apparat“44 zur Sicherung der Rechtspositionen des Einzelnen gegenüber der Gemeinschaft sei. Demgegenüber rechtfertige sich eine positive Rechtsordnung im Sinne der völkischen Rechtsidee allein ,in der rechtlichen Gestaltung des Gemeinschaftslebens [...] und der Konkretisierung des völkischen Rechtsgefühls“" ${ }^{\text {“5 }}$. Daraus folgt unmittelbar eine Verschiebung der Rechtsquellen von einer formalen, positiven in eine materielle, überpositive Rechtsordnung: So ist „nach der nationalsozialistischen Weltanschauung oberste Rechtsquelle ,das Recht‘ und nicht ,das Gesetz““46. Damit könne insbesondere die Einheit von Recht und Moral wiederhergestellt werden, die in einem ,entarteten Liberalismus ${ }^{\text {“47 }}$ gerade verloren gegangen sei. Für die Auslegung von Recht bedeutet dies, dass nicht mehr die korrekte Anwendung der Rechtstechniken entscheidend sei, sondern die Verwurzelung des Juristen in der überpositiven, völkischen Rechtsordnung. Die Zugehörigkeit zu dieser völkischen Rechtsordnung wird nur über die essentiellen Faktoren ,Blut und Boden“ vermittelt und muss darüber hinaus von jedem einzelnen Volksgenossen erlebt werden. Dieses Erlebnis ist das Spezifikum von Koellreutters völkischer Rechtsanschauung und verweist als geschichtliches Motiv bereits auf die zweite von ihm behauptete Geltungsressource des Rechts.

43 Ebd., S. 7.

44 Otto Koellreutter: Quellen des nationalsozialistischen Staatsrechts, in: Lammers/ Pfundtner, Die Verwaltungsakademie, 1935, S. 1-15, hier: S. 2.

45 Ebd.

46 Ebd.

47 Ebd. 


\subsection{Geltungsgrund des Rechts: Das Gemeinschaftserlebnis als Kategorie des Politischen}

Besteht erstens das funktionale Motiv einer Rechtsordnung darin, die Lebensnotwendigkeiten einer völkischen Gemeinschaft abzubilden und kann zweitens allein das geschichtliche Motiv die völkische Rechtsanschauung begründen, so stellt sich die Frage nach dem Ursprung der völkischen Gemeinschaft und den sich daraus ergebenden Prämissen für die Rechtsgestaltung. In der Antwort auf diese Frage liegt nicht nur eine Behauptung über die Geltungsgründe des Rechts, die das Recht selbst transzendiert. Koellreutter vermag zugleich mit der Antwort auf die Frage nach dem Ursprung der völkischen Gemeinschaft in einer biographischen Volte Carl Schmitt von der Quelle richtiger nationalsozialistischer Rechtserkenntnis auszuschließen.

Die Auseinandersetzung über den Ursprung der völkischen Gemeinschaft beginnt Koellreutter mit einer Diskussion von Schmitts Begriff des Politischen, der in dessen Schrift Staat, Bewegung, Volk zur zentralen Kategorie für die Bestimmung des Verhältnisses von Rechtsordnung, staatlicher Organisation und nationalsozialistischer Ideologie gerate. $^{48}$ Darin aber bestehe ein grundlegender Fehler. Denn Schmitts Freund-FeindDenken sei eine rein formale Kategorie, die von ihm inhaltlich nicht gefüllt werde. Ihre Ausrichtung am Feind als Bezugsgröße der Gemeinschaftsbildung lasse jeden Sinn dafür vermissen, was den Zusammenhalt eines Volkes ausmache. ${ }^{49}$ Im Kern jedoch ist dieser Vorwurf mangelnder politischer Substanz der Versuch, Schmitt die zentralen Erkenntnisquellen des völkischen Gemeinschaftslebens abzuschneiden. Er habe keinen Zugang zur Kategorie des Freundes. Der Freund aber sei die historisch nachweisbare Grundkategorie des Denktypus des Nationalsozialismus und damit Ausgangspunkt sämtlicher Überlegungen über den Staat, das Führertum und das Recht. Die zentrale Freundschaftserfahrung liegt für Koellreutter im Gemeinschaftserlebnis der Frontsoldaten des Ersten Weltkriegs. Dieses

48 Vgl. Otto Koellreutter: Volk und Staat in der Weltanschauung des Nationalsozialismus, Berlin 1935.

49 Koellreutter interpretiert Schmitt in einigen Passagen sinnentstellend, wenn er beispielsweise darauf abhebt, dass bei Schmitt ,der Kriegszustand aber der eigentliche politische Zustand" sei (Koellreutter, Volk und Staat, 1935, S. 8) oder die Feindkategorie ihren „Sinn in der Betonung des rein individualistischen Kampfmoments" sieht (ebd., S. 7). 
Erlebnis habe eine Intensität, die gemeinschaftsbildend sei. „Nicht der Feind, sondern der ,Kamerad' als der geistige Typus des Trägers der Gemeinschaft bildet deshalb für ein völkisches politisches Denken den eigentlichen politischen Begriff. “50

Indem Koellreutter auf das Fronterlebnis abstellt, verschließt er Schmitt gerade die zentrale Erkenntnisquelle für den Denktypus der völkischen Idee, da Schmitt im Gegensatz zu Koellreutter „nie eine Kugel pfeifen“ hörte, und stattdessen in der Etappe „Schriften voll schwülstigen Aesthetizismus ${ }^{\text {“51 }}$ verfasste. Daher auch Koellreutters Schluss: „Träger des heutigen politischen Denkens und politischer Gestaltung können deshalb nur Menschen sein, denen das Gemeinschaftserlebnis wirklich zuteil geworden ist. “52

Ist die „,völkische Gemeinschaft der Kern des Politischen“53, so kommt es Koellreutter anschließend darauf an, zu zeigen, wie sich das Verhältnis zwischen Volk einerseits und Staat und Recht andererseits bestimmt. Während Schmitt das Volk als die unpolitische Seite der politischen Einheit begreift, ${ }^{54}$ besteht Koellreutter gerade auf dem Freund-Status des Volks als Ausgangspunkt für alles Politische. Das Volk bestehe konstitutiv als Einheit aus ,Blut und Boden“. „Diese Wesenseinheit bildet die Grundlage für die Gestaltung des Volkes als politischer Willensgemeinschaft, der

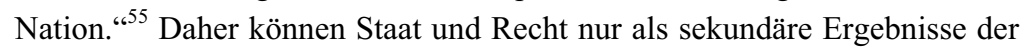
politischen Einheitsbildung begriffen werden. ${ }^{56}$ Für das Recht als völkisches Recht bedeutet dies, dass es allein auf einer völkischen Grundlage aufruhe. Völkisches Rechtsdenken soll nach Koellreutter eminent politisch sein, im Gegensatz zum sich selbst unpolitisch gebenden liberalen Rechtsdenken und im Gegensatz zum sich an der irrigen Feind-Kategorie orientierenden Denken Schmitts.

Die Kategorie des Politischen gerät daher bei Koellreutter zum zentralen Geltungsgrund des Rechts. Eine völkische Gemeinschaft gibt sich

50 Ebd., S. 9.

51 Beide Zitate finden sich in einem Brief Koellreutters an Werner Weber vom 12.06.1937, zitiert nach Jörg Schmidt: Otto Koellreutter: 1883-1972. Sein Leben, sein Werk, seine Zeit, Frankfurt a.M. 1995, S. 86.

52 Koellreutter, Volk und Staat, 1935, S. 9.

53 Ebd., S. 10.

54 Vgl. Schmitt, Staat, Bewegung, Volk, 1993, S. 12.

55 Koellreutter, Volk und Staat, 1935, S. 11.

56 Vgl. ebd., S. 12. 
Recht, das seine Geltung aus funktionalen und geschichtlichen Motiven begründet, dann, wenn sie sich zu einer politischen Willensgemeinschaft zusammenfindet. Dafür wird das mythische Gemeinschaftserlebnis letzter Bezugspunkt der Argumentation. Das Recht dieser völkischen Gemeinschaft hat dann eine funktionale Balance zwischen subjektiven Gerechtigkeitsansprüchen und völkischen Lebensnotwendigkeiten herzustellen. Es kann aber auch nur von den Angehörigen einer völkischen Gemeinschaft als legitimes Recht erlebt werden. Die Angehörigkeit zu einer völkischen Gemeinschaft bestimmt sich dabei nicht allein über die Voraussetzung einer Gemeinschaft in ,Blut und Boden“. Notwendige Bedingung für die Legitimität des völkischen Rechts ist das subjektive Erlebnis der völkischen Gemeinschaft. Erst diese subjektiv erlebte Teilhabe an einer Kultur- und Schicksalsgemeinschaft in besonderen historischen Krisensituationen ebnet den Weg für eine völkische Willensgemeinschaft. Wem dieses völkische Gemeinschaftserlebnis nicht zu teil wurde, dem bleibt auch die Legitimität des völkischen Rechts verschlossen. ${ }^{57}$

\section{REINHARD HÖHN UND DAS RASSISCH GEWENDETE RECHTSDENKEN}

\subsection{Dekonstruktion: Die juristische Staatsperson und die formale Konstruktion von Werten}

Höhn ist von den drei analysierten Autoren aus der Zeit des Nationalsozialismus der, unjuristischste‘. Er zeigt wenig Interesse an systematischen Fragen der Rechtsgeltung. So gerät ihm seine Dekonstruktion der

57 Konträr zu diesen Ergebnissen steht die Systematik politischer und vitalistischer Verfassungslehren von Majer, Rechtstheoretische Funktionsbestimmung, 2002, S. 7. Danach sind Koellreutter und Reinhard Höhn Vertreter der sogenannten „vitalistischen Verfassungslehre“, derzufolge kontingente kulturelle und geschichtliche Faktoren der Gemeinschaftsbildung ausgeblendet werden und die „Frage nach der einheitsbildenden Kraft im Staat“ (ebd.) von Koellreutter nicht beantwortet wird. Koellreutter (Der Deutsche Führerstaat, 1934, S. 7) spricht aber beispielsweise von der „Kultur- und Schicksalsgemeinschaft“ als Voraussetzung für die Einheitsbildung eines durch ,Blut und Boden' zusammengehörenden Volkes. Dazu zähle insbesondere das Kameradschafts- und Fronterlebnis des Ersten Weltkrieges als Erweckungserlebnis der nationalsozialistischen Bewegung. Diese Merkmale lassen Koellreutter als einen Vertreter einer politischen Verfassungslehre erscheinen. 
Geltungsgründe des liberalen Rechts auch wenig innovativ. Er schließt einerseits an die von Koellreutter vertretene Meinung an, wonach jede Zeit ihr eigenes Denken mit eigenen Ideen und Anschauungen hervorbringt und damit maßgeblichen Einfluss auf die Gestaltung von Staat und Recht nimmt. Sobald sich dieses Denken verändere, stünden Staat und Recht dazu in einem Widerspruch, was eine Anpassungsleistung herausfordere. Andererseits bedient er sich bei der Darstellung der neuen Ideen und Anschauung dem Begriffsarsenal des konkreten Ordnungsdenkens von Carl Schmitt. Gleichzeitig zeigt Höhn eine interessante Distanz zu jenen rechtsphilosophischen Erwägungen, die bestehende Rechtsordnungen unter Verweis auf überpositive, ewige Rechtswerte kritisieren.

Originell ist Höhn jedoch in seiner ideen- und rechtsgeschichtlichen Herleitung des Widerspruchs zwischen dem neuen gemeinschaftsbasierten Rechtsdenken einerseits und den alten Staats- und Rechtsstrukturen andererseits. So nimmt Höhn zwar ebenfalls das individualistische Denken als den Ausgangspunkt des Problems liberal-demokratischer Rechtsstaatlichkeit. ${ }^{58}$ Er begreift das individualistische Rechtsdenken jedoch nur als den markantesten Ausdruck eines übergreifenden Problems der souveränen Staatlichkeit. Erst souveräne Staatlichkeit mache den Individualismus mit seinen Rechtsansprüchen und Rechtspositionen möglich. Souveräner Staat auf der einen Seite, Individuen auf der anderen Seite müssen so als Erscheinungsformen einer notwendigen geschichtlichen Entwicklung verstanden werden, an deren Ausgangspunkt die solidarische Volksgemeinschaft stand. ${ }^{59}$ Gerade die souveräne Allmacht von Fürst und Staat habe die Entwicklung individueller Rechtspositionen gegen den Staat notwendig

58 Vgl. Reinhard Höhn: Vom Wesen der Gemeinschaft, Berlin 1934, S. 15-16.

59 Höhn begreift diesen Aspekt nicht systematisch, sondern geschichtlich. Dabei folgt er einem historiographischen Phasenmodell, an dessen Beginn die unverstellte germanische Volksgemeinschaft steht. Diese wird dann in verschiedenen Entwicklungsstufen vom souveränen Fürsten über den souveränen Staat als juristischer Persönlichkeit abgelöst. Hier habe die liberale Entgegensetzung von subjektiven Schutzrechten und allmächtiger Herrschaftsform ihr historisches Recht. Vgl. zu diesem geschichtlichen Entwicklungsmodell Reinhard Höhn: Vom Wesen der Gemeinschaft, 1934, S. 21-24. Ausführlicher ist dies nachzulesen in ders.: Die Wandlung im staatsrechtlichen Denken, Hamburg 1934, S. 13-33; ders.: Der individualistische Staatsbegriff und die juristische Staatsperson, Berlin 1935 sowie ders.: Volksgemeinschaft und Rechtsgemeinschaft, Hamburg 1935. 
gemacht. Darin liege das Verdienst des liberalen Denkens. ${ }^{60}$ Jedoch verkomme das liberale Denken zu einer leeren Idee, die von der neuen Idee der Volksgemeinschaft verdrängt werde.

Dieser Verdrängungsprozess ist für Höhn eine schwierige Phase des Umbruchs, in der die Begriffe neu geordnet werden müssten. Sämtliche juristische Begriffe bedürften danach einer Neubewertung auf der Grundlage einer ,gemeinschaftsmäßigen Grundhaltung ${ }^{\text {c61 }}$. Fehler seien dabei unausweichlich. So versuche sich das neue Rechtsdenken durchaus von Vorstellungen des Individualismus zu lösen und die Begriffe auf gemeinschaftliche Vorstellungen umzupolen. Diese Strategie sei jedoch zum Scheitern verurteilt, wenn die übergreifende Vorstellung von der juristischen Staatsperson als zentraler liberaler Staats- und Rechtsgedanke nicht auch verabschiedet werde. ${ }^{62}$ In einer nationalsozialistischen Volksgemeinschaft gebe es keinen Gegensatz mehr zwischen den Einzelnen und der Gemeinschaft, folglich sei es auch nicht mehr notwendig, Konstruktionen von Individuum und Staat zu verwenden. Es sei sogar schädlich, weil es die Weiterentwicklung des Rechtsdenkens hemme. Dies zeige der Versuch, die Volksgemeinschaft als Rechtsgemeinschaft zu denken. Gerade der Begriff der Rechtsgemeinschaft atme den Geist des Gegensatzes von Individualismus und souveräner Staatlichkeit. Verständlich wird diese Behauptung Höhns nur vor dem Hintergrund der Annahme, dass die - pejorativ gemeinte Rechtsgemeinschaft lediglich atomisierte Individuen zusammenfasse, die als einander Gleiche vor dem Recht begriffen werden. Dieses ,Begreifen“ als intellektuelle Tätigkeit führt für Höhn, wie alle Vorstellungen des liberalen Rechts in formale Konstruktionen, die nichts mit dem Leben der Volksgemeinschaft zu tun haben. Insofern verschärft er Schmitts konkretes Ordnungsdenken als Gegenentwurf zum juristischen Positivismus des 19. Jahrhunderts noch einmal. Rechtswerte sind nur noch idealisierte, und damit: inhaltsleere Bestimmungen. „Gerechtigkeit als Wert“63 existiert nicht. Ein solcher Rechtsnihilismus wendet sich konsequent in die Parolen

60 Höhn gibt sich in der Bewertung des Liberalismus sehr viel konzilianter als Schmitt, der eine historische Leistung des Liberalismus aus seiner konservativen Gegnerschaft heraus nur schwer anzuerkennen vermag.

61 Höhn, Die Wandlung im staatsrechtlichen Denken, 1934, S. 42.

62 Vgl. ebd., S. 15.

63 Höhn, Volksgemeinschaft, 1935, S. 80. 


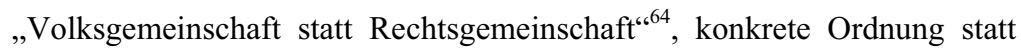
positivem Recht, Gemeinschaftsrecht statt subjektivem Rechtsschutz.

\subsection{Konstruktion: ,Blut“}

Höhn behandelt die Geltungsgründe eines ,gemeinschaftsmäßigen` Rechts der konkreten Ordnungen des deutschen Volkes aus einer anderen Perspektive, als dies bei Schmitt und Koellreutter mit der Rechtsquellenlehre geschieht. Stattdessen erarbeitet sich Höhn einen Zugang zum Problem der Rechtsgeltung über die staatsrechtliche Frage nach der politischen Einheit. Sämtliche bereits bestehende Ansätze, seien dies die Integrationslehre von Smend, ${ }^{65}$ die Repräsentationstheorie von Gerhard Leibholz ${ }^{66}$ oder die Schicksalsgemeinschaft von Koellreutter, werden als formale Konstruktionen einer lebensfernen Anschauung, die bloß Werte und Ideen vorstellen, zurückgewiesen. ${ }^{67}$ „Eine Gemeinschaft, die lediglich in einer Welt der Vorstellungen vorhanden ist, ist nicht in der Lage, den Menschen voll zu erfassen und will es auch nicht. “68

Oder um es mit den Worten eines anderen Autors der Zeit zu sagen: „Blut, nicht eine Idealität“69 ist der Ursprung der politischen Einheit. Somit kann nur die rassisch homogene Volksgemeinschaft die legitime Größe im Prozess der Einheitsbildung sein. Ihre Ordnung als „,konkrete Gemeinschaft ist der Ausgangspunkt des Rechts “70. Damit macht sich Höhn auch in dieser Hinsicht anschlussfähig für das konkrete Ordnungsdenken von Carl Schmitt, ohne im Einzelnen dessen Schlussfolgerungen zu übernehmen. Stattdessen konkretisiert er das Ordnungsdenken, indem er die Grundbegriffe der Gemeinschaftsbildung auf „Blut und Boden, Volk, Gemeinschaft und Führer“"71 begrenzt. Das Recht ist dann nicht mehr identisch mit positiv

64 Ebd., S. 72.

65 Vgl. Smend, Verfassung und Verfassungsrecht, 1994.

66 Vgl. Gerhard Leibholz: Das Wesen der Repräsentation unter besonderer Berücksichtigung des Repräsentativsystems. Ein Beitrag zur allgemeinen Staatsund Verfassungslehre, Berlin 1929.

67 Vgl. für die Kritik an Smend und Leibholz die Passagen in Höhn, Volksgemeinschaft, 1935, S. 46-47 und für die Kritik an Koellreutter ebd., S. 73.

68 Höhn, Volksgemeinschaft, 1935, S. 74.

69 Andreas Pfenning: Gemeinschaft und Staatswissenschaft. Versuch einer systematischen Bestimmung des Gemeinschaftsbegriffes, in: Zeitschrift für die gesamte Staatswissenschaft 96 (1936), S. 299-318, hier: S. 313.

70 Höhn, Volksgemeinschaft, 1935, S. 61.

71 Ebd., S. 70. 
gesetztem Recht. Höhn begreift stattdessen „Recht als Gemeinschaftsordnung ${ }^{\text {(772 }}$, Recht also, das sich vorfindbar aus bereits bestehenden, etablierten und in Krisenzeiten bewährten Ordnungen herausarbeiten lässt. Höhn kann somit in Übereinstimmung mit Diemut Majers Systematik als ein Vertreter einer vitalistischen Verfassungslehre gekennzeichnet werden, die Aussagen allein auf organisch gedachte Volksgemeinschaften bezieht und dabei ,Blut und Boden ${ }^{6}$ zum Ausgangspunkt des Rechtsdenkens nimmt. ${ }^{73}$

Mit der Beschränkung auf das Blut als entscheidendem Faktor der Volksgemeinschaft löst Höhn ein Problem der nationalsozialistischen Rechtswissenschaft, das Koellreutter mit der Kultur- und Schicksalsgemeinschaft implizit in die Diskussion eingespeist hat: In der Schicksalsgemeinschaft der Frontsoldaten sind auch Deutsche jüdischen Glaubens und jüdischer Herkunft enthalten. Das euphemistisch genannte Gesetz zur Wiederherstellung des Berufsbeamtentums von 1933 sah sich ebenfalls dieser Problematik ausgesetzt. ${ }^{74}$ Aus Sicht der Nationalsozialisten löste das Gesetz diese Schwierigkeit durch Ausnahmetatbestände ( 33 Abs. 2) für jene Beamte, die dieser Schicksalsgemeinschaft der Frontsoldaten faktisch angehörten. Dass die Ausnahmetatbestände lediglich als Zugeständnis an das Gerechtigkeitsempfinden der Zeit begriffen werden müssen, zeigt die Praxis der Anwendung des Gesetzes, das in vielen Fällen durch Funktionsträger der Nationalsozialisten hintertrieben wurde. ${ }^{75}$ Trotzdem blieben jüdische Beamte ein Problem für die nationalsozialistische Ideologie. Mit der Beschränkung auf den Faktor ,Blut' sind schließlich auch als, volksfremd' bezeichnete Frontsoldaten aus der Volksgemeinschaft ausgeschlossen.

72 Ebd., S. 16.

73 Vgl. für diese Zuordnung Majer, Rechtstheoretische Funktionsbestimmungen, 2002.

74 Vgl. Gesetz zur Wiederherstellung des Berufsbeamtentums vom 7. April 1933, RGB1. I 34, S. 175-177.

75 Anna Maria Gräfin von Lösch zeigt diese Praxen paralegaler Vertreibung jüdischer Professoren aus ihren Ämtern am Beispiel der Berliner rechtswissenschaftlichen Fakultät. Vgl. dazu Anna-Maria Gräfin von Lösch: Der nackte Geist. Die Juristische Fakultät der Berliner Universität im Umbruch 1933, Tübingen 1999, S. 143-219 und S. 301-375. 


\subsection{Geltungsgrund des Rechts: Rassisches Gemeinschaftsdenken}

Der Geltungsgrund des Rechts findet sich bei Höhn im Gemeinschaftsdenken. Diese Geltungsgründe sind ganz und gar unjuristisch. Höhn macht sich auch nicht die Mühe, diese Geltungsgründe in eine juristische Sprache einzufassen. Stattdessen wird das Gemeinschaftsdenken, wie Michael Stolleis bemerkt hat, mythisch überhöht und nie präzise definiert. ${ }^{76}$ Die Werte der Gemeinschaft sind bei Höhn so unklar, wie absolut verbindlich. Gemeinschaftsrechte können nur den Gemeinschaftsgenossen zuteilwerden, die das Gemeinschaftsrecht ,gefühlsmäßig auf Gemeinschaftsboden“677 stehend anerkennen. Aus der Exklusivität von ,Blut und Boden“ bezieht Gemeinschaftsrecht seine stabilisierende Funktion für die konkreten Ordnungen. Die Bindungswirkungen des Gemeinschaftsrechts begründet Höhn nicht etwa wie Koellreutter mit dem Versuch einer rationalistischen Begründung eines faktisch stattgefundenen Gemeinschaftserlebnisses. Vielmehr sieht er die völkische Persönlichkeit bereits von einem Gemeinschaftsgeist durchdrungen.

„Die Einzelperson legt in der Gemeinschaft ihre Einzelpersönlichkeit ganz ab, sie fühlt sich nicht mehr als Einzelperson, sie geht auf im Gemeinschaftsgeist und handelt aus dem Gemeinschaftsgeist heraus. Sie wird Träger dieses Geistes und ist dann auch bereit, zu opfern und zu dulden, selbst wenn ihre einzelpersönlichen Interessen dadurch auf das schwerste geschädigt werden.“78

Die Opferbereitschaft des Individuums ist hier noch das deutlichste Zeichen für die Legitimität der Geltungsgründe des Rechts, dessen Charakter sich seinerseits vollkommen wandelt. Dieser begriffliche Wandel wird am Verhältnis von Volksgemeinschaft und Führer deutlich.

In einer Volksgemeinschaft besteht ein - nicht durch demokratische Wahlen zu durchschneidendes - Band zwischen Gemeinschaft und Führung. Hitler ist so weder ein demokratisch gewählter, noch ,souveräner Herrscher, er ist Führer und kann als solcher keine Untertanen, sondern nur

76 Vgl. Michael Stolleis: Gemeinschaft und Volksgemeinschaft, in: ders.: Recht im Unrecht. Studien zur Rechtsgeschichte im Nationalsozialismus, Frankfurt a.M. 1994, S. 94-125, hier: S. 121-125.

77 Höhn, Vom Wesen der Gemeinschaft, 1934, S. 14.

78 Ebd., S. 15. 
Gefolgsleute haben“"79. Die Verbindung zwischen Volk und Führer besteht aus Befehl und Gehorsam, Autorität und Vertrauen. Dem Führer obliegt es, dem Willen der Volksgemeinschaft zum Ausdruck zu verhelfen. Er handelt „im Geiste der Gemeinschaft ${ }^{\star{ }^{80}}$. ,Gemeinschaftsgeist ${ }^{\star}$ und ,Geist der Gemeinschaft tauchen so in verschiedenen Kontexten auf, werden auf das konkrete Recht konkreter Ordnungen bezogen und sollen erklären helfen, warum die Volksgemeinschaft nicht nur ihrem eigenen, bereits vorhandenen und praktizierten Ordnungsrecht Verbindlichkeit zuspricht, sondern auch, warum dem Führer Gehorsam für seine im Geiste der Gemeinschaft gegebenen Befehle bis zur Selbstaufgabe gebührt. Gemeinschaftsdenken wird somit Mittel und Zweck der Argumentation. ${ }^{81}$ Als Mittel ist das Gemeinschaftsdenken jene Ressource, die den Gemeinschaftsgeist im Einzelnen und dessen Opferbereitschaft hervorrufen soll. Das Gemeinschaftsdenken soll aber gleichzeitig auch der Zweck sein, den der Führer im Auge hat, wenn er seiner Gefolgschaft jene Befehle gibt, die erst „das ganze Volk zur Volksgemeinschaft ${ }^{\star{ }^{82}}$ verbinden sollen.

Diese Ambivalenz des Geltungsgrundes zwischen Mittel und Zweck ist das Ergebnis einer Argumentation, die sich von klaren Begrifflichkeiten fernhält und stattdessen mythische Untiefen auslotet. Kelsen, der diese geistige Strömung schon am Abend der Weimarer Republik erfasste, kritisiert an ihr die Geeignetheit zur Verschleierung der dann ins monströse kippenden Herrschaftstechniken der Nationalsozialisten:

„Fort von der jetzt als Flachheit verschrieenen Klarheit des empirisch-kritischen Rationalismus, diesem geistigen Lebensraum der Demokratie, zurück zu der für Tiefe gehaltenen Dunkelheit der Metaphysik, zum Kultus eines nebulosen Irrationalen, dieser spezifischen Atmosphäre, in der seit je die verschiedenen Formen der Autokratie am besten gediehen sind. ${ }^{\text {(83 }}$

79 Höhn, Die Wandlung, 1934, S. 36.

80 Ebd., S. 40.

81 Diese Ambivalenz, wonach die völkische Anschauung einerseits als Voraussetzung der politischen Gemeinschaft gedeutet wird, andererseits aber die völkische Anschauung unter den Volksgenossen ein anzustrebende Ziel nationalsozialistischer Politik sei, findet sich auch bei Koellreutter und Schmitt. Bei Höhn gerät das Gemeinschaftsdenken zum zentralen Geltungsgrund des Rechts.

82 Höhn, Die Wandlung, 1934, S. 35.

83 Hans Kelsen: Verteidigung der Demokratie, in: ders./Norbert Leser (Hrsg.): Demokratie und Sozialismus. Ausgewählte Aufsätze, Wien 1967, S. 60-69, hier: S. 61. 


\section{Karl Polak UND deR historische MATERIALISMUS}

\subsection{Dekonstruktion: Formalismus in Recht, Demokratie, Staat}

Aus der Perspektive des wissenschaftlichen Marxismus ist die bürgerliche Staats- und Rechtswissenschaft in ihrem Klassenstandpunkt gefangen. Als Instrument der Bourgeoisie diene sie zwar zunächst der Befreiung des Individuums von feudaler und absolutistischer Herrschaft. Jedoch wende sie sich dann in eine wissenschaftsferne Apologie, wenn die bürgerliche Klasse einmal die Macht über Staat und Recht errungen hat. ${ }^{84}$ Die Wissenschaft der bürgerlichen Klasse „,beschränkt sich auf die Darlegung der Formen der Herrschaft ihrer Klasse, auf die bloße Deskription der äußeren Erscheinungsformen, in denen sich die Abstraktionen der gesellschaftlichen Entwicklung ausdrückt ${ }^{485}$. Da sie nicht die Einsichten in die historischen Notwendigkeiten habe und daher in ihrem Bewusstsein als bourgeoise Wissenschaft gefangen bleibe, stellt sie sich sowohl der geschichtlichen Entwicklung entgegen, als sie auch der Entwicklung der sozialistischen Staats- und Rechtswissenschaft hinterherläuft. ${ }^{86}$ Dabei wird eine Doppelstrategie verfolgt: Erstens versuche die bürgerliche Staats- und Rechtswissenschaft sich den wissenschaftlichen Einsichten der geschichtlichen Entwicklungsprozesse mit dem Argument einer reinen Rechtswissenschaft, die streng von metajuristischen, politischen und weltanschaulichen Erwägungen zu trennen sei, zu verschließen. Zweitens werden mit dem strategischen Beharren auf der Abstraktion allgemeiner Begriffe und den Ewigkeitswerten ,Recht' und ,Staat' die realen Entwicklungstypen von Recht und Staat der Erkenntnis entzogen. ${ }^{87}$ Mit der „Widerspiegelung der Entwicklung des Klassenbewußtseins der Bourgeoisie ${ }^{\text {c88 }}$ in ihren allein deskriptiven Ansätzen würde lediglich der status quo aufrecht erhalten.

Die Geltungsgründe des Rechts der bürgerlichen Gesellschaft stellt Polak in eine historische Entwicklungsperspektive. Zunächst habe die

84 Vgl. Karl Polak: Marxismus und Staatslehre, in: ders.: Zwei Aufsätze zur Staatsund Rechtstheorie, hrsg. von Max Fechner, Berlin 1948, S. 5-42, hier: S. 29.

85 Karl Polak: Zur Dialektik in der Staatslehre, Berlin 1963, S. 213.

86 Vgl. ebd., S. 204-213.

87 Vgl. ebd., S. 214.

88 Ebd., S. 213. 
bürgerliche Staats- und Rechtswissenschaft den Staat aus Geltungsgründen der ,Vernunft‘ oder der ,Natur' abzuleiten versucht. Diese Begründungsversuche, die auf Geltungsressourcen außerhalb der Ordnung verweisen, erscheinen dem juristischen Positivismus auf dem Höhepunkt seiner Macht wie „,Kinderkrankheiten“ der Staatsrechtslehre“ ${ }^{\text {c89 }}$. Jedoch kann der dann voll ausgebildete Positivismus auf jene Geltungsgründe verzichten, die außerhalb des Geltungszusammenhangs von Recht und Politik liegen. Dies ist aber nicht deswegen möglich, weil der Positivismus eine bessere, immanente Begründung der Ordnungsgeltung gefunden habe. Die Geltungsgründe werden stattdessen durch die gesellschaftliche Entwicklung, deren Analyse der juristische Positivismus gerade verweigert, hervorgebracht. Es ist die, durch die politische Macht des Bürgertums gesicherte Evidenz der Ordnung, die nicht mehr hinterfragt wird:

„Die Ideologen des Positivismus halten die Herausbildung des bürgerlichen Staates für den Endpunkt der Entwicklung. In dem Augenblick, wo das Resultat da war und der ,Staat` seine ganze Macht durchzusetzen vermochte, hielt man solche Stützen und Rechtfertigungen für überflüssig. Der Staat rechtfertigt sich selbst durch seine Existenz und die Wirksamkeit seines Rechts. ${ }^{\text {“90 }}$

Das Recht ist jedoch nur eine historische Erscheinungsform und spezifisches Machtinstrument der jeweils herrschenden Klasse. Die bürgerliche Rechtswissenschaft gehe zwar von abstrakten Normen und vom Ewigkeitswert des Rechts aus. Dies sei jedoch eine Strategie der Herrschaftssicherung und Unterdrückung der Arbeiterklasse. Denn: „Es gibt kein Recht, an sich “. ${ }^{،}{ }^{91}$ Besondere Merkmale des bürgerlichen Rechts sind seine Formalität, sein Beharren auf der Rechtsgleichheit und der Annahme der Neutralität des Rechts als Instrument zur Steuerung und Kontrolle staatlichen Handelns. ${ }^{92}$ Polaks Bestimmung des Wesens des bürgerlichen Rechts bewegt sich dabei in bemerkenswerter Nähe zu Carl Schmitt. Danach ist das bürgerliche Recht nur „eigentlich Gesetzesrecht ${ }^{\star 93}$. Im Unterschied zum Recht hat das Gesetz die Eigenschaft der Formalität: „Das Gesetz [...]

89 Ebd., S. 216.

90 Ebd., S. 216-217.

91 Ebd., S. 264.

92 Ebd., S. 287.

93 Polak, Marxismus und Staatslehre, 1948, S. 39. Schmitt spricht vom „Gesetzesstaat", der dem Recht entgegengesetzt ist. Vgl. dazu Schmitt, Nationalsozialismus und Rechtsstaat, 1934 sowie Schmitt, Über die drei Arten, 1993. 
abstrahiert vom realen Leben, von den wirklichen Beziehungen der Menschen zueinander. “94

Die Allgemeinheit des Gesetzes, die die Gleichheit der Bürger vor dem Recht gewährleisten soll, kehrt sich hier in den Vorwurf des Formalismus um. Abstraktes Recht produziert so formales Recht. Es erfasst nicht mehr die Lebensumstände der Rechtsunterworfenen, und ist stattdessen nur noch Herrschaftsinstrument.

„Der wirkliche Mensch, die konkret-gesellschaftlichen Beziehungen des wirklichen Lebens verschwinden aus diesem Recht. Es ist beherrscht von bloßen Fiktionen, von in abstrakte Formen gebrachte Beziehungen abstrakt gefaßter Individuen - eine Geisterwelt, in der abstrakte Gesetze herrschen statt des lebendigen Lebens. “95

\subsection{Konstruktion: Recht als Instrument der Politik}

Der Ausgangspunkt eines sozialistischen Staats- und Rechtsbegriffes ist für Polak die intensive Auseinandersetzung mit dem bürgerlichen Recht. Der Kampf um ,sozialistische Organisationsformen in Staat und Recht“ ist ein Kampf „mit der bürgerlichen Methode des Staats- und Rechtsdenkens ${ }^{\text {“96 }}$. Allgemeingültigkeit und Ewigkeitsanspruch bürgerlichen Rechtsdenkens und bürgerlicher Rechtswerte sind allein schon dadurch in Frage gestellt, dass die Einsicht in den Klassenstandpunkt sowie die geschichtlichen Gesetzmäßigkeiten die ,zeitliche Bedingtheit““97 des bürgerlichen Rechts aufgedeckt haben.

„Die abstrakt normative Methode, die vielfach heute noch als ,juristische überhaupt gilt und überall dort angewandt wird, wo von rechtlichen Institutionen die Rede ist und juristisches Denken gefordert wird, muß an ihren historischen Ort gestellt und als das erkannt werden, was sie wirklich ist: die bürgerliche Methode, Fleisch vom Fleische der bürgerlichen Staatsmacht, der Macht des Kapitals, die Methode der Unterwerfung der Gesellschaft und der Praxis der Menschen unter diese Macht. Die

94 Polak, Marxismus und Staatslehre, 1948, S. 39.

95 Ebd. Polaks Formulierung von der ,Geisterwelt abstrakter Begriffe“ steht Schmitts Formulierung von der "Gespensterwelt von Allgemeinbegriffen“ gegenüber. Vgl. Schmitt, Nationalsozialistisches Rechtsdenken, 1934, S. 225.

96 Polak, Dialektik, 1963, S. 201.

97 Ebd. 
bürgerliche Methode entwickelt sich und wurde in dem Maße herrschend, wie die bürgerliche Klasse sich entwickelt hat und herrschend wurde.، “98

Für die Politik der Partei würde ein Beibehalten dieser Methode zu dramatischen Konsequenzen führen. Wissenschaft und Praxis der marxistischen Herrschaft würden auseinanderfallen. Klar ist, dass die Wissenschaft dies durch eine Anpassungsleistung verhindern muss. Sie habe sich auf die Einsichten der historischen Gesetzmäßigkeiten umzustellen, wo sie dies noch nicht geleistet hat und deswegen der voranschreitenden Partei nur hinterher eilt.

Das erkenntnistheoretische Problem der bürgerlichen Rechtsanschauung sei ihre statische Sichtweise, die sie daran hindert, zu erkennen, dass die Gesellschaft sich in einem historischen Entwicklungsprozess befinde. Daher hält sie ,den bürgerlichen Staat und sein Recht für den Staat und das Recht überhaupt ${ }^{* 99}$. Solange Teile der sozialistischen Staatsrechtswissenschaft dieses Erbe der bürgerlichen Rechtswissenschaft nicht überwinden, entfernen sie sich von der Praxis der marxistisch-leninistischen Partei. Eine Hinwendung bestehe jedoch nicht einfach in der empirischen Reflektion der praktischen Arbeit der Partei. Polak spricht der Rechtswissenschaft stattdessen eine Führungsrolle in der geschichtlichen Entwicklung zu: Aufgabe der Staats- und Rechtswissenschaft sei es ,die Leitung des gesellschaftlichen Umwälzungsprozesses vom Kapitalismus zum Sozialismus ${ }^{\text {“100 }}$ zu übernehmen. Daher ist es „Aufgabe der Staatswissenschaft, die geschichtliche Notwendigkeit und Gesetzmäßigkeit dieser Bewegung darzulegen“"101. Danach bestimmt sich der Begriff des sozialistischen Rechts als ein Instrument der Politik zur Durchsetzung der historischen Gesetzmäßigkeiten. Dieses Instrument wird von der Staats- und Rechtslehre entwickelt und in die Hände der Partei der Arbeiterklasse gelegt. Rechts- und Staatsbegriff sind so zunächst den Mystifikationsversuchen der bürgerlichen Rechtswissenschaft zu entziehen. Das Recht dürfe nicht mehr als neutrales Instrument der Steuerung von Staat und Gesellschaft begriffen werden. Ein ,neutraler Staat‘ wäre ein bürgerlicher Klassenstaat, der weiterhin mit seiner Bürokratie herrschen würde. Ein solcher Klassenstaat gehört jedoch dem alten System antidemokratischer, reaktionärer und auto-

98 Ebd. (Hervorhebung im Original).

99 Ebd., S. 202 (Hervorhebung im Original).

100 Ebd., S. 203.

101 Ebd. 
ritärer Staatlichkeit an, die Kriege vorbereite, Völker unterdrücke und ausbeute sowie demokratische Rechte und Freiheiten negiere. In dieser Hinsicht sei der Staat nicht neutral. Deswegen muss die sozialistische Staatsund Rechtswissenschaft einen neuen Staat errichten, der ebenfalls nicht neutral ist und der auf wahrer Volksdemokratie aufruhe. Die alten bürgerlichen, formal-demokratischen Einrichtungen müssten beseitigt werden. Dieser sozialistische Staat habe zu allererst das Wohl das Volkes zu befördern und damit vor allem die Arbeiter zu bevorzugen. Sein Recht könne damit gar nicht nach dem Prinzip der Gleichheit operieren. ${ }^{102}$

\subsection{Geltungsgrund des Rechts: historische Gesetzmäßigkeit und der Genius des Tatmenschen}

Wenn das sozialistische Recht seine Geltung nicht aus Rechtswerten, wie Gleichheit bezieht; und wenn die Rechtssicherheit, konsequent gedacht, ebenfalls als Geltungsgrund wegfällt, da Recht keinen Wert an sich hat, zeitlich bedingt ist und immer nur der Durchsetzung der jeweils herrschenden Klasse dient, dann muss der Geltungsgrund des Rechts für Polak außerhalb der Rechtsordnung liegen. Sozialistisches Recht ist demnach legitim, weil und solange damit die Politik der Arbeiterklasse durchgesetzt wird. Es ist ein Instrument in den Händen der Politik, dass den jeweiligen historischen Entwicklungsstufen der Arbeiterklasse angepasst werden muss. Die Politik der Arbeiterklasse beruht auf der wissenschaftlichen Einsicht in die Notwendigkeiten. Diese Notwendigkeiten ergeben sich aus den von Marx erkannten historischen Gesetzmäßigkeiten. Indem das Recht im Einklang mit diesen historischen Gesetzmäßigkeiten steht, erfüllt es die ihm spezifische Aufgabe für die Vollendung der Geschichte.

Ein Problem bleibt jedoch: Das Problem von Theorie und Praxis. Zwischen dem Moment der richtigen Einsicht in die Notwendigkeiten und dem Moment der faktischen Umsetzung dieser Notwendigkeiten tut sich für Polak ein breiter Graben auf. Die einen wissen es besser, die anderen können es besser. Die Lösung hierfür liegt zunächst in der politischen Entscheidung der Wissenschaft, die Führungsfunktion der Partei der Arbeiterklasse anzuerkennen. Doch auch dies ist nur eine theoretische Lösung für ein praktisches Problem. Die praktischen Probleme aber häuften sich in

102 Vgl. Karl Polak: Die Entwicklung unserer Staatslehre durch Walter Ulbricht, in: Demokratischer Aufbau 7 (1953), S. 245-248, hier: S. $245 f$. 
einem Maße, dass die Rechtswissenschaft an den Rand ihrer Problemlösungskapazität kam. Dafür stehen zwei Ereignisse der jungen DDR, die auf besonders deutliche Weise den geringen normativen Wert des Rechts herausstellten. Das ist zum einen die Abschaffung der verfassungsrechtlich gesicherten Länder zwischen 1952 und $1953 .{ }^{103}$ Und das ist zum anderen der Aufstand vom Juni 1953, bei dem besonders deutlich wurde, dass das verfassungsrechtlich gesicherte Streikrecht ${ }^{104}$ keine normative Schranke für die Machthaber darstellte. Für Polak zeigte sich hier auf dramatische Weise, dass die Rechtswissenschaft ihre Orientierungsfunktion für die Gesellschaft einbüßt. Die Lösung allein darin zu suchen, die Wissenschaft unter die Partei der Arbeiterklasse zu stellen, reichte nicht aus, um den Graben zwischen Theorie und Praxis hinreichend zu schließen. Die Legitimität der Politik der Arbeiterklasse erschien dadurch, dass sie dem Recht regelmäßig ,enteilte', gefährdet. Polak findet für dieses Problem eine Lösung, die im Juli 1953 inmitten einer massiven Legitimitätskrise in der Zeitschrift ,Demokratischer Aufbau'veröffentlicht wird.

Theorie und Praxis werden im Genie und politischen Führer Walter Ulbricht versöhnt. „Mit genialem Blick sieht Walter Ulbricht"“105, in welchem Entwicklungsstadium sich die sozialistische Gesellschaft gegenwärtig befindet. Er zieht daraus zuallererst die richtigen Schlüsse, welche die Notwendigkeiten der Politik der Arbeiterklasse sind. Gleichzeitig aber ist Ulbricht derjenige, der auch die politische Durchsetzungskraft hat, um die Einsicht in die Notwendigkeiten in politische Taten zu verwandeln. Ulbricht ist der „Bahnbrecher“106 der Ideen des Sozialismus. Gerade weil in der Person Ulbricht diese Fähigkeiten zusammenfallen, ist das sich wandelnde Recht, das auf seine Einsichten in die Theorie und seine Fähigkeiten in der Praxis zurückgeht, das legitime, das historisch notwendige und schließlich: das richtige Recht.

„Walter Ulbricht schuf die Grundlagen unseres Staates durch die konkrete Anwendung der Theorie von Marx, Engels, Lenin und Stalin. Walter Ulbricht entschied die

103 In der Verfassung der DDR fand sich keine explizite Gewährleistung der Länder. Ihre Existenz wurde durch die Regelungen der Art. 71-80 Verf-DDR vorausgesetzt.

104 Vgl. Art. 14 Verf-DDR: „Das Streikrecht der Gewerkschaften ist gewährleistet.“

105 Polak, Die Entwicklung unserer Staatslehre, 1953, S. 246.

106 Ebd., S. 245. 
Staatsprobleme als der große politische Führer, [...] der von dem Bewusstsein durchdrungen ist, daß die Befreiung des Volkes nur durch die demokratische Selbstgestaltung seines ökonomischen und politischen Lebens möglich ist, und das seine Staatsmacht einsetzen muß, um diese Selbstbefreiung zu verwirklichen.“107

Polak mag diese Unterordnung unter Ulbricht als führender, aber durch Ränkespiele allgegenwärtig bedrohter Rechtstheoretiker der DDR vermutlich nicht allzu schwer gefallen sein, da er mit Ulbricht besonders eng verbunden war und diesen in allen Rechtsfragen beriet. ${ }^{108}$ Im Ergebnis aber wird der Graben zwischen Theorie und Praxis nicht durch die wissenschaftspolitische Unterordnung der Rechtswissenschaft unter die Partei der Arbeiterklasse geschlossen. Vielmehr schüttet Polak den Graben behelfsmäßig zu, indem der politische Führer kurzerhand zum ersten Wissenschaftler des Landes erklärt wird.

\section{ZUSAMMENFASSUNG}

Die destruktiven Entwertungen der immanenten Letztbegründung des juristischen Positivismus haben eine Gemeinsamkeit: Sie verweisen auf Gründe oder auf eine Bezugsgröße, die jenseits des Geltungszusammenhangs von Politik und Recht liegen. Indem die hier diskutierten Autoren den inneren Verweisungszusammenhang der Legeshierarchie des Rechts sprengen, überantworten sie die Geltungsgründe des Rechts einem Bezugspunkt, der außerhalb des Rechts und außerhalb demokratischer Politik liegt. Als metaphysischer Geltungsgrund ist dieser damit nicht mehr im Bereich des verhandelbaren Geltungszusammenhangs von Politik und Recht angesiedelt. Der Versuch, diese Geltungsgründe zu prüfen, zu kritisieren und in Frage zu stellen, wird damit nicht nur für einen demokratischen Diskurs unmöglich. Auch die wissenschaftliche Diskussion kann so zum Lackmustest der Gesinnung werden. Deutlich sichtbar wird dies an den zunehmend verschärften Geltungsbehauptungen, die in der wissenschaftlichen Konkurrenz der Staatsrechtslehre jeweils unhintergehbare, nur noch steigerbare Bezüge kennt. Damit erklärt sich auch die Tendenz zur Selbstauflösung der Rechtswissenschaft als Wissenschaft: die Geltungsgründe, die sie anruft, sind nicht mehr ihr Metier.

107 Ebd., S. 248.

108 Vgl. Howe, Karl Polak, 2002. 
Als transzendente Geltungsgründe werden so zum einen die Verweise auf eine materielle Rechtsordnung vorgestellt, die der Rechtspositivismus mit guten Gründen inhaltlich unbesetzt lassen muss. Transzendente Geltungsgründe können zum anderen auch außerrechtliche Ordnungen oder metaphysische Bezugsgrößen, wie die ,Lebensnotwendigkeiten des Volkes', das ,Blut' oder die ,historischen Gesetzmäßigkeiten' sein, die der angegriffene Rechtspositivismus nicht ausreichend berücksichtige. Materielle Rechtsvorstellungen sind bei Schmitt das ,Lebensrecht des Volkes', das in den konkreten Ordnungen Ausdruck findet. ,Recht' und ,Gerechtigkeit ${ }^{\star}$ werden dort wieder vereint, wo sie der Rechtspositivismus fälschlicherweise getrennt habe. Außerrechtliche Ordnung kann, wie im Fall Koellreutters, die gemeinsam erlebte Kameradschaft der Frontsoldaten sein. Die sich im wechselseitigen ,Erleben des Kameradschaftsgefühls" bildende politische Gemeinschaft entwickelt ein Rechtsverständnis von den Lebensnotwendigkeiten dieser sich erst im Erlebnis zusammenfindenden Gemeinschaft her. Individuelle Ansprüche werden so zugunsten des Überlebens der Gemeinschaft zurückgedrängt. Die metaphysische Bezugsgröße kann aber auch die essentielle Annahme gemeinsamen ,Blutes' sein, wie dies bei Höhn der Fall ist. Inklusion und Exklusion wirken hier durch die Vermeidung kontingenter Faktoren umso trennschärfer. Die homogene Volksgemeinschaft gewährt nur dem ,Artgleichen' das Recht, welches im Gemeinschaftsdenken seine Legitimitätsressource findet und damit den totalitären Zugriff - das Opfer für die Gemeinschaft - auf den Einzelnen rechtfertigt. Eine metaphysische Bezugsgröße kann schließlich auch die ,objektive Gesetzmäßigkeit der Geschichte' sein, der das Recht, ob es will oder nicht, zu folgen hat, wie dies von Polak behauptet wird.

In allen vier Fällen wird das Recht zur Disposition einer undemokratischen und illiberalen Politik gestellt. Recht wird so zu einer Funktion für eine andere Größe degradiert, sei es das Lebensrecht des Volkes, die Lebensnotwendigkeiten der völkischen Gemeinschaft, das notwendige Opfer für die Gemeinschaft oder schließlich die Vollendung der Geschichte. Diese Verfügbarmachung des Rechts für die Politik kann aber von Seiten der Rechtswissenschaft selbst nicht mehr kontrolliert und beschränkt werden. Es ist daher bemerkenswert, das zwei der vier Autoren trotzdem von einem gewissen Normativismus nicht lassen können. ${ }^{109}$ Sowohl

109 Ähnliche Schlüsse zieht Rüthers, Geschichten und Legenden, 2000, S. 2870, demzufolge ,auch die systemloyalen Juristen wegen ihrer normativen Denk- 
Schmitt als auch Koellreutter geben das Recht nur mittelbar in die Hand der Politik, wenn sie die Politik an den höheren Geltungsgrund der Gerechtigkeit, siehe Schmitt, oder an den Ewigkeitswert des Rechtsstaates, siehe Koellreutter, binden wollen. Faktisch ist die Gerechtigkeit eine äußerst schwache Bindung für die totalitäre Herrschaftspraxis der Nationalsozialisten, zumal auch ihre Ausdeutung allein in die Hand der Politik gelegt wurde. Ähnliches ist über Koellreutter zu sagen: Sein Beharren auf dem Ewigkeitswert des Rechtsstaates, an dem auch der nationalsozialistische Staat Anteil haben müsse, um politische Macht und rechtliche Ordnungskraft zu einem Ausgleich zu bringen, stellt ebenfalls einen normativen Standpunkt dar, mit dem faktische Erscheinungen kritisiert werden konnten. $^{110}$

Bei Polak stellt sich die Situation noch einmal anders dar. Hier wird ebenfalls ein normativer Standpunkt entwickelt, der die Rechtsordnung transzendiert. Dieser normative Standpunkt begreift sich selbst aber nicht als mythische Tiefe, sondern klarste Objektivität und Wissenschaftlichkeit. Einsichtsfähigkeit ist hier die Grundvoraussetzung, um nur noch das zu vollziehen, was die geschichtliche Gesetzmäßigkeit ohnehin einfordern werde. Die Übereignung des Rechts in die Hände der Politik wird so als das Ergebnis notwendiger wissenschaftlicher Erkenntnis dargestellt.

Das, für konstitutionelle Demokratien, typische Spannungs- und Balancierungsverhältnis von Politik und Recht wird in jedem analysierten Fall als Fessel begriffen und zugunsten eines Primats der Politik aufgelöst. Keine der hier vorgestellten Konstruktionen gibt sich die Mühe, das Recht als eine autonome Größe neben der Politik zu behaupten und zu begründen. Keine der hier vorgestellten Konstruktionen sieht im Recht einen Eigenwert, dessen Behauptung gegenüber der politischen Macht als lohnenswertes Ziel ausgegeben wird.

weisen fast regelmäßig irgendwann Probleme mit den jeweiligen Machthabern" bekamen.

110 Genau dieses kritische Potential wurde Koellreutter auch von Forsthoff mit Blick auf die Konzentrationslager vorgeworfen, denen Koellreutter in Verkennung der neuen Machtlage einen außerrechtlichen Zustand attestiert habe. Vgl. dazu noch einmal Koellreutter, Der Deutsche Führerstaat, 1934 sowie Forsthoff, Rezension Koellreutter, 1934. 



\section{Die Willensnation Schweiz im Spannungsfeld konkurrierender Transzendenzbezüge}

Angelo Maiolino

\section{EinLeitung}

„Die Schweiz ist eine Willensnation: Sie bildet weder ethnisch noch sprachlich oder religiös eine Einheit. Seit 1848 ist sie ein Bundesstaat. Der staatliche Aufbau der Schweiz ist föderalistisch und gliedert sich in die drei politischen Ebenen Bund, Kantone und Gemeinden." ${ }^{11}$ Mit diesen Worten stellt sich die schweizerische Eidgenossenschaft auf ihrer offiziellen Internetseite vor. Dabei werden der Reihenfolge nach die sozialpsychologische, die historische und die institutionelle Dimension erwähnt. Gemeinsam bilden sie das dominante politische Narrativ und prägen das offizielle politische Selbstverständnis der Schweiz.

Der moderne Bundesstaat Schweiz, wie er 1848 gegründet wurde, baut demnach auf eine institutionelle Architektur auf, die im Föderalismus, in der direkten Einbeziehung des wahlberechtigten Volkes in die politische Entscheidungsfindung und somit in der Spiegelung des politischen Willens an die sich vollziehende Volkssouveränität ihre raison d'être findet und daran ihre Vergangenheits-, Gegenwarts- und Zukunftsgewissheit bindet. Trotz ihres flickenteppichartigen Gebildes, das aus unterschiedlichen ethnischen, sprachlichen und kulturellen Gemeinschaften besteht, entwirft sich der moderne Bundesstaat Schweiz als ein staatliches Gemeinwesen mit

1 Das Zitat ist der Selbstbeschreibung der Schweizerischen Bundesbehörden unter http://www.admin.ch/org/polit/index.html?lang=de (07.9.2012) entnommen. 
einer politischen Ordnung, die sich aus dem Willen der Zugehörigkeit und der politischen Selbst- und Mitbestimmung ihrer Bürger nährt, und so scheinbar auf starke Transzendenzbezüge, d.h. auf Diskurse und Praktiken, die soziale und politische Ordnungen im Rekurs auf Unverfügbarkeiten begründen, verzichtet. In der Performanz der politischen Willensbildung und -bekundung werden Gemeinsinnorientierungen für sprachlich, ethnisch und kulturell unterschiedliche Gemeinschaften hergestellt, womit die Willensnation auch Integrativkräfte und Zusammengehörigkeitsgefühle stärkt, die sich aus diesem Prozess der Deliberation ergeben. In dieser Auslegung präsentiert sich also das politisch-theoretische Design der Willensnation Schweiz, das bereits von den Vorvätern des Bundesstaates gemalt und mit der Entstehung des liberalen Bundesstaates 1848 verfassungsrechtlich realisiert wurde.

Diese ,Einheit in der Differenz', wie sie mit dem Begriff der ,Willensnation' versinnbildlicht wird, ruht auf dem modernen Gedanken, dass keine essentialistischen oder partikularen Eigenschaften, sondern die permanente diskursive Selbstversicherung der Bürger die Nation konstituieren. Im Schatten dieser offiziellen Narration kreuzen sich jedoch andere Diskursmuster und politische Bedeutungsreservoirs, die mit einer Logik der Homogenisierung und der politischen, sozialen und moralischen Differenzierung zwischen Eigenen und Anderen Transzendenzbezüge und festgefahrene Gemeinsinnvorstellungen an den Tag treten lassen, die das liberale Konzept der Willensnation unterhöhlen. Nun lässt sich ohne Weiteres behaupten, dass ein jedes demokratisch verfasstes Gemeinwesen neben seiner institutionellen Ausstattung, die es dem einzelnen Bürger und der einzelnen Bürgerin erlaubt, am politischen Entscheidungsprozess zu partizipieren, auch auf Transzendenzbezüge rekurrieren muss, die die überpartikularen Kriterien vorgeben, an denen die politische Gemeinschaft ihr Zusammengehörigkeitsgefühl rückversichern kann. Will ein staatliches Gemeinwesen nämlich Loyalität, Gemeinwohlüberzeugungen und so etwas wie gemeinsam geteilte und somit das politische System stabilisierende Werthaltungen und Orientierungen hervorrufen, braucht es einen Transzendenzhorizont, an dem die gemeinsinnstiftenden Merkmale aufscheinen und damit eine Homogenisierung und ein für das einzelne Subjekt vertrauensbildendes und Geborgenheit stiftendes Gemeinschaftsgefühl ermöglichen. Diese bewirken, um es mit Ernst Wolfgang Böckenförde zu sagen, „eine auch emotionale Zugehörigkeit und Gemeinsamkeit, die dahin tendiert, ein 
Stück weit auch existentiellen Charakter anzunehmen, nicht nur den Verstand, sondern auch die Seele der Menschen zu treffen“‘2.

Böckenfördes Präzisierungen sind auch für die vorliegende Analyse konkurrierender Transzendenzbezüge in der Willensnation Schweiz zentral. Sie sprechen gerade die emotionale Seite der politischen Selbstbewusstwerdung von Bürgern und Bürgerinnen aus und öffnen so die Sicht auf die politische Kultur eines Landes. Gleichwohl betont Böckenförde, dass „Homogenitätsbildung und -tragende Kräfte mehrere sein [können] ${ }^{\text {*3 }}$. Gerade für ein Staatswesen, das keine primären ethnischen, sprachlichen oder religiösen Gemeinschaftskategorien aufweisen kann und sich daher als Willensnation konzipieren und fortwährend bestätigen muss, ist die Frage nach der Homogenisierung und vor allem nach den Kriterien, die einer solchen ,Vereinheitlichung' zugrunde gelegt werden, zentral.

Die These, die hier vertreten wird, behauptet, dass die Willensnation Schweiz, auch aufgrund des Mangels einer faktisch bereitstehenden allgemeinen Identifikationskategorie wie es die gemeinsame Sprache, Ethnie oder Religion sein könnte, auf zwei dominante und wechselseitig konkurrierende Transzendenzbezüge rekurriert, deren erster im Geiste des staatstragenden Liberalismus die Unverfügbarkeit im politischen Willen der Bürger und Bürgerinnen sichtet, wohingegen der zweite, seinen Transzendenzbezug an reaktionäre und völkisch konnotierte Ideen von schweizerischer Eigenart und Homogenität knüpft. Zu fragen wäre hiermit, welchen dieser zwei Transzendenzbezüge eine Willensnation wie die Schweiz verteidigen müsste, um ihren demokratischen Idealen gerecht zu werden.

Im Folgenden wird eine kurze historische Rückblende den analytischen Boden vorbereiten, auf dem die konkurrierenden Transzendenzbezüge dieses Wechselspiel im Lichtgefälle zwischen einer schillernden und sich im institutionellen Setting manifestierenden liberal-demokratischen Selbstgewissheit und der schattenhaften, aber nicht umso weniger wirksamen sozialpsychologischen Verführungsmacht einer reaktionär-antiliberalen

2 Ernst-Wolfgang Böckenförde: Die Zukunft der Autonomie. Demokratie und Staatlichkeit im Zeichen von Globalisierung, Europäisierung und Individualisierung, in: Georg Kohler/Martin Mayer (Hrsg.): Die Schweiz für Europa? Über Kultur und Politik, München 1998, S. 63-90, hier: S. 72.

3 Böckenförde spricht sinngemäß von einer „relativen Homogenität“, die sich unter anderem an der Konfession, an einem gemeinsamen Volksbewusstsein, an einem nationalen Bewusstsein oder an einem mental verinnerlichten Erbe konstituieren kann (vgl. ebd., S. 73). 
Narration - näher untersucht werden können. Im Schlusswort werden die getätigten Untersuchungen nochmals kurz zusammengefasst und mit einem Ausblick auf die Zukunft der Willensnation Schweiz ergänzt.

\section{EINE KURZE HISTORISCHE RÜCKBLENDE}

Wie bereits erwähnt, ruht das Konzept der Willensnation auf der nicht unwesentlichen Prämisse, dass keine partikularen Eigenschaften, seien sie ethnischer, sprachlicher oder kultureller Eigenart, den transzendenten Horizont bilden, im Lichte dessen die Mitglieder des Staatswesen Identität gewinnen, sondern einzig und allein ihre Willensbekundung, ebensolche Mitglieder sein zu wollen. Dieses politische Bewusstsein, das die Nation an der „volonté générale“ spiegelt und erst hier konstitutiv werden lässt, hat den politischen Eliten des schweizerischen Bundesstaates schon von Beginn an und bereits vor der Gründung des Bundesstaates 1848 als Kompass für die Ausarbeitung einer neuen politischen Rationalität gedient. Die allzu unübersehbare sprachlich, kulturell und religiös fragmentierte Realität auf dem Territorium verlangte eine neuartige Staatskonzeption. Diese sollte die bestehenden Differenzen und Gräben zwischen den unterschiedlichen Gemeinschaften derart vereinigen, dass sie ihre Charakteristiken in einem sie umspannenden Staatswesen weiterhin ausleben konnten, ohne hierbei zentralistisch aufgezwungene Vereinheitlichungen eingehen zu müssen, aber auch ohne Segregationstendenzen aufzubauen. Ziel war somit eine Staatsverfassung, die in ihrer rechtlichen Kodierung der bestehenden Vielfalt Eingang bot und sie damit in Einheit brachte. Der Bundesstaat Schweiz wurde von Anfang an als Staat ohne Nation konzipiert, der in einem neuen institutionellen Kleid erscheint und auf eine politische Kultur des gemeinsinnorientierten Staatsbürgerbewusstseins, der „Concordia“ zwischen den verschiedenen religiösen und sprachlichen Gruppierungen und des willentlichen „Dazugehören-Wollens“ aufbaut.

So ist es bereits der Luzerner Arzt und Philosoph Ignaz Paul Vital Troxler, Student bei Schelling und Hegel sowie Verfechter der liberalen Ideen Constants, der in den 1830er Jahren für eine neue Verfassung plädiert, in welcher die bestehende und vielfältige Pluralität zur organischen Einheit, d.h. zur Nation werde. Troxler sichtete in dieser Einheit der Vielfalt die einzige Möglichkeit, um eine Schweiz zu wahren, die frei und unabhängig von den umliegenden Großmächten sei. Der Staatenbund, wie 
er zu dieser Zeit noch die politische Karte der Schweiz prägte, gab den Kantonen Verfügungsrechte und Handlungsfreiheiten, mit denen sie faktisch als selbstständige Kleinstaaten nicht nur in Konkurrenz mit ihren Nachbarkantonen - die eigene Währungen und Rechtssprechungen besaßen - treten ließ, sondern ihnen auch Tür und Tor für Allianzen und militärische Abkommen mit den Großmächten öffnete, die für die jeweiligen Eliten äußerst lukrativ waren. ${ }^{4}$ „Das Schweizervolk“ so Troxler, sei mehrmals „um seine Nationalität gebracht worden“5. Notwendigerweise müsse deshalb eine neue Form entstehen, die nicht nur die verschiedenen Realitäten und Gemeinschaften auf dem Territorium, sondern auch ,die scheinbar sich widerstreitenden Prinzipien"6 in einer neuen Form miteinander versöhnt. Damit gab Troxler schon vor der Gründung des modernen Bundesstaates diesem Begriff den Sinn, den er heute noch hat.

Dieser liberale Aristokrat hat die staatstheoretische Debatte in der Schweiz und den daraus siegreich hervorgegangenen Liberalismus wegweisend geprägt. Sein Denken reiht sich in die Tradition des politischen Liberalismus ein, der in der Selbstbestimmung des Volkes nicht nur die Existenz- und Grundbedingung für eine politische freiheitliche Ordnung, sondern auch den Stützpfeiler für eine auf Vernunft gegründete wirtschaftliche, politische und soziale Entwicklung sichtet. Mit diesem liberalen Denken verknüpfte sich auch sein Enthusiasmus für die amerikanische Verfassung. Das darin festgelegte Zweikammersystem empfahl Troxler auch für die Schweiz. In der Nation der freien und gleichen Staatsbürger sah er das Firmament am demokratischen Himmel und drängte auf eine liberale Erneuerung des schweizerischen Staatswesen, das gerade trotz der Vielfalt in Einheit und Unabhängigkeit frei und selbstbestimmt leben könne. In Amerika sah er ein ,leuchtendes und lehrreiches Beispiel einer

4 Es sei hier daran erinnert, dass das Söldnerwesen und seine ökonomische Währung, das ,Blutgeld‘, als ertragreicher Wirtschaftsfaktor auf Verträgen beruhte, die zwischen den jeweiligen Kantonsregierungen, Privatunternehmen und ausländischen Großstaaten ausgehandelt wurden, und die einer dünnen Oberschicht ein Luxusleben sowie politische Privilegien - beispielsweise das Zensuswahlrecht - ermöglichte. Ausführlicher hierzu: Tobias Kästli: Freiheitsbegriffe - Freiheitsvorstellungen. Auf dem Weg zum Nationalstaat, in: Andreas Ernst/Albert Tanner/Matthias Weishaupt (Hrsg.): Revolution und Innovation. Die konfliktreiche Entstehung des schweizerischen Bundesstaates von 1848, Zürich 1998, S. 35-47.

5 Zitiert nach: ebd., S. 45.

6 Ebd. 
Eidgenossenschaft mit Bundesverfassung und der Verbindung der Centralität mit Föderalismus"“7. Die neue Bundesverfassung von 1848 wird dann auch das Unikum einer kollektiven Regierung zwecks Eintracht unter den Sprachgruppen schaffen und Bürgerrechte, Gewaltenteilung und einen Rechtsstaat sichern. Das Konzept der Willensnation, obwohl es die geistige Grundlage dieser Verfassung darstellt, bleibt als argumentatives Instrumentarium jedoch unterbelichtet.

Erst der Blick von außen wird dieses Konzept hervorheben und an die politische Nabelschnur des modernen Bundesstaates Schweiz binden. Genauer gesagt ist es der französische Historiker Ernest Renan, der in seiner berühmten Rede „Was ist eine Nation?“, vor dem Pariser Publikum am 11. März 1882, den Begriff der Willensnation in einer klassisch gewordenen Formulierung zur Charakterisierung der Schweiz verwendet. Diese, so Renan, zählt zwar drei oder vier Sprachen, sei aber dennoch so wohlgelungen, weil sie durch Übereinkunft ihrer verschiedenen Teile entstand. Dasjenige nämlich, was beim Menschen der Sprache übergeordnet sei, so Renan weiter, ist der Wille und es ist der Wille der Schweiz, gerade trotz der Vielfalt der Idiome geeint zu sein, der eine viel wichtigere Tatsache darstellt, als eine oft nur unter Quälerei erlangte Ähnlichkeit zwischen den unterschiedlichen Menschen. ${ }^{8}$ Mit der Einführung politischer Mitbestimmungsinstrumente wie dem Referendumsrecht 1874 und der Volksinitiative 1891 erhält die Willensnation diejenigen Verfahrensmechanismen, die ihr geistiges Fundament - dem Dazugehören-Wollen - mit einer politischen Praxis verbinden, deren Resultat die performative Selbstvergewisserung seiner Teilnehmer und konstitutive Grundlage der Nation sein wird.

Neben diesen Institutionalisierungen der politischen Mitbestimmung entstehen zu dieser Zeit auch Narrative, die die Etablierung eines kollektiven Bewusstseins und einer gefühlsmäßigen Bindung der Bürger an den jungen Bundesstaat zum Inhalt haben. Im selben Jahr in dem das politische

7 Zitiert nach: Simon Netzle: Die USA als Vorbild für einen schweizerischen Bundesstaat, in: Ernst/Tanner/Weishaupt, Revolution und Innovation, 1998, S. 49-60, hier: S. 56.

8 „La Suisse, si bien faite, puisqu'elle a été faite par l'assentiment de ses différentes parties, compte trois ou quatre langues. Il y a dans l'homme quelque chose de supérieur à la langue: c'est la volonté. La volonté de la Suisse d'être unie, malgré la variété des ces idiomes, est un fait bien plus important qu'une similitude obtenue par des vexations." (Ernest Renan: Discours et Conférences, Paris 1887, S. 298f.) 
Instrument der Volksinitiative in die Verfassung genommen wird, wird der ,1. August` als nationaler Feiertag erfunden. Damit sollte den Verlierern des Sonderbundskrieges - den Katholisch-Konservativen - in dem vom siegreichen liberalen Freisinn anberaumten Bundesstaat ein Erinnerungsort und ein gemeinsames historisches Narrativ geboten werden, der auch ihnen Grund zum Feiern geben würde - die Alte Eidgenossenschaft. Die junge Confoederatio Helvetica entwarf sich 1891 somit als eine Nation, die in genealogischer Abfolge zum ,Rütli-Schwur' von 1291 stand. Dieser Schwur, der so bezeichnet wird, weil er auf dem Rütli, einer Wiese am Vierwaldstättersee, von den drei Waldstätten Uri, Schwyz und Unterwalden geleistet wurde, war ein Bündnis zur Abwehr der äußeren Feinde und zur Sicherung der Wirtschaftsinteressen und der zentralen Verkehrswege über die Alpen. In der Narration des jungen Bundesstaates wurde dieser Schwur zu einem „lieux de mémoire“9 ${ }^{\text {“9 }}$ hochstilisiert, der die Eintracht, Selbstbestimmung und gemeinsame Wehrhaftigkeit und Freiheit aller Eidgenossen versinnbildlichen sollte. Sinn und Zweck dieses Mythos war die Bereitstellung einer gemeinsamen Geschichte und schicksalhaften Verbundenheit aller Eidgenossen, die die Konkordanz zwischen Siegern und Verlierern des schweizerischen Bürgerkrieges, also zwischen katholisch Konservativen und vorwiegend protestantischen Liberalen sichern sollte.

Im Laufe der Jahrzehnte und nachdem in den 1910er und 1920er Jahren die blutige Niederschlagung der Arbeiterstreiks in Olten und Genf gezeigt hatte, dass die organisierte Arbeiterschaft und die sie repräsentierenden linken Parteien nicht mehr ruhig gehalten werden konnten, wird auch die Linke in die Regierung aufgenommen. In institutioneller und politischer Hinsicht etabliert sich damit das Prinzip der Konkordanz und der Einbeziehung des politischen Gegners, das bis heute die schweizerische Demokratie prägt. Diese Entwicklung bedeutete insbesondere für den staatsgründenden und für lange Zeit auch staatstragenden liberale Freisinn und die ihn vertretende Freisinnig Demokratische Partei (FDP) eine schmerzhafte

9 Mit den ,lieux de mémoire“ wird eine Symbolgeschichte geschrieben, in welcher die Selbstverständlichkeiten, die Deutungsmuster und gemeinsam geteilten Codes einer Gemeinschaft in gleichsam symbolischer Form verfestigt sind und durch ihre Wiederholung die Erinnerung und die Selbstverständigungsprozeduren einer Gemeinschaft prägen und eichen. Vgl. Nora, Pierre: Das Abenteuer der Lieux de mémoires, in: Francois Etienne/Hannes Siegrist/Jakob Vogel (Hrsg.): Nation und Emotion. Deutschland und Frankreich im Vergleich, Göttingen 1995, S. 83-92. 
Machtteilung. ${ }^{10}$ In politisch-kultureller Hinsicht führte sie indes zur Schärfung eines politischen Bewusstseins, das sich darüber im Klaren ist, dass demokratische Willensbildung aus Konflikten entsteht, die fern davon vermieden oder umgangen zu werden, vielmehr in ihrer Austragung geregelt, gebändigt, zivilisiert und befriedet werden müssen. Dabei geht es nicht nur darum die politische Kontroverse zu ertragen, sondern auch darum, die im Konflikt Unterlegenen nicht zu demütigen, wenngleich von diesen verlangt werden kann, dass sie ihre Niederlage, so sie nach den allgemeingültigen Regeln der Konfliktaustragung zustande kam, akzeptieren. ${ }^{11}$

Zusammenfassend lässt sich somit sagen, dass der junge Bundesstaat Schweiz von Beginn an mit dem Föderalismus, dem Subsidiaritätsprinzip zwischen den drei politischen Einheiten Gemeinde, Kanton und Staat und den zwei politischen Partizipationsschleusen für die direkte Willensbekundung des Volkes den institutionellen Boden bereitet, auf dem er sich heute noch bewegt. Gleichzeitig werden auch in politisch-kultureller Hinsicht Narrative und Orientierungsmuster etabliert, die einerseits komplementär zur institutionellen Ausgestaltung des Bundesstaates sind und diese durch das Prinzip der, Concordia' unterstützen, und andererseits auf mythisch und völkisch besetzte Unverfügbarkeiten rekurrieren, die die politischen, sozialen und kulturellen Entwicklungen des kleinen Landes im Herzen Europas in befremdlicher Weise bis heute prägen und die in ein paradoxes Verhältnis mit dem liberalen Verständnis der Willensnation treten. Beide Narrative rekurrieren auf Unverfügbarkeiten, wenngleich sie in diesem Rekurs je andere Konnotationen, Ideale und Zielvorstellungen verfolgen. Das erste Narrativ ließe sich als liberaler Rekurs auf Unverfügbarkeiten etikettieren, das zweite hingegen, als „helvetofundamentalistische" Naturalisierung des Unverfügbaren bezeichnen. ${ }^{12}$

10 Vgl. hierzu: Angelo Maiolino: Wie die FDP den Staat und die europäischen Revoluzzer rettete, in: Blick. Die Tageszeitung der Schweiz, 28.03.2012, S. 2-3 sowie ders.: Wie die FDP auf Arbeiter schiessen lässt und dann die SP in den Bundesrat holt, in: Blick. Die Tageszeitung der Schweiz, 29.03.2012, S. 3.

11 Sinngemäß auch: Kaspar Villiger: Eine Willensnation muss wollen. Die politische Kultur der Schweiz: Zukunfts- oder Auslaufmodell?, Zürich 2009, S. 25.

12 Gerade aufgrund seiner polemischen Wirkung vermag der Begriff des „Helvetofundamentalismus" die Trennlinien zwischen diesen zwei konkurrierenden Transzendenzbezügen stärker zu betonen, ohne deswegen an analytischer Kraft einbüßen zu müssen, zumal die Funktionsweise dieses Fundamentalismus, wie die jedes anderen Fundamentalismus auch, auf die imperative Fundierung einer Wahrheit mittels Naturalisierung und somit angeblicher Verfügbarstellung von 


\section{Der liberale RekURS AUf UnVerfügbarkeiten}

Die Grundlage des liberalen Verständnisses der Willensnation bildet die Idee der deliberativen, direkt partizipierenden Bevölkerung. Die Selbstbestimmung des Volkes als performativer Prozess der normativen und politischen Selbstvergewisserung ist Dreh- und Angelpunkt des liberalen Verständnisses der Willensnation. Das politische und institutionelle Design der Schweiz, das auf die hohe Selbstverantwortung von Gemeinden und Kantonen und auf die politische Partizipation und die daraus sich ergebende Verantwortung der darin lebenden Bürger und Bürgerinnen für das Gemeinweisen baut, unterstreicht dieses liberale Verständnis. Mit dieser politischen Gestaltung des föderalistischen Staates entwirft sich die Schweiz nicht als dezentralisiertes, sondern als nichtzentralisiertes Land - nicht als eine Top-down-, sondern als eine Bottom-up-Demokratie. Als Willensnation ist sie auf den politischen Willen und auf die Partizipation ihrer Bürger und Bürgerinnen angewiesen. Ohne eine politisch engagierte Bürgergesellschaft, die die politischen und öffentlichen Räume zu besetzen im Stande ist und hier im Modus der Konfliktaustragung mehrheitlich getragene Entscheidungen geltend macht, bleibt die Willensnation innerlich ausgehöhlt. Um eine lebendige Demokratie ,von unten“ zu sein, muss sie also Bürger voraussetzen, die in einem hohen Maß Verantwortung für das Gemeinwohl zu übernehmen bereit sind. ${ }^{13}$ Sie muss auf eine politische Kultur der Offenheit, des gegenseitigen Respekts, der Toleranz für Minderheiten und der auf Altruismus ausgerichteten Bürgertugenden rekurrieren, damit sie die in ihr gespeicherten Quellen der Gemeinsamkeit systemstabilisierend und im Wissen ihrer Modifizierbarkeit stärken kann. Dies bedingt jedoch die faktische und im Alltag eingeübte Öffnung für das Andere, das einem in den mancherorts fremd wirkenden regionalen Bräuchen und Sitten oder im alltäglichen gesellschaftlichen Leben begegnen kann. Kurz gesagt, der Respekt für die Minderheiten und der Wunsch, diesen einen zentralen

Unverfügbarkeiten rekurrieren muss. Der Begriff des „Helvetofundamentalismus" ist einem Aufsatz von Georg Kohler entnommen. Vgl. Georg Kohler: Die eigensinnige Willensnation und Europas Verfassungslücke. Warum die Schweiz nicht so klein ist, in: ders./Mayer, Die Schweiz für Europa?, 1998, S. 11-28, hier: S. 21.

13 Vgl. auch: Paul Widmer: Willensnation Schweiz, unter: http://www.nzz.ch/ aktuell/startseite/willensnation-schweiz-1.9237274 (07.9.2012) sowie ders.: Die Schweiz als Sonderfall. Grundlagen, Geschichte, Gestaltung, Zürich 2008. 
Platz im Gemeinwesen einzuräumen und ihnen eine möglichst freie und selbstbestimmte Entwicklung - solange diese nicht mit den Grundsätzen der Verfassung kollidiert - zu gewähren, sie also nicht von einer politischen Zentrale aus an eine vorgegebene Identität anzupassen, sind weitere Eckpfeiler dieser liberal konnotierten Willensnation und der ihr zugrundeliegenden politischen Kultur.

Die Willensnation muss aber nicht nur auf den toleranten, offenen und kritikfähigen politischen Austausch seiner Bürger und Bürgerinnen zählen können, sie muss auch wollen, wie dies der ehemalige Bundesrat Kaspar Villiger im Titel seines letzten Buches betonte. ${ }^{14}$ Doch was soll sie denn wollen? Letztlich ist ja ein jeder Wille nur dann ein solcher, wenn er auf einen Zweck ausgerichtet ist. Die historische Rückblende und die bis anhin skizzierte liberale Konzeption der Willensnation lassen bereits erahnen, worauf dieser Wille zielt - auf die im Bewusstsein des gegenseitigen Respekts gründenden und von der aktiven, praktischen, kritikfähigen und gemeinwohlorientierten politischen Einbringung des/der Einzelnen stets wieder zu versichernden Freiheit.

Mit einem solchermaßen konnotierten Prinzip der Willensnation, als permanentes Verfahren der politischen Selbstvergewisserung und Selbstbestimmung, scheinen starke Transzendenzbezüge als Geltungsgrundlage für die politische Ordnung zu entfallen. Der Gemeinsinn wird hierbei als Resultat der vitalen und konstitutiven politischen und öffentlichen Auseinandersetzungen in direkt-demokratischen Verfahren begriffen, in welchen sowohl die kollektiven Überzeugungen in konflikthafter Manier immer wieder in Erinnerung gerufen werden, als auch Bürgertugenden und Gemeinwohlverpflichtungen immer wieder erneuert und konsolidiert werden. Die Willensnation Schweiz entwirft sich im Rahmen dieser Narration als ein politisches Gemeinwesen, das auf starke Transzendenzbezüge verzichten kann, um vielmehr im prozeduralen Selbstbestimmungsprozess kontingente Gemeinsinnüberzeugungen und dauerhafte Bürgertugenden zu etablieren. Der Legitimations- und Legitimitätsnachweis des Bundesstaates Schweiz rekurriert auf keine gemeinsame Sprache, Religion oder Ethnie, die als eine quasi-ewige Entität die zugrundeliegende Unverfügbarkeit böte. Es kommt stattdessen auf die Verfahrensmechanismen aktiver politischer Einmischung

14 Vgl. Villiger, Willensnation, 2009. 
durch das Volk und damit einhergehend, auf die demokratische Selbstbestimmung der Bürger und - erst ab 1971 - auch der Bürgerinnen an. ${ }^{15}$

Die Idee des Willens gewinnt in dieser Auslegung somit die Konnotation einer Handlungsmatrize und einer konstituierenden Grundlage für den Bürgersinn. Zugleich soll damit eine formalistische Engführung des demokratischen Selbstbestimmungsprozesses abgewendet werden. Die offenen politischen Partizipationsschleusen (Volksinitiative und Referendum) sollen den Sinn für Zugehörigkeit und Loyalität zum nationalen Ganzen performativ erzeugen und überpartikulare Mentalitäten, die auf eine Kultur der direkten demokratischen Aushandlung zwischen unterschiedlichen kulturellen, sprachlichen, ethnischen und religiösen Gruppen aufbauen, stärken. Damit zielt diese liberale Konzeption der Willensnation auf einen unbefleckten, zumal nicht vorbelasteten, sondern vielmehr im deliberativen Prozess sich entwickelnden und stärkenden Patriotismus, dessen Inhalt und Geltungsgrund die Wechselwirkungen zwischen Bürgern, Gemeinwesen und Verfassung sind.

Obwohl sich diese Konzeption der Willensnation auf dem ersten Blick als eher transzendenzarm präsentiert, wird bei genauerem Hinsehen ersichtlich, dass sie sehr wohl auf Unverfügbarkeiten rekurriert. Der Transzendenzbezug liegt nämlich genau im Rekurs auf den Willen. Der Wille der Willensnation wird nämlich insofern unverfügbar gestellt, als dieser den Status einer ordnungsgarantierenden Transzendenz einnimmt. Er fundiert nicht nur die politische Ordnung, zumal er Prinzip und Modus ihrer Selbstvergewisserung und Geltung ist, sondern transzendiert sie auch als eine Entität, die außerhalb des verfügbaren politischen Geschehens angesiedelt ist und von außen quasi auf dieses korrigierend eingreift. Ein solchermaßen konzipierter (Volks-)Wille ist Bestandteil der säkularen politischen Theologie. Von der Erde wird er nämlich in den Kosmos projiziert, um von hier aus wieder zurückzuwirken. Zudem haftet ihm als philosophische Kategorie bereits die Eigenschaft des Unverfügbaren an. Frei nach Arthur Schopenhauers berühmter These könne der Mensch zwar tun, was er will, er kann aber niemals wollen, was er will. Da der Wille nicht gewollt werden kann, bleibt er, obwohl er von seinen Trägern zum politischen

15 Die Frauen im Kanton Appenzell Innerrhoden mussten für die Ausübung ihrer politischen Rechte innerhalb der Kantonsgrenzen noch weitere 19 Jahre warten, nachdem erst eine Intervention des Bundesgerichts auch ihnen die politischen Mitbestimmung auf allen föderalen Stufen ermöglichte. 
Dreh- und Angelpunkt der schweizerischen Demokratie deklariert wird, Letzteren unverfügbar.

Es erstaunt demnach nicht, dass diese irdisch-kosmische Entität aufgrund ihrer Unverfügbarkeit, Bestrebungen zu ihrer Profanierung und Domestizierung - kurz: zu ihrer Verfügbarmachung generiert. Die Versuche diesen Willen fassbar, verfügbar und somit handhabbar zu machen, kulminieren in Diskursen und Praktiken, die ihn an feste, unverrückbare Kategorien der ,schweizerischen Eigenart " verknüpfen wollen. Gerade in den letzten Jahren und Jahrzehnten sind solche Diskurse, die auf eine national-kulturelle Homogenität hinzielen, implizit und explizit zu politischen Zwecken verwendet worden und haben sich im kollektiven Bewusstsein eingenistet. Die Willensnation wird dadurch zur Nation derjenigen verkürzt, die die angeblich genuin schweizerischen Eigenschaften aufweisen und daher als einzige auch befähigt sein dürfen, ihren politischen Willen kund zu tun. Das was die Schweiz auszeichnet, ihre fehlende sprachliche, religiöse oder kulturelle Eigenart, wird nun paradoxerweise zum plagenden Mangel deklariert, der die politische und gesellschaftliche Entwicklung nicht unwesentlich beeinflusst. Es handelt sich hierbei um einen Mangel, der - psychoanalytisch gesprochen - von gewissen politischen Kreisen als unheimlich empfunden wird, zumal das, was bis anhin im Heimlichen verborgen lag und nicht weiter störte, nun von diesen Kreisen zur primären politischen Sorge erklärt und damit un-heimlich gemacht wird. ${ }^{16}$

\section{Helvetofundamentalistische NATURALISIERUNG DES UNVERFÜGBAREN}

Grundsätzlich lässt sich sagen, dass jede Gemeinschaft den Einzelnen transzendiert - ihm als nicht fassbares Ganzes unverfügbar bleibt. Entsprechend groß kann der Wunsch und können die Bestrebungen sein, das Unverfügbare mit einheitlichen und für die gesamte politische Gemeinschaft gültige Kategorien wie Sprache, Religion oder Ethnie verfügbar zu machen. Ein solcher Prozess und Wille zur Verfügbarmachung des Unver-

16 Für Freud ist das Unheimliche das, was nicht mehr heimlich gehalten werden kann, und dadurch eben auch den Ort, an dem es hervortritt, zu einem macht, der nicht mehr „heimelig“ ist. Vgl. Sigmund Freud: Das Unheimliche, in: ders.: Der Moses des Michelangelo. Schriften über Kunst und Künstler, mit einer Einleitung von Peter Gay, Frankfurt a.M. 1993, S. 135-172. 
fügbaren ist bereits im Funktionsmodus moderner Demokratien angelegt. Diese benötigen nämlich, um die Legitimationsbereitschaft ihrer Bürger und Bürgerinnen immer wieder aufbieten zu können, nicht nur Institutionen, sondern auch Quellen der Gemeinsamkeit, die nicht gleich versiegen. Während Institutionen vorderhand das Politische - also jener Bereich einer Gesellschaft, in der sie sich über Recht und Ordnung und über die Geltungsbedingungen der Legitimationsverfahren einig wird - demokratisch zu regeln und zu gestalten erlauben, stärken vorrationale Quellen, das heißt ,mentale Traditionen, praktizierte Sitten und Lebensformen, auch Mythen, religiöse Überzeugungen, bestimmte kulturelle Erbschaften und Bewusstseine“"17 den Gemeinschaftssinn. Für die Willensnation Schweiz, die aufgrund ihres politischen Designs und ihrer kulturellen, ethnischen, religiösen und politischen Pluralität, nur auf den ,kühlen' Willen ihrer Bürger und Bürgerinnen als einheitliche unverfügbare Kategorie rekurrieren kann, nimmt die Verfügbarmachung ,warmer' politisch-kultureller Quellen der Gemeinschaftsstiftung eine schon nahezu existentielle Bedeutung an. Die alleinige politische Willensbekundung und der damit verknüpfte liberale Bürgersinn, auf dem die Willensnation aufruht, scheinen nicht zu genügen, um Identifikation und Gemeinschaftssinn zu garantieren. In der Geschichte des jungen Bundesstaates wurden wiederholte Versuche gestartet, um eine unverrückbare schweizerische Eigenart definieren zu können, die Orientierung, kollektive Wärme und Vertrauen in die Stabilität des Selbst angesichts der unsicheren Zukunft spenden würde. Verschiedene Diskurse wurden hierfür mobilisiert, die, auch wenn sie in ihren je eigenen Dispositionen und Methoden unterschiedlich waren, alle das gemeinsame Ziel verfolgten - die Beantwortung der Frage: Was ist die Natur des Schweizers? Diese Anstrengungen kulminierten in der Suche nach dem ,homo alpinus helveticus', in der politischen und gesellschaftlichen Einigelung der Schweiz durch das Konzept der ,geistigen Landesverteidigung“ und nicht zuletzt im schweizerischen Neologismus der ,Überfremdung'.

Im Kontext der Rassendiskurse der 1930er Jahre wurde von offiziellen Stellen eine ganze Wissensapparatur und -infrastruktur eingerichtet, die den ,homo alpinus helveticus‘, diesen Genotypen der Schweizerrasse finden sollte. Durch eine Reihe von Wissenschaftsdisziplinen, worunter vor allem die Anthropometrie und die Eugenik hervortraten, die beide einem bio-

17 Böckenförde, Die Zukunft der Autonomie, 1998, S. 71. 
logisch-deterministischen Rasse-Konzept verpflichtet waren, sollte endlich der Nachweis einer ,schweizerischen Rasse" gelingen. In den Jahren zwischen 1927 und 1932 wurde eine breit angelegte anthropologische Rekrutenuntersuchung durchgeführt (aber erst 1946 veröffentlicht), die zeigte, dass nur 8,661 Prozent aller vermessenen Schweizer dem angehörte, was man sich damals unter einer ,reinen Rasse" vorstellte. Der , homo alpinus helveticus', dessen Urstätte die Gegend um den Gotthard hätte sein sollen, war nur mit kläglichen 1,41 Prozent vertreten. ${ }^{18}$ Daraufhin verlagerte sich das nationale Selbstverständnis vom ,Blut' auf den ,Boden'.

Die offizielle Schweiz rekurrierte nun auf das, was der Zürcher Geograph Emil Egli die ,völkische Gestaltungskraft des Schweizerbodens ${ }^{\text {“19 }}$ nannte. Das Blut als Klebestoff und nationale Erkennungsmarke der Schweizer rückt hinter einen neuen dominanten Diskurs, der das Schweizertum als Produkt von tektonisch-geologischen Faktoren, das heißt des Bodenprofils und der Landschaftsbeschaffenheit verstand. Diese ,Gotthard-Schweiz', die vor allem während des Zweiten Weltkrieges im militärisch-strategischen Réduit-Denken zum Hort von Wehrhaftigkeit, Identität und Heimat emporstilisiert wird, ermöglichte es der Schweiz, sich als Naturmonument zu begreifen. Darin liegt auch die beruhigende Implikation, dass die schweizerische Eigenart, auch wenn sie keine rassische Grundlage habe, immerhin ein geistiges Fundament aufbieten könne, das aus dem harten Gotthardgranit zu entsteigen schien. An diesem ließen sich Mythen und identitätsstiftende Bilder konstruieren. Die Berge boten in geistiger wie auch militärischer Hinsicht eine Ewigkeitsgarantie, und die männlichen Bauern, die an ihren Hängen den Boden beackerten, symbolisierten einerseits die freien, arbeitsamen und demokratischen Bürger, und andererseits die potentiellen Soldaten mit dem ungebrochenen Willen zur wehrhaften Verteidigung von Freiheit, Unabhängigkeit und Neutralität. Dieses mythische Bild einer Schweiz, die ihre gemeinschaftsstiftenden Wurzeln in der alpinen Landschaft und im Boden sichtet, zeigt sich auch als Wandbild im schweizerischen Parlament, wo das Panorama der Berg-

18 Vgl. Jakob Tanner: Nationalmythos und „Überfremdungsängste“. Wie und warum die Immigration zum Problem wird, dargestellt am Beispiel der Schweizer Geschichte des 19. und 20. Jahrhunderts, in: Udo Rauchfleisch (Hrsg.): Fremd im Paradies. Migration und Rassismus, Basel 1994, S. 11-25, hier: S. 20.

19 Zitiert nach: ebd., S. 20. 
welt um den Vierwaldstättersee in der Innerschweiz den Volksabgeordneten vor Augen steht.

In den 1920er und 1930er Jahren entwickelt sich mit dieser wissenschaftlichen, politischen und narrativen Anstrengung zur Definition dessen, was die Schweizer im Kern verbindet, auch eine Abwehrhaltung gegen Fremde. Mit dem Neologismus der ,Überfremdung' appelliert die offizielle Schweiz an ein kollektives und individuelles Angstgefühl, das mit der Befürchtung verbunden ist, dass eine unkontrollierte Einwanderung fremder Menschen Leib und Seele der heimischen Bevölkerung bedrohen könne. ${ }^{20}$ Diese Abwehrstrategie richtet sich in ihren Anfängen gegen die Ostjuden, um später Sozialisten, andere ,vaterlandlose Gesellen` und dann vor allem Ausländer mit ihrem Bann zu belegen. Fundament dieser nationalen Integrationstheorie war die Bewahrung und Verteidigung eines schweizerischen Staats- und Kulturgedankens. Mit der Ausrufung der ,geistigen Landesverteidigung;, vom damaligen Bundesrat Philipp Etter orchestriert und gewollt, wurde eine bewusste Pflege des schweizerischen Kultur- und Sprachgutes sowie eine Rückbesinnung auf alteidgenössische Traditionen propagiert. Besorgt um die nationale Einheit und um die Schaffung eines Gemeinschaftssinns festigt die Landesregierung im Rahmen der ,geistigen Landesverteidigung“ eine mythisch-nationale Identität, die ,nicht aus der Rasse, nicht aus dem Fleisch“, sondern ,aus dem Geist geboren“ wurde. ${ }^{21}$

Ein Geist, der 1291 an den Hängen des Gotthards den berühmten RütliSchwur und damit die Entstehung der Eidgenossenschaft inspiriert hätte und der auch in Zukunft Identität, Orientierung und Schutz vor dem Fremden geben würde. Mit seinem üblichen Scharfsinn notierte Friedrich Dürrenmatt, dass das Konzept der , geistigen Landesverteidigung' präfaschistische Züge in der Schweiz aufzeige, da sie, fern davon, den demokratischen Streit zu fördern, eine bestimmte Norm des ,gehorsamen Demokraten“ etabliere, an dem der Patriot zu messen sei. Entsprechend war dann, wer kritisierte, „Kommunist oder Nihilist, je nach politischer

20 Vertiefend hierzu: Angelo Maiolino: Als die Italiener noch Tschinggen waren. Der Widerstand gegen die Schwarzenbach-Initiative, Zürich 2011 (bes. das Kapitel „Überfremdung von Volk und Heimat“, S. 99-105).

21 Schweizerischer Bundesrat: Botschaft des Bundesrates an die Bundesversammlung über die Organisation und die Aufgaben der schweizerischen Kulturwahrung und Kulturwerbung vom 9. Dezember 1938, in: Bundesblatt, Bd. II (1938), Nr. 50, S. 999. 
Wetterlage“ ${ }^{\text {‘22 }}$. Mit dem Konzept der ,geistigen Landesverteidigung ‘ und dem schweizerischen Neologismus der ,Überfremdung', wie er ab den 1920er Jahren im offiziellen politischen Diskurs Anwendung findet und bis heute keineswegs an Aktualität verloren hat, lässt sich zeigen, dass der liberale Bundesstaat Schweiz nur wenig auf die gemeinsinnstiftenden und integrativen Willensbekundungen seiner Bürger vertraut. Stattdessen wurde und wird hier ein Wille zum Wissen über eine imaginäre schweizerische Eigenart angereizt, die ihm als Transzendenzhorizont und als Ewigkeitsgarantie dienen soll.

Diese ideologische Kampfdisposition gegen unerwünschte Fremde und im Namen der Wahrung einer mythisch überhöhten nationalen und kulturellen Identität hat in der Geschichte der modernen Schweiz eine lange Spur hinterlassen, deren Fortläufer in die heutige Gegenwart hineinreichen und die die liberale Idee der Willensnation unterhöhlen. Durch den Rekurs auf nationalistisch besetzte Unverfügbarkeiten werden der politische Diskurs und die öffentlichen Debatten derart emotional aufgeladen, dass eine vernünftige Abwägung der Sachlage ins Hintertreffen rückt. Der Nationalismus spielt hier die Rolle des Kittmaterials und manifestiert sich als gesellschaftliche Selbstverehrung und als öffentlich praktizierte kollektive Selbstanbetung. Jede nüchterne Analyse eines gesellschaftlichen Problems gerät in diesen nationalistischen Sog und wird durch seine Dynamiken neu ausgerichtet. Die Willensbildung der einzelnen Bürger und Bürgerinnen ist damit von einer geistigen Hypothek belastet, die ihre Zinsen vorwiegend an der hochgepeitschten Furcht vor einer fremdartigen Zerstörung der nationalen und kulturellen Identität einlöst.

Auf der anderen Seite und damit einhergehend, werden staatsbürgerliche Teilnahmerechte im hochmodernen Einwanderungsland Schweiz hartnäckig mit dem Rekurs auf diesen nationalistischen Transzendenzhorizont verteidigt, womit auch die Eintrittshürden für ausländische Gesellschaftsmitglieder hoch gehalten werden. Unzählige Volksinitiativen bezeugen diesen Sachverhalt - von den sich wiederholenden Überfremdungsinitiativen in den 1970er Jahren, über die erfolgreiche Initiative gegen eine erleichterte Einbürgerung zu Beginn des neuen Jahrhunderts bis hin zu den mehrheitlich verworfenen kantonalen Abstimmungen, die eine politische Mitbestimmung zumindest auf Gemeindeebene für langjährig in der

22 Friedrich Dürrenmatt: Monstervortrag über Gerechtigkeit und Recht nebst einem helvetischen Zwischenspiel, Zürich 1969, S. $70 \mathrm{ff}$. 
Schweiz lebende Ausländer vorschlugen. Aber auch die politischen Erfolge der schweizerischen Volkspartei (SVP) sind zu erwähnen, die mit ihren diffamierenden und xenophoben Volksinitiativen gegen religiöse Bauwerke und zugunsten der Ausschaffung krimineller Ausländer das Prinzip der Willensnation auf einen politischen Kampf um die Verteidigung einer angeblich unveränderbaren schweizerischen Eigenart zu reduzieren versucht.

Es ist also nicht so, dass eine kulturelle Homogenität einen Nationalismus anstachelt, sondern vielmehr so, dass ein Nationalismus auf kulturelle Homogenität aufzubauen hat und diese auch institutionell durchsetzen kann, wie dies die Verweigerung politischer Teilnahmerechte für ausländische Gesellschaftsmitglieder zeigt. Das Argument, das zur Rechtfertigung dieser politischen Segregation verwendet wird, lautet oftmals, dass die Ausübung politischer Rechte eine lange Einübung in die politischkulturellen Mechanismen und Gefühlswelten des Landes erfordere und somit nicht jedem zugänglich sei. Die Staatsbürgerschaft wird damit zum Schutzschild einer imaginären kulturellen und nationalen Identität gemacht, die im jus sanguinis ihre Grundlage findet und deren Erwerb für ausländische Personen somit von Grund auf erschwert wird. Die Prinzipien der Abstammung, des Blutes oder der mythisch durchsetzten Vorstellung von unveränderbaren nationalen und kulturellen Eigenarten bilden nach wie vor die vom kollektiven Bewusstsein getragene und gepflegte unsichtbare Barriere, an der sich auch diejenigen Ausländer den Kopf stoßen, die in der Schweiz geboren und aufgewachsen sind und die hier das wirtschaftliche, soziale und kulturelle Leben längst mitgestalten und somit faktisch bereits vollwertige Gesellschaftsmitglieder sind. Die Willensnation Schweiz bekundet damit wenig Interesse für den Willen der restlichen 23 Prozent der Bevölkerung, die an der wirtschaftlichen, sozialen und kulturellen Entwicklung des Landes nicht unwesentlich beteiligt sind. Sie hat trotz ihrer liberalen Wurzeln und der institutionellen Infrastruktur für die direktdemokratische politische Selbstbestimmung, auf die sie so stolz ist, immer noch Mühe mit der Einbeziehung des Anderen und verteidigt weiterhin in hartnäckiger Weise die engen Eintrittsschleusen in die schweizerische Staatsbürgerschaft. Damit stabilisiert sie aber gerade solche Transzendenzbezüge, die in der Trennung zwischen angeblich kulturkonformen Eigenen und kulturfremden Anderen die Grundmatrize einer nationalistischen politischen und politisch-kulturellen Rationalität vorgeben und gleichzeitig rechtfertigen. 
Dieser Rekurs auf angeblich unverrückbare oder nur auf die Gefahr des nationalen Untergangs hin veränderbare Eigenschaften des ,Schweizerischen" offenbart nicht nur Transzendenzbezüge, die starke Gemeinsinnstiftungen an der Schneide sublimierter Freund-Feind-Konstellationen erzeugen, sondern auch antiliberale politisch-kulturelle Muster, die im kollektiven Imaginären schlummern, im Alltagsverstand sedimentiert ${ }^{23}$ sind und immer wieder mit Politiken der Bedrohung aktiviert werden können.

Solche helvetofundamentalistische Versuche, Unverfügbarkeiten - wie die angeblich unverrückbare nationale und kulturelle Identität - zu naturalisieren und sie somit aufgrund klar definierbarer Kriterien des ,Schweizertums' verfügbar zu machen, haben für das politische Gemeinwesen in der Schweiz und für das Konzept der Willensnation, in welchem ersteres aufzugehen behauptet, politisch-kulturelle Konsequenzen. Auf der einen Seite sind sie gerade für die in jeder Hinsicht pluralistische Schweiz das Zeichen einer schwerwiegenden sozialen Pathologie, die Linderung in der Angleichung der politischen Kultur an einer partikularistisch aufgeladenen Mehrheitskultur sucht. Auf der anderen Seite haben diese nationalistisch kodierten Transzendenzbezüge die Tendenz, dasjenige zu verdecken, worum es in der Politik geht - um das Arrangement von partikularen Interessen.

In diesem Transzendenzgefüge nisten sich nämlich auch solche Diskurse ein, die sozio-ökonomische Schieflagen mit Rekurs auf das nationale Selbstwertgefühl von der öffentlichen Debatte verdrängen und damit gleichzeitig, ent-schulden'. Dadurch werden Probleme der Wohlstandsverteilung mit der Deutungsschablone des ,Wohlstandschauvinismus' entziffert. Der Erfolg dieser Diskursstrategie und ihrer Transzendenzbezüge zeigte sich im Herbst 2010. Die völkerrechtswidrige Ausschaffungsinitiative der rechtpopulistischen SVP wurde damals angenommen, während die gleichzeitig vor das Volk gebrachte linke Volksinitiative, die auf eine Umverteilung der Steuerlasten zielte, verworfen wurde. Beide Abstimmungsvorlagen wurden von der SVP mit ihrer Angstökonomie gewonnen. Einerseits mobilisierte die Partei die konstruierte und in inflationärer Weise medial aufgebauschte Angst vor angeblich unzivilisierten und bar-

23 Zum Aspekt der Sedimentierung von Sinn- und Orientierungsmustern in das politisch-kulturelle Geflecht einer Gesellschaft und zu ihrer hegemonialen Funktionsweise, siehe meinen Aufsatz: Politische Kultur und Hegemonie, in: Stephan Dreischer u.a. (Hrsg.): Jenseits der Geltung. Konkurrierende Transzendenzbehauptungen von der Antike bis zur Gegenwart, Berlin 2013, S. 143-157. 
barischen Horden krimineller Ausländer, die Leib und Leben der Schweizer bedrohen würden. Andererseits bediente sie sich eines Bedrohungsszenarios, in welchem, bei Annahme der linken Vorlage, vermögende auch ausländische - Steuerzahler die Schweiz verlassen könnten.

Das unterwürfige Verhalten des Volkes gegenüber den Reichsten, die im Falle dieser Initiative vor Erpressungsversuchen wie der Androhung, bei einer ihnen unliebsamen Entscheidung das Land $\mathrm{zu}$ verlassen, nicht zurückschreckten, spricht nicht unbedingt für eine selbstbewusste demokratische politische Kultur. Wenn außerdem das Volk eher bereit ist, die Fremden zu bestrafen als die Reichen, so, weil es wahrscheinlich die Macht der Reichen fürchten muss und die eigenen politischen Erwägungen dieser Furcht anpasst. Damit lässt sich aber auch unschwer erkennen, wer in letzter Instanz die Zügel der demokratischen Entscheidungsfindung und der kollektiven Willensäußerung tatsächlich in den Händen hält.

Ein solchermaßen aufgeschrecktes Volk widerspricht nicht nur der mythisch überhöhten Selbstbeweihräucherung, die sich in politästhetischer Weise im symbolträchtigen Bild des wehrhaften Bauern und Soldaten und im hochgehaltenen Qualitätsmerkmal der selbstbestimmten und volkssouveränen politischen Gestaltung von Gesellschaft, Recht und Ordnung zeigt, sondern offenbart eben auch die zugrundeliegende politisch-kulturelle Pathologie, auf der es aufliegt. Seine aufgestaute Wut und kumulierte Frustration angesichts steigender Lebenskosten und stagnierender Löhne entlädt ein dermaßen entpolitisiertes und aufgeschrecktes Volk nie gegen die Mächtigen, die diese Gefühle verursachen, sondern immer gegen die Schwachen der Gesellschaft. Je enger nämlich die Verteilungsspielräume in einer Gesellschaft werden, desto mehr wächst die Versuchung, sogenannten ,Randgruppen“ von Ressourcen, Zugehörigkeit und Teilnahme am sozialen Leben auszuschließen. Die Angst vor dem Verlust des eigenen Wohlstandes entfesselt die privaten Interessen und lenkt die gemeinsamen Frustrationen auf diejenigen, die aufgrund ihrer bereits prekären rechtlichen, wirtschaftlichen und sozialen Lage immer weniger am Wohlstand teilhaben. Gerade für die in jeder Hinsicht pluralistische Willensnation Schweiz ist dieser Ablasshandel auf Kosten der Fremden ein Zeichen schwerwiegender sozialer Pathologien. Im politisch-kulturellen Geflecht sedimentieren sich nämlich solche Selbst- und Weltverständnisse, die den „,besitz- 
egoistischen Nationalprotektionismus ${ }^{\text {‘24 }}$ und den Wohlstandschauvinismus zur leitenden Rationalität der politischen Willensbekundung deklarieren. Solche Entwicklungen unterhöhlen nicht nur das Prinzip der Willensnation, die damit zur Nation der akkumulierten subjektiven Egoismen wird, sondern bedrohen jede Form der Demokratie. Wer nämlich Wohlstand und privates Glück höher schätzt als Freiheit und politische Mitbestimmung, und wer den Zusammenhang zwischen dem eigenen Wohl und dem Wohlergehen aller aus den Augen verliert, der ist rasch bereit, sich von Nationalismen oder Wohlsstandschauvinismen verführen zu lassen und sich schlimmstenfalls, wie dies Alexis de Tocqueville ${ }^{25}$ anmahnte, einem Despoten zu unterwerfen. Dieser muss dann nicht unbedingt auf galoppierendem Pferd daherkommen. Es genügt, wenn er als geistiges Bewusstsein die Köpfe der Leute durchdringt.

\section{FAZIT}

Das Resultat der hier vorliegenden Analyse ist die nüchterne, keineswegs neue, aber für eine demokratietheoretische Auseinandersetzung mit der Frage, wie sich politische Ordnungen in der Hochmoderne konstituieren, zentrale Einsicht, dass liberale Demokratien auf Gemeinschaftsgefühle und Gemeinsinnorientierungen angewiesen sind, die - und das ist der entscheidende Aspekt - immer auch die Gefahr einer nationalistischen Verführung bergen. Der liberale Verfassungsstaat, wie dies der britische Kulturtheoretiker Stuart Hall pointiert zum Ausdruck brachte, versteht sich als nicht partikular und deshalb universell, als nicht kulturell signifiziert und deshalb offen - dennoch kann er nur aufgrund der versteckten Forderung bestehen, dass seine positiven Eigenschaften nur dann funktionieren, wenn unterstellt wird, dass die Regierten eine weitgehende politisch-

24 Tanner, Nationalmythos und „Überfremdungsängste“, 1994, S. 24.

25 ,Entwickelt sich in einem dieser Völker die Vorliebe für materielle Genüsse schneller als die Bildung und die freiheitliche Gewohnheit, so tritt ein Augenblick ein, da die Menschen vom Anblick der neuen begehrten Güter fortgerissen werden und sie außer sich sind. Nur auf das Reichwerden bedacht, bemerken sie nicht mehr das enge Band, welches das Wohlergehen jedes Einzelnen von ihnen mit dem Gedeihen aller verknüpft. Man braucht solchen Bürgern die Rechte, welche sie besitzen, nicht zu entreißen; sie lassen sie selber gerne fahren." (Alexis de Tocqueville: Über die Demokratie in Amerika, hrsg. von Jacob P. Mayer, 2. Aufl., München 1984, S. 630) 
kulturelle und wertbehaftete Homogenität aufweisen. ${ }^{26}$ Für die Willensnation Schweiz, die ja, gemäß ihrer offiziellen Selbstdarstellung und im Gegensatz zu anderen Staaten und Nationen, auf keine sprachlich, religiös oder kulturell vorgefundenen und vereinheitlichenden Eigenschaften rekurrieren kann, hieße dies, dass sie ihre politisch-kulturelle und wertbehaftete Homogenität einzig und allein am sich vollziehenden gemeinsamen Verfahren der politischen Willens- und Entscheidungsbildung und am hierfür notwendigen politischen und gemeinwohlorientierten Engagement ihrer Bürger und Bürgerinnen misst. Eine solche politische Kultur, die ihre Loyalitätsbeziehungen, Wertorientierungen und Selbst- und Weltverständnisse im Rahmen eines ,Verfassungspatriotismus‘ absteckt, müsste angesichts der sozialen, kulturellen, religiösen und sprachlichen Fragmentierung der schweizerischen Gesellschaft Fundament und Kompass der Willensnation sein. Mit dem liberalen Rekurs auf einen kollektiven Willen, der im gemeinsamen Verfahren der Willens- und Entscheidungsbildung und innerhalb eines institutionalisierten Rahmens direkt-demokratischer Partizipation die Geltungs- und Verfahrensgrundlagen darstellt und zugleich artikuliert, entwirft sich die offizielle Schweiz als eine Willensnation, die keine starken Transzendenzbezüge braucht.

Die einzige Unverfügbarkeit, die in dieser Konzeption Platz findet, zumal sie Fundament, Motor und gleichsam zukunftsversichernde Projektion ist, ist die kollektive Willensbezeugung. Diese ist zwar auf die Trägerschaft der einzelnen Mitglieder der politischen Ordnung angewiesen, als kollektive und gemeinsame Artikulation aber, bleibt sie ihnen entrückt und eben unverfügbar. Was diesen , liberalen“ Transzendenzbezug also auszeichnet, ist der Umstand, dass er in seiner diskursiven Ausgestaltung und Rechtfertigung nicht nur mit einem Minimum an Transzendenz auskommt, sondern darüber hinaus, dass er - im Prinzip zumindest - auf jede völkische Ideologie verzichten und vielmehr auf ein nicht-nationalistisches Nationalbewusstsein aufbauen kann, das sich aus dem offenen und direktdemokratischen Legitimationsverfahren speist. Diese offizielle Selbstdarstellung der Schweiz als Willensnation, die zugleich ihre demokratische Identität unterstreichen soll, ist zum Markenzeichen des kleinen Landes in der

26 Stuart Hall: Die Frage des Multikulturalismus, in: ders.: Ideologie, Identität, Repräsentation. Ausgewählte Schriften 4, Hamburg 2004, S. 188-227, hier: S. $210 f$. 
alpinen Mitte Europas geworden und ,wirkt auch nach außen als Vorbild und Sympathieträger ${ }^{، 27}$.

Ein kritischer Blick auf die Geschichte des schweizerischen Bundesstaates, der sich von der hegemonialen Politästhetik abwendet - die mal im Gewand der direkt-demokratischen Willensnation, mal im Mantel der ,geistigen Landesverteidigung', des einigelnden ,Sonderfalls` oder der aufgepeitschten Furcht vor ,Überfremdung' daherkommt - und sich auf die verborgenen Strukturen der politisch-kulturellen Mechanismen konzentriert, öffnet das Analysefeld für andere Diskurse und Transzendenzbezüge, die in Widerspruch zur liberalen Idee der Willensnation stehen. Der liberale Transzendenzbezug auf den kollektiven Willen, der aus dem direkt-demokratischen Verfahrensmechanismus, in dem er eingebettet ist und den er zugleich gestaltet, überpartikulare Gemeinsinnorientierungen erzeugen soll, wird von Diskursen und Praktiken herausgefordert, die auf konkurrierende Unverfügbarkeiten aufsitzen, deren Suggestionskraft sich am Horizont einer partikularen, unverrückbaren und an bestimmten Merkmale zu eruierenden schweizerischen kulturellen und nationalen Identität manifestiert.

Fern davon, nur auf die gemeinsinnstiftenden und integrativen Willensbekundungen seiner Bürger aufzubauen, hat der liberale Bundesstaat Schweiz immer wieder Diskurse bemüht, die nationale Mythen, damit einhergehende und für diese konstitutive Abwehrreflexe, sowie Erfindungen von Traditionen und von nationaler Eigenart hervorbrachten, an denen ein normatives Bild des ,Schweizers' und später auch der ,Schweizerin' konstruiert werden konnte. Frappierend ist hierbei die Paradoxie, die mit dieser völkisch anmutenden und helvetofundamentalistischen Auslegung der Schweiz und ihrer Bürger und Bürgerinnen einhergeht. Was die Schweiz nämlich auszeichnet, ist der historisch und politisch zentrale Aspekt, dass sie die Gründung ihrer modernen politischen Ordnung am liberalen Bewusstsein geknüpft hat, dass es keine kulturelle oder nationale Eigenart gibt, sondern bloß einen potentiellen gemeinsamen Willen zur gemeinsamen Gestaltung des jederzeit veränderbaren Gemeinwesens. Es ist diese Leerstelle, die mit keiner sprachlichen, religiösen, kulturellen oder ästhetischen Eigenschaft gefüllt werden kann, die die Willensnation ausmacht. Sie kann im liberalen Sinne und im Sinne einer aufgeklärten und modernen Gesellschaft nur vom sich prozessierenden politischen Willen

27 Paul Nolte: Was ist Demokratie? Geschichte und Gegenwart, München 2012, S. 63. 
ihrer Regierungsunterworfenen und zugleich -gestalter und immer nur für die Kontingenz des jeweiligen historischen Moments gefüllt werden.

Zum Schluss lässt sich also sagen, dass die liberale Konzeption der Willensnation Schweiz mit ihrem für die Gründung des Bundesstaates fundamentalen Bezug zu den alten Leitwerten der französischen Revolution „Freiheit, Gleichheit, Brüderlichkeit“ und zur Einbeziehung des sprachlich, religiös oder kulturell Anderen von Transzendenzbezügen herausgefordert wird, die nicht nur das Unverfügbare des Volkswillens nationalistisch einfärben und dadurch die integrative Kraft der Willensnation einschränken, sondern auch einen kollektiven Bewusstseinshorizont aufscheinen lassen, in welchem das Gemeinschaftsgefühl, der demokratische Gemeinschaftssinn und der politische Gestaltungswille nur noch am Konstrukt des ,aufrechten Patrioten' gemessen wird, der die richtige ,schweizerische' Gesinnung, Blutlinie und Kultur besitzt. Das Einwanderungsland Schweiz, das sich als Willensnation ohne starke Transzendenzbezüge entwirft und damit die besten Voraussetzungen für die Einbeziehung des Anderen bieten würde, konserviert in ihrem kollektiven Bewusstsein reaktionäre und antiliberale Deutungsmuster, die auf diffuse und auf das kollektive Bewusstsein äußerst machtvoll einwirkende Unverfügbarkeiten gründen und die die Willensnation auf eine exklusive Gemeinschaft von angeblich ,echten' Schweizern reduzieren, die nur das wollen, was so ist, wie sie zu sein glauben.

Es sind aber nicht die Prinzipien der Abstammung und des Blutes oder die mythisch durchsetzte Vorstellung von unveränderbaren nationalen und kulturellen Eigenheiten, die das Einwanderungsland und die Willensnation Schweiz für die Herausforderungen der globalen Dynamiken wappnen. Vielmehr und im Einklang mit dem liberalen Rekurs auf einen sich prozeduralisierenden politischen Willen und der damit unverfügbar gestellten Willensnation, sind es die Idee des ,Ankommens', die immer schon gegebene Möglichkeit, die bestehenden Lebensräume gemeinsam neu zu gestalten und nicht zuletzt die demokratische Tugend, die Provokation des Andersseinkönnens zu ertragen, die die Schweiz zu dem machen könnten, worauf sie politisch angelegt ist - ein Land, das seinen Patriotismus aus dem Verfahren der offen gehaltenen politischen Entscheidungs- und Willlensbildung gewinnt, mit der Verfassung in Symbiose steht und das in der Einbeziehung des Anderen - wer oder was auch immer dieser oder dieses ist - seine erste Verpflichtung sichtet. 



\title{
Ordnungsbegründung \\ als politisch-kultureller Deutungskampf
}

\author{
Der Verfassungsdiskurs im demokratischen Polen
}

nach 1989

MAIK HEROLD

Politischen Neugründungen ist eine besondere Spannung eingeschrieben. Einerseits werden sie per definitionem mit Diskontinuität, Spontaneität und einer gewissen Willkür in Verbindung gebracht, andererseits muss jeder Neuanfang selbst, um seine Geltung auf Dauer zu stellen und in seiner Legitimität nicht angezweifelt zu werden, in ein Absolutes hineinprojiziert werden, das jenseits des konstituierten politischen Raumes verortet wird und aus dem er ,rational' erklärt werden kann. ${ }^{1} \mathrm{Zu}$ allen Zeiten begaben sich die großen Gründerväter, Verfassunggeber und Revolutionäre bald nach dem politischen Umsturz daher auf die, bisweilen ,,verzweifelt“ anmutende Suche nach einem solchen Absoluten. ${ }^{2}$ Sie fanden es meist in der

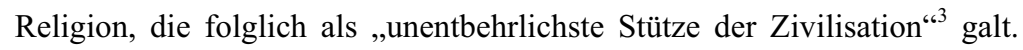
Wollte man einer politischen Ordnung dauerhafte Geltung und Stabilität verleihen, dann erschien es notwendig, sie mit der „Weisheit der Götter“

1 Hans Vorländer: Gründung und Geltung. Die Konstitution der Ordnung und die Legitimation der Konstitution, in: Gert Melville/Hans Vorländer (Hrsg.): Geltungsgeschichten. Über die Stabilisierung und Legitimierung institutioneller Ordnungen, Köln/Wien/Weimar 2002, S. 243-263, hier: S. 245.

2 Hannah Arendt: Über die Revolution, München 2000, S. 265.

3 Niccolò Machiavelli: Discorsi. Gedanken über Politik und Staatsführung, übersetzt, eingeleitet und erläutert von Rudolf Zorn, 3., verbesserte Aufl., Stuttgart 2007, S. 44. 
oder, allgemeiner formuliert, mit einer „Autorität anderer Ordnung“ zu schmücken, die „ohne Gewalt mitreißen und ohne zu überreden überzeugen“ konnte. ${ }^{4}$ Auf diese Weise erschien der politische Neuanfang „nicht mehr willkürlich, sondern in etwas verankert, was die menschliche Vernunft übersteigen mag, aber dennoch eine ihm eigentümliche Rationalität besitzt" ${ }^{* 5}$. Aus heutiger Sicht muss diese Spannung zwischen der gleichzeitigen Inanspruchnahme von Autonomie und Heteronomie wohl etwas allgemeiner formuliert und das in der politischen Ideengeschichte oft geschilderte Absolute eher in funktionaler Hinsicht bewertet werden. Wie die Erfahrung zeigt, scheint dieses Absolute nämlich nicht zwingend im religiösen oder theologischen Sinne gedeutet werden zu müssen, sondern kann durchaus verschiedene Formen annehmen: Vermeintliche gemeinsame Traditionsbestände, kollektive Identifikationsmuster und geteilte Überzeugungen wurden und werden ebenso zur Letztbegründung politischer Ordnungsentwürfe herangezogen, wie allgemeine Verfahrensgrundsätze oder moralische Wertmaßstäbe. Welche dieser absoluten Bezugspunkte im jeweiligen Fall als verbindlich gelten, kann letztlich nur empirisch bestimmt werden.

Verfassunggebungsprozesse und Verfassungsdiskurse stehen in modernen demokratischen Ordnungen dabei in besonderem Maße im Zentrum des Interesses. Im Rahmen der gleichzeitigen Konstruktion, Dekonstruktion und Umprägung der jeweils als gültig, wirksam oder legitim erachteten Geltungsgründe ist die Spannung zwischen Verfügbarkeitsannahmen und Unverfügbarkeitsbehauptungen eben gerade dann relevant, wenn es gilt, die Grundzüge einer neuen Ordnung in einem rechtsverbindlichen Dokument zu verschriftlichen. ${ }^{6}$ Von den Akteuren im Diskurs wird dabei einerseits über die eigene, neu gewonnene Freiheit und die Möglichkeiten ihrer Ge-

4 Jean-Jacques Rousseau: Vom Gesellschaftsvertrag oder Die Grundsätze des Staatsrechts, in Zusammenarbeit mit Eva Pietzcker neu übersetzt und hrsg. von Hans Brockard, Stuttgart 2001, S. 46.

5 Arendt, Revolution, 2000, S. 265.

6 In demokratischen Gesellschaften sind Verfassungsdiskurse daher immer auch kollektive Selbstverständigungsdiskurse. Sie bilden die Foren, auf denen der Streit um die absoluten Geltungsgründe der neuen Rechtsordnung sowie um die unantastbaren Fundamente der politischen Gemeinschaft ausgetragen wird. Vgl. hierzu: Hans Vorländer: Verfassung und politische Kultur. Anmerkungen aus aktuellem Anlass, in: Jürgen Gebhardt (Hrsg.): Verfassung und politische Kultur, Baden-Baden 1999, S. 75-83, hier: S. 81. 
staltung reflektiert, gleichzeitig aber ein neues Set verbindlicher Maßstäbe ins Spiel gebracht, die ihrerseits den Anspruch erheben, der neu zu gründenden Ordnung vorauszuliegen und sich folglich einer aktiven Einflussnahme gerade zu entziehen. Das Besondere an Verfassungsdiskursen besteht daher auch in der gezielten Inanspruchnahme, Konstruktion und Signifikation von Unverfügbarkeit. Sowohl in der politischen Argumentation als auch in der fertigen Verfassung selbst werden entsprechende Invokationen eines absoluten Orientierungsrahmens dabei durch bestimmte Formeln, Andeutungen und Verweise zum Ausdruck gebracht. ${ }^{7}$ Für den Verfassungsdiskurs wiederum wirken insbesondere jene Topoi ordnungsbezogener Letztbegründung strukturprägend, die einerseits als symbolische Bezugspunkte positions- und lagerübergreifend von allen Diskursteilnehmern übereinstimmend in Anspruch genommen und mit der neuen politischen Ordnung assoziiert werden, dabei andererseits aber völlig unterschiedliche inhaltliche Prägungen erhalten. ${ }^{8}$ Als „Prinzipien der Ausschlie-

7 Insbesondere der Verfassungspräambel fällt dabei die Aufgabe zu, diese jenseits der Konstitution verorteten Quellen des Rechts zum Ausdruck zu bringen und auf diese Weise öffentlich einen „Sinnbezug zu den prinzipiell nicht disponiblen Voraussetzungen“ der Existenz des von ihr begründeten politischen Systems herzustellen (Hermann Lübbe: Staat und Zivilreligion. Ein Aspekt politischer Legitimität, in: Heinz Kleger/Alois Müller (Hrsg.): Religion des Bürgers. Zivilreligion in Amerika und Europa, 2. Aufl., Münster 2004, S. 195-221, hier: 206). Indem sie auf diese Weise die „tieferen Schichten“ vorpositiver Basis- und Glaubenswahrheiten eines politischen Gemeinwesens zur Geltung bringen, sind Präambeln folglich nicht nur als „Grundlegung“, sondern auch als „Bekenntnis“ zu verstehen (Peter Häberle: Präambeln im Text und Kontext von Verfassungen, in: Joseph Listl/Herbert Schambeck (Hrsg.): Demokratie in Anfechtung und Bewährung, Berlin 1982, S. 211-249, hier: S. 231f.).

8 Hier von „leeren“ (Laclau, Ernesto: Emanzipation und Differenz, Wien/Berlin 2010, S. 65ff.) oder „deutungsoffenen“ (André Brodocz: Die symbolische Dimension der Verfassung. Ein Beitrag zur Institutionentheorie, Wiesbaden 2003, S. 238ff.) Signifikanten zu sprechen scheint allerdings nicht ganz treffend, da im Diskurs die Relevanz eines symbolischen Bezugspunktes nicht vom Grad seiner vermeintlichen „Offenheit“ oder gar „Öffnung“, sondern umgekehrt die „Unterschiedslosigkeit gegenüber unterschiedlichen Deutungen“ eines in jedem Falle unterschiedlich interpretierbaren Signifikanten (André Brodocz: Chancen konstitutioneller Identitätsstiftung. Zur symbolischen Integration durch eine deutungsoffene Verfassung, in: Hans Vorländer (Hrsg.): Integration durch Verfassung, Wiesbaden 2002, S. 101-119, hier: S. 107) vom Grad seiner diskursiven Inanspruchnahme abhängt. Insofern sind zur Beantwortung der Fragen nach der "Selbstbezeichenbarkeit“ und den "Chancen der Identitätsstiftung“ eines (Verfassungs-)Diskurses eher seine historischen und politisch-kulturellen Rahmenbedingungen in den Blick zu nehmen. Die Rede von ,äquivoker“ 
Bung" strukturieren sie den Diskurs und zeichnen die zentralen Konfliktfelder vor, an denen sich die politische Auseinandersetzung abarbeitet. ${ }^{9}$ Weil sie damit de facto für den Gründungsdiskurs selbst die unverfügbare Grundlage argumentativer Aushandlungsprozesse bilden, sollen sie hier als Formen diskursiver Transzendenz bezeichnet werden.

Worin aber bestehen diese Formen diskursiver Transzendenz und in welcher Weise sind sie in der Lage, einen Verfassungsdiskurs zu strukturieren? Dieser Frage soll im Folgenden anhand eines konkreten Beispiels der Verfassunggebung in Polen zwischen 1989 und 1997 - nachgegangen werden. Grundlage dafür bildet eine Analyse der Protokolle der zentralen Verfassungsdebatte in der polnischen Nationalversammlung im Februar und März 1997 sowie - in Auszügen - der Aufzeichnungen der Sitzungen des entsprechenden Verfassungsausschusses zwischen 1993 und $1996 .{ }^{10}$ Dabei steht weniger die politisch-inhaltliche Beurteilung, sondern vor allem die systematische Gegenüberstellung der hier vorgetragenen Argumente für und gegen jenen Entwurf im Mittelpunkt, den der Verfassungsausschuss der Nationalversammlung zwischen 1993 und Ende 1996 erarbeitet hatte, der am 24. Februar 1997 zur ersten Lesung dem Plenum vorgestellt und nach zahlreichen Änderungen - schließlich am 2. April 1997 als neue Verfassung der Dritten Polnischen Republik verabschiedet wurde. ${ }^{11}$ Auf diese Weise können insgesamt drei thematische Felder identifiziert werden, an denen sich die Argumente der Befürworter und Gegner des Verfassungsentwurfes der Nationalversammlung in der beschriebenen Weise ausrichtete. Diese drei Topoi werden im Folgenden, nach einigen kurzen Bemerkungen zum polnischen Fallbeispiel (1) - mit den entsprechenden Schlagworten ,Legitimität‘ (2), ,Kompromiss‘ (3) und ,nationale Identität‘ (4) -

(Laclau, Emanzipation, 2002, S. 65) oder „plurivalenter“ Signifikation dürfte daher die hier untersuchten Formen diskursiver Transzendenz besser charakterisieren.

9 Michel Foucault: Die Ordnung des Diskurses, Frankfurt a.M. 1993, S. 33.

10 Die Protokolle der Nationalversammlung finden sich gesammelt im OnlineArchiv des Sejm unter http://orka2.sejm.gov.pl/Debata2.nsf, Verzeichnis: „Zgromadzenie Narodowe“, letzter Abruf: 18.10.2012. Die Protokolle der Sitzungen des Verfassungsausschusses der Nationalversammlung der II. Legislaturperiode sind erschienen bei Kancelaria Sejmu: Komisja Konstytucyjna Zgromadzenia Narodowego, Wydawnictwo Sejmowe, Warschau 1993-1997.

11 Ein besonderer Dank geht dabei an Sophie Quadt für ihre Hilfe bei der Recherche und Übersetzung des polnischen Quellenmaterials. 
nacheinander erläutert und kontextualisiert, bevor ein kurzes Fazit ihre Wirkungsweise nochmals zusammenfasst (5).

\section{Polens Verfassunggebung ALS KULTURELLER KONFLIKT}

Der Verfassunggebungsprozess im postsozialistischen Polen ist durch einige Besonderheiten gekennzeichnet. ${ }^{12}$ Dass es am 2. April 1997, über acht Jahre nach Beginn des politischen Umbruchs, in Polen überhaupt noch zur Verabschiedung einer neuen Verfassung kam, wird gelegentlich als ein „Wunder" ${ }^{\text {"13 }}$ bezeichnet, denn in rein staatsrechtlicher Hinsicht war die oft als ,verspätet' empfundene Verfassung von 1997 nicht zwingend notwendig gewesen. ${ }^{14}$ Zahlreiche Erweiterungen und Teilnovellierungen der

12 Für einen Überblick zur polnischen Verfassungsgeschichte vgl. Andrzej Ajnenkiel: Konstytucje Polski w Rozwoju Dziejowym. 1791-1997, Warschau 2001. Zur Entstehung des Verfassungsentwurfes der Nationalversammlung vgl. Ryszard Chruściak: The role of the Constitutional Committee of the National Assembly in Creating the New Constitution of the Republic of Poland, in: Droit Polonais Contemporain (1995) 1/4, S. 105-115 sowie Ryszard Chruściak: The Constitution of the Republic of Poland of 2 April 1997. The Course of Parliamentary Work from 1995-1997, in: Droit Polonais Contemporain (1997) 1/4, S. 163-176. Zur Präambel der polnischen Verfassung vgl. Małgorzata Ewa Stefaniuk: Preambuła Aktu Normatywnego w Doktrynie Oraz w Procesie Stanowienia i Stosowania Polskiego Prawa w Latach 1989-2007, Lublin 2009.

13 Wiktor Osiatyński: A Brief History of the Constitution, in: East European Constitutional Review 6 (1997) 2/3, S. 66-76, hier: S. 66.

14 „It does not seem, however, that the new constitution could bring any major constitutional change in comparison with the situation it originated in." (Paweł Sarnecki: Central Ideas of the Constitution of the Republic of Poland of 2 April 1997, in: Droit Polonais Contemporain (1997) 1/4, S. 5-24, hier: S. 6) Obwohl Polen - im Gegensatz zu anderen Ländern Osteuropas - zum Zeitpunkt des politischen Umbruchs bereits über eine Vielzahl gut organisierter politischer Kräfte mit jahrelanger Erfahrung im Widerstand gegen das kommunistische Regime verfügte, war der polnische Verfassunggebungsprozess der längste im Rahmen der postkommunistischen Systemtransformation in Osteuropa. Vgl. hierzu Jerzy Maćków: Verfassungsnorm und -praxis in der polnischen Verfassunggebung 1989 bis 1997. Das Ende einer Asymmetrie, in: Zeitschrift für Parlamentsfragen 29 (1998) 4, S. 660-675, hier: S. 660f. sowie überblicksartig Rett R. Ludwikowski: Constitution-Making in the Region of Former Soviet Dominance. With Full Texts of all New Constitutions Ratified Through July 1995, Durham NC 1996; Jerzy Maćków: Parlamentarische Demokratie und Autoritarismus. Erfolge und Mißerfolge der postkommunistischen Verfassungsgebung, Hamburg 1998, S. 65ff.; Jon Elster/Claus Offe/Ulrich K. Preuß: Institutional Design in Post- 
geltenden, ehemals kommunistischen Verfassung von 1952 hatten dazu geführt, dass der anfänglich als Provisorium gesehene staatsrechtliche Ist-Zustand nach 1989 schrittweise verändert und den neuen politischen und gesellschaftlichen Notwendigkeiten angepasst worden war. Bereits im Herbst 1991 schien es für einen einheitlichen, umfassenden und symbolträchtigen Verfassunggebungsakt ohnehin zu spät, denn die politische Kultur Polens war längst im Alltag einer parlamentarischen Demokratie angekommen. Die Aussicht auf Verabschiedung einer neuen Verfassung schien dabei den politischen Pluralisierungs- und Fragmentierungsprozessen zum Opfer zu fallen. Die Erinnerungen an den real-existierenden Sozialismus wurden von den jüngsten Erfahrungen der radikalen, zum Teil chaotisch ablaufenden ökonomischen Transformation in den Schatten gestellt und die Verhandlungen über eine neue konstitutionelle Grundlage von den Konflikten, Verwerfungen und Machtmechaniken des alltäglichen Politikbetriebes überlagert. Einer angestrebten Konstitution kam nun nicht mehr vorrangig die Aufgabe zu, mit revolutionären und innovativen institutionellen Veränderungen den sprichwörtlichen politischen Neuanfang zu initiieren, sondern das bereits existierende, wohl austarierte Geflecht staatsrechtlicher Arrangements abzubilden und mit Verfassungsrang zu versehen. ${ }^{15}$

Bereits die strukturellen Rahmenbedingungen der polnischen Transformation rückten damit eher die symbolische Bedeutung einer neuen Verfassung ${ }^{16}$ in den Vordergrund und ließen die allgemein als notwendig erachtete Zurschaustellung nationaler Autonomie und wiedererlangter Selbstbestimmung zur vielleicht entscheidenden Triebfeder des Verfassungge-

Communist Societies. Rebuilding the Ship at Sea, Cambridge 2000; George Sanford: Democratic Government in Poland. Constitutional Politics since 1989, Basingstoke 2002, S. 74ff.

15 Vgl. Pawel Spiewak: The Battle for a Constitution, in: East European Constitutional Review 6 (1997) 2/3, S. 89-96, hier: S. 89; Sarnecki, Central Ideas, 1997, S. 6.

16 Zur symbolischen Dimension der Verfassung vgl. Jürgen Gebhardt: Die Idee der Verfassung: Symbol und Instrument, in: Adolf Kimmel (Hrsg.): Verfassungen als Fundament und Instrument der Politik, Baden-Baden 1995, S. 9-24; Hans Vorländer: Die Verfassung als symbolische Ordnung. Perspektiven einer kulturwissenschaftlich-institutionalistischen Verfassungstheorie, in: Michael Becker/ Ruth Zimmerling (Hrsg.): Recht und Politik. PVS-Sonderheft 36, Wiesbaden 2006, S. 229-249; Brodocz, Symbolische Dimension, 2003. 
bungsprozesses werden. ${ }^{17}$ Folglich war es in fast allen politischen Lagern Konsens, dass das Land trotz der bereits gefundenen staatsrechtlichen Lösungen einer neuen Verfassung bedürfe. ${ }^{18}$ Jenseits dieser grundlegenden Einigkeit aber muss der Verfassunggebungsprozess in Polen allerdings rückblickend weniger als Folge eines spezifischen ,constitutional moment“ (Bruce Ackerman), sondern vielmehr als das Ergebnis eines jahrelangen Ringens um die ,symbolische Macht“ (Pierre Bourdieu), als ,struggle for the real" (Clifford Geertz) bewertet werden. ${ }^{19}$ Die Diskussion um eine mögliche Verfassung für das neue, demokratische Polen wurde dementsprechend in besonderem Maße als kultureller Konflikt, als Auseinandersetzung um die unverfügbaren Grundlagen des eigenen Selbstverständnisses ausgetragen und gewann - insbesondere in den letzten Jahren vor 1997 - eine

17 Der Erfolg des Verfassunggebungsprozesses in Polen, so beschrieb es Tadeusz Mazowiecki, sei demnach vor allem wichtig für das Bild, das Polen nach außen abgebe. Es wäre ein bedeutendes Zeugnis wiedererlangter Souveränität und ein Signal für die politischen und gesellschaftlichen Reformbemühungen: „Wiele jest powodów, dla których potrzebujemy konstytucji i potrzebujemy jej teraz. [...] To jest kwestia obrazu Polski. Kwestia obrazu Polski w czasie, kiedy podejmujemy niezwykle ważne dla jej suwerenności, dla jej bezpieczeństwa i dla jej rozwoju cywilizacyjnego starania." (Tadeusz Mazowieki: Rede vor der Nationalversammlung am 24.02.1997) Soweit nicht anders angegeben sind die hier und im Folgenden zitierten Reden vor der Nationalversammlung verfügbar im Online-Archiv des Sejm (vgl. Fn 10).

18 „Naiv und schädlich“ sei es zu glauben, dass Bürger und Staat dauerhaft ohne „diesen fundamentalen Akt“ der Verfassunggebung auskommen könnten: „Wiara w to, że obywatele i państwo mogą na dłuższą metę obyć się bez tego fundamentalnego aktu, bez ustawy zasadniczej odpowiadającej wymogowi czasu, wydaje się być wiarą naiwną i szkodliwą. “ Darüber hinaus gebe es eine enorme öffentliche Erwartungshaltung, ,die Dauer von fast acht Jahren Arbeit an der Verfassung der Republik endlich abzuschießen“ (Marek Mazurkiewicz: Rede vor der Nationalversammlung am 24.02.1997). Es wäre eine „nicht hinnehmbare Verschwendung von Zeit und Ressourcen" (Marek Minda: Rede vor der Nationalversammlung am 24.02.1997), wenn Polen es im aktuellen Anlauf wieder nicht schaffen würde, eine Verfassung zu erhalten, die ,würdig eines großen europäischen Landes" (Ryszard Bugaj: Rede vor der Nationalversammlung am 24.02.1997) sei.

19 Der Warschauer Soziologe Paweł Śpiewak spricht diesbezüglich gar von einer „,verpassten Chance“: „If Bruce Ackerman is right, that every country goes through a constitutional moment connected with the breakdown of its old political structures and is characterized by a mobilization of pervasive and widely shared convictions about the shape of a new political order, then we can conclude that in Poland the moment was overlooked or unappreciated." (Śpiewak, The Battle for a Constitution, 1997, S. 89) 
enorme Schärfe. ${ }^{20}$ Der polnische Politikwissenschaftler und ehemalige Berater des Ministerpräsidenten Tadeusz Mazowiecki, Aleksander Smolar, schrieb, dass dabei der Eindruck vermittelt würde, als ständen die „christlich-national-patriotischen “ ${ }^{\text {21 }}$ Verteidiger des polnischen Volkes, seines Glaubens und Vaterlandes, seiner Werte und Familien einer unheiligen Allianz aus Liberalen, Kommunisten, Freimaurern, Juden, Relativisten, Atheisten und Postmodernen gegenüber. Zur emotionalen Mobilisierung der eigenen Anhänger für das Verfassungsreferendum am 25. Mai 1997 wurde der Ton nochmals verschärft. ${ }^{22}$ Die Bedrohung für die nationale Souveränität Polens, die vom Entwurf der Nationalversammlung ausgehe, so betonte Marian Krzaklewski, der Vorsitzende der Gewerkschaft Solidarność, sei nicht weniger schwerwiegend als der Ansturm der bolschewistischen Roten Armee im Jahre $1920 .{ }^{23}$ Die neue, ,antipolnische ${ }^{6}$ Verfassung schütze Diebe und Hochstapler, erlaube dem Staat den polnischen Familien ihre Kinder zu rauben und führe auf direktem Wege in die Tyrannei. ${ }^{24}$

Die gegenüberstehenden politischen Lager bestanden dabei aus der linksliberalen „Verfassungskoalition“ ${ }^{65}$ auf der einen Seite, sowie den

20 Dies wird bereits daran deutlich, dass der Verfassungsdiskurs als „Kampf“ (Markus Mildenberger: Zwischen Konsens und Polarität. Zur Entwicklung der demokratischen politischen Kultur in Polen, in: Jochen Franzke (Hrsg.): Polen, Staat und Gesellschaft im Wandel. Beiträge zur Debatte, Berlin 1998, S. 76-86, hier: S. 76), „Schlacht“ (Śpiewak, The Battle for a Constitution, 1997, S. 89) oder gar „Krieg der Welten“ (Aleksander Smolar: Wojna swiatow, in: Gazeta Wyborcza, Nr. 124, 30.05.1997) bezeichnet wurde.

21 Smolar, Wojna swiatow, 1997, S. 18.

22 Zum Verfassungsreferendum in Polen vgl. Stanisław Gebethner: The 1997 Referendum on the Constitution in Poland. The Controversies and the Compromise, in: Droit Polonais Contemporain (1997) 1/4, S. 135-162; Wyrzykowski, Mirosław: Die Herausbildung der Verfassung - Demokratie Legitimation am Beispiel Polens, in: Peter Häberle u.a. (Hrsg.): Staat und Verfassung in Europa, Baden-Baden 2000, S. 53-71, hier: S. 64ff.

23 Robert Brier: Culture and Constitutional Politics in the Polish Transition to Democracy. Solidarity's Legacy to Poland's Third Republic, in: Dariusz Aleksandrowicz/Stefani Sonntag/Jan Wielgohs (Hrsg.): The Polish Solidarity Movement in Retrospect. A Story of Failure or Success?, Berlin 2009, S. 88127, hier: S. 89.

24 Mirosław Wyrzykowski: Legitimacy: The Price of a Delayed Constitution in Poland, in: Jan Zielonka (Hrsg.): Democratic Consolidation in Eastern Europe. Institutional Engineering, Oxford 2001, S. 431-454, hier: S. 451f.

25 Diese sogenannte „Verfassungskoalition“ bestand aus den beiden Regierungsparteien (der sozialdemokratischen SLD und der Bauernpartei PSL) sowie der oppositionellen Arbeiterunion (UP) und der linksliberalen Freiheitsunion (UW). 
rechtsnationalen, zum Teil außerparlamentarisch organisierten Gegnern des Verfassungsentwurfes der Nationalversammlung auf der anderen Seite. ${ }^{26}$ Diese Opposition lehnte den offiziellen Entwurf der Nationalversammlung unter demonstrativer Geringschätzung des Parlaments vehement ab, diffamierte die parteiübergreifende Zusammenarbeit von Regierungs- und Oppositionsparteien im Verfassungsausschuss als ,Landesverrat' und wollte stattdessen einen eigenen Verfassungsentwurf - den mit schließlich knapp zwei Millionen Unterschriften unterstützten, sogenannten ,Bürger-Entwurf ${ }^{*}$ - dem Volk zur Abstimmung vorlegen. ${ }^{27}$

\section{2 ,LEgitimität‘ ALS ARgument}

Ein zentrales Feld der politischen Auseinandersetzung im polnischen Verfassungsdiskurs nach 1989 war die Frage nach Legitimität. ${ }^{28}$ Als Argument in der Debatte wurde die Behauptung oder Infragestellung von Legitimität dabei als Frage nach der Berechtigung zur Teilnahme am Prozess der Verfassunggebung verstanden. Der Verweis auf die von allen Seiten geteilte Bedingung eines ,rechtmäßigen“ Zustandekommens der neuen Verfassung diente hier dazu, völlig verschiedene Positionen unter einem nicht weiter hinterfragten, sondern allgemein akzeptierten Schlagwort zusammenzufassen und auf diese Weise den jeweiligen politischen Gegner in grundlegender Weise zu attackieren. Die Behauptung der rechts-konservativen Opposition, die nach 1993 eingesetzte Verfassungskommission der Nationalversammlung besitze nicht die notwendige Legitimität, um eine derart grund-

26 Dieses Lager der Kritiker umfasste unterschiedliche nationalliberale, konservative und rechtsnationalistische Parteien sowie das 1996 gegründete Wahlbündnis der „Wahlaktion Solidarność“ (Akcja Wyborcza Solidarność - kurz: AWS) und wurde von der Gewerkschaft Solidarność und Teilen der katholischen Kirche unterstützt.

27 Mildenberger, Zwischen Konsens und Polarität, 1998, S. 82f.

28 Zur empirisch-soziologischen Dimension der Konstruktion von Legitimität(sglauben) vgl. Max Weber: Wirtschaft und Gesellschaft. Grundriß der verstehenden Soziologie, Tübingen 1990, S. 122ff.; Peter Graf Kielmansegg: Legitimität als analytische Kategorie, in: Politische Vierteljahresschrift 12 (1971) 3, S. 367-401; Thomas Luckmann: Einige Bemerkungen zum Problem der Legitimation, in: Cornelia Bohn u.a. (Hrsg.): Sinngeneratoren. Fremd- und Selbstthematisierung in soziologisch-historischer Perspektive, Konstanz 2001, S. 339345, hier: S. 342ff.; sowie Thilo Raufer: Die legitime Demokratie. Zur Begründung politischer Ordnung in der Bundesrepublik, Frankfurt a.M. 2005, S. $22 \mathrm{ff}$. 
legende Frage zu entscheiden, wurde dabei zu einem der wichtigsten Argumente der Gegner des Entwurfes.

\subsection{Der Legitimitätsdiskurs als verfassungspolitische Grundlage der Dritten Republik}

Bereits vor 1989 war der Vorwurf mangelnder Legitimität der von Moskau gestützten Volksrepublik Polen und ihrer Eliten ein zentraler Baustein in der Argumentation der oppositionellen Regimekritiker gewesen. Durch die Vereinbarungen des Runden Tisches vom Frühjahr 1989 und den begleitenden Geheimverhandlungen zwischen den Spitzen von Solidarność und der Polnischen Vereinigten Arbeiterpartei ${ }^{29}$ wurde dieser Einwand de facto - in gleicher Weise wie Teile der politischen Führung des alten kommunistischen Regimes - ohne Umwege in das neue, demokratische Polen überführt. ${ }^{30}$ Denn während nach den Wahlen vom Juni 1989 eine am Runden Tisch vereinbarte Quotenregelung der Kommunistischen Partei 65 Prozent der Sitze im Sejm garantierte, konnte der neu geschaffene Senat als erste, vollständig frei gewählte Vertretungskörperschaft eines polnischen Staates seit den Zeiten der Zweiten Republik gelten. Entsprechend den damit bewirkten unterschiedlichen Mehrheitsverhältnissen entwickelte sich bald eine starke Rivalität zwischen den beiden Kammern, die sich auch an unterschiedlichen Auffassungen über mögliche Vorgehensweisen und Kompetenzverteilungen für die Erarbeitung und Verabschiedung einer neuen Verfassung entzündete.

Aufgrund dieser besonderen Situation behielt der Vorwurf mangelnder Legitimität seine Relevanz in der politischen Diskussion und trug nun dazu

29 Polska Zjednoczona Partia Robotnicza - kurz: PZPR.

30 Gemäß dem Abkommen vom Runden Tisch wurde der Staatsratsvorsitzende und erste Sekretär der PZPR, der 1981 das Kriegsrecht verhängt hatte, General Wojciech Jaruzelski, am 19. Juli 1989 in das neu geschaffene Amt des Staatspräsidenten gewählt. $\mathrm{Zu}$ den Verhandlungen am Runden Tisch vgl. Wiktor Osiatyński: The Roundtable Talks in Poland, in: Jon Elster (Hrsg.): The Roundtable Talks and the Breakdown of Communism, Chicago 1996, S. 21-69; Jan Kubik: The Polish Round Table of 1989. The Cultural Dimension(s) of the negotiated Regime Change, in: Michael D. Kennedy u.a. (Hrsg.): Negotiating Radical Change. Understanding and Extending the Lessons of the Polish Round Table, Ann Arbor, MI 2008, S. 88-109; zu den begleitenden Geheimverhandlungen vgl. Krzysztof Dubiński: Magdalenka. Transakcja Epoki. Notatki z Poufnych Spotkań Kiszczak - Wałęsa, Warschau 1990. 
bei, das neugewählte Parlament in einen Zustand innerer Blockade zu führen und auf diese Weise indirekt aber wirksam die Verabschiedung einer neuen Verfassung zu verhindern. Zwar waren sich Sejm und Senat einig, dass eine wirtschaftliche und staatsorganisatorische Neuordnung nur durch die baldige Annahme einer neuen Verfassung vollendet werden könne, doch fehlte ihnen für die dafür notwendige Übereinkunft der ,,politische Wille، ${ }^{31}$. Während der von Solidarność dominierte Senat dem Sejm ${ }^{32}$ die demokratische Legitimität absprach, argumentierte man von Seiten des Sejm, dass aufgrund der im Zuge der Reformpolitik bereits übernommenen politischen Verantwortung eine entsprechende legitimatorische Basis geschaffen worden sei. Als der Sejm dann am 7. Dezember 1989 einen eigenen Verfassungsausschuss einsetzte, zog der Senat kurzerhand nach und ernannte ebenfalls ein entsprechendes Komitee. ${ }^{33}$ Beide arbeiteten in der Folge an verschiedenen, zum Teil unvereinbaren Entwürfen, zu denen sich zahlreiche weitere Verfassungsentwürfe von politischen Parteien, gesellschaftlichen Gruppen und Einzelpersonen gesellten. ${ }^{34}$ Hinzu kamen erste Spannungen und Zerfallserscheinungen der politischen Sammlungsbewegung Solidarność, die den Aushandlungsprozess einer neuen Verfassung weiter verzögerten. Als nach der Direktwahl Lech Wałęsas zum Präsidenten der Republik am 9. Dezember 1990 die Stellung der kommunistischen Partei und damit die nicht demokratisch legitimierte Sejm-Mehrheit weiter geschwächt wurde, entschied man sich schließlich für vorgezogene Neuwahlen im Oktober 1991. Das gemeinsame, zur politischen Einigung motivierende Ziel, am symbolisch höchst bedeutungsvollen 3. Mai 1991, dem 200. Jahrestag der ersten polnischen Verfassung, eine neue demokratische Verfassung zu verabschieden, war damit nicht mehr erreichbar. ${ }^{35}$

31 Janusz Dobrosz: Rede vor der Nationalversammlung am 25.02.1997.

32 Da seine Zusammensetzung zum Teil den Vorgaben eines politischen Abkommens entsprach wurde dieser Sejm auch als „Kontrakt-Sejm“ bezeichnet.

33 Vgl. Wyrzykowski, Legitimacy, 2001, S. 437f.

34 Trotz der politischen Blockadesituation entstanden somit zwischen 1989 und 1991 zahlreiche Verfassungsentwürfe. Vgl. dazu: Marian Kallas: Projekty Konstytucyjne 1989-1991, Warschau 1992.

35 Der Rechtssoziologe Wiktor Osiatyński, der zwischen 1990 und 1997 mehreren Verfassungsausschüssen des polnischen Parlaments als Berater angehörte, stellte im Nachhinein resigniert fest: „Unfortunately, we overlooked that moment, committing countless and avoidable mistakes. We had no draft project in hand, convinced that there was no need to hurry, and we created two separate constitutional committees (in the Sejm and in the Senate), without conclusively estab- 
Nach den ersten vollständig freien und demokratischen Parlamentswahlen vom 27. Oktober 1991 entstand nun wiederum eine Situation, in der kein Mangel, sondern eher ein „Überschuss an Legitimität“36 die erfolgreiche Erarbeitung und Verabschiedung einer neuen Verfassung verhinderte. Diese neue politische Konstellation, in der insgesamt mehr als 20 Parteien und Gruppierungen Mandate im neuen Parlament gewannen und über 15 Fraktionen bildeten, ${ }^{37}$ war nicht nur einem novellierten Wahlgesetz, sondern vor allem den schnellen und radikalen ökonomischen Maßnahmen der Systemtransformation und den damit einhergehenden Veränderungen in der polnischen Wählerschaft geschuldet. Mit dem Wegfall des einst übermächtigen politischen Gegners bestimmte nun nicht länger die verbindende Tradition eines gemeinsamen Kampfes gegen das kommunistische Regime, sondern die neu entstandenen oder sichtbar gewordenen Interessengegensätze völlig unterschiedlicher Wählergruppen die politische Geographie Polens. ${ }^{38}$ Aufgrund der damit vorherrschenden relativen politischen Instabilität sowie der zeitweisen Eskalation institutioneller Konflikte zwischen dem Parlament und dem teilweise autokratisch auftretenden Präsidenten Lech Wałęsa gelang es am 23. April 1992 im „,Verfassungsgesetz zur Vorbereitung und Verabschiedung der Verfassung der Republik Polen“339 zwar den rechtlichen Rahmen eines möglichen Verfassunggebungsprozesses klar zu definieren, nicht jedoch diesen Prozess selbst zum Erfolg zu führen. ${ }^{40}$

lishing their rank in relation to each other or determining how their segregated work would be coordinated and later joined-all this demonstrates our shortsightedness." (Osiatyński, A Brief History of the Constitution, 1997, S. 68)

36 Jerzy Szmajdziński: Rede vor der Nationalversammlung am 24.02.1997.

37 Vgl. unter: http://www.sejm.gov.pl/archiwum/kluby/kadencja1/kluby.htm.

38 Vgl. Maćków, Parlamentarische Demokratie und Autoritarismus, 1998, S. 70. Im Zentrum stand dabei der Konflikt zwischen zwei Gruppierungen, die sich als die „echten Polen“ bzw. die „laizistische Linke“ bezeichneten. Vgl. Jacek Kurczewski: Von der Solidarność bis zum Parlament, und was weiter, oder Dilemmata der polnischen Demokratie, in: Zdzisław Krasnodębski (Hrsg.): Kulturelle Identität und sozialer Wandel in Osteuropa. Das Beispiel Polen, Hamburg 1999, S. 169-193, hier: S. 171.

39 Vgl. unter: http://orka.sejm.gov.pl/proc1.nsf/opisy/16.htm (Ustawy Konstytucyjnej o Uchwaleniu Konstytucji Rzeczypospolitej Polskiej).

40 Lediglich ein umfangreiches Paket von Verfassungsänderungen wurde von einer breiten Parlamentsmehrheit - bezeichnenderweise gegen den Willen der Regierung - durchgesetzt. Vgl. zu dieser sogenannten ,Kleinen Verfassung' vom 17. Oktober 1992: Wyrzykowski, Legitimacy, 2001, S. 440ff.; Janina Zakrzewska: Grundprobleme der polnischen Verfassung, in: Jahrbuch für Politik 
Obwohl es viele Veränderungen in Staatsorganisation und Verfassungspraxis auf den Weg gebracht hatte, war damit auch das Parlament der I. Legislaturperiode ${ }^{41}$ als Konstituante gescheitert.

\section{2 ,Legitimität' als Argument im polnischen Verfassungsdiskurs bis 1997}

Die lähmende Wirkung, die die Legitimitätsfrage auf den Verfassunggebungsprozess in Polen entfaltet hatte, setzte sich auch nach den Neuwahlen von 1993 fort. Denn durch eine weitreichende Änderung des Wahlrechts mit der Einführung einer Fünfprozenthürde war nun wiederum die besondere Situation eingetreten, dass - zum größten Teil eigenen strategischen Fehlern geschuldet - weite Teile des politisch stark fragmentierten rechtsnationalen Post-Solidarność-Lagers den Wiedereinzug ins Parlament verpassten und sich daraufhin als außerparlamentarisches Wahlbündnis Akcja Wyborcza Solidarność (AWS) neu formierten. Über 30 Prozent der Wählerstimmen blieben damit ohne parlamentarische Vertretung. Die Wahlgewinner aus Sozialdemokraten (SLD) und Bauernpartei (PSL) - beides die Nachfolger ehemaliger Blockparteien im kommunistischen Polen konnten hingegen, trotz lediglich 35 Prozent der Stimmen, mit annähernd Zweidrittelmehrheit regieren. ${ }^{42} \mathrm{Ob}$ damit das neu gewählte Parlament aufgrund seiner eingeschränkten Repräsentativität überhaupt ein notwendiges $\mathrm{Ma}$ an Legitimität besaß, wurde insbesondere dann intensiv diskutiert, als sich die neue Regierung zügig daran machte, ihre Mehrheit zu nutzen, um erneut eine gemeinsame Verfassungskommission von Sejm und Senat zu institutionalisieren. Selbst Vertreter der später an der sogenannten ,Verfassungskoalition“ beteiligten linksliberalen Freiheitsunion (UW) zogen unter diesen Umständen die Berechtigung des neugewählten Parlaments zur Ver-

2 (1992) 1, S. 109-134; Kai-Olaf Lang: Die kleine Verfassung der polnischen Republik, in: Recht in Ost und West 37 (1993) 6, S. 172-177.

41 In der offiziellen Zählung wird die Zeit bis zur Parlamentswahl vom 27. Oktober 1991 noch als X. Legislaturperiode der Volksrepublik Polen gewertet.

42 Spätestens mit der Abwahl Lech Wałęsas bei den Präsidentschaftswahlen im November 1995 war somit die Mehrzahl der früher in der antikommunistischen Opposition zusammengefassten politischen Gruppierungen - ironischerweise aufgrund zuvor selbst mitbeschlossener Änderungen des Wahlrechts - gewissermaßen über Jahre von der unmittelbaren politischen Machtausübung ausgeschlossen. 
abschiedung einer Verfassung in Zweifel. Es sei wichtig, so gab der frühere Ministerpräsident Tadeusz Mazowiecki zu bedenken, hier genau zwischen der zweifellos vorhandenen, „rechtlichen Legitimation“ und einer fraglichen ,politischen Legitimation“ zu unterscheiden. ${ }^{43}$

Vor allem die Gegner der Verfassung von 1997 griffen diesen Legitimitätsdiskurs auf und sprachen der aus Sejm und Senat konstituierten Nationalversammlung folglich die Berechtigung ab, das polnische Volk angemessen zu vertreten. Man könne nicht für einen Entwurf die Hand heben, der zwar den Willen des Volkes zum Ausdruck bringen möchte, dabei aber nur von vier politischen Gruppierungen unterstützt werde. ${ }^{44}$ Mit Blick auf die in der ,Verfassungskoalition“ federführenden Nachfolgeparteien der ehemaligen Polnischen Vereinigten Arbeiterpartei wurden die Vorwürfe besonders emotional vorgetragen. Es sei geradezu ein „Paradoxon der Geschichte“, dass acht Jahre nach der Wiedererlangung der nationalen Unabhängigkeit ein so wichtiges Dokument von einer Gruppierung erarbeitet werde, die in einem totalitären System ihre politischen Wurzeln habe. ${ }^{45}$ Der Entwurf der Nationalversammlung sei demnach eine „Verschwörung vier parlamentarischer Fraktionen“, die jeden Gemeinsinn vermissen lassen und sich - im eigenen Interesse handelnd und unter Ausnutzung der aktuellen politischen Krise - lediglich der erfolgreichen Verabschiedung einer Verfassung rühmen wollen. ${ }^{46}$

43 „Od początku pracy w tej Komisji było jasne, że trzeba odróżnić legitymizację prawną do uchwalenia konstytucji, czego nikt rozsądny nie kwestionuje, w każdym razie mój klub tego nie kwestionuje, od legitymizacji politycznej, na co sami członkowie Klubu SLD zwracali uwagę.“ (Kancelaria Sejmu: Komisja Konstytucyjna Zgromadzenia Narodowego. Biuletyn V, Wydawnictwo Sejmowe, Warschau 1994, S. 6, Beitrag von Tadeusz Mazowiecki vom 23.02.1994) Weil über 30 Prozent der abgegebenen Stimmen nicht im Parlament repräsentiert seien, besitze dieses nicht die notwendige politische Legitimation zur Verabschiedung einer neuen Verfassung. Bekanntlich änderte Mazowieki seine Meinung später und wirkte maßgeblich an der neuen Verfassung mit.

44 Krzysztof Kaminski: Rede vor der Nationalversammlung am 24.02.1997; Grzeskowiak, Alicja: Rede vor der Nationalversammlung am 24.02.1997.

45 Andrzej Gąsienica-Makowski: Rede vor der Nationalversammlung am 25.02.1997.

46 Adam Słomka: Rede vor der Nationalversammlung am 24.02.1997: „Z punktu widzenia naszego klubu, Klubu Parlamentarnego Konfederacji Polski Niepodległej i Bezpartyjnego Bloku Wspierania Reform, projekt ten jest w istocie zmową czterech klubów parlamentarnych, które chcą na wybory pochwalić się sukcesem i konstytucją. Jest im obojętne, jaka to jest konstytucja. Zdają sobie sprawę, że jest ona wewnętrznie niespójna, zdają sobie sprawę, że 
Die Unterstützer des Verfassungsentwurfes der Nationalversammlung wiesen den Vorwurf mangelnder Legitimität vehement zurück und betonten die demokratische Legitimation ihrer Arbeit. Der Entwurf sei keine Verschwörung einiger weniger Parteien, sondern - wenn überhaupt - eine „Verschwörung der überwiegenden Mehrheit der Bevölkerung ${ }^{647}$, denn sie habe dem polnischen Parlament schließlich in freien Wahlen einen entsprechenden Auftrag erteilt. Im Gegensatz zu dem ,,von einer Gruppe von Juristen entwickelten“ alternativen Bürgerentwurf der rechtsnationalen Opposition besitze der Verfassungsentwurf der Nationalversammlung eine wesentlich breitere demokratische Legitimationsgrundlage. Die beharrlich vertretene These vom „Vier-Parteien-Projekt“ sei daher eine „offensichtliche Lüge “48.

\section{3 ,Kompromiss‘ als ARgument}

Dass Verfassungen ,,von ihrer Genese her Kompromissgebilde der an der Verfassunggebung beteiligten politischen Kräfte“ ${ }^{49}$ sind, gilt in der rechtsund politikwissenschaftlichen Diskussion als allgemein anerkannte Tatsache. Als Argumentationsfigur gewinnt die Behauptung oder Infragestellung des Kompromisscharakters entsprechender Positionen, Vorschläge oder Entwürfe jedoch eine zusätzliche politische Funktion. Im polnischen Verfassungsdiskurs vor 1997 nahmen derartige Verweise auf einen scheinbar unverfügbaren und - zumindest in der öffentlich vorgetragenen Argumentation der einzelnen Akteure - grundsätzlich nicht infrage gestellten, aber doch unterschiedlich ausgedeuteten Verfahrensgrundsatz eine zentrale Stellung ein.

obecny układ w parlamencie jest niereprezentatywny, że ponad połowa wyborców nie jest reprezentowana obecnie w tym Zgromadzeniu Narodowym i że w innych warunkach nie miałyby szans na przeprowadzenie tak oryginalnego rozwiązania legislacyjnego.“

47 Krzysztof Kozłowski: Rede vor der Nationalversammlung am 24.02.1997.

48 Jerzy Szmajdziński: Rede vor der Nationalversammlung am 24.02.1997.

49 Hans Vorländer: Emergente Institution. Warum die Verfassung ein Prozeß ist, in: Hubertus Buchstein/Gerhard Göhler (Hrsg.): Politik der Integration. Symbole Repräsentation Institution, Baden-Baden 2006, S. 247-259, hier: S. 248. 


\subsection{Kompromissbereitschaft als verfassungspragmatische Grundlage der Dritten Republik}

Das Argument des Kompromisses verdankt seinen zentralen Stellenwert zum Teil der Art und Weise, wie die antikommunistische Opposition die dramatischen Ereignisse infolge der Ausrufung des Kriegsrechts im Dezember 1981 verarbeitete. Besonders die gemäßigt-liberalen Interpreten dieser Niederlage sannen in der Folge darauf, auf revolutionäre Umsturzversuche weitestgehend zu verzichten und stattdessen durch Verhandlungen mit dem Regime einen eher evolutionären Wandel herbeizuführen. Bereits die erste Phase institutioneller Veränderungen in Polen wurde im Rahmen dieser Strategie herbeigeführt und konnte nur deshalb eingeleitet und zum Erfolg geführt werden, weil sich beide Seiten - das kommunistische Regime unter Führung General Wojciech Jaruselskis und die Spitzen der Gewerkschaft Solidarność um Lech Wałęsa - am sogenannten ,Runden Tisch' kompromissbereit gezeigt hatten. Teil der hier beschlossenen machtpolitischen Übereinkunft war es bekanntlich gewesen, das autoritäre Regierungssystem der Volksrepublik Polen zunächst in eine Art ,gelenkte Demokratie‘ zu überführen. Der daraus hervorgehende ,Kontrakt-Sejm ‘ das erste zum Teil frei gewählte Parlament - war Teil dieses Kompromisses, der sowohl die politische Macht, vor allem aber auch die politische Verantwortung für die dringend notwendigen wirtschaftlichen und sozialen Reformen auf die oppositionellen Sammlungsbewegung Solidarność übertragen sollte. Als dann nach der folgenden ökonomischen ,Schocktherapie' die antikommunistische Opposition rasch in viele kleinere Parteien und Gruppierungen zerfiel und so die politische Basis für eine umfangreichere konstitutionelle Neuordnung in weite Ferne rückte, konnten mit der ,Kleinen Verfassung' vom Oktober 1992 - auf der Basis einer umfassenden Kompromisslösung zwischen damaliger Regierung und Opposition - wenigstens diejenigen verfassungsrechtlichen Änderungen umgesetzt werden, die für die Stabilisierung und Anpassung der staatsrechtlichen Ordnung an die veränderten machtpolitischen und sozio-ökonomischen Rahmenbedingungen unbedingt erforderlich schienen.

Auch im polnischen Verfassungsdiskurs nach 1992 waren sich alle Beteiligten - zumindest prinzipiell - einig, dass den Verfahrensgrundsätzen der Kompromissfindung ein hoher ideeller Wert zuzurechnen sei. Der 
Kompromiss sei nun einmal „die einzige mögliche Methode, um kontro-

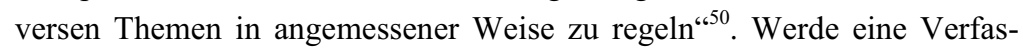
sung hingegen in einer „Atmosphäre der Konfrontation“ verabschiedet, so könne dies ,einen Verlust für die gesamten Nation“ bedeuten. ${ }^{51}$ Selbst die katholische Geistlichkeit halte die Spielregeln des Kompromisses für einen unverzichtbaren Teil der „Grundlagen der Demokratie“"52. Eine umfassende Kompromisslösung könne dabei womöglich gar die fragwürdige Legitimationsgrundlage der „Verfassungsväter“" kompensieren. ${ }^{53}$

\section{2 ,Kompromiss‘ als Argument im polnischen Verfassungsdiskurs bis 1997}

Im Verfassungsdiskurs der II. Legislaturperiode zwischen 1993 und 1997 entwickelte sich der affirmative Verweis auf den Kompromisscharakter des eigenen Verfassungsentwurfes zur zentralen Argumentationsfigur der sozialdemokratisch-liberalen Parlamentsmehrheit. Der Entwurf des Verfassungsausschusses wurde von seinen Unterstützern dementsprechend als „fairer und vernünftiger Kompromiss“"54, als „,große Synthese“ und „Ergebnis einer tiefen politischen und ideologischen Auseinandersetzung “55 gefeiert. Umfassend wurde in den Redebeiträgen der Vertreter der „Verfassungskoalition“ ausgeführt, inwiefern er „viele Begriffe, viele Schulen, viele Ansichten, viele Stile und viele politische Kräfte“ in sich vereine und

50 Józef Olesky: Rede vor der Nationalversammlung am 25.02.1997.

51 Waldemar Pawlak: Rede vor der Nationalversammlung am 24.02.1997. Ähnlich auch Piotr Ikonowicz: Rede vor der Nationalversammlung am 24.02.1997: „Dzisiaj musi zapanować na tej sali atmosfera rzetelnej dyskusji. Nam nie wolno ulegać konfrontacyjnym nastrojom, które muszą doprowadzić do błędów $\mathrm{w}$ pracy nad ustawą zasadniczą. $\mathrm{Z}$ dużym niepokojem obserwowałem coś w rodzaju meczu czy przepychanki między dwoma projektami, między dwiema siłami politycznymi, które już niedługo - cierpliwości - zetrą się w powszechnych wyborach parlamentarnych.”

52 Jerzy Szmajdziński: Rede vor der Nationalversammlung am 24.02.1997. In dieser Rede berief sich der SLD-Abgeordnete Jerzy Szmajdziński dabei - nicht ohne ironischen Unterton in Richtung der Gegner des Ausschussentwurfes - auf eine Äußerung des Erzbischofs Henryk Muszyński.

53 Diese Auslegung stellt etwa der Verfassungsrechtler Mirosław Wyrzykowski (Die Herausbildung der Verfassung, 2000, S. 58) als rhetorische Frage in den Raum.

54 Jerzy Szmajdziński: Rede vor der Nationalversammlung am 24.02.1997.

55 Marek Mazurkiewicz: Rede vor der Nationalversammlung am 24.02.1997. 
damit als „Beweis politischer Reife“56 interpretiert werden könne. Um die breite Basis des Entwurfes zu verdeutlichen, verwies man außerdem immer wieder auf diejenigen Quellen, aus denen er sich angeblich speise und aus denen ganz explizit Teile, Formulierungen oder Ideen entnommen wurden - etwa die prominenten Vorbilder aus der Verfassungsgeschichte Polens, ${ }^{57}$ die Entwürfe von Sejm und Senat der X. und I. Legislaturperiode, Entwürfe prominenter Professoren und Intellektueller oder gar Entwürfe der jetzigen Kritiker des Ausschussentwurfes, wie etwa der Entwurf des ehemaligen Präsidenten Lech Wałęsas. ${ }^{58}$ Darüber hinaus wurde die explizite Einladung von Vertretern der außerparlamentarischen Opposition in den Verfassungsausschuss besonders betont, Ähnlichkeiten mit dem konkurrierenden „Bürgerentwurf" dementsprechend hervorgehoben.$^{59}$ Insbesondere die auffälligen alternativen Doppelformeln in der Präambel, mit ihrer Unterteilung in "Gläubige“ und „Ungläubige“ dienten dabei immer wieder als Beispiel eines gelungenen Kompromisses. ${ }^{60}$ Den politischen Gegnern des Parlamentsentwurfes wurde hingegen strategisches Handeln und mangelnder Gemeinsinn unterstellt. Ihnen gehe es, so der Vorwurf, nicht um das gemeinsame Ganze, sondern ausschließlich um ihre eigenen Interessen. Die Kritik am Verfassungsentwurf des Ausschusses der Nationalversammlung sei, so argumentierten dessen Verteidiger, daher in Wirklichkeit „,nichts anderes als ein weiterer Versuch, die Gesellschaft zu spalten “61. Es sei den Kritikern vor allem daran gelegen, ,aus der Diskreditierung des Parlamentes und der eigenen demonstrativen Standfestigkeit politisches Kapital zu schlagen“ - die AWS etwa wolle auf diese Weise ihr Profil schärfen,

56 Piotr Ikonowicz: Rede vor der Nationalversammlung am 24.02.1997. „Fakt, że w Zgromadzeniu Narodowym i w Komisji Konstytucyjnej doszło do kompromisu partii, które na co dzień ścierały się jako władza i opozycja, jest dowodem dojrzałości polityków, którzy umieli osiągnąć ten kompromis.“(ebd.)

57 Insbesondere die Verfassungen von 1791 und 1921 wurden dabei als inhaltliche Vorbilder dargestellt. Vgl. etwa Jerzy Szmajdziński: Rede vor der Nationalversammlung am 24.02.1997.

58 Die sieben Verfassungsentwürfe, die 1993 den Ausgangspunkt der Arbeit des Verfassungsausschusses bildeten, finden sich gesammelt in Kancelaria Sejmu: Komisja Konstytucyjna Zgromadzenia Narodowego. Projekty Konstytucji, Wydawnictwo Sejmowe, Warschau 1993.

59 Etwa bei Waldemar Pawlak: Rede vor der Nationalversammlung am 24.02.1997 oder Krzysztof Kozłowski: Rede vor der Nationalversammlung am 24.02.1997.

60 Etwa bei Piotr Ikonowicz: Rede vor der Nationalversammlung am 24.02.1997 oder Andrzej Micewski: Rede vor der Nationalversammlung am 25.02.1997.

61 Jerzy Szmajdziński: Rede vor der Nationalversammlung am 24.02.1997. 
ihren inneren Zusammenhalt stärken und sich für den anstehenden Wahlkampf eine gute Ausgangsposition verschaffen. ${ }^{62}$

Eng verbunden mit derartigen Formen der Zuschreibung einer normativen Vorrangstellung des eigenen Verfassungsentwurfes durch den Verweis auf seinen komplexen Kompromisscharakter war in den Redebeiträgen in der Nationalversammlung stets die Unterstellung der damit gelungenen Orientierung an höherer Rationalität, Vernunft und dem Gemeinwohl. So lasse sich aus einer Perspektive „ohne Emotion, politischen und ideologischen Starrsinn oder Selbstsucht“ leicht erkennen, wie die Verfassungskommission der Nationalversammlung ,liberal-demokratische, sozialdemokratische, christlich-demokratische und nationale Elemente" miteinander verwoben und dabei auch religiöse und säkulare Positionen abgewogen habe. ${ }^{63}$ Dieses Etikett der Überparteilichkeit wurde weiter betont, indem auf die aktive Mitarbeit kompetenter Berater aus der Wissenschaft sowie auf die Anhörung und Einbeziehung renommierter Vertreter der katholischen Kirche verwiesen wurde. ${ }^{64}$

Die Gegner des Entwurfes des Verfassungsausschusses der Nationalversammlung zweifelten diese grundsätzliche Notwendigkeit einer angemessenen Kompromisslösung in ihrer Rhetorik nicht an, kritisierten aber, dass dies für den diskutierten Verfassungstext gerade nicht zutreffe. So müsse der Entwurf weniger als Kompromiss, sondern eher als „bizarrer“ Handel vierer, sich ideologisch nahestehender politischer Gruppierungen betrachtet werden, bei dem vor allem die ,postkommunistische“ Sozialdemokratie (SLD) und die linksliberale Freiheitsunion (UW) federführend waren. Entwürfe nationaler Gruppierungen, der Entwurf des Senats der X. Legislaturperiode sowie der sogenannte „Bürgerentwurf“ der außerparlamentarischen Opposition seien hingegen - trotz der erklärten Bereitschaft

62 Vgl. Mildenberger, Zwischen Konsens und Polarität, 1998, S. 83.

63 „Jeśli zatem popatrzymy na tekst ustawy zasadniczej bez emocji, politycznego zacietrzewienia i światopoglądowego egoizmu, dostrzeżemy łatwo, iż spełnia on aspiracje liberalno-demokratyczne, socjaldemokratyczne, chrześcijańsko-demokratyczne i narodowe." (Jerzy Szmajdziński: Rede vor der Nationalversammlung am 24.02.1997)

64 Etwa durch die explizite Aufzählung derjenigen Professoren und Kirchenvertreter, die zu einzelnen Sitzungen des Verfassungsausschusses der Nationalversammlung eingeladen wurden. Vgl. Jerzy Szmajdziński: Rede vor der Nationalversammlung am 24.02.1997. 
zu Kompromisslösungen - bewusst boykottiert worden. ${ }^{65}$ Dies alles habe sich abgespielt in einem Parlament ,dominiert von denselben politischen Kräften, die bereits in der ehemaligen Volksrepublik Polen den Ton angaben“. Der Entwurf sei daher das traurige Ergebnis der ,andauernden politischen Strategie des Runden Tisches“, welche Veränderungen nur unter der strengen Kontrolle der noch immer herrschenden sozialistischen Eliten erlaube. ${ }^{66}$ Einige Gegner der Arbeit des Verfassungsausschusses argumentierten hier auf einer noch grundsätzlicheren Ebene, indem sie das Vorliegen notwendiger Bedingungen für eine faire Kompromissfindung anzweifelten. „Zwischen Gut und Böse“ könne es dementsprechend keinen Kompromiss geben, denn in der Mitte seien nur „Lüge und Heuchelei“ zu finden. Es habe keinen Sinn, an den demokratischen Wert des Ausschussentwurfes zu glauben, wenn die Früchte dieser parlamentarischen Arbeit derart „,vergiftet“ seien. Das „Zauberwort“ des Kompromisses erfreue sich zwar allgemein großer Beliebtheit, doch müsse ein solcher Kompromiss auch auf einer geeigneten Basis aufbauen. In der polnischen Geschichte hätten faule Kompromisse schließlich bereits mehrmals dazu gedient, die Souveränität und Würde des Vaterlandes zu beschädigen. ${ }^{67}$

\section{4 ,Nationale Identität‘ als Argument}

Eine weitere Argumentationsfigur, deren zentrale Relevanz von Gegnern wie von Befürwortern des Verfassungsentwurfes vom Frühjahr 1997 nicht bestritten wurde, war die Frage nach der Entsprechung jeder denkbaren konstitutionellen Lösung mit den Besonderheiten polnischer Nationalität und Identität. Dieser Teilaspekt erscheint im Rückblick bisweilen als so dominant, dass gelegentlich der Verfassungsdiskurs im postkommunis-

65 Alicja Grzeskowiak: Rede vor der Nationalversammlung am 24.02.1997; Słomka, Adam: Rede vor der Nationalversammlung am 24.02.1997.

66 Ebd. Die kritische Distanzierung vom Abkommen des „Runden Tisches“ und das dabei zum Tragen kommende Narrativ einer „unvollendeten Revolution“ wird von der politischen Rechten noch heute als eine Art ,negativer Gründungsmythos" und als unverzeihliche Hypothek der Dritten Polnischen Republik gedeutet. Vgl. Jan Kubik/Amy Linch: The Original Sin of Poland's Third Republic. Discounting ,Solidarity' and its Consequences for Political Reconciliation, in: Polish Sociological Review 153 (2006) 1, S. 13-34.

67 Andrzej Gąsienica-Makowski: Rede vor der Nationalversammlung am 25.02.1997. 
tischen Polen insgesamt als Suche, Bestimmung und Aushandlung der eigenen nationalen Identität interpretiert wurde. ${ }^{68}$ Demnach galt es, die Traditionsbestände der polnischen Nation als unverfügbare Grundlage jeder neuen Verfassunggebung zu akzeptieren: „Wir glauben, dass die Verfassung nicht einfach aus dem Nichts, von unserem Willen, entspringen kann, sondern dass sie eine Fortsetzung des historischen Erbes, des Bewusstseins, der Kultur und der rechtlichen Traditionen der polnischen Nation ist. “69

Selbst bei zentralen Überlegungen zur konkreten Gestaltung des politischen Systems, wie etwa der Frage nach dem Ausmaß des staatlichen Einflusses im sozio-ökonomischen Bereich, der Frage nach dem rechtlichen Verhältnis von Staat und Kirche oder der Frage, ob eher ein präsidentielles oder ein parlamentarisches Regierungssystem den aktuellen politischen Herausforderungen am besten gerecht werde, wurde ein ums andere Mal auf die polnische Nation, deren Identität, Kultur und Traditionen verwiesen und vorrangig danach gefragt, ob die entsprechende institutionelle Lösung dem ,Willen der Nation“ einen möglichst authentischen Ausdruck verleiht. ${ }^{70}$ Interessensgegensätze und Positionsdifferenzen wurden auf diese Weise immer wieder ins Grundsätzliche verlagert und nahmen die Gestalt kultureller Auseinandersetzungen an. Die Entscheidung für oder gegen eine bestimmte institutionelle Alternative geriet zur Wahl zwischen verschiedenen Lebensentwürfen, mit denen man sich jeweils identifizierte und die deshalb auch durch die selbstgegebene Konstitution zum Ausdruck gebracht werden sollten. Nicht das Instrumentelle der Verfassung, sondern ihre symbolische Dimension stand damit de facto im Mittelpunkt der Dis-

68 So etwa bei Geneviève Zubrzycki: The Crosses of Auschwitz. Nationalism and Religion in Post-Communist Poland, Chicago/London 2008, S. 77ff.

69 So äußerte sich der Solidarność-Vertreter und Senator Piotr Andrzejewski im Verfassungsausschuss der Nationalversammlung: „Uważamy wreszcie, że konstytucją nie jest znikąd, z naszej woli, tylko jest kontynuacją dziejową dorobku, świadomości, kultury i tradycji prawnej narodu polskiego. Stąd manipulowanie tego typu kryteriami uwazamy za niedopuszczalne." (Kancelaria Sejmu: Komisja Konstytucyjna Zgromadzenia Narodowego. Biuletyn XLI, Wydawnictwo Sejmowe, Warschau 1997, S. 123, Beitrag von Piotr Andrzejewski vom 27.11.1996)

70 Vgl. Robert Brier: Diskursanalyse: Chancen und Möglichkeiten einer kulturwissenschaftlichen Forschungsperspektive am Beispiel des polnischen Verfassungsdiskurses 1989-1997, in: Birgit Schwelling (Hrsg.): Politikwissenschaft als Kulturwissenschaft. Theorien, Methoden, Problemstellungen, Wiesbaden 2004, S. 107-127, hier: S. 119. 
kussion. ${ }^{71}$ Nur so war die eingangs geschilderte starke emotionale Aufladung der polnischen Verfassungsdiskussion zu verstehen.

\subsection{Der polnische Identitätsdiskurs als verfassungskulturelle Grundlage der Dritten Republik}

Die politische Inanspruchnahme des nationalen Identitätsdiskurses hat in Polen eine lange Tradition und ist nicht erst als eine Folge der Transformationserfahrung nach 1989 und einem damit verbundenem gesteigertem Bedürfnis nach Sicherheit und Selbstvergewisserung zu begreifen. ${ }^{72}$ Als spezifisches Argumentationsfeld der politischen Auseinandersetzung sind die Ursprünge dieses Topos tief mit der polnischen Geschichte verwurzelt, denn im Gegensatz zu vergleichbaren Gesellschaften mit einer ähnlich angelegten republikanischen Tradition wurden der Staat, seine Institutionen und deren Vertreter von den Polen meist ,als Repräsentanten einer fremden und der polnischen Tradition, Sprache, Kultur und Konfession gegenüber feindlich eingestellten Obrigkeit" erlebt und empfunden. ${ }^{73}$ Diese, im Laufe von Jahrhunderten entstandene und gepflegte ,oppositional identity ${ }^{674}$ hatte seinen Ursprung in der politischen Geographie des Landes, seiner zeitweise verhängnisvollen Mittellage zwischen den europäischen Großmächten (Russland, Preußen, Schweden und Österreich - später: Deutschland, Russland/Sowjetunion) sowie der daraus folgenden, bis ins 20. Jahrhundert hinein fast durchgängigen Kolonisierung und Aufteilung

71 „The issue was not [...] the content of the constitution, but to whom the constitution would ,belong'“" (Osiatyński, A Brief History of the Constitution, 1997, S. 68)

72 Vgl. Anna Wolff-Powęska: Identität in der Wendezeit, in: Jochen Franzke (Hrsg.): Polen. Staat und Gesellschaft im Wandel. Beiträge zur Debatte, Berlin 1998, S. 11-25.

73 Mildenberger, Zwischen Konsens und Polarität, 1998, S. 76. Dieser wahrgenommene, grundsätzliche Gegensatz von Gesellschaft und Regierenden wird häufig mit dem Schlagwort des „My i oni“ (,wir“ und „sie“) bezeichnet und gehört, so wird häufig diagnostiziert, zu einem typischen Merkmal der politischen Kultur Polens. Vgl. Stefan Garsztecki: Die polnische politische Kultur. Kontinuität und Wandel, in: Zdzisław Krasnodębski (Hrsg.): Kulturelle Identität und sozialer Wandel in Osteuropa. Das Beispiel Polen, Hamburg 1999, S. 131168, hier: S. 135ff.

74 Geneviève Zubrzycki: „We, the Polish Nation“: Ethnic and Civic Visions of Nationhood in Post-Communist Constitutional Debates, in: Theory and Society 30 (2001) 5, S. 629-668, hier: S. 638. 
des polnischen Territoriums unter diesen Mächten. Nicht der eigene Staat, sondern die ,imagined community“ (Benedict Anderson) einer, vor allem ethnisch und kulturell definierten Gemeinschaft der Polen entwickelte sich daher zum dominierenden Deutungsrahmen polnischer Identität. „Begründet in der überlieferten Aufstandstradition des 19. Jahrhunderts, bestätigt durch die Unterdrückung und Verfolgung während der deutschen Okkupation und konserviert durch die sowjetische Dominanz in der Zeit der Volksrepublik Polen“ entwickelte sich die konsequente Unterscheidung zwischen nationaler Gemeinschaft und staatlicher Obrigkeit, zu einem wesentlichen Bestandteil der politischen Kultur Polens. ${ }^{75}$ Dieser Antagonismus zwischen Staat und Nation erfuhr nach dem Zweiten Weltkrieg eine deutliche Aktualisierung, als mit Hilfe Moskaus das Territorium Polens nach Westen verschoben und ein kommunistisches Regime errichtet wurde. So war in den 1980er Jahren die „Integration heterogener Gruppierungen und weiter Teile der polnischen Gesellschaft in eine oppositionelle Massenbewegung vor allem das Ergebnis der symbolischen Konstitution einer kulturell definierten Gemeinschaft", die sich moralisch von den Funktionären der Polnischen Vereinigten Arbeiterpartei und den als fremd gedeuteten kommunistischen Machthabern abgrenzte. ${ }^{76}$

Entsprechend der aus der Nationalismusforschung bekannten Dichotomie von „bürgerlichen“ und „ethnischen“ Einheitsvorstellungen bzw. „westlichen“ und „östlichen“ Formen des Nationalismus ${ }^{77}$ können - gerade im polnischen Verfassungsdiskurs - dabei zwei Idealtypen der Interpretation des eigenen kollektiven Erbes unterschieden werden. Sie werden in der

75 Mildenberger, Zwischen Konsens und Polarität, 1998, S. 76.

76 Brier, Culture and Constitutional Politics, 2009, S. 109. Auch das kommunistische Regime hatte vor 1989 versucht, den polnisch-nationalen Identitätsdiskurs rhetorisch aufzugreifen und sich auf diese Weise neue Wege der Rechtfertigung seiner Herrschaft zu erschließen. Vgl. hierzu etwa das Konzept eines ,Sozialistischen Patriotismus“ der Regierung von Edward Gierek (1970-1980) sowie die 1982 gegründete „Patriotische Bewegung der nationalen Wiedergeburt“ (Patriotyczny Ruch Odrodzenia Narodowego). Vgl. Jan Kubik: The Power of Symbols against the Symbols of Power. The Rise of Solidarity and the Fall of State Socialism in Poland, University Park, PA 1994, S. 31ff.; Dieter Bingen: Die neue polnische Sammlungsbewegung PRON und die Reform des Wahlsystems, Köln 1984.

77 Vgl. Rogers Brubaker: Citizenship and Nationhood in France and Germany, Cambridge, MA 1992; John Plamenatz: Two Types of Nationalism, in: Eugene Kamenka (Hrsg.): Nationalism. The Nature and Evolution of an Idea, London 1976, S. 22-37. 
Literatur oft als unterschiedliche „Master-Narrative“ gedeutet, die beide das Dispositiv der polnischen Nation als unverfügbare Geltungs- und Gestaltungsgrundlage der politischen Ordnung in unterschiedlicher Weise ausdeuten. ${ }^{78}$ Die eine Seite betont dabei die ethnische, kulturelle und sittliche Homogenität der polnischen Bevölkerung und sieht das christlich-katholische Erbe der Nation am besten in einem konfessionellen Staat gewürdigt. Auf der anderen Seite hingegen betonen insbesondere Intellektuelle, Liberale und gemäßigte Christen die weltanschauliche Heterogenität und gesellschaftliche Toleranz der Polen und fordern - ebenfalls im Namen nationaler Traditionen - eine klare Trennung zwischen Kirche und Staat. ${ }^{79}$ Obwohl beide Interpretationen im Laufe der polnischen Geschichte stets konkurrierten ${ }^{80}$ wurde die polnische Nation traditionell als ethnische Einheit definiert. Insbesondere die Religion spielte dabei eine entscheidende Rolle. Umgeben von protestantischen (Preußen, Schweden), christlichorthodoxen (Russland) oder betont atheistischen (Sowjetunion) Großmächten war es bereits seit dem 18. Jahrhundert zu einer Art Symbiose zwischen Katholizismus und polnischer Identität gekommen. ${ }^{81}$

Diese Tendenz wurde nach dem Zweiten Weltkrieg und der Gründung der Volksrepublik Polen weiter verstärkt. Als Symbol der Bewahrung

78 Vgl. hierzu etwa Zdzisław Krasnodębski (Modernisierung und Zivilisierung in Polen: Tradition und Gegenwart, in: ders. (Hrsg.): Kulturelle Identität und Sozialer Wandel in Osteuropa. Das Beispiel Polen. Hamburg 1999, S. 69-108, hier: S. 97), der vom „Konflikt zweier Zivilisationen“ spricht oder Robert Brier, der in ähnlicher Weise wie Geneviève Zubrzycki (,We, the Polish Nation“, 2001) mit Blick auf die Zeit vor 1989 die Narrative von „Katholischer Nation“ und „Sozialistischem Patriotismus“ (Robert Brier: The Roots of the „Fourth Republic“. Solidarity's Cultural Legacy to Polish, in: East European Politics and Societies 23 (2009) 1, S. 63-85, hier: S. 71ff.) und für den polnischen Verfassungsdiskurs nach 1989 ,zentrale Metaphern zur Konstruktion politischer Wirklichkeit“" (Brier, Diskursanalyse, 2004, S. 117f.) unterscheidet.

79 Zubrzycki, „We, the Polish Nation“, 2001, S. 637.

80 Auch der bürgerlich-rechtlichen Interpretation polnischer Identität kann eine gewisse Tradition nachgewiesen werden. Vgl. Zubrzycki, „We, the Polish Nation“, 2001, S. 661 Fn. 33. Die Inanspruchnahme nationaler und religiöser Symbole durch die Gewerkschaft Solidarność in den 1980er Jahren ist demnach in zweifacher Weise interpretierbar: nämlich einerseits als Forderung nach allgemeinen Bürgerrechten sowie andererseits als Beschwörung einer gemeinsam geteilten, ethnischen Identität. Vgl. Michael Carpenter: Civil Society or Nation? Re-evaluating Solidarity Ten Years after the Revolution, in: Polish Sociological Review 127 (1999), S. 333-351, hier: S. 347.

81 José Casanova: Public Religions in the Modern World, Chicago 2008, S. 92. 
nationaler Werte entwickelte sich - insbesondere nach den Beschlüssen des Zweiten Vatikanischen Konzils in den 1960er Jahren sowie nach der Ausrufung des Kriegsrechts 1981 - die katholische Kirche in Polen zum sicheren Zufluchtsort, zum lebhaften Ideengeber und zur organisatorischen Stütze der regimekritischen Opposition. Die katholische Theologie lieferte ein Vokabular, mit dem sich nicht nur die marxistische Ideologie und das als Fremdherrschaft empfundene kommunistische Regime hinterfragen ließ, sondern das auch die Forderungen nach der Gewährung von Freiheits-, Menschen- und Bürgerrechten mit einer genuin transzendenten Argumentationsgrundlage versorgte. Die umfangreiche Inanspruchnahme religiöser Symbole, Rituale und Positionen stellte daher auch für die Gewerkschaft Solidarność eine Selbstverständlichkeit dar und war ein entscheidendes Instrument politischer Mobilisierung.

Erst nach dem politischen Umbruch 1989 und der Spaltung der oppositionellen Sammlungsbewegung kam es zu einer gewissen Aufwertung und Emanzipation eines bürgerlich-liberalen Gegendiskurses von den vorherrschenden ethnisch-religiösen Deutungsparadigmen des dominanten rechten Flügels von Solidarność. Das daraus hervorgehende alternative „bürgerlichnationale“ Narrativ ordnete die polnische Nationalgeschichte eher in gesamteuropäische und universalhistorische Zusammenhänge ein, nach denen es ein gewisses wahrgenommenes ,Zivilisationsdefizit“ aufzuholen galt. Es stellte das Bekenntnis zu universellen Werten und zu individuellem Verantwortungsbewusstsein in den Mittelpunkt und das moralische Monopol der katholischen Kirche offensiv infrage. ${ }^{82}$

82 Brier, Diskursanalyse, 2004, S. 118; Zubrzycki, „We, the Polish Nation“, 2001, S. 638ff. Im Rahmen dieser Argumentation wurden ebenfalls zahlreiche, zum Teil mythisch verklärte Bezugspunkte der nationalen Geschichte aufgegriffen und instrumentalisiert: „Intellectuals have thus tried to sell this vision to the public by reconstructing a distinctively Polish civic narrative emphasizing the civic heritage of the nation in Poland, by, for example, going back to sixteenthcentury religious tolerance, to the 1st Republic's multi-ethnic state, to the Democracy of Nobles and the elective monarchy, to the Constitution of the Third of May (1791), to the Polish legions, fighting for our freedom and yours and to the end of nineteenth-century Warsaw positivism." (ebd., S. 640f.) 


\section{2 ,Nationale Identität' als Argument im polnischen Verfassungsdiskurs bis 1997}

Auch die politische Kultur der Dritten Republik scheint sich in diesen Deutungsrahmen einzufügen. Da die Ereignisse von 1989 in erster Linie als Befreiung von jahrzehntelanger Unterdrückung, die neue politische Ordnung als lang ersehnte Vereinigung von Nation und Staat erschienen, wurde der Verfassung - als Grundlage des neuen Staates - nun vorrangig die Aufgabe zuwiesen, den Souverän, die polnische Nation, angemessen zu beschreiben. ${ }^{83}$ Nach der politischen und moralischen „Wiedergeburt“ des Landes $^{84}$ sollte in ihren Artikeln und Absätzen der spezifisch nationale „Geist ${ }^{685}$, die ,pulsierende polnische Seele ${ }^{686}$ zum Ausdruck gebracht werden. Das Verbindende dieser gemeinsamen Identität wurde in der Diskussion dabei sowohl politisch als auch moralisch herzuleiten versucht.

\subsubsection{Die Nation als politisches Kontinuum}

Als besonders zentral in den Auseinandersetzungen um das richtige Verständnis des eigenen nationalen Erbes war der Verweis auf die vermeintlich festen Maßstäbe politischer und rechtlicher Kontinuität gegenüber den historischen Vorbildern der eigenen Geschichte. Parteiübergreifend galt dabei der Konstitutionalismus selbst - die Tradition sich eine Verfassung zu geben - als wesentlicher Teil des polnischen Erbes. Die Verfassung wird in diesem Deutungskontext traditionell als wichtigstes Symbol nationaler Autonomie und Selbstbestimmung gedeutet, die erste polnische Verfassung von 1791 als historisches Vorbild idealisiert und mythisiert. ${ }^{87}$ In die Tradi-

83 So argumentiert auch Zubrzycki, „We, the Polish Nation“, 2001, S. 637: „Since the newly independent state is meant to be a state of and for Poles, and the Constitution is the foundation on which the state is built, the document must specify the nature of Polish national identity. In other words, specifying who Poles are and should be is the first step toward the establishment of a ,proper constitutional order and a ,proper" (i.e. ,genuinely Polish') state."

84 Waldemar Pawlak: Rede vor der Nationalversammlung am 24.02.1997.

85 Janusz Dobrosz: Rede vor der Nationalversammlung am 25.02.1997.

86 Andrzej Gąsienica-Makowski: Rede vor der Nationalversammlung am 25.02.1997.

87 Diese Verfassung der sogenannten Polnisch-Litauischen Adelsrepublik (Rzeczpospolita Obojga Narodów) vom 3. Mai 1792 gilt als ,die erste geschriebene Verfassung Europas“ (Leszek Moczulski: Rede vor der Nationalversammlung am 25.02.1997). Ihr wurden oft hohe - wie einige klagen - gar „unerreichbar 
tionslinie dieser ,Maiverfassung' wird nahtlos die konstitutionelle Ordnung der Polnischen Zweiten Republik eingereiht, die in der sogenannten ,Märzverfassung' vom 17. März 1921 ihre Grundlage fand und ebenfalls in keiner eindeutigen Abhängigkeit zu einer benachbarten Großmacht stand.

Nach dem Willen des konservativen Lagers galt es nach 1989 ausschließlich an diese Tradition nationaler Selbstbestimmung anzuschließen. Bereits mit der offiziellen Bezeichnung des neuen demokratischen Polen als ,Dritte Republik', hatte man hier eindeutig Position bezogen. ${ }^{88}$ Die rechtsnationalen Gegner des Entwurfes von 1997 lehnten dementsprechend den Gedanken einer lückenlosen Kontinuität der polnischen Verfassungsgeschichte - unter Einbeziehung aller polnischen Staaten und Verfassungen vehement ab. Die Frage der Kontinuität sei eben weniger, ,von den Institutionen her“ bedeutsam, sondern vor allem bezüglich ,des Gefühls von Identität“. Man könne sich unmöglich etwa in die Tradition der kommunistischen Verfassung vom 22. Juli 1952 stellen, die ,zwar mit schön klingenden ideologischen Formeln“ reich verziert war, aber keinerlei Garantien besaß, dass ihre Grundsätze auch in der sozialen Praxis erfüllt würden. ${ }^{89}$ Die im offiziellen Entwurf der Nationalversammlung nicht deutlich genug zum Ausdruck gebrachte Distanzierung von diesem kommunistischen Vorgängerstaat impliziere eine „formale Fortsetzung der Volksrepublik Polen“ und sei daher eine „Schande für die polnische Tradition des Konstitutionalismus“. 90

Ganz anders argumentierten die Unterstützer der Verfassung von 1997. Für sie war die polnische Verfassungsgeschichte als kontinuierlicher Prozess zu beschreiben, von dem man nicht Teile ,wie die Pause zwischen zwei aufeinanderfolgenden Schulstunden“ einfach aus dem Gedächtnis löschen könne. Die Jahre zwischen 1944 und 1989 als ein „schwarzes

hohe moralische Ansprüche“ beigemessen, obwohl sie eigentlich „eher in einer Art Staatsstreich“ durchgesetzt worden war (Jan Zaborowski: Rede vor der Nationalversammlung am 24.02.1997).

88 Die damit erfolgte Ausklammerung der kommunistischen Volksrepublik Polen wurde dadurch unterstrichen, dass bis 1990 eine polnische Exilregierung in London existierte. Ihre aus der Zeit der Zweiten Republik stammenden Staatsinsignien wurden in einer feierlichen Zeremonie am 22. Dezember 1990 offiziell an Lech Wałęsa, dem damals amtierenden Präsidenten der Dritten Republik, übergeben. Vgl. Zbigniew Wilkiewicz: Gibt es eine IV. Republik Polen?, in: Aktuelle Ostinformationen 39 (2007) 1/2, S. 4-16, hier: S. 4.

89 Piotr Andrzejewski: Rede vor der Nationalversammlung am 24.02.1997.

90 Adam Słomka: Rede vor der Nationalversammlung am 24.02.1997. 
Loch" zu behandeln sei nicht redlich - gerade weil man noch heute den Preis für diesen Teil der Geschichte zahlen müsse. Im Übrigen seien auch andere Verfassungen der polnischen Geschichte ,nicht gerade demokratisch ${ }^{\text {“91 }}$ zustanden gekommen. Trotz der vielen Unterschiede zwischen dem vorliegenden Verfassungsentwurf der Nationalversammlung und seinen historischen Vorbildern sei ihnen allen jedoch ,eine sehr wichtige Sache gemein, die für die Polen in den Jahren ihrer Geschichte vielleicht der größte Wert ist, für den sie in allen Generationen gearbeitet und gekämpft haben: der Wunsch nach einem unabhängigen Staat. ${ }^{\text {“92 }}$ Auf diese Weise habe die Erinnerung an die großen Werke der polnischen Geschichte in den vergangenen Jahren auch die Arbeit an der neuen Verfassung beflügelt. Sie sei daher ein „Zeugnis der Reife und Weisheit der heutigen Generation der Polen. “933

\subsubsection{Die Nation als moralisch-kulturelles Kontinuum}

Ein weiterer Aspekt des Verweises auf nationale Identitäts- und Traditionsbestände im Rahmen des Verfassungsdiskurses in Polen war mit der Frage nach gemeinsam geteilten Werten und religiösen Überzeugungen verbunden. ${ }^{94}$ Die besondere Wertigkeit dieses Themas unterstrich etwa Marian Krzaklewski, der einflussreiche Vorsitzende der Gewerkschaft Solidarność:

„Ein nationaler Kompromiss über die Verfassung wird dann möglich sein, wenn wir endlich alle anerkennen, dass es in Polens Geschichte bestimmte Fakten gibt, die nicht interpretiert werden können. Einer dieser Fakten ist, dass Polen sowohl sein

91 Ryszard Bugaj: Rede vor der Nationalversammlung am 24.02.1997.

92 „Różne były, w oczywisty sposób odmienne od obecnych, historyczne uwarunkowania Konstytucji 3 maja i konstytucji marcowej. Jednak nasz projekt konstytucji ma z oboma tymi aktami jedną niezwykle ważną wspólną cechę: jest nią to, co w ponadtysiącletniej historii Polaków jest bodaj największą wartością, na którą pracowały i o którą walczyły wszystkie pokolenia. Tą wartością jest dążność do niepodległego państwowego bytu.“ (Jerzy Szmajdziński: Rede vor der Nationalversammlung am 24.02.1997)

93 Ebd.

94 Der Streit um die Verfassung, so fasste es der Sozialdemokrat Józef Olesky am 25.02.1997 vielsagend in seiner Rede in der Nationalversammlung zusammen, sei deshalb „nicht nur eine politische Auseinandersetzung“, sondern ,ein Streit um Prinzipien“, „ein Streit über die Quellen der rechtlichen Normen und Werte, über den Ort der Religion im Leben von Individuen und Gemeinschaft" (Józef Olesky: Rede vor der Nationalversammlung am 25.02.1997). 
Wertesystem als auch seine Verfassungsgesetzgebung schon immer auf christlichen Werten aufgebaut hat [...]. Wenn wir uns also auf eine Kontinuität dieser Werte, auf eine Kontinuität der Geschichte verständigen, dann bin ich sicher, dass eine gute Chance darauf besteht, sich auch in anderen - ökonomischen, sozialen und politischen - Fragen zu einigen. “95

Um diesen „Fakten“ polnischer Identität gerecht zu werden, wurden selbst scheinbar unwichtige Detailfragen als moralische Konflikte behandelt, in denen sich die Verteidiger der polnischen Kultur, Identität und soziomoralisch-religiösen Integrität den selbst ernannten Wächtern wahrer westlicher Demokratie, europäischer Standards der Zivilisation und einer liberalen und offenen Gesellschaft gegenüberstanden. ${ }^{96}$

Auch im Rahmen der Verfassungsdebatte in der Nationalversammlung im Februar 1997 wurde diese Frontstellung zur Geltung gebracht. Die Gegner des offiziellen Entwurfes beklagten dabei, dass mit der „utopischen“ Vision einer Bürgergemeinschaft die polnische Nation ,,von seiner Tradition und Geschichte enteignet" werde. Dass dieser positivistische Ansatz in den direkten Untergang führe, hätten jedoch gerade im 20. Jahrhundert bereits ähnlich gelagerte ideologische Projekte, wie die Sowjetunion oder Jugoslawien, gezeigt. ${ }^{97}$ Im vorliegenden Verfassungsentwurf jedoch sei „die polnische Nation praktisch in der Verfassung nicht existent“. Sie werde ,als moralisch, kulturell und sprachlich gestaltende Kraft“ nicht erwähnt und stattdessen durch den inhaltslosen Begriff der Gesellschaft ersetzt. ${ }^{98}$ Das nationale Symbol der Unabhängigkeit des polnischen Staates, der gekrönte weiße Adler, werde damit in die „Knechtschaft unleserlicher Aufzeichnungen“ gezwungen, deren Verabschiedung einem erneuten Verlust

95 „Kompromis narodowy będzie możliwy wtedy, gdy wszyscy uznamy, że są fakty w historii Polski, które są nie do interpretowania. Tym faktem jest to, że Polska zawsze opierała zarówno swój system wartości, jak i później prawodawstwo konstytucyjne na wartościach chrześcijańskich, które równocześnie były pozytywnie kierowane ku ludziom o różnych poglądach, przekonaniach, wyznaniach i różnych narodowości. Dlatego jeżeli zgodzimy się co do ciągłości wartości, co do ciągłości historii, jestem pewny, że w innych sprawach - gospodarczych, społecznych i politycznych - jest szansa na dobry konsensus." (Marian Krzaklewski: Rede vor der Nationalversammlung am 25.02.1997)

96 Vgl. Brier, Culture and Constitutional Politics, 2009, S. 89.

97 Andrzej Gąsienica-Makowski: Rede vor der Nationalversammlung am 25.02.1997.

98 Alicja Grzeskowiak: Rede vor der Nationalversammlung am 24.02.1997; Słomka, Adam: Rede vor der Nationalversammlung am 24.02.1997. 
der polnischen Identität und Unabhängigkeit gleichkomme. Das Dokument sei nichts als ein Versuch, den einstmals herrschenden ,primitiven Marxismus“ durch einen ähnlich „primitiven Positivismus und Liberalismus“ zu ersetzen. ${ }^{99}$ Insbesondere der katholische Teil der Bevölkerung werde sich aber „,wie Fremde im eigenen Land fühlen“, wenn die Verfassung den Sinn und Wert ihres Lebens in der staatlichen Gemeinschaft ignoriere. ${ }^{100}$

Vor allem der vorliegende Entwurf einer Verfassungspräambel diente im Rahmen dieser Argumentation als Nachweis für den unterstellten „moralischen Nihilismus": So bleibe mit der ausdrücklichen Gleichsetzung von Gott und den unspezifischen und undefinierten ,anderen Quellen“ etwa völlig unklar, welche Werte von Verfassungsrang seien und welche nicht. Eine solche Präambel missachte die unverfügbaren und einzigartigen moralischen Vorgaben aus dem jahrhundertealten Erbe der polnischen Geschichte und könne stattdessen prinzipiell in jedem x-beliebigen Land der Welt, ja selbst in einem relativistischen Wertesystem gültig sein. ${ }^{101}$ Die unzureichende Bezugnahme auf die vermeintlichen naturrechtlichen Grundlagen der Rechtsordnung ${ }^{102}$ sowie die fehlende Invocatio Dei, so die einhellige Kritik, wiegen dabei besonders schwer. Die Präambel des vorliegenden Entwurfes spreche zwar von Gott, jedoch nicht vom allmächtigen, dreieinigen und persönlichen Gott des katholischen Christentums, sondern stattdessen von Gott als einem „Produkt der idealistischen Philosophie für die Nutzung durch irgendeine Ideologie“. Gerade der Bezug auf Gott in der Verfassung sei es jedoch, auf dem die moralische und soziale Ordnung gründe und der die Würde des Menschen und dessen unveräußerliche Rechte garantiere. ${ }^{103}$

Auch die Unterstützer des Verfassungsentwurfes der Nationalversammlung versuchten das Argument der moralischen Bindung an die eigene

99 Adam Słomka: Rede vor der Nationalversammlung am 24.02.1997.

100 Andrzej Gąsienica-Makowski: Rede vor der Nationalversammlung am 25.02.1997; Alicja Grzeskowiak: Rede vor der Nationalversammlung am 24.02.1997.

101 Alicja Grzeskowiak: Rede vor der Nationalversammlung am 24.02.1997.

102 Zur umfangreichen Debatte um die Bedeutung des Naturrechts für die Verfassung vgl. stellvertretend die Redebeiträge von Jan Rokita: Rede vor der Nationalversammlung am 24.02.1997 und Józef Olesky: Rede vor der Nationalversammlung am 25.02.1997.

103 Andrzej Gąsienica-Makowski: Rede vor der Nationalversammlung am 25.02.1997; Alicja Grzeskowiak: Rede vor der Nationalversammlung am 24.02.1997. 
nationale Tradition in ihrer Weise zu instrumentalisieren. Die Sakralität der polnischen Nation und die Unhintergehbarkeit ihres kulturellen Erbes werde demnach gerade durch Prinzipien wie Toleranz, Weltoffenheit und die Achtung von Vielfalt zum Ausdruck gebracht. Bereits die polnischen Könige hätten stets den Grundsatz akzeptiert, „nicht Herr des Gewissens der Menschen“ sein zu wollen und die Rechte anders Denkender zu achten. ${ }^{104}$ Man dürfe die Deutungshoheit über den Begriff der Nation und ihre Traditionsbestände daher keinesfalls den rechten Kräften überlassen. ${ }^{105}$ Auch deshalb sei es wichtig, die Präambel mit den Worten „Wir, die polnische Nation“ beginnen zu lassen, denn ausschließlich die Nation sei der Garant für die Gewährleistung unveräußerlicher Menschenrechte. ${ }^{106}$ An die Gegner des Verfassungsentwurfes und deren alternativen ,Bürger-Entwurf wurde auf diese Weise der Vorwurf mangelnden Nationalbewusstseins zurückgereicht. Das in der polnischen Tradition verankerte Bewusstsein für Vielfalt und Pluralismus schließe den völlig eindimensionalen und konfrontativen Umgang der Opposition mit der Frage nach den Quellen kollektiver Werte und Überzeugungen nämlich eigentlich gerade aus. ${ }^{107}$ Auch und gerade religiöse Bezüge - etwa in der Präambel - seien deshalb mit Sorgfalt zu wählen, denn es gebe bekanntlich ,,verschiedene Wege, Gott zu gefal-

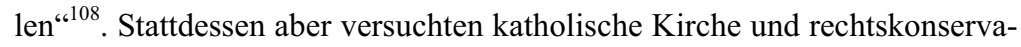
tive Presse mit autoritärem Gebaren und ,intellektuellem Terror“ den gesellschaftlichen Diskurs für ihre Zwecke zu monopolisieren. Auf diese Weise sei ein politisches Klima entstanden, in dem jede Kritik automatisch als Angriff auf Kirche, Religion und Nation gedeutet werde und in dem viele liberale Intellektuelle keinen öffentlichen Widerspruch mehr wagen würden. ${ }^{109}$ Mit dem gegenwärtigen Verfassunggebungsprozess hätten die Polen jedoch endlich die Chance, ,das erste Mal in ihrer modernen Geschichte in demokratischer Art und Weise, in Ruhe und ohne unmittelbare Bedrohung von außen“ gemeinsam eine Verfassung zu diskutieren und zu verabschieden. Der vorliegende Verfassungsentwurf ziele dabei nicht auf

104 Tadeusz Mazowieki: Rede vor der Nationalversammlung am 24.02.1997.

105 Ryszard Bugaj: Rede vor der Nationalversammlung am 24.02.1997.

106 Waldemar Pawlak: Rede vor der Nationalversammlung am 24.02.1997.

107 Józef Olesky: Rede vor der Nationalversammlung am 25.02.1997.

108 Tadeusz Mazowieki: Rede vor der Nationalversammlung am 24.02.1997.

109 Jan Zaborowski: Rede vor der Nationalversammlung am 24.02.1997. 
einen „Kirchenstaat“, sondern auf die Standards der „europäischen Zivilisation" $"$ "110.

\section{FAZIT: FORMEN DISKURSIVER TRANSZENDENZ IM POLNISCHEN VERFASSUNGSDISKURS}

Der Verfassungsdiskurs in Polen nach 1989 wurde - jenseits staatsrechtlicher Fachdiskussionen - vor allem als politisch-kultureller Deutungskampf geführt. Im Rahmen dieser „Auseinandersetzung um das Wirkliche“"111 kamen unterschiedlichste Argumentations- und Begründungsfiguren zum Einsatz, von denen drei jedoch eine herausgehobene Rolle spielten. Als Kristallisationspunkte der politischen Auseinandersetzung dienten sie dazu, den Prozess der Gründung und Institutionalisierung der neuen politisch Ordnung auf vermeintlich unverfügbare Grundlagen rückzubeziehen. Als Formen diskursiver Transzendenz besaßen sie in allen politischen Lagern einen unumstrittenen Status. Einerseits wurde die Notwendigkeit der Übereinstimmung mit diesen Grundsätzen von ,Legitimität', ,Kompromiss' und ,nationaler Identität' in der politischen Argumentation nicht angefochten, ihre Geltung als bestimmende Maßstäbe einer neuen Verfassung nicht weiter hinterfragt. Befürworter wie Gegner des Ausschussentwurfes der Nationalversammlung waren sich darin einig, dass eine neue Verfassung diesen drei Anforderungen genügen müsse. Andererseits aber wurden sie für die synchrone Darstellung völlig unterschiedlicher, bisweilen gar gegensätzlicher Inhalte und politischer Positionen in Anspruch genommen. Gerade dank ihrer hervorgehobenen Verbindlichkeit konnten sie in besonderem Maße für die politische Auseinandersetzung instrumentalisiert werden. Die gegenseitigen Vorwürfe zielten dabei jeweils auf die politischen Entscheidungsstrukturen (polity), die Spielregeln des politischen Prozesses (politics) sowie die politischen Inhalte (policy), an denen sich der Verfassunggebungsprozess zu orientieren hatte. Die damit verbundene Strategie, den Verfassungsdiskurs immer wieder im Modus ungelöster Kompetenz-, Verfahrens- oder Identitätsfragen zu verhandeln, wog deshalb so schwer, weil auf diese Weise jeder inhaltlichen Argumentation ausgewichen werden

110 Jerzy Szmajdziński: Rede vor der Nationalversammlung am 24.02.1997.

111 So Robert Brier(Diskursanalyse, 2004, S. 116) in Anlehnung an Clifford Geertz. 
konnte, ohne - nach außen hin - die gemeinsame Grundlage geteilter und öffentlich eingeforderter Prinzipien zu verlassen.

Die Bestreitung ausreichender Legitimität etwa diente dazu, den Anspruch des politischen Gegners zur Teilnahme am Gründungsdiskurs insgesamt infrage zu stellen. Aufgrund einer wechselseitig nicht anerkannten demokratischen Legitimation konnten sich die Mitglieder der linksliberalen ,Verfassungskoalition“ auf der einen, sowie der rechtsnationalen Verfassungsgegner auf der anderen Seite jeweils gegenseitig die generelle Berechtigung absprechen, überhaupt eine Verfassung erarbeiten oder verabschieden zu dürfen.

Hinter dem immer wiederkehrenden Argument des ,Kompromisses hingegen stand die Frage nach der Fairness der politischen Auseinandersetzung und damit auch nach Vernunft und Reife ihrer Akteure. Dabei diente sowohl die Behauptung, der eigene Entwurf entspreche einer austarierten Kompromisslösung, als auch die Infragestellung des Kompromisscharakters der jeweiligen Gegenposition dazu, jeden inhaltlichen Einwand aus formalen Gründen zurückzuweisen. Da die als ,Kompromiss' deklarierte Lösung bereits alle vertretenen Positionen angemessen berücksichtige, sei ihr erneutes ,Aufschnüren“ allein schon aus pragmatischen Gründen nicht möglich. Konnten die entsprechenden Bedingungen eines gerechten Interessenausgleiches bei der Entstehung des Kompromissvorschlages jedoch nicht nachvollzogen werden, so galt es, die fälschlicherweise als Kompromiss bezeichnete Lösung aus den gleichen Motiven abzulehnen. Wurde dem Gegenüber bei seiner vermeintlichen ,Verletzung der Spielregeln“ gar Absicht unterstellt, dann gewann das Kompromissargument auch eine moralische Dimension. Sowohl die Verteidigung eines ,faulen“ Kompromisses als auch die anhaltende Ablehnung des eigenen ,gerechten“ Kompromissvorschlages durch den politischen Gegner wurde dann dessen ideologischer Borniertheit, politischer Radikalität oder gemeinwohlschädlicher, strategischer Interessenkalkulation zugeschrieben. ${ }^{112}$

112 Das Argument einer gelungenen überparteilichen Kompromisslösung wurde nach 1997 auch in der rechts- und politikwissenschaftlichen Fachliteratur zur polnischen Verfassunggebung aufgegriffen und weitestgehend unkritisch übernommen. Vgl. hierzu ausführlich: Wyrzykowski, Die Herausbildung der Verfassung, 2000, S. 58ff. Dass die rechtsnationalen Gegner der Verfassung von 1997 - die sich ab 2001 zum Teil in der Partei „Recht und Gerechtigkeit“ (Prawo i Sprawiedliwość - PiS) neu organisierten, eine grundlegende Überarbeitung der Verfassung und damit gar die Gründung einer „IV. Republik“ 
Der Verweis auf die Nation und die gemeinsam geteilte Identität schließlich bildete im polnischen Verfassungsdiskurs in konkret-inhaltlicher Hinsicht den von allen Seiten geteilten, unhinterfragten Maßstab, an dem sich die Argumentationslinien von Befürwortern wie Gegnern ausrichteten. Der Vorwurf an den politischen Gegner, er verkenne, vernachlässige oder missachte die kulturellen, historischen oder moralisch-religiösen Traditionsbestände der eigenen politischen Gemeinschaft, wurde dabei als wohl häufigstes und zugleich wirkungsmächtigstes Argument gebraucht. Unterstützern und Kritikern der Verfassung von 1997 diente dieser Topos dazu, sich jeweils wechselseitig symbolisch „die Zugehörigkeit zur nationalen Gemeinschaft" und damit in sozialer und moralischer Hinsicht die Berechtigung zur Erarbeitung und Verabschiedung einer neuen Verfassung abzusprechen. ${ }^{113}$

Alle drei, hier systematisch differenzierten Aspekte diskursiver Transzendenz waren dabei auf das Engste miteinander verwoben. So wurden die Vorwürfe mangelnder Legitimität, fehlender Kompromissbereitschaft und unzureichender Beachtung der nationalen Identitäts- und Traditionsbestände sowohl von den Befürwortern als auch von den Gegnern des Verfassungsentwurfes der Nationalversammlung meist in Kombination gebraucht - auch wenn damit völlig unterschiedliche Vorstellungen verbunden waren, was eine ausreichende Legitimationsgrundlage, einen fairen Kompromiss oder eine angemessene Wahrung des kulturellen Erbes denn eigentlich konkret ausmache. Der polnische Verfassungsdiskurs gewann dadurch in dreifacher Hinsicht jene enorme Schärfe, die im Nachhinein von vielen Protagonisten insgesamt durchaus kritisch beurteilt wurde. So bedauerte etwa der frühere Ministerpräsident Tadeusz Mazowiecki in seiner Rede vor der Nationalversammlung am 24. Februar 1997, dass der Verfassunggebungsprozess in Polen nicht in den Jahren direkt nach dem politischen Umbruch zum Erfolg gekommen sei, denn dann hätte die damals noch vorherrschende allgemeine Begeisterung es wesentlich erleichtert, die Zustimmung der Öffentlichkeit zu gewinnen. Später aber, so Mazowiecki, sei die Arbeit

forderten - bis heute in der internationalen Diskussion eher unterrepräsentiert sind, mag auch damit zusammenhängen, dass sich die Unterstützer der „Verfassungskoalition" von 1997 hier in weitaus stärkerem Maße zu Wort gemeldet haben.

113 Vgl. Brier, Diskursanalyse, 2004, S. 109. 
an der Verfassung weniger durch Enthusiasmus, sondern vielmehr durch die nüchterne Logik politischer Vernunft geprägt gewesen. ${ }^{114}$

114 „Stało się z pewnością niedobrze, że w tym czasie, w owych latach 1989-1990, nie uchwalono nowej konstytucji. Wtedy $\mathrm{z}$ pewnością zyskałaby ona $\mathrm{w}$ prostszy sposób aprobatę społeczną, towarzyszyłby jej entuzjazm. Dziś, można powiedzieć, pracujemy nad konstytucją nie $\mathrm{z}$ pobudek entuzjazmu, ale $\mathrm{z}$ pobudek rozumu politycznego." (Tadeusz Mazowieki: Rede vor der Nationalversammlung am 24.02.1997) 



\title{
Von der Gründung zur Begründung?
}

\author{
Über die Rolle der Imagination im globalen
}

\section{Konstitutionalismus}

\section{Oliviero ANGEli}

\section{EinLeitung}

In der neueren verfassungstheoretischen Literatur hat sich die These verfestigt, dass der Konstitutionalismus einem umfassenden Wandel unterliegt. ${ }^{1}$ Verfassungstheoretiker begegnen diesem Wandel mit gemischten Gefühlen. Für die einen verkommt der Konstitutionalismus zur leeren Phrase. Es ist sogar vom „Ende“2 oder vom „Zwielicht des Konstitutionalismus ${ }^{\text {‘3 }}$ die Rede. Die anderen begrüßen den Wandel des Konstitutionalismus als längst überfällig und bitter notwendig. Überfällig, weil der überkommene Konstitutionalismus der Praxis der internationalen, euro-

1 Anne Peters: The Merits of Global Constitutionalism, in: Indiana Journal of Global Legal Studies 16 (2009) 2, S. 397-411; Christine E. J. Schwöbel: Global Constitutionalism in International Legal Perspective, Leiden/Boston 2011; Hans Vorländer: Die Verfassung vor, nach, über und unter dem Staat. Die Konstitutionalismusdebatte in der Suche nach einem anderen Verfassungsbegriff, in: Helena Lindemann u.a. (Hrsg.): Erzählungen vom Konstitutionalismus, BadenBaden 2012, S. 23-42.

2 Kuo Ming-Sung: The End of Constitutionalism as we know it?, in: Transnational Legal Theory 1 (2010) 3, S. 329-369.

3 Petra Dobner/Martin Loughlin (Hrsg.): The Twilight of Constitutionalism? Oxford 2010. Siehe auch Alexander Somek, der in Anlehnung an Hegels berühmte philosophische Formel der „Eule der Minerva“ einen seiner letzten Artikel mit The Owl of Minerva - Constitutional Discourse Before its Conclusion (in: The Modern Law Review 71 (2008) 3, S. 473-489) überschreibt. 
päischen, aber auch nationalen Gerichtsbarkeit nicht mehr entspricht. ${ }^{4}$ Notwendig, weil er „das Bewusstsein für die kognitiven Schranken des“, wie

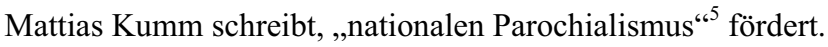

Doch so klar die Fronten zu sein scheinen, bei näherem Hinsehen verschwimmen die Konturen der Debatte. Es gibt mittlerweile eine Fülle an Begriffsbestimmungen, die teilweise auf die unterschiedlichen Forschungsgegenstände zurückgehen und ihrerseits Ausgangspunkte ganzer Theorierichtungen darstellen. Der Konstitutionalismus ist derzeit ,staatlich' oder ,gesellschaftlich', ,holistisch“ oder ,pluralistisch', ,politisch' oder ,managerial $^{\star}$ - um nur einige der am häufigsten verwendeten Unterscheidungen zu nennen. Überlagert werden diese Unterscheidungen von einer weiteren, die inzwischen den Charakter einer fundamentalen, allumfassenden Unterscheidung angenommen hat: die Unterscheidung zwischen dem nationalstaatlichen und dem globalen Konstitutionalismus. ${ }^{6}$

Die Rollen sind klar verteilt: Der nationalstaatliche Konstitutionalismus verkörpert das altgediente und etwas in die Jahre gekommene Verfassungsdenken. Der globale Konstitutionalismus steht für das aufkommende und zukunftsgewandte Verfassungsparadigma. In der Tat hat zuletzt kaum ein Zweig oder eine Disziplin der Verfassungstheorie so viel Aufwind genossen wie der globale Konstitutionalismus. Joseph Weiler spricht in diesem Zusammenhang sogar von einer ,akademischen Pandemie“"

4 Anne Peters: Compensatory Constitutionalism: The Function and Potential of Fundamental International Norms and Structures, in: Leiden Journal of International Law 19 (2006) 3, S. 579-610.

5 Mattias Kumm: The Cosmopolitan Turn in Constitutionalism, in: Jeffrey L. Dunoff/Joel P. Trachtman (Hrsg.): Ruling the World? Constitutionalism, International Law, and Global Governance, Cambridge 2009, S. 257-324, hier: S. 307 (meine Übersetzung).

6 Bei dem Begriff ,globaler Konstitutionalismus' handelt es sich um einen Import aus der jüngeren verfassungstheoretischen Diskussion in den USA. Samantha Besson sieht seinen Ursprung allerdings schon im Österreich der 1920er Jahre als Alfred Verdross - ein Kelsen-Schüler - das inzwischen etwas in Vergessenheit geratene Werk Die Verfassung der Völkerrechtsgemeinschaft verfasste (Samantha Besson: Whose Constitution(s)? International Law, Constitutionalism and Democracy, in: Dunoff/Trachtman, Ruling the World?, 2009, S. 381407, hier: S. 381).

7 Joseph H.H. Weiler: Prologue: global and pluralist constitutionalism - some doubts, in: Gráinne de Búrca/Joseph H.H. Weiler (Hrsg.): The Worlds of European Constitutionalism, Cambridge 2012, S. 8-18, hier: S. 8 (meine Übersetzung). Der globale Konstitutionalismus befindet sich - nach Meinung von Weiler - auf dem Weg zu einer selbstständigen akademische Disziplin, die in- 
Konstitutionalismusforschung seit den 1990er Jahren erfasst hat (vor allem im angelsächsischen Sprachraum). Dabei lässt sich der Wesensgehalt des ,globalen Konstitutionalismus' bislang überwiegend ex negativo bestimmen, nämlich aus der Negation dessen, was den modernen, nationalstaatlichen Konstitutionalismus ausmacht. Eine Grundannahme des nationalstaatlichen Konstitutionalismus sticht dabei besonders hervor. Sie lautet: die Autorität der Verfassung beruht, zumindest teilweise, auf ihrer Rückführbarkeit auf die verfassunggebende Gewalt. Aus der Negation dieser Grundannahme lässt sich eine zentrale These des globalen Konstitutionalismus ableiten: Die Autorität der Verfassung beruht nicht auf ihrer Rückführbarkeit auf die verfassunggebende Gewalt. Sie geht aus der Verfassung selbst oder aus Prozessen der Konstitutionalisierung hervor.

Die ,Wende' zum globalen Konstitutionalismus impliziert somit eine ,Internalisierung ${ }^{8}$ und zugleich Verfügbarmachung der verfassunggebenden Gewalt. Die verfassunggebende Gewalt materialisiert sich nicht mehr in einem verfassungstranszendenten Moment. Sie soll in die verfassungsrechtliche Praxis integriert werden. ${ }^{9}$ Dieser Vorgang kann nicht ausschließlich im Sinne eines normativen Wandels erklärt werden. Dagegen spricht der Umstand, dass Verfassungsnormen kein von den sozialen Repräsentationen des Rechts abgelöstes Eigenleben führen. Der Konstitutionalismus als normative Deutungssemantik gründet auf bestimmte Narrative und Vorstellungen, die auf das Verständnis verfassungsrechtlicher Normen und Prinzipien einwirken. Wer also bei der Frage nach der Autorität einer Verfassung ausschließlich auf die Analyse verfassungsrechtlicher Normen und Prinzipien abstellt, greift m. E. eindeutig zu kurz. Was sich verändert sind nicht ausschließlich konstitutionelle Normen und Prinzipien, sondern zugleich jene Bilder und Vorstellungen, aus denen sich diese Normen und Prinzipien speisen. Die Grundthese dieses Aufsatzes ist dementsprechend, dass der globale Konstitutionalismus auf einen tief greifenden Wandel der konstitutionellen Imagination reagiert oder diesen zumindest theoretisch vorwegnimmt.

zwischen über eine eigene wissenschaftliche Zeitschrift mit dem Titel Global Constitutionalism verfügt.

8 Vgl. Chris Thornhill: Contemporary constitutionalism and the dialectic of constituent power, in: Global Constitutionalism 1 (2012), S. 369-404.

9 Vgl. kritisch Ming-Sung, The End of Constitutionalism, 2010, S. 329-369. 
Bevor ich mich mit dem Wandel der konstitutionellen Imagination beschäftige, muss ich allerdings eine wichtige begriffliche Klärung hinsichtlich der Bedeutung des Begriffs ,Imagination' beziehungsweise ,konstitutionelle Imagination" vornehmen. Anschließend werde ich die Bedeutung der konstitutionellen Imagination am Beispiel von zwei wichtigen Denkfiguren des Verfassungsdenkens veranschaulichen: die Analogie beziehungsweise der Präzedenzfall und die Verfassungsgründung. Diese zwei Denkfiguren dienen zugleich als Hinweis auf den schon erwähnten Wandel der konstitutionellen Imagination. Wie ich zeigen möchte, lässt sich dieser Wandel an zwei Entwicklungen deutlich ablesen: Zum einen an der Einbeziehung ausländischer Präzedenzfälle in die jüngere Verfassungsrechtsprechung und zum anderen an der verstärkten Orientierung der Verfassungsrechtsprechung am Gebot der verfahrensgerechten Abwägung zwischen konfligierenden Rechten. Die erste Entwicklung weist auf eine gewisse Kosmopolitisierung der konstitutionellen Imagination hin, die zweite zeugt von der Abkehr von einem narrativen Kohärenzverständnis zugunsten einer normativen Perspektive. Dieser letzte Vorgang setzt zugleich den Versuch der Enttranszendierung der, verfassunggebenden Gewalt" voraus.

\section{WAS HEISST, KONSTITUTIONELLE IMAGINATION “?}

Der Begriff ,Imagination“ ist - von wenigen Ausnahmen ${ }^{10}$ abgesehen - in den Verfassungsdebatten bislang kaum nennenswert in Erscheinung getreten. Der Frage nach der Bedeutung der konstitutionellen Imagination muss daher die Frage nach der Bedeutung der Imagination vorangestellt werden. Was also heißt Imagination? Nach Kant deutet die Imagination auf die Fähigkeit hin, Vorstellungen auch ohne die Gegenwart des Objekts zu haben. ${ }^{11}$ Das hört sich abstrakt an, entspricht aber weitestgehend dem

10 Ausnahmen sind James B. White: The Legal Imagination: Studies in the Nature of Legal Thought and Expression, Boston 1973 und jüngst Mark Antaki: The Turn to Imagination in Legal Theory: The Re-Enchantment of the World?, in: Law and Critique 23 (2012) 1, S. 1-20 sowie Ulrich Haltern: Recht und soziale Imagination, in: Werner Gephart (Hrsg.): Rechtsanalyse als Kulturforschung, Frankfurt a.M. 2012, S. 89-102.

$11 \mathrm{KrV}$ B 151. Zitate aus der „Kritik der reinen Vernunft“ $(\mathrm{KrV})$ werden, wie allgemein üblich, nach der ersten (z.B. A 205) oder zweiten Auflage (z.B. B 250) der Originalausgabe zitiert. Alle übrigen Kant-Zitate werden nach der Ausgabe der Königlich-Preußischen Akademie der Wissenschaften (Akademie- 
Gebrauch des Begriffs ,Imagination“ in den Sozialwissenschaften. Benedikt Anderson behauptet beispielsweise, dass eine Nation, imaginiert' (imagined) ist, weil deren Mitglieder eine Vorstellung davon haben, wer zur Nation gehört, obschon keiner von ihnen die meisten Mitglieder je zu Gesicht bekommen wird. ${ }^{12}$ Moderne Gemeinschaften zeichnen sich gerade dadurch aus, dass sie sich niemals in Form einer Ansammlung von Menschen in Zeit und Raum materialisieren. Für Hannah Arendt, die sich in ihren New Yorker Kant-Vorlesungen eingehend mit Kants Begriff der ,Einbildungskraft' (imagination) ${ }^{13}$ beschäftigt hat, besteht die menschliche Urteilskraft aus zwei Vorgängen: der Imagination und dem eigentlichen Vorgang des Urteilens - der Reflexion. Die Einbildungskraft ist deshalb so wichtig, weil ohne sie das Urteilen alternativlos wäre. „Sie re-präsentiert, was gerade nicht vorliegt, nämlich Beispiele und Vorbilder. Ohne Einbildung ist das Urteil blind, ohne Urteil ist die Einbildung leer."14

Das erklärt freilich noch nicht, was genau die Imagination tut, wenn sie Dinge ,repräsentiert' und sie der Urteilskraft als Reflexionsmasse übermittelt. Für Kant übt die Imagination (beziehungsweise Einbildungskraft) im Wesentlichen zwei Funktionen aus: eine synthetische und eine repräsentative Funktion. Zum einen ordnet sie die Mannigfaltigkeit der Wahrnehmungen. Sie leistet, was Kant eine „empirische Synthesis“15 genannt hat. Zum anderen hat die Einbildungskraft den Zweck, wie Kant schreibt, ,das Mannigfaltige der Anschauung in ein Bild [zu] bringen“16. Letztere stellt die repräsentative Funktion der Imagination dar. Die Imagination erzeugt also Bilder, die Vergangenes oder Künftiges im Denken repräsentieren. ${ }^{17}$

In der Kritik der Urteilskraft findet die Idee des Bildes seine Entsprechung im Beispiel. Arendt schreibt: „Das Beispiel ist das Besondere, das

Ausgabe $=\mathrm{AA})$ angegeben. Römische Ziffern geben den Band an, arabische Ziffern die betreffende Seitenzahl im Band.

12 Benedict Anderson: Die Erfindung der Nation. Zur Karriere eines erfolgreichen Konzepts, Berlin 1998.

13 Die Begriffe ,Imagination` und ,Einbildungskraft‘ werden fortan synonym verwendet.

14 Hannah Arendt: Denktagebuch, Bd. 2, hrsg. von Ursula Ludz, München 2002, S. 680.

15 Vgl. Kant KrV A 103.

16 Kant KrV A 120.

17 Die ,Synthesis' und die Repräsentation sind keine im engeren Sinne moralische Vorgänge. Die Imagination ordnet zunächst die mannigfaltige Erscheinungswelt nach Regeln der Einheit und bedient sich dabei gewisser Bilder. 
einen Begriff oder eine allgemeine Regel in sich enthält oder von dem angenommen wird, dass es sie enthält. “"18 Der Unterschied liegt darin, dass Bilder stets auf allgemeine Regeln verweisen, während Beispiele einen gewissen Grad an Allgemeinheit dadurch erhalten, dass sie als mitteilbar und nachvollziehbar gelten. So gesehen, ist der Gebrauch von Beispielen keine eigensinnige, sondern eine gemeinsinnige Handlung. Beispiele setzen das Vermögen voraus, das Kant sensus communis genannt hat - ein Vermögen, welches u.a. die Fähigkeit, an „der Stelle jedes andern““19 zu denken, impliziert.

Von hier aus ist der Weg zum konstitutionellen Denken nicht mehr weit. Auch die Praxis des verfassungsrechtlichen Urteilens wäre blind, könnte sie nicht auf Bilder beziehungsweise Beispiele zurückgreifen, die insofern imaginiert sind, als dass sie weder räumlich noch zeitlich präsent sind. Für den US-amerikanischen Rechtswissenschaftler (und früheren Justizminister) Edward H. Levi gehört das Denken in Beispielen und Analogien zu den Wesensmerkmalen des Rechts überhaupt. Er schreibt: „The basic pattern of legal reasoning is reasoning by example. ${ }^{620}$ Dieses Denken in Beispielen bezieht sich dabei nicht nur auf Analogien und Präzedenzfälle, ${ }^{21}$ sondern schließt - wie ich noch zeigen möchte - auch den Gründungsakt einer Verfassungsordnung ein.

Aber der Reihe nach: Präzedenzfälle rufen bestimmte, vergangene Ereignisse und Gerichtsentscheidungen ins Gedächtnis, um sie als Entscheidungsmaßstab für gegenwärtige Fälle zu nutzen. ${ }^{22}$ Als Präzedenzfälle

18 Hannah Arendt: Das Urteilen. Texte zu Kants politischer Philosophie, hrsg. und mit einem Essay von Ronald Beiner, München 2012, S. 128. Allerdings vergleicht Arendt Beispiele mit Kants Schemata, was ich - aus Gründen die ich hier nicht näher ausführen kann - für unplausibel halte.

19 Kant AA V, 294.

20 Edward H. Levi: An Introduction to Legal Reasoning, Chicago 1962, S. 1.

21 Präzedenzfälle spielen im Common Law eine weitaus größere Rolle als beispielsweise im deutschen Recht. Für meine Fragestellung ist aber diese Unterscheidung nicht ausschlaggebend, da es mir primär darum geht, die Bedeutung teils bewusster, teils unbewusster Vorstellungen und Bilder für das konstitutionelle Denken zu erläutern.

22 Der Rechtsquellencharakter von Präzedenzfällen ist im kontinentaleuropäischen Rechtskreis umstritten. Prinzipiell orientieren sich Urteile an Gesetzen und nicht an den Urteilen anderer Gerichte. Von einem Präzedenzfall kann man allenfalls dann sprechen, wenn ein Gericht in einem Urteil einen älteren Fall (Präzedenz) zur Auslegungshilfe heranzieht. Vgl. Robert Alexy: Theorie der juristischen Argumentation, Frankfurt a.M. 1978, S. 334-340. 
gelten diese Entscheidungen nur unter der Bedingung, dass die ihnen zugrunde liegende ratio decidendi (d.h. die im betreffenden Fall ausschlaggebende Norm) verallgemeinerungsfähig ist. So gesehen, kann nicht von einem Präzedenzfall unmittelbar auf die zu fällende Entscheidung geschlossen werden. Vielmehr muss man einen Umweg machen: Vom Präzedenzfall ,schließt man auf die ihm zugrunde liegende Norm, die ratio decidendi; alsdann subsumiert man [die $\mathrm{zu}$ fällende Entscheidung] unter diese Norm“23. Durch diesen ,Umweg‘ gewinnt man den Eindruck, dass die Bestimmung von Präzedenzfällen ein deduktiver Vorgang sei. In Wahrheit liegt jeder Berufung auf Präzedenzfälle ein imaginäres Moment zugrunde, ${ }^{24}$ das sich der rechtlichen Deduktion entzieht. Dieses ist nicht in der Rechtfertigung für die Berufung auf einen bestimmten Präzedenzfall, sondern in der vorausgehenden Suche nach den zu vergleichenden Fällen zu finden. ${ }^{25}$ Dieser Vorgang gehört freilich zum vorreflexiven Stadium eines Urteils und damit zum Vermögen der Imagination, das nach Kant immer einen gewissen Grad an Freiheit involviert. ${ }^{26}$ Es ist dieser Grad an Freiheit, der für viele Rechtstheoretiker die Unvorhersehbarkeit beziehungsweise Irrationalität des In-Analogien-Denkens ausmacht. ${ }^{27}$ Dabei hat die Imagination lediglich die Funktion, rechtliche Analogien so zu präsentieren, dass anschließend

23 Martin Kriele: Theorie der Rechtsgewinnung, Berlin 1967, S. 270.

24 Scott Brewer (Exemplary Reasoning: Semantics, Pragmatics and the Rational Force of Legal Argument by Analogy, in: Harvard Law Review 109 (1996), S. 923-1028, hier: S. 954) spricht in diesem Zusammenhang von einem ,uncodifiable imaginative moment in exemplary, analogical reasoning“. Das erinnert an Kants Beschreibung der Einbildungskraft als eine ,verborgene Kunst in den Tiefen der menschlichen Seele“ (KrV B 180).

25 Einschlägig in diesem Zusammenhang ist Richard Posners Bemerkung: „Analogy belongs to the logic of discovery rather than to the logic of justification." (Richard Posner: How Judges Think, Cambridge, Mass. 2010, S. 183)

26 In Anlehnung an Kant kann man in diesem Zusammenhang vom Wirken der Einbildungskraft als „freie Gesetzmäßigkeit“ (Kant AA V, 240) oder als „Gesetzmäßigkeit ohne Gesetz“ (ebd.) sprechen.

27 So zum Beispiel Charles Fried: „Analogy and precedent are the stuff of the law because they are the only form of reasoning left to the law when general philosophical structures and deductive reasoning give out, overwhelmed by the mass of particular details. Analogy is the application of a trained, disciplined intuition where the manifold of particulars is too extensive to allow our mind to work on it deductively. This is not a denial of a reason; on the contrary; it is a civilized attempt to stretch reason as far as it will go." (Charles Fried: The Artificial Reason of the Law or: What Lawyers Know, in: Texas Law Review 60 (1981), S. 35-62, hier: S. 57) 
reflexiv darüber nachgedacht werden kann und insbesondere über deren Eignung als Präzedenzfall entschieden werden kann. Schlechte Analogien werden reflexiv verworfen, gute Analogien nehmen die Rolle von Präzedenzfällen ein.

Natürlich stellt sich hier gleich die Frage, was gute von schlechten Analogien unterscheidet. Ein formales Kriterium habe ich bereits angeführt: die Universalisierbarkeit. Damit wird allerdings sofort eine weitere Schwierigkeit offenkundig: Es gibt im Recht keine perfekten Analogien. Ein Unterschied lässt sich stets finden. Andererseits geht die (konstitutionelle) Imagination bei der Suche nach passenden Beispielen und Analogien nicht willkürlich vor. Sie ist frei, geht aber zugleich nach gewissen Bestimmungskriterien vor. Diese Bestimmungskriterien lassen sich am besten entlang zeitlicher und räumlicher Koordinaten untersuchen. Dabei dürfte klar werden, ob und inwiefern die konstitutionelle Imagination einem Wandel unterliegt.

\section{VERFASSUNGSGRÜNDUNG ALS TRANSZENDENZ}

Wenn man die Imagination unter einem zeitlichen Gesichtspunkt untersucht, so fällt zunächst ihr Vergangenheitsbezug auf. Die Imagination kann Vergangenes vergegenwärtigen und aus Vergangenem Beispiele und Analogien hervorbringen, auf die man Bezug nehmen kann. Aber damit ist noch nicht alles gesagt. Denn die Art des Bezugs kann unterschiedlich sein. Eine dieser Bezugsarten entspricht dem Kriterium der narrativen Kohärenz und knüpft an Arendts Interpretation von Kants Einbildungskraft an.

Wie ich bereits erwähnt habe, hängt die Kommunizierbarkeit und Nachvollziehbarkeit eines Urteils - für Arendt - maßgeblich von den verwendeten Beispielen und Analogien ab. ${ }^{28}$ Wenn ich erklären will, was ,mutig' ist, dann brauche ich nur auf Beispiele verweisen, die - wie Kant selbst angenommen hat - meinem Urteil „exemplarische Gültigkeit ${ }^{‘ 29}$ verleihen können. Der „Grieche“, so nimmt Arendt an, mag bei dem Be-

28 Siehe auch Leslie Paul Thiele: „Our judgments prove to be good or bad, in large part, depending upon which examples, which narratives, inform them. Arendt concludes her lectures on Kant with a discussion of the importance of ,exemplary validity“." (Leslie Paul Thiele: The Heart of Judgment: Practical Wisdom, Neuroscience, and Narrative, Cambridge, Mass. 2006, S. 48)

29 Kant AA V, 239. 
griff ,Mut' an Achilles denken. ${ }^{30}$ Solche Beispiele zeigen aber auch zugleich, wie sehr Urteile in narrativen Strukturen verwoben sind. Will man nachvollziehbare Urteile fällen, so ist es ratsam, auf narrative Beispiele zurückzugreifen, die in der Vorstellungswelt der Anderen verankert sind. Das gilt auch für Rechtsdiskurse. In der Tat baut ein beträchtlicher Teil der rechtssoziologischen Forschung auf der These auf, dass Menschen ihren Zugang zum Recht und insbesondere zum Verfassungsrecht über Narrative finden und dass die Analyse von Verfassungsnarrativen einen Zugang zum Rechts- und Verfassungsverständnis der Menschen eröffnet. ${ }^{31}$ Die Verfassung gewinnt für die meisten Menschen nur dann Gestalt, wenn sie Teil einer Geschichte wird, an der sie selbst teilhaben oder der sie zumindest Glauben schenken. ${ }^{32}$

Das führt mich zum Thema der Gründung. Gründungsgeschichten zählen schließlich zu den bedeutsamsten Verfassungsnarrativen. ${ }^{33}$ Sie beschreiben den Übergang von einem vorrechtlichen zu einem rechtlichen Zustand und üben dabei eine entscheidende normative Funktion aus. Sie verleihen der Verfassung jene Autorität, die nicht aus der Verfassung selbst hervorgeht. ${ }^{34} \mathrm{Zu}$ diesem Zweck wird der Anfang der „Geschichte“ - die Verfassungsgründung - in einen der Verfassung vorausliegenden, vorrechtlichen Raum verlegt, von dem aus die Verfassung mit der nötigen Autorität ausstatten werden kann, um sie auf Dauer zu stellen. Dieser Vorgang suggeriert nach Günter Frankenberg die Sehnsucht nach einer „säkularisierten

30 Arendt, Das Urteilen, 2012, S. 128.

31 Siehe in diesem Zusammenhang Alasdair MacIntyre: Der Verlust der Tugend, Frankfurt a.M. 1997, S. 288: „Der Mensch ist in seinen Handlungen und in seiner Praxis ebenso wie in seinen Fiktionen im wesentlichen ein Geschichten erzählendes Tier.“

32 Vgl. Robert M. Cover: The Supreme Court 1982 Term. Foreword: Nomos and Narrative, in: Harvard Law Review 97 (1983) 1, S. 4-68.

33 Die vielleicht bekanntesten Gründungsgeschichten gehören zur religiösen Überlieferung oder zum klassischen Bestand der Weltliteratur, so zum Beispiel die Orestie des Aischylos oder die Geschichte der Entgegennahme der Zehn Gebote durch Moses auf dem Berg Sinai; siehe dazu Shulamit Almog: From Sterne and Borges to lost storytellers: Cyberspace, narrative, and law, in: Fordham Intellectual Property, Media \& Entertainment Law Journal 13 (2002), S. 1-34.

34 Vgl. Christian Waldhoff: Die Gründungserzählung der Verfassung als Idee des Staates, in: Otto Depenheuer (Hrsg.): Erzählungen vom Staat. Ideen als Grundlage von Staatlichkeit, Wiesbaden 2011, S. 61-79. 
Ersatz-Transzendenz ${ }^{635}$, die sich in der Gestalt eines sakral aufgeladenen Schöpfungsaktes (creatio ex nihilo) manifestiert.

Ähnlich wie ihr sakrales Pendant bedarf jede narrative Verfassungsauslegung des beständigen Heraufbeschwörens ihrer „Ersatz-Transzendenz“ sprich der verfassunggebenden Gewalt des Volkes ${ }^{36}$-, damit diese weiterhin als Quelle von verfassungsrechtlicher Autorität dienen kann. Dem klassischen Konstitutionalismus zufolge kommt diese Aufgabe vor allem den (Verfassungs)Richtern $\mathrm{zu}^{37}{ }^{37}$ die sich der Figur der verfassunggebenden Gewalt (des Volkes) zur (narrativen) Begründung ihrer Urteile bemächtigen. ${ }^{38}$ Bekannt ist in diesem Zusammenhang Ronald Dworkins Metapher des Fortsetzungsromans (chain novel). ${ }^{39}$ Auf die Verfassungsrechtsauslegung übertragen, deutet diese Metapher darauf hin, dass der Verfassunggeber mit dem Gründungsakt das erste und wichtige Kapitel einer langen Geschichte verfasst, die von den Verfassungsgerichten im Wege der Rechtsanwendung nach und nach - nach Maßgabe eines narrativen Kohärenzverständnisses - fortgeschrieben wird. Die Verfassungsrechtsauslegung wird damit zu einem holistischen Unterfangen, das sich an der Vorstellung der narrativen Kohärenz orientiert. ${ }^{40}$ Jeder Schritt der Verfas-

35 Günter Frankenberg: Die Verfassung der Republik. Autorität und Solidarität in der Zivilgesellschaft, Baden-Baden 1996, S. 85.

36 Als verfassunggebende Gewalt ist das Volk aber auch eine verfassungstranszendente Größe, weil es nur außerhalb der Verfassung in Erscheinung treten kann - zum Beispiel indem es eine bestehende Verfassung auflöst oder eine neue gründet. Als verfassungsrechtliche Größe bleibt das verfassunggebende Volk stets unverfügbar.

37 Hans Vorländer: Gründung und Geltung. Die Konstitution der Ordnung und die Legitimation der Konstitution, in: Gert Melville/Hans Vorländer (Hrsg.): Geltungsgeschichten. Über die Stabilisierung und Legitimierung institutioneller Ordnungen, Köln/Wien/Weimar 2002, S. 243-263, hier: S. 254.

$38 \mathrm{Im}$ Lissabon-Urteil beispielsweise hat das BVerfG ganze neun Mal die verfassunggebende Gewalt des Volkes bemüht. Damit hat es sich über die Bedenken hinweggesetzt, die Rechtswissenschaftler wie Josef Isensee bewogen haben, die Idee des verfassungstranszendenten Volkes als „Klapperstorchmärchen für Volljuristen“ zu betrachten. Siehe Josef Isensee: Das Volk als Grund der Verfassung. Mythos und Relevanz der Lehre von der verfassungsgebenden Gewalt des Volkes, Opladen 1995, S. 73.

39 Demnach ist der Prozess der Verfassungsauslegung in sogenannten hard cases mit der Art zu vergleichen, wie ein Schriftsteller - der auf die vorherigen Kapitel anderer Autoren aufbauen muss - ein Kapitel des Romans verfasst. Siehe Ronald Dworkin: Law's Empire, Cambridge, Mass. 1986, S. $228 \mathrm{ff}$.

40 Siehe dazu Neil MacCormick: Rhetoric and the Rule of Law, Oxford 2005. Weiterführend Peter Brooks/Paul Gerwitz (Hrsg.): Law's Stories: Narrative and 
sungsauslegung muss sich - nach Dworkin - an das vorherige Ganze anpassen (entsprechend der These des interpretativen „fit“"). Das, durch die konstitutionelle Imagination ermöglichte, narrative Verständnis der Verfassung übt damit eine wichtige heuristische Funktion aus. Es dient als Sensorium für die Relevanz von Analogien:

„The facts of a particular (legal) case are constructed and reconstructed at each stage of the process $[\ldots]$, through a selection of those features $[\ldots]$ of the situation which $[\ldots]$ are regarded as pertinent. That selection of pertinent traits will evoke a mental image or will be judged ,relevant" to one of a stock of narratives which represent the social knowledge of the group concerned.“ ${ }^{* 41}$

\section{Von der GRündung zUR Begründung}

Die historisch ausgerichteten Verfassungsnarrative konkurrieren in den jüngeren Verfassungsdebatten mit analytisch-normativen Modellen, die dem Gründungsmoment einer Verfassung keine narrative Funktion und keine verfassungstranszendente Bedeutung zuweisen. Dies hat zum einen pragmatische, zum anderen normative Gründe. Die pragmatischen Gründe liegen in dem Umstand, dass die Entstehung von internationalen beziehungsweise globalen Verfassungen kaum als „Anfangserzählung“ dienen kann, „mit deren Hilfe wir uns erzählen und erklären, wie es zu einer demokratischen Ordnung kam und was sie bedeutet ${ }^{\text {“42 }}$. Globale Verfassungsprozesse eigenen sich deshalb nicht zur narrativen Überhöhung und stellen keinen Zusammenhang mit einem verfassunggebenden Volk her. Hinzu kommen normative Bedenken. Zwei seien hier genannt: Während erstens das verfassunggebende Volk als verfassungstranszendente Instanz per definitionem nur durch vorrechtliche beziehungsweise vorstaatliche Merkmale definiert werden kann, zeichnet sich ein staatlich verfasstes Volk vor allem durch ein primär rechtliches Merkmal aus: seinen Status als Gesetzgeber und Gesetzesunterworfener. Daran wird eine problematische Diskrepanz zwischen zwei widersprüchlichen Modi der Zugehörigkeit

Rhetoric in the Law, New Haven, CT 1998 und Robert P. Burns: A Theory of the Trial, Princeton, NJ 1999.

41 Bernard S. Jackson: Law, Fact and Narrative Coherence, Liverpool 1988, S. 170.

42 Christoph Möllers: Demokratie - Zumutungen und Versprechen, Berlin 2008, S. 96. 
erkennbar: Dem vorstaatlichen Volk liegt eine gewisse Homogenitätsvorstellung zugrunde, die ein staatlich verfasstes Volk nicht erfüllen kann. Zweitens, Gründungsnarrative bergen für den Rechtstheoretiker Frank Michelman die Gefahr, dass sie die Frage nach der normativen Autorität der Verfassung in die Frage nach der Autorität der Verfassunggeber verwandeln - mit der Konsequenz, dass Urheberschaft (authorship) und Autorität (authority) zu austauschbaren Begriffen werden. Dementsprechend spricht Michelman von einem ,authority-authorship-syndrome“433, das viele dazu verleitet hat, der Verfassung deshalb normative Autorität zuzusprechen, weil sie von den Gründungsvätern so gewollt wurde (,because they said so"). ${ }^{44}$

Vor diesem Hintergrund ist es nicht überraschend, dass sich die Verfassungsrechtsauslegung für den globalen Konstitutionalismus immer weniger an der Vorstellung der narrativen Kohärenz orientiert, wonach Verfassungen ihre Identität als einheitliche Rechtsordnungen primär aus ihrer eigenen Geschichte beziehen. Der Fokus liegt stattdessen auf der Begründung der Rechtsnormen nach Maßgabe eines normativen und gegenwartsbezogenen Verständnisses der rechtlichen Kohärenz. ${ }^{45}$ Demnach bezieht jede Verfassung ihre Identität aus der Einheit ihrer grundlegenden Normen im Moment ihrer Auslegung beziehungsweise Anwendung. ,Normative Kohärenz' verkörpert das, was Joseph Raz ein „momentary legal system ${ }^{\text {“46 }}$ genannt hat.

Die graduelle Abkehr von narrativen Kohärenzvorstellungen - und damit auch der Verzicht auf das evokative Moment der Gründung - kann als eine Wende von der ,Interpretation' der Verfassung zur ,Begründung“ der in der Verfassung enthaltenen Rechtsnormen auf der Grundlage des

43 Frank Michelman: Constitutional Authorship by the People, in: Notre Dame Law Review 74 (1999), S. 1605.

44 Siehe Frank Michelman: Constitutional Authorship, in: Larry Alexander (Hrsg.): Constitutionalism: Philosophical Foundations, Cambridge, Mass. 1998, S. 64-98.

45 „Narrative coherence relates necessarily to the flux of events in time. Narratives replicate in analytical time events supposed or imagined to have occurred in real time. A coherent narrative fits events and acts together [...] in convincing diachronic linkages. Normative coherence, by contrast, is at-one-time, rather than through-time, coherence; normative coherence has an essentially synchronic character contrasting with the essentially diachronic character of narrative coherence." (MacCormick, Rhetoric and the Rule of Law, 2005, S. 229)

46 Joseph Raz: The concept of a legal system, Oxford 1970, S. 34. 
Verhältnismäßigkeitsgrundsatzes interpretiert werden. ${ }^{47}$ Damit kommt der konstitutionellen Imagination eine etwas andere Funktion zu. Sie dient nicht der Rekonstruktion von Vergangenem, sondern der Erweiterung des Spektrums der Argumente und Betrachtungsweisen. Gerade der Grundsatz der Verhältnismäßigkeit zwingt Urteilende, sich in die Situation der von einer Rechtsmaßnahme Betroffenen hineinzuversetzen, um deren Grad an Betroffenheit zu evaluieren und ihre Interessen gegenüber denen der anderen Betroffenen abzuwägen. Robert Alexy sieht in diesem Vorgang eine Form der ,argumentativen Repräsentation der Bürger ‘, ${ }^{48}$ welche den demokratischen Weg der Repräsentation ergänzt.

\section{EINE KOSMOPOLITISCHE KONSTITUTIONELLE IMAGINATION?}

Die Imagination kann Vergangenes oder Gegenwärtiges zum Inhalt haben. Aber kann sie auch Fernes beziehungsweise Fremdes erfassen? Hat die Imagination auch eine räumliche Dimension? Diese Auffassung vertritt zumindest Hannah Arendt, wenn sie schreibt, dass man seine Imagination lehren soll, „Besuche zu machen“ (go visiting). ${ }^{49}$

„Kritisches Denken spielt sich nach wie vor in der Einsamkeit ab: doch durch die Einbildungskraft macht es die anderen gegenwärtig und bewegt sich damit in einem Raum, der potentiell öffentlich, nach allen Seiten offen ist. Kritisches Denken nimmt, mit anderen Worten, die Position von Kants Weltbürger ein. “50

47 Gerade die zunehmende Anwendung des Verhältnismäßigkeitsprinzips wird gern als Beleg für einen ,universal, Esperanto-like discourse of constitutional adjudication and reasoning" angeführt (Mattias Kumm: The Idea of Socratic Contestation and the Right to Justification: The Point of Rights-Based Proportionality Review, in: Law \& Ethics of Human Rights 4 (2010) 2, S. 141-175). Vgl. dazu auch Moshe Cohen-Eliya/Iddo Porat: American Balancing and German Proportionality: The Historical Origins, in: I-Con: International Journal of Constitutional Law 8 (2010), S. 263-286; Dieter Grimm: Proportionality in Canadian and German Constitutional Jurisprudence, in: University of Toronto Law Journal 57 (2007), S. 383-397; Alec Stone Sweet/Jud Mathews: Proportionality Balancing and Global Constitutionalism, in: Columbia Journal of Transnational Law 47 (2008), S. 73-165.

48 Vgl. Robert Alexy: Balancing, Constitutional Review, and Representation, in: International Journal of Constitutional Law 3 (2005), S. 572-81.

49 Arendt, Das Urteilen, 2012, S. 68.

50 Ebd. 
Die Imagination macht sich also auf die Reise, wenn sie Bilder oder Geschichten aus dem Leben der Menschen in anderen Ländern in Betracht zieht und dadurch Menschen befähigt, sich in andere Lebenskonstellationen hineinzudenken. ${ }^{51}$ Die von der Imagination erzeugten Beispiele sind daher nicht nur „Gängelwagen der Urteilskraft" ${ }^{452}$, wie Kant selbst in der Kritik der reinen Vernunft bemerkt hat, sondern eine wichtige Bedingung für die Herausbildung eines kosmopolitischen Standpunktes (was Hannah Arendt den Standpunkt eines, Welt-Zuschauers' nennt).

Nun mag man sich fragen, was das alles mit dem Wandel des Verfassungsdenkens zu tun hat? Es ist nicht schwierig, Analogien zu finden. Wenn man der verfassungstheoretischen Literatur der letzten Jahre Glauben schenkt, so ist tatsächlich von einer verstärkten Tendenz zur Einbeziehung ausländischer Analogien und Beispiele auszugehen. Das trifft freilich mehr auf Europa und Südamerika als auf die USA zu. ${ }^{53}$ Allerdings sorgen neuerdings auch Verweise des Supreme Court auf ausländisches oder internationales Recht (foreign precedents) ${ }^{54}$ für lebhafte Debatten in der verfassungstheoretischen Literatur. Ebenso überraschend und - verfassungstheoretisch gesehen - frustrierend ist der Umstand, dass die Art und Weise der Einbeziehung ausländischer Analogien primär keine reflexive, sondern eine intuitive und assoziative ist. Zumindest hat sich bisweilen kein US-amerikanischer Verfassungsrichter die Mühe gemacht, diesen Vorgang zu rechtfertigen. Wie Jeremy Waldron konstatiert: „The justices who cited foreign law simply gave the impression they thought it was a good idea. ${ }^{\text {“55 }}$

51 Siehe in diesem Zusammenhang Arjun Appadurai (Modernity at Large: Cultural Dimensions of Globalization, Minneapolis 1998), demzufolge die Globalisierung die Bilder und Narrative für eine soziale Imagination anderer möglicher Leben liefert.

52 Kant KrV A 134.

53 Ich danke Mattias Kumm für den Hinweis. Siehe auch Frank Cross u.a.: Citations in the U.S. Supreme Court: An Empirical Study of their Use and Significance, in: University of Illinois Law Review (2010) 2, S. 489-576.

54 Im Fall Atkins v. Virginia geht es beispielsweise um die Frage, ob die Verhängung der Todesstrafe gegen geistig Behinderte gegen die Menschenrechte verstößt. In einem anderen, vieldiskutierten Fall (Lawrence v. Texas) geht es um die Frage, ob Einzelstaaten homosexuelle Handlungen unter Strafe stellen können.

55 Jeremy Waldron: „Partly Laws Common to All Mankind“: Foreign Law in American Courts, New Haven, Conn. 2012, S. 122. 
So problematisch diese Entwicklung verfassungstheoretisch auch sein mag, sie zeigt doch, wie ähnlich letztlich das Denken eines Richters - in seinen imaginären Quellen - dem eines verfassungsrechtlichen Laien ist. Beide orientieren sich bei der Berufung auf die ausländische Rechtsprechung - mit Charles Taylor gesprochen - an der ,impliziten Landkarte“56 ihres rechtlichen Vorstellungsraums, die der verfassungsrechtlichen Landkarte nicht entspricht. Sie setzen sich damit über die, durch die Verfassungsnormen eng gezogenen, Grenzen des Verfassungsrechts hinweg und richten ihre Aufmerksamkeit darauf, wie andere politische Gemeinschaften Rechtsprinzipien wie Gleichheit und Freiheit in konkreten Fällen auslegen. Diese Erfahrungen können die Wahrnehmung der eigenen Rechtsansprüche und die Würdigung der Rechtsansprüche ihrer Mitbürger verändern. So lassen sich Minderheitenrechte in vergleichsweise homogenen Gesellschaften in einem anderen Licht betrachten, wenn einschlägige rechtliche Beispiele aus multikulturellen Gesellschaften in Betracht gezogen werden. Ähnliches gilt für die Bestimmung des Rechts auf Eigentum in postsozialistischen Gesellschaften. ${ }^{57}$

Dienen Verweise auf ausländisches Recht dazu, demokratische Spielregeln zu umgehen? Die zwei oben erwähnten Beispiele scheinen eher das Gegenteil zu belegen. Die demokratieförderliche Komponente des ausländischen Rechts tritt deutlich hervor, wenn die öffentlichen Rechtsvorstellungen und das Verfassungsrecht auseinanderdriften. Oder anders formuliert: Wenn sich Bürger zunehmend der Beispiele aus anderen Rechtskontexten zur Begründung der eigenen Rechtsansprüche bedienen und diese keinen Ausdruck in den überkommenen Auslegungen des Verfassungsrechts finden, dann droht ein Legitimations- beziehungsweise Responsivitätsproblem. ${ }^{58}$ Verfassungsgerichte leisten dann keine ,,argumentative Repräsentation“"59 der Rechtsadressaten, sondern verharren in

56 Taylor, Charles: Ein säkulares Zeitalter, Frankfurt a.M. 2012, S. 298.

57 Beide Beispiele lehnen sich an Vlad Perju: Cosmopolitanism and Constitutional Self-Government, in: International Journal of Constitutional Law 8 (2010) 3, S. 326-353, hier: S. 344 an.

58 Dieses Problem entsteht, wenn Verfassungsgerichte nicht in einer Art und Weise auf die Klagen der Bürger reagieren, die den Vorstellungen der Bürger zugänglich ist. Vgl. Perju, Cosmopolitanism, 2010.

59 Alexy, Balancing, 2005, S. 572-581. Robert Alexy unterscheidet zwei Formen der demokratischen Repräsentation. Politische Repräsentation erfolgt vor allem durch periodisch durchgeführte Wahlen. Argumentative Repräsentation be- 
einer Art verfassungsinterpretatorischem Solipsismus. ${ }^{60}$ In solchen Fällen können richterliche Verweise auf ausländisches Recht den Charakter eines legitimatorischen Korrektivs annehmen. Sie tragen dazu bei, Erfahrungen und Perspektiven einzubeziehen, die Wahrnehmung und Anerkennung individueller Rechtsvorstellungen verändern können. ${ }^{61}$

\section{Schluss}

Die konstitutionelle Imagination stellt eine Form des vorreflexiven, verfassungsrechtlichen Denkens dar. Sie besitzt die Fähigkeit, Abwesendes in Form von bildhaften Vorstellungen zu vergegenwärtigen. Sie ist deshalb von besonderer Bedeutung, weil es ohne sie keine Erinnerungen an vergangene Verfassungsereignisse, keine narrative Rekonstruktion der Verfassungsgeschichte und keine Projektionen von der Zukunft einer Verfassung gäbe. Kantisch formuliert: Verfassungstheorien wären ohne konstitutionelle Imagination leer, die konstitutionelle Imagination wäre ohne Theorien beziehungsweise ohne Reflexion blind.

Ziel des vorliegenden Beitrages war es zu zeigen, dass der globale Konstitutionalismus von einem veränderten Temporalitäts- und Raumverständnis des konstitutionellen Denkens ausgeht. Sein Erfolg oder Misserfolg hängt somit von einer zeitlichen und räumlichen Neuausrichtung der konstitutionellen Imagination ab. Zur empirischen Grundlage des globalen Konstitutionalismus gehört die Annahme, dass die konstitutionelle Imagination nicht mehr von einem ,narrativen' Verständnis der verfassungsrechtlichen Kohärenz zehrt und sich damit keiner legitimatorischen Gründungsgeschichte bedient, die der Verfassung Autorität verleiht. Dieser Vorgang impliziert eine Enttranszendierung der verfassunggebenden Gewalt. Die verfassunggebende Gewalt materialisiert sich nicht mehr außerhalb der Verfassung. Sie soll in die verfassungsrechtliche Praxis integriert werden, die sich zum Ziel setzt, normative Kohärenz durch Abwägung und Verhältnismäßigkeitsprüfung herbeizuführen. Kurzum, der einmalige Akt der Gründung wird durch das Verfahren der Begründung

zwecken auch Gerichte, die zwar nicht vom Repräsentierten gewählt sind, sich aber bemühen, die Positionen der Rechtsadressaten argumentativ zu würdigen.

60 Vgl. Eliezel Rivlin: Thoughts on Referral to Foreign Law, Global Chain-Novel, and Novelty, in: Florida Journal of International Law 21 (2009), S. 1-27.

61 Vgl. Perju, Cosmopolitanism, 2010, S. 326-353. 
ersetzt. Eine weitere Voraussetzung des globalen Konstitutionalismus stellt die Kosmopolitisierung der konstitutionellen Imagination dar. Der globale Konstitutionalismus geht von einer räumlichen Ausdehnung der konstitutionellen Imagination aus, die Menschen dazu befähigt, Beispiele aus anderen Rechtskontexten zur Begründung von Rechtsnormen zu nutzen. 



\section{Autorenverzeichnis}

Angeli, Oliviero, Dr. phil., wissenschaftlicher Mitarbeiter am Lehrstuhl für Politische Theorie und Ideengeschichte der Technischen Universität Dresden. Jüngste Publikationen: „Das Volk als Transzendenz? Die ,Erfindung“ des Volkes in Kants geschichts- und rechtsphilosophischen Schriften“, in: Oliviero Angeli u.a. (Hrsg.): Transzendenz, Praxis und Politik bei Kant, Berlin 2013 (i.E.); ,Das Recht auf Einwanderung und das Recht auf Ausschluss“, in: Zeitschrift für Politische Theorie 2 (2011) 2, S. 171-184.

Asch, Ronald G., Dr. phil., Professor für Geschichte der Frühen Neuzeit an der Universität Freiburg und stellvertretender Sprecher des Sonderforschungsbereichs 948 „Helden, Heroisierungen, Heroismen“. Wichtige Publikationen: „Sacral Kingship between Dis-enchantment and Re-enchantment: The French and English Monarchies 1587-1688“, London 2014; „Europäischer Adel in der Frühen Neuzeit“, Köln 2008.

Gebhardt, Jürgen, Dr. phil., emeritierter Professor für Politische Wissenschaften an der Friedrich-Alexander-Universität Nürnberg-Erlangen sowie Vorsitzender des Vorstands des Bayerisch-Amerikanischen Zentrums in München. Jüngste Publikationen: „Michael Walzer. Radikaler Dissenter und demokratischer Sozialist", in: Karl-Heinz Nusser (Hrsg.): Freiheit, soziale Güter und Gerechtigkeit, Baden-Baden 2012, S. 31-56; „Politische Ordnung und bürgerschaftliche Selbstregierung - Idee und Wirklichkeit des republikanischen Ordnungsdiskurses“, in: Gisela Riescher/Beate Rosenzweig (Hrsg.): Partizipation und Staatlichkeit, Stuttgart 2012, S. 21-51.

Herold, Maik, M.A., wissenschaftlicher Mitarbeiter im Teilprojekt „Demokratische Ordnung zwischen Transzendenz und Gemeinsinn“ am Sonderforschungsbereich 804 „Transzendenz und Gemeinsinn“ an der 
Technischen Universität Dresden. Jüngste Publikationen: „Die Republik und das Heilige“, in: Oliver Hidalgo (Hrsg.): Der lange Schatten des Contrat social. Demokratie und Volkssouveränität bei Jean-Jacques Rousseau, Wiesbaden 2013, S. 103-122; „Die Macht der Machtbeobachtung", in: André Brodocz/Stefanie Hammer (Hrsg.): Variationen der Macht, Baden-Baden 2013, S. 243-259.

Kohler, Georg, Dr. phil., emeritierter Professor für Philosophie, mit besonderer Berücksichtigung der Politischen Philosophie an der Universität Zürich sowie Leiter des Teilprojektes „Die Kontingenz des Unverfügbaren - Die ,Willensnation Schweiz““ am Sonderforschungsbereich 804 „Transzendenz und Gemeinsinn“. Jüngste Publikationen: „Zauberbeeren und die Volksherrschaft. Zur Kritik und Apologie der Demokratie“, in: Studia Philosophica. Jahrbuch der Schweizerischen Philosophischen Gesellschaft, Bd. 71, Basel 2012, S.43-60; „Sokrates' Stachel. Oder: Warum wir in Rationalität verstrickt sind“, in: Brigitte Boothe/Andreas Cremonini/Georg Kohler (Hrsg.): Psychische Regulierung, kollektive Praxis und der Raum der Gründe. Ein Problemaufriss, Würzburg 2012, S.163-193.

Maiolino, Angelo, Dr. des., bis 2011 wissenschaftlicher Assistent und Dozent am Lehrstuhl für politische Philosophie der Universität Zürich und wissenschaftlicher Mitarbeiter im Teilprojekt „Die Kontingenz des Unverfügbaren - Die ,Willensnation Schweiz““ am Sonderforschungsbereich 804 „Transzendenz und Gemeinsinn“ an der Technischen Universität Dresden. Gegenwärtig Gymnasiallehrer. Wichtige Publikationen: „Als die Italiener noch Tschinggen waren. Der Widerstand gegen die Schwarzenbach-Initiative“, Zürich 2011; „Überfremdung und Mediterranisierung der Schweiz. Identitäten im Spannungsfeld“, in: Widerspruch 58 (2010), S.177-193.

Münkler, Herfried, Dr. phil., Professor für Theorie der Politik an der Humboldt-Universität zu Berlin. Mitglied der Berlin-Brandenburgischen Akademie der Wissenschaften. Wichtige Publikationen: „Mitte und Maß. Der Kampf um die richtige Ordnung“, Berlin 2010; „Gemeinwohl und Gemeinsinn. Band 1-4“, Forschungsberichte der interdisziplinären Arbeitsgruppe ,Gemeinwohl und Gemeinsinn' der Berlin-Brandenburgischen Akademie der Wissenschaften, hrsg. zusammen mit Harald Bluhm und Karsten Fischer, Berlin 2001-2002. 
Pinzani, Alessandro, Dr. phil., Professor für Ethik und Politische Philosophie an der Universidade Federal de Santa Catarina, Florianópolis (Brasilien) und Forscher der Conselho Nacional de Desenvolvimento Científico e Tecnológico (CNPq). Wichtige Publikationen: „An den Wurzeln moderner Demokratie“, Berlin 2009; „Jürgen Habermas (Reihe Denker)“, München 2007.

Portinaro, Pier Paolo, Dr. phil., Professor für Politische Philosophie an der Universität Turin sowie Leiter des Teilprojektes „Die Sakralisierung der Kulturnation im italienischen Risorgimento“ am Sonderforschungsbereich 804 ,Transzendenz und Gemeinsinn“ an der Technischen Universität Dresden. Wichtige Publikationen: „La giustizia introvabile. Lezioni di filosofia politica“, Torino 2012; „I conti con il passato. Vendetta, amnistia, giustizia“, Milano 2011.

Röder, Jan, M.A., wissenschaftlicher Mitarbeiter im Teilprojekt „Demokratische Ordnung zwischen Transzendenz und Gemeinsinn“ am Sonderforschungsbereich 804 ,Transzendenz und Gemeinsinn“ an der Technischen Universität Dresden. Jüngste Publikation: „Die Präambel des Grundgesetzes zwischen Sachlichkeit und Numinosität“, in: Stephan Dreischer u.a. (Hrsg.): Jenseits der Geltung. Konkurrierende Transzendenzbehauptungen von der Antike bis zur Gegenwart, Berlin/Boston 2013, S. 370-387 (zusammen mit Maik Herold).

Rudolph, Enno, Dr. theol., emeritierter Professor für Philosophie an der Universität Luzern. Jüngste Publikationen: „Machtwechsel der Bilder. Bild und Bildverstehen im Wandel“, Zürich 2012, hrsg. zusammen mit Thomas Steinfeld; Artikel „Hans Blumenberg“, in: Ralf Konersmann (Hrsg.): Handbuch für Kulturphilosophie, Stuttgart 2012, S. 181-185.

Schäller, Steven, M.A., wissenschaftlicher Mitarbeiter im Teilprojekt „Demokratische Ordnung zwischen Transzendenz und Gemeinsinn“ am Sonderforschungsbereich 804 „Transzendenz und Gemeinsinn“ an der Technischen Universität Dresden. Wichtige Publikationen: „Das Bundesverfassungsgericht und der Europäische Bundesstaat. Das Lissabon-Urteil im Licht einer Verfassungstheorie des Föderalismus“, in: Zeitschrift für Politische Theorie 2 (2011) 1, S. 41-62; ,Fernsehen, Demokratie und Ver- 
fassungsgerichtsbarkeit", in: Martin Moellers/Robert Chr. van Ooyen (Hrsg.): Das Bundesverfassungsgericht im politischen System, Wiesbaden 2006, S. 243-252 (zusammen mit André Brodocz).

Schulz, Daniel, Dr. phil., wissenschaftlicher Mitarbeiter im Teilprojekt „Demokratische Ordnung zwischen Transzendenz und Gemeinsinn“ am Sonderforschungsbereich 804 „Transzendenz und Gemeinsinn“ an der Technischen Universität Dresden. Wichtige Publikationen: „Verfassung und Nation. Formen politischer Institutionalisierung in Deutschland und Frankreich“, Wiesbaden 2004; „Jenseits der Geltung. Konkurrierende Transzendenzbehauptungen von der Antike bis zur Gegenwart“, hrsg. zusammen mit Stephan Dreischer, Christoph Lundgreen und Sylka Scholz, Berlin/Boston 2013.

Schulze Wessel, Julia, Dr. phil., wissenschaftliche Mitarbeiterin am Lehrstuhl für Politische Theorie und Ideengeschichte an der Technischen Universität Dresden. Wichtige Publikationen: „Ideologie der Sachlichkeit. Hannah Arendts politische Theorie des Antisemitismus“, Frankfurt a.M. 2006; „Grenzfiguren. Über die Staatenlosigkeit, undokumentierte Migration und die Permanenz der Grenze", in: Zeitschrift für Politische Theorie 3 (2012) 2, S. 151-165.

Vorländer, Hans, Dr. phil., Professor für Politikwissenschaft, Inhaber des Lehrstuhls für Politische Theorie und Ideengeschichte an der Technischen Universität Dresden, Gründer und Sprecher des Sonderforschungsbereichs 804 „Transzendenz und Gemeinsinn“ sowie Leiter des Teilprojektes „Demokratische Ordnung zwischen Transzendenz und Gemeinsinn“, außerdem Direktor des Zentrums für Verfassungs- und Demokratieforschung (zvd) in Dresden. Wichtige Publikationen: „Die Verfassung. Idee und Geschichte“, 3., überarbeitete Aufl., München 2009; „Demokratie. Geschichte, Formen, Theorien“, 2., überarbeitete Aufl., München 2010. 


\section{Edition Politik}
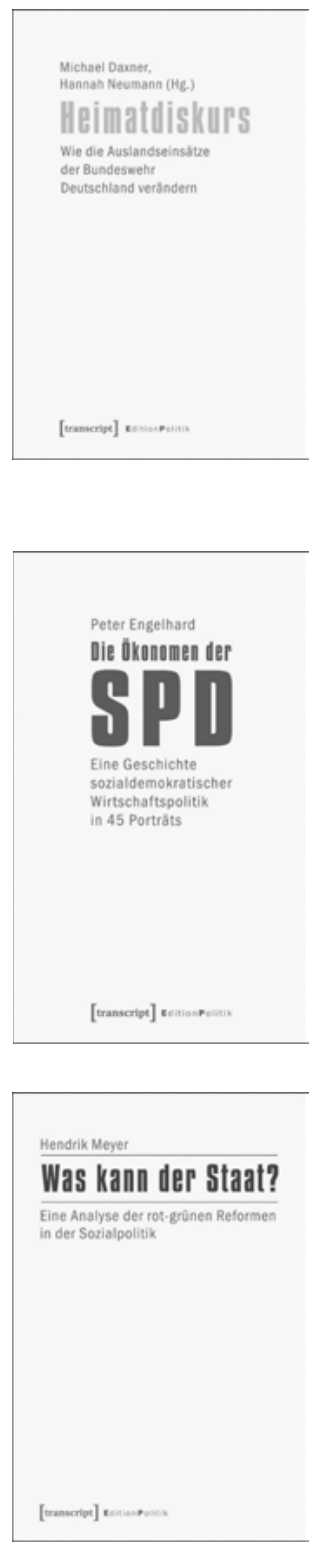

Michael Daxner, Hannah Neumann (Hg.) Heimatdiskurs

Wie die Auslandseinsätze der Bundeswehr Deutschland verändern

20I2, 340 Seiten, kart., zahlr. Abb., 32,80€, ISBN 978-3-8376-2219-5

\section{Peter Engelhard}

\section{Die Ökonomen der SPD}

Eine Geschichte sozialdemokratischer

Wirtschaftspolitik in 45 Porträts

20I0, I4 8 Seiten, kart., zahlr. Abb., I6,80€, ISBN 978-3-8376-I53I-9

\section{Hendrik Meyer}

Was kann der Staat?

Eine Analyse der rot-grünen Reformen in der Sozialpolitik

Februar 20I3, 282 Seiten, kart., ca. 32,80€, ISBN 978-3-8376-23I2-3 


\section{Edition Politik}
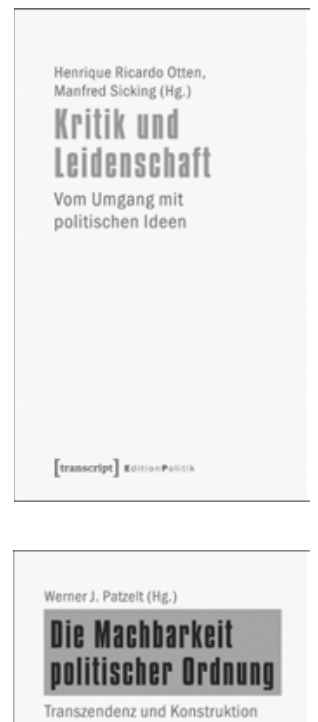

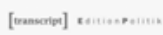

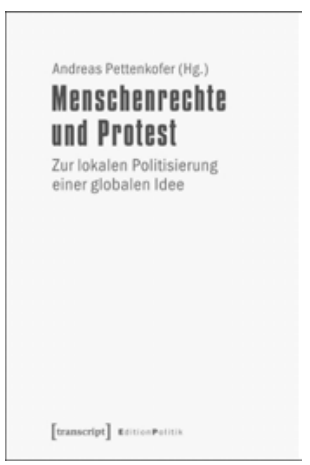

Henrique Ricardo Otten, MANFREd Sicking (Hg.)

Kritik und Leidenschaft

Vom Umgang mit politischen Ideen (unter Mitarbeit von Julia Schmidt)

20II, 3I0 Seiten, kart., 29,80€, ISBN 978-3-8376-I590-6

Werner J. Patzelt (Hg.) Die Machbarkeit politischer Ordnung

Transzendenz und Konstruktion

März 20I3, 472 Seiten, kart., 38,80€, ISBN 978-3-8376-2247-8

Andreas Pettenkofer (Hg.)

Menschenrechte und Protest

Zur lokalen Politisierung einer globalen Idee

September 2013, ca. 250 Seiten, kart., ca. $28,80 €$, ISBN 978-3-8376-2II2-9 


\section{Edition Politik}

Alexander Brand

Medien - Diskurs - Weltpolitik

Wie Massenmedien die internationale

Politik beeinflussen

20I2, 530 Seiten, kart., zahlr. Abb., 39,80€,

ISBN 978-3-8376-I83I-O

LUCYNA DAROWSKA

Widerstand und Biografie

Die widerständige Praxis

der Prager Journalistin Milena Jesenská

gegen den Nationalsozialismus

20I2, 528 Seiten, kart., $39,80 €$,

ISBN 978-3-8376-I783-2

SHAMim Rafat

Ethik und Qualität

in der Politikberatung

Zur Entwicklung von professionellen

Standards und Grundsätzen

20I2, 272 Seiten, kart., zahlr. Abb., 32,80 €,

ISBN $978-3-8376-2085-6$

PAtrick Schreiner

Außenkulturpolitik

Internationale Beziehungen

und kultureller Austausch

20II, 448 Seiten, kart., $35,80 €$,

ISBN 978-3-8376-I647-7

JANA TRUMANN

Lernen in Bewegung(en)

Politische Partizipation und Bildung

in Bürgerinitiativen

Januar 2013, 298 Seiten, kart., 29,80 €,

ISBN 978-3-8376-2267-6 
